


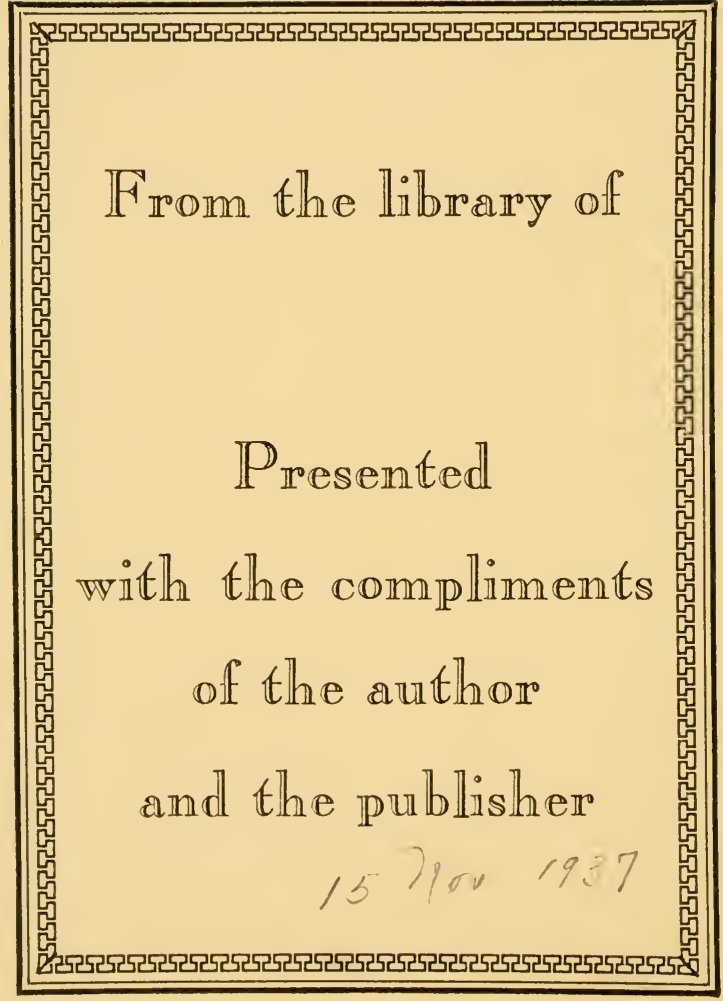




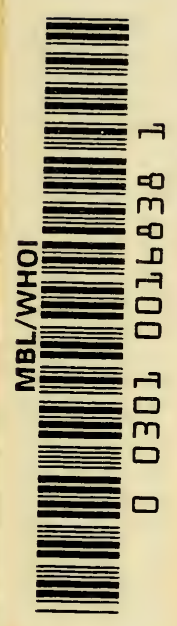





REGENT ADVANGES IN ENTOMOLOGY 


\section{A TEXTBOOK OF PLANT VIRUS DISEASES}

By Kenneth Sмitu, D.Sc., Ph.D. Ior Illustrations.

By the same Author

\section{REGEN'T ADVANGES IN THE STUDY OF PLANT} VIRUSES

I Coloured Plate and 67 Text-figures.

\section{RECENT ADVANGES IN GYTOLOGY}

By C. D. Darlington, D.Sc., Ph.D. Second Edition. if Plates, itoo Text-figures and $8 \mathrm{I}$ Tables.

\section{RECENT ADVANCES IN AGRIGULTURAL} PLANT BREEDING

By H. Hunter, Hon. M.A.(Cantab.), D.Sc.(Leeds), and H. Martin LEAKE, M.A., Sc.D.(Cantab.). Io Plates.

\section{REGENT ADVANGES IN PLANT GENETIGS}

By F. W. Sansome, Ph.D., F.L.S., F.R.S.E., and J. Philp, B.Sc., F.L.S. 56 Illustrations.

\section{RECENT ADVANGES IN BOTANY}

By E. C. Barton-Wright, M.Sc.(Lond.), F.R.S.E. 60 Illustrations.

\section{AN INTRODUGTION TO GOMPARATIVE ZOOLOGY}

A Text-book for Medical and Science Students.

By F. G. Sarel Whitfield, F.R.E.S., F.R.M.S., and A. H. Wood, M.A. I I I Illustrations.

\section{THE MICROTOMIST'S VADE-MEGUM}

\section{(Bolles Lee)}

Edited by J. Brontë Gatenby, Ph.D., D.Sc., and Theophilus PAinter, A.M., Ph.D. Tenth Edition. I I Illistrations. 


\title{
RECENT ADVANCES IN ENTOMOLOGY
}

\author{
BY \\ A. D. IMMS \\ M.A., D.Sc., F.R.S.
}

Reader in Entomology, University of Cambridge

SECOND EDITION

With 94 Illustrations

PHILADELPHIA

P. BLAKISTON'S SON \& GO. ING. 1012 WALNUT STREET 


\section{PREFACE TO THE SEGOND EDITION}

Is preparing a second edition of this book two reasons have led to the decision to confine its scope within the original limits. Firstly, in any attempt to discuss recent advances in entomology, at all exhaustively, several volumes, each the size of the present one, would be needed. Even to include adequate extra chapters the size of the book would need to be increased a good deal beyond its prescribed limits. Secondly, those other aspects of entomology that commend themselves for inclusion are, to a large extent, provided for elsewhere. In this connection, insect physiology, insects and climate, general morphology, insects and plant viruses, for example, have already formed the subjects of recent books or monographs. The writers of these several books have discussed such subjects far more adequately than could be expressed within the limits of single chapters.

Certain aspects of entomology, naturally, have required more revision than others. Under morphology, while current views on Wing Venation have undergone but little change, Head Segmentation and the Genitalia have needed considerable revision. Also, recent studies of the musculature have led to revision of views respecting the homologies of certain of the appendages and their parts. As regards Metamorphosis, discoveries in regard to the presence of hormones are discussed. Palæontology has developed so rapidly as to require very full revision of the original chapter: several new illustrations, taken from recent papers by Dr. F. M. Carpenter, have been included in this chapter with the author's permission. In dealing with the Sense Organs the subject of response to visual stimuli has been extended so as to include the results of a good deal of recent investigation. In this connection valuable help has been given by Dr. M. Hertz, which is here gratefully acknowledged. The subject of Stimulatory Organs has also been included. With regard to Biological Races, 
the incorporation of new material has amplified this section, while Locusts and the Phase Problem form a subject which has been rewritten and expanded. Finally, the two chapters on Biological Control have required extensive revision in order to bring them more nearly up to date. Minor additions and alterations, which are numerous, do not require individual mention.

It will become apparent, on comparing the present edition with its predecessor, that certain sections of the book are reprinted in toto or with only slight modifications. This does not necessarily imply that no recent work has appeared with reference to the sections in question. On the other hand, it may be taken that the results of such work do not materially alter the conclusions or better exemplify the facts or phenomena concerned.

As compared with the first edition, this book has been enlarged to the extent of 56 pages. Of the illustrations, twenty-seven are new, while eighteen of the earlier figures no longer appear. It needs to be reiterated that the book is for students and teachers, and does not cater for specialists in the particular fields that are covered. The necessity for a second edition is regarded as an indication that the book has, on the whole, fulfilled its purpose.

\section{A. D. IMMS.}

Zoological Laboratory, 


\section{PREFACE TO THE FIRST EDITION}

DURING the past fifteen years entomology has accumulated a multitude of facts and has advanced along many paths of inquiry. It attracts to-day a larger band of investigators and devotees than any other province of zoology. The day of the general entomologist is passing by, and it is becoming increasingly difficult for any one individual to view the subject in full perspective. The tracing of its many-sided recent developments, not only in the field of purely scientific research but also in more direct relation to human activities, has become a task of considerable magnitude. This book makes no claim to fulfil so ambitious a scheme. It attempts to review and discuss certain aspects of the subject along which recent advances have been fertile in new facts and ideas. Shortcomings will inevitably assert themselves in this connection, and specialists will perhaps maintain that the treatment meted out to their particular spheres is lacking in detail, or that other aspects of entomology have been omitted altogether. In answer to just criticism of this kind it can only be urged that the dimensions of the book necessarily limit its scope. Also, it does not presume to instruct the specialist in his own field. Further, the theory and practice of insecticides, along with certain other aspects of applied entomology, have been omitted for the reason that they have already been adequately treated in more than one very recent text-book.

It is hoped that this book will enable the student to become better acquainted with some of the more recent developments in entomology. Particular stress has been laid upon aspects of the subject that are but little discussed in modern text-books. A general elementary knowledge of the subject on the part of the reader is assumed, and the bibliographies provided at the ends of the chapters will serve as a guide to the sources of further information. In addition to students of entomology, there is a growing 
body of more advanced workers interested in its general problems. Some approach the subject from the standpoint of unfettered research ; many others are practical entomologists whose occupation is largely directed towards insect control ; and there are those who teach entomology and whose outlook requires them to combine those of the others just mentioned. If this volume fulfils their several requirements, to the extent that they derive some profit by reading it, the author will feel amply repaid.

Opportunity is taken here of expressing indebtedness to Dr. F. Muir for reading and criticising parts of the book when in manuscript, and to all those whose writings have been drawn upon in preparing it. M. d'Emmerez de Charmoy has kindly supplied information with respect to biological control measures in Mauritius. Dr. Anton Handlirsch has generously consented to the use of several illustrations contained in his article "Ueber die fossilen Insekten," published in the Proceedings of the First International Entomological Congress. Mr. Arthur Gibson, Dominion Entomologist for Canada, has loaned several original drawings pertaining to publications issued by his Division. Dr. R. J. Tillyard has also granted permission to use several illustrations from his papers. Indebtedness is also expressed to Sir Guy Marshall for the use of Fig. 94, which is taken from the Bulletin of Entomological Research; to Mr. Clyde W. Mason for three figures taken from his articles dealing with structural colours in insects; to Dr. R. E. Snodgrass and Dr. H. E. Ewing for the use of several illustrations taken from their respective publications issued by the Smithsonian Institution. Thanks are also due to the latter body for its consent to their adoption. A number of other figures have been borrowed, or adapted, from various sources and acknowledgments are made to the authors concerned in the respective legends.

A. D. IMMS.

July, 1930 . 


\section{GONTENTS}

Preface to the Second Edition

CHAP'TER I

Some Aspects of Morphology

Segmentation of the Head. Wing Venation. The Metameric

Appendages.

\section{CHAP'TER II}

Some Aspects of Morphology (continued)

The Metameric Appendages (contimued). The Genitalia.

Literature.

\section{CHAPTER III}

Metamorphosis

Berlese's Theory. Types of Larva. General Remarks on

Insect Metamorphosis. Literature.

\section{CHAPTER IV}

\section{Palæontology .}

Introduction. Orders only known as Fossils. The Geological History of Insects. The Phylogeny of Recent and Fossil Orders of Insects. Literature.

\section{CHAP'TER V}

The Sense Organs and Reflex Behaviour

Introductory Remarks. The Eyes and Light Perception.

Chemical Stimuli and their Receptor Organs.

\section{CHAPTER VI}

The Sense Organs and Reflex Behaviour (continued)

The Tactile Sense. Chordotonal Organs and Reactions to Vibrations. General Stimulatory Organs. Reflex Behaviour and Practical Entomology. Literature.

\section{CHAPTER VII}

The Fundamental Aspect of Coloration

Structural Colours. Pigmentary Colours. Combination

Colours. Further Remarks on Insect Coloration.

Literature. 


\section{CHAP'TER VIII}

Temperature.

\section{CHAPTEL IX}

Some Aspects of Ecology (continued) .

Humidity. Light. Atmospheric Pressure. Food. Climate. Literature.

\section{CHAPTER X}

The Practical Application of Ecology .

Regulation of the Growth of the Crop. Resistant Varieties.

\section{CHAPTER XI}

The Practical Application of Ecology (continued) .

Host Selection and Biological Races. Ecological Aspects of the Locust Problem. Literature.

\section{CHAP'TER XII}

Parasitism

Introductory Remarks. Host Selection. Phases of Parasitism.

\section{CHAPTER XIII}

Parasitism (continued)

Types of Life-cycle. Host Relations of Parasites. Polyembryony and Related Phenomena. The Behaviour of Adult Parasites. Literature.

\section{CHAP'TER XIV}

\section{Biological Control}

Biological Control of Insect Pests. I. Parasite Introductions.

\section{CHAP'TER XY}

Biological Control (continued)

II. Factors Governing Parasite Introductions. III. The Utilisation of Indigenous Parasites. Biological Control of Noxious Weeds. Literature. 


\section{RECENT ADVANGES IN ENTOMOLOGY}

\section{CHAPTER I \\ SOME ASPECTS OF MORPHOLOGY}

1. Segmentation of the Head, p. 4. 2. Wing Venation, p. 16. 3. The Metameric Appendages, p. 21. A. Thoracic Appendages, p. 23 ; B. The Pleura, p. 28 ; C. The Primitive Insect Leg, p. 31 ; D. The Cephalic Appendages, p. 32.

THE importance of an adequate and exact knowledge of morphology has become increasingly evident in connection with many aspects of entomology. Two notable text-books have appeared within the last four years-one by Weber (1933) in Germany, and the other by Snodgrass (1935) in the United States. A perusal of these two works will make it evident to the reader that the subject is emerging on a more exact and scientific footing than hitherto. While morphology is essentially a descriptive subject, it is becoming less divorced from function. In dealing with exoskeletal organs and parts, not so much emphasis is being laid upon sclerites and sutures alone, as primary criteria, and more recognition is being accorded to the underlying musculature. The morphology of the labium, for example, when studied in conjunction with the musculature, is becoming better understood and placed upon a surer basis. The requirements of taxonomy, alone, will long provide a field for the application of morphological knowledge, and advances in the latter will gradually influence the systematic side of entomology. Progress in this direction is naturally very slow, since it is only the established, or more or less stabilised, morphological conclusions that concern 
the taxonomist. 'The difficult subject of the genitalia, especially when taken in conjunction with the facts of development, is becoming more clarified and we are beginning to see an underlying fundamental similarity in these parts. It is to be deplored that morphology, as a whole, is becoming involved in a confusing terminology and a consistent nomenclature will sooner or later have to be adopted if a complex synonomy is to be avoided.

The most significant change of attitude to-day is seen in the increasing appreciation of the importance of insect physiology. A vast literature on this subject already exists ; most of the older work is now of little value in view of the great progress made in experimental technique. Some idea of the recent growth of this subject may be gathered from a valuable article by Hoskins and Craig (1935). These authors mention having considered some 1,200 papers published during the five years 1931-35, and they cite 444 of these in the useful bibliography which is appended. We may pause for a moment and consider the causes contributing to the rapid growth of this type of investigation. For one thing, the applied entomologist, in his efforts to find a surer foundation than purely empirical methods for the control of noxious insects, is devoting attention to the possibilities of insect physiology. He is realising that the most promising line of approach lies in a better knowledge of the inner working of insects themselves. The growing importance of insects as carriers of disease organisms of man and domestic animals is likewise creating a demand for similar knowledge. Applied entomology, therefore, as a whole, in its need for information of this kind, is focussing the attention of many workers on physiological problems. It needs also to be remembered that the rapid growth of the experimental viewpoint among general zoologists is another contributing influence, since an increasing number of zoologists is being attracted to the study of problems of a physiological nature afforded by the insect world. Already more than one academic body has been led to provide for some measure of teaching and research in insect physiology. A very large literature on the subject in question is appearing in an extraordinary diversity of periodicals, many of 
which it has not been previously necessary to consult in connection with entomology at all. The future burden of the worker in insect physiology of keeping pace with this literary growth seems likely to become increasingly difficult for this reason. One result from this increase in physiological knowledge seems to be that the morphologist will become better able to develop his subject, since it will be in the light of increased acquaintance with basic functions. Growth of physiological knowledge, also, is likely to involve the re-examination of many features of the minute structure of insects, with possibilities of interpretations being made from another angle of vision. In connection with the foregoing remarks, reference needs to be made to an introductory manual of insect physiology by Wigglesworth (1934). It formulates what is virtually a new subject and co-ordinates much scattered information not readily accessible or easily evaluated.

In order properly to appreciate the morphological significance of a good deal of insect structure it is necessary to look outside the limits of entomology. While insects, as a class, show a fundamental organisation common to the Arthropoda, their own basic characters have been evolved by a long and complex process of modification. The morphological interpretation of these characters is essentially a study of homologies. which is hampered owing to lack of evidence as to the course taken by insects in their evolution. While a number of writers claim that the origin of these creatures was either in common with that of the Myriapoda, or from some individual class among that assemblage, other writers bring forward reasons suggesting derivation from an early crustacean type. On the whole, both anatomically and physiologically, insects appear to show a balance of characters favouring the idea of descent from a myriapodan rather than from a crustacean prototype (Imms, 1936). This contention forms the basis upon which some of the more general morphological deductions made in this chapter are founded.

In the present chapter the following aspects of morphology are discussed: (1) the segmentation of the head; (2) the wing venation; and (3) the metameric appendages. 


\section{Segmentation of the Head}

Phylogenetic studies have led to the conclusion that arthropods were originally descendants of annelids. The reader may be reminded that in the latter animals the only differentiated head is the prostomium, which projects in front of the mouth as an outgrowth of the first body-segment. Situated within the prostomium is a pair of nerve ganglia forming the archicerebrum or primitive

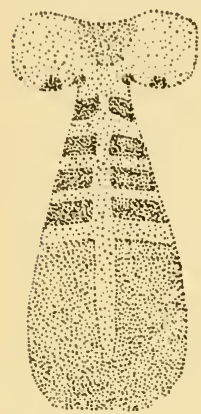

Fig. 1. An early e mbryo of Lepisma, showing division into A, the protocephalic or primary head region, and $B$ the protocormic or primary trunk region. (From Heymons.)

brain. Each of the post-oral regions or segments

A of a Polychate worm carries a pair of appendages : each segment is innervated by its own nerve centre, and its cavity is formed by the coalescence of a pair of embryonic cœlom sacs. It was pointed out by Lankester in 1881, and by Goodrich in 1898, that the arthropod head is

$B$ derivable from that of the annelid by the fusion together of the prostomium along with a definite number of the original body-segments which follow it : in other words, it is a syncephalon. It follows, therefore, that those head-segments and their appendages which are pre-oral in arthropods, must have secondarily acquired that position. The arthropod brain is similarly a syncerebrum, formed by the fusion of the annelid archicerebrum with the nerve centres of certain of the segments behind.

Without following the evolution of the syncephalon in different groups of arthropods, it may be mentioned that among insects the embryo becomes differentiated at an early period into a greatly expanded protocephalic or primary head region, and a protocormic or primary trunk region (Fig. 1). The primary head, or protocephalon, is represented by the large cephalic lobes in connection with which the acron and first three head-segments develop. The primary head, as thus constituted, is an embryonic and presumably recapitulatory phase only, and the completed head of an insect is formed by the coalescence of the first three protocormic segments with those of the protocephalon. 
On the basis of these contentions it will be observed that six segments enter into the composition of the insect head, and this conclusion is now widely accepted. Embryology affords three fundamental criteria which provide the surest evidence with regard to segmentation, viz., the existence of paired appendages, of neuromeres and of primitive colom sacs. Taking these three criteria as the basis, the composition of the head will be discussed in the light of recent investigations. A noteworthy addition to knowledge of insect embryology is the work of Leuzinger, Wiesmann and Lehman (1926) on the stick insect (Carausius morosus). It is Wiesmann's contribution in this memoir that is of special importance in the present connection. Besides confirming much of what was previously known regarding the composition of the insect head, this author brings forward new facts of considerable theoretical significance. According to him the head of Carausius is composed of an acron and six, or possibly seven, embryonic segments, and his findings are expressed in tabular form below.

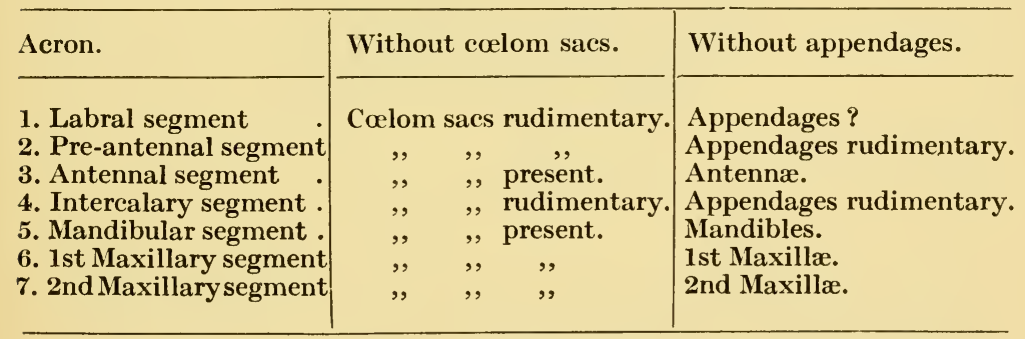

Wiesmann's discovery of rudimentary cœlom sacs in the labral region (Fig. 2, B) was wholly unexpected, and this author has suggested that a true somite, in front of the protocerebral segment, is present. The labrum itself develops from paired lobes which he believed may represent the appendages of this segment since they are closely associated with the cœlom sacs just mentioned. Eastham (1930) states that in Pieris the labrum similarly arises from a pair of lobes : these outgrowths fuse at their bases, pass backwards with the stomodæum and become connected with the epipharynx. The pre-oral mesoderm becomes secondarily divided into a principal anterior part, which passes into the hollow labral 
rudiments, and a smaller posterior part, which comes to lie at the sides of the epipharynx. Cavities of doubtful significance may appear in both these mesoderm masses, but, Eastham remarks, they are so irregular and so unlike those of the well-defined somites of the body that it is doubtful whether they have any metameric importance. This author, in discussing the general problem of
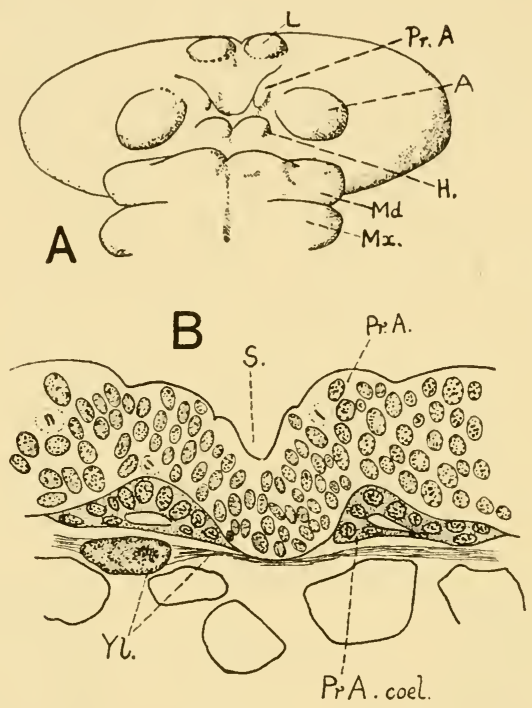

Fis. 2. A. Anterior extremity of an embryo of the Stiek Insect, Carausius morosus, showing rudiments of developing appendages. $A$, antenna ; $\boldsymbol{I}$, hypopharynx ; $L$, labrum ; $\boldsymbol{M} d$, mandible ; $\boldsymbol{M} x$, maxilla ; $\boldsymbol{P r} . \boldsymbol{A}$, pre-antenna. B. Transverse section across a similar embryo, passing through the pre-antennal rudiments $(\operatorname{Pr} A) . \operatorname{Pr} A . c o e l$, pre-antennal cœlom sac ; $S$, stomodæum ; $Y l$, layer of yolk cells. (From Wiesmann.)

head-segmentation, supports the established opinion that six somites are involved, but concludes that the paired labral rudiments represent the appendages of the protocerebral segment. Very recently the occurrence of cœlom sacs in close association with paired labral rudiments has been described and figured in two other insects: viz., by Mellanby (1936) in the Reduviid bug Rhodnius prolixus and by Roonwal (1937) in the African Migratory Locust (Locusta migratoria, subsp. migratorioides, Fig. 3). Both 
these writers conclude that the labrum represents the first true cephalic segment.

Whatever may be the true interpretation of the foregoing observations, it needs to be recollected that in the Collembola and in Lepisma, Campodea and Japyx the labrum develops as an unpaired rudiment from its first stage of growth. The same condition is found in Scolopendra and also in Blatella, Mantis,

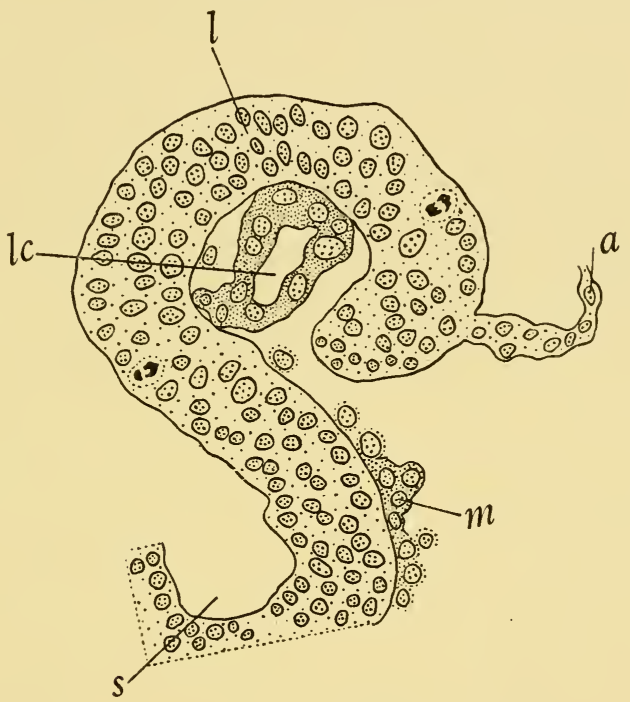

Fig. 3. Portion of a longitudinal vertical section of a fifty-nine hours' old embryo of Locusta, showing the labral colom. $\times$ 375. $a$, amnion; $l$, labrum ; $l c$, labral colom ; $m$, mesoderm; $s$, stomodæum. (After Roonwal.)

Gryllus and Forficula. On the other hand, the labrum develops from paired lobes in Carausius, Locusta, Stenobothus, Rhodnius and in Lepidoptera and Coleoptera. Among Hymenoptera its rudiments may be either paired (Chalicodoma) or unpaired (Apis). The labrum, therefore, may differ as to its mode or origin within the limits of a single order of insects. We are thus faced with the difficulty of deciding which of these two conditions is to be regarded as the original or primary state. Since the labrum develops from unpaired rudiments in the Chilopoda and 
Apterygota, besides in some of the Orthoptera, it might be claimed with some justification that this condition is primitive. In those examples where it is initiated in the form of paired lobes it might be assumed that a secondary division occurs during development and that the unpaired condition is re-acquired later. Without pursuing this matter further it needs to be taken into account that the process of the amalgamation of the cephalic segments is phylogenetically an extremely ancient phase in arthropod evolution: secondary changes have almost certainly supervened to the extent of partially obliterating the original condition. Furthermore, since the complete arthropod head is believed to have been formed by the successive incorporation of additional postcephalic segments with the primitive cephalon, the most anterior segments are the most ancient in the process of cephalisation. It is these anterior segments, therefore, that are most likely to have become so transformed, in the lengthy process of evolution, as to betray but little evidence of their individuality. If what is known of the segmental constitution of the head in all classes of Arthropoda be taken into account, it appears unlikely that two pre-antennary segments (protocerebral and labral) should occur in the Insecta and in no other class. The subject is discussed by Manton (1928), who doubts whether the labral cœlom sacs are independent of those of the protocerebral segment. If this conclusion be correct it may be inferred that only a single preantennary segment is involved and that it has undergone secondary division. Further discussion of this problem, however, is scarcely profitable until more evidence is available, and Manton's hypothesis is to be regarded as a tentative effort to reconcile conflicting evidence.

Up to this point the embryological interpretation of the constitution of the insect head has been considered. Hanström (1927-30), from a comparative study of the structure of the cephalic ganglia of Annelida and Arthropoda, arrived at a different conclusion. While his theoretical deductions have not gained wide acceptance, his work, as a whole, forms a valuable contribution to invertebrate neurology. The arthropod protocerebrum and deutocerebrum, he claims, are secondary 
developments from a single ganglionic centre, representing the highly modified annelidan archicerebrum. The tritocerebrum, according to Hanström, is the ganglion of the first true headsegment. The arthropod head, on the basis of his theory, is composed of four segments only, viz., those represented by the second antennæ, mandibles, maxillæ and labium, together with a pre-oral or prostominal region bearing the labrum, eyes and first antennæ. The cœlomic cavities present in front of the tritocerebrum are interpreted by him as being of secondary origin and devoid of metameric significance. The first antennæ and preantennæ come under the category of prostomial tentacles and are consequently not regarded as being true appendages. Hanström's views are accepted by Snodgrass (1935), and without going into details it needs to be stressed that great importance is given to the general occurrence of corpora pedunculata, or mushroom bodies, as indicating cerebral homologies. These structures constitute the largest and most important association centres in the insectan brain. They are, furthermore, present in all arthropods and are also of common occurrence in the archicerebrum of annelids. Relatively slightly developed in the Polychæte family Hesionidæ they become more highly differentiated structures in the families Aphroditidæ and Nereidæ and ultimately attain their greatest development among the Insecta. The evidence brought forward by Hanström leads to the conclusion, at any rate, that the annelidan archicerebrum forms a large part of the arthropodan protocerebrum. Hanström also maintains that the optic centres or arthropods have been evolved from homologous tracts located in the optic lobes of the archicerebrum, as seen in the Polychæte family Eunicidæ. While these primitive optic centres in the Polychæta have a very simple structure, they appear to grade into the more elaborate, but still elementary, optic centres found in the Branchiopod Crustacea. While the value of Hanström's studies is not likely to be disputed, his conclusions appear to be the result of too much stress being laid upon brain structure alone. While it may be granted that evidence of the existence of pre-antennæ in insects is scanty, it is difficult to accept his conclusions relative to the deutocerebrum with its undoubted cœlom sacs and well- 
defined appendages (antennæ). To disregard the evidence of metamerism afforded by this segment and to accept similar evidence betrayed by the segments that follow renders his theory untenable in so far as morphological values are at present interpreted.

A third view as to the segmental composition of the insect head is based upon the conclusions of Hansen. In 1893 this well-known Danish morphologist claimed the existence of a pair of reduced but true appendages situated between the mandibles and the first maxillæ in most Apterygota and some of the more primitive pterygote insects. He termed these appendages maxillulæ, since it appeared probable that they are homologous with the first maxillæ (maxillulæ) of the Crustacea. In his most recent studies Hansen (1930) confirms his earlier opinions and brings forward more detailed evidence in their support. If this contention be well founded it follows that the insect head would have to be interpreted as being composed of seven segments, as shown below.

\begin{tabular}{l|l|l|l}
\hline Segment. & Appendages. & Colom sacs. & \multicolumn{1}{c}{ Neuromere. } \\
\cline { 2 - 3 } & Embryonic & Rudimentary & Protocerebrum \\
\hline 2 & Antennæ & Present & Deutocerebrum \\
\hline 3 & Embryonic & Rudimentary & Tritocerebrum \\
\hline 4 & Mandibles & Present & Mandibular \\
\hline 5 & Maxillulæ & Absent & Absent \\
\hline 6 & 1st Maxillæ & Present & Maxillary \\
\hline 7 & 2nd Maxillæ & Present & Labial \\
\hline
\end{tabular}

Comparison of the above table with that given on p. 5 will make it evident that these seven suggested segments do not entirely correspond with those recognised by Wiesmann. In the Collembola, for example, Hansen claims that the maxillulæ have hitherto been identified as maxillary palpi notwithstanding the fact they are a perfectly free pair of mouth-parts with separate articulations. In Japyx the maxillulæ likewise have separate articulations and 
are only comnected with the maxillæ by membrane : hitherto they have been interpreted as being the palpi and galeæ of the maxillæ. On anatomical data only, Hansen's conclusions appear to have much in their favour. He does not lay much stress on the value of embryological evidence and only briefly discusses the work of Folsom (1900) on the development of Anurida. In this connection he states that the pair of developing lobes ( $p$. in Figs. 4 and 5) associated with the first maxillæe are the fundaments of the maxillulx. Folsom, he maintains, has misinter-

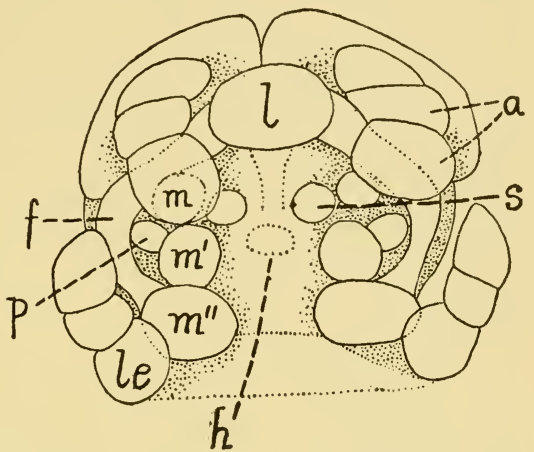

Fig. 4. Ventral aspect of the head region of an embryo of Anurida, showing developing appendages. $a$, antenna ; $f$, oral fold; $h$, hypopharynx; $l$, labrum ; le, leg ; $m$, mandible ; $m^{\prime}$, maxilla ; $m^{\prime \prime}$, labium ; $p$, maxillary palp ; $s$, superlingua. (From Folsom.) preted them as being maxillary palpi. Hansen's views, however, receive no support from the embryological studies of Philiptschenko

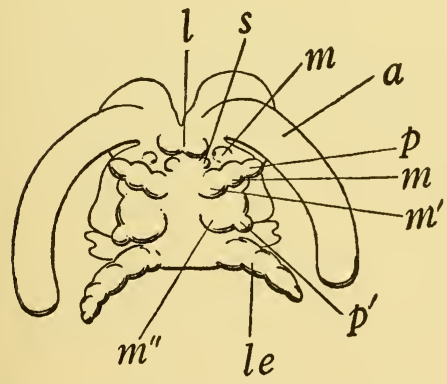

Fig. 5. Head and first thoracic segments of embryo (about $\mathbf{1 \cdot 2 0}$ $\mathrm{mm}$. long) of Japyx major. Lettering as in Fig. 4. Adapted from Silvestri. logous with the paragnaths of the higher Crustacea which are
non-appendicular in character. Hansen, in discussing Crampton's logous with the paragnaths of the higher Crustacea which are
non-appendicular in character. Hansen, in discussing Crampton's These observers find no traces whatever of a maxillulary segment either in the form of a neuromere, appendages or coelom sacs. The lobes identified as maxillary palpi by Folsom are shown by Silvestri to develop into those parts as stated by the first-mentioned writer. Crampton (1921) made a rather superficial study of the whole question and claimed that the maxillulæ of Hansen are homo-

(1912) and of Silvestri (1932). 
conclusions, showed that the pair of small plates (superlinguæ of Folsom) overlying the hypopharynx in Collembola and Thysanura Entognatha are probably homologous with paragnaths. On the other hand, he contended that true maxillula co-exist with them in the groups just named and therefore cannot be their homologues as Crampton thought. In summing up the position it may be said that non-appendicular plates or superlingux (paragnaths) undoubtedly exist among the Apterygota, but evidence of the occurrence of maxillulæ is very unconvincing and points to the contrary.

The available evidence relative to the segmentation of the insect head leads to the conclusion that it has resulted from the amalgamation of at least six embryonic somites. The present status of knowledge of the problem may be summarised as follows :

1. The pre-antennal or ocular segment is usually regarded as being the first true cephalic segment, its neuromere being the protocerebrum or first division of the brain. The protocerebrum is probably composite since it is believed to comprise also the primitive archicerebrum. The existence of rudimentary colom sacs and very small evanescent appendages pertaining to the preantennal segment in the Phasmid Carausius (Fig. 2B) has not so far been confirmed in any other insect. It is now tolerably well established that colom sacs, in close association with labrum, occur in Carausius, Locusta and Rhodnius. It appears unlikely that two pre-antennal segments are exhibited in the Insecta and no other Arthropoda and the possiblity that the labral coelom is part of that pertaining to the ocular segment cannot be overlooked. Evidence that the labrum itself represents a pair of true appendages is very hypothetical, especially in view of the fact that this organ arises from an unpaired fundament in the Apterygota and other insects.

2. The antennary segment is innervated by the deutocerebrum or second neuromere of the brain : its appendages are the antennæ and colom sacs are present in the embryo.

3. The intercalary segment is vestigial, but evidence of its existence is found in the embryos of most insects. Rudimentary cœlom sacs are retained in some cases, and vestigial evanescent 
appendages (homologous with the second antennæ of Crustacea) occur in certain Apterygota, as well as in the cockroach, silkworm and honey bee among Pterygota. In Campodea (Uzel, 1897) and the grasshopper Dissosteira (Snodgrass, 1928) rudiments, which appear to represent these appendages, are discernible in the adult insect. Its nerve centre, or tritocerebrum, forms the third neuromere of the brain, but it subsequently becomes largely incorporated with the deutocerebrum.

4, 5, 6. The mandibular, first maxillary and second maxillary segments are all well developed, and bear corresponding appendages. Cœlom sacs are present in the embryo, and the neuromeres coalesce to form the infra-œsophageal ganglion.

The completed head-capsule is so highly modified and consolidated that it no longer betrays obvious evidence of its segmental composition. It becomes, therefore, a difficult and largely speculative problem to assign the regions, or parts of the head, to their original segments. The whole subject is admirably discussed from a comparative standpoint by Snodgrass (1928), who points out that since the segments of the protocephalic region are never distinct, even in the earliest embryonic stages, it seems fruitless to hazard what areas of the adult head are to be attributed to them individually. The original protocephalic region must at least be the area occupied by the labrum, clypeus and frons, together with the compound eyes and antennæ. Also, since the muscles of the three pairs of gnathal appendages have their origins in the posterior part of the head, Snodgrass concludes that the areas upon which these muscles arise are parts of the walls of those segments that have been added to the protocephalic region. It seems probable that the frontal suture marks off the original prostomial area from that derived from the segmental elements, and, if this be correct, the labrum, clypeus and frons represent differentiations of the original prostomium. In the primitive Machilidæ the posterior part of the epicranium is crossed by a prominent suture just behind the eyes. This suture extends downwards to a point between the bases of the mandible and maxilla. Snodgrass advances reasons which suggest that this suture separates the mandibular segment from that of the maxilla 
on the cranial wall. Further back on the cranial wall lies the post-occipital suture, which is very constant in its occurrence and
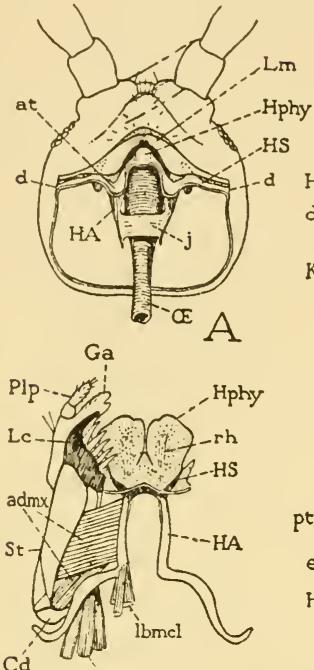

ilc D
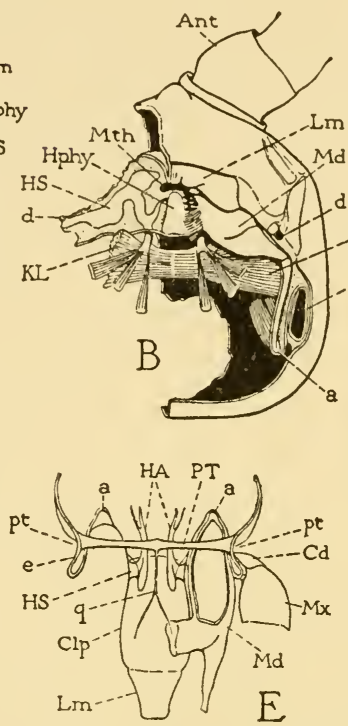

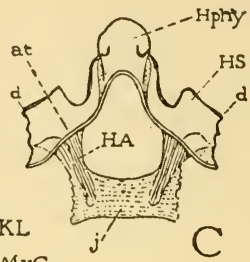

$\mathrm{MxC}$

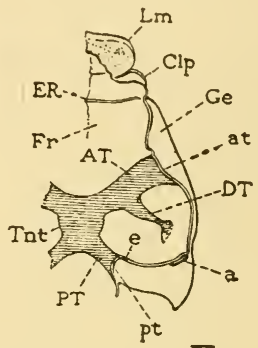

F

FIG. 6. The hypopharyngeal apophyses and the tentorium. A, Under surface of head of Lithobius, mandibles and maxillæ removed, showing suspensorial plates $(I I S)$ of hypopharynx suspended from points $(d)$ on margins of head, and hypopharyngeal apophyses $(I A)$ invaginated from their inner ends and connected by ligamentous bridge $(j)$ beneath pharynx. B, Head of Scolopendra, ventral, maxillæ and right half of cranium removed, showing attachment of mandibular adductors $(K L, K L)$ on ligament uniting the hypopharyngeal apodemes. C, Scutigera forceps, ventral view of hypopharynx (IIphy), suspensorial plates $(H S)$, their apodemes $(H A)$ and uniting ligament $(j)$. D, IIeterojapyx gallardi, ventral view of right maxilla, hypopharynx (Hyph), and hypopharyngeal apodemes $(I A A)$, upon which arise the muscles of the maxilla $(a d m x)$, the labium (lbmcl), and the mandibles (not shown). E, Nesomachilis maoricus, posterior view of unconnected anterior and posterior arms of tentorium (IIA, PT), part of the head wall with clypeus $(C l p)$ and labrum $(L m)$, base of maxilla $(M x)$, and mandible $(M d)$. F, Ephemerid nymph, ventral view of tentorium and part of left side of head, showing anterior tentorial arms $(A T)$ arising from ventral margin of gena $(\mathrm{Ge})$. (After Snodgrass.)

appears to be of definite morphological significance. Internally it forms the post-occipital ridge, which appears to be a true inter- 
segmental phragma between the maxillary and labial segments. The hypothesis that this suture marks the division between those two segments is borne out by the positions of the maxillary and labial articulations with reference to it.

After the gnathal segments became added to the protocephalon, it appears probable that their sternal parts lost their identities. From the fact that the ventral adductor muscles of all the mouthparts have their origins on a pair of apophyses, arising from the base of the hypopharynx in Chilopods and most Apterygota, Snodgrass concludes that at least part of each of their sterna has become incorporated into the hypopharyngeal region-a conclusion which is supported to some extent on embryological grounds. From a comparative study of Crustacea, Myriapoda and Apterygota he has advanced an ingenious theoretical interpretation of the origin and evolution of the insect tentorium (Fig. 6). Without going fully into his lines of reasoning, it may be said that the beginnings of that structure are to be seen in the hypopharyngeal apophyses previously alluded to. From their original position, at the sides of the hypopharynx, it appears that they have migrated outward in the ventral wall of the head to the lateral edges of the cranium, but retain the original muscle attachments. In Odonata and Ephemeroptera these apophyses come to lie in the sub-genal sutures, but in all other Pterygota they have proceeded further to take up their usual position on either side of the clypeo-frontal suture. The hypopharyngeal apophyses have, according to this interpretation, become the anterior arms of the tentorium. The posterior arms are invaginations in the lower extremities of the post-occipital suture, which unite with the anterior arms to form the typical four-branched skeletal structure: they are undeveloped, it may be added, in Myriapoda and most Apterygota. The dorsal arms arise as processes of the anterior pair, and may subsequently acquire secondary connection with the cranial wall. The condition of the tentorium in Machilis appears to be largely intermediate between that found in most Apterygota and Pterygota, since the anterior and posterior elements are present, but still independent of each other. 
The morphology of the neck region and the cervical sclerites is extremely difficult to interpret, and many speculative views have been advanced to explain it. It is obvious that if the postoccipital suture marks the division between the maxillary and labial segments, the tergal region of the latter segment is represented by the narrow band-like area behind this suture, and forms the greater part of the boundary of the occipital foramen. The fact that the dorsal muscles of the prothorax pass through the neck and are attached anteriorly-not to the posterior margin of the labial segment, but to the post-occipital ridge beyond-appears to be a morphological fact of importance. This relationship has led some morphologists to conclude that an intersegmental region has become deleted somewhere in the neck. The cervical sclerites are consequently regarded as dismembered portions either of the labial segment or of the prothorax. Other morphologists maintain that the neck itself is the greatly enlarged intersegmental region, and that the cervical sclerites are sclerotised areas which have developed in the membrane of that region.

\section{Wing Venation}

The determination of the origin and homologies of the wing veins has, in the past, been embarrassed by the various systems of nomenclature employed by different workers. As a rule, the terminology of an author was only applicable within the limits of the particular group or order of insects which he studied. The establishment of these different systems has been the inevitable outcome of specialised studies, uninfluenced by modern conceptions of evolution. These defects could scarcely be remedied at the time because no criterion had yet been explored upon which homologies might have been based. Such deficiencies have been realised for more than forty years, and it was in 1886 that Redtenbacher published an important and well-illustrated memoir in which he proposed a uniform system of venational nomenclature; he named the veins costa, subcosta, radius, media, cubital and anal respectively. Redtenbacher, furthermore, reaffirmed the importance of the fact that the main veins primi- 
tively alternate as convex and concave veins, a feature previously noted by Adolph in 1879. He also claimed that the oldest insects exhibit the richest venation, which disappeared to a marked extent, among recent forms, by reduction. Subsequent researches by him in conjunction with Brauer, and also by Spuler, considerably extended what little had been previously known of the relations of venation to the antecedent tracheation. It was not, however, until 1898 that any comprehensive ontogenetic studies were undertaken. In that year Comstock and Needham began their investigations of the homologies and development of the wing veins in all orders of insects and, in 1918, Comstock extended and

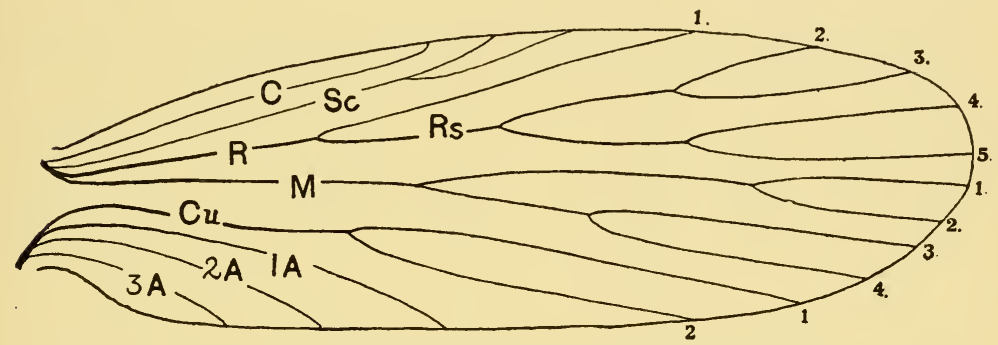

Fig. 7. Hypothetical scheme of wing venation according to Comstock and Needham. $C$, costa ; $S c$, sub-costa ; $R$, radius ; $R s$, radial sector ; $M$, media ; $C u$, cubitus ; $1 A, 2 A, 3 A$, anals.

consolidated this work in his well-known text-book on the subject. It may be said, very briefly, that, in the Comstock-Needham system, the original vein nomenclature of Redtenbacher is followed, but with many modifications with regard to his theoretical deductions. By means of an extensive study of the trachex which precede and, in a general sense, determine the courses of the veins, these authors came to the conclusion that existing types of venation (living and fossil) are all derivable from a common hypothetical ancestor, and that the veins in different orders of insects can consequently be homologised with one another. They further concluded that deviations from the hypothetical ancestral type resulted, either by the addition or by the reduction of veins, as the case may be. No great importance was attached to Redtenbacher's theory that convex and concave veins alternate 
with one another, probably because this condition is regularly apparent in certain orders only. Also the theory that the ancestral winged insects had the richest venation, from which later types were derived by reduction, was not accepted. While we owe to Comstock and Needham what is one of the greatest advances ever made in the study of insects, the importance of the earlier fundamental work of Redtenbacher should not be overlooked. The Comstock-Needham system (Fig. 7) is now well known and, for this reason, it is not necessary to recapitulate here what has often been described since in text-books. It will be necessary, however, to discuss certain more recent investigations on wing venation and their bearing upon the general theory.

The contributions of Tillyard, dating from 1919, have greatly extended our knowledge of the subject in many orders, and this
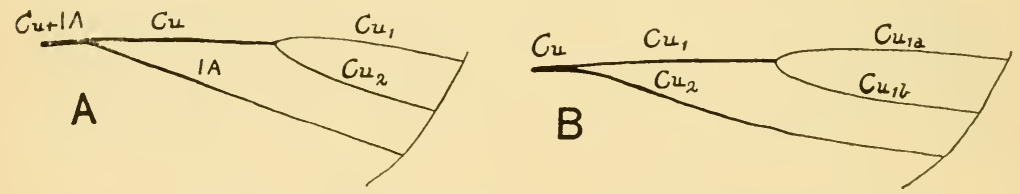

Fig. 8. Diagram of the branching of the cubital vein ; $A$, according to Comstock and Needham; $B$, according to Tillyard and later authorities. $C u$, cubital vein ; $1 A$, first anal vein.

author's detailed studies of early fossil types shed further light on venation from the palæontological aspect. In his papers on the Panorpoid complex, ${ }^{1}$ Tillyard arrived at the conclusion that Comstock and Needham's hypothetical type is not entirely applicable as one from which the venation, of the orders forming this complex, was presumably derived. The most important feature brought to light by Tillyard's earlier discoveries refers to the composition of the cubital vein. He was able to show on ontogenetic grounds that this vein is primarily three-branched, and not two-branched as Comstock and Needham believed (Fig. 8). The vein which the latter authorities regarded as the first anal, which had become secondarily associated with the

1 The Panorpoid Complex includes the Mecoptera, Neuroptera, Trichoptera, Lepidoptera and Diptera, together with related extinct orders only known as fossils. 
cubital stem, Tillyard maintains is the branch $\mathrm{Cu}_{2}$. In other words, the primary bifurcation of the cubital vein takes place much nearer the base, and the forked cubital vein of Comstock and Needham represents its anterior branch only. The primitively three-branched cubital vein is present in the lower orders, as well as among Holometabola, and it is evident that it is to be regarded as a fundamental character in any hypothetical venation scheme for insects.

The views of Redtenbacher regarding the significance of the alternation of convex and concave veins are supported in general by modern researches. If, for example, two convex veins occur

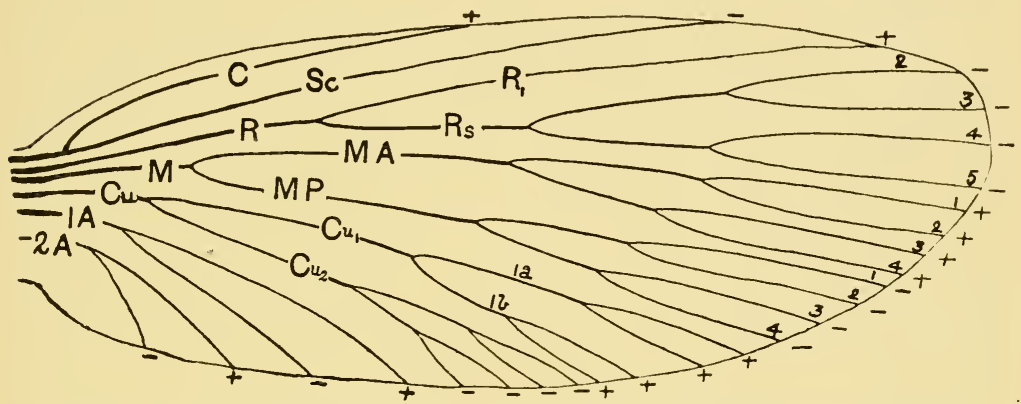

FIG. 9. Hypothetical scheme of wing venation according to Lameere.

in proximity to each other on an insect wing, a strong presumption arises that an intervening concave vein has either been merged with one or other of the convex veins, or has been suppressed. Reasoning along these lines has helped to establish the identity of veins in both fossil and recent insects. The important researches of Lameere (1922) are largely based upon deductions of this kind, drawn from a study of both recent and fossil insects. He concludes that no living insect possesses as complete a venation as that found in the early fossils of the coal measures. In this contention he affords strong support to the views of Redtenbacher, which were not accepted by Comstock (1918). Lameere's study of the Palæodictyoptera led him to stress the importance of following the alternation of convex and concave veins, and, according to him, there are six principal veins on the primordial 
insect wing (Fig. 9). Each vein bifurcates into an anterior or convex branch $(+)$, and a posterior or concave branch (or sector, - ). The concave subcostal vein, he believes, represents the posterior branch of the costal, while his conception of the radius does not differ from that of Comstock. The division of the media into an anterior convex branch (MA) and a posterior concave branch (MP) is a conclusion of prime importance. The logical deduction to be drawn is that the media of Comstock, being a concave vein, is the counterpart of the posterior media (MP) of Lameere. This interpretation, however, was not advanced by Lameere, who believed that MP is wanting in Holometabola with the exception of a rudiment which had been previously regarded by Tillyard (1919) as representing $\mathbf{M}_{5}$. Since, however, $\mathbf{M}_{5}$ according to Tillyard (1925) is convex in character, Lameere's homology is improbable. It needs to be pointed out, however, that Tillyard stated definitely in his earlier writings that $\mathbf{M}_{\mathbf{5}}$ is a concave vein and that Lameere based his conclusions upon this assertion. ${ }^{1}$ With regard to the cubitus, Lameere's anterior branch corresponds with $\mathrm{Cu}_{1}$ (convex), and his posterior branch with $\mathrm{Cu}_{2}$ (concave). His interpretation of the anal veins differs from those of his predecessors in that he claims that two bifurcate veins are present in the anal area. This conclusion can scarcely be reconciled with the more usually accepted interpretation (Fig. 7), and the theoretical assumption, that every wing vein conforms to a regular basic system, remains to be proved.

When Lameere's hypothetical scheme is applied to recent insects several important modifications become apparent, more especially with regard to the media. It would seem that this vein is only rarely represented by both of its branches-MA and MP. This condition is retained among Ephemeroptera and is certainly present in the Orthoptera. A comparative study of the venation of both recent and fossil representatives of the last-

1 The oblique vein $\mathbf{M}_{5}$ is a characteristic feature of the orders forming the Panorpoid Complex, and is evident in their Upper Permian fossil representatives also. Tillyard (1919) regarded it as a basal concave vein connecting M with $\mathrm{Cu}_{1}$ to form the cubito-median Y-vein. In a later paper (1925) the results of further study led him to conclude that it is little more than a convex strut, which has arisen as a secondary development, in order to provide rigidity to the base of $\mathrm{Cu}_{1}$. 
mentioned order is necessary, however, before it is possible to generalise in this immediate connection. Among Odonata, Tillyard has brought forward evidence indicating that the anterior media (MA) only is retained in this order and it is probable that this same condition will be obtained among Plecoptera. In other orders, excepting the Diptera, it is very doubtful whether MA is ever present. Among Diptera the so-called vena spuria appears to be the vestigial MA, and occurs in the Ptychopterinæ and in various members of the Syrphidæ.

Notwithstanding the large amount of study that has been concentrated upon the problem of venational homologies, our conceptions of the subject are not, as yet, by any means stabilised. The results of palæontological investigations have been to give increased importance to the significance of convexity and concavity of veins as the criterion upon which their homologies largely rest. The fact that the tracheation so often does not precede and, therefore, determine the courses of the veins obviously limits its application. The reader who is desirous of following recent theoretical views should consult papers by Vignon $(1929,1932)$ and by Vignon and Séguy (1929), whose work has special reference to Diptera. The hypothetical generalised scheme of venation promulgated by Vignon (1929) involves heterodox views which require much wider study before the truth or falsity of his ideas can be determined.

\section{The Metameric Appendages}

The reader may be reminded that the structure of Arthropoda presents a unity of plan rendering it highly improbable that these animals had a polyphylectic origin. Many years ago Lankester claimed that arthropods have developed from a single line of primitive Gnathopoda which arose by modification of parapodiabearing Annelida, and this same view holds to-day. It therefore follows that the annelid parapodia and the arthropod limbs are genetically identical structures. Among the most primitive classes, i.e., Crustacea and Trilobita, a biramous type of limb is very general, but in all other Arthropoda morphologically uniramous limbs prevail. Evidence of the occurrence of biramous 
limbs in any class other than the two aforementioned cannot be accepted as proven. In view of the remoteness of affinity between insects and Crustacea, the structural differences in the appendages of the two classes are very marked. Since it has long been customary to regard the crustacean biramous limb as the standard

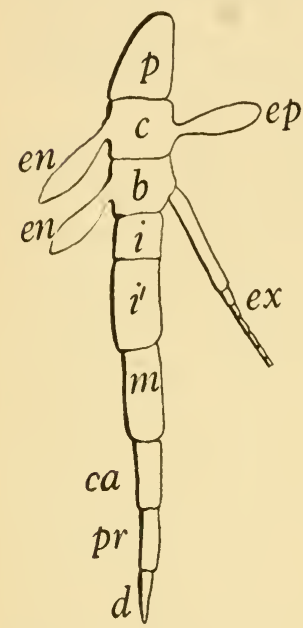

Fig. 10. Diagram of a complete biramous crustacean appendage. $p$, precoxa ; $c$, coxa ; $b$, basis ; $i$, preischium ; $i^{\prime}$, ischium; $m$, merus ; $c a$, carpus ; $p r$, propodus ; $d$, dactylus ; $e n$, en, endites ; $e p$, epipodite ; ex, exopodite.

for comparison, discussion of arthropodan limb-morphology usually has reference to that type of appendage. While advantage may be derived from a uniform standard for comparison, it involves homologies which require due precaution before being accepted as being proven.

A complete biramous appendage (Fig. 10) consists of a basal region or protopodite which bears the main shaft or endopodite and a usually smaller shaft or exopodite. The protopodite is divisible into a basal sclerite or precoxa, an intermediate sclerite or coxa, together with a distal element or basis. The endopodite consists of six clearly defined segments, each of which has received an individual name, viz., preischium, ischium, merus, carpus, propodus and dactylus (Hansen, 1930). The exopodite is composed of a variable number of divisions or sub-segments, while the coxa often bears an outer lobe or exite (commonly termed an epipodite). Both coxa and basis may ear's develop an inwardly directed masticacory process or endite (often known as a gnathobase).

The recent works of Hansen (1930), Snodgrass (1935) and of Ewing (1928) have contributed to the better understanding of the morphology of insect appendages. Much confusion has prevailed in the past owing to the neglect of evidence afforded by the musculature, with the result that there has been a great diversity of opinion with respect to the homologies of many of the parts concerned. The extensive researches of Hansen form a valuable 
contribution to the morphology of arthropod appendages in general, but this author, unlike Snodgrass and Ewing, has not concerned himself, other than incidentally, with their musculature.

A. Thoracic Appendages. In attempting to trace the homologies of the parts of the insect leg, the best starting point is the thoracic limb of a primitive Thysanuran such as Japyx or Campodea (Fig. 11). The leg is seen to be a uniramous appendage and it is

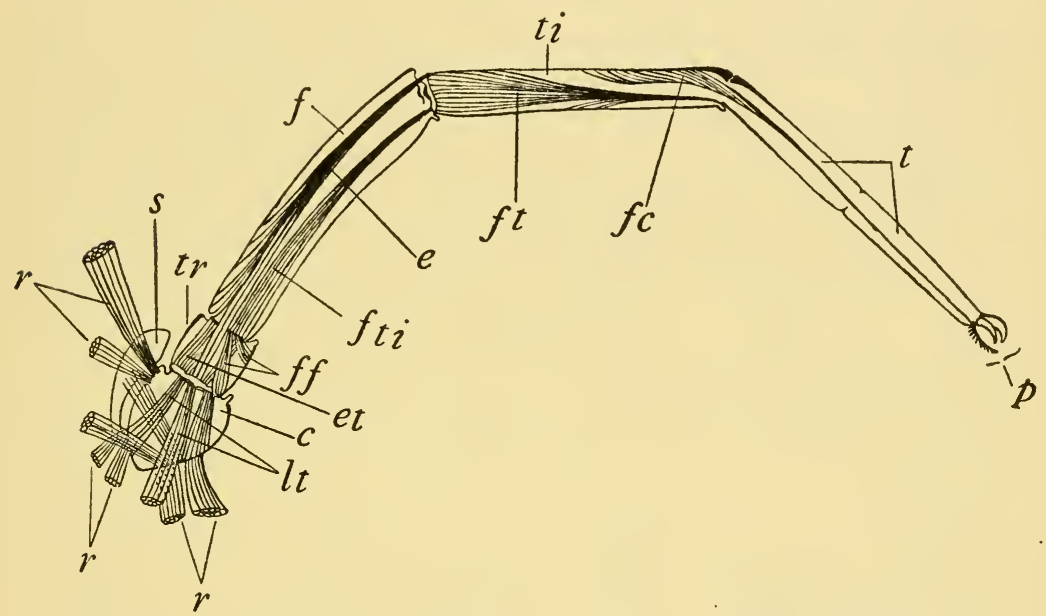

Fig. 11. Second leg of Campodea. $c$, coxa ; $e$, extensor of tibia ; $e t$, extensor of femur; $f$, femur ; $f c$, flexor of claws ; $f f$, flexor of femur ; ft, flexor of tarsus ; fti, flexor of tibia ; lt, levator of trochanter; $p$, pretarsus ; $r, r$, rotators of coxa ; $s$, subcoxa; $t$, tarsus ; $t$, tibia ; $t r$, trochanter. (From Ewing.)

generally agreed that it represents the protopodite and endopodite of a generalised crustacean limb. Examining such an appendage at its distal extremity, it will be observed that the apex of the tarsus bears a somewhat complex structure or pretarsus (transtarsus of Hansen) which is composed of the claws and their associated basal parts. The pretarsus is regarded as the homologue of the dactylus which has become highly modified so as no longer to show the character of a simple, claw-like segment. The variations in form and structure of the claws, and other parts of the pretarsus, found among insects and their 
larvæ, are familiar to entomologists. Most Thysanura exhibit a biungulate condition, the two claws being secondary formations situated on the base of the pretarsus. The claw of the original dactylus is retained in Japyx in a greatly reduced condition, while in Campodea it has either disappeared or is represented by a plumose arolium. In Lepisma, on the other hand, the feet are three-clawed owing to the retention of the claw of the dactylus between the paired or secondary claws. A simple, dactylus-like claw is retained in most Myriapoda, some Protura and among many insect larvæ. In the great majority of insects the original dactylus is represented only by the base of the pretarsus, which is partially invaginated within the tarsus. Among both insects and myriapods only a single muscle is associated with the pretarsus. This muscle, the flexor (depressor) of the claws, arises from the tibia, or from the tibia and femur, and, traversing the length of the tarsus, is inserted on a long tendon which is attached to the tractor plate of the pretarsus. The extensor (levator) muscle is never developed in these two classes, whereas in Crustacea both flexor and extensor muscles are evident, as well as in most of the Arachnida.

The tarsus, in its simplest form, is an undivided segment, well seen in the Symphyla, Japyx, Protura and many larvæ. There is little doubt that it is the homologue of the propodus of the biramous limb. Its division into segments, so characteristic of the Pterygota, is evidently a secondary condition possibly acquired to ensure greater flexibility. In whatever condition the tarsus is present, it never possesses intrinsic muscles : it is movable solely by means of either a flexor muscle, or by both flexor and extensor muscles, attached to its proximal border. The origins of these muscles are variable; in the Thysanura and the Symphyla they are located in the tibia, or in the femur and the trochanter, whereas in the Pterygota they commonly originate in the tibia.

The tibia or carpus is similarly movable by flexor and extensor muscles which arise within the femur to be inserted in association with the margin of the base of the tibia. The femur or merus varies greatly in its degree of development. Thus in polypodous forms, like the Symphyla and other Myriapoda, it is commonly 
a small segment only, but, with the development of the hexapodous condition, it acquires greater relative size and importance. In the Symphyla and other of the lower arthropods the femur is movable by muscles originating within the trochanter or coxa. Among the Insecta it is usually only provided with a reductor muscle whose origin is in the trochanter: in cases where there is no movement between the femur and trochanter this muscle is undeveloped.

The homologies of the next three leg-segments, viz., trochanter, coxa and subcoxa, have been productive of much diversity of opinion. In some insects, e.g., Machilis, certain Coleopterous larvæ such as Dytiscus and Philonthus (Fig. 12), together with the nymphs and imagines of Odonata (Fig. 13, C), the trochanters are double. The condition in the Odonata has been investigated by Snodgrass (1927), who has pointed out that the reductor femoris muscle arises in the second trochanter and is attached to the base of the femur. It is evident, therefore, that the first trochanter is without muscles and simply functions as the articulatory sclerite between the coxa and the second trochanter. Hansen has shown that the reductor femoris muscle is similarly located in the second trochanter in the larva of Dytiscus. The few writers who have
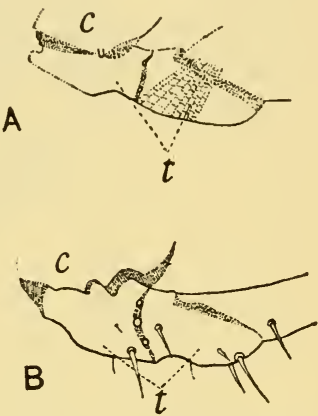

FIG. 12. A. Dytiscus sp. larva. Part of first left leg showing divided trochanter, $t$. B. Philonthus aneus larva. Part of third left leg showing divided trochanter, $t$. $c$, apex of coxa. (From Hansen, 1930.) studied these parts, viz., Verhoeff (1903), Snodgrass (1927) and Hansen (1930), see in the divided trochanters a primitive condition. Hansen homologises them with the preischium and ischium of such Crustacea as the Pericarda and Anaspidacea. He further comments upon the fact that these two parts are fused in the majority of the Insecta, as in most Decapod Crustacea. In view of the remoteness of the affinity between insects and crustaceans, Hansen's conclusions are unlikely to find general acceptance. It is extremely unlikely that preischium and ischium would retain 
their individuality in such a highly evolved class as the insects, especially in view of the fact that they are only developed as separate sclerites among some of the more generalised Malacostraca.

On turning to the Chilopoda it will be noted that two segments similarly intervene between the coxa and femur-these are the trochanter and præfemur of Hansen or the first and second

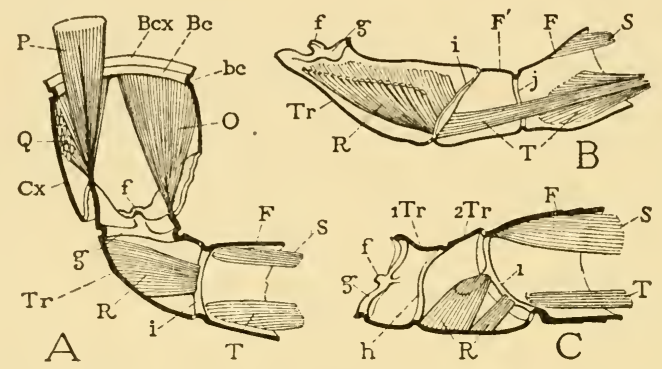

Fig. 13. Structure and musculature of the coxa, trochanter and base of femur. A, diagram of typical musculature of coxa, trochanter, and base of femur ; $B$, trochanter and base of femur of an ichneumonid (Megarhyssa), showing basal subdivision $\left(F^{1}\right)$ of the femur $(F) ; C$, trochanter and base of femur of middle leg of dragon-fly nymph (Aeschnidæ), showing double structure of the trochanter $(1 T r, 2 T r) . B c$, basicosta of coxa ; $b c$, basicostal suture ; $\boldsymbol{B} c x$, basicoxite ; $\boldsymbol{C} x$, coxa ; $\boldsymbol{F}$, femur ; $F^{1}$, basal subdivision of femur ; $f$, posterior coxo-trochanteral articulation; $g$, basicosta of trochanter; $h$, ridge between subdivisions of trochanter; $i$, basicosta of femur; $j$, femoral ridge setting off basal subdivision of femur ; $O$, levator muscle of trochanter; $\boldsymbol{P}$, thoracic branch of depressor of trochanter; $Q$, coxal branch of depressor of trochanter; $R$, reductor muscle of femur ; $S$, levator of tibia ; $T$, depressor of tibia ; $T r$, trochanter ; $1 \mathrm{Tr}, 2 \mathrm{Tr}$, first and second subdivisions of trochanter. (After Snodgrass.)

trochanters of other authors. The possibility that these parts are homologous with the divided trochanters of the Odonata should not be overlooked, and in Lithobius the first trochanter is greatly reduced, as in the Insecta.

In many of the parasitic Hymenoptera it is well known that the trochanter appears to consist of two segments, but comparative study over a series of genera reveals the fact that the second segment is merely the separately differentiated proximal end of the 
femur. In many cases the separation is complete, but in numerous other instances the so-called second trochanter is only demarcated from the rest of the femur by a weak suture or a slight constriction (Fig. 14). This conclusion is borne out by the relations of the reductor femoris muscle which is inserted on an inflexion from the base of the second segment of the trochanter : furthermore, the depressor muscle of the tibia passes through this segment and is attached anteriorly close to the insertion of the muscle just mentioned (Fig. 13, B).

The homologies of the coxa now require consideration. Snodgrass believes that the insect coxa is the homologue of the part bearing the same name in Crustacea and that the first trochanter of the

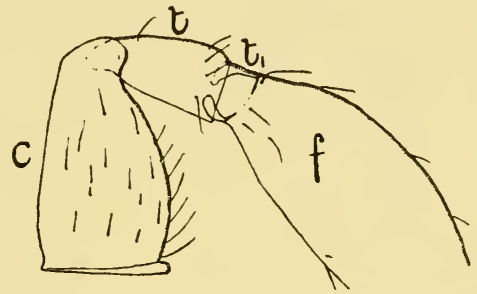

Fig. 14. Basal segments of fore leg of a Cynipid, Rhoptromeris eucera, female, showing rudimentary second trochanter $\left(t_{1}\right)$. c, coxa ; $t$, true trochanter; $f$, base of femur.

Odonata represents the basis which is otherwise wanting among insects. Hansen sees in the insectan coxa the counterpart of the basis, while the trochanter he believes corresponds with the true or primitive coxa of the biramous limb. The term subcoxa is not employed by Hansen, who uses the name pretrochantin (precoxa) for the sclerite in question. A great difficulty in this connection is the complex and extremely variable condition presented by the small basal leg-sclerites in different insects. The subject is discussed by Snodgrass (1927, 1935), who maintains that in the primitive insect leg a single proximal sclerite the subcoxa (præcoxa of Hansen) intervened between the coxa and the thoracic wall. Further discussion of this subject is given in the next section dealing with the pleura. All that need be stressed here is that while the homologies of the four distal segments of 


\begin{tabular}{|c|c|c|}
\hline 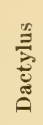 & 芶 & 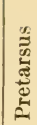 \\
\hline $\begin{array}{l}\stackrel{\text { D }}{\Xi} \\
\stackrel{\Xi}{0} \\
\stackrel{0}{0}\end{array}$ & 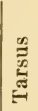 & 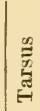 \\
\hline 产 & 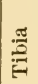 & 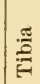 \\
\hline 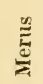 & 总 & 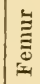 \\
\hline$\underset{\Xi}{\Xi}$ & 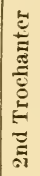 & 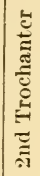 \\
\hline 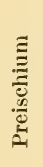 & 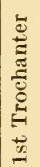 & 1 \\
\hline $\begin{array}{l}\frac{m}{3} \\
\dddot{m}\end{array}$ & iّ & 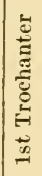 \\
\hline ֻّ & 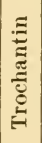 & 论 \\
\hline 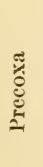 & 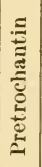 & 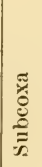 \\
\hline & 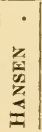 & 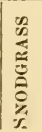 \\
\hline
\end{tabular}

the insect leg are tolerably clear, those of the proximal parts are highly involved. It is by no means certain whether any exact serial comparison with the generalised biramous appendage is possible in view of the evolutionary changes that have supervened. In the present stage of knowledge the interpretation of Snodgrass is in closer accord with the observed facts than that of other morphologists. A comparison of the views of Hansen and Snodgrass is given in tabular form on this page.

B. The Pleura. The origin and differentiation of the pleuron have been much discussed by morphologists in recent years, and, in this connection, the names of Heymons (1899), Prell (1913), Crampton (1914, 1926), Börner (1921), Becker (1923, 1924), Weber (1924) and Snodgrass (1929) may be specially mentioned. It is probable that Heymons' general contention that the pleural sclerites are in part, or mainly, derived from the subcoxa is substantially correct. Among the Apterygota the pleural sclerites are so variably developed that they exhibit no obvious indications of having been evolved along any common line of development. As Ewing (1928) has pointed out, in Campodea, Scutigerella and certain Collembola they are represented by a simple subcoxal or basal segment of the leg (Fig. 11). In Machilis a single, although reduced, sclerite is also present. In other cases there is no defined subcoxa, and its place is taken by two or more sclerites which present diverse phases of development. It is possible, however, to group these sclerites into a proximal, and usually arched, plate or trochantin over the base of the coxa, and a distal plate or series of plates forming the eupleuron. Single proximal and distal sclerites are evident, for example, in Acerentulus (Ewing), and in Isotoma and other Collembola (Fig. 15). In Lepisma, Snodgrass (1927) 
has shown that the same general arrangement holds good, except that the trochantin itself has apparently undergone division into two pieces. In Eosentomon germanicum, Prell (1913) has described eight small sclerites in the eupleural region, together with a typically arched band-like trochantin. The ill-defined and fragmented condition of the pleurites in this species renders it scarcely possible to homologise the eupleural plates individually with those of other insects.

In the Pterygota, notwithstanding the diversity of the sclerites that are developed in the pleural region, they appear to have been evolved to some extent along a definite line in response to the need for rigidity occasioned by the presence of wings. As Snodgrass remarks, they serve to brace the tergum against the downward pull exerted by the tergosternal muscles which function as elevators of the wings. He advances theoretical conclusions which suggest that the Pterygote pleuron was derived from the undivided subcoxa $(S c x)$ which became incorporated into the side wall of the body (Fig. 16). According to his theory the ventral part of the subcoxa has either become membranous or has united with the sternum $(S)$, while the remainder has given rise to the pleuron. In the early Pterygota

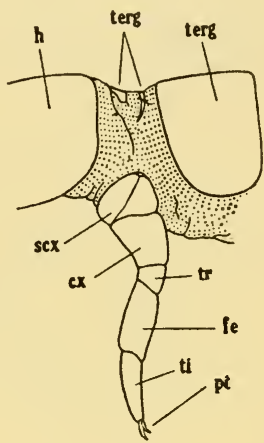

FIG. 15. Prothorax and leg of a Collembolan (Isotoma). $c x$, coxa ; fe, femur; $h$, base of head ; $p t$, pretarsus ; $s c x$, subcoxa ; terg, tergum ; $t i$, tibia ; $t r$, trochanter.

Ewing.) the subcoxa became divided into a narrow, arched trochantin $(T n)$, bearing a dorsal articulation $(a)$ with the coxa, and a larger sclerite or eupleuron $(E p l)$. The whole pleuron subsequently became strengthened by an internal ridge formed by a lateral inflexion of its wall, thus giving rise to the pleural suture (P.S.). The areas lying anteriorly and posteriorly to this suture become the episternum $(\boldsymbol{E})$ and epimeron $(\boldsymbol{E} p)$ respectively. In the more primitive insects the trochantin remains as a separate sclerite in front of the suture, while, posteriorly, it becomes merged into the epimeron. The 
sclerotised parts of the subcoxa, situated anteriorly and posteriorly to the coxa $(C x)$, form the pre- and post-coxal bridges $\left(P . B ., P^{\prime} . B^{\prime}.\right)$ and the ventral part of that sclerite may form, with the lateral edge of the sternum, a defined element termed the laterosternite $(L s)$. This, in few words, expresses the salient points in Snodgrass's views. In order to instance how hypothetical the problem is, it may be mentioned that Hansen (1930) rejects the theory as a whole and homologises the eupleuron and trochantin of Snodgrass with the subcoxa (precoxa) and coxa (çoxopodite) of Malacostraca; he further maintains that the insect coxa is the

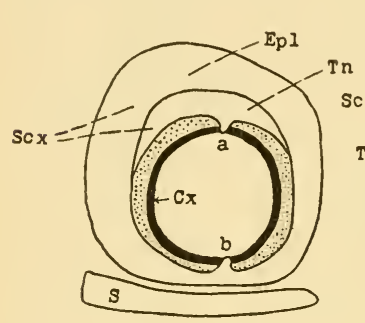

A

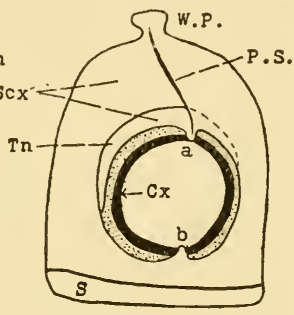

B

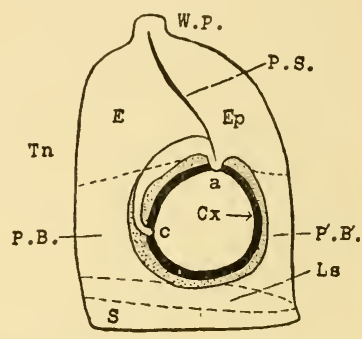

C

FIG. 16. Simplified diagrams representing the possible origin of the Pterygote thoracic pleurites from the subcoxa, according to Snodgrass (1929). A, hypothetical primitive condition; B, intermediate condition ; $\mathrm{C}$, stage with a differentiated pleuron ; $a$ and $b$, dorsal and ventral articulations of coxa $(C x) ; c$, secondary articulation with trochantin; W.P., pleural wing process. For explanation of other lettering, vide pp. 29 and 30.

homologue of the basipodite. The subcoxal origin of the pleuron is dismissed by him, and it would appear that he regards the episternum and epimeron as independently developed sclerites.

The foregoing conception of the origin of the insect pleuron is substantiated by following the development of the parts concerned among the lower Pterygota. Thus in the cicada Tibicina the original subcoxa shows in the nymph differentiation into rudimentary pleurites with the beginning of a demarcation with a small basal sclerite or trochantin. Roonwal (1937) has followed the development of the parts in question in Locusta and has demonstrated that the subcoxa is the fundament from which the future pleuron is derived. 
C. The Primitive Insect Leg. It will be gathered from the foregoing remarks that the primitive insect leg is composed of the following parts (Fig. 17). An undivided basal segment or subcoxa articulated distally with the coxa, the latter segment being hinged to the femur by means of the trochanter. Distally the femur articulated with a slender tibia, which in its turn carried an unjointed tarsus. At its apex the tarsus terminated in the pretarsus, which included a single median claw. From this primitive type it appears probable that the legs of all insects have been derived by various processes of modification. In certain of the Thysanura the primitive type is retained in an almost unaltered condition; in others the subcoxa becomes reduced and divided, while the tarsus may exhibit indications of imperfect segmentation. In the Collembola the most important ieatures are the functional subcoxa, a double trochanter in certain genera and the general absence of a tarsus. Among the Pterygota the subcoxa has disappeared as a definite entity and has become modified and incorporated in the thoracic wall to form the pleuron. The coxa, on the other hand, has for the most part assumed increased importance, but among Plecoptera it may be greatly

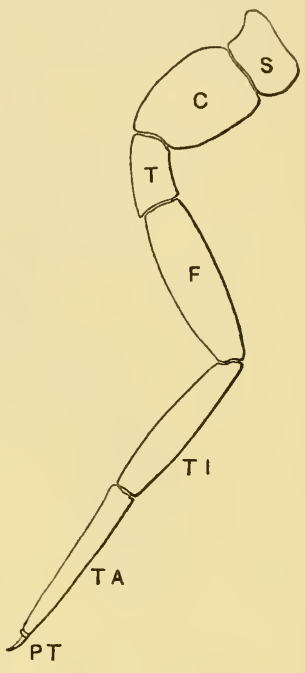

Fig. 17. The segments of a primitive insect leg. $C$, coxa ; $\boldsymbol{F}$, femur ; $P T$, pretarsus ; $S$, subcoxa ; $T$, trochanter ; $T A$, tarsus ; $T I$, tibia. reduced or even vestigial. The trochanter may undergo secondary division (Odonata) or receive a spurious additional joint formed from the proximal end of the femur (parasitic Hymenoptera). The femur remains as an independent segment, but in most coleopterous larvæ the tibia fuses with the tarsus. The lastmentioned segment is extremely variable, and most commonly becomes divided into five subsegments. The claws are frequently single in the larvæ, but paired in adult insects.

The more or less elongated femora and the small trochanters of 
the Insecta are features which seem to be correlated with hexapodous locomotion. In the Symphyla (Fig. 18) the same components of the leg are present as in the Insecta, but, on the other hand, in the first-mentioned class the femora are very short and the trochanters large and elongated. These same two features are also betrayed in Lithobius, Scolopendra and other Chilopoda, where they are correlated with polypodous locomotion in these animals. Once an hexapodous condition is assumed it

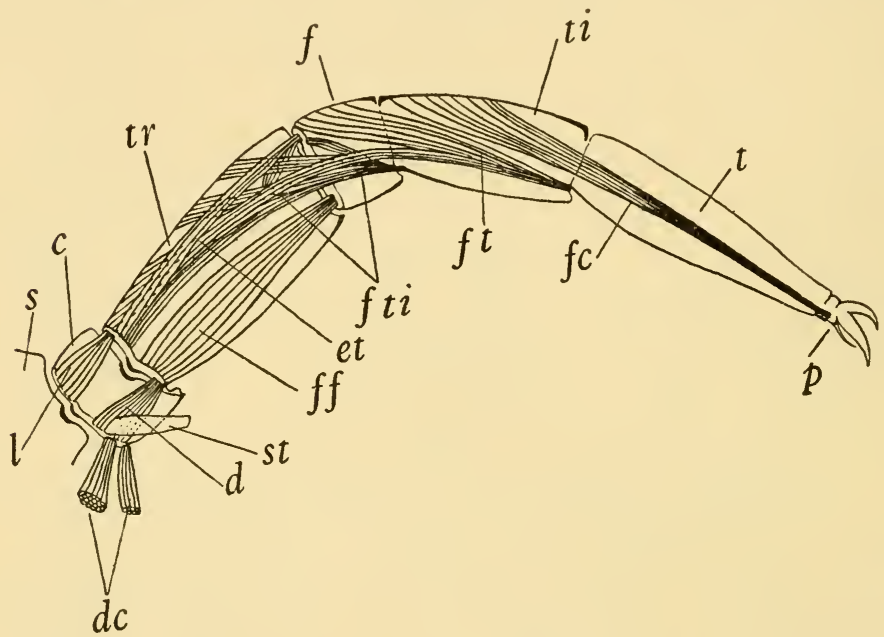

Fig. 18. Antepenultimate leg of Scutigerella. $d$, depressor of trochanter ; $d c$, depressor of coxa ; $l$, levator of coxa ; $s t$, stylus. Other lettering as in Fig. 11. (From Ewing.)

would appear that the trochanters lose some of their functional importance, while the femora become larger and more powerful.

D. The Cephalic Appendages. (a) The First Maxille. The generalised cephalic appendages are the first maxillx, and consequently the morphology of these latter organs is of primary significance in the interpretation of the homologies of the remaining gnathal appendages. The first maxilla is divisible into a basal region of complex structure bearing a serially segmented distal organ or palpus. It is generally agreed that the palpus represents the ramus or telopodite of a locomotory appendage, 
but very diverse views have been advanced to explain the morphology of the basal region of the maxilla. In recent years three interpretations have been put forward, viz., those of Börner (1909, 1921), Crampton (1922) and Snodgrass (1928). These are briefly summarised below.

1. According to Börner the cardo of the maxilla is the counterpart of the subcoxa, and the stipes the homologue of the coxa,

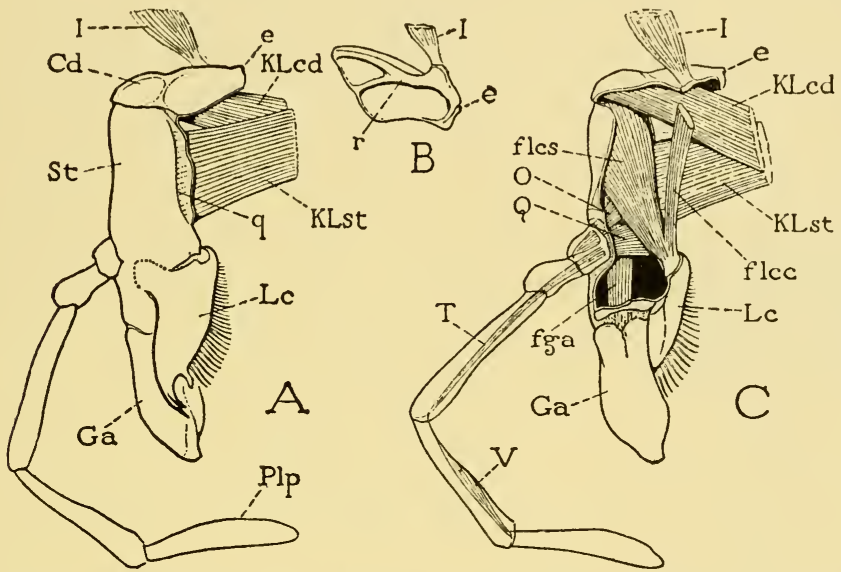

F1G. 19. Maxilla of Periplaneta. A, left maxilla, posterior (ventral) surface. $\mathrm{B}$, internal surface of cardo. $\mathrm{C}$, right maxilla, anterior (dorsal) view, showing muscles. $\boldsymbol{C d}$, cardo ; $e$, articulation of cardo with cranium ; fga, flexor of galea ; flcc, cranial flexor of lacinia ; flcs, stipital flexor of lacinia ; $\boldsymbol{G} a$, galea ; I, promotor of cardo ; $K \boldsymbol{L} \boldsymbol{c} \boldsymbol{c}$, adductor of cardo ; $K \boldsymbol{L} \boldsymbol{s t}$, adductor of stipes ; $L c$, lacinia ; $O$, levator of palpus ; $P l p$, palpus ; $Q$, depressor of palpus; q, sub-marginal suture (and internal ridge) near inner margin of stipes ; $r$, internal ridge of cardo ; $S t$, stipes ; $T$, depressor of fourth segment of palpus ; $V$, depressor of fifth segment of palpus. (After Snodgrass.)

while the galea and lacinia are coxal endites. The palpifer is a subdivision of that part of the stipes which bears the palpus and galea; it is, therefore, not a true segment.

2. According to Crampton the cardo represents the coxa, and the stipes is the homologue of the basis, while the galea and lacinia are endites belonging respectively to the stipes and palpifer. In this interpretation the palpifer is a true segment and represents the first segment (or ischium) of the palpus. 
3. The theory of Snodgrass is more in accordance with that of Börner than of Crampton. According to him the cardo and stipes, however, are not separate segments, but represent the secondary division of a single original basal segment. The galea and lacinia are endites of this basal segment and the palpifer is a secondarily demarcated portion of the stipes as maintained by Börner.

The theoretical views of Snodgrass are largely formulated from a study of the basal musculature of the maxillæ (Fig. 19), and in this connection it needs to be borne in mind that such muscles may not necessarily retain their original functions or their former dispositions. In accordance with alterations in the basal articulation of an appendage, and in the number of its constituent segments, the muscles concerned may shift their positions or become segregated into secondary groups of fibres. Comparative studies of progressive changes in the muscles are greatly needed before we are in a position to ascribe to such criteria their due morphological values. Snodgrass's contribution is important in that it discountenances attempts to determine homologies solely upon the basis of a study of the sclerotised parts, without reference to other considerations.

Since the margin of the basal cavity of the maxilla in the more primitive insects surrounds the bases of the cardo, stipes and lacinia, and the tergal and sternal muscles of the maxilla are distributed to these parts, Snodgrass concludes that the latter are all differentiations of a single primitive basal segment. The galea and lacinia he regards as subdivisions of a single endite carried by the stipes, since they are flexed by muscles having their origin in the latter sclerite. In supporting Börner's contention that the palpifer does not represent an independent segment, he lays stress on evidence afforded by the basal palpal muscles. These muscles, which move the palp as a whole, have their origin within the stipes and pass directly through the palpifer to be inserted with the proximal segment of the palpus; furthermore, no muscles arise within the palpifer or are inserted upon it.

While the study of the completed maxillæ and their musculature affords scope for more exhaustive investigation, the differentiation 
of the parts involved during the later phases of development remains to a large extent unexplored. Fvidence afforded by the musculature is unquestionably important, but, for reasons already stated, too exclusive reliance upon this one criterion is undesirable. It is more especially on this account that Börner's contention that the cardo is homologous with the thoracic subcoxa remains an open question. Furthermore, additional evidence is necessary, perhaps more especially from the developmental aspect, before Crampton's view that the palpifer is a reduced segment bearing the galea as an endite can be regarded as untenable.

(b) The Labium (Second Maxilla). Evidence, afforded by development and by comparative morphology, provides proof that the labium is formed by the fusion of the second maxillæ. The correspondence of the free distal parts of each half of the labium with similar parts of the first maxillæ is undisputed. Consequently it is agreed that the palpi are homologous in the two cases, and that the paraglossæ and glossæ are the respective counterparts of the galea and lacinia of the first maxillæ. In so far as the basal labial sclerites are concerned, the homologies are problematical, and it has been too

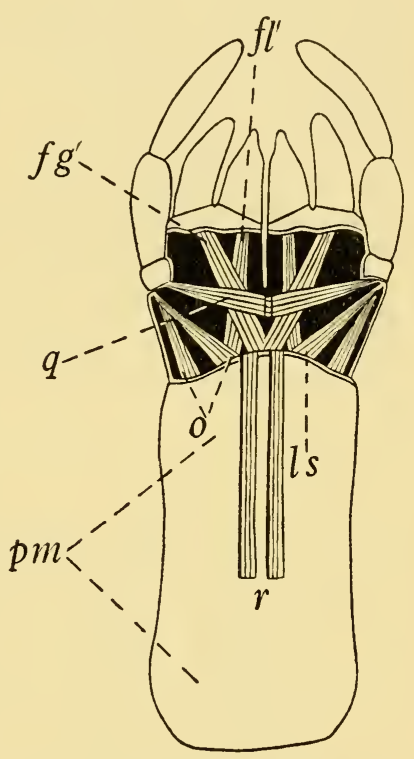

FIG. 20. Labium of Mastotermes. pm, postmentum. For explanation of other lettering, see Fig. 21. readily assumed that the mentum and submentum are formed by the simple fusion of the stipites and cardines respectively.

A comparative study of primitive types points to the conclusion that the labium is composed primarily of a distal region or prementum which is demarcated by means of the labial suture from a proximal or basal region-the postmentum (Fig. 21). The prementum may be defined as the region bearing the ligula and 
palpi, and from which the muscles of these parts take their origin. In its most generalised condition it is a paired structure, as is seen, for example, in the Machilidæ, Blattidæ, Plecoptera and Isoptera (Fig. 20). It is probable that these paired components are the equivalents of the stipites of the first maxillæ. Furthermore, the muscles of the prementum appear to be directly comparable with those of the palpi and the terminal lobes of the

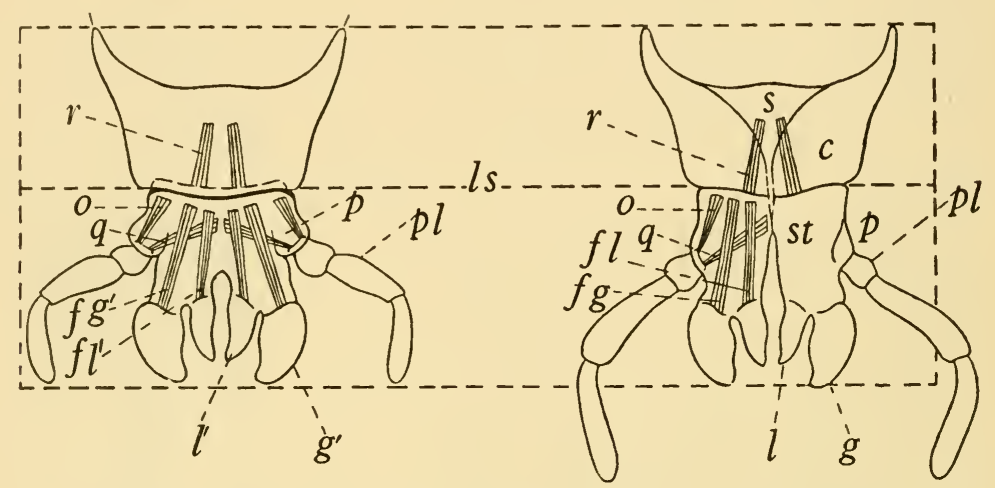

FIG. 21. Diagram expressing the origin of the labium from a pair of united maxillæ. Left, generalised labium. Right, theoretical union of second maxillæ incorporating, in part, the labial sternum. $c$, cardo ; $f l$, flexor of lacinia ; $f l^{1}$, flexor of glossa ; $f g$, flexor of galea; $f g^{\prime}$, flexor of paraglossa ; $g$, galea ; $g^{\prime}$, paraglossa ; $l$, lacinia ; $l^{\prime}$, glossa ; $l s$, labial suture ; $o$, levator of palpus ; $p$, palpiger ; $p l$, palpus ; $q$, depressor of palpus ; $r$, median or stipital refractors; $s$, labial sternum. The broken line $(l s)$ leading to the labial suture divides the labium into a proximal element or postmentum and a distal element or prementum. (Adapted from Snodgrass, 1931.)

first maxillx. 'The postmentum is, in many insects, subdivided in mentum and submentum : much importance, from the morphological standpoint, has been given to these two subdivisions in the past, but it now appears probable that their development is solely due to a secondary division of an original single and entire postmentum. The only muscles arising from the postmentum are the median retractors of the labium: neither the mentum nor submentum develops any muscles other than those already evident in relation with the postmentum. These muscles, further- 
more, undergo no modification whether the latter region be in its undivided or subdivided condition.

The homologies of the basal region of the labium (postmentum or mentum plus submentum, as the case may be) have given rise to considerable discussion. The lateral articulation of the basal angles of this plate with the margin of the cranium, in Orthopteroid insects, shows considerable similarity with the articulations of the cardines of the maxillæ. Snodgrass (1935) maintains that the postmentum corresponds with the cardines of the first maxillæ which have become completely amalgamated with the primitive sternum of the labial segment (Fig. 21). Other writers have claimed that the postmentum, or at least the submentum, is wholly a sternal derivative. The recent studies of Roonwal (1937), on Locusta, show that the postmentum contains no sternal component. If this conclusion be substantiated it would appear that the postmentum has been formed entirely by the fusion of the originally separate parts comparable with the cardines of the first maxillæ. Those who wish to follow recent work on the morphology of the labium should consult the writings of Snodgrass (loc. cit.) and Walker (1931).

Reference needs to be made to the gula, which is most usually developed in insects in which the heads are prognathous (Walker, 1932). In such cases the ventral (or, morphologically, the posterior), side of the head becomes lengthened by an extension of the postgenal areas. The result is that articulations of the maxillæ and labium become carried forwards so as to become separated by a more or less variable distance from the occipital foramen (Fig. 22). It is in the intervening area thus formed that the gula is developed. The researches of American morphologists, notably Crampton (1921, 1928), Stickney (1923) and Snodgrass (1928), have done much to establish the morphological identity of the gula upon a sound basis. It is more frequently developed in Coleoptera than in any other order, but it also occurs in Neuropterous larvæ. The gula is a sclerite which has become demarcated by the forward migration of the tentorial pits, or mouths, of the invaginations of the posterior arms of the tentorium (Fig. 22). According to Snodgrass, the ventral parts of the post-occipital sutures terminate 
around the tentorial pits, but when the latter pass forwards the sutures just named are carried with them, and are termed the gular sutures. The median cranial area, thus delimited by these sutures, is the gula, and it partly or wholly occupies the region between the submentum and the occipital foramen. A graduated

A

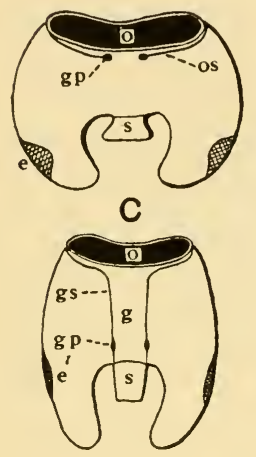

B

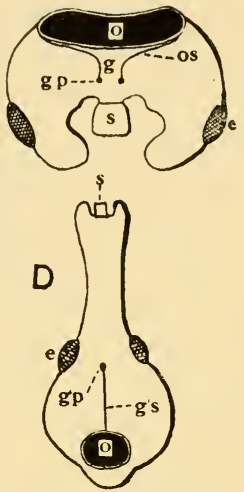

FIg. 22. Diagrammatic figures of the ventral region of the head illustrating the origin and development of the gula among Coleoptera. Excepting the submentum, the mouth-parts are not shown. A, generalised condition ; $\mathrm{B}$, rudimentary gula; C, complete, well-developed gula; D, condition found in weevils and a few other Coleoptera in which the gular sutures are confluent. $e$, compound eye ; $g$, gula ; $g p$, tentorial (or gular) pit ; gs, gular suture; $o$, occipital foramen ; $o s$, post-occipital suture; $s$, submentum. series of stages, from the beginnings of the formation of the gula up to its evolution as a large chin plate, can be traced among different Coleoptera. When it is fused with the submentum, or its frontal margin is illdefined, the anterior limit of the gula can be generally fixed by an imaginary line between the two tentoriai pits. Among termites, the postmentum and gula are fused, in the soldiers, to form one continuous and greatly elongated ventral plate. In the Rhynchophora (Fig. 22, D) and a few other beetles, the gula is suppressed owing to the meeting of the two gular sutures in the mid-ventral line of the head.

It is by no means certain, however, whether the gula is invariably formed in the manner thus described. Thus in the Embioptera there is no evidence to show how the gula region in those insects has been formed, since there are no traces of gula sutures present (vide Walker, 1933). The so-called gula region of Hemiptera requires investigation, especially in view of the classificatory importance attached to it by some systematists.

(c) The Mandibles. In the Apterygota the prevailing type of 
mandibles differs in important features from that of the higher insects (vide Snodgrass, 1931, 1935). In their musculature the mandibles of Japyx, for example, show a very evident resemblance to that displayed in the jaws of the Chilopoda and some of the lower Crustacea. The mandible of Japyx is an elongated organ which is hinged to the head by means of a single dorsal articulation. It is moved by means of four muscles, two being dorsal and two ventral (Fig. 23, A). The dorsal muscles are the promotor and
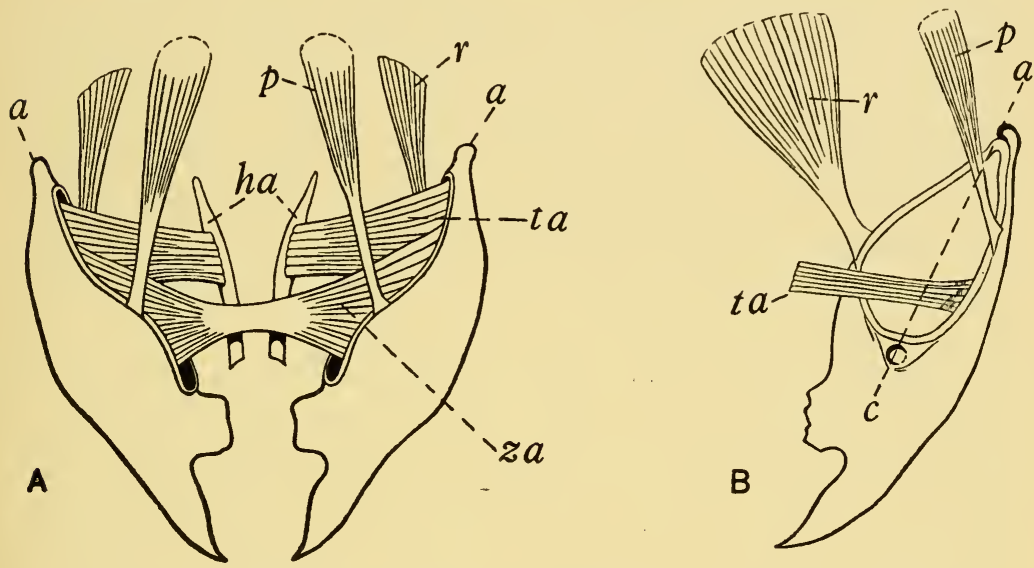

Fig. 23. Diagram of typical A, apterygote, and B, pterygote mandibles. $a$, primary articulation with cranium; $a-c$, secondary longitudinal axis of movement on cranium; ha, hypopharyngeal apophysis; $p$, dorsal promotor; $r$, dorsal remotor; $t a$, tentorial adductor; $z a$, zygomatic adductor. (After Snodgrass, 1931.)

remotor muscles, while the ventral muscles comprise two groups of fibres that are, functionally, adductors-the zygomatic and tentorial adductors of Snodgrass. As the latter author has pointed out, in the Pterygota (Fig. 23, B) each mandible has developed a long axis of attachment and instead of having a single articulation it has developed two. One of these is the condyle which represents the single articulation of the Apterygota, while the other, the facet or ginglymus, is a secondary acquisition. Owing to this change in the articulation, the muscles undergo correlated modifications. The promotor and remotor muscles become respectively 
the abductor and adductor muscles. The ventral adductor muscles of the Apterygota either disappear or are represented by a greatly reduced tentorial adductor which is found in the Orthoptera, Isoptera and the nymphs of some of the lower orders. Since the mandibles perform their hardest work by means of inward movement, the adductor muscles are more powerfully developed than the abductors.

(d) The Antenna. That the insect antenna is the homologue of the crustacean antennule is generally accepted. This conclusion receives support from the fact that in many of the lower insects the tritocerebrum bear evanescent appendages which are to be regarded as the last traces of the crustacean antennæ. It naturally follows that at some remote stage in their evolution the insects and the myriapods, along with them, were deriver from some early crustacean form, otherwise the occurrence of these tritocerebral appendages is left unexplained and cannot be accounted for.

The scape of the insect antenna is the protopodite, and in the majority of insects the muscles which move the flagellum as a whole are located in this segment. In the Entognatha, however, researches by the present writer, not at present published, show that in the Entognatha among Thysanura a very different condition prevails. The moniliform antennæ of these primitive insects bear muscles in each individual segment and a similar arrangement prevails in the Symphyla and certain other myriapods. The relations of the multiannulate antenna of Machilis and Blatta, for example, with the segmented antenna of Japyx is being studied, but insufficient data are at present available to justify further discussion on the subject for the time being. 


\section{CHAPTER II}

\section{SOME ASPEGTS OF MORPHOLOGY_continued}

E. The Abdominal Appendages, p. 41. 4. The Genttalia, p. 43. The Female, p. 43 ; The Male, p. 45 ; Literature, p. 49.

E. The Abdominal Appendages. The frequent retention of abdominal appendages in insect embryos is interpreted as a survival of primitive organs inherited from polypodous ancestors. In the larvæ of Lepidoptera, and of some other orders, certain of these appendages develop into functional organs, while the remainder become resorbed. In the imagines a variable number of abdominal appendages are retained in the Apterygota, but among the Pterygota their sole survivals are represented in parts of the genitalia (vide p. 43) and by the cerci.

In the Machilidæ, among Thysanura, the abdominal sterna are more or less triangular shields, while in Nicoletia each is divided into an anterior and posterior sclerite (Fig. 24). In close contact with each sternum is a pair of lateral plates

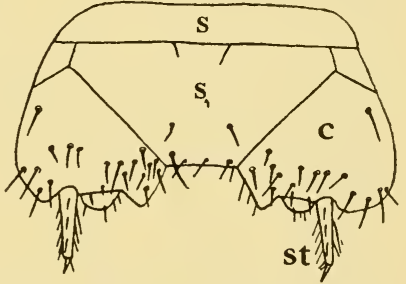

Frg. 24. Nicoletia (Anelpistina) wheeleri. Third abdominal sternum $s, s_{1} ; c$, coxite ; st, stylus. (From Silvestri.) or coxites which frequently meet along the median line. The latter plates are believed to represent the basal parts of true appendages whose distal parts have atrophied. They are termed coxites for the reason that it is maintained they represent greatly flattened coxæ, but, in some cases at least, possibly other of the basal segments may have become incorporated with them. In Japyx and related Thysanura, the coxites are completely fused with the sternum, and the entire plate thus constituted is a coxosternum. 
In the Machilidæ the second to ninth pairs of coxites each bear styli, but in other families the styli are more restricted, and in the Lepismidæ they may be present only in relation with the eighth and ninth pairs of coxites ; in the Japygidæ they are borne on the first to seventh coxosterna.

In the Protura the first three abdominal segments bear greatly reduced appendages, which, in the Eosentomonidx, are twojointed. These appendages are comparable with coxites which, in the two-jointed condition, include the rudiment of a second leg-segment (Fig. 25). The appendages of the first abdominal segment in the Campodeidx appear to be of a comparable nature. In the Collembola true abdominal appendages are represented by

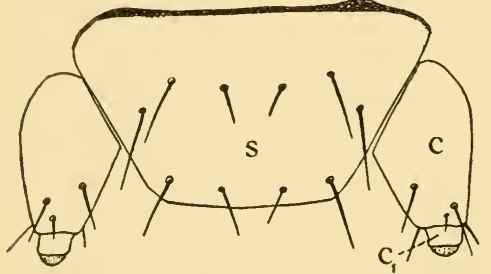

Fig. 25. Eosentomon. Third abdominal sternum $s$, showing, two-segmented appendages; $c$, coxite; $c_{1}$ second segment of appendage. Berlese.) the ventral tube, the hamula and the furcula which are derived by direct conversion from rudiments borne on the corresponding segments in the embryo.

The morphological significance of the styli has been so often discussed that only brief reference to the subject is required here. It appears probable that the styli which are borne upon a variable number of the abdominal segments in Thysanura (Fig. 24) are homologous with similar organs present in the relation with the limb bases in Symphyla (Fig. 18). In two groups these styli are in similar close relations with eversible sacs. It follows, therefore, from this homology that the styli of Thysanura are not to be regarded as vestiges of true limbs as has often been contended. The styli borne on the ninth sternum of the males of the Isoptera, Ephemeroptera and of many Orthoptera are evidently homodynamous with those just referred to.

As regards the cerci, it is well established on embryological grounds that they are the persistent true appendages of the eleventh abdominal segment. Each cercus is borne on the membrane between the epiproct and paraprocts, the two latter 
sclerites being the remains of the sternum of the eleventh segment (Fig. 26). In cases when the cerci apparently arise from the tenth abdominal segment, the eleventh segment having atrophied, examples are afforded of Lankester's sixth law of metamerism. The atrophy of the eleventh segment has resulted in its appendages becoming transferred to the tenth segment. The terminal pair of abdominal appendages found on the ninth or tenth abdominal segments of various larva are of a problematical nature, especially those which are devoid of articulation and arise from the dorsum of their segment. They are probably best referred to under the general term of cercoids in reference to their frequent resemblance to cerci.

\section{The Genitalia}

During recent years much attention has been given to the genitalia of insects, and more especially to the male organs, in view of their importance in taxonomy. The whole subject has become greatly involved owing to the lack of any convenient, uniform terminology, and to uncertainties which exist with respect to the homologies of the parts concerned in different orders. The greater part of the literature deals with the completed organs and especially those of the male. Ontogenetic studies have not been pursued with the same enthusiasm. They are dependent upon obtaining supplies of material in the proper successive stages which are often difficult to provide. This fact, coupled with the obscurity which so often attends the initial growth phases of the genitalia and the difficulties of interpretation that are involved, has resulted in a large field, so far, being inadequately explored. Nevertheless, the writings of Singh Pruthi (1924, 1925), Mehta (1933), Metcalfe (1932) and others have advanced our knowledge of the developmental aspects of the subject.

The Female. It is well known that a typical, completely formed insect ovipositor is composed of three pairs of valves which are located in relation with the eighth and ninth abdominal segments (Fig. 26). These valves arise in connection with the basal plates or coxites of their respective segments, so that the coxites of the eighth segment bear one pair of such valves, while 
the coxites of the ninth segment bear two pairs. The anterior and posterior valves are outgrowths of the medio-lateral margins of their respective coxites and are regarded as secondarily developed formations known as the gonapophyses. The lateral pair of valves borne by the ninth segment on the other hand represent the greatly drawn out coxites and are therefore the modified bases of an original pair of abdominal appendages. The styli, however, are very rarely retained: they are present, for

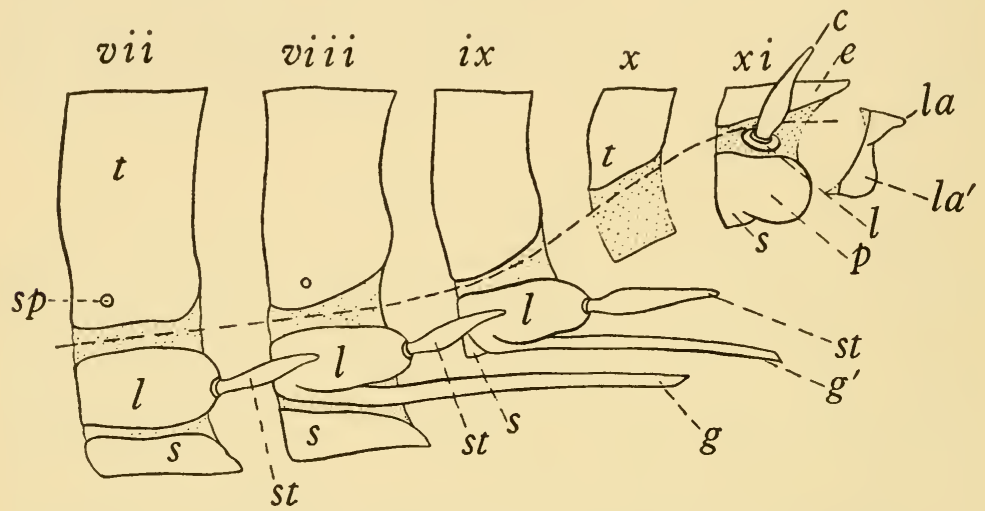

Fig. 26. Diagram illustrating structure of abdomen and morphology of the ovipositor. $c$, cercus ; $e$, epiproct; $g, g 1$, first and second gonapophyses; $l$, limb base (coxite); la, lanina supraanalis ; $l a^{1}$, lamina subanalis ; $p$, paraproct ; $s$, sternum ; $s p$, spiracle; $s t$, stylus ; $t$, tergum ; vii-xi, seventh to eleventh terga. (From Snodgrass, 1931.)

example, in the rudimentary ovipositor of Mastotermes (Fig. 27) and in the more highly developed organs of some of the Odonata.

It is well known that in Machilis the anterior and posterior valves develop alike in connection with their respective segments and form the ovipositor. The lateral valves are undeveloped as such and remain as unmodified coxites, bearing long styli. While the homologies of these lateral valves have been believed to remain constant in different orders, observations by Nel (1929), on the development of the ovipositor in Locustana, Colemania and Blatella, appear to indicate that the anterior valves are modified coxites like the lateral pair, and are consequently not 
homologous with the inner valves. Also, Walker's figures (1919) of the developing ovipositor of the grasshopper Conocephalus are suggestive of a similar homology. On the other hand, careful ontogenetic studies are needed from the first instar onwards in order to ascertain whether or not any change in the relative positions of the valves in question takes place during growth. The study by Denny (1897) of the ovipositor of Blatta orientalis shows that the anterior and posterior valves are homologous parts, the lateral valves alone being derived from coxites. It would seem remarkable if, in such closely allied genera as Blatta and Blatella, the anterior valves of the ovipositor should develop in a different manner in the two cases, and it is evident that further research is necessary before any conclusions to the effect that the lateral ovipositor valves are of different origin among insects belonging even to the same major group.

The Male. In the males of those insects whose genitalia are fully developed two sets of organs, forming the completed parts, are present. These organs arise from rudiments which

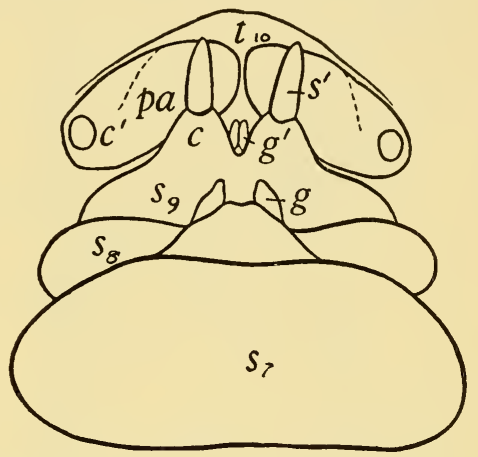

Fig. 27. Ventral terminal abdominal segments of a female soldier of Mastotermes. $c$, coxite ; $c^{\prime}$, base of cercus ; $g$, ventral or anterior valve of ovipositor ; $g^{\prime}$, intermediate or posterior valve of ovipositor; $p a$, paraproct ; $S_{7}-S_{9}$, seventh to ninth sterna ; $s^{\prime}$, stylus or dorsal (lateral) valve or ovipositor; $t_{10}$, tenth tergum. (Adapted from Crampton.) develop in relation with the ninth sternum of the abdomen. The outer organs are known as claspers, harpagones or valves and are the functional organs used for grasping the abdomen of the female during coitus. These organs will be considered first. They are commonly regarded as developments of the coxites of their segments, but Snodgrass $(1935,1936)$ has claimed that the balance of evidence is in favour of their being regarded as modified styli rather than coxites (Fig. 28). As this morphologist points out, the claspers are movable lobes which, in some cases, are supported 
on definite basal plates, or coxites, while in others the coxites are amalgamated with the ninth sternum to form a compound plate or coxosternum. The claspers are each provided with muscles arising either from the coxites or from the coxosternum, as the case may be, and inserted into their bases. It appears probable that in cases where the coxites are fused with the adjacent sternum the styli alone form the claspers, as Snodgrass maintains. In other cases where the coxites are free, they themselves may be movable by muscles arising from the sternum of their segment,

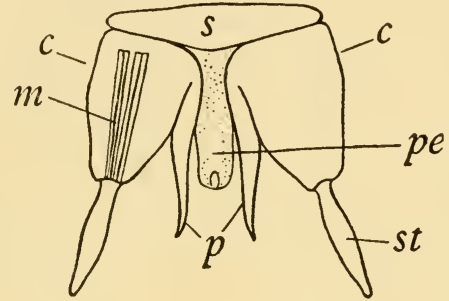

A

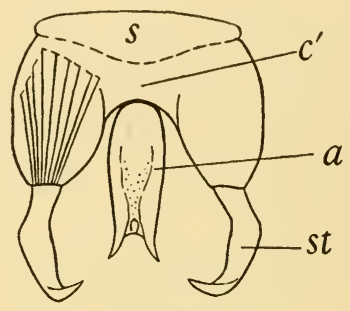

B

FIG. 28. Morphology of male external genitalia. A, generalised condition. B, specialised condition (penis and parameres united). $\quad a$, ædeagus ; $c$, coxite or limb base ; $c^{1}$, fused coxites ; $m$, muscle of stylus ; $p$, parameres ; $p e$, penis ; $s$, ninth sternum ; $s t$, stylus. (From Snodgrass, 1931.)

and in such cases the functional clasping organs are formed by the coxites together with their styli.

Among Orthoptera the claspers are not developed. In Grylloblatta, Walker (1922) has shown that the coxites are free and bear but little modified styli at their apices (Fig. 29). This condition is evidently a primitive one and does not differ in essentials from that prevalent in the Machilidx among the Thysanura. In other Orthoptera the coxites are fused with the sternum to form a coxosternum: in the Blattidx and some other families unmodified styli are retained, but they perform no copulatory function. The same condition is found among Isoptera. Among the Ephemeroptera, Mecoptera and Trichoptera the coxites are large and free and these plates, along with their styli, are to be regarded as forming the functional clasping organs. 
In most of the Lepidoptera and in some of the Diptera the only movable organs are formed by the modified styli. In the Lepidoptera the coxosternum is termed the vinculum, while the claspers are often known as harpes (vide Mehta, 1933). Among Diptera, Snodgrass has shown that in the lower forms (Tipulidæ) the coxites and styli are both separate and distinct, but more commonly the coxites are fused with their sternum. In the Homoptera, Singh Pruthi (1924, 1925), George (1929) and Metcalfe (1932) have shown that claspers are undeveloped as such since their rudiments come to form the subgenital plates. In Heteroptera, Snodgrass (1935) states that claspers are present, but the ontogenetic studies of Christophers (1922) seem to point to the conclusion that the organs in question are parameres. The true condition of affairs in the Hemiptera as a whole requires thorough investigation and generalisations either from the study of the completed organs alone or from an ontogenetic study of one or two types only are not trustworthy. In Coleoptera, claspers are

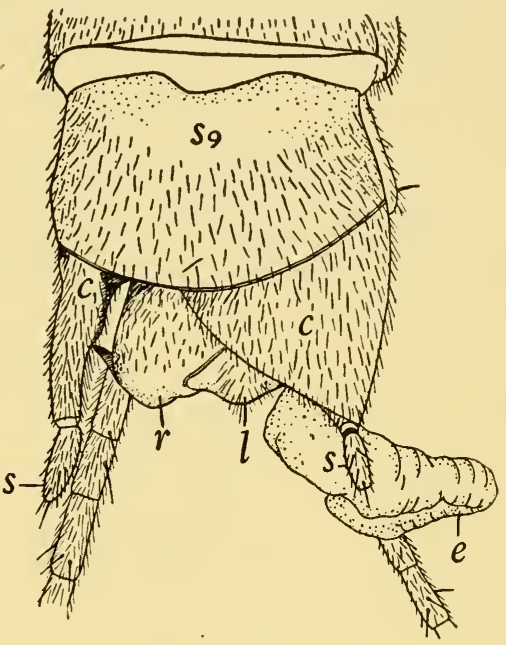

Fig. 29. Grylloblatta, male; ventral view of terminal segments. $c, c$, coxites ; $e$, eversible sac ; $r, l$, right and left lobes of paramere; $s, s$, styli ; $s_{9}$, ninth abdominal sternum. (From Walker.) wanting : in Tenebrio, a pair of evanescent papillæ are recognised by Singh Pruthi (1924A) as being vestiges of these appendages. Among the Hymenoptera claspers are usually regarded as being present, although Snodgrass concludes that they are seldom to be found in that order.

The penis and its associated parts form the inner organs of the male genitalia. A number of workers have shown that a pair of lobes arise in a median position in regard to the ninth sternum. These lobes develop as apparent outgrowths near the hind border of 
that segment or within a genital cavity or pocket which surrounds the gonopore. In either case, the lobes in question ultimately fuse to form the penis. This relatively simple condition has been described by Metealfe (1932A) in Gastroidea and Anthonomus among Coleoptera and by Mehta (1933) in Pieris and some other Lepidoptera. In other cases these lobes undergo subdivision, thus giving rise to a pair of outer components or parameres and an inner pair which unite to form the penis. This condition has been
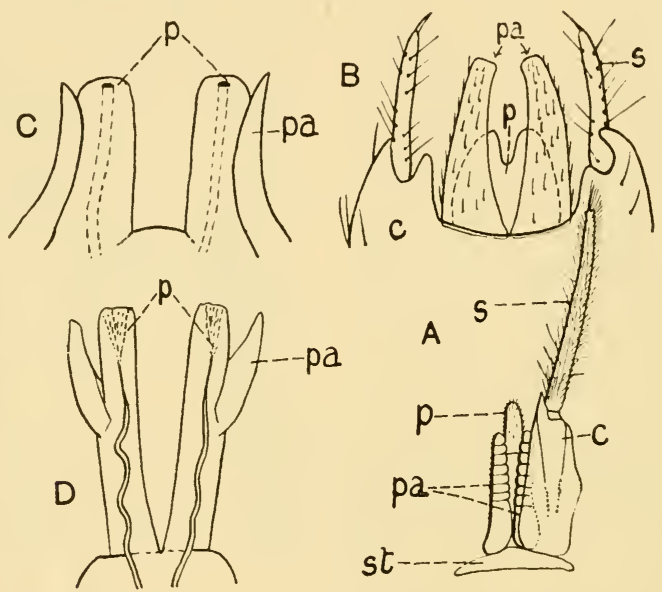

FIg. 30. Penis $(p)$ and parameres $(p a)$ of $A$, Pedetontus palcarcticus Silv. (Machilidæ). (After Silvestri.) B, Nicoletia wheeleri Silv. (Lepismidæ). (After Silvestri.) C, Ephemeroptera (Callibatis). (After Walker.) D, Dermaptera (Anisolabis). (After Walker.) (c, coxite ; $s$, stylus ; st, ninth sternum.)

shown to obtain in certain Coleoptera (Singh Pruthi, 1924; Metcalfe, 1932A). Earlier observers have also described the same state of affairs in some Lepidoptera as well as in Orthoptera, Hymenoptera and Diptera. It is generally accepted that the penis was originally a paired organ, and this generalised state of affairs is retained among Ephemeroptera (Fig. 30, C) and Dermaptera (Fig. 30, D). Among generalised members of the last-mentioned order the parameres, however, instead of being free, have become mere outgrowths of the penes. In the Thysanura 
Nicoletia (Fig. 30, B) the penis is slightly bifurcate distally and apparently thus still retains traces of its former double origin.

With regard to the homologies of the genitalia in the two sexes, the present state of knowledge does not shed much light on the subject. The claspers of the male, however, appear in a general way to be the counterpart of the lateral valves of the female ovipositor. When the coxites actually participate in the formation of the claspers they are homologies with the ovipositor valves just referred to. On the other hand, the styli, which are so important a part of the male genitalia, are, except in a few rare cases, no longer evident in the female. With regard to the inner parts of the male genitalia, it is not possible, on the evidence at present available, to discuss the subject to any advantage or arrive at a definite conclusion respecting their homologies.

\section{General}

\section{Literature}

Hoskins and Craig, 1935. Physiol. Rev., XV., 525.

Imмs, 1936. Trans. Soc. Brit. Ent., III. Also "Nature," March 9th, 1937.

SNODGRASS, 1935. "Principles of Insect Morphology." New York and London.

WeBER, 1933. " Handbuch der Entomologie." Jena. Wigglesworth, 1934. "Insect Physiology." London.

\section{Segmentation of the Head}

Easthai, 1930. Phil. Trans. Roy. Soc. B., CCXIX., 1.

Folson, 1930. Bull. Mus. Comp. Zool. Harvard, XXXVI., 87.

Hansen, 1930. "Studies on Arthropoda,"' III. Copenhagen.

Hanströм, 1927-30. Zeitschr. Morph. Ökol. Tiere, VII., 543 ; XI., 152 ; XIII., 329 ; XIX., 732.

1928. "Vergleichende Anatomie des Nervensystems der wirbellosen Tiere." Berlin.

Manton, 1928. Phil. Trans. Roy. Soc. B., CCXVI.

Mellanby, 1936. Quart. Journ. Mic. Sci., LXXIX., 1.

Philiptschenko, 1912. Zeits. wiss. Zool., CIII., 519.

Roonwal, 1937. Phil. Trans. Roy. Soc. B., CCXXVII.

Silvestri, 1932. Ve Cong. Internat. d'Ent. Paris, 329.

Snodgrass, 1928. Smithsonian Misc. Coll., 80, No. 1.

1935. "Principles of Insect Morphology." New York and London.

Uzel, 1897. Zool. Anz., XX., 232.

Wiesuann, 1926. Inaug. Diss. Jena.

\section{Wing Venation}

Coмsтоск, 1918. " The Wings of Insects." Ithaca, N.Y.

Constock and Needhai, 1898-99. Amer. Nat., XXXII., 43 ; XXXIII., 118.

HaNdlirsch, 1925. In Schröder's IIandbuch der Entomologie, III., 117. 
Lameere, 1922. Bull. Clas. des Sci., Acad. Roy. Belg., Ser. 5, VIII., 138.

Redtenbacher, 1886. Ann. des K.K. nat. Hofmus., Bd. I., 153.

Tillyard, 1919. Proc. Linn. Soc. N.S.W., XLIV., 533.

1925. Amer. Journ. Sci., IX., 328.

1926. "Insects of Australia and New Zealand." Sydney.

Vignon, 1929. Arch. Mus. Hist. Nat. Paris (6), IV., 89.

1932. Encycl. Ent., Diptera, VI., 133.

Vignon and Séguy, 1929. C.R. Acad. Sci., CLXXXVIII., 1699; Bull. Soc. Ent. France, XIV., $22 \%$.

\section{Metameric Appendages}

Becker, 1923-24. Zool. Anz., LVII., 137 ; LX., 169.

Börner, 1909. Zool. Anz., XXXIV., 100.

1921. In Lang's Handbuch der wirbellosen Tiere, IV., 649.

Crampton, 1914. Zool. Anz., XLIV., 56.

1921. Ann. Ent. Soc. Amer., XIV., 65.

1922. Proc. Ent. Soc. Washington, XXIV., 65.

1926. Trans. Amer. Ent. Soc., LIII., 199.

1928. Journ. Ent. and Zool., XXI., 1.

Ewing, 1928. Smithsonian Misc. Coll., 80, No. 11.

Hansen, 1930. " "Studies on Arthropoda,' III. Copenhagen.

Heymons, 1899. Nova Acta Abh. Kaiserl. Deut. Akad. Naturf., LXIV., 349.

Prell, 1913. Zoologica, XXV., Heft 64.

Roonwal, 1937. Phil. Trans. Roy. Soc. B., CCXXVII.

SNodgrass, 1928. Smithsonian Misc. Coll., 80, No. 1.

1928. Ibid., 81, No. 3.

1929. Ibid., 82, No. 2.

1931. Ibid., 85, No. 6.

1935. "Principles of Insect Morphology." New York and London.

Stickney, 1923. Illinois Biol. Monog., VIII., No. 1.

Verhoeff, 1903. Zool. Anz., XXVI., 25.

1904. Nova Acta Abh. Kaiserl. Deut. Akad. Naturf., LXXXI., 211.

WALker, 1931. Canad. Ent., LXIII., 75.

1932. Ibid., LXIV., 223.

IVeber, 1924. Zool. Anz., LX., 17, 57.

\section{Genitalia}

Christophers, 1922. Indian Journ. Med. Res., X., 530.

DENNy, 1897. "Commemoration Volume," 169. Sheffield.

GeOrge, 1929. Quart. Journ. Mic. Sci., LXXII., 447.

MehtA, 1933. Ibid., LXXVI., 35.

MetCalfe, 1932. Ibid., LXXV., 49.

1932A. Ibid., LXXV., 467.

NEL, 1929. Ibid., LXXIII., 25.

Singh Pruthi, 1924. Ibid., LXIX., 59.

1924A. Proc. Zool. Soc., 857.

1925. Trans. Ent. Soc. London, 127.

Sxodgrass, 1935. "Principles of Insect Morphology." New York and London.

1936. Smithsonian Misc. Coll., 95, No. 14, 61.

Walker, 1919. Aun. Ent. Soc. Am., XII., $26 \%$.

1922. Ibid., XV., 1. 


\section{CHAPTER III}

\section{METAMORPHOSIS}

Berlese's Theory, p. 51. Types of Larve, p. 56. 1. The Protopod Type, p. 56 ; 2. The Polypod Type, p. 58; 3. The Oligopod Type, p. 60 ; 4. The Apodous Type, p. 60. General Remarks on Insect Metamorphosis, p. 61. Nymphs and Pupæe, p. 63; Hormones and Metamorphosis, p. 64. Literature, p. 70.

THF general features of insect metamorphosis are well known and consequently do not require recounting. The present chapter, therefore, will be confined to a discussion of the more recent aspects of the subject, and the theories that have been advanced to account for some of the phenomena associated therewith. For many years past the compodeiform type of larva has been claimed to be the most primitive form of immature insect, while departures from this condition have been explained as being the result of secondary and adaptive modifications. While there is considerable truth in this idea, it fails as a complete explanation of insect transformation, and leaves many problems unsolved.

\section{Berlese's Theory}

A comprehensive and largely new interpretation of insect metamorphosis was advanced by the late Antonio Berlese in 1913, and was subsequently incorporated by him in his well-known treatise, "Gli Insetti." His views attracted little or no attention until 1925, when the present writer adopted certain of Berlese's main conclusions as a general theoretical explanation of the diverse facts of metamorphosis. During the five years that have followed, the writings of de Gryse (1926), James (1928), Eastham (1929), Chrystal (1930), and others have contributed facts bearing upon the theory, but the latter has not received the recognition it merits.

In the first place, Berlese's theory takes into consideration the 
progressive development of metamerism in insect embryos. In a broad general way, segmentation commences anteriorly and extends backwards as development proceeds. The head and thorax, for example, are usually clearly defined, along with their developing segmental appendages, before the abdomen has undergone any marked differentiation. Although embryonic development is a continuous process, and none of its phases are sharply marked off from another, three important stages or "landmarks" in the process can be recognised in many insects. These are termed by Berlese the protopod, polypod and oligopod

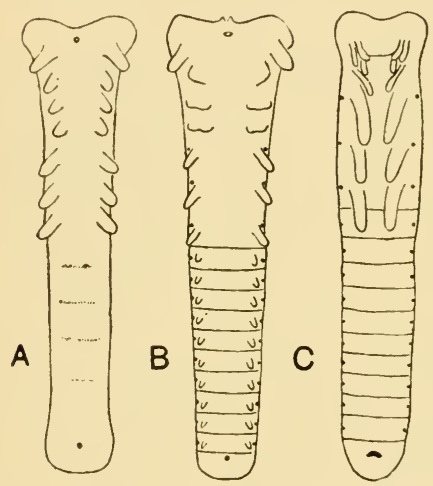

FIG. 31. Embryonic phases according to Berlese. $A$, protopod ; $B$, polypod ; $C$, oligopod. phases respectively.

In the protopod phase (Fig. 31, A) the embryo, as a whole, is as yet incompletely differentiated both externally and internally. Although the head and thorax bear evident limb rudiments, the abdomen as a rule is imperfectly segmented at this stage, and is always devoid of appendages. In the earliest aspect of the phase the abdomen may betray no evidences of metamerism, but as development advances a greater or smaller number of its segments become defined: in Berlese's terminology, growth proceeds from an oligomerous to a polymerous condition. The internal organs are not fully differentiated, and even their fundaments may be, as yet, very rudimentary, particularly as regards the digestive, circulatory and nervous systems, while the tracheal invaginations have yet to be formed.

The polypod phase (Fig. 31, B) follows upon the protopod, and its chief characteristic is the completely segmented abdomen, each somite bearing a pair of rudimentary limbs. The tracheal system now becomes evident by the presence of spiracular invaginations, while the digestive, nervous and circulatory organs are clearly defined and more or less completely formed. 
The oligopod phase (Fig. 31, C) is derived from the polypod by a process of further differentiation. The thoracic limbs have markedly increased in size; the mouth parts have attained fuller growth ; the fundaments of the tracheal system become evident, while the abdominal appendages, excepting those destined to form genitalia and cerci, have undergone resorption.

Comparison of the embryonic development of various insects shows that the above-mentioned three phases can be identified in varying degrees of definition in different groups. The reader is referred to the standard embryological memoirs, dealing with the more important types, in order to follow the growth changes affecting these phases and the sequence in the ontogeny. The typical protopod phase, for example, is clearly evident in the embryos of Campodea (Uzel), Lepisma (Uzel), Ecanthus (Wheeler), Xiphidium (Wheeler), Mantis (Viallanes), etc. In these instances the abdomen is at first unsegmented and its metamerism is subsequently acquired. In other cases the abdomen appears to undergo segmentation simultaneously with the rest of the body, as in Coleoptera. The polypod phase, which immediately follows, is probably an ontogenetic feature common to all Hemimetabola and to many of the Holometabola. In certain of the more specialised members of the latter division all the abdominal appendages may be suppressed from the ontogeny, as occurs in Diptera and, according to Nelson (1915), in the hive bee; or, the appendages of the first, or first and second segments, alone are developed, as in Donacia (Hirschler), Dytiscus (Th. Bang), and certain other Coleoptera. When the development of embryonic abdominal limbs is thus suppressed it is obvious that a polypod phase, in the strict implication of the term, can scarcely be said to exist. The incidence of the phase can only be inferred from the occurrence of other correlated features such as the presence of spiracles, and the general advance in development following the preceding phase. The oligopod phase is the final embryonic stage among Coleoptera and many Neuroptera ; it probably also occurs in the Diptera and in the higher Hymenoptera, but in a greatly modified and masked condition which renders its recognition by no means obvious.

According to Berlese the moment of birth, or eclosion from the 
egg, is a definite crisis of paramount significance in the ontogeny of all insects. The theory maintains that, in all Hemimetabola, the three phases alluded to are passed through in the egg, and eclosion takes place when the insect has assumed a post-oligopod phase, termed the nymph. In the Holometabola, on the other hand, the young insects (or larva) invariably issue from the egg at any earlier ontogenetic stage than the nymphs of the Hemimetabola. The stage in organisation in which eclosion takes place determines in a large measure both the form and subsequent development of any given insect. The more advanced the condition at the time of emergence, the lesser are growth changes required for an insect to attain its ultimate organisation. In the Holometabola, the stage in which eclosion takes place corresponds more or less closely with one or other of the embryonic phases alluded to. Some groups emerge as veritable embryos; others may be polypod larvæ or oligopod forms ; or they may be apodous and have lost all traces of trunk limbs.

The factors which determine the moment of eclosion from the egg are obscure. Even William Harvey, as long ago as 1651, considered that premature birth in insects is due to paucity of food reserves in the egg. There is little doubt that the main influence is physiological, and depends to a considerable extent upon the amount of yolk available in the egg, in proportion to the size of the embryo. This aspect of embryology has, however, been very little studied, and information respecting relative amounts of yolk in the eggs of different insects, and its comparative nutritive values, is a practically unexplored field. Precocious emergence is also intimately related with the immediate environment of the newly-born larvæ, and the egg-laying instincts of the female parent. If, for example, the eggs are deposited in situations providing the young larvæ with an abundance of food immediately at hand the early hatched, and more or less inert, offspring would have chances of survival. On the other hand, if the young larvæ have to seek out their food survival would be impossible, unless emergence be delayed until their development had advanced to the stage where they had become endowed with the necessary locomotory and sensory organs. 
Nymphs and Larvæ. It will be convenient at this stage to emphasise the fundamental differences between nymphs and larvæ. In the strict zoological sense such differences scarcely hold good and, whenever the young differ fundamentally from their parents, the term larva becomes applicable. It has, however, long been both customary and convenient to distinguish between these two types of immature insect.

An insect undergoing incomplete metamorphosis leaves the egg in a relatively advanced condition of morphological development. In its general structure and body-form it prefigures the imago. Furthermore, it adopts a mode of life similar to that of its parents, it frequents the same habitat, and feeds upon similar food. Its mouth-parts exhibit but slight, if any, structural differences from the final condition assumed by those organs, and compound eyes, usually accompanied by dorsal ocelli, are the functional visual receptors. Rudiments of wings and genitalia develop gradually as external rudiments, and the final transformation comprises little or no marked morphological change other than the acquisition of those organs in their fully developed condition. Physiologically the main change is involved in the increasing development of the sexual organs up to maturity. Immature insects exhibiting these gradual growth changes are termed nymphs.

It is noteworthy that in the Plecoptera, Ephemeroptera and Odonata the nymphs are exceptional in being aquatic, while their imagines adopt an aerial mode of life. In the possession of special respiratory organs and of other adaptive modifications, which fit them for an aquatic existence, the nymphs of these three orders exhibit more or less evident coenogenetic development. The final transformation into the adult consequently involves more drastic morphological change than usually obtains with typical incomplete metamorphosis. This feature has been emphasised by Comstock (1918), who proposed the term naiad for the immature insect in each of the three orders named, and adopted the expression in his subsequent text-book, "An Introduction to Entomology" (1924). The distinctions between nymphs and naiads, therefore, are of a purely adaptive nature and are not absolute. In certain Plecoptera, for example, 
the adaptations are so slight that the term naiad is scarcely applicable.

Larva may be defined as immature insects which leave the egg in a relatively early stage of morphological development. In general, they differ fundamentally in form, structure and behaviour from the imagines. Their mouth-parts and other appendages usually exhibit marked or even profound differences of form and structure, while lateral (or adaptive) ocelli, with only very rare exceptions, are the functional visual organs. Throughout larval life the reproductive system is in a very rudimentary condition. Coenogenetic development has become so highly specialised that transformation into the imago has involved the intercalation of a quiescent pupal instar in the ontogeny. Prior to the assumption of the pupal condition, the developing buds of the genitalia, wings and other appendages lie concealed beneath the body-wall.

In the present discussion the term Hemimetabola has been used to include both the Hemimetabola sensu stricto and the Paurometabola of many authorities. The differences exhibited by the transformations in the two cases are essentially those of degree.

In Giard's interpretation, the Hemimetabola (sens. lat.) undergo transformation as opposed to true metamorphosis which is featured only in the Holometabola.

\section{Types of Larvæ}

Insect larvæ may be grouped into three principal types depending upon the stage in their ontogeny in which eclosion from the egg takes place. In addition to these a fourth type, derived from the third, has to be recognised.

1. The Protopod Type. This type is characteristic of the primary larvæ of certain species of endoparasitic Hymenoptera. The eggs in such species are either almost devoid of yolk, or but poorly supplied with nutrient material, and the young larvæ consequently issue at a very early ontogenetic stage of development. Their survival is rendered possible from the fact that they are enclosed either in the eggs or bodies of their hosts, where they develop immersed in an abundance of easily assimilated food, usually in the form of yolk or of hæmolymph. 
Some of the most typical examples of protopod larvæ are found in the Platygasteridæ, which are very prevalent parasites of the larvæ of Cecidomyidæ. The primary larva of Platygaster herricki is represented in Fig. 32, and is shown in comparison with the embryo of Xiphidium in the protopod phase of development. The extremely close morphological similarity in the two cases is particularly striking, and it is evident that the Platygaster larva is

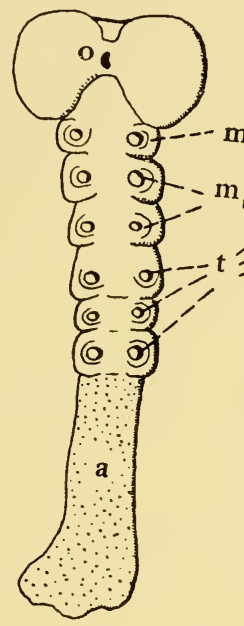

A

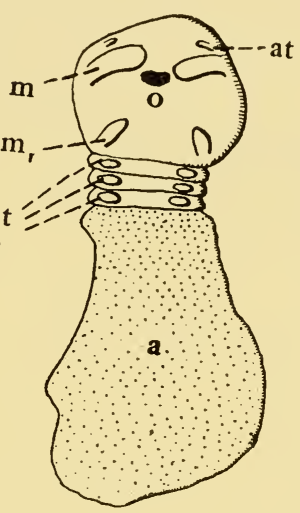

B

Fig. 32. A, Protopod phase of embryo of Xiphidium. (From Wheeler.) B, Protopod larva of Platygaster. (From Kulagin.) Adapted from Berlese. $a$, Abdomen (unsegmented); $a t$, antenna ; $m$, mandible; $m_{1}$, maxillæ; $o$, stomodæum ; $t$, thoracic legs.

little more than a precociously emerged embryo. The abdomen in this stage has not acquired segmentation, the thoracic appendages are merely rudimentary outgrowths; the nervous and respiratory systems are, as yet, undeveloped, and the digestive organs are still largely in an embryonic condition. Another prevalent type of protopod larva is the cyclopoid primary larva (Fig. 33) found in other members of the same family. Its general features are well known through the researches of Marchal (1906). The large inflated cephalothorax bears head-appendages and a 
single pair of thoracic limbs, while the abdomen is segmented. The mandibles are specially large and adapted to hold on to the host-tissues. The digestive system is represented by an extensive sac-like mesenteron and the proctodæum is, as yet, hardly evident. The nervous system does not exist as such and its fundaments are undifferentiated from the ectoderm; the circulatory and tracheal systems are likewise undeveloped. The so-called eucoiliform larva (Fig. 34) present in the Cynipid family Figitidæ (vide James, 1928), whose members are common parasites of

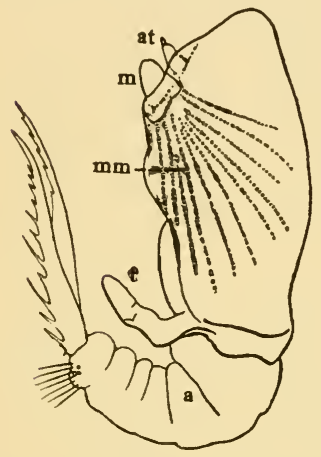

FIG. 33. Protopod (cyclopoid) first instar larva of Synopeas rhanis (Platygasteridæ), lateral view. $m m$, Mandibular muscle ; other lettering as in Fig. 32. (From Marchal.)

Dipterous larvæ, is evidently a specialised protopod type. Both thorax and abdomen are segmented, and the limbs of the first-mentioned region are often greatly developed, possibly functioning as a means of rupturing the enclosing embryonic membrane. Other types of protopod larvæ without thoracic limbs occur in the Mymaridæ, Scelionidx and certain other families of parasitic Hymenoptera. Alongside the primitive embryonic characters of protopod larvæ there exist also specialised adaptive features. The great development of the thoracic limbs in certain of the eucoiliform larvæ and the caudal prolongation, often bifurcated in the Platygasteridæ, can only be interpreted as adaptional developments whose functional significance is obscure.

2. The Polypod Type. Typical examples of polypod larvæ are afforded by the caterpillars of the Lepidoptera and the Tenthredinidæ and by the very similar larvæ of the scorpion-flies or Panorpidæ. Their essential features are the retention of abdominal limbs and the presence of a peripneustic tracheal system. The presence of a polypod instar in the larval development of the parasitic Hymenoptera is a recent discovery. It occurs among the Cynipoidea in certain genera of Figitidæ (James, 1928) and in Ibalia, which is a parasite of Sirex (Chrystal, 1930). 
It has also been described by Eastham (1929) in the Proctotrypid Phonoserphus viator which parasitises larvæ of the beetle Pterostichus niger. In the Figitidx the polypod stage follows the protopod or eucoiliform stage, but in Ibalia and Phanoserphus
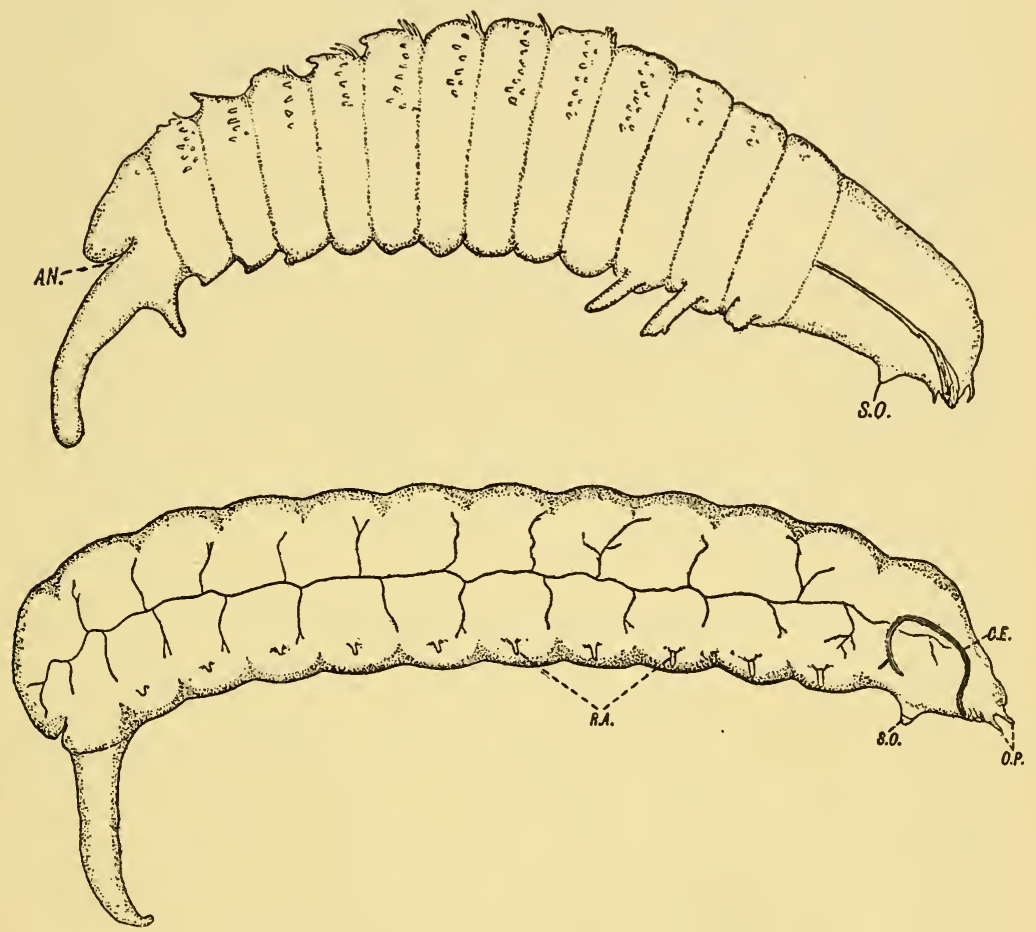

Fig. 34. Figites anthomyiarum. Above, protopod larva $\times 140$; below, polypod larva $\times 90 . A N$., Anus ; C.E., endo-skeleton of head; O.P., oral papillæ; R.A., rudimentary appendages ; S.O., sensory organ. (After James (reduced).)

the protopod stage is presumably passed within the egg, since the first observed instar is polypodeiform. During the polypod stage these parasitic forms live immersed in the blood of their hosts, and, as is the rule in such cases, respiration is cutaneous. In consequence of this adaptation the typical peripneustic condition is not acquired until a later instar. The number of pairs of 
abdominal appendages present varies from eight in Phcenoserphus, to ten in the Figitidæ (Fig. 34), and twelve in Ibalia.

3. The Oligopod Type. The oligopod type, in its most highly developed condition, is represented by the so-called campodeiform larva of many Coleoptera and Neuroptera. It is eminently active, with highly developed locomotory and sensory organs, and has, in the past, usually been regarded as the most primitive type of insect larva. Almost every stage of adaptive modification and degeneration is exhibited, among different insects, between this highly developed type and the legless phase dealt with in the next paragraph.

4. The Apodous Type. The apodous type, which is devoid of all true locomotory appendages, appears to have been derived, in the majority of cases, from the oligopod phase as the result of degeneration. Larvæ of this type are characteristic of Diptera and all the Hymenoptera Apocrita; they are also prevalent in certain families of Coleoptera, besides occurring as a rare condition in leaf-mining Lepidoptera.

Among Diptera the general suppression of body-appendages, from all stages in their ontogeny, has resulted in the antecedent protopod and polypod phases becoming largely obliterated. Keilin (1915) has shown that three pairs of sensory papillæ are present in the larvæ of this order, and are in direct relation with the developing imaginal leg-buds, thus occupying the positions of ancestral thoracic legs. These sensory papillæ appear to be the transformed vestiges of former thoracic limbs, and their presence points to the conclusion that Dipterous larva are to be regarded as highly specialised derivatives from the oligopod type.

In all the higher Hymenoptera the prevalent larval type is apodous. Among the Aculeata it persists through all instars, while, as has already been shown, in certain of the Parasitica it is preceded by earlier phases. The apodous type in this order is most probably a derivative of the oligopod phase, as in Diptera. In support of the contention it may be mentioned that vestiges, in the form of papillæ, of what appear to be the remains of thoracic appendages have been detected in Polysphincta and certain other of the Ichneumonoidea. Furthermore, in the Tenthredinoidea a 
long series of transitional forms are traceable from typical polypod types, through various phases of reduction, to oligopod types, until a completely apodous condition is attained. Thus, in the Xyelidæ their polypod larvæ retain nine pairs of abdominal appendages, while among the Tenthredinidæ (sens. str.) this number suffers reduction. In the Pamphiliidæ, Cephidæe and Siricidæ, abdominal appendages have atrophied and their larvæ are oligopod; the thoracic limbs are never well developed and exhibit varying degrees of reduction towards the apodous condition. In Oryssus the latter phase becomes evident, the thoracic limb-rudiments having atrophied. The legless condition of the larva in this genus is correlated with the unique parasitic life that is unknown elsewhere among the Symphyta.

Among Coleoptera an apodous larval type has been independently acquired among different families. It is characteristic of the majority of the Rhynchophora, besides occurring in certain of the Buprestidæ and Cerambycidæ; in Cercyon, in the Elaterid sub-family Eucneminæ and in the Bruchidæ. In the lastmentioned family the apodous condition may be preceded by oligopod instars, while among the Curculionidæ the last remnants of thoracic limbs are retained as sensory protuberances in Hypera (Phytonomus) according to Perez (1911). In Coleoptera, therefore, evidence points to the apodous type being derived from the oligopod, and almost every transition between the two may be found, sometimes in members of the same family. In Lepidoptera the leaf-mining genera Phyllocnistis and Eriocrania are apodous, but, unlike the preceding examples, the legless condition appears to have been directly derived from the polypod phase.

\section{General Remarks on Insect Metamorphosis}

It will be apparent that Berlese's theory is in accordance with the general facts of ontogeny and phylogeny. Criticisms, however, may be raised wherever a given larval type does not appear to conform with his premises and deductions. Due reflection will show that it is obviously improbable that every form of larva that issues from the egg will be in a stage exactly comparable with one or other of the embryonic phases alluded to. Intermediates are 
bound to occur, and, at the same time, the ancestral form of any given larva is liable to be masked by superimposed adaptive or secondary modifications. Embryological development, although recapitulatory in the main, is well known to be subject to abbreviation and to exhibit secondary features which in no way represent ancestral characters. This is exemplified in the suppression of ancestral appendages from the trunk segments in the embryos of Diptera. In so highly specialised an order many primitive features, common to more generalised insects, are no longer reproduced in the ontogeny. Developmental features of this kind, in their turn, modify the morphological characters of the resulting larvæ. There are, consequently, potent influences affecting the forms assumed by insect larvæ other than those of ancestry. This fact is abundantly evident in the remarkable adaptations to special modes of life exhibited by many insect larvæ, which frequently mask the actual ontogenetic phases which such larvæ represent. In the past the tendency has been to overstress the influence of adaptation in determining the evolution of larval forms. The perennial difficulty of determining which characters are ancestral and which are purely secondary thus presents itself. Berlese's theory maintains that insect larva represent, primarily, ontogenetic phases in the history of the species concerned. They are subject to the same laws affecting other organisms, and, consequently, the particular ontogenetic phase exhibited in the species of one group may be largely obscured by secondary features, and yet be plainly evident in another group.

In cases of hypermetamorphosis, where there is a definite sequence of larval types in the ontogeny of a single species, further support is afforded to Berlese's theory; the sequence follows that of the corresponding embryonic phases of normal insect development. This has been shown to be the case in the hypermetamorphoses of certain parasitic Hymenoptera (Fig. 34). Furthermore, in those Coleoptera where hypermetamorphosis prevails, and in the Mantispidæ among Neuroptera, the first instar is a typical campodeiform oligopod larva. In the second instar, change of habit has led to its transformation into an inert maggot-like phase with vestigial thoracic limbs and other 
correlated modifications. 'This instar, in its turn, may be followed by an apodous stage which is well exhibited in the Meloidæ. In the Strepsiptera the campodeiform first larvæ instar is directly followed by an apodous stage.

In a few words, it may be said that Berlese's theory co-ordinates and explains the significance of diverse larval types which can only, otherwise, be interpreted as intercalated and purely adaptive phases.

Nymphs and Pupæe. The general characters of the nymphs of the Hemimetabola have already been referred to. Nymphs share many features in common with campodeiform larvæ, but, on the other hand, they exhibit in their visual organs and in the developing external rudiments of wings and genitalia features which appear only in the pupal instar among Holometabola. In other words, nymphs have attained a more advanced stage of ontogenetic development than larvæ, and the protopod, polypod and the true oligopod phases are passed through in the egg. In the Hemimetabola the nymphal instars are preparatory to the development of the imago, while in the Holometabola the larval instars are preparatory to the development of the pupa. We may, therefore, conclude that the pupa, along with the antecedent prepupa, are the ontogenetic counterparts of the nymphal instars of the lower orders of insects. It seems that tachygenesis, or shortening of development, has resulted to the extent that the whole series of nymphal instars has become concentrated into these two stages, with the elimination of intervening ecdyses. In support of this contention we may pause to consider certain groups of Hemimetabola, which already exhibit well-defined tendencies towards the holometabolous condition. Thus, among the Coccidæ definite evidence of a pupal instar occurs in the males. Furthermore, in this family the insect leaves the egg not as a nymph, but as an oligopod larva. In the sub-family Diaspinæ an apodous instar follows, and this, in its turn, is succeeded by three quiescent nymphal instars delimited by separate ecdyses. These nymphal instars are unquestionably incipient pupal stages, and much the same condition prevails in Thysanoptera, except that there are but two such stages. Among the Holometabola 
the prepupa is the sole vestige of the existence of more than a single pupal instar, and even the ecdysis between the last larval instar and this phase has been eliminated, except in very few instances. In the metamorphoses of the fly Rhagoletis, for example, Snodgrass (1924) showed that an extra-cuticular coat intervenes between that of the pupa and the wall of the puparium. Evidence of a prepupal ecdysis has also been noted by Raff (1934) in the case of sawflies of the genus Perga, where the exuvix in question are located near the caudal extremity in the pupal cocoon. Such instances, however, are few, but the matter has attracted very little attention.

The pupal instar represents, therefore, the abbreviated recapitulation of ancestral nymphal stages. Change of function, however, has resulted in the evolutionary process and an acquired quiescent condition has been assumed. This condition became necessary in order to allow the larval body and its component organs to become remodelled, in order to adapt them to the requirements of the future imago.

It is well known that, during the usual process of ecdysis between any two nymphal or larval instars of a given insect the old cuticle is cast off. Prior to the consummation of this event, the formative cells beneath not only secrete a new cuticle, but also remodel the outer configuration of the body and the appendages into the new form to be assumed. This process goes on gradually from instar to instar, and in many insects the changes involved are but slight, but in others they are considerable. In the Anoplura, for example, they are so trivial as to be scarcely evident, while in many of the Heteroptera remarkable changes in body-form and the appendages may result. In the Holometabola this same formative process is continued in the pupa, but it lies concealed, and drastic changes are involved. The descendants of the ectodermal formative cells, which modelled the larval appendages from instar to instar, give rise to the imaginal buds, and it is from these rudiments that the corresponding imaginal parts are derived. It is too commonly implied that there is entire discontinuity during pupation, and that the imaginal appendages are new developments, apart from those of the larva. If a graded series of pupal types be studied, it will be seen the change from the larval appendages into those of the adult is a matter of degree only-there is no real diseontinuity in the process.

Hormones and Metamorphosis. One of the most notable results of recent work in experimental entomology has been the discovery 
of what are comparable with endocrine organs. Facts are being brought to light which lead to the conclusion that ecdysis, metamorphosis, and also the full maturing of the gonads, are controlled through the intervention of certain secretions. Since the evidence all points to the fact that these secretions are discharged into the blood, they are therefore comparable with hormones of the endocrine type. As in Vertebrata, they appear to be produced by ductless glands and have a very definite effect upon other organs and tissues. In insects, a pair of small bodies, known as

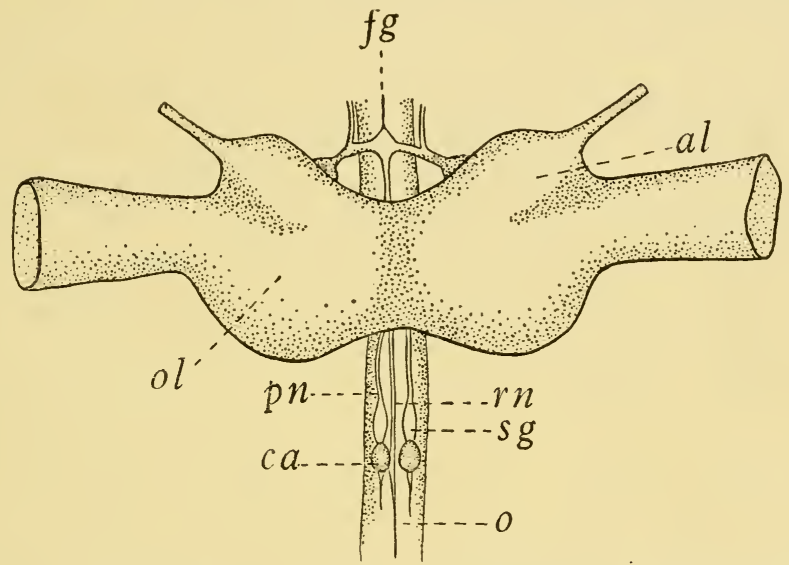

F1G. 35. Dorsal view of brain and associated parts of a winged Termite. $a l$, antennary lobe ; $c a$, corpus allatum (left) ; $f g$, frontal ganglion ; $o$, œesophagus ; ol, optic lobe ; $p n$, posterior sympathetic nerve (left); $r n$, recurrent nerve; $s g$, osophageal sympathetic ganglion (right). Original.

the corpora allata (Fig. 35), found in association with the sympathetic nervous system, a short distance behind the brain, are almost certainly endocrine organs. The corpora allata arise in the embryo as ectodermal invaginations, usually of the mandibular segment. Subsequently they lose all connection with the exterior and finally assume the form of small, ovoid, whitish bodies which were formerly mistaken for a pair of posterior sympathetic ganglia. Histologically, they differ from nervous tissue and have rather the features of glandular organs. 'They occur in all orders of insects and their structure was studied in considerable detail 
by Nabert in 1913. Wigglesworth (1934) showed that these organs exhibit cyclic changes in that they pass through a secretory stage associated with moulting, which is followed by a resting condition. In the blood-sucking Reduviid bug Rhodnius, Wigglesworth states that ecdysis takes place at a definite interval after feeding, only one meal being necessary during each instar. There is a " critical period" in the moulting cycle and decapitation before the advent of this period prevents moulting. The critical period synchronises with the beginning of mitosis in the cells of the hypodermis. He further states that insects which have passed the critical period contain a hormone in their blood. If blood from an insect in this stage be transferred into an insect which has been decapitated before the critical period, moulting, which otherwise does not take place, is induced. (The critical period referred to is about seven days after feeding in the fifth instar and about four days after in the earlier nymphs.) 'That the corpora allata are the organs involved is suggested by the fact that the cells of these bodies show their greatest secretory activity during the critical period. In a later communication, Wigglesworth (1936) showed that the moulting hormone from Rhodnius will induce moulting in the allied genus Triatoma and in the bed-bug Cimex. While the available evidence points to the corpora allata as the seat of the hormone involved, complete proof is, as yet, not available : for one thing, their extirpation is extremely difficult to carry out. Rather indirect evidence, however, is afforded by some other experiments described by Wigglesworth as follows: "fourth-stage nymphs of Rhodnius in two groups ( $\mathrm{A}$ and $\mathbf{A}^{\prime}$ ) were decapitated seven days after feeding and joined to groups of fourth-stage nymphs (B and $\mathrm{B}^{\prime}$ ) twenty-four hours after these had fed. Of these, B were transected through the prothorax, the corpus allatum being removed, while $\mathrm{B}^{\prime}$ were transected through the posterior part of the head behind the brain but in front of the corpus allatum.

"Groups B and B' both showed that moulting was beginning ${ }^{1}$

1 At the onset of moulting, when the epidermal cells separate from the cuticle and divide, there are visible changes in the abdominal tergites of the living insect (see Wigglesworth, 1934). 
at the end of five days. The pairs were then separated and $\mathrm{B}$ and $\mathrm{B}^{\prime}$ were joined to further groups of fourth-stage nymphs $\left(\mathrm{C}\right.$ and $\left.\mathrm{C}^{\prime}\right)$ transected through the prothorax twenty-four hours after feeding. At the end of eight days the group $\mathrm{C}^{\prime}$, i.e., insects whose partners retained the corpus allatum, were obviously beginning to moult; the group C was probably just starting to moult. The pairs were then separated once more and joined to groups $\mathrm{D}$ and $\mathrm{D}^{\prime}$, cut through the prothorax twenty-four hours after feeding. At the end of seven days $\mathrm{D}^{\prime}$ were clearly beginning to moult; but $\mathrm{D}$ died several weeks later without showing any signs of moulting beginning.

"Thus in the series A, B, C, D, in which no corpus allatum was present, the moulting hormone appeared to diminish in concentration until it ceased to induce moulting at all. Whereas in the series $\mathrm{A}^{\prime}, \mathrm{B}^{\prime}, \mathrm{C}^{\prime}, \mathrm{D}^{\prime}$, in which $\mathrm{B}^{\prime}$ retained the corpus allatum (and was presumably able, therefore, to supply an adequate amount of the hormone to $\mathrm{C}^{\prime}$ ), there was no sign of diminished activity in the moulting hormone-the group $\mathrm{D}^{\prime}$ being caused to show signs of moulting as soon after joining to $\mathrm{C}^{\prime}$ as $\mathrm{B}^{\prime}$ did after joining to $\mathrm{A}^{\prime}$.,"

Wigglesworth has also brought forward evidence which appears to indicate that metamorphosis is controlled by an "inhibiting hormone" which is also secreted by the corpora allata. Thus it was found that if a fourth instar nymph had only the apex of the head removed six days after feeding and was then joined to a fifth instar nymph decapitated twenty-four hours after feeding, the latter moulted into an extra nymphal stage instead of becoming an adult. The head is, therefore, necessary for the production of the inhibiting hormone. Also, fifth instar nymphs, twentyfour hours after feeding, had the corpora allata from third or fourth instar nymphs (removed a day or two after feeding) implanted within them. These fifth instar nymphs moulted to " sixth instar" nymphs. As the result of similar experiments, " sixth instar" nymphs may give rise to "seventh instar" nymphs when they moult again. In some cases the resulting characters were intermediate between those of adults and nymphs : in others they were wholly nymphal in type. From these and 
other experiments it is concluded that the corpora allata control the characters of the various instars and also secrete an "inhibitory hormone" which prevents metamorphosis taking place until the insect attains its fifth instar. In this phenomenon of " inhibition of metamorphosis" there seem to be two phases involved : (i.) deposition of new cuticle following rapidly upon the initiation of growth and hence the arrestation of adult characters; (ii.) so long as differentiation is arrested in this way the cells are capable of new growth and will respond to the moulting hormone. Whether the latter hormone is biochemically distinct with that concerned with the inhibition of metamorphosis has not been proved.

In contrast with Wigglesworth's experiments it is noteworthy that Weed (1936A), in an experimental study of moulting in the grasshopper Melanoplus differentialis, obtained different results. The account, however, of these experiments is very short and they are stated to be preliminary only. It appears that in this work the corpora allata themselves were removed from grasshopper nymphs one to nine days after they had entered the last stadium. In each case moulting resulted, and it was concluded that the corpora allata do not influence this process. It is necessary, however, to await more extensive experiments before drawing definite conclusions.

With regard to the Holometabola, it has been known for some time that removal of the brain prevents pupation. The earlier observers did not associate the corpora allata with any significant rôle in the metamorphosis, and it is extremely probable that their removal took place along with the brain in, at any rate, most of the experiments recorded. Thus Kopec (1922) removed the brain from caterpillars of Lymantria dispar in their last instar. If the brain be excised ten days before the last ecdysis, or later, the caterpillars pupated, but if the experiment be performed seven days after that moult, pupation did not oceur. Kopec concluded from these, and other experiments, that a hormone is produced in the brain and that this seeretion induces pupation. Quite recently Caspari and Plagge (1935) obtained very similar results with larva of Sphinx ligustri and Deilephila euphorbice. Bounhoil 
(1936), on the other hand, obtained very different results with silkworms (Bombyx mori). The corpora allata were removed (by a surgical method to be described by him in a later paper) from larva in their last instar at times varying from thirty-six hours up to sixteen days after the last moult. As the result of these experiments he concludes that the corpora allata do not influence pupation. Out of forty-two larvæ operated upon, twenty-four produced pupa: of the latter, thirteen gave rise to imagines. The time of onset of the " critical period," however, is not stated. The author states that considerable mortality ensued owing to unfavourable weather prevailing at the time; given better circumstances still more convincing results, he believes, could be obtained. These results appear to be in accordance with experiments by Kühn (1936), who used larvæ of Ephestia. By grafting brains of larve into individuals from which the brains had already been excised, a very high death-rate supervened. Only eight cxamples out of 150 pupated, and from among these individuals five of them had no corpora allata in the graft. Kühn, by a series of ligaturing experiments, had previously determined the incidence of a " critical period," but his experiments obviously need repeating owing to the high mortality which prevailed.

Fraenkel (1935) has brought convincing evidence that it is the action of a hormone which brings about pupation in the fly Calliphora. It is secreted about sixteen hours before pupation at a temperature of $20^{\circ} \mathrm{C}$. Fraenkel was unable to locate the actual hormone-producing organ, but showed that it was either the main ganglionic centre or in its immediate neighbourhood. After the hormone is discharged into the blood he found that pupation takes place without the co-operation of the central ganglia.

In the present state of knowledge, of a very recent line of inquiry, it would be obviously premature to draw hard and fast conclusions from rather conflicting results. One thing, however, emerges, and that is the existence of hormones which control both ecdysis and metamorphosis. While there is strong evidence in Rhodnius that the corpora allata are the organs secreting the hormones concerned, proof that these bodies perform a similar function in the Holometabola is less convincing. It needs also to 
be borne in mind that the onocytes may also perform a significant function in connection with ecdysis. They appear to be gland cells of a specialised type which discharge their secretion into the blood. Furthermore, they show a very marked cycle of secretory activity which synchronises with the process of moulting (Albro, 1930 ; Wigglesworth, 1933). Koller (1929) has suggested that they secrete a hormone which induces moulting, but Wigglesworth does not consider that this is likely and is inclined to believe that they are concerned with the synthesis of some of the non-chitinous constituents of the cuticle during ecdysis.

Although not directly concerned with the metamorphosis, the functions of the corpora allata in adult insects may also be referred to here. Wigglesworth (1936) has shown that these organs are necessary for the production of ripe eggs in Rhodnius. - Further- more, it was found that the corpora allata of Triatoma females will induce egg-development in Rhodnius. In the absence of the secretion from the corpora allata the oocytes continue to grow so long as they are connected with the nurse cells, but when their nutrition is taken over by the follicular cells they die and are absorbed. Further evidence shows that the moulting hormone of the nymphs will not induce egg-development in the adult female; nor will the egg-forming hormone bring about moulting. In the male the corpora allata are necessary for the full activity of the accessory glands. Their secretion will also induce eggdevelopment in the female and similarly the secretion of the female will activate the male acccssory glands. It is noteworthy that Weed (1936) has obtained very similar results with the grasshopper Melanoplus differentialis. By removing the corpora allata, in a series of preliminary experiments, it was concluded that these bodies are necessary for the normal development of the eggs and that, further, secretion in the glandular portion of the oviducts is also influenced by the corpora allata.

\section{Literature}

Albro, 1930. Journ. Morphol., L., 527.

Berlese, 1913. Redia, IX., 121.

Bounhoil, 1936. C.R. Acad. Sci., CCIII., 388.

Caspari and Plagge, 1935. Naturwiss., XXIII., 751. 
Chrystal, 1930. Oxford Forestry Memoirs, XI.

Coustock, 1918. Ann. Ent. Soc. Am., II., 222.

192.4. "An Introduction to Entomology." Ithaca, 179.

EasthaM, 1929. Parasitology, XXI., 1.

Fraenkel, 1935. Proc. Roy. Soc. B., CXVIII., 1.

DE Gryse, 1926. Trans. Roy. Soc. Canada, XX., Sect. V., 483.

Iuns, 1925. "General Textbook of Entomology." 1st Edition. London, 179.

Javes, 1928. Ann. Appl. Biol., XV., 287.

Kéllin, 1915. Bull. Sci. Fr. et Belg., XLIX., 166.

Koller, 1929. Biol. Rev., IV., 269.

Kopé, 1922. Biol. Bull., XLII., 323.

KüHN, 1936. Gesell. zviss. Göttingen; Nach. aus der Biol., XI., 141.

Marchal, 1906. Archiv. Zool. Exp. et Gen., IV., Ser. IV., 485.

Nabert, 1913. Zeits. wiss. Zool., CIV., 181.

Nelson, 1915. "The Embryology of the Honey Bee." Priuceton.

PÉrez, 1911. Comp. Rendu Soc. Biol. Paris, LXXI., 498.

Ween, 1936. Proc. Soc. Exp. Biol. and Med., XXXIV., 883. 1936A. Ibid., 885.

Wigglesworth, 1933. Quart. Journ. Mic. Sci., LXXVI., 269.

1934. Ibid., LXXVII., 191.

1936. Ibid., LXXIX., 1. 


\section{CHAP'TER IV}

\section{PALAONTOLOGY}

Introduction, p. 72. Orders only KNown as fossils, p. it Palceodictyoptera, p. 74; Protorthoptera, p. 75 ; Megasecoptera, p. 77 ; Protodonata, p. 79 ; Protoperlaria, p. 80 ; Protohemiptera, p. 81 ; Protocoleoptera, p. 82 ; Prolelytroptera, p. 83; Incerte Sedis, p. 84. The Geological History of Insects, p. 86. Dezonian, p. 86 ; Carboniferous, p. 86 ; Permian, p. 87 ; Trias, p. 90 ; Jurassic, p. 90 ; Cretaceous, p. 92 ; Tertiary, p. 92. The Pirlogeny of Reclent and Fossil Orders of Insects, p. 94. Literature, p. 102.

\section{Introduction}

In the fossil condition insects are only found in certain gcological strata especially favourable for their preservation. Under such conditions they are often abundant, and this appears to be due to the probability that most of the speeimens got drowned and were quickly covered with silt or other deposit before their remains had time to decay completely. Some of the richest stores of fossil inseets are consequently found either in vegetable deposits like coal, lignite and peat, or in ancient freshwater basins. A great many insects have also been found in amber, where they became entangled in the resin which speedily enveloped them before they had any chance of freeing themselves. Specimens sealed up in and impregnated by this natural medium are retained in a wonderfully perfect state of preservation.

For the most part, insect fossils are represented by wings only. It appears that under the conditions of fossilisation decay speedily sets in, with the result that the bodies of the insects soon disintegrated and became separated from the wings. The lightness of the latter caused them to float away and to aceumulate in certain beds where their more durable structure enabled them to resist destruction. The natural result has been that insect palacontology is mainly a study of venation, and knowledge of 
the bodies, mouth-parts, legs, and other parts of most fossils is of a more fragmentary character. It is only when we come to the amber fossils of Miocene age that complete whole insects prevail, but owing to their comparatively recent date they lack the importance and exceptional interest associated with the earlier and more imperfect remains. Altogether about 11,500 species of fossil insects are known, and of these approximately one-fifth belong to orders or families no longer existing to-day. Recent advances in insect palæontology have, to a marked degree, filled in conspicuous gaps in our knowledge of the evolution of most of the main orders, but we are still faced with want of direct evidence from fossils with regard to the two most important problens of insect phylogeny, viz., the origin of insects as a class, and the origin of wings. The oldest winged insects are of Upper Carboniferous age (North America), but the fact that these forms are both abundant and in some cases already specialised, leads to the conclusion that the earliest Pterygota must have developed not later than Devonian or Lower Carboniferous times. Among arthropod remains found in flakes of Rhynie Chert from the Old Red Sandstone of Scotland are fragments of what appear to be Apterygota, and, if this conclusion be correct, these remnants constitute the oldest known fossil insects. The oldest living insects are the Blattidx, which have persisted through the ages, with comparatively slight evolutionary changes, from Carboniferous times to the present day.

The strata where the richest and most important recent discoveries in fossil insects have been made are of Permian and Triassic age. The fossils disclosed in these rocks have revealed so remarkable an insect fauna that our whole outlook has undergone marked changes. In a few words, it may be said that these discoveries have resulted in the Permian and Triassic records of insect life being transformed from among the least known to almost the best known geological epochs with respect to these animals. The strata in question are (1) the Upper Triassic Beds of Ipswich, Queensland : these were discovered many years ago, but have been more carefully explored recently by B. Dunstan, Queensland Government Geologist; (2) the Upper Permian Beds 
of Belmont and Newcastle, New South Wales : the discovery and exploration of these rocks is largely due to J. Mitchell; (3) the lower Permian Beds of Kansas, U.S.A. : originally discovered by A. C. Sellards of Yale, they have been explored by the Yale University Expedition under C. Dunbar and more recently by F. M. Carpenter of Harvard; (4) the Upper Permian Beds of North Russia: these have been explored during 1926-28 by A. B. Martynov and M. Edemsky. Of these four series the most important are those of Kansas, and many of the insect remains preserved in these beds are among the most perfect so far known. A number of the specimens show the colour-pattern and the finest details of the trichiation on the reins and membrane of the wings. In addition to the foregoing, mention needs to be made also of studies by Martynov on the Jurassic insects of Turkestan; by Ping on the Cretaceous insects of China; and by Tillyard on Liassic forms from Europe.

\section{Orders only Known as Fossils}

The palæozoic and earlier mesozoic fossil insects include representatives of orders which no longer exist at the present day. The chief extinct orders, including those brought to light by recent research, are the following.

Palæeodictyoptera Gold. The oldest and most primitive order of winged insects and its members are characterised by the following features. The head is rounded and bears setaceous antennæ. The prothorax is generally provided with conspicuous lateral notal outgrowths resembling vestigial wings. The mesothorax and metathorax are subequal in size and subquadrate in form. The wings are elongate and attached to the thorax by broad bases : the two pairs are closely alike in form and venation, the hind wings being without the fan-like anal lobe characteristic of many early groups. The venation is more complete than in any other insects (zide Lameere, p. 19), and its outstanding features are (1) the greatly developed branching of most of the principal reins ; (2) the presence of well-developed branches MA and MP to the media ; (3) the retention of at least three, and usually more than three, anal reins or branches; and (4) the presence of an 
irregular network, or archedictyon, of fine veinlets over the whole wing membrane (Fig. 36). The abdomen is elongate and 10-segmented, each segment often with conspicuous side-lobes of a similar nature to those of the prothorax, although much less pronounced. At the apex of the abdomen is a pair of slender and often greatly elongated cerci, and, in some genera, a median caudal filament is also present.

The order is almost exclusively confined to the lower and middle strata of the Upper Carboniferous, and about 160 species

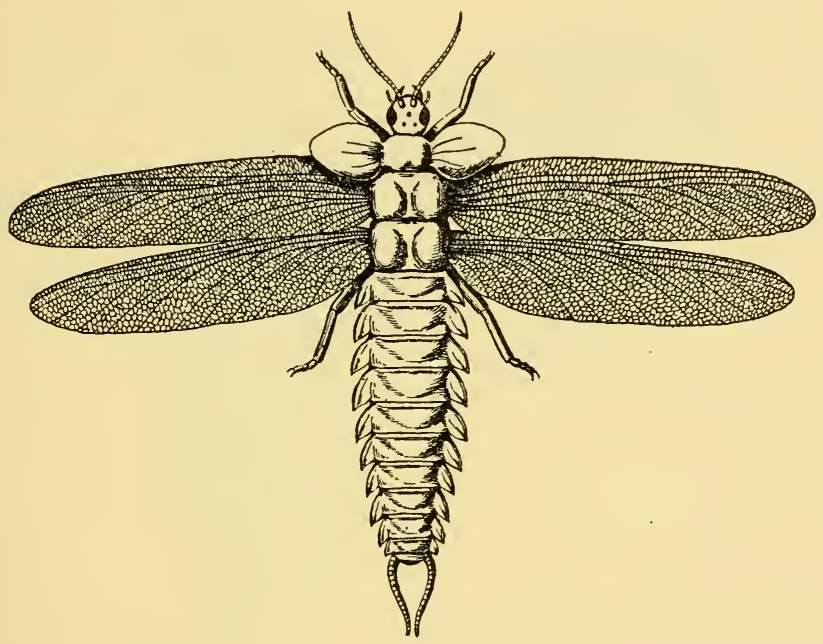

Fig. 36. Stenodictya lobata Brongn., restoration. (After Handlirsch.)

are known. It appears to have declined comparatively abruptly, since there are very few representatives in the later Carboniferous and Permian rocks. Handlirsch (1925) recognises twenty-four families, and among the more important genera are the following : Stenodictya Brongn. (Fig. 36), Commentry (France); Stilbocrocis Handl., Germany ; Mecynoptera Handl., Belgium ; Lithomantis Woodward, Scotland; Homoioptera Brongn., Commentry (France); Homaloneura Brongn., Commentry (France); Styne Handl., Germany ; Dunbaria 'Till., Kansas ; and many others.

Protorthoptera Handl. This order comprises a miscellaneous 
assemblage of Orthopteroid forms ancestral to some of the existing cursorial and saltatorial groups. It is an early offshoot of the Palxodictyoptera, whose members retain many of the venational characteristics of the latter, but are distinguished by the following features. The prothoracic notal expansions, so prominent among Palæoclictyoptera, are present in certain forms only ; the prothorax

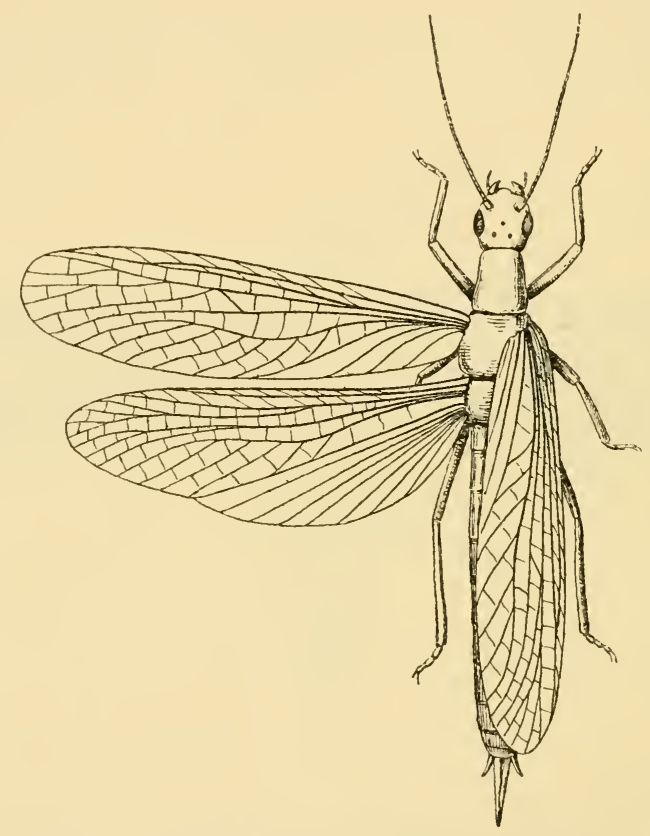

Fig. 37. Dieconeura areuata Scud., restoration.

(After Handlirsch.)

is more specialised, being markedly elongated in some forms and broader and more shield-like in others. The hind wings are broader than the fore wings, owing largely to the development of a fan-like anal lobe (Fig. 3\%). The renation resembles that of the more specialised of the Palcodictyoptera, the median vein exhibits the branches MA and MP and the primitive archedictyon is retained. Handlirsch's order Protoblattoidea (Fig. 37) which comprises ancestral cockroach-like formis does not appear to merit 
separation as an order distinct from the Protorthoptera and is here regarded as a superfamily of the latter. The tarsi are 5-jointed and there is often a well-developed ovipositor.

The Protorthoptera occurred from the Upper Carboniferous until the Trias, and number about 200 species. They comprise about eighteen families, and at least another twelve are included in the Protoblattoidea. Representative genera include Spaniodera Handl.. Dieconeura Scud. (Fig. 37), and Gerarus Scud., from

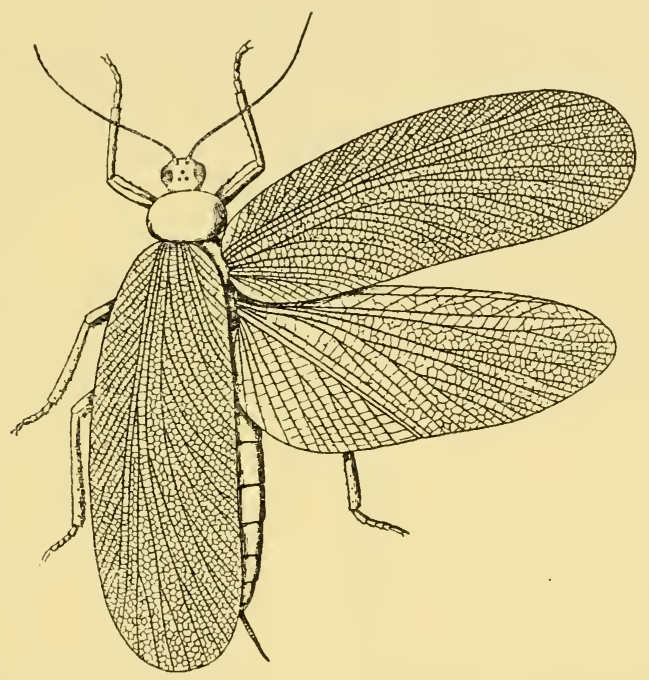

Fig. 38. Protophasma dumasi Brongn., restoration. (After Handlirsch.)

Illinois, U.S.A., and Ischnoneura Brongn., Cnemidolestes HandI., Stenoneura Brongn., Protophasma Brongn. (Fig. 38), from Commentry, France, and Euccenus Scud., Illinois.

Megasecoptera Brongn. Related to the Protodonata, but distinguished from that order by the elongate cerci, narrowed or subpetiolate wing-bases and the single anal vein, with or without descending branches (Fig. 39). The dense network of transverse veinlets characteristic of Protodonata is wanting in this order. Remains of these insects occur in the Upper Carboniferous of Commentry (France), England and North 
America, and the Lower Permian of North America (Kansas). Seven families are recognised by Handlirsch, and representative genera include Corydaloides Brongn., Campyloptera Brongn., Brodia Scud. (Fig. 46, A), Mischoptera Brongn. (Fig. 39), Kuloja Mart., Protohymen Till., and Asthenohymen Till. The two last-

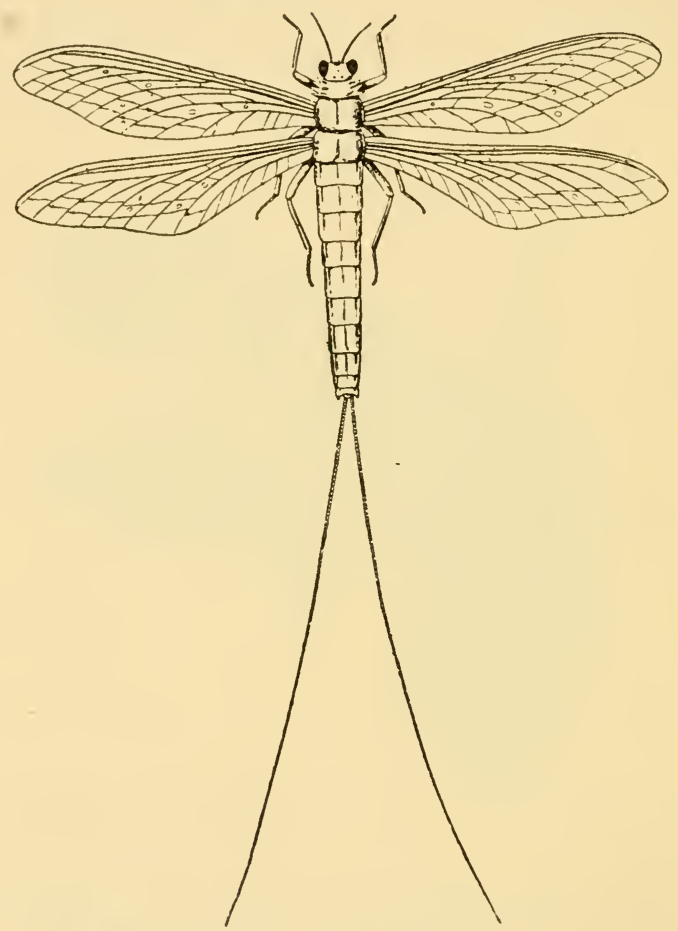

Fig. 39. Mischoptera woodwardi Brongn., restoration. (After Handlirsch.)

named genera were placed by Tillyard (1924A) in a separate order which he termed Protohymenoptera. This group it was claimed was ancestral to the Hymenoptera. Carpenter (1930) and others maintain that this conclusion is erroneous and that the "Protohymenoptera" are specialised Megasecoptera without direct affinity with the Hymenoptera. The presence of an 
ovipositor in Asthenohymen (vide Tillyard, 1936.) seems to be the only character which might suggest affinity with Hymenoptera.

Protodonata Handl. These insects are readily separated from Odonata by the absence of a true nodus and pterostigma from

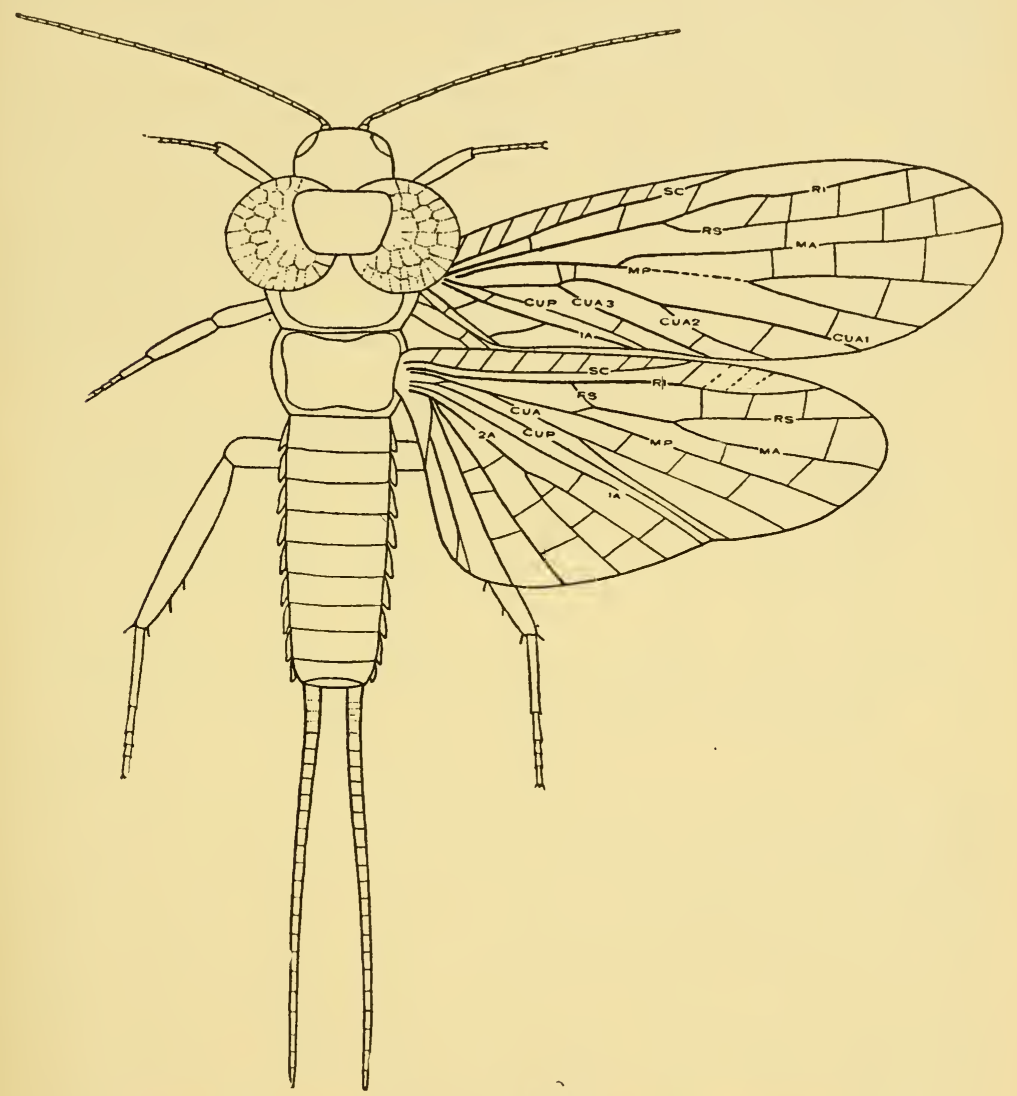

FIG. 40. Reconstruction of Lemmatophora typa Sellards. (After Carpenter.)

the wings. Their venation is distinguished from that of the Palæodictyoptera by $(a)$ the network of cross-veinlets being at right angles to the main veins and their branches, instead of forming an irregular and obliquely distributed meshwork; and 
(b) by the single anal vein (Fig. 41). In the latter feature they approach the Megasecoptera, but the broad wing bases and the close meshwork of cross-veins readily separate them. The Meganeuridae include the largest of all fossil insects with a wing expanse in sone species which exceeds 2 feet. The order may be divided into two families.

1. Fam. Protagriide. Both the main branches of $\mathbf{M}$ and $\mathbf{C u}$ present. Protagrion Brongn, Upper Carboniferous of Commentry, France. Caliertiella 'Till., Lower Permian of Kansas.

2. Fam. Meganeurida. Veins $\mathrm{MP}$ and $\mathrm{CU}_{1}$ vestigial or absent Meganeura Brongn., Upper Carboniferous of Commentry, France ; Lower Permian of Germany and North America. Megatypus Till., and Typus Sell.. Lower Permian of Kansas. Boltonites.

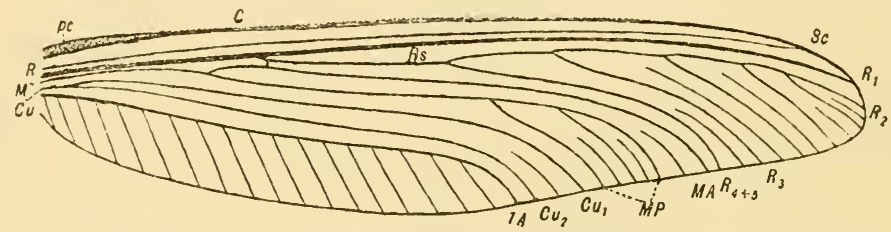

F1G. 41. Wing of Protagrion audouini Brongn. Restoration of wing ; cross-veins omitted (length about $90 \mathrm{~mm}$.). (After Tillyard, Rec. Ind. Mus., XXX., 1928.)

Upper Carboniferous of Somerset, England. Paralogus Scud., Upper Carboniferous of North America.

Protoperlaria Till. (Miomoptera, partim Martynov). This order differs from the Plecoptera (or Perlaria) in the presence of 5segmented tarsi, well-developed pronotal expansions to the prothorax and of both main branches (MA and MP) to the media (Fig. 40). Its limits are as yet imperfectly understood, and probably eertain types relegated to other groups belong here. So far representatives have only been found in the Permian rocks of Kansas and of North Russia. The Kansas examples were originally placed by Sellards in new families of Protorthoptera and subsequently Martynor (1927) erected the order Miomoptera for their reception along with the family Palxomantidie Handl., and new forms diseovered in North Russia. The Miomoptera as 
defined by Martynov appear to be an unnatural assemblage of diverse forms, including, for example, the Delopteridæ, which are relegated by Tillyard to the Psocoptera. In 1928, Tillyard, from a study of abundant Kansas material, showed that Lemmatophora and its allies, which were referred by Sellards to the Protorthoptera, exhibit relationships with the recent order Plecoptera, and proposed the new order Protoperlaria for their inclusion. Members of this order agree with the most primitive living Plecoptera in their general facies, including the presence of cerci and the absence of a median caudal prolongation, in the general shape of the wings and the possession of a large fan-like anal area to the hind pair, and in the partial fusion in the hind wings of Rs and MA. The well-developed anal lobe and the absence of an irregular network of obliquely arranged veinlets easily separate this order from the Palreodictyoptera.

The discovery by Carpenter (1935) of nymphs belonging to the Protoperlaria is of great interest. They possessed nine pairs of lateral abdominal gills which still remain as vestiges seen in the imagines (Fig. 42). In these features they are closely

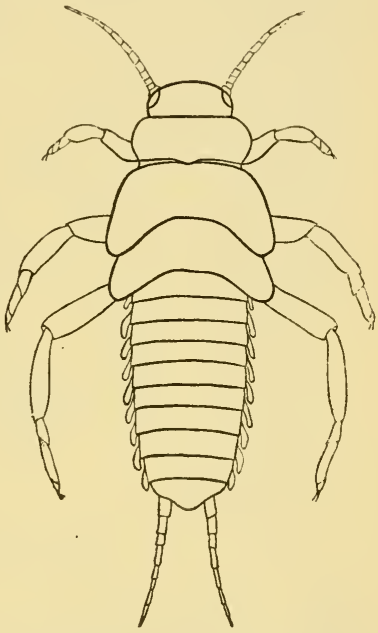

Fig. 42. Nymph of Protoperlaria. (After Carpenter.) paralleled by the Eustheniidæe, which form the most primitive family of living Plecoptera.

The order comprises only the single family Lemmatophoride, which includes the following genera: Lemmatophora Sell., Paraphrisca Handl., Leconium Sell., Artinska Sell., and Sellardsia 'Till., along with certain forms from North Russia (Martynor, 1928A).

Protohemiptera Handl. The existence of this order is based upon well-preserved but fragmentary remains of two genera, probably belonging to separate families, viz., Eugereon Dohrn. 
(Fig. 43), from the Lower Permian of Germany, and Mesotitan Till. from the Middle and Upper Trias of New South Wales. The Protohemiptera are among the largest fossil insects so far discovered, and the wing-expanse of Eugereon boeckingi Dohrn. is estimated by Handlirsch at $16 \mathrm{~cm}$. Except for the discovery of the head and prothorax of this remarkable fossil palæontologists would have been faced with a puzzling problem in settling its affinities from the wing remains only.

The Protohemiptera are characterised by pronotal expansions very similar to those of the Palaeodictyoptera and Protoperlaria. The head is rather small, with projeeting mouth-parts of the

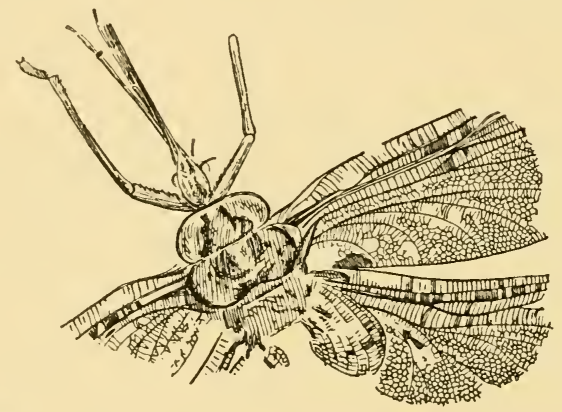

Fig. 43. Eugereon boeckingii Dohrn. Reproduced by permission of the Trustees of the British Museum.

piercing and suctorial type. The whole of the wing is covered with a meshwork of delicate and very closely set transverse veinlets. The venation is markedly reduced with $R_{1}$ and $\mathrm{Cu}_{\mathbf{1}}$ simple unbranehed convex veins, but Sc is well developed and gives off numerous costal veinlets. M is represented by MA only and $\mathrm{Cu}_{2}$ is pectinately branched.

Protocoleoptera Till. The order Protoeoleoptera was founded. by 'Tillyard (1924) for an example of an elytron (or tegmen), about $24 \mathrm{~mm}$. long, discovered in the Upper Permian of Belmont, N.S.W. This speeimen, Protocoleus mitchelli Till., appears to point to the existence of a primitive order ancestral to the Coleoptera, but having flattened teguminous elytra with straight sutural margin and a complete system of venation. Tillyard, in 1928, also 
referred to this order Permofulgor Till., which he had originally placed in the Homoptera. In this genus there is a complete, although narrow, sutural margin and a distinct alula, resembling that of the Hydrophilidx, situated at the base of the elytron. In Permofulgor the venation is more reduced than in Protocoleus, and the genus appears to lead to the extinct truc beetles of the family Permophilidie, whose remains occur contemporaneously in the same strata.

The venation of these early Coleopteroid types (Fig. 44) is totally unlike that of the elytron of any known true Coleoptera, since in the latter insects the main veins are simple and unbranched throughout their courses and the anal area much reduced. In 1928, Forbes pointed out that the deep notch at the articulation and the basally extended anal area are common Orthopteroid features, together with the richly branched condition of the main veins. On these and other features he refers Protocoleus to the group Gryllacridiidæ of the Orthoptera. The resemblance between this genus and a typical Gryllacrid, however, is not very marked, the venation being very different in the two cases and the absence of the

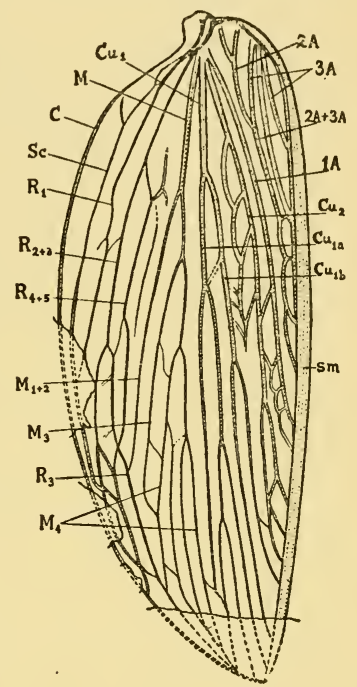

FIG. 44. Protocoleus mitchelli Till. elytron $\times 3$. (After Tillyard, Proc. Linn. Soc. N.S.W., XLIX., 1924.) characteristic cross-veinlets of Gryllacris is particularly noticeable.

Protelytroptera Till. Some of the most remarkable insect remains found in the Elmo limestone of the Lower Permian rocks of Kansas are those to which Tillyard (1931) gave the ordinal name of Protelytroptera. The discovery of further material has enabled these fossils to be studied more fully by Carpenter (1933). While a certain amount of detail is known with regard to their general external form and structure, no light has, so far, been shed as regards the character of their mouth-parts. In the more generalised types such as Protelytron the fore wings were convex 
elytra (Fig. 45) with a widened costal area : R was 2-branched, M single-branched, while $\mathrm{Cu}$ divided basally in $\mathrm{Cu}_{1}$ and $\mathrm{Cu}_{2}$. There were three simple anal veins and a general absence of cross veins. In other genera the renation was more specialised by reduction. The hind wings were evidently adapted for folding and, as in Dermaptera, the anterior veins are much modified and

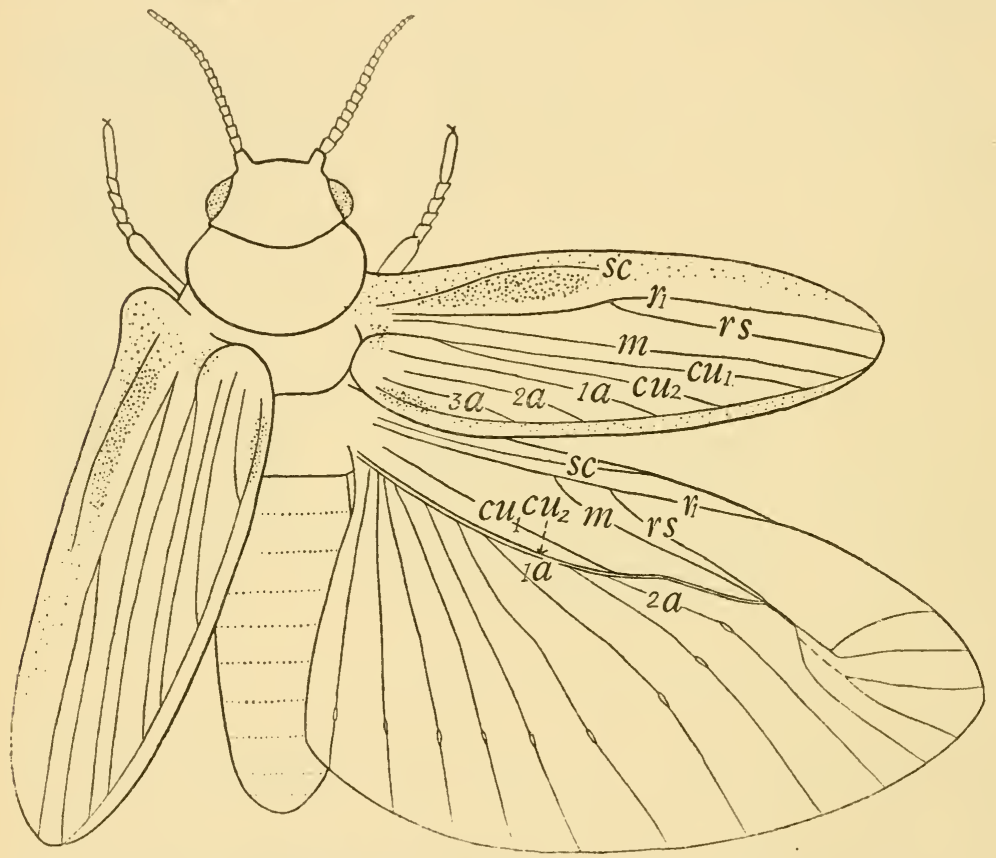

F1(:. 4.). Protelytron permianum Till. Reconstruction.

(From Carpenter.)

there is a large anal lan formed by a number of radiating anal veins. The prothorax is large. the tarsi 5 -segmented and the antennac composed of about twenty-two joints. The order is divisible into five families which take their names from the following genera. Protelytron Till., Megelytron Till., Blattelytron 'Till., Archelytron Carp.. and Elytroneura Carp.

Incertæ Sedis. In addition to the foregoing there are a number 
of smaller groups, many of them of very unccrtain affinities, which have been given ordinal rank by Handlirsch. For the most part they are based upon anomalous fossil remains, usually few in number, which have been made the types of provisional orders more especially to emphasise their essential differences as compared with other groups of insects. The orders Paramecoptera, Paratrichoptera and Protodiptera of Tillyard are also only doubtfully separate and distinct. No parts other than wings have so far been discovered, and from their venational characters it is presumed that their nearest living relatives are the Mecoptera. In his later communications Tillyard (1935, 1937) regards them as being sub-orders of this originally extensive order (the Mecoptera). They are all characterised by a primitive venation, which was essentially similar in both fore and hind wings, and by the singlebranched $\mathrm{Cu}_{1}$.

The Paramecoptera are represented by the genera Belmontia Till. and Parabelmontia Till. from the Upper Permian of Belmont, N.S.W. They are characterised by the rather extensive dichotomy of $\mathrm{Rs}$ and $\mathrm{M}$, and in Belmontia there is a short distal fork to $\mathrm{Cu}_{\mathbf{1}}$. In so far as the last-named genus is concerned, its features betray no insuperable barrier to its being regarded as a remnant of a. group which was ancestral to the Trichoptera and Lepidoptera.

The Paratrichoptera are characterised by both Rs and M having four branches only, arranged dichotomously. They comprise Mesopsyche Till., Neuropsyche Till., Aristopsyche Till., and Triassopsyche Till., from the Upper Trias of Queensland: Pseudopolycentropus Handl., Lias of Europe and Liassophila 'Till., Upper Lias of England.

The Protodiptera are based upon a dipterous type of wing to which Tillyard (1929) gave the name of Permotipula. This discovery was followed several years later by the finding of a four-winged insect with very similar venation in both pairs of wings (Tillyard, 1937). Both these fossils were found in Upper Permian rocks of Warner's Bay, New South Wales. The second example is clearly that of a four-winged insect whose wings are of a type still to be found in the most primitive living families of Diptera. The wings bear a marked dipterous facies in their 
narrow bases and correspondingly reduced anal area. The venation is characterised by $R$ s with three or four branches; II with four branches; $\mathrm{Cu}_{2}$ reduced and approximated to $\mathrm{Cu}_{1}$, and the anal veins reduced to $1 \mathrm{~A}$ or with a vestige of $2 \mathrm{~A}$ also.

The Protodiptera arc undoubtedly the most distinct of the above supposed sub-orders, but so far no annectant forms have been found between them and the true Diptera.

It is probable that future discoveries may result in bringing to light forms connceting the Paramecoptera (Belmontia) with existing Protomecoptera, justifying the merging of the former with the latter. Whether Parabelmontia is really closely connected with Belmontia seems doubtful.

\section{The Geological History of Insects}

The sequence of the appearance of insect remains in geological times is displayed in the accompanying table (p. 101), and the chief facts in the past history of these animals will be briefly discussed in the light of recent discoveries. It may be pointed out that no insect fossils have so far been found in any pre-Devonian rocks.

Devonian. The presumed insect remains of this period are extremely small and fragmentary, and have been found in flakes of Rhynie Chert from the. Middle Old Red Sandstone of Scotland. The most complete remains consist of portions of the headcapsule, mouth-parts and antennæ of the species Rhyniella precursor Hirst and Maulik, which is regarded by Tillyard (1928A) as being an early Collembolan. The other fossils consist of mandibles only, and the species to which they have been relegated, viz., Rhyniognatha hirsti Till., may possibly have been a Thysanuran. If, as appears very probable, Rhyniella is a species of true Apterygota, it is remarkable that no evidence of the existence of such insects has so far been revealed in intervening rocks until the Oligocene period.

Carboniferous. Remains of insect life are found in comparative abundance during this period, and the earliest undoubted examples of the class occur in the lower layers of the Upper Carboniferous of North America. This early fauna consisted almost cntirely of Palæodictyoptera, Protorthoptera (including Protoblattoidea), 
Protodonata, Megasecoptera and Blattidx. With the exception of the last mentioned, all these groups are extinct to-day-they are ancestral forms from which more recent types have been derived. None of these early orders gives any clue as to the origin of insects as a class, while their abundance, together with their relatively high grade of specialisation in some cases, clearly indicate that more ancient relics of insect life still await disclosure in antecedent rocks.

The primordial and heterogenous order Palacodictyoptera appears to have already attained its maximum development in the middle strata of the Upper Carboniferous and the famous beds of Commentry in France, those of Mazon Creek in North America and other beds of the same age in England and Belgium have yielded many remarkable forms. This order, together with the Megasecoptera, appears to have declined relatively quickly, and towards the end of the Carboniferous age their remains become very scanty. In addition to the orders mentioned, a number of isolated fossils of doubtful affinities occur during this age, and have been raised by Handlirsch to the rank of separate orders. Among them are the primordial mayfly, Triphlosoba Handl., which forms the sole representative of Handlirsch's order Protephemeroidea, and the Hadentomoidea, which he regards as forerunners of the Embioptera.

Many of the Carboniferous insects were of large size, and included some of the giants of their class. For the most part they appear to have been slow and weak fliers, a feature which may have contributed to their early extinction. The Blattidæ, however, are an exception, since they have retained their general facies, with comparatively slight modifications, down to the present day.

Permian. Recent discoveries, previously alluded to, have revealed a rich and highly interesting fauna in Permian times. In rocks of Lower Permian date are found the earliest known Holometabola which are represented by several families of Mecoptera (vide Tillyard, 1935 ; Carpenter, 1930A) and Neuroptera (Tillyard, 1932). Of the Mecoptera the family Permochoristidx has thirteen species in five genera, while the single species of Anomochorista gives its name to a second family. It is remarkable 
that even these early fossils already exhibit in the Anomochoristidae a venation specialised by reduction. Among the Neuroptera are found representatives of the existing Raphidiodea, in the genus Permoraphidia. The Sialiodea are also met with in Martynovia and Choristosialis. while the earliest known Planipennia appear in Permoberotha. It is noteworthy that all these early Neuroptera are comparatively highly specialised types. The curious beetlelike Protelytroptera are confined to the rarious rocks of this period, which also contain an abundant series of Megaseeoptera. In the same strata there also occur the earliest known true mayfly (Protereisma) and a number of generalised Perlid-like forms which constitute the order Protoperlaria. In the lower Rothliegende of Birkenfeld, in Germany, there is to be found the remarkable fossil Eugereon Dohrn.. belonging to the order Protohemiptera. It is noteworthy that the earliest undoubted fossil records of truc Hemiptera are of approximately the same age, and occur in the Lower Permian of Kansas. They comprise Homoptera only, and appear to indicate that both the divisions Sternorrhyncha and Auchernorrhyncha were already clearly differentiated at that period. True dragon-flies also appear in Lower Permian times, but they differ sufficiently from living forms to form a separate suborder, the Protozygoptera. The remarkable genus Kennedya is the most important type (Fig. 46, B), and it shows that in these early dragon-flies the specialised discoidal cell and the sub-nodus of recent forms were undeveloped and, at the same time, they retained a vestige of vein $\mathrm{Cu}_{1}$ within the petiole of the wings ('Tillyard, 1925). 'The Psocoptera were also of great antiquity, and recent researches ('Tillyard, 1926c, 19281, 1935в) have brought to light examples of species which appear to represent two new and extinct sub-orders- the Permopsocida and the Embiopsocida. In the latter group is the genus Permembia Till., which combines apparent Embiid affinities with those of the Psocoptera.

Coming to Upper Permian times, rocks of this age in Australia and Northern Russia have diselosed abundant records of insect life which have been the subject of recent studies by Tillyard and by Martynor. In Australia the Belmont beds of New South Wales have afforded further evidence of the existence of 
Hemiptera-Homoptera, and among the latter the family Scytinopteridæ was dominant. The earliest true Plecoptera make their appearance at this period. They are represented by Stenoperlidium ('Iillyard, 1935A), a member of the existing family Eustheniidx. The Paramecoptera, possible ancestors of both the Trichoptera and Lepidoptera, make their appearance, and along with them are the earliest known fossil Coleoptera. The latter consist of two families, the Permophilidæ and Permosynida. Of these, the first mentioned appear to be the direct ancestors of the existing Hydrophilidx, while the Permosynidx evidently lead on to genera existing in the Upper Triassic rocks. Remains of what appear to be even more generalised Coleopteroid types occur in the same strata as these ancient beetles, and they are regarded by Tillyard as forming his order Protocoleoptera. Neuroptera also occur during the Upper Permian age and are represented by four genera forming the family Permithonidæ.

From Russia Martynov (1928A) has described some early examples of the Megaloptera in his genus Permosialis : although related to living Sialidx its more specialised features have led him to place it in a separate family-the Permosialidx. The Planipennia are represented by the new family Palæomerobiidæ which appears to be allied to, but more primitive than, the Australian Permithonidæ. Homoptera were apparently a dominant group and the early families Prosbolidx and Scytinopteridx were well represented. Remains of what appear to be May-flies allied to Protereisma, Mecoptera and Psocoptera are also recorded, together with a number of forms which are referred to his order Miomoptera (see p. 80).

All the ancient Carboniferous orders extended into Permian times. Protorthoptera and Blattidx were abundant, but the Megasecoptera, although common in the early Permian, appeared to have died out at the end of this period: the genus Kuloja Mart., from the Upper Permian of North Russia, appears to be the last-known survivor, but the remains of this fossil are too scanty for ascertaining their affinities with certainty. Palæodictyoptera, already much on the decline, are represented by Dunbaria Till. and Permoneura Carp. in the Lower Permian 
of Kansas, and possibly by some wing fragments from the Upper Permian of Russia. Protodonata likewise were on the decline, and among their last representatives are Calvertiella Till. and Megatypus Till. from the Kansas beds.

Trias. Recent discoveries among Australian rocks of Triassic age have revealed a rich insect fauna. In the Ipswich beds of New South Wales Hemiptera show a greater development and specialisation as compared with the previous epoch. In the family Dunstaniidæ Pentatomid affinities appear to be present, while the Triassocoridx are possibly ancestral to the Notonectidx and related aquatic forms. Homoptera were a dominant group and were represented by a great variety of forms, including the large Mesogereonidx, which were evidently ancestors of the Cicadidx, numerous Fulgoroidx and some early Jassidx. It is noteworthy that in the discovery of Mesotitan Till. from these same beds we have the second known genus of Protohemiptera. Among Mecoptera, the sub-order Protomecoptera is represented by Archipanorpa in a remarkably perfect condition of preservation, while Aristopsyche and its allies, which were regarded by Tillyard as forming a separate order (Paratrichoptera), also occur in the Ipswich beds. Neuroptera of this age include the family Prohemerobiidæ, together with Triassopsychops, which is a forerunner of the existing Psychopsidæ; in the Trias of Europe are found some remains of alder-flies. Among dragon-flies are the genera Triassolestes, a true Zygopteron; and Triassagrion, a member of the sub-order Archizygoptera which became extinct in Liassic times. True Coleoptera were also abundant in the form of elytra and include already specialised types, some of which have been referred to the families Chrysomelidxe and Curculionidx. It is also noteworthy that the Carboniferous order Protorthoptera extends into the Trias, and some of the Triassic Blattidæ differ remarkably little from those present during the Palæozoic era. Accompanying these primitive Orthopteroid types were true Acridiidxe and forms related to the Mantidæe and Tettigoniidae.

Jurassic. The Jurassic period is notable from the fact that all the main orders of insects, with the exception of the 
Lepidoptera, had come into existence before it terminated. The earliest true Hymenoptera occur in Upper Jurassic strata and include both Symphyta and Parasitica. In the Lower Purbeck beds of England, but more especially in the contemporaneous Solenhofen slates of Bavaria, there are abundant remains of primitive wood-wasps of the genus Pseudosirex. From rocks of similar age at Montsech in Spain there has been found an Ichneumonoid genus, Ephialtites, which is regarded by Handlirsch as intermediate in character between the Symphyta and Apocrita. The recent discoveries of Martynov (1925) in Turkestan have brought to light (a) Paroryssus, a genus which appears to be annectant between the living Oryssidæ and the most primitive Ichneumonoidea ; (b) Anaxyela, a form antecedent to Xiphidria ; (c) Mesaulacinus, which is referred to the Evaniidæ; and $(d)$ the Proctotrypoid Mesohelorus.

True Diptera, belonging to the orthorrhaphous series, appear for the first time in the Upper Lias of Europe, together with the earliest known fossil Trichoptera. The Diptera include Rhyphidæ, Bibionidæ and other Nematocerous families from the Upper Lias of Mecklenberg and the Upper Jurassic of England. The remains of Upper Rhætic crane-flies, described by Wieland in 1925, from South America, have since been referred by Tillyard to the Homopterous family Scytinopteridx. In the Upper Lias of England are also found early Diptera of the family Architipulidx (Tillyard, 1933). The Trichoptera are referred to the family Necrotaulidx, which has close affinities with the existing Rhyacophilidæ. In Liassic times in Europe dragon-flies of the now almost extinct sub-order Anisozygoptera were abundant and true Anisoptera first appear in the Upper Jurassic. In rocks of Middle Jurassic date a few wings and nymphs of some early Plecoptera have been found in Siberia. Neuroptera are well represented in the Lias and Upper Jurassic of Europe by the Prohemerobiidæ, the large and striking Calligrammatidæ, together with allied forms. Other dominant Jurassic insects include Coleoptera, which are plentiful in rocks of this age in Europe, while both sub-orders of the Hemiptera are represented by wellpreserved fossil remains. Several recent families of Heteroptera, 
including the Reduviidx, Lygaidx, Hydrometridx and Belostomatidæ, existed at this period. The Palæontinidæ from the Solenhofen slates, which are regarded by Handlirsch as the earliest known Lepidoptera, are referred by 'Tillyard to the Homoptera and appear to have been Cicada-like forms. It is also noteworthy that Mecoptera occur plentifully in the Lower Lias of England. Among the genera are Orthophlebia, which appears to be ancestral to the living Panorpidx, and Probittacus, which connects the recent Bittacidæ with the Permochoristidx. The sub-order Paratrichoptera also extends into the Lower Lias where it is represented by a fore wing of Liassophila from rocks in Warwickshire ('Tillyard, 1933).

Cretaceous. Only scanty and fragmentary remains of insects occur in rocks of this date. On the whole, Coleoptera predominated in the Lower Cretaceous of England, and the Upper Cretaceous of Bohemia. Fragments referable to other orders have also been disclosed in the last-mentioned strata, but they are, for the most part, too poorly preserved for accurate determination. The most considerable recent discoveries among Cretaceous insects are those of Ping (1929) in China, where a wide and very scattered series of forms has been disclosed ranging, among the higher orders, from Paraulicus (Evaniidæ) and Chironomidx to Perlidx and Blattidx. All the examples disclosed in China appear to belong to existing families. Taken as a whole the insect remains during Cretaceous times are scarce, but this is not to be attributed to actual paucity of those animals during that period, but rather to the absence of suitable freshwater deposits wherein examples might have accumulated and become fossilised. The comparatively sudden appearance of highly organised Lepidoptera, Aculeata and cyclorrhaphous Diptera, in the early Tertiary period, suggests that these groups must have been represented by forerunners in Cretaceous times.

Tertiary. Many of the Tertiary deposits are extremely rich in insects and they have yielded nearly three-fourths of the known fossil species, almost all modern orders being represented. Taken as a whole the fauna of these times did not differ markedly in composition from that of to-day-even during the Oligocene, 
which is relatively early in the 'Tertiary period, the insects were very much the same as those which prevail at present.

Among the strata richest in insect remains are those of the Green River of Wyoming, of Eocene date; the famous Baltic amber beds of Oligocene age, and the White River deposits of Colorado ; the Miocene deposits of Florissant in Colorado, together with those of Oeningen and Radaboj in Europe, and others.

Collembola and Thysanura are well represented in Baltic Amber, and excepting the Devonian remains previously referred to (p. 86) they are unknown from pre-Tertiary deposits. The Collembola, which have been revised by Handschin (1926), are representatives of living genera pertaining both to the Arthropleona and Symphypleona, while the Thysanura comprise Machilida, Lepismidæ and a species of Campodea.

The earliest undoubted Isoptera occurred in Eocene times and became more abundant in the Oligocene and Miocene. The most interesting forms are Mastotermes and Archotermopsis, which are the most primitive known genera and are each represented by a single species at the present day. Specialised genera such as Eutermes and Termes were also living in Oligocene and Miocene times.

Lepidoptera are present in rocks of Eocene age onwards, but it is practically certain that the orcler is of pre-Tertiary origin, and it may be added that certain leaf mines of Upper Cretaceous agc are very possibly the work of their larvæ. In Lower Oligocene times a few butterflies and more numerous moths, referable to living families, occurred in Baltic amber, and some further remains of the order have been disclosed in the deposits of Miocene date. Fossil Lepidoptera, however, give no information relative to the evolution of the order, and we have still to seek for the existence of Homoneura in geological times. According to Professor Cockerell, the Micropterygidxe are represented by a specimen in Burmese amber (in the British Museum) and this seems to be the only record.

Coleoptera are extremely abundant in Tertiary rocks. A number of modern genera were existing in Eocene times and more than 430 species of beetles are known from Baltic amber, while 
an even larger number have been collected from the Miocene of Florissant.

The earliest known Aculeate Hymenoptera date from the Eocene period, and it is evident that they were one of the latest of the great groups to be evolved. Both Parasitica and Aculeata are abundant as fossils; Chalcids of the genus Eurytoma are described from the Eocene of Green River, and all the great groups of the parasitic forms were existing in the Lower Oligocene. Considerably over 300 species of ants are known from Tertiary strata, and among them male, female and worker castes were differentiated much as to-day. Wheeler has remarked upon the absence of polymorphism among the worker caste, and it appears that differences which separate individuals into true workers and soldiers were not evident until the Pleistocene.

The higher Diptera occur as fossils in Eocene rocks and became abundant in the Oligocene. Syrphidæ are especially prevalent as fossils, and this family, together with the Tachinidac, were already existing in the Eocene period of the Green River in Wyoming.

Little needs to be said of the remaining orders, since most are represented in Tertiary times, including the smaller groups Embioptera, Strepsiptera and Aphaniptera.

\section{The Phylogeny of Recent and Fossil Orders of Insects}

The earliest fossil remains of insects found in Carboniferous rocks were exopterygote forms endowed with large and tolerably efficient wings. Along with them are fragments of contemporaneous nymphs, thus indicating that these insects underwent incomplete metamorphosis. Many of these ancient insects are grouped to form the order Palrodictyoptera which comprises a large assemblage of generalised forms divisible into a number of families. New genera are frequently being discovered and knowledge of the order has greatly devcloped in recent years. A revisional monograph is much needed to-day wherein the venational features of the earlier described forms are re-studied in the light of more recent knowledge. Much the same condition of affairs prevails with regard to other Palacozoic insects and the limits of some of the orders require re-definition. There is 
undoubtedly a good deal of intergrading among different groups wherein differentiation has not proceeded very far, and many forms which have to be regarded as of generic status display characters which would be classed as of family, or higher, significance, among recent forms.

The Protorthoptera exhibit definite advance on the Palaodictyoptera; for example, the structure of their thorax indicates that they had developed some capacity for running, whereas the ancestral order probably had feeble powers of terrestrial locomotion and resorted to short spontaneous flights. These early Orthopteroid forms show increased development of the hind wings, and the expanded anal area of those organs is a
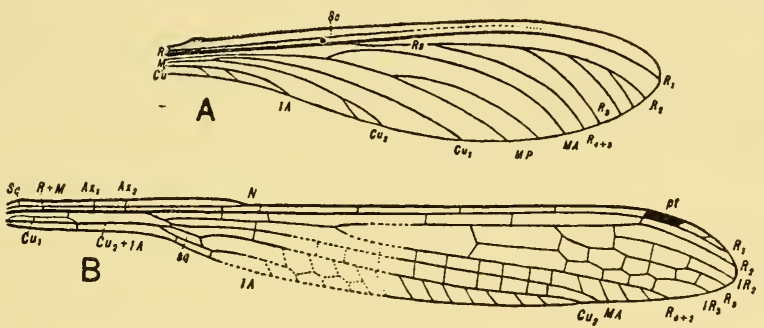

Fig. 46. A, Brodia priscotincta Scud. wing (58 $\mathrm{mm}$. long), with cross-veins omitted. B, Kennedya mirabilis Till. wing $(44 \mathrm{~mm}$. long). (Adapted from Tillyard, Rec. Ind. Mus., XXX., 1928.)

distinct advance upon the closely similar fore and hind wings of the Palæodictyoptera. The Protoblattoidea were early cockroachlike forms which connected the Protorthoptera with the true Blattidx that co-existed with them. Other of the Protorthoptera exhibit modifications in different directions, and $O E d i s c h i a$ Brongn., for example, has the unmistakable facies of a primordial longhorned grasshopper. Some of the Protorthopterans carried pronotal expansions and thereby resembled the Palæodictyoptera. The presence of these expansions, however, is sometimes coupled with evidences of an ovipositor-an organ which is not developed in the Palæodictyoptera.

The Megasecoptera were an evidently specialised order: the narrowing of their wing-bases and the reduction of their venation 
indicate that they must have been a special offshoot from the Palreodictyoptera. In the genus Brodia Send. Tillyard (1928B) clains that we have a type ancestral to the Protodonata and Odonata and that these two orders are collateral developments from the Megasecoptera (Fig. 46). Great stress has been laid upon the discovery of the primitive true dragon-fly Kennedya 'Till.. and its bearing on the evolution of the Odonata. This theory of Tillyard involves the derivation of the broad-winged Anisopterous forms from narrow-winged Protozygoptera which has been disputed by Carpenter (1931). As this writer points out, Tillyard's grounds for his conclusions rest on a slender basis, and, in view of more recent discoveries, his theory will have to be abandoned. The discovery of the ancient sub-order Protanisoptera,

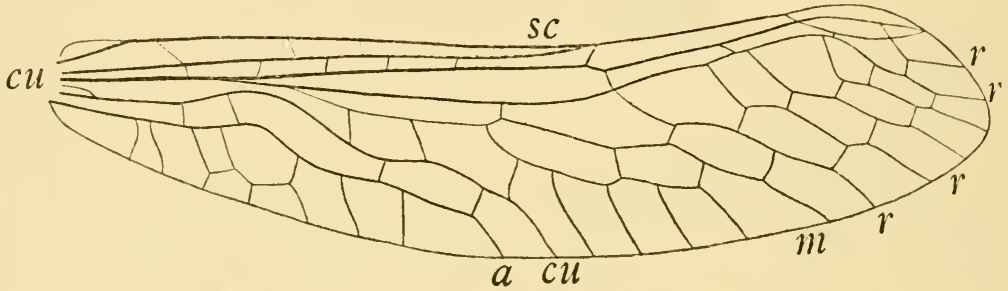

Fig. 47. Wing of Ditaxineura anomalostigma 'Till.

(From Carpenter.)

represented by Ditaxineura (Fig. 47) from the Lower Permian, shows that this type extends equally far back in geological time as the Protozygoptera, represented by Kennedya. Without going into a long and complex argument it may be affirmed that no group ancestral to these two ancient sub-orders of dragon-flies has yet been discovered. In Kennedya $\mathrm{Cu}_{2}+\mathbf{1 A}$ combine to form a long stalk traversing the petiole of the wing, whereas in Ditaxineura there is no petiole and these two vcins remain separate. It would seem clear, therefore, that on this feature alone the last-named genus is the more primitive. Tillyard's belief that the Protozygoptera were derived from the Megasecoptera has very slight evidence for its support. Carpenter sees no elose affinity between the last-named order and either the Protanisoptera or the Protodonata. In our present state of knowledge we have to 
recognise that the Odonata probably arose along two separate lines of modification from common ancestors. These ancestors were evidently related to the Protodonata, but the relationships of the Protodonata with the Megasecoptera are obscure.

Arising apparently as another offshoot of the Palæodictyoptera are the Protoperlaria, which exhibit a type of venation foreshadowing the recent Plecoptera. The more advanced types of Protoperlaria, such as Artinska Sell., show features ancestral to the more primitive of the living Perloids and indicate that the latter were probably descendants of the former. The presence of prothoracic lobes and 5-segmented tarsi in the Protoperlaria affords characters which are well known to be wanting in all recent Plecoptera. The discovery of a true Plecopteron, viz., Stenoperlidium ('Tillyard, 1935A), which clearly belongs to the living family Eustheniidæ, is one of the more striking disclosures in insect palæontology. The fact that a representative of a living family of insects should be preserved in Palæozoic rocks (Upper Permian) is only paralleled among the Blattidx.

The Ephemeroptera reveal evident Palæodictyopteroid characters in their primitive venation and their long cerci. The Upper Carboniferous genus Triphlosoba, which constitutes the order Protoephemeroidea of Handlirsch, appears to be related to the genus Homaloneura of the Palæodictyoptera. These forms lead to the true May-flies of the Lower Permian epoch which belong to the genus Protereisma. In the latter insects the fore and hind wings were closely alike in size and venation, and the archaic living family of the Siphlonuridæ has not diverged very markedly from these early fossils.

Another ancient order - the Protohemiptera (Fig. 43)--had a type of wing venation which suggests that it may have arisen from a specialised family of the Palæodictyoptera, but it combines primitive venational characters with specialised Hemipterous mouth-parts. Up to the present the fossil record has afforded no indication as to how the latter organs were derived from generalised biting jaws.

The Protohemiptera may, or may not, have been on the direct line of descent of modern Hemiptera, but they indicate the 
probability that the latter order had a common ancestry with the other Exopterygota mentioned. The most primitive true Hemiptera occurred as early as Lower Permian times, and their most ancient families are referable to the sub-order Homoptera. The oldest of the Heteroptera are the Dunstaniidæ, from the Upper Trias, but palæontology has not so far shed much light on their derivation and relationships with the Homoptera. The only evidence so far revealed is the discovery of an upper wing in the Trias of Queensland belonging apparently to the Homopterous family Scytinopteridæ (Auchenorrhyncha). According to Tillyard (1936) this specimen shows evidence of transformation into a true Heteropterous tegmen.

Discoveries of Lower Permian Homoptera, belonging to the extinct family Archescytinidæ, have demonstrated venational affinities with early types of Psocoptera found along with them. It appears likely that the Hemiptera and Psocoptera are divergent developments from a common stock and that, later on in geological time, the Anoplura were evolved as descendants of wingless Psocids which had become adapted for a parasitic life upon warm-blooded vertebrates.

Mention has been previously made of the resemblance between certain of these early Psocids and the Embioptera. If this reveals anything more than parallelism, or convergence, we may have to seek for the ancestry of the last-mentioned order in this direction. The palrontological history of the Embioptera, however, is so scanty that their ancestry remains enveloped in obscurity, and no undoubted evidences of the order occur until the Tertiary period. The Isoptera similarly have left no certain indications of their ancestry. Structurally, they betray very evident Blattoid characters and there is little doubt that they arose from cockroach-like forms which subsequently developed a complex social organisation. In Tertiary times their genera were very much as we find them to-day, and it is evident that ancestral forms will have to be sought in rocks of considerably earlier date. Palæontology likewise reveals nothing with respect to the affinities of the Thysanoptera, but, from a study of recent forms, we are led to conclude that they have more in common with the Hemiptera 
than with any other order. Possibly they arose as offshoots of some early Psocopterous group, but evidence of this contention is not forthcoming.

The oldest order of the Holometabola are the Mecoptera which were already well represented in Lower Permian times. The venation of these early Mecoptera (Fig. 48, A), however, is so fundamentally different from either that of the Palæodictyoptera, or of the Protorthoptera, that we are led to the conclusion that
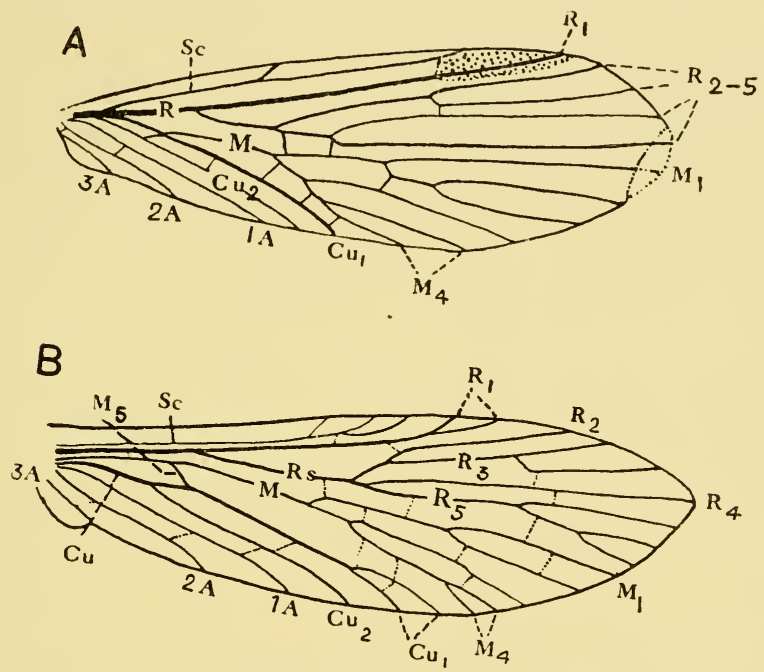

Fig. 48. A, Permochorista jucunda Till. fore wing. $\times 6.5$.

$B$, Belmontia mitchelli Till. $\times 2.5$. (Adapted from Tillyard.)

a long series of transitional forms must have existed in early Carboniferous times, of which we have as yet no evidence. Although its ancestry is, therefore, obscure, the order itself is of great phylogenetic importance, since all the main groups of the Holometabola (excepting the Coleoptera and Hymenoptera) are perhaps referable to a Mecopterous ancestry The extinct sub-order Protomecoptera, with its tendency to a more profusely branched venation and the widened costal space, included Meropelike forms which may well have been ancestral to the Neuroptera. The sub-order Paramecoptera (Fig. 48, B) of the Upper Permian 
exhibit features ancestral to the Trichoptera and Lepidoptera on the one hand, and which ally them with the Mecoptera on the other. The Triassic Mesopsychidæ (forming the order Paratrichoptera of Tillyard) combine characters which suggest that they are on the line of descent of the Protodiptera. The true Diptera, however, have no known annectant forms connecting them with the Protodiptera.

Among Hymenoptera the venation is specialised to a degree which proclaims the singularly isolated position of the order. Even among the most primitive of the saw-flies there is no indication of apparent relationship with any other orders.

The Protelytroptera ('Tillyard, 1931) are a tegmen-bearing order whose affinities are far from clear. That they bear an apparently close resemblance to the Dermaptera as regards the hind wing is obvious: furthermore, pentamerous tarsi are also found in the Jurassic earwig Protdiplatys Mart. from Turkestan. It is probable that they are to be regarded as early forerunners of the earwigs, and according to Carpenter (1933) the venation of the tegmina suggests their derivation from certain Blattids of Upper Carboniferous date. The venation of both the tegmen and hind wings is more specialised than that of the Protocoleoptera and Tillyard's suggestion that the last-named order may prove a remnant of the Protelytroptera-at a stage when the elytra were still tegmen-like and flattened--seems to be in harmony with the facts at present available. The scanty remains of Protocoleoptera so far discovered, however, scarcely warrant any but very tentative conclusions being drawn.

The conclusions to be derived from recent advances in insect palæontology may be briefly summarised as follows :-

1. At least nine recent orders are known to have existed from Palæozoic times. Of the remainder, the Trichoptera, Hymenoptera and Diptera are known from Jurassic strata, while the Thysanura, Isoptera and Lepidoptera have, so far, only been traced back to the Tertiary period (Table I, p. 101).

2 . Three recent families have persisted apparently from Palæozoic times, viz., the Poduridx (Collembola) from Middle Devonian; the Blattidie sen. lat. (Orthoptera) from Upper 
TABLE I.

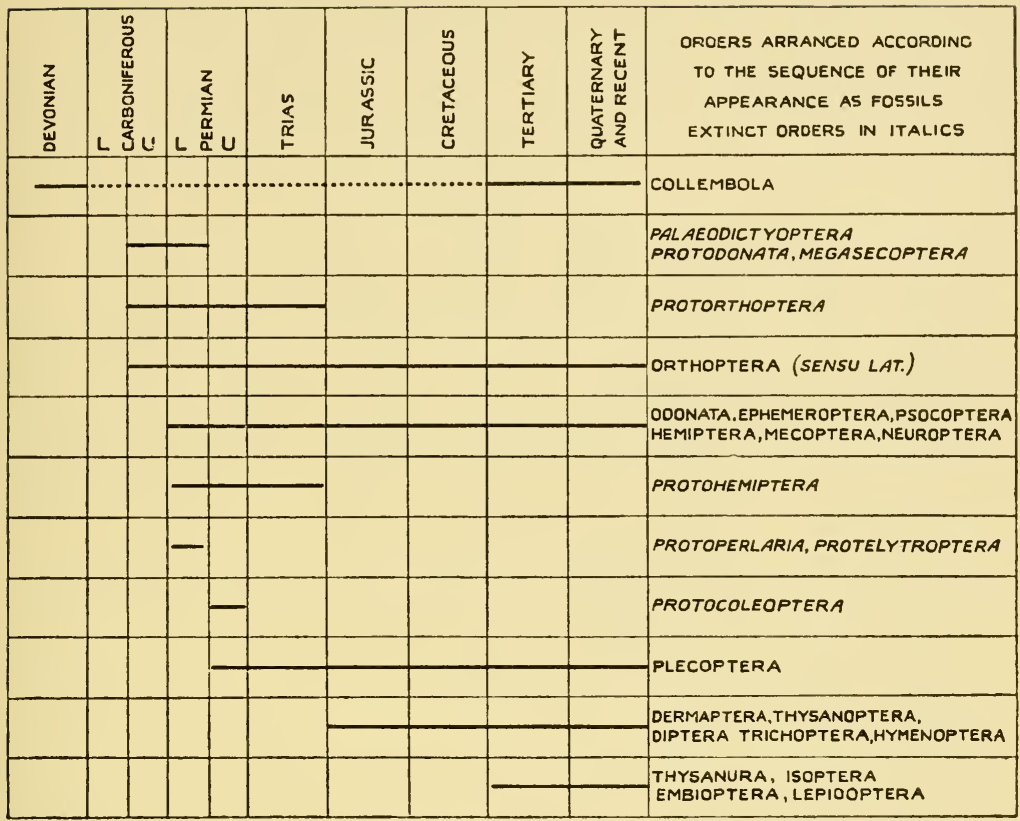

Carboniferous; and the Eustheniidæ (Plecoptera) from Upper Permian.

3. The Palæodictyoptera come nearest to the theoretical conception of ancestral winged insects. The Protodonata, Megasecoptera and Protorthoptera were contemporaneous with them in Upper Carboniferous times. Since these three orders were already sharply differentiated from the Palæodictyoptera it is concluded that actual ancestral insects remain undisclosed in still earlier strata.

4. The existing Ephemeroptera àppear to be nearest related to the Palæodictyoptera (Dictyoneuridæ), while the Orthoptera and Plecoptera are clearly derivations of the Protorthoptera. The Odonata apparently arose in common with the Protodonata, but the ancestry of the Hemiptera and Psocoptera is obscure.

5. The majority of the Holometabalous orders appear to have 
arisen from Mecopteroid ancestors, and the origin of the latter may have been from a specialised Palæodictyopterid stock (Paolia or allies). The relationships of the Hymenoptera are unknown, while those of the Coleoptera are very uncertain, but may have been. through Protocoleoptera, from the Protorthoptera.

\section{Literature}

Carpenter, 1930. Psyche, XXXVII., 343.

1930A. Bull. Mus. Comp. Zool. IIarvard., LXX., 69.

1931. Am. Journ. Sci., XXI., 97.

1933. Proc. Am. Acad. Sci. and Arts, LXVIII., 411.

1935. Ibid., LXX., 103.

Forbes, 1928. Psyche, XXXV., 32.

Handursci, 1908. "Fossilen Insekten." Leipzig.

1925. " Palaontologie," in Schroder's Handbuch der Entomologie, III., 117.

Handschix, 1926. Ent. Mitt., Berlin, 161, 211, 330 ; also Zool. Anz., LXV., 179.

Lameere, 1922. Bull. Acad. Roy. Belg., 138.

Martynov, 1925. Bull. Acad. Sci. U.R.S.S., XIX., 233, 569, 753.

1927. Zool. Anz., LXXII., 99.

1928. Ann. Mag. Nat. II ist., Ser. X., I., 319.

1928A. Trav. Mus. Geól. Leningrad, IV., 1.

1930. Ibid., VI., 69.

1931. Ibid., VIII., 202.

P'ING, 1928. Palcon. Sinica, XIII., 1.

'Tiliyard, 1924. Proc. Linn. Soc. N.S.W., XLIX., 429.

1924A. Amer. Journ. Sci., VIII., 111.

1925. Ibid., X., 41.

1925A. Ibid., X., 315.

1928. Amer. Journ. Sci., XVI., 185, 313.

1928A. Trans. Ent. Soc. London, 65.

1928в. Rec. Ind. Mus., XXX., 151.

1929. Nature, May 18th,

1931. Am. Journ. Sci., XXI., 232.

1932. Ibid., XXIII., 1.

1933. "The Panorpoid Complex in the English Rhætic and Lias."

British Museum (N.H.).

1935. Ann. Ent. Soc. Am., XXVIII., 1.

1935a. Proc. Linn. Soc. N.S.W., LX., 374.

1935в. Ibid., LX., 265.

1936. Nature, October 24th, 719.

1936. Amer. Journ. Sci., XXXII., 43.5.

1937. Nature, January 9 th, 66. 


\section{CHAP'TER V}

\section{THE SENSE ORGANS AND REFLEX BEHAVIOUR}

1. Introductory Remarks. The Sensory Neurons, p. 103 ; Trichoid Sensilloe, p. 104; Other Types of Sensille, p. 104; The Functions and Classification of Sensillae, p. 106. 2. THE EyES AND LigirT Perception. Compound Eyes, p. 107 ; Ocelli, p. 109 ; Differential Response to Light Rays, p. 113 ; General Reflex Behaviour to Light, p. 121. 3. Chemical Stimuli and Their Receptor Organs, p. 123. The Olfactory Sense, p. 124 ; The Gustatory Sense, p. 132.

\section{Introductory Remarks}

The Sensory Neurons. Sensory perception in insects is achieved by means of a variety of receptors or sensillix. It is possible that the majority of types of sensillæ are dcrivable originally from primitive clothing hairs, differing from their fellows by having acquired relations with the central nervous system. The innervation is brought about by means of a specialised hypodermal cell, at the base of the hair, which is connected with a nerve axon. The hypodermal cell thus becomes a sense cell, but the origin of its connection with the axon is an open question. When the sensory nerves of insects are traced inwards they terminate within the ganglia of the central nervous system as fine fibrillæ which form the sensory neuropiles. The only cells so far detected which can be regarded as sensory cytons are those, just mentioned, that lie at the peripheral terminations of the axons. If this contention be correct, we are led to conclude that the axons develop as inwardly growing processes from the hypodermal sense cells. There appears to be no direct evidence, however, that this actually takes place, and, on the other hand, it may be that the true sensory cytons yet remain to be discovered. This latter view is maintained by Vogel (1923), who followed the development of the antennal nerve in the larva of the wasp. According to him the nerve axons grow outwards and become secondarily connected 
with the hypodermal sense cells. In the light of this finding he concluded that the cytons related with this nerve are located in the deutocerebrum, but no investigator has yet revealed the existence of any sensory cytons within the central ganglia. The subject is more fully discussed by Snodgrass (1926), to whose paper the reader is referred.

Trichoid Sensillæ. 'The simplest type of sensilla is hair-like in form, it is secreted by a special trichogenous cell and innervated

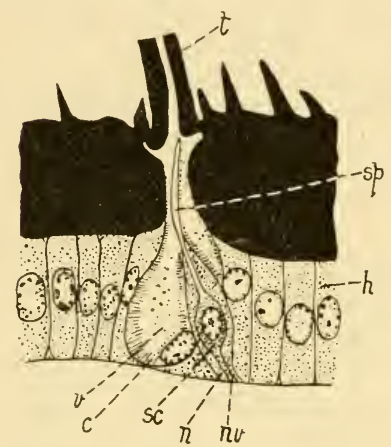

Fig. 49. Simple trichoid sensilla from the cercus of Gryllus campestris (integumental parts decp black). $c$, chitogenous cell; $h$, hypodermis ; $n$, neurilemma ; $n v$, nerve fibre; $s c$, sense cell and its process $s p ; t$, base of hair ; $v$, vacuole. (From Sihler.)

by a bipolar sense cell (Fig. 49). The sense cell, it will be observed, lies within the hypodermis, and its distal process, after penetrating the trichogenous cell. passes to the base of the hair; both the sense cell and its distal process are invested by neurilemma. Trichoid sensilla of this type are well described by Sihler (1924) in his paper on the sense organs of the cerci of various insects. In many cases the trichogenous cell contains a large central vacuole in which is lodged the sensory process of the nerve cell. It would appear that the vacuolar fluid extends into the cavity of the hair, and certain kinds of stimuli received outside the latter would be transmitted through the fluid to the sensory process. More usually a trichoid sensilla exhibits a more elaborate structure in that the hair is attached to its socket by an articular membranc which is the product of a special membrane cell, distinct from the principal trichogenous cell. Membrane cells, which are little more than individualised hypodermal cells, may also be detected in association with ordinary covering hairs of a non-sensory character.

Other Types of Sensillæ. In the well-known classification of Schenk most of the prevailing types of sensillæ are grouped according to characters afforded by their external cuticular parts. 
They differ in various ways from the simple trichoid type just described, and may become either scale-like, peg-like or conical ; or, the hair shaft may be wanting and the cuticular structure represented by plates, papilla, dises, or flattened domes. In other cases, their only external manifestation is marked by a pit or a mere cuticular thickening. Whatever their external form may be, they are all presumably derived from originally simple hairs. Furthermore, they all exhibit the same general similarity of internal structure in that they consist of a trichogenous cell, a membrane cell and a sense cell. In many cases the distal process of the latter becomes differentiated at its apex into a sense-rod or scolopale, which is directly attached to the inner side of the cuticular portion of the sensilla. The exact nature of this structure is not entirely clear, but its staining reactions and optical appearance seem to indicate that it is cuticular in nature. This belief receives support from Sihler's observation that the scolopales in connection with trichoid sensilla on the cerci of the Acridian Gompliocerus rufus are cast at each ecdysis. Structurally, scolopales exhibit considerable diversity; they may be mere caps or cones over the

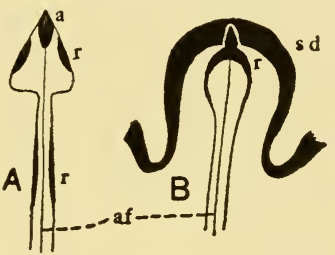

Fig. 50. Scolopalæ or terminations of sensory processes of $A$, a trichoid sensilla of Gryllus (from Sihler), and $B$, a campaniform sensilla of Dytiscus (from Hochreuther). $a$, Apical body; $a f$, axial fibre; $r$, rib; $s d$, sense dome or cuticular covering of sensilla. apices of the sensory processes, or they become elongate with their walls thickened by a variable number of longitudinal ribs (Fig. 50). The extremity of such a rod often contains a deeply staining apical body, which is connected with an axil fibre extending through the sensory process into the nerve cell itself. In other cases, there is no apical body, and the axial fibre terminates at the extremity of the scolopale.

Most sensillæ, in their simpler forms, pertain to the general type just described. The chief exception is met with in the visual receptors whose evolution is probably traceable originally from mere localised areas of light-sensitive pigment. Visual 
receptors, therefore, bear no relation to trichoid sensillæ or their derivatives.

The Functions and Classification of Sensillæ. Recent research, employing modern refined methods of technique, has added much to our knowledge of the histology of different types of sensillæ. Experimental studies have extended our acquaintance with the reactions of insects to various stimuli. Notwithstanding knowledge thus gained, it has to be admitted that the fundamental aspects of the subject are, as yet, but little explored. We are not in a position to classify many of the prevailing kinds of sensory receptors on a functional basis, and are forced, in consequence, to attempt to argue function from structural characters alone. Data afforded by the structure of sensillæ and the positions they occupy on the body are valuable up to a point, but the ultimate test is obviously the experimental one. Experiments upon the living insect enable general ideas to be gained with respect to its behaviour in relation to different stimuli. Amputation of particular appendages or of defined regions of the body, their cauterisation, or the coating of such parts with varnishes, wax, or other material, enables the positions of specific receptors to be located. Histological examination of the same parts may enable the existence of a particular type of receptor organs to be correlated with a specific kind of response of the individual. When, however, the receptors are of a heterogenous character, the method immediately becomes encompassed with difficulties. It would appear, therefore, that the main stumbling block is the paucity of exact experimental evidence. This, in its turn, is bound up with the difficulties attending the investigations of organs of minute size, often of scattered distribution and often intermingled with those of a different type. These few remarks will serve to emphasise the general character of the problems involved, and we may now proceed to discuss certain of the more outstanding facts and principles of reflex behaviour among insects. It will be convenient for present purposes to deal with the subject under the headings of the different kinds of external stimuli ; to discuss the organs accredited to the reception of such stimuli and to examine the nature of the responses involved. 


\section{The Eyes and Light Perception}

The eyes, or photo-receptors of insects, vary greatly in structure and degree of development. Almost every condition of differentiation of these organs is met with among various insects or their larve. In their simplest phase the eyes consist of single visual elements, or sensillæ, sensitive mainly to variations in light intensity. The most complex and highly developed organs consist of aggregations of many thousands of sensillæ, and are capable of forming images of external objects. It has been customary to group the different types of visual organs of insects into two categories, viz., compound eyes and ocelli, and certain features respecting them will be briefly considered.

Compound Eyes. Compound eyes are composed of variable numbers of individual sensillæ, or ommatidia, closely apposed to one another. In certain aberrant or degenerate forms only a few ommatidia, or even a single ommatidium, may compose the eye, but, as a rule, these elements are much more numerous, and 20,000 or more may be involved. The well-developed compound eye is the highest type of visual organ found in insects. Notwithstanding its complex structure, it is a less perfect optical instrument than the vertebrate eye, for the reason that no general focussing mechanism is known to be present. In the dragon-flies, Vigier (1904) states that a means of accommodation, consisting of myofibrils and tracheal branches, is present between the ommatidia. By the contraction of these fibres compression of the crystalline cones is presumed to result, while the action of air pressure on the tracheæ may allow of a certain amount of elongation. This interesting observation has attracted but little attention, and the subject is one requiring fuller exploration. In the general absence of any focussing mechanism, it follows that in the vast majority of insects the capability of compound eyes for image formation can only be effective in producing a clear impression within a very limited focal distance. The distinctness of the image, therefore, depends partly upon the nearness of the object concerned. This, however, is not the only factor, since the number and size of the ommatidia are also important, for a larger number of small ommatidia will, on the mosaic theory, 
produce a sharper and more detailed impression than if the same visual area be occupied by a smaller number of larger visual elements. The unknown photo-receptive capacity of the nervous centres within the optic lobes must also be involved.

It is well known that compound eyes are divisible into two main types, namely, those giving an apposition image, and those giving a superposition image. In the first type the vision is essentially diurnal, and the images are composed of a large number of apposed points of light: such images are true mosaics as implied by the theory of mosaic vision. It has been generally believed that the direct image so formed is an inverted one, but apparently this is not always the case, since Eltringham (1919) has observed a direct image with the eucone eye of a butterfly. Compound eyes giving a superposition image differ from the previous type in the disposition of the components of their ommatidia. The rhabdoms are not in contact with the apices of the crystalline cones, and the two elements are separated by a space filled with a transparent medium. The ommatidia in this kind of eye are consequently greatly elongated. The distribution of the pigment surrounding these elements is capable of adjustment according to the amount of light available, and consequently this type of eye is most highly developed in nocturnal or crepuscular species. At night time the pigment congregates far forward, so as to expose a larger area of the apices of the crystalline cones, with the result that rays of light entering adjacent ommatidia traverse the space already alluded to, and contribute to those entering the same retinula. In this type of vision there is an overlapping of points of light, and the image thus formed is termed a superposition inage. It will be evident that, in an eye of this description, a limited amount of light: will produce a better image than in an eye giving an apposed image where so much of the light is absorbed by pigment. 'The eyes of nocturnal insects are adapted, therefore, for the perception of movement and general form only, and, as already stated, they are able to take advantage of varying degrees of light. In the presence of daylight the pigment moves backwards like a dark sleeve cutting off more and more of the peripheral rays, this tending to give a sharper image, and one more resembling the apposition type. 
It will be obvious that in conducting experiments relative to insect vision it is important to take into account the type of compound eye present in the subjects utilised. So far no comparative studies have been made with respect to the photic reactions in the two types mentioned, and a wide field for enquiry remains for future investigators. Apparently, most observations have been made with insects whose eyes give apposition images. Such types are essentially adapted for diurnal vision only. Their focal range as regards form-perception is very limited, and, in the case of Vanessa urtica, Eltringham gives reasons for concluding that it does not exceed 3 feet. Perception of movement, it would appear, may be effective over a greater distance, and, in the case of dragonflies, Tillyard has observed that the species Petalura gigantea can be frightened away by waving a net at a distance of 20 yards. In this connection the observations of Vigier with regard to the existence of a capacity for focal accommodation may be significant. While appreciation of form is probably of great importance in the pairing of species, there is a considerable evidence that compound eyes are endowed more especially for the perception of movement, and that insects rely upon this capacity to escape from their enemies. With eyes adapted for daylight, the movement of even small objects in the field of vision would be registered as a fleeting impression on the retinal cells, and it becomes transmitted to the brain of the insect, which responds accordingly. It is often possible to approach an insect without occasioning its alarm. If the approach be sufficiently slow and gradual the change of position passes apparently unnoticed. The explanation appears to be that an object as large as a human being affects all the ommatidia more or less equally and simultaneously. Since the movement occurs very slowly, the change of position entails only very slight and gradual changes in the character of the retinal image as a whole. A sudden movement of a part of the body of the person, however, is sufficient to bring about immediate departure of the insect, for the reason that it has caused an abrupt change in the retinal image by affecting a number of ommatidia in rapid succession.

Ocelli. Ocelli present so many different types that they are not definable upon any common structural basis. In some few 
instances they appear to be the degenerate vestiges of compound eyes, but for the majority they have no direct relations with the latter organs and, if there is any community of ancestry in the two cases, evidence of such is not forthcoming within the class Insecta. Ocelli may be grouped into two classes, viz., dorsal or primitive ocelli and lateral or adaptive ocelli.

Dorsal ocelli are characteristic of nymphs and adults and occur in all the chief orders of Pterygote insects, but are not present in larvæ. They share the common structural feature of being composed of a greater or smaller number of retinulæe grouped together in relation with a single lêns. In the compound eye it will be recalled that there is a separate lens, or facet, in direct association with each visual element or ommatidium. Dorsal ocelli differ from compound eyes as regards their innervation. Whereas the nerves supplying the compound eyes are in connection with the optic lobes, the ocellar nerves are traceable to ocellar lobes located in the protocerebrum, between the mushroom bodies.

The typical number of dorsal ocelli is three : they are disposed as a triangle on the head-capsule, with the apex median in position and indicated by the unpaired ocellus of the group. There is a certain amount of evidence in favour of the view that the median ocellus represents the fusian product of original paired organs, and that the primitive number of dorsal ocelli was four. This conclusion is based upon the fact that among Hymenoptera the nerve supply of the median ocellus is frequently double. Furthermore, as Patten showed a number of years ago, the median ocellus in the wasp is represented in the prepupa or late larva by a pair of pit-like rudiments which ultimately coalesce. Evidence of paired structure is also present in the median ocellus of Odonata and of Bombus, while Wheeler (1936) has recorded a high percentage of double anterior ocelli in the ant Atta cephalotes.

Glaser (1925) records an example of the grasshopper Melanoplus differentialis in which the usual median ocellus is replaced by paired organs. These latter, however, are of smaller size and their total superficial arca scarcely exceeded that of a normal unpaired ocellus. He also refers to records by Blackman of a similar phenomenon in another species of the same genus, and by Smulyan in a species of saw-fly. That these tetralogical examples may have a phylogenetic 
significance, and represent reversions to an ancestral condition, will immediately suggest itself in the light of foregoing remarks. Such an explanation, however plausible, remains an open question in the absence of any knowledge of the directing eauses involved.

Little is known with respect to the functions of the dorsal ocelli. The fact that the lens is strongly biconvex indicates that their visual powers are limited to the perception of very near objects. The small number of visual elements which compose an ocellus is strongly suggestive that any image-forming capacity it may possess would be of a crude and indefinite kind. The perfection and complexity of the structure of ocelli in many insects argue that they are functionally important organs, but it needs to be emphasised that the power of perceiving even only crude images apparently necessitates a somewhat complex visual organ.

It has been suggested that the dorsal ocelli are adapted for the perception of very near objects and for vision in darkness or subdued light. This view seems, however, to have no proper evidence based upon actual experiment. In so far as ants and bees are concerned, it has been shown by Müller (1931) that when the compound eyes of these are painted over the creatures no longer exhibit the capacity of orientating themselves in relation to light. A growing opinion favours the idea that dorsal ocelli are general stimulatory organs which have the property of " toning up " the nervous system and increasing general sensitivity of the brain. It is now believed that apart from any imperfect phototactic function the ocelli exercise a photokinetic influence in, at any rate, day-flying insects, by helping to maintain the sensitivity of the visual centre of the brain to light stimuli. It is possible, therefore, that the dorsal ocelli perform this function as important accessories to the compound eyes. Here again the experimental evidence is rather meagre, but Bozler (1925) has shown that in Drosophila the response to light stimuli, received through the compound eyes, is more acute and lasting when the dorsal ocelli are in their normal condition than when painted over with an opaque substance. A similar function has been ascribed to the ocelli of Lepidoptera by Friedrich (1931). 
Lateral ocelli present no general uniformity of structure. They are the functional visual organs of insect larvæ and are antecedent to the future compound eyes of the imago. It has already been explained in an earlier chapter that insect larvæ represent phylogenetically earlier phases of development than either nymphs or imagines. They issue from the egg at a stage before the adult eyes appear, and consequently have acquired provisional visual organs that are functional only so long as the larval period lasts.

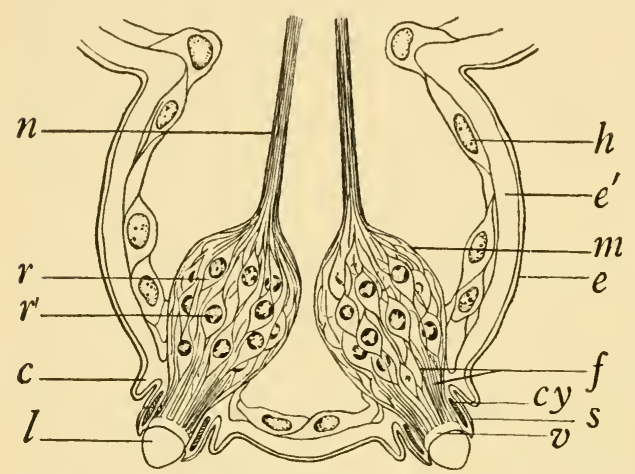

Fig. 51. Section through a pair of ocelli of a Lucilia larva. $\times 450$. $c$, collar; cy, cuticular cylinder; $e$, outer cuticle; $e^{1}$, inner cuticle; $f$, nerve fibrils from retinal cells, $r$; $h$, hypodermis ; $l$, cuticular lens ; $m$, limiting membrane; $n$, nerve; $r$, retinal cell; $r^{1}$, nucleus of retinal cell; $s$, sheath, within which the lens moves outward or inward ; $v$, preretinal membrane. (From Ellswortlı, 1933.)

In their very simple form, as seen in larvac of Lucilia, for example, the ocelli consist merely of groups of bipolar sensory cells, devoid of pigment, while thc overlying cuticle has been modified into a lens-like structure for the condensation and transmission of incident light rays (Fig. 51). According to Ellsworth (1933) these larvæ are extremely sensitive to light, and by localising the latter into a small "pencil" he was able to show that this sensitivity is confined to the organs just mentioned. In larva of the Lepidoptera, certain Coleoptera and Neuroptera the lateral ocelli occur, as a rulc, in a group on either side of the head and in close association with the site where the imaginal eyes are to be developed. In these orders cach ocellus is usually separate from its fellows : it is provided with a cuticular lens with differentiated visual cclls and sensory rods beneath. In larva of the saw-flies there is a single lateral ocellus on either side which exhibits a structure very similar to a typical dorsal 
ocellus. The Collembola are exceptional in that their so-called ocelli are the functional adult eyes : they occur in a group comprising up to eight such organs on either side of the head, and each ocellus has the general structure of an ommatidium. It will be obvious that the visual properties of ocelli of these diverse types will vary more or less directly in relation with their structure. Mere groups of pigmentary sense cells can appreciate little beyond variations in light intensity. The more highly developed lateral ocelli appear to have visual properties adapted for near vision only, but their image-forming capacity can only be of a rudimentary kind. Certain experiments conducted with lepidopterous larva appear to show that they are only able to perceive objects at a distance of about $2 \mathrm{~cm}$.

Differential Response to Light Rays. Recent research on insect vision substantiates the conclusion that colour perception exists in insects but that it does not apply to the whole range of the spectrum visible to human beings and, at the same time, involves the application of rays entirely invisible to man. In his well-known experiments von Frisch $(1914,1924)$ has shown that the honey bee, which has been the chief subject of colourvision experiments in insects, can be conditioned so as to associate certain colours with food. A number of pieces of paper of diverse colours, but of the same shape and size, were disposed in a sort of chequer-board fashion. A watch-glass containing an inodorous sugar solution is placed over one of the colours. After this has been repeated a number of times the food-solution is omitted, but it was found that the bees still went straight to the colour upon which the watch-glass had previously been placed. A series of fifteen shades from white through various tints of grey up to black were laid out, and a blue paper introduced. An empty watch-glass was then placed over each piece of paper and the whole covered with a sheet of glass. Bees previously conditioned to blue at once gathered over that colour, notwithstanding repeated changes in its position, when they searched for the non-existent food. Von Frisch showed that bees conditioned on scarlet or black failed to discriminate between those two colours, or dark grey. He therefore concluded that bees are blind to red. 
He also found that bees are capable of being conditioned to yellow, but that they failed to discriminate between that colour and orange or yellow-green : similarly, bees conditioned to blue turned indiscriminately to violet or purple. Von Frisch failed to train bees to visit any particular shade of grey in preference to any other shade. This important result affords a strong argument against the objection that a highly developed response, on the part of the insects, to different degrees of brightness might account for their supposed differential colour responses. Von Frisch's conclusions proved to be sound when training experiments with bees were repeated subsequently, by using monochromatic light, by Kühn (1927) in Göttingen. In addition to the two main colours (yellow and blue), which von Frisch found to be responded to by the bee, Kuhn was able to include blue-green and ultraviolet. It appears, therefore, that four regions of the spectrum exercise separate and definite stimulus qualities with respect to the bee, i.e., $650^{1}$ to $500 \mu \mu, 500$ to $480 \mu \mu, 480$ to $400 \mu \mu, 400$ to $313 \mu \mu$. By training insects along lines very similar to those adopted by von Frisch, Knoll (1921) found that the Humming Bird Moth (Macroglossa stellaturum) showed good capacity for differentiating between yellow and blue, but was likewise unable to discriminate between red and black. It must not, however, be assumed that all insects are red blind, since Kugler (1930) succeeded in training Bombus to a pure red Hering paper and Ilse (1928) found that in Pieris and related butterflies responses are mainly to red and to purple papers, while in the case of Vanessa they were to yellow and to violet. Both Knoll (1921) and Ilse (1928) state that a predilection for definite colours is inborn in butterflies since the latter visited certain coloured but inodorous surfaces, in preference to all shades of brightness, just after emergence from pupæ.

Further important experiments, bearing upon colour vision in insects, have been carried out by means of a screen which revolves round a circular horizontal platform covered with white paper

1 According to Bertholf (1931) the upper limit for the bee extends to at least wavelength $677 \mu \mu$ in the red end of the spectrum; a difference in the intensity of the spectral light used probably explains why these results do not conform with those obtained by Kühn. 
upon which the insects are placed. Schlieper (1927) first showed by means of experiments, in which the wall of the screen was lined with adjacent vertical stripes of different shades of grey and of various colours, that insects do not respond to the movement of the pattern if the grey and coloured stripes appear of equal brightness for the eyes of the creatures (an analogous effect is known in human sense physiology). By this means it was possible to determine, not only the relative brightness of different coloured papers, but also to discover different colours which appear of equal brightness for a given insect. If the insect responds to the movement of a pattern, which consists only of stripes of equal brightness, but of different colour, it becomes evident that it is able to differentiate colours. If under the same circumstances it

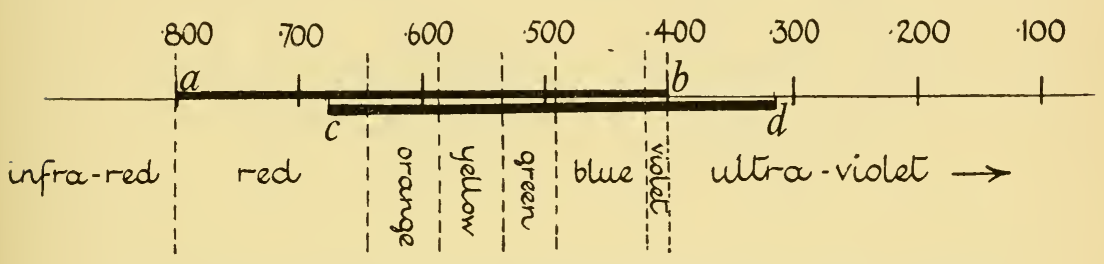

FIg. 52. Approximate limits of visible spectrum for man $(a-b)$ and the bee $(c-d)$.

does not respond, the insect may be regarded as being colour-blind. By using this method Schlegtendahl (1934) showed that several beetles, including Geotrupes, the fly Fannia canalicularis, and also some night-flying Noctuidæ, all show evidence of colour vision.

Little is known concerning the actual physiological nature of colour vision in insects. Kuhn (1927) made the suggestion that blue and yellow in the one case and blue-green and ultra-violet in the other might be complementary colours. At present, however, there is very little evidence available in connection with this suggestion. Kuhn, however, carried out experiments wherein he trained bees to visit blue surfaces and made sure that there was no interfering tendency to visit the yellow. He then exposed a series of square pieces of card of different shades of grey and placed one single yellow card among them. Over each card was a paper ring of a contrasting shade of grey. He noted that the bees 
visited in numbers the grey ring on the yellow background, but the other grey cards received no visits. The conclusion seems to be that where grey is surrounded by yellow, in the above manner, it produces a physiological effect of blue in the eye of the bee. The experiment also affords further evidence that mere brightness of shade is not involved or the bees would have visited some or other of the grey cards.

The experiments of Hertz (1931-35) on the recognition of form and pattern by bees are significant. It was shown that, as a whole, bees tend to visit those patterns which show the largest

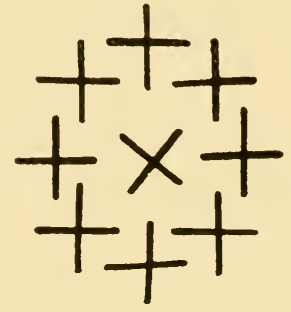

(l

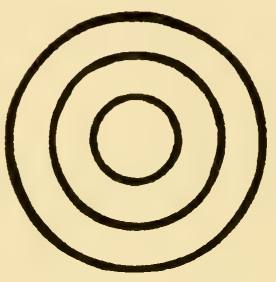

b

FIG. 53. 'The anount of outline displayed in patterns $a$ and $b$ is approximately the same, and bees can be trained to visit either. Nevertheless, after short training bees showed a mueh higher preference for $a$, while $b$ becomes neglected when both patterns are exposed simultaneously. The preference is for complex patterns of many small units in variable directions, as compared with regular patterns of few units and simple lines. (After Hertz.)

amount of contours or outlines within a given dimension. Hertz distributed in various ways several black stripes of equal length and breadth in areas of similar size. There resulted different patterns with the same amount of contrast and of black and white. The behaviour of the bees proved that patterns with the most crossing-over and isolated units were much more attractive than those which mainly showed regular parallel or concentric lines. Thus in Fig. 53, for example, the pattern of crosses was visited in preference to the concentric circles. In a similar way it was found that bees could be conditioned to visit either patterns P15 and F12, or G5 and P20 in Fig. 54, but not P15 and G5 or F12 
and P20. It is easy to condition bees so that they visit a pattern composed of relatively many contours or outlines such as crosses or a chessboard and to avoid a plain circle or square of the same colour. So far, however, it has not proved possible to condition bees to show the opposite preference. Hertz's conclusion that a predilection for patterns with many contrasting outlines is present in bees, before any training to visit specific patterns has taken place, has been confirmed by Zerrhan (1933). These samie results

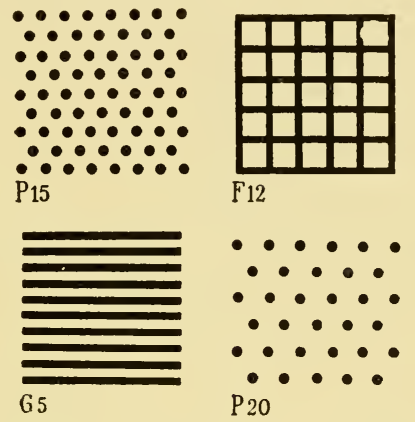

Fig. 54. In this figure all the patterns extend over equal sized superficial areas. G.5 shows the largest amount of outlines $(2,000 \mathrm{~mm}$.$) , but, because of its uniformity, it is less attractive$ to bees than P20, which is composed of numerous small units with a greatly reduced amount of outlines $(570 \mathrm{~mm}$.). F12 $(1,600)$, however, is much more attractive than either of the foregoing patterns ; it is only eclipsed in attractiveness by one composed of a very large number of small units P15, but with reduced amount of outlines $(1,026 \mathrm{~mm}$.). An experiment of this kind forms an infrequent example in which bees ean be trained both ways with regard to a pair of patterns. Thus, P20 is more attractive than G.5 but less so than F12. (After Hertz.)

have also been obtained for other insects. Ilse (1932) used the same patterns as those employed by Hertz in connection with experiments with butterflies. She found that if the colour of the pattern were very attractive to the insect that pattern which had the largest area of colour and less outlines was preferred to a pattern of smaller area but greater amount of outlines. Where, however, the colour used only exercised a weak stimulus, the behaviour of the butterflies was of the reverse kind and the same response was obtained as that described by Hertz. The last- 
mentioned observer (Hertz, 1931) carried out further experiments, using three-dimensional objects fashioned out of white paper and placed on a white background. These different objects were characterised only by their form and the distribution of shadows. An overwhelming response was obtained, showing preference for the more differentiated forms over the simple ones. Thus in

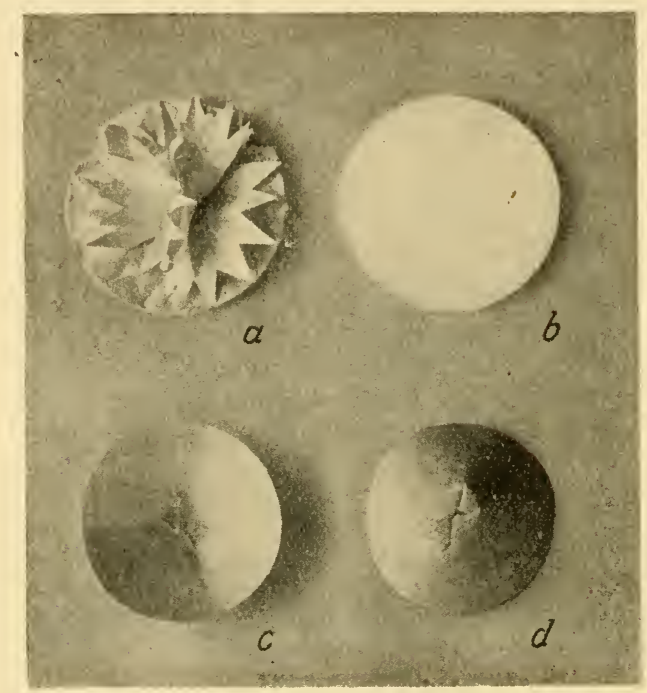

FIG. 55. In this figure $a, c, d$ are three-dimensional objects and $b$ is a flat object; all are made of the same material as the background (white paper). Bees can be trained to visit any of these objects when exposed singly. When they are exposed simultaneously high preference is shown for the object with the most complex form $(a)$ which is due to the large amount of contrasting outline and shadows. (After Hertz.)

Fig. 55 that simulating a flower $(a)$ was preferred to the plain flat object $(b)$. It was further noted that the pattern of the shadows exercises an important influence. The more complicated the shadows of an object are the more attractive the object becomes: also, the deeper and darker the shadows on the objects the more attractive they are. Certain experiments were carried out by von Buddenbrock (1935) by using other insects such as 
Coccinella and Eristalis. 'The insects were placed at some distance from a light towards which they walked by a straight path flanked by cardboard walls bearing a pattern of black and white stripes. The insects became regularly attracted off the direct path to the wall which bore a pattern or, if the pattern were on both walls, to that wall which bore the pattern containing the most detail or outlines. There was no difference in effect between vertical and horizontal stripes.

This capacity for a primitive discrimination of pattern seems to be intimately connected with the responses of insects to visible movements. Hertz (1933) showed that so long as a bee is moving the image of the surrounding objects is moving on the retinulæ of the compound eyes. Similarly, a type of pattern with many outlines involves a high frequency of alternating stimuli on the retinulæ. Great emphasis is laid on this feature by Wolf (1933), who, as the result of his own experiments with intermittent illumination, suggests that the whole effect of pattern on the insect eye is nothing but that of flickering.

The two principal qualities of pattern, i.e., the amount and effectiveness of the distribution of outline, also play an important rôle in the reaction of insects to visible movement. In experiments where an insect is in the middle of a small table around which a cylindrical screen, with black and white vertical stripes, is revolving the animal moves in the same direction. Up to a certain limit the effect increases with the velocity of the movement and with the number of stripes (i.e., the amount of outlines): this has been shown by Wolf (1933) for the bee and by Gaffron (1934) for flies. Hertz (1934) found that for flies where there are a number of stripes an equidistant distribution of outlines is more effective than an alternation of narrower and broader intervals between the stripes. The best effect to be obtained with the minimum amount of outlines is by means of small spots regularly distributed on the revolving screen. As a consequence of the foregoing experiments, the question arises as to whether the insect is able to differentiate between the appearance of movement resulting from a change of position to surrounding objects and from the movements of the animal itself in relation to such 
objects. On the whole it appears quite improbable, but experiments dealing with problems of this kind are very few. Gaffron raised the question as to whether stroboscopic movement and after-images of movement occur in insects also. The answer appears to be partly in the positive and partly in the negative. The nymph of the dragon-fly Eschna responds to the movement of any small object and will never respond to any kind of food which is stationary. This ereature ean. however, be made to do so by previous or simultaneous strong movements in the surrounding field. such as a screen which revolves around the receptacle in which the animal is contained. When such movement has been actuated for about ten minutes, the after-effect lasts for about half an hour after such movement has ceased. Flies which are responding very regularly to a striped revolving sereen cease to move if this real movement is replaced by an irregular appearance and disappearance of the stripes at different points on the screen (which produce a semblance to movement in the human eye). Thus, there appears to be no appreciation of stroboscopic movement in these insects at any rate. On the other hand, insects like Coccinella, which are known to display light-compass reactions. do respond to the interrupted appearance and disappearance of a pattern if the change be not too fast. Experiments of this kind show that it is necessary to differentiate between movement responses and light-compass reactions which have sometimes been confused with them.

In connection with the subject of light intensity and its wavelength, it may be noted that the most modern work of this kind has been carried out by Sander (1933) in Göttingen. In his experiments the light energy of twelve different spectral lines, including ultra-violet $(366 \mu \mu)$, was made equal to that of the weakest line, the absolute amount of energy of any line being $436 \cdot 10^{-4}$ watt per $\mathrm{cm}^{2}$ Each one of the twelve different rays was compared with another in the two windows of a small dark eage in which a group of bees was confined. The number of bees passing, during repeated exposures, at the two windows was counted and results plotted in twelve curves. The curves showed two maxima-in the yellow and blue; and three minima-in 
the orange, green and ultra-violet. Rays of a wavelength longer than $630 \mu \mu$ were not visited at all. By raising the energy of a less effective colour its stimulatory influence could be made equal to that of a more effective colour. Sander further determined that with different wavelengths the effects do not increase in the same degree with the energy. The increase proved to be relatively slow with the green rays and faster near the ends of the spectrum. It thus appeared that the effects of light of different wavelengths of equal energy may be very different for different amounts of absolute energy. Thus it may be that the effect of green is greatest in very low and that of ultra-violet in very high intensity.

A relatively strong stimulatory effect of ultra-violet has been observed by Peterson and Heussler (1928) in their experiments on the photic responses of the Oriental Peach Moth (Laspeyresia molesta) and the Codling Moth (Cydia pomonella). Bertholf (1931) also obtained a strong response to ultra-violet in the case of both Drosophila and the hive bee. In the case of the lastnamed insect he found that there are two zones of maximum stimulative efficiency-one in the yellow-green at wavelength $553 \mu \mu$ and the other in the ultra-violet at $365 \mu \mu$-the latter being about four and one-half times as great as the former. In view of the work of Sander, which stresses the unequal increase of effect in different wavelengths, it is possible that Bertholf's conclusions may require modification. Bertholf, it may be added, used lights of unequal energies and determined the relative effect of equal energies by calculation. It is noteworthy that Priebatsch (1938) found that the relative responses to different wavelengths alter when the amount of energy is altered. With Carausius morosus it was found that this insect becomes black when resting on a black background and becomes darker in proportion to the amount of illumination. The effect, however, does not depend on the energy alone. If monochromatic light of equal and relatively high energy is used the effect is most pronounced in ultra-violet light, whereas with weak illumination the effect of green is the most pronounced.

General Reflex Behaviour to Light. The responses of insects to rays of specific colours have already been discussed, and there 
remains for consideration their reactions to ordinary white light and its absence. Positive and negative responses to light have been explained by Loeb (1918) on the basis of tropisms. His theory states that when a bilaterally symmetrical animal responds positively to a given stimulus, it approaches that stimulus owing to the continuous action of the latter in provoking symmetrical muscular activity. If the stimulus does not fall equally on the two sides of the body, it provokes asymmetrical muscular activity, which results in the animal orienting itself so that its long axis comes directed towards the source of the stimulus. If the responsc be negative, the muscles of the side nearest the source of the stimulus are less active, which has the result of turning the animal away from the stimulus. Although many facts relative to the behaviour of insects appear to be in accord with this general theory, a larger number seem to imply the existence of differential sensitivity to the stimulus, rather than a compulsory and irresistible response. In such cases orientation is not wholly of the mechanical nature implied by the theory of tropisms. Thus Urban (1932) found that the hive bee can be so conditioned that it will choose one of two equal light sources and move directly toward it. If the eye of one side be blinded, it may still be conditioned to pursue a straight course toward the light. If one or more legs on either side be removed the bee will still go to the light in a straightforward course.

There are also insects which move at a constant angle to a source of light, this type of response being termed menotaxis. The light-compass orientation shown by ants and bees has been studied more recently by von Buddenbrock $(1931,1935)$ and his pupils. With certain Coleoptera it was found that when walking on a plain surface these insects maintain a straight course at a definite angle towards a light some metres distant. If the position of the light be only slightly altered, corresponding to the opening angle of a single ommatidium, the insect reacts by means of a slight change in its direction of walking. Beetles, kept in the dark between experiments, maintain the same angle towards the light for hours and even days. They turn into the exact angle required by the shortest possible movement. 
Heliotropism or response to the stimulus of light, for example, is frequently correlated with differential sensitiveness to variations of luminous intensity. This results in a less direct form of orientation towards, or away from, the stimulus, the orientation being the resultant reflex response to a combination of heliotropism and differential sensitivity. Thus, McIndoo (1929) found that larva of the Codling Moth are weakly positively heliotropic, but they were not found to move and orient themselves with the precision implied by the theory of tropisms. They pursued sinuous paths towards the light, and larvæ in the second to fourth instars proved to be positive to weak light and indifferent to strong light. When about to spin their cocoons they appeared to lose all differential sensitiveness and became strongly photonegative. More defined examples of differential sensitivity are afforded by the behaviour of many butterflies which are strongly positive to strong sunlight. They become inactive immediately the sun becomes obscured, and, when resting, some species direct the long axis of the body so that the head is turned away from the source of light. Certain species, when alarmed, no longer maintain their flight in the full sunlight, but dart away and seek concealment in shade. In such examples differential sensitiveness to light is a predominant feature.

It is a matter of common observation that most insects are active either only by day or only by night. We are led to the conclusion that this kind of behaviour is activated, not by any tropism, but by a periodic rhythm dependent upon some internal factor operating through the nervous system. This rhythm is correlated with the regular diurnal alternation of daylight and darkness, and cannot be explained as being solely due to the stimulus of variations of light intensity. Many nocturnal insects will remain quiet and motionless in a dark room throughout the day and, without any change in illumination of the chamber, will become active at a regular time each night.

\section{Chemical Stimuli and their Receptor Organs}

The reception of chemical stimuli is believed to take place in insects by means of a variety of types of sensillæ, whose functions are largely deduced from their structure and their location. 
Chemical receptors are those of smell and taste; while smell is the perception of such stimuli acting from a distance, with taste the distance factor hardly enters into account. It is probable that among insects the two kinds of sensation are often not sharply demarcated and that such a distinction may not be necessarily valid. The antennæ and palpi, for example, are used to "explore" volatile substances, both at a distance and by actual contact-a fact that suggests that their sensilla may function both as distance (smell) and contact (taste) receptors. If this be true the sensations appreciated may be merely those of degree rather than different impressions. As Wheeler has observed, the words "taste" and "smell" are charged with anthropomorphism, and as the stimuli in both cases are chemical in nature, it is better to refer to the receptors involved simply as chemoreceptors. While admitting the force of this argument, it appears desirable to recognise, at any rate tentatively, a distinction between olfactory and gustatory organs. It must be remembered that we have no evidence that sensille located within, or in close association with. the oral cavity can function otherwise than as gustatory or chemical contact receptors.

The Olfactory Sense. It has long been known that insects are highly sensitive to volatile substances, but the results of many different experimenters are not in complete accord with regard to the location of the olfactory sensillæ. Various types of sensillæ occur distributed over the insect body and its appendages which may conceivably function as olfactory receptors, but since two or more types may occur grouped together, it often becomes a difficult matter for the experimenter to determine which particular type may be concerned with the sense in question. It is easy to prove that a given insect is definitely attracted or repelled by certain volatile compounds, and there is now an extensive literature on the purely empirical aspect of this subject. Frequently it will be found that the olfactory sense is developed more or less in inverse proportion to that of vision. Odonata and Ephemeroptera, with their highly developed compound eyes and dorsal ocelli, have their antennæ reduced to small setiform appendages. Chironomidx and Paussidæ, with their highly 
developed antennie, have only moderate-sized compound eyes, and ocelli are usually wanting. Many dipterous larvæ are devoid of eyes of any kind, but their olfactory sense is highly dereloped, as for exaniple in Calliphora. Among many of the higher Hymenoptera and Diptera, however, both senses are acutely developed in the adults.

For many years it has been believed that the true seat of the olfactory organs is the antennæ. It will serve no useful purpose to discuss the extensive literature on this subject, and it will be sufficient to stress certain features lending support to the belief mentioned. Elongated, movable organs, projecting outwards from the body like antennæ, are especially favourable as situations for the location of olfactory sensillæ. As Forel has pointed out, the position of such sensillæ, externally on the antennæ, gives to the insect better olfactory powers at a distance than if the odoriferous particles had to be drawn into an olfactory chamber, as occurs in terrestrial vertebrates. It is a matter of common observation that the antennæ of many insects betray, by their agitation and differential movements, an apparent acute sensitivity to odours in their vicinity. Furthermore, elimination of their functions by coating the antennx with impervious material or by the amputation of those appendages has shown that certain insects so treated no longer respond to odours, or do so much more tardily. McIndoo rejects the view that the antennæ in general are the seat of the olfactory sensillæ. In a long series of papers he has investigated the structure of supposed olfactory sensillæ and described the results of a number of experiments. He criticises experiments involving amputation of the antennæ in that it induces abnormal reactions, yet, nevertheless, this operation was carried out in some of his own experiments ! There is no doubt that amputation should be avoided wherever possible, and more natural reactions are likely to result when these appendages are put out of action by coating over only. McIndoo maintains that the olfactory sensillæ occur scattered over various regions of the body, particularly on the bases of the legs and wings. When these sensillæ are varnished over a much slower response results than when the antennæ are amputated. Without 
going into the details of his experiments, it may be said that McIndoo has given considerable evidence that the olfactory receptors do occur on regions of the body other than the antennæ. He has not, however, advanced sufficiently convincing proof to discount the accumulated evidence that the latter organs play a definite part, and in many insects a predominating part, in olfactory sensation.

Olfactory Sensillæ. It will be convenient at this point to consider the general structure of presumed olfactory sensillx. Berlese (1909) maintained that a chemoreceptor contains both glandular and sensory cells. The glandular secretion serves to keep the cuticular part of the sensillæ moist, and therefore in a condition for the reception of stimuli. It is presumed that the secretion fills the cavity of the organ and reaches the exterior either by filtration through the covering membrane, or by means of minute pores in the latter. The belief that a liquid, or mucous layer, is a necessary component of such a type of sensilla implies that the particles of a volatile compound must either become soluble in that liquid, or enter into some form of combination with it, before any stimulus will be appreciated by the nerve-ending. Obviously, such a conception is based upon analogy with the vertebrate olfactory organ, but Berlese considers that what evidence there is points to the same process occurring with insects. He quotes observations of Erichson made in 1847 and of Saulcy in 1891, that the antennæ of insects are covered with a delicate film of liquid. Recent investigators have advanced little support to Berlese's contention, since they have found no clear evidence of gland cells in connection with any type of presumed olfactory sensilla. On the other hand, Snodgrass (1926), in his very clear account of insect sense-organs, suggests that the vacuole which surrounds the process of the sense-cell in many of these organs may be a possible source of a solvent liquid. It is noteworthy, as he also points out, that the cuticular walls of insect sensilla are often extremely delicate, in many cases not more than half a micron in thickness. They are frequently so thin that in section they do not show a double border when viewed under the highest magnification. There is good reason to believe that such 
membranes may be permeable to liquids, and the existence of the merest film bathing the exterior of a sense-organ would be extremely difficult to deny or affirm. The alternative hypothesis is that the membrane is of a texture permeable to many types of odoriferous particles, which pass into solution immediately upon coming into contact with the vacuolar fluid surrounding the nerve-ending of the sense-cell within.

In the study of chemoreceptors we are met with a baffling variety of sensilla often widely distributed over the insect body. As Wheeler remarks (1928), the confusion is increased by the difference of opinion prevailing in regard to their structure in relation to their possible functions. It grades from sensillæ which may be either tactile or olfactory, through a variety of presumably olfactory and gustatory to the Hicksian or campaniform sensillæ, which have been variously interpreted as organs of pressure, temperature, humidity, or vibration.

The usual course has been to determine by suitable experiments which appendages or regions of the body afford evidence of response to olfactory stimuli. The parts in question are then subjected to histological examination, and those sensillæ present which appear structurally adapted for the reception of the stimulus in question are regarded as olfactory receptors. Thus placoid sensillæ are abundant upon the antennæ of certain Homoptera, many Coleoptera and most Hymenoptera. In many of the Parasitic Hymenoptera they are elongated structures sometimes termed rhinaria; in Aphididxe they are commonly circular in form, while in the hive bee they are more ovoid. As a general rule placoid sensillæ are more abundant in the male than in the female; in aphides they are most numerous in the alate forms. In the hive bee, for example, Vogel computed that in the drone each antenna bears about 30,000 of these sensillæ; in the worker about 6,000; and in the queen between 2,000 and 3,000. The general conclusion is that the greater number of these organs in the male is correlated with the more highly developed olfactory powers in that sex, which come into play in seeking the female. Furthermore, sexual odour emanated by the female, acting upon the great number of receptors in the male, stimulates the male 
to a degree of excitability which leads to the consummation of the sexual act. Whether the placoid sensilla are actually the receptors involved has not been absolutely proved. Structurally, rhinaria appear to be well adapted for this function, since they are invested by an extremely thin cuticle and are innervated by a multinucleate sense-cell (vide Chrystal. 1930). but in the hive bee. for example, the placoid sensillie appear to be but poorly adapted for their presumed function. As Snodgrass points out, the

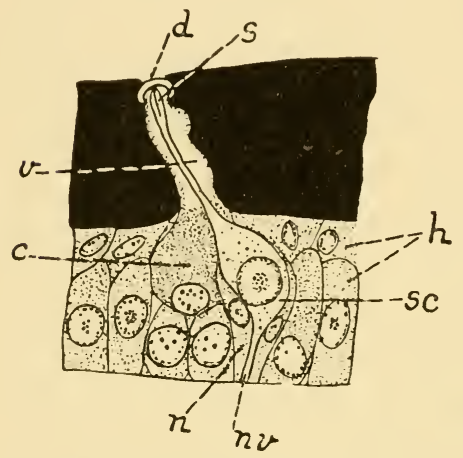

Fig. j6. Campaniform sensilla from the cercus of Blatta orientalis. $\quad c$, Chitogenous cell; $d$, dome-like cuticular covering; $h$, hypodermis ; $n$, neurilemma ; $n v$, nerve fibre; $s$, scolopala ; $s c$, sense-cell ; $v$, vacuole ; (integument deep black). (From Sihler.) plates themselves are about $1 \cdot 5 \mu$ in thickness, but the peripheral membrane of the surrounding groove is not more than $0 \cdot 5 \mu$ in thickness. It would seem, therefore, that it would be necessary to assume that a liquid filters through the thin membrane of the groove and spreads itself over the surface of the plate. There is as yet, however, no proof that this actually takes place. MeIndoo regards the eampaniform sensilla as being the true olfactory receptors. He termed these structures "olfactory pores" for the reason that he claims that the covering nembrane of these minute dome-like structures is perforated by a central pore which thus allows the process of the sense-cell concerned to come in direct contact with odoriferous particles. Notwithstanding the large amount of histological study that has been devoted to these structures, no other observer has detected the presence of the central pore which he claimed to be evident. The most recent workers, including Sihler (1924) and Newton (1931), state that the covering membrane of the sensilla is continuous and devoid of any kind of pore. It seems probable that what McIndoo deseribed is merely an optical effect caused by a thin central area of cuticle wherein the apex of the scolopala is lodged. 
The delicacy of the covering membrane of the campaniform sensilla suggests that, in many cases, these organs may function as olfactory receptors. They occur distributed over the body and on the wings, halteres, legs, antennæ, palpi, sting, cerci and other parts in different orders of insects. This very wide range of location has rather argued in the past against any idea that they are of olfactory significance. They have been assumed by some authorities to be receptors of vibrations or of changes in atmospheric pressure, but the only experimental evidence relative to their function is afforded by McIndoo. While it appears from the results of his extensive observations that these sensilla function as olfactory receptors. his data are insuflicient to invalidate the conclusions of other skilled experimenters that olfactory sensillae, of different types, are also present and are chiefly located on the antennie. Certain experiments by Minnich (1924) may be quoted here, since they appear to afford an example of how the two points of view may be reconciled. He showed that by coating one antenna of Pieris rape either FIg. 5\%. Diagram of with vaseline or with a mixture of paraffin and vaseline, or by directly amputating the appendage, olfactory reaction to apple juice was only affected by 6 per cent. When

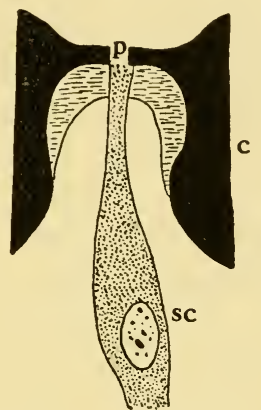
an olfactory (campaniform) sensilla, according to MeIndoo. $c$, Cuticle ; $p$, olfactory pore ; sc, sense-cell. both antennae were treated in a similar manner the response was reduced by 58 per cent. Minnich states that the treatment described resulted in no general abnormal behaviour; even with amputation of the antennæ little disturbance was noted, and clear-cut results were obtained. Although the histology of the sensillæ involved was not investigated, Minnich concludes that the abundance of these structures on the antennx, taken in conjunction with the reactions mentioned, indicates that these appendages represent probably the most important olfactory region of the body. On the other hand, he points out that the responses of the insect show that a considerable proportion of 
the receptors must be located on some other part of the body, since after all antennal function was eliminated the insects were still responsive to an extent of 42 per cent.

The series of experiments conducted by von Frisch (1921) with regard to the olfactory responses of the hive bee showed that this insect is just as insensible to odours when the eight terminal segments of the antennæ are excised as when the entire appendages are amputated. He emphasises the fact that bees trained to respond to a specific odour no longer respond to that odour after amputation of their antennæ. The absence of the olfactory reaction, he maintains, is due to loss of the organs of smell, and not to shock caused by the operation. In support of this conclusion he points out that bees conditioned to respond to a certain colour still seek that colour, and no other, after deprivation of their antennæ. It is further noteworthy that the most conspicuous antennal sensilla are of the placoid type, and these are located on the last eight flagellar segments. Von Frisch concluded on these grounds that the olfactory sense resides in the antennx and that the placoid sensillæ are the chief receptors involved. McIndoo (1914), on the other hand, came to the conclusion that the antenna are organs bearing little or no relation to olfactory sensation and that the true organs concerned are the so-called olfactory pores which are distributed over various regions of the body.

As Snodgrass has pointed out, McIndoo's experiments were conducted under confined conditions, whereas those of von Frisch related to bees free in the apiary. Furthermore, the latter observer experimented with floral cxtracts, whereas McIndoo used more powerfully smelling volatile oils. There is, therefore, a very evident difference in the experiments in the two cases. McIndoo's observations only showed that antennaless bees can perceive strong odours when in close proximity to them, while von Frisch demonstrated that bees so treated are unable to sense the presumably much milder floral odours when in a state of natural freedom around the apiary. It appears likely therefore that, in all experiments dealing with olfactory responses, the use of powerful or irritant compounds, especially those which do not enter into the normal experience of a given insect, needs special 
precautions. Unless applied in very dilute concentrations, or used at a sufficient distance to ensure adequate dilution by the intervening air, erroneous results may ensue. It is probable that substances of this type may produce merely irritant sensations capable of affecting almost any type of receptor organ, after the analogy of pungent vapours which directly affect the nose, eyes and throat in human beings. It will be obvious that a very erroneous conception may arise with regard to the location of the true olfactory organs of insects, unless adequate precautions are taken to exclude the possibility of a different kind of reaction being involved at the same time.

In his most recent experiments, using certain kinds of "blowflies," McIndoo $(1933,1934)$ reasserts his previous conclusions regarding the location of the olfactory sense being elsewhere than on the antennæ. Among recent workers, Glaser (1927) and Valentine (1931) arrived at very different opinions with respect to other insects. Glaser concluded that olfactory chemoreceptors in Periplaneta are present not only on the antennæ, but also on the labial and maxillary palpi. The antennæ, he claims, are capable of longer distance olfactory perception than either of the two pairs of palpi. Valentine carried out a number of experiments with reference to sex responses in Tenebrio molitor (the meal-worm beetle). He found that individuals of both sexes responded to a glass rod smeared with gland secretion pertaining to the opposite sex, provided the antennæ were intact. Males without antennæ were unable to discover the females and they betrayed no responses when brought into close proximity to individuals of the opposite sex. Similar results, it may be added, were obtained when using food stimuli (aqueous bran extract). He was further able to show that olfactory perception was located in the apical four segments of the antennæ. When employing essential oils of clove, bergamot and thyme, he found that they exercised an irritating effect, and he concluded that they reacted upon other senses besides that of olfaction and also affected the respiratory system. A summary of the subject of olfactory receptors in insects is given by Marshall (1935), to which the reader is referred for a fuller reference to the literature. At the 
present time certain of the results obtained by McIndoo cannot be reconciled with those of other workers, and it is evident that the subject requires further exploration under carefully standardised conditions.

The Gustatory Sense. 'The probability that, in many cases, insects do not experience "taste" and " smell" as separate and distinct sensations has been previously referred to. Nevertheless, the positions of certain sensilla in relation with the oral cavity strongly suggest that such organs are adapted to perceive chemical stimuli by actual contact only. Proof of such a contention is extremely difficult to attain, since the location and minute size of the organs concerned do not render their functions amenable to determination by exact experiment. Sensillæ situated on the lining membrane of the epipharynx of mandibulate insects, the two groups of sensory hairs mentioned by Deegener as situated on the floor of the pharynx in Lepidoptera, and the elaborate pharyngeal organ of Hemiptera appear to be almost certainly gustatory in function. The organ in Hemiptera (Fig. 60, A) lies in the clypeal region of the head and is located on the roof of the pharyngeal duct. As described by Bugnion and Popoff (1911), the cuticular lining of the duct at this point is differentiated into a cribriform plate whose pores appear to be occupied by processes of sense-cells. The organ has a definite nerve-supply, but its whole structure, and its range of development in different families of Hemiptera, need further elucidation. In some species the pores are few in number, but they range up to about 600 in others. This organ, from its structure and location, appears to be adapted for testing the qualities of the plant-sap passing up the pharyngeal duct and before entry into the cavity of the pharynx; there seems little doubt, therefore, that it can only function as a contact (taste) organ. The blood-sucking bug, Rhodnius, will seldom imbibe salt solution through a membrane unless a small amount of hæmoglobin be added (Wigglesworth). It is probable in this instance that the gustatory organ. just referred to, is involved in testing any fluid taken up.

The various sensillæ that occur distributed on the mouth-parts of different insects have also been regarded as gustatory organs. 
They include the styloconic sensillae found abundantly on the proboscis in many Lepidoptera, and several types of hair-like organs found on the mandibles, maxillæ, palpi, etc., of different insects. They are abundant, for example, on the mouth-parts of the hive bee, but McIndoo (1916) concludes that the thickness of their cuticular covering precludes their performing any gustatory function, and that they are more probably tactile organs. This observer maintains that the only sensillæ present in the bee which function as chemoreceptors are the so-called " olfactory pores." These, he states, are olfactory in function, as their name implies,

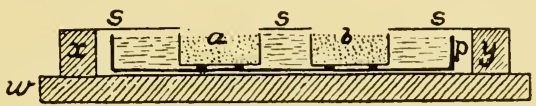

A
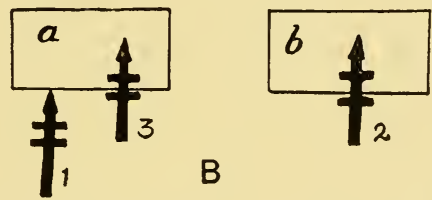

B

F1G. 58. A, cross-section of apparatus used by Minnich. B, The arrows 1, 2, 3 represent the positions in which the insects were tested, the walking legs being indicated by crossbars. Explanation of lettering in the text. (Adapted from Minnich.)

and he finds no evidence of true gustatory organs being present. There is the perennial difficulty, however, of advancing sufficient experimental proof that sensillæ located on the mouth-parts perceive taste and smell as separate impressions. Opinion is inclining to the view that they are probably chemoreceptors, in the broad sense, which are capable of appreciating stimuli both by actual contact (taste) and at a distance (smell).

The experiments of Minnich (1921) indicate that certain butterHies (Pyrameis atalanta, Vanessa antiopa) are able to respond to non-volatile substances by means of the tarsi of the middle and hind pairs of legs. The apparatus (Fig. 58) used consisted of a square wooden platform $w$, bearing two cross-pieces $x, y$, which supported a tightly stretched wire screen $s$. The dimensions of 
this construction werc such that a Petri dish $p, 15 \mathrm{~cm}$. in diameter and $1 \mathrm{~cm}$. deep, could just be passed beneath the screen without coming in contact with it. Within the Petri dish were mounted two tin receptacles $(a$ and $b), 4 \mathrm{~cm}$. long, $2 \mathrm{~cm}$. wide, and of such a height that their upper edges were on a level with the rim of the Petri dish. Two rectangular openings were cut in the screen, so that when the Petri dish was in position they were directly over the tin receptacles. Owing to the fact that the insects in question are well known to feed upon the juices of fallen or decayed fruit, apple juice was used in the experiments and poured into the Petri dish. Two packs of cheese cloth were folded to fit the pans: one was saturated with apple juice (in $a$ ), and the other with distilled water (in $b$ ). An individual butterfly was held by a specially devised arrangement which gripped the closed wings, and was tested in the apparatus in three positions. In the first position (Fig. 58, B) it was placed as near as possible to the edge of the receptacle $a$ with the antennx reaching out over the cloth saturated with apple juice, but with the four walking legs upon the screen. In the second position the insect was placed in relation to receptacle $b$, so that the middle tarsi were in contact with the distilled water : in the third position the same experiment was performed in relation to receptacle $a$.

The conditions of chemical stimulation in the three positions may be summarised as follows :-

Position 1. Distance stimuli from apple juice.

Position 2. Distance stimuli from apple juice in the surrounding Petri dish plus contact stimulus of distilled water on the tarsi.

Position 3. Distance and contact stimuli from apple juice.

The experiments were carried out with starved individuals, and the response was judged by the coiling and uncoiling of the proboscis. The maximum duration of each trial was one minute, and if no visible uncoiling of the proboscis occurred during that intcrval "no response" was recorded. With Pyrameis 29 per cent. of the individuals responded in position 1, only 17 per cent. in position 2, and 100 per cent. in position 3. After removal of the antenna, palpi and vestigial fore legs the experiments were 
repeated and the responses in the three positions were 4 per cent., 17 per cent., and 65 per cent. respectively. The responses with Vanessa were in some respects less striking, but they were similar in nature. In a further series of experiments it was shown that Pyrameis, by means of its tarsi alone, is able to distinguish $1 \mathbf{M}$ saccharose solution from distilled water and such solutions as $1 \mathrm{M} \mathrm{HCl}, \mathrm{M} / 600$ quinine sulphate, and $1 \mathrm{M} \mathrm{NaCl}$ from either $1 \mathrm{M}$ saccharose or distilled water. Distilled water alone is a very effective stimulus when applied to the tarsi. Minnich gives reasons for concluding that chemoreceptors are located in all four tarsi of the walking legs of Pyrameis, but gives no information with respect to the structure and exact location of the sensillax involved. Since perception takes place by means of actual contact with the stimulus, he regards the organs involved as being gustatory in function.

In 1922 Minnich repeated his former tests and obtained very similar results, and, according to the scheme adopted in this second paper, the total responses of all the individuals tested were 100 per cent. to $1 \mathrm{M}$ saccharose, 84.7 per cent. to $\mathrm{M} / \mathbf{1 0}$ quinine hydrochloride, and 51.6 per cent. to $2 \mathrm{M} \mathrm{NaCl}$. An intensive study of the differences of response showed that Pyrameis could differentiate between almost all, or probably all, these solutions.

In a further series of experiments (Minnich, 1922A) it was shown that contact of the four ambulatory tarsi with 1M saccharose solution will always effect an extension of the proboscis, irrespective of the nutritional condition of the insect. After a prolonged period of inanition with respect to saccharose the tarsal sensitivity may be so delicate as to appreciate as low as $M / 12,800$, and may thus be as much as 256 times that of the human tongue. This highly developed sensitivity is doubtlessly correlated with the fact that sugars form the chief food constituent in Pyrameis.

Additional observations and experiments were carried out by Minnich (1926) with regard to the responses of three species of common Muscid flies (Phormia regina, P. terre-nova and Lucilia serricata). The results obtained were very similar to those derived from the experiments with Nymphalid butterflies. When 
the tarsi are in contact with distilled water 95 to 100 per cent. response ensued, while without tarsal contact only 1.4 to $13 \mathrm{per}$ cent. response was observed. With paraffin oil the response was very small, while with 1M saccharose solution the response varied from 80 to 100 per cent., depending upon the nutritional state of the insects. By means of their tarsi they were able to discriminate between water and saccharose solution and between water and paraffin oil. The oral lobes of the proboscis appear also to be equipped with taste sensilla which are more sensitive to saccharose than are the tarsi. In a subsequent paper (1926A) Minnich states that gustatory hairs are present on the proboscis of Calliphora. A fly, after being abundantly supplied with water, but otherwise starred, does not exhibit any response when distilled water is brought into contact with these hairs. When they are touched with a minute brush moistened with sugar solution the proboscis becomes quickly extended. The sensitivity of these hairs is stated to be so great that a single one, when stimulated in this way, produces the proboscis response. It is, therefore, concluded that a true gustatory response is involved. Minnich subsequently extended these observations while working in the laboratory of Professor K. von Frisch in Munich. Thus, he determined the range of chemical sensitivity of the legs of the blow-fly (Calliphora romitoria) to various sugar solutions (Minnich. 1929). In 1931 he published the results of studies on the reactions of the mouth-parts of that same insect. He found that the aboral surfaces of the oral lobes of the proboscis are clothed with marginal hairs which appear to be gustatory in function. The minimum concentration of saccharose which, when applied by a fine brush to the hairs in question, will produce proboscis extension, is about 1/100 M and much higher than that for the legs. The threshold for glucose is at least four to eight times higher than that for saccharose, while lactose was the least effective of the sugars that were tested. The fact that saccharose is sixteen to sixty-four times more effective than lactose suggests that the hair-receptors concerned are chemical sense organs rather than tactile or osmotic in function, since equimolar solutions of these two sugars are similar as regards their viscosity and osmotic 
pressure. From Minnich's data it seems that the general order of effectiveness for the four sugars tested is-saccharose and maltose $>$ glucose $>$ lactose. In other words, it is essentially the sanie as that observed both by von Frisch $(1927,1928)$ and by Kunze (1927) for the mouth-parts of the hive bee.

In 1932 Minnich published the results of experiments with the hive bee, the responses being judged by the extension of the proboscis. The bee is able, by means of the antennæ or the fore leg, clearly to distinguish between 64/100 M saccharose solution from an equimolar solution of lactose and from water. The antennæ are well known to function as distance receptors, and it appears that they are used as contact receptors also. Although it seems clear from these experiments that the apex of the antennæ bears contact chemoreceptors, it is by no means certain which type, of the five kinds of sensoria present, actually function in the process.

Other investigators, including Abbott (1928), Anderson (1932), Crow (1932) and Weis (1930), have confirmed and extended Minnich's chief results and conclusions, with the outcome that it appears quite certain that the legs of certain butterflies and flies, at any rate, are highly sensitive to chemical

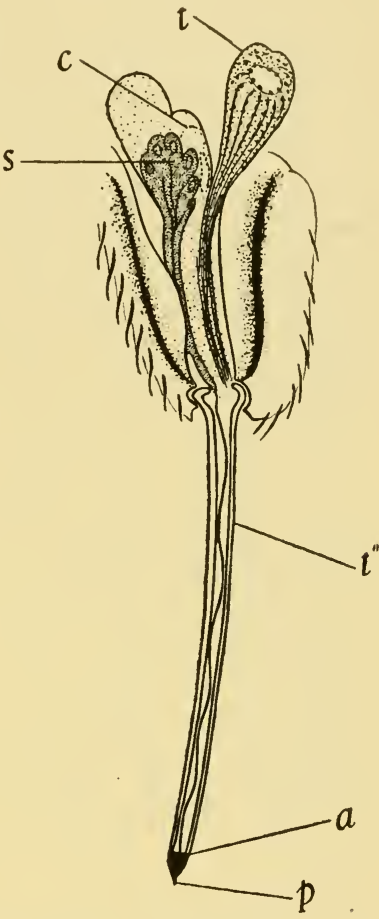

Fig. 59. Chemoreceptor of Pyrameis atalanta, highly magnified. $t$, trichogen; $c$, probable cap-cell; $s$, sensory cells ; $t^{\prime \prime}$, tube of chemoreceptor ; $a$, darkstaining end of tube ; $p$, papilla. (From Eltringham.) stimuli. In 1934, McIndoo contested certain conclusions of Minnich with respect to blow-flies and claims that it is not necessary, in order to explain the proboscis response, to assume that the tarsi bear gustatory organs. He describes experiments 
wherein the flies are easily able to distinguish between chemically pure saccharose water and distilled water when the tarsi are about $3 \mathrm{~mm}$. distant from these liquids. The act of touching the tarsi by means of a brush, moistened with the substance to be tested, produces the initial stimulus and brings the liquid almost in contact with certain campaniform sensillæ in the tarsi. He further states that a high response resulted by merely touching the tarsi with a needle, the proboscis being protruded when the sugar solution was $3 \mathrm{~mm}$. away. It is possible, therefore, that the tarsi of the blow-fly, like the antennæ of the bce, bear both contact and distance receptors. For other inscets, tarsal sensoria are described by Eltringham (1933) as being extremely slender, thin-walled tubes in the butterfly Pyrameis atalanta (Fig. 59).

The work of Minnich opened up a new field of experimentation in so far as insects are concerned. It is noteworthy that several previous investigators have shown that the walking legs in the higher Crustacea are sensitive to contact with foods and other chemical stimuli. B. M. Patten has also demonstrated that the modified anterior legs of the whip-tail scorpion are likewise sensitive to water and other chemical stimulation. In the light of the foregoing evidence, Minnich considers that contact chemoreceptors, located in the distal extremities of the thoracic legs, are of general occurrence among Arthropods. 


\section{CHAPTER VI}

\section{THE SENSE ORGANS AND REFLEX BEHAVIOUR- continued}

4. The Tactile Sense, p. 139. 5. Сhordotonal Organs and Reactions to Vibrations, p. 140. Chordotonal Sensille, p. 141 ; Simple Ligamentous Chordotonal Organs, p. 142; Johnston's Organs, p. 143 ; Tympanal Organs, p. 143 ; The Functions of the Chordotonal Organs, p. 145. 6. General Stimulatory Organs, p. 153. 7. Reflex Behaviour and Practical Entonology, p. 155. Reactions to Chemical Stimuli, p. 155; Reactions to Light, p. 164; Concluding Remarks, p. 167. Literature, p. 168.

\section{The Tactile Sense}

THE simplest kinds of sensillæ present in insects are innervated hairs, and several types of these structures have been regarded as being tactile in function. Among the more recent investigators, McIndoo (1926) has described sensory hairs, bristles and peg-like organs, which are believed to be tactile in function, on various regions of the body in the Cotton Boll Weevil. They are present in the head, antennæ, mouth-parts, thorax, legs, wings, abdomen and genitalia. Histologically, they are regarded as being too thick-walled to function as chemoreceptors; they are innervated by delicate nerve terminations, and movably articulated with the general integument. Such sensillæ appear to be only adapted for tactile sensation, and even very slight pressure exercised by any external object would seem to be appreciated by organs of this nature, whereas the general cuticle of the body would fail to register such stimuli.

It is well known that many insects betray what is regarded as a positive contact reflex (often termed thigomotropism). Such species ensconce themselves in crevices, beneath bark, under stones or logs, etc. The same kind of reaction is betrayed when oviposition occurs in fissures, crevices, etc., and beneath the 
soil, the highly sensitive apex of the abdomen being provided with sensillax that are presumably tactile in function. Many lepidopterous larva, when about to pupate, seek fissures or dark crevices or pass beneath the soil at that period. It would seem that at this vulnerable phase in their life such responses are brought about by a change in their reflex behaviour. Prior to pupation many species live openly on foliage and exhibit different behaviour. It has been argued that these responses are due to negative phototropism and not to thigomotropism, but in certain cases, at least, the light factor appears to be of minor significance. Thus, McIndoo (1929) states that when larvæ of Cydia pomonella are about to spin their cocoons they seek concealment in some dark, tight situation, but if a dark crevice be not available, they do not hesitate to adopt a well-lighted place instead. Locb also came to the conclusion that in the case of certain moths which rest in fissures and crannies in the bark of trees, contact stimulilus alone is involved. There is, however, very little experimental evidence available with reference to contact responses, and it is possible that, in many cases, a complex kind of differential sensitivity is brought into play, involving negative response to light and positive responses to gravity and to contact with external objects.

\section{Chordotonal Organs and Reactions to Vibrations}

Insects belonging to very diverse groups are known to respond to aerial vibrations of different degrees. In some cases these vibrations are imperceptible to the human senses, and, in others, vibrations which produce a very pronounced auditory sensation in man appear to exercise little or no stimulatory effect upon certain insects. In a large number of instances there is no evidence that the perception by insects of aerial vibrations is of the nature of hearing, in the anthropomorphic meaning of the word. On the other hand, the power of sound production and the presence of highly developed tympanal organs in certain families, together with the behaviour of the insects possessing these organs, indicate that in these instances a sense closely akin to hearing is present.

Before discussing this subject further, it is necessary to consider 
briefly the nature of the sensory organs concerned. These may be grouped under the general term of chordotonal organs, which

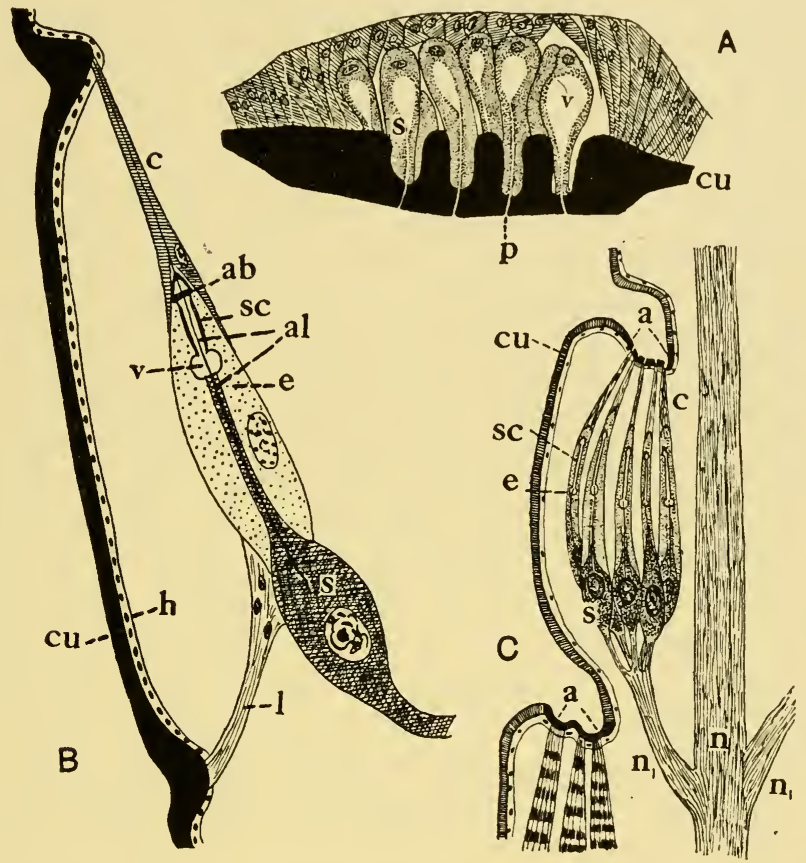

Fig. 60. A. Section through presumed gustatory organ of an Hemipteron (Graphosoma lineatum). (Adapted from Bugnion and Popoff.) B. Diagram of a simple chordotonal organ consisting of a single sensilla. C. Diagrammatic longitudinal section through the second antennal segment of a Geometrid moth (left side), showing .Johnston's organ. (Adapted from Eggers.) $a$, articular membrane; $a b$, apical body; $a l$, axial fibre ; $c$, cap-cell ; $c u$, cuticle ; $e$, envelope-cell ; $h$, hypodermis; $l$, ligament; $n$, antennary nerve and branches: $n_{1}, n_{1}$, to Johnston's organ ; $p$, cuticular pore ; $s$, sense-cell ; $s c$, scolopala ; $v$, vacuole.

implies the presence of chords or filaments sensitive to tones or vibrations.

Chordotonal Sensillæ. The sensillæ composing chordotonal organs may occur singly, but more often in small groups, or larger numbers may be combined to form more elaborate structures. 
The simplest type of chordotonal organ consists of a single sensilla which exhibits the following structure (Fig. 60, B). An ovoid or fusiform sensory cell is provided with a distal prolongation terminating in a sense-rod or scolopale. The scolopale is strengthened by a variable number of internal ribs and is usually capped by a deeply staining apical body. A delicate axial fibre extends from the sense-cell and traverses the axis of the scolopale to terminate in the apical body. The prolongation of the sensory cell, together with the scolopale, are enclosed within an envelopecell. The latter, in its turn, is closely associated with an elongated cap-cell, which serves to connect the sensilla with the integument. The scolopale itself is often connected with the integument by means of a terminal fibre which traverses the envelope-cell. At the point where the distal extremity of the sensilla is fixed to the cuticula, there may be a pit or a thickened disc, but there is no special receptive structure. Proximally, the sensilla is attached to the integument by a special ligament which is inserted into the base of the sense-cell. It will be observed, therefore, that a typical chordotonal sensilla is suspended between two points of the integument. In some cases, it may be added, the scolopale appears to be hollow. and its cavity is connected basally with a vacuole filled with fluid. The scolopale is immersed in the semifluid protoplasm of the envelope-cell, within which it is free to vibrate.

Chordotonal organs may be grouped into three classes arranged in order of increasing complexity of structure : (1) simple ligamentous organs ; (2) Johnston's organs ; and (3) tympanal organs. These three types are only briefly dealt with in the following sections, since their structural features are well described in modern text-books. A very full and admirably illustrated treatise on the subject will be found in the recent work by Eggers (1928).

Simple Ligamentous Chordotonal Organs. Organs of this type, comprising small groups of one or more sensillæ, occur in a great many different groups of insects and their larva. Among larval insects they are commonly segmentally arranged with an organ on either side of each of the first seven or eight abdominal segments (Fig. 60, B). Structures of this type are well known from Graber's 
familiar studies in larvæ of the Diptera, Lepidoptera, Coleoptera and Tenthredinidæ.

In adult insects simple chordotonal organs are likewise very widely spread among different orders, where they occur chiefly on the antennæ, wings, halteres and legs. They are especially constant in relation with the bases of the wings, and in this position they are known to be present in all the major orders of Pterygota.

Johnston's Organs. Organs bearing this name are located in the pedicel, or second segment, of the antenna, and are prevalent in all the main orders of insects, and also in Lepisma anong the Thysanura. They are not the only chordotonal organs present in the antennæ, and smaller groups of sensillæ may occur in other of the segments of those appendages. A Johnston's organ consists of a group of usually very numerous chordotonal sensillæ disposed in the form of a sheath around the antennal nerve, and when it is highly developed, as in the Culicidæ and Chironomidæ, the pedicel of the antenna is greatly enlarged. The distal extremities of the sensillæ are usually attached to the articulatory membrane between the second and third antennal segments, and are indicated by a series of pits or annuli in that membrane. Proximally, the sensillæ are directly connected by means of nerve fibres with the main sensory nerve of the antenna (Fig. 60, C).

Tympanal Organs. As their name implies, these organs consist of a sound amplifier or tympanum developed in close relation with one or more defined groups of chordotonal sensillæ. They are present in grasshoppers and cicadas, which are well known to be capable of producing loud and often shrill sounds, as well as in some other insects whose sound-producing capacity is far less evident.

Some of the most highly specialised of these organs are found in the saltatorial Orthoptera, but since their structure has so often been described and figured, this aspect of the subject will not be dilated upon here. It will be recalled that in the Acridiidre a tense vibratory membrane or tympanum surrounded by a cuticular ring is clearly visible externally on either side of the first abdominal segment. In the Tettigoniidæ and Gryllidæ there is often a pair 
of tympanal organs near the proximal extremity of the tibia of each fore leg.

In the Cicadida the presumed absence of any receptor organs for sound vibrations had for many years been an outstanding difficulty in interpreting the function of their highly developed powers of sound production. It was not until 1923 that Vogel, in Germany, proved on histological grounds that true tympanal organs are present in both sexes of these insects. In the male the cavity bencath the operculum of the sound-producing organ is

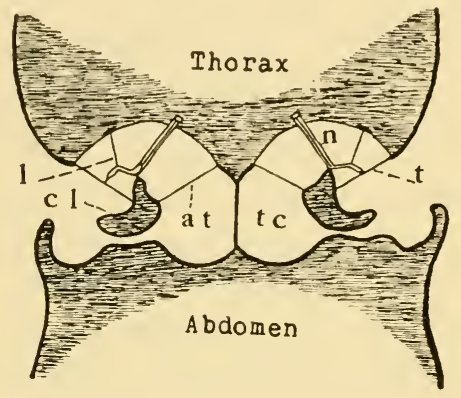

Fig. 61. Horizontal section across portions of thorax and abdomen of a Noctuid moth, passing through the right and left tympanal organs. at, Accessory tympanum ; $c l$, chitinous lamella; $l$, ligament supporting chordotonal organ ; $n$, chordotonal nerve ; $t$, tympanum ; $t c$, right tympanic chamber. (Adapted from Eggers.) bounded posteriorly by a structure commonly termed the mirror. The latter organ had long been claimed to be a resonator, and it remained for Vogel to show that it is the tympanum ${ }^{1}$ of an auditory organ. The true pereipient part of this organ consists of a group of an immense number (about 1,500) of chordotonal sensilla stretching across the cavity of what may be termed the auditory capsule. At one of their extremities these sensillx are attached, by ligamentous prolongations, to a cuticular process connected with the mirror or tympanum. At their other cxtremities the sensillæ are attached to the outer wall of the auditory capsule. In the female the tympanum is also well developed but somewhat reduced in size.

In many Lepidoptera highly developed tympanal organs are also present. The comprehensive studies of Eggers (1919, 1928) have shown that these structures are present on either side of the

1 Swinton, as long ago as 1877 , gave reasons for concluding that the so-called mirror was the tympanum of an auditory organ. As is pointed out by Myers in his book on Cicadas (1929), this account had been long overlooked, and Vogel only discovered Swinton's paper when his own detailed studies were nearing completion. 
thorax or the base of the abdomen in different families, while they are totally wanting in many others. 'The tympanal organs (Fig. 61) consist of a pair of vesicles-onc on each side of the body. Each resicle is lined by tracheal epithelium and is lodged in a cavity formed by the invagination of the integument of its segment. It communicates with the exterior by means of an opening on the side of the body, and this aperture is guarded by an integumentary flap or shield. Just within the opening there is found the glistening membrane of the true tympanum, and closely associated with it there is a group of chordotonal sensillæ connected with a special tympanic nerve derived from the metathoracic ganglion. Lying more deeply within the tympanic vesicle there is, in many species, an accessory tympanum which is not, however, associated with any sensillæ.

Tympanal organs are also described by Hagenıann (1910) in Corixa and its allies. 'They are located on either side of the metathorax and in close relation with the second pair of spiracles.

The Functions of the Chordotonal Organs. No definite proof exists with regard to the functions of the simple ligamentous chordotonal organs, and the subject is highly problematical. Snodgrass (1926) lays stress upon Eggers' view (1923) that they function as "rhythmometers." The last-mentioned authority claims that most of the movements of insects result in rhythms. In the case of the wings, for example, the action of these organs sets the whole body into rapid vibration. He points out that the movements of the antennx and legs tend to become rhythmic. and the same applies to the pulsations of the dorsal vessel and the movements of respiration. The body-movements of locomotion in certain aquatic insects, the motion of the gills and of other parts likewise tend to become rhythmic. Eggers suggests, therefore, that the chordotonal sensillæ are organs for the purpose of co-ordinating and regulating muscular movements of this character. Notwithstanding this hypothesis, we must conclude that similar kinds of sensillæ in association with a tympanum, or other cuticular receptive organ or membrane, are capable of perceiving vibrations in the surrounding medium wherein the insects live. As will be mentioned later, evidence in favour of 
tympanal organs being auditory in function is too well established to admit of any other interpretation. Wherever chordotonal sensilla occur in relation with a cuticular membrane capable of transmitting vibrations set up in the surrounding medium to the underlying scolopalx, the latter are presumably able to respond on their own part by vibratory movement, since they are immersed within the vacuolar fluid of the envelope-cells. It will, therefore, appear possible that chordotonal sensillæ are general muscletension receptors which may function in relation to muscular activity in accordance with Eggers' view and, in other cases, as receptors of vibrations external to the insects.

The locations of the simpler types of chordotonal organs in relation with many parts of the body suggest that they serve to detect, or register, stresses or strains put on those parts by muscular activity. This especially applies to the joints of the appendages (Fig. 62). In the grasshopper Melanoplus, for example, there are, according to Slifer (1936), at least seventy-six pairs of chordotonal organs, each organ being composed of two or more scolopalia. It is probable, also, in this connection, that they serve to coordinate muscle action so as to adjust it on the two sides of the body. Without some such perceptor organs there appears to be no means by which an insect is enabled to orientate itself in relation to the effects of gravitation-especially when in flight. Hertweck (1931) also came to the conclusion that in insects response to a gravitational field is by means of tension receptors or kinesthetic sensitivity. The theory of geotropism developed by Crozier and his co-workers has established that the direction of an animal in a gravitational field is determined by the bodyweight acting upon tension receptors in the musculature of the appendages. Barnes (1930) has shown that the angle described by an ant crawling up an inclined plane is a function of the sine of the angle of inclination of the plane. He states that the insect turns until the "pull" of the body-weight on both sides of the symmetrical muscles is reduced below threshold value. This author (1931) also showed that the slightest movement in the leg of Periplaneta produced a discharge of sensory impulses which were led off through electrodes and reproduced by an amplifier 
wired to a loudspeaker. His observations are to be regarded as giving further evidence supporting Crozier's theory of geotropic

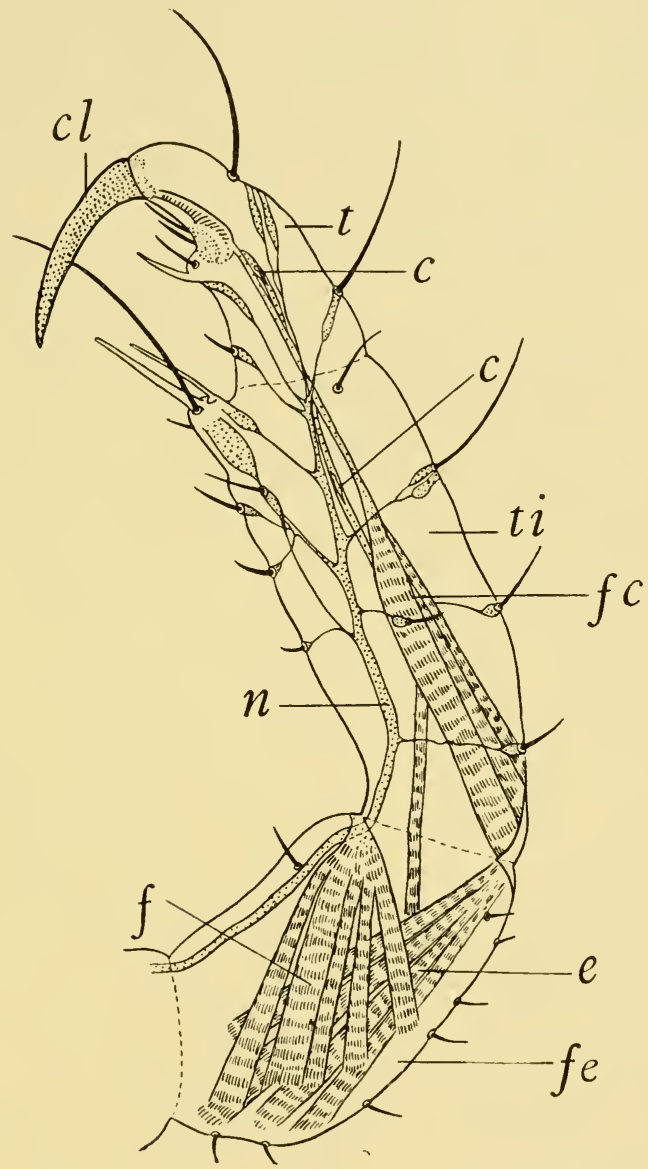

Fig. 62. Third leg of first instar nymph of Pediculus. $c$, monoscolopal chordotonal organ; $c l$, claw ; $e$, extensor muscle of tibia ; $f$, flexor muscle of tibia ; $f c$, flexor muscle of claw ; $f e$, femur ; $n$, nerve of leg; $t$, tarsus ; $t i$, tibia. (From Keilin and Nuttall.)

orientation, which involves the presence of tension receptors. So far, no sensory nerve endings have been detected in insect muscle, 
but it seems probable that in some way or other these afferent impulses are registered by chordotonal organs.

The significance of Johnston's organs is equally problematical. 'The constancy of their occurrence in so many different groups of insects and their essential similarity of structure, which only varies in its complexity and the number of sensilla involved, suggests that these organs play an important rôle in the lives of the insects possessing them. Eggers holds the view that they register antennal movements, which exercise varying stresses upon the intersegmented membrane to which the component sensilla are attached. It has also been suggested that wind pressure, air currents, mechanical vibrations, etc., might also be perceived by these organs. In this connection, it may be pointed out, the general structure of the cuticle investing the antennal segment bearing Johnston's organ does not exhibit any special adaptation for the reception of such stimuli. In the case of Chironomida and Culicidx, however, where these organs are greatly developed. the distal extremities of the sensilla are all attached to a special conjunctival plate. Maycr (1874) claimed that in these insects the whorls of antennal seta, so highly developed in the males, are caused to vibrate when stimulated by certain tones. It is believed that in such cases the vibrations of these setxe are transmitted to the conjunctival plate and hence to the sensillx, and that insects possessing this special type of organ are able to appreciate sound waves of certain qualities. The mere fact, however, that certain hairs of specific insects can be caused to vibrate by different pitches of sound may be of little significance. It is well known that a cord of a one-stringed instrument responds to that of another instrument set in vibration in a similar key !

Pumphrey and Rawclon-Smith (1936) have shown that the long sensory hairs on the cerci of the cricket (Gryllus domesticus) and cockroach (Periplaneta americana) are sensitive to auditory stimuli. The sensitivity of the cercus to low frequencies is much greater than that of the human ear, a marked response being obtained to a stimulus completely inaudible to man. It is possible that the acoustic function of the cerci is merely incidental. The difficulty of distinguishing between acoustic and vibratory 
stimuli for such an organ is stressed, but the relative insensitivity of the cercus of the cricket to all but the lowest frequencies, together with the fact that the organ is frequently in contact with the ground, leads these authors to suppose that its main function here is to mediate the detection of earth-borne vibrations. In the cockroach, where the cerci are carried upwardly inclined, it seems likely that their function as wind gauges may be equal in importance to their function as acoustic organs. They found that there is a close parallel between the response in the cercal nerve and that in the mammalian eighth nerve-a fact of considerable physiological interest.

It needs to be borne in mind that mechanical stimuli, appreciable to man as touch and sound, probably intergrade as phases of a single type of sensation in the majority of insects. Aerial vibrations may be appreciated by those creatures through the medium of generalised tactile receptors. In certain caterpillars there is definite evidence that sound waves produce marked responses when impinging upon their body-hairs. It has long been known that various lepidopterous larvæ, and also those of some Coleoptera, show evident indications of stimulation to particular types of sounds. Minnich (1925), however, appears to have been the first to locate the sense involved. He found that larvæ of Vanessa antiopa respond to appropriate sound stimuli by throwing the anterior one-third of the body dorsally or dorsolaterally. He used sounds produced by the human voice, piano, organ, violin, Galton whistle, tone modulator, tuning forks and by other means, and observed that the larva responded in the manner described in all cases except to the whistle and tone modulator. The extent of the response varied according to the intensity of the sound, and responses were obtained from vibrations ranging from 32 to 1,024 per second. Decapitated bodies, and fragments of bodies, will respond to sounds, and he concludes that certain hairs, located chiefly in the anterior two-thirds of the body, probably constitute the receptor organs involved. This conclusion is based upon the fact that responsiveness to sounds increases as the number of hairs increase in successive instars. Partial destruction of the hairs by singeing either greatly reduces 
or abolishes the response; heavy loading of the hairs with fine droplets of water, or with flour particles, produces a similar effect. During ecdysis, when the old hairs are more or less disconnected from the underlying parts and the new hairs are not yet functional, the response is either feeble or nil. Larvæ subjected to a tone stimulus of short duration, repeated at intervals of five seconds, showed little or no fatigue in the course of 100 trials. Individuals subjected to continuous tone stimulation, however, generally became fatigued and ceased to respond after a period ranging from five to sixty seconds. Minnich further observed that continuous air currents inhibit the response to sounds. This is due, in general, to one form of stimulation inhibiting the response to another kind. When the air current is prolonged, however, another factor, probably that of fatigue, also becomes involved. Larvæ fatigued to $\mathrm{C}(256 \mathrm{~V} / \mathrm{S})$ or $\mathrm{G}(38+\mathrm{V} / \mathrm{S})$ will not respond to $\mathrm{C}^{\prime}(512 \mathrm{~V} / \mathrm{S})$. When fatigued to $\mathrm{C}^{\prime}$, however, larva still gave 100 per cent. response to $\mathrm{C}$ and about 50 per cent. response to $\mathrm{G}$. These results suggest the tentative conclusion that hairs of different lengths are affected by the various pitches of sound indicated. Abbott (1927) carried out very similar observations with larvæ of the moth Datana (fam. Notodontidæ). Definite responses were noted to air currents, sudden jars, and to the two notes only, viz., $\mathrm{C}^{\prime \prime}(512 \mathrm{~V} / \mathrm{S})$ and $\mathrm{F}$ sharp $(728 \mathrm{~V} / \mathrm{S})$; larvæ thus stimulated elevated the anterior and posterior regions of the body. During the experiments the larvæ were protected from air currents : they were several feet from the instruments used, and vibrations from the substratum were eliminated. No responses were observed when the body-hairs were coated with water or shellac, or when the body-surface was anæsthetised with a 2 per cent. solution of procain. Baier (1930) has also shown that larvæ of Pieris rape react to certain acoustic stimuli in much the same manner as those of Datana. His experiments, however, were by no means extensive, but he showed that when stimulated by a whistle or by vocal means the extent of the reaction varied directly with the nearness of the stimulus, its intensity and its suddenness. The fact that larva whose body-hairs had been entangled with cotton fibres responded very feebly, and when 
relieved of the fibres again responded normally, suggested that the hairs are the receptors involved, as was found by the two previously mentioned investigators. The results drawn from foregoing experiments, with lepidopterous larvæ, point to the conclusion that these animals are sensitive to air currents and to certain aerial vibrations. They obviously afford no evidence that any sense of hearing in the anthropomorphic meaning is involved, but lend support to the dictum already stated that, in many insects, the tactile and auditory senses are very questionably differentiated. No relation between the responses mentioned and the segmentally arranged chordotonal sensillæ, known to occur in lepidopterous larvæ, has been recorded, and it appears improbable that they play any part in the process.

There now remains for consideration the functions of tympanal organs. It is noteworthy in this connection that in the saltatorial Orthoptera, the Cicadiclæ and Corixidæ, sound-producing organs are present. This fact in itself suggests that if these sounds are of significance in the lives of the species concerned, some type of perceptor organs is necessary. In species devoid of any capacity for sound-production tympanal organs are wanting : this happens, for example, in the wingless Tettigoniidx and in the primitive soundless genus Tettigarcta among the Cicadidæ. That the tympanal organs are auditory in function is supported by the ingenious and controlled experiments of Baier (1930) with field crickets and other Orthoptera. Individuals of species whose sexes were segregated, and previously conditioned to a life in cages, were placed in different rooms sufficiently distant to be beyond the range of sound perception. A microphone, placed in the cage containing the males, was connected by telephone with a receiver in the cage containing females of the same species. The femalcs responded to the stridulation of the males by orienting themselves when they perceived the sound : this they did by approaching the receiver with actively moving antennæ and by performing movements indicative of search for the summoning partners. When the current was temporarily interrupted, the females may move away from the receiver, and in any case no longer betray their former signs of attention. On restoring the circuit the females at once 
approached the receiver again. The cages, it may be added, were insulated so as to guard against solid vibrational stimulation. None of the responses came from females whose tympana were excised, and a local anæsthetic (ethyl chloride) applied to these organs had only the same effect just so long as its influence lasted, normal response being ultimately restored. The use of gramophone records of the male stridulatory notes had an effect similar to that exercised by the living insects themselves.

In their investigation of auditory responses in Locusta, Pumphrey and Rawdon-Smith (1936) deny any ability on the part of this insect to discriminate frequency of vibrations by means of its tympanic organ. They find no differentiation of nervous response for different frequencies of stimulus and conclude that the physical structure of the tympanal organ is such as would not permit of discrimination of frequency by means of a differentially resonant mechanism. They remark, however, that the organ is well adapted to enable the insect to localise the source of a sound whose frequency falls within its auditory spectrum, e.g., the stridulation of another locust. The organ resembles the human ear only in its relatively greater sensitivity to the higher frequencies of sound waves. On this subject references should also be made to the paper by Wever and Bray (1933), which deals with nerve impulses originating in the tympanal organs of crickets and katydids. These organs respond to sound frequencies of from 250 to over 11,000 vibrations per second: the quality of the response was found not to vary with the frequency. Myers (1929) has collected a large amount of circumstantial evidence relative to the "songs" of Cicadas and their significance. The primary function of the notes of these insects, according to this observer, is an assembling one, and it may also serve to arouse the necessary stimulus leading to the consummation of the sexual act. There does not appear to be any conclusive experimental evidence with regard to sound perception in these insects, but anatomical and observational data, relating to their behaviour, appear to offer little reason to doubt the auditory functions of their tympanal organs. The tympanal organs of Lepidoptera likewise appear to be organs for 
sound perception. This conclusion is in accordance with their gross and minute structure and is also supported by analogy with the better-known organs, of a somewhat similar nature, found in the Acridiidx. Certain experiments carried out by Eggers afford further support to this belief. This observer states that when the tympana of both organs are destroyed, the moths so treated no longer react to tests with sounds. When, however, a single tympanum is destroyed, the insects responded to sound stimuli, in more than half the cases tested, by flying. With both organs left intact reaction to different sounds was expressed either by flying or by elevating and moving the wings. Amputation of the antenna did not interfere with response to sounds, while insects whose wings had been cut off still responded, either by running or by movements of the antennæ or legs. The most puzzling feature is the real significance of sound receptors in an order where sound production appears to be confined to relatively few species. In some cases, e.g., Vanessa butterflies, a faculty for sound production prevails and yet tympanal organs are wanting. It is possible that sound vibrations-inaudible to human senses in many cases-may be produced by Lepidoptera and be perceived by the organs in question. In this way individuals may perhaps become aware of the proximity of other members of their species, but it has to be admitted, however, that the suggestion is merely hypothetical.

\section{General Stimulatory Organs}

Stimulatory organs are sensory organs whose functions are to send continuous afferent stimuli to the central nervous system. These stimuli, it is claimed, are essential to the normal and proper working of the nerve-muscle system or of certain reflex arcs. They are necessary for the production and maintenance of muscle tonus and to increase the kinetic efficiency or the contractility of the muscles. Most sensory organs, in addition to their normal specific receptor ability, also probably exercise stimulatory functions in keeping the nervous system in a reactive condition (vide Wolsky, 1933).

In the modern interpretation the dorsal ocelli of adult insects 
are considered to be photokinetic stimulatory organs (vide also p. 111), a view which has some evidence of an experimental nature in its support: optic investigations of the ocelli are also in conformity with this interpretation.

The halteres of Diptera, according to von Buddenbrock (1929), probably come under the category of stimulatory organs. It would seem on this interpretation that they produce afferent stimuli owing to their swinging or vibratory movement when an insect is in flight. The receptors of such stimuli are said to be either the campaniform or chordotonal sensilla at their bases. The continuous production of such stimuli, it is claimed, maintains the requisite muscle tonus required during flight. It is doubtful, however, whether this explanation covers their whole function, since their extirpation may lead to complete loss of ability for flight. Also, certain wingless Diptera still retain well-developed halteres.

According to Wigglesworth (1934) the antennæe in Rhodnius exercise a stimulatory function. When both antennæ are amputated the insect falls in a condition of torpor from which it is only aroused with difficulty, but even then its movements are less active than in the uninjured insect. Normal insects are highly responsive to slight air currents, but those without antennæ give no response even when blown upon strongly. The torpor, it is claimed, is not a shock effect due to the amputation of the antennæ, since it is not apparent until an hour or two later. Furthermore, it does not occur when the wings, legs or proboscis are cut off. Wigglesworth concludes that an important function of the antennæ in Rhodnius is a kinetic one, which maintains the nervous system in a responsive condition so that it will readily react to stimuli.

It is possible that the campaniform sensillx, which have been investigated for many years by McIndoo, are stimulating organs. Their extremely wide distribution over the insect body and appendages in some insects is in accordance with this view, and it may be that their function is called into activity by thermal and olfactory stimuli. A tendency, however, to ascribe a stimulatory function to sensillæ whose functions are very 
inadequately understood does not advance knowledge of the subject unless backed by proper experimental evidence.

\section{Reflex Behaviour and Practical Entomology}

The aim of the practical entomologist is insect control, and in seeking to attain this object his first step is the investigation of life-histories. If this study has been more or less thorough a certain amount of data will probably have been collected with respect to the behaviour of the species concerned. In the haste to achieve practical results, further investigation of this kind will probably be discarded, and the serious work of control embarked upon. Unsatisfactory results so often follow this procedure that it is coming to be realised that more basic studies are required, and an increasing tendency is being shown to explore the wide field of insect behaviour. It has come about that the sensory reactions of insects now often form part of the programme in the search for more adequate means of repression. The study of these reactions is fundamental to many problems of applied entomology, in that it affords possibilities that advantage may be taken of specific kinds of behaviour in devising methods of control.

Reactions to Chemical Stimuli. The most promising field in the practical study of insect behaviour is afforded by their reactions to chemical stimuli, which have come to be included under the general term of chemotropism. Since the first critical experiments were conducted in this subject by Barrows in 1907, a very considerable literature has accumulated. It will serve, however, no useful purpose to review all these numerous publications, and for bibliographical information reference may be made to papers by Imms and Husain (1920) and by McIndoo (1927). Almost all the investigations so far conducted in this field are of a purely empirical kind, and have been prompted by need for discovering chemical compounds attractive or, less often, repellent to specific insects. The Aristotelian view, that an animal only moves for a purpose, has been the guiding principle in investigations of this kind. The habits of a particular species, for example, frequently suggest the practical ultilisation of chemical compounds improbable to come under notice, except fortuitously, in other ways. Alongside work 
prompted by such metaphysical ideas, there is a need for a more scientific analysis of insect behaviour, and for the discovery of any quantitative laws that may govern their reactions. In this connection it may be pointed out that insects have been shown to be attracted to chemical compounds that are neither associated components of their food, nor occur in the natural environment of the species concerned.

The fact that insects are powerfully attracted to certain kinds of food materials is a matter of common observation. It has only been during about the last twenty years, however, that economic entomologists have made systematic efforts to take advantage of this phase of behaviour in devising methods of repression. The practice of exposing traps or baits, containing molasses as their chief chemical constituent, has now become a widespread and familiar measure. Little is definitely known with respect to the specific attractive ingredients of this mixture of substances, but all observations show that its chemotropic properties are greatly enhanced in the presence of fermentation. It is especially attractive to many species of moths, particularly to those of the family Noctuidæ, while numerous species of Diptera, whose larva inhabit decaying organic matter, likewise respond. Molasses baits were at one time a common method of controlling grapevine moths in Europe, but in recent years it has fallen into disrepute. At the present time much attention is being given to chemotropic measures in the control of the Codling Moth (Cydia pomonella) and the Oriental Peach Moth (C. (Grapholitha) molesta). Yothers (1927) has described the results of three years" experiments in trapping the first-mentioned insect. A number of substances were tested, but fermented molasses proved the most efficient, and captured many thousands of moths per acre during a season. About 55 to 60 per cent. of the insects captured were females, and among them about 95 per cent. were gravid, having laid none or very few of their eggs before capture. He stresses the use of such baited traps for determining the beginning and end of the season of flight of the insect, the beginning and end of each generation, and the period of maximum abundance. Information thus gained may be used to advantage in arranging 
dates of application of spraying. Temperature affected the efficacy of the measure. since the majority of the insects responded while the mean thermometer reading was $70^{\circ} \mathrm{F}$. or above. A sudden fall in temperature will practically stop all moths visiting the baited traps. His conclusion is that a sufficiently attractive lure may be discovered which will destroy a large enough number of moths at a cost that may recommend its adoption as a supplementary control measure. Fowler (1927) carried out very similar experiments in South Australia, using fermented apple juice, with and without the addition of 10 per cent. by weight of sugar, and a solution of molasses to which a small amount of yeast powder had been added. On the whole it was found that apple juice proved the more attractive of the three mixtures. He concludes that it would probably be profitable to maintain traps during the maximum emergence periods of the insect rather than for the whole flight season. Their greatest value lies in their use in determining dates of maximum emergence, so as to make it possible to fix the most advantageous times for spraying.

The control of the Oriental Peach Moth by chemotropic means has been the subject of experiments by Peterson (1925), who found that large numbers of this insect responded to a molasses-yeast mixture. He later (1927) tested about 250 aromatic chemicals as possible attractants, but several fermenting sugar-producing substances proved the most efficient. Fermenting fruits (dried fruit in water) were also found to attract large numbers of the moth. Several other investigators have found that the insect responds readily to suitable chemical stimuli : Frost (1928) believes that chemotropic methods may find a definite place in the control of this insect, notwithstanding the fact that the incidence of prolonged low temperatures or high precipitation exercises an adverse influence upon their efficacy. The inexpensiveness of the method, the simplicity of the apparatus (pails only being used) and the small amount of labour required, all point in its favour. Stear (1928), on the other hand, using a 10 per cent. solution of molasses in water, arrived at an opposite opinion. He states that two years' experiments failed to give appreciable control. By marking moths and releasing them, and noting the 
numbers of such insects that were caught in the traps, he found that 30 per cent. was the maximum number caught over a period of nine days after release. Assuming that this percentage is approximately the percentage taken of the entire local population of the species, the particular chemotropic method adopted is ineffective, especially since many of the moths caught have opportunity for oviposition before capture.

Lloyd (1920) recommends the use of chemotropic measures against the moth Hadena (Polia) oleracea, whose larvæ are destructive to tomatoes grown under glass in England. $\mathrm{He}$ found that a mixture of cane molasses, ale and 1 per cent. sodium fluoride is an effective means of control, particularly when following periods during which spraying against the larva is impracticable. The relatively constant environmental conditions afforded by glasshouse cultivation greatly favours the use of this measure, which is now regularly practised by growers.

In 1910 Verschaffelt conducted experiments in order to ascertain the factors which determine the adoption of specific food-plants by phytophagous larva. He utilised caterpillars of Pieris which feed upon certain of the Cruciferæ along with Tropceolium and Reseda. In these plants there occurs a group of glucosides-the mustard oils-and Verschaffelt took a solution of sinigrin, which is a constituent of black mustard, and spread it uniformly over leaves of plants the Pieris larva had previously refused to eat. Leaves thus treated were readily devoured, and he concluded that Pieris larvæ exhibit a strong positive reaction to mustard oils, and it is their presence in the leaves of certain plants that determines the selection of the latter by the larvæ for their food. By similar methods this same investigator showed that larva of the saw-fly Priophorus (Cladius) pyri, which feed upon certain Rosaceæ, are apparently attracted by the glucoside amygdalin.

McIndoo (1926) has described a laboratory instrument which he terms an "olfactometer" designed for the purpose of testing the chemotropic responses of insects. His main object was to prove that plants attract insects by the odours which they emit. A small potted potato plant was placed in a special chamber of the instrument and a gentle current of air was drawn over it into 
one fork of a $\mathbf{Y}$-tube by means of a suction apparatus. Experiments carried out with the Colorado potato beetle (Leptinotarsa decemlineata) showed that when individuals were introduced into the $Y$-tube an average of $62 \cdot 7$ entered the arm through which air from the chamber containing the potato plant was being drawn. The insects also responded to the odours of water extracts of potato tubers and potato foliage ; odour from the steam distillate of the tubers was only slightly attractive, while a more pronounced response was obtained in the case of distillates of the potatofoliage. Power and Chesnut (1925), acting upon the assumption that the cotton boll weevil is attracted to its food-plant by some odorous volatile substance, undertook to isolate this substance. Among the twelve substances isolated three appeared to be of some significance, viz., an essential oil, ammonia and trimethylamine. The percentage of oil isolated appeared to be too small to be of chemotropic significance, and, despite the fact that more ammonia than trimethylamine was found, they concluded that if the cotton plant contains a positive chemotropic constituent it is probably trimethylamine. No very conclusive results appear to have been derived from this work, and McIndoo doubts whether it is possible to reproduce accurately the odour or odours, which emanate from a plant, by using certain constituents obtained from the plant by chemical means. In 1927 Richmond, experimenting with various essential oils with reference to the discovery of agents attractive to the Japanese beetle (Popillia japonica), found sassafras oil to be by far the most efficient in this respect. The constituent of this oil which exercised the most powerful attraction to the insect proved to be geraniol, which is an unsaturated alcohol belonging to the class of terpene compounds. This alcohol appears to be one of the most powerful specific chemotropic agents so far discovered, and enormous numbers of the Popillia have been caught, through its agency, in suitably designed traps. Although geraniol occurs as a constituent of the apple, which is one of the favourite food-plants of the beetle, it is by no means clear as to what part it plays as an agent influencing the selection of this and other plant species by the insect in question.

A considerable amount of investigation has been devoted to 
the chemotropic responses of Diptera. especially those breeding in decaying organic material of varions kinds. Many species are attracted to various individual by-products produced as the result of fermentation of different kinds. 'The early experiments of Barrows dealt with the reactions of Drosophila melanogaster (ampelophila), which occurs in great numbers around cider presses, packing sheds, orchards, and other situations where fermenting fruit is present: within the latter it deposits its eggs and its larvac develop. Barrows' experiments were made with various constituents of fermenting fruit: ethyl alcohol, ethyl acetate and acetic and lactic acids were tested separately and in mixture. The insect was found to exhibit the maximum response to a mixture of ethyl alcohol of 20 per cent. strength and acetic acid of 5 per cent. It was further ascertained that cider vinegar, and fermented cider, contain alcohol and acetic acid in percentages closely approximating to those just mentioned. Subsequent investigators have deroted a considerable amount of attention to the repression of the house-fly by chemotropic means. Many highly complex food materials have been advocated as baits for trapping this insect, leaving the specific attractive constituents undetermined. Among individual reagents tested, low concentrations of ethyl alcohol (3 to 8 per cent.) and other alcohols are definitely attractive, while the addition of sugars is stated to enhance this property. Speyer (1920) found that alcohols, aldehydes and acids containing the methyl group $\mathrm{CH}_{3}$, and whose molecular weight is $\mathbf{3 0}$ or over, are positively chemotropic, especially when the methyl group is united to $\left(\mathrm{CH}_{2}\right)$ x. He suggests that the molecular group $\mathrm{CH}_{3}\left(\mathrm{CH}_{2}\right) x$ is the actual food stimulus concerned, but his experiments were of too restricted a character to be regarded as other than purely tentative. Imms and Husain (1920) tested a range of substances by means of field traps. Ethyl alcohol alone exhibited little or no chemotropic properties in various concentrations, but with the addition of small amounts of butyric, valerianic or acetic acids it exercised a powerful stimulus. Since dilute acids themselves did not prove attractive, the respective esters were probably the agents involved. Both sexes of species of Rhyphus, Sarcophaga, Calliphora and various Muscidæe and 
Anthomyidæ responded in large numbers. Roubaud and Veillon (1922) experimented with the attraction of simple products of fermentation with regard to nineteen species of flies. They found that sugars, non-fermented sugar products, alcohols and ammonia produced little or no positive reactions on the part of the insects. Among the various compounds resulting from organic fermentation the most attractive were ammonium sulphohydrate, ammonium valerianate, valerianic acid and trimethylamine. Peterson (1924) found that fermenting yeasts were highly attractive to the flies Hylemyia cilicrura and $H$. antiqua, probably, as he remarks, on account of the alcohols and ethereal odours produced. Various alcohols, added to honey and water, proved powerfully attractive, especially alyl alcohol and isopropyl alcohol. A number of other papers of a kindred nature to the foregoing have appeared, and the results obtained indicate the complexity of the subject. By no means all the substances tested induce feeding reflexes, and in many cases the significance of the responses is unknown-they appear to be non-purposeful in that they are unconnected with any vital functions. There are other instances where certain compounds have been shown to exercise an influence in connection with oviposition. Both Roubaud and Veillon, and Richardson, have pointed out that the female house-fly, for example, is attracted to the manure heap for purposes of egg-laying, feeding mainly taking place elsewhere. The part performed by chemical stimuli in inducing oviposition has been discussed by Richardson (1925), who gives reasons for concluding that, in the house-fly, ammonia is one of the volatile constituents of the manure heap that is important in this respect. Crumb (1924) has published the results of experiments showing that the addition of hydrogen sulphide, old yeast infusion, methane or stale urine to water, in each case, tends to induce oviposition in the mosquito Culex pipiens. Ordinary tap water, used as a control, exercised no influence.

There are, again, other examples where specific compounds have proved attractive to the male sex only. This was well shown in the important experiments of Howlett (1912), dealing with the reactions of certain Indian fruit-flies. He found that citronella oil 
excrcises a remarkable attraction for the males of Dacus diversus and $D$. zonatus, and suggested that possibly this reagent is allied to a secretion emitted by the females, and that the phenomenon of the male alone being attracted is to be regarded as a reproduction, by artificial means, of a sexual attraction similar in kind to that which operates in most cases of " assembling." In a later paper (1915) Howlett conducted a further series of experiments, confirming his previous results that certain odours are remarkably attractive to male flies of the genus Dacus and that, by the employment of attractive substances, the movements of the flies can to a great extent be controlled in any direction. Three of the common species ( $D$. diversus, ferrugineus and zonatus) normally breed respectively in (1) anthers of Cucurbitaceæ, (2) fruits of Solanaceæ and mango, and (3) peach, guava, mango and other fruits. $D$. diversus ( 1 ) is most strongly attracted by iso-eugenol, zonatus by methyl-eugenol, and ferrugineus (2) by both iso- and methyl-eugenol. The odours of these substances have not yet been identified with those of the plants which constitute the normal breeding places, but male flies have been found attracted to mango, papaya, a Cycad and Colocasia, plants with a very characteristic smell similar to that of eugenol-derivatives. Females have never been seen to frequent these places or to breed in them, but more extended observation on this point is needed. Three explanations suggest themselves. (a) That the smell is a direct sexual guiding smell, emitted by the female, as previously suggested, but, nevertheless, the young crushed females were not found to attract males. (b) The smell is not emitted by the female, but may be termed an "indirect" sexual guide to the plants where the females are accustomed to congregate for breeding purposes. Under these circumstances it is difficult to see why females should not be attracted by the odoriferous chemicals. (c) The odour is a food smell ; if this be so it can only be attractive to males. None of these fundamental questions has so far been solved, but, nevertheless, Howlett's researches have proved a landmark on the applied side of the subject, and have indicated some of its possibilities. Mention needs also to be made of the work of the Severins (1914), who followed up the reactions of another species 
of fruit-fly, viz., Ceratitis capitata. They showed that certain mineral oils, including kerosene, naphtha and benzene, similarly exercise a powerful chemotropic attraction for the males of this species. The significance of the phenomenon, however, remains unexplained.

Practical measures designed to exploit the reactions of insects to chemical stimuli afford abundant promise of extended application. Much of the data at present available, however, is of a purely tentative character. It is too heterogeneous and scanty to allow of any fundamental conclusions being drawn. We know as yet, for example, very little with respect to the relations between chemical constitution and the attractive properties of different compounds. An indication of possibilities in this direction, however, has been given by Cook (1926), but his results are marred by the fact that, although about 50,000 insects were involved in his experiments, their specific identities are unstated. The discovery of chemical attractants is only one aspect of the problem. Due cognisance needs to be taken of the fact that reactions to such substances are only the end-results of a series of interacting stimuli. On the one side are external factors, including temperature, humidity and light, and on the other are the internal physiological states of the insects themselves.

The preliminary study of the reactions of insects in the laboratory under properly controlled conditions is obviously an important aspect of any work designed to exploit the subject from an economic standpoint. A variety of instruments or " olfactometers" has been used. One devised by McIndoo (1926) has already been referred to. When investigating blowflies this worker used an instrument of different pattern (McIndoo, 1933) and partly made of wood. Other kinds have been described by Barrows (1907) in connection with experiments with Drosophila: by Ripley and Hepburn (1929) in their studies with the South African fruit-fly Pterandus rosa: by Hoskins and Craig (1934) with reference to Lucilia : and by Marshall (1935A) for the hive bee. Some of these instruments show obvious disadvantages: either they are too slow in operation or give inconclusive results, or are not easily washed and rendered inodorous. Also, the 
conditions under which the tests were carried out were not always above criticism. The reader who is interested in this aspect of the subject is advised to consult the papers by Hoskins and Craig and by Marshall.

Reactions to Light. In many countries practical entomologists have made use of light traps as a means for the quantitative attraction and destruction of noxious species of Lepidoptera, and in some cases of Coleoptera also. These traps are usually so constructed that insects flying to the light fall into a surrounding receptacle containing either oil, or water covered by a film of oil. On the whole, the results derived from the application of this method cannot be regarded as commensurate with the trouble and expense involved. In temperate countries the success of such a method, as with chemotropic traps, is considerably influenced by meteorological conditions. Temperature, for example, is significant in that when it falls below certain limits, varying according to the time of the year and the species concerned, phototropic responses almost cease. Such factors as precipitation, general humidity, wind, etc., appear to exercise a variable effect, but little has been determined with regard to their respective influences. In the tropics, on the other hand, where much more uniform conditions prevail, such variable factors are far less in evidence. It is frequently claimed that the preponderance of male insects that are attracted discounts the value of light traps. A further disadvantage that has been emphasised is that the female insects have, for the most part, already deposited a quota of their eggs before being trapped. In some cases these drawbacks are obviously well founded, but in others premature conclusions have been drawn on account of insufficiency of experimental data. Due allowance needs to be made for the fact that the males of a number of species tend to appear earlier in the season than the females. Also, cases are known where the males are on the wing during one part of the night, and the females during another. There seems, also, little doubt that more can be done towards improving the efficiency of the light source itself. More attention needs to be given to light rich in violet and ultra-violet rays (vide p. 121). In this connection it may be added that very large 
catches of moths have been recorded by Neustadt (1913), using incandescent lamps containing mercury vapour, in which these component rays were well represented.

More or less detailed analyses with respect to the species of Lepidoptera attracted to light traps, the proportions of the sexes represented and other data will be found in publications by Willcocks (1916), Criddle (1918), Ainslie (1917), Shiraki (1917), Turner (1918, 1920), Ballard (1923), Theobald (1926), Husain and Khan (1934), and others. For the most part the results recorded by these observers are not encouraging, but in some cases the experiments were far too inadequate to be conclusive. Shiraki, however, has obtained promising results from the use of light traps with reference to the paddy borer moth (Schoenobius incertellus) in Formosa. He records five years' observations, and during this period many thousands of individuals were captured by the method in different localities. In practically all cases his figures show a great preponderance of females, although at the time of the commencement of the emergence of each generation of moths, more males than females responded. Shiraki's observations are supported by those of Ballard (1923) in India, who likewise demonstrated that an enormously greater number of female moths of this species, as compared with males, are caught by means of light traps. He also showed that out of 13,640 trapped females, 35.5 per cent. had previously laid their eggs before being caught. Theobald (1926) has recorded the results of two years' experiments in England, and concluded that acetylene lamps are beneficial in destroying Tortrices in orchard districts where these pests are serious. Unlike some observers, he fcund that no objection could be raised against light traps on the grounds that large numbers of beneficial insects were destroyed at the same time.

Husain and Khan (1934) carried out investigations with light traps in the Punjab with reference to the Pink Bollworm Moth (Platyedra gossypiella), which is a well-known pest of cotton. After enumerating certain disadvantages attendant upon the use of this method, they concluded that a light trap, instead of minimising attacks in the field where the trap was stationed, only concentrated 
moths from adjoining fields and thus intensified the attack in the area concerned.

The use of light traps for the destruction of injurious Coleoptera has been principally applied against members of the Scarabæidæ, more especially the genus Lachnosterna. Sanders and Fracker (1916) record the great attraction artificial light has for various species of this genus. During May and June, 1914, 440,000 examples were captured by this means in a single locality, while forty light traps in five localities captured 1,036,400 of the beetles. The males caught greatly exceeded the females in number, but in some of the commoner species females formed a larger proportion earlier in the season. In Porto Rico, Van Zwaluwenburg records the attraction of large numbers of Lachnosterna to light, the sexes responding in about equal numbers, and he estimates that only about 17 per cent. of the females had completed oviposition at the time of capture.

An investigation of the activity and frequency of insects based upon those caught in light traps has been carried out for several years by Williams $(1935,1936)$ at the Rothamsted Experimental Station. In the analysis of the figures obtained it was demonstrated that, taking all insects together, the maximum number was trapped at the beginning of the night with a steady decline towards the morning. The Diptera, which composed about 76 per cent. of the total, showed a maximum in the first part of the night and the Lepidoptera, which formed 16 per cent. of the total, were caught in largest numbers in the second to fourth periods-the night being subdivided into eight periods of equal length. When there is a marked difference in respect to the number of individuals of each sex, the females appeared earlier in the light trap than the males. The total captures of insects in two successive years exceeded 100,000 specimens per year, so the numbers appear to be sufficient to warrant the deductions drawn. An examination of the insects captured during three successive years was made in order to test the validity of the general belief that the nocturnal activity of certain kinds of insects is reduced at full moon. The analysis had special reference to the Noctuidæ, and it was considered that the lunar effect on the captures at a light trap 
had been demonstrated. The opinion is advanced that a physiological effect on the insects is involved and that a reduction in the efficiency of the trap when the moon is shining is not the explanation. Further experiments to test this conclusion are being carried out by using traps not dependent upon light as the source of their attracting power.

The use of light traps for determining the population density of the Rice-Borer by Harukawa, Takato and Kumashiro (1935) has not proved reliable over a period of years. The larvæ may become very abundant even when the moth population, as determined by light traps, is not very large or, in other words, the larval population is not proportional to that of the number of moths captured. The light trap captures, therefore, are not a trustworthy index of the abundance of larvæ to be expected in the next generation. The population density can be best determined by collecting injured rice haulms and by direct counting of the larvæ found.

The reactions of insects to colour (vide also p. 113), apart from questions of light intensity, have certain practical applications, and merit more extended study than has been accorded to them. Nuttall showed many years ago that mosquitoes have a marked tendency to congregate and rest on a dark blue surface--a fact which has led to certain practical developments. Lloyd (1921) demonstrated that the white-fly Asterochiton vaporariorum is powerfully attracted to a yellow colour, while Folsom and Bondy (1930) found that applications of calcium arsenate dust to cotton plants are often followed by heavy infestations of Aphis gossypii. One of the factors operating in this case was found to be due to the positive phototropic reaction of the winged aphides to the white deposit of calcium arsenate on the plants. Other white dusts, such as calcium carbonate, starch or flours, were also found to induce a similar response on the part of that insect. In tropical Africa the method of trapping tsetse-flies, on tanglefoot screens attached to moving automobiles, appears to offer room for exploration with respect to the colour surfaces most attractive to those species.

Concluding Remarks. Reactions to chemical stimuli, and to 
light rays, are the only reflex responses of insects that have been found to lend themselves to practical utilisation to any considerable extent. It has been shown that chemotropic responses afford a highly promising field for exploration, while, on the other hand, the phototropic responses of insects have so far yielded less encouraging results. It is unlikely that matcrial advances will come from the application of existing methods of utilising these, or other phases of insect behaviour, until much more thorough exploration of their fundamental aspects has been undertaken. Up to the present so many of the experiments have neglected to take into account the numerous interacting factors involved. Until their influence can be adequately evaluated the empirical methods, so far practised, are scarcely amenable to material improvement. Properly controlled experiments, using the most scientific equipment available, afford the only sure method of obtaining knowledge capable of being turned to practical advantage.

\section{A. The General Subject}

\section{Literature}

Berlese, 1909. "Gli Insetti." Milan.

von Frisch, 1924. "Sinnesphysiologie und 'Sprache' der Bienen." Berlin. Loeb, 1918. "Forced Movements, Tropisms and Animal Conduct." London and Philadelphia.

McIndoo, 1926. Journ. Agric. Res., XXXIII., 1095.

1929. Smithsonian Misc. Coll., LXXXI., No. 10.

Sinler, 1924. Zool. Jahrb., Abt. Anat. Ont., XLV., 519.

SNodgrass, 1926. Smithsonian Misc. Coll., LXXVII., No. 8.

Voget, 1923. Zeits. wiss. Zool., CXX., 281.

WheEler, 1928. "The Social Insects." London.

\section{B. The Eyes and Light Perception}

Bertholf, 1931. Journ. Agric. Res., XLII., 379 ; XLIII., 703.

1932. Zeits. vergl. Physiol., XVIII., 32.

BOZLER, 1925. Ibid., III., 145.

BUdDENBROCK, 1931. Ibid., XV., 597.

Buddenbrock and Schultz, 1933. Zool. Jahrb., Abt. Physiol., LII., 513.

Ellsworti, 1933. Ann. Ent. Soc. Am., XXVI., 203.

Eltringhay, 1919. Trans. Ent. Soc., 1.

Friedrich, 1931. Internat. Ent. Zeits., XXV., 326.

von Frisch, 1914. Zool. Jahrb., Abt. Physiol., XXXV., 1.

Gaffron, 1934. Zeits. vergl. Physiol., XX.

Glaser, 1925. Psyche, XXXII., 285.

Hertz, 1931. Zeits. vergl. Physiol., XIV., 629.

1933. Biol. Zentralb., LIII., 10.

1934. Zeits. vergl. Physiol., XXI., 579.

1935. Die Natureiss,, XXXVI., 618. 
Ilse, 1928. Zeits. vergl. Physiol., VIII., 658. 1933. Ibid., XVII.

KNols, 1921-26. "Insekten und Blumen." Wien.

Kugler, 1930. Planta, X.

KüHN, 1927. Zeits. vergl. Physiol., V., 762.

Müller, 1931. Ibid., XIV., 348.

Peterson and Heussler, 1928. Ann. Ent. Soc. Am., XXI., 353.

Priebatsch, 1933. Zeits. vergl. Physiol., XIX., 453.

SANDER, 1933. Ibid., XX., 267.

SCHLEgTENDAHL, 1934. Ibid., XX., 545.

Schlieper, 1927. Zeits. vergl. Physiol., XX., 267.

Urban, 1932. Zeits. wiss. Zool., CXL., 291.

Vigier, 1904. C. R. Acad. Sci., CXXXVIII., 775.

Wheeler, 1936. Biol. Bull., LXX., 185.

Wolf, 1933. Zeits. vergl. Physiol., XX., 151.

Zerrain, 1933. Zeits. roiss. Zool., XX., 117.

\section{Chemical Stimuli and their Receptor Organs}

Аввотт, 1928. Psyche, XXXV., 201.

Anderson, 1932. Journ. Exp. Zool., LXIII., 235.

Bugnion and Popoff, 1911. Archiv. Zool. Exp., 5 ser., VII., 664.

Cirystal, 1930. Oxford Forestry Memoirs, No. 11.

Crow, 1932. Physiol. Zool., V., 16.

Eltringham, 1933. Trans. Roy. Ent. Soc., LXXXI., 33.

von Frisch, 1921. Zool. Jahrb., Zool. u. Physiol., XXXVIII., 449.

1927. Naturwiss., XV., 321.

1928. Ibid., XVI., 307.

1930. Ibid., XVIII., 169.

Glaser, 1927. Psyche, XXXIV., 209.

Kunze, 1927. Zool. Jahrb., Abt. Zool. u. Physiol., XLIV., 187.

Marshall, 1935. Trans. Roy. Ent. Soc., LXXXIII., 49. 1935A. Journ. Exp. Biol., XII., 17.

McINDoo, 1914. Journ. Exp. Zool., XVI., 265.

1916. Smithsonian Misc. Coll., LXV., No. 14.

1933. Journ. Agric. Res., XLVI., 607.

1934. Journ. Morph., LVI., 445.

Minnich, 1921. Journ. Exp. Zool., XXXIII., 173.

1922. Ibid., XXXV., 57.

1922A. Ibid., XXXVI., 445.

1924. Ibid., XXXIX., 339.

1926. Biol. Bull., LI., 166.

1926A. Anat. Record., XXXIV., 126.

1929. Zeits. vergl. Physiol., XI., 1.

1931. Journ. Exp. Zool., LX., 121.

1932. Ibid., LXI., 375.

Newton, 1931. Quart. Journ. Mic. Sci., LXXIV., 647.

Ripley and Hepburn, 1929. Dept. Agric.'S. Africa., Ent. Mem., VI., 55.

VAlentine, 1931. Journ. Exp. Zool., LVIII., 168.

WeIs, 1930. Zeits. vergl. Physiol., XII., 206.

D. Chordotonal Organs and Reactions to Vibrations

Аввотт, 1927. Psyche, XXXIV., 129.

BaIER, 1930. Zool. Jahrb., Abt. Allg. Zool., XLVII., 151.

Barnes, 1930. Journ. Gen. Psych., II., 318.

1931. Ann. Ent. Soc. Am., XXV., 824. 
Eggers, 1919. Zool. Jahrb., Anat. Ont., XLI., 272.

1923. Zool. Anz., LVII., 224.

1928. "Die Stifführenden Sinnesorgane." Zool. Bausteine, Bd. II.,

Heft 1. Berlin.

Hagemann, 1910. Zool. Jahrb., Anat., XXX., 394.

Hertweck, 1931. Zeits. rviss. Zool., CXXXIX., 559.

Hess, 1917. Ann. Ent. Soc. Am., X., 63.

MAYer, 1874. Amer. Nat., VIII., 577.

Minnich, 1925. Journ. Exp. Zool., XLII., 443.

Myers, 1929. " Insect Singers." London.

Pumphrey and Rawdon-Silth, 1936. Proc. Roy. Soc. B., CXXI., 18.

Slifer, 1936. Ent. Neres, XLVII, 174.

Vogel, 1923. Zeits. Anat. u. Entwicklungs., LXVII., 190.

Wever and Bray, 1933. Journ. Cell. Comp. Physiol., IV., 79.

\section{E. Stimulatory Organs}

Bozler, 1926. Loc. cit. (p. 168).

Buddenbrock, 1919. Pflüger's Archiv., CLXXV., 125.

1924-28. "Grundriss der vergleichenden Physiologie." Berlin.

Wigglesworth, 1934. Journ. Exp. Biol., XI., 120.

WOLSKY, 1933. Biol. Rev., VIII., 370.

\section{F. Reflex Behaviour and Practical Entomology}

Ainslie, 1917. Journ. Econ. Ent., X., 114.

Ballard, 1923. Mem. Agric. Dept. India, Ent. Series, VII., No. 10.

Barrows, 1907. Journ. Exp. Zool., IV., 515.

Соок, 1926. Journ. Agric. Res., XXXII., 347.

Criddle, 1918. Canad. Ent., L., 73.

Crunb, 1924. Ent. News, XXV., 242.

Folsom and Bondy, 1930. U.S. Dept. Agric., Circ. 116.

Fowler, 1927. Journ. Dept. Agric. S. Australia, XXXI., 480.

Frost, 1928. Journ. Econ. Ent., XXI., 339.

Harukawa, Takato and Kumasmiro, 1935. Berohara Inst. f. Landwirts. Forsch. in Kuraschiki, VI., 1.

Howlett, 1912. Trans. Ent. Soc. London, 412.

1915. Bull. Ent. Res., VI., 297.

Husain and Khan, 1934. Ind. Journ. Agric. Sci., IV., 261.

Imis and Husain, 1920. Ann. App. Biol., VI., 269.

LLOYD, 1920. Ibid., VII., 66. 1921. Bull. Ent. Res., XII., 355.

McINDOo, 1926. Journ. Econ. Ent., XIX., 545.

1927. Journ. Agric. Res., XXXIII., 1095.

1928. Journ. Econ. Ent., XXI., 903.

Neustadt, 1913. Journ. d'Agric. trop., January 31st.

Peterson, 1924. Journ. Econ. Ent., XVII., 87.

1925. Ibid., XVIII., 181.

1927. Ibid., XX., 174 .

Power and Chesnut, 1925. Journ. Am. Chem. Soc., XLVII., 1751.

Richardson, 1925. Bull. 1324, U.S. Dept. Agric.

Richmond, 1927. Proc. Ent. Soc. Washington, XXIX., 36.

Roubaud and Veillon, 1922. Ann. Inst. Pasteur, XXXVI., 752.

SANDERS and Fracker, 1916. Journ. Econ. Ent., IX., 253.

Severin and Severin, 1914. Journ. Anim. Behav., IV., 223.

Shinaki, 1917. "Paddy Borer, Shoenobius incertellus," Taihoku Agric. Expt, Sta, 
Speyer, 1920. Ann. App. Biol., VII., 124.

Stear, 1928. Journ. Econ. Ent., XXI., 565.

Theobald, 1926. Journ. Roy. IIortic. Soc., LI., 314.

Turner, 1918. Journ. Agric. Res., XIV., 135.

1920. Ibid., XVIII., 475.

Verschaffelt, 1910. Amsterdam, Proc. Sci. k. Akad. Wet., XIII., 536. (English.)

Willcocks, 1916. "The Insect and Related Pests Injurious to the Cotton Plant." Cairo. 314.

Williams, 1935. Trans. Roy. Ent. Soc., LXXXIII., 523.

1936. Phil. Trans. Roy. Soc. B., CCXXVI., 357.

Yothers, 1927. Journ. Econ. Entom., XX., 567. 


\section{CHAPTER VII}

\section{THE FUNDAMENTAL ASPECT OF COLORATION}

Structural Colours, p. 172. Diffraction, p. 174; Interference, p. 175; Scattering of Light by Minute Particles, p. 179; Selective Reflection, p. 180. Pigmentary Colours, p. 183. 1. Chlorophyll and other Derived Pigments, p. 183; 2. Hamoglobin and Allied Pigments, p. 189 ; 3. Pigments of Protein Origin, p. 190 ; 4. Pigments with Purine Bases, p. 193. Combination Colours, p. 194. Further Remariks on Insect Coloration, p. 195. Literature, p. 203.

INSECT coloration has attracted a large amount of attention from biologists in connection with the relations of both the individual and the race to the environment. Extensive recourse has been made to the amazing variety of colour patterns and markings of insects with the aim of adding fresh arguments bearing upon the central doctrine of natural selection. The relations of colour phenomena to current biological theories have been repeatedly discussed, and consequently it is not intended to deal with this aspect in the present chapter. Attention will be more especially directed to recent research bearing upon the fundamental phenomena of insect colours and pigments, their derivation, and their significance in the physiological processes of the individual.

It is well known that insect colours fall very naturally into three groups : (1) structural or physical colours, (2) pigmentary or chemical colours, and (3) combination or physico-chemical colours.

\section{Structural Colours}

Structural colours are often extremely difficult to clucidate, and the findings of recent research have not in all cases been in general agreement.

White is usually the result of the scattering of light by reflection 
and refraction by minute structural details exhibited in the scales or other cuticular parts. As Mason (1926) observes, whenever we have practically colourless cuticle, in such a form as to present many more or less unordered reflecting surfaces, whiteness is produced. All whites in insects are ultimately explainable upon a purely structural basis. Proof of this is afforded by the fact that if the air in contact with the parts in question be replaced by a colourless liquid, whose refractive index closely approximates to that of chitin (i.e., $n=1.55-1 \cdot 6$ ), whiteness disappears ; after removal of the liquid and drying the white appearance becomes fully restored. In the white Pierine butterflies, Hopkins showed, a number of years ago, that uric acid becomes stored in the wing scales of certain of these insects, and he regarded the phenomenon as an example of an excretory product functioning as a colour producer. According to Mason, the white Pierine butterflies form no exception to the rule that whiteness is a structural feature only. Although uric acid is white, and might well function as a pigment when finely divided, he states that it plays only a very minor part in producing the white appearance of the butterfly scales. He mentions that, after such solvents as dilute alkalies have dissolved out the uric acid, the white remains undiminished after the wings have been washed and dried. On the other hand, a white Pierine wing becomes transparent when submerged in liquids of the appropriate refractive index. He therefore concludes that, in so far as whiteness is concerned, the presence or absence of uric acid is of little importance.

A variety of possible causes has been regarded as responsible for the production of "metallic" or iridescent colours, and the subject has been treated at length by Onslow (1921), and more recently by Suffert (1924), and by Mason (1927). The theories which have been advanced fall under four categories.

1. Diffraction of light at the surface of a grooved structure or "grating."

2. Interference of light at the surfaces of single or multiple "thin films."

3. Scattering of shorter light-waves by minute particles smaller in diameter than the waves themselves. 
4. Selective reflection of light from extremely opaque highly reflecting surfaces.

The history of the subject need not detain us here, but those who are specially interested should refer to Onslow's paper previously mentioned. The phenomena involved are so diverse, and the wealth of material for study so immense, that the tendency to generalisation involving the application of any one single theory to account for all cases is beset with pitfalls.

Diffraction. The scales of most insects, whether iridescent or not, bear striations parallel to their long axes and numbering almost anything between 4,000 to 16,000 to a centimetre. Onslow has described a method of taking scale impressions on colourless collodion films, by which the effect of any surface pattern can be analysed and isolated from colours produced in other ways. These replicas show that the upper surfaces of most scales give good "gratings." Onslow's observation that all insects, the impressions of whose scales yield spectra, do not themselves necessarily exhibit iridescence makes it doubtful whether diffraction is ever a main source of colour, especially as he found that the brilliant scales of the butterfly Morpho cypris, and others with the same structure, give an almost flat impression. It is also noteworthy that the changing colours of the unpigmented wings of dragon-flies and other insects cannot be explained upon the basis of a diffraction grating, since striæ are entirely wanting in these cases. The conclusions of Onslow, Suffert, and Mason are contrary to any idea that diffraction plays much part in insect coloration. That it may be responsible in certain special cases, however, cannot be excluded. Mason (1927), who is a very decided opponent to diffraction being an explanation of iridescence, states that an exception occurs in the Lamellicorn beetle Sericea sericea. The elytra of this insect show brilliant iridescence in direct sunlight and much less in ordinary light. The variations in iridescence under different tests have led him to look for some oriented structure as the cause of the phenomenon. This was found in the presence of fine strix running transversely to the length of the elytra. The striæ are shallow $(0.5-1.0 \mu)$ and very evenly spaced apart $(1-1.5 \mu$ or about 20,000 per inch). 
Collodion impressions retain the same pattern, and the iridescence exhibited by these impressions is as good as that shown by the insect itself. All the properties exhibited are in accord with those of diffraction gratings and are not manifested by thin films or any other colour-producing structure known.

Interference. The majority of recent investigators are in favour of the interference theory as being the one which explains by far the largest number of cases of iridescent colours. In the wings of many insects colours are exhibited which recall the iridescence of soap bubbles. It is obvious that these colours are structural, since they prevail not only in entirely unpigmented wings, but also in pigmented wings after subjection to bleaching. When examined by transmitted light, an iridescent insect wing exhibits only very pale hues which are complementary to those shown in the same area by reflection. Immersion in liquids of the correct refractive index largely destroys such colours, which become restored after thorough washing and drying. The iridescence is not destroyed by the separation of the upper and lower wing lamellæ, while collodion impressions of either surface show no iridescence. Mason, who has paid some attention to iridescent wing membranes, concludes that the phenomenon is explainable on the basis that the colours are due to multiple thin films separated by material of slightly different refractive indices. He maintains that microscopical demonstration of an actual laminated structure in the upper or lower cuticle is hardly to be hoped for, since the thinness of the films as calculated (circa $0 \cdot 2 \mu$ ) must be about at the limit of resolution. Great difficulties would be involved in making microscopical preparations sufficiently reliable to avoid the possibility of spurious diffraction images. He concludes, therefore, that optical tests are more reliable, in this case, than histological study, and it may be added that the tests as applied by him afford definite support to his conclusions.

The explanation of scale iridescence is not so obvious as in the case of wing-membranes, and the subject has received a good deal of attention by all writers on the structural colours of insects. The striking resemblances between the optical properties of insect scales and of thin, colour-producing, artificial films, can be substantiated 
by detailed comparisons. Also, the histological evidence afforded by scale-structure is consistent with the optical phenomena exhibited.

Mason points out that the colours of the scales are readily recognised by comparison with artificial thin films, as corresponding to those of Newton's series, in the second or third orders. This relationship is confirmed by the change in hue which takes place with increasing angle of incidence. In every case this is towards a colour lower in order (change towards violet, the colour lowest in the second order), and duplicates

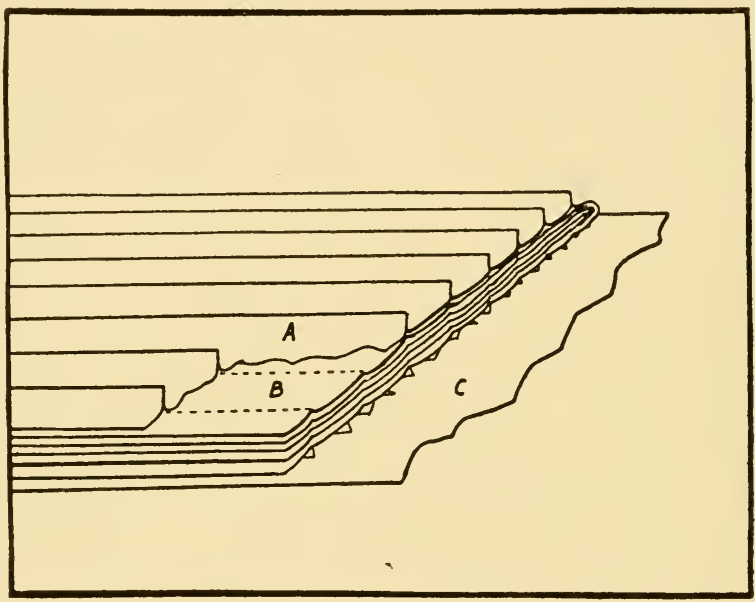

Fig. 63. Scale of Urania type (schematic). A, thin vanes or ridges comprising longitudinal striations. B, multiple films, the seat of the colour. C, lower lamella. (After Mason.)

that of an artificial thin film held parallel to the reflecting surface of the scale. The colour produced by swelling a scale is predictable in all cases as that corresponding to an increase in order (thicker film), while by compressing a scale the colour changes are predictable in all cases as corresponding to a decrease in order (thinner film). The destruction of colour where extreme pressure is applied to the scale corresponds to bringing the lamellæ into optical contact. The loss of iridescence and metallic lustre, when a scale is permeated by a liquid of its own refractive index, corresponds to that of thin films under similar conditions. The fact that liquids markedly higher or lower in refractive index do not cause total loss of colour is also consistent. The existence of lamellæ, more or less parallel to the plane of the scale, is borne out at the fractured edges of scales : distorted sections, furthermore, may show the lamellæ separated. Penetration by a viscous liquid is not immediate, but tends 
to proceed in layers, as if it were filling inter-lamellar spaces. The dimensions of the colour-producing structure are consistent with the foregoing data, the lamellæ of which would only be about 0.3 to $0.5 \mu$ in maximum thickness : there is space for a number of such films in any of the specimens examined.

Iridescent scales as studied by Mason are grouped by that observer into three main types, each of which owes its colour to multiple films separated by air, viz. :-

1. The Urania type, in which the colour-producing lamellæ are

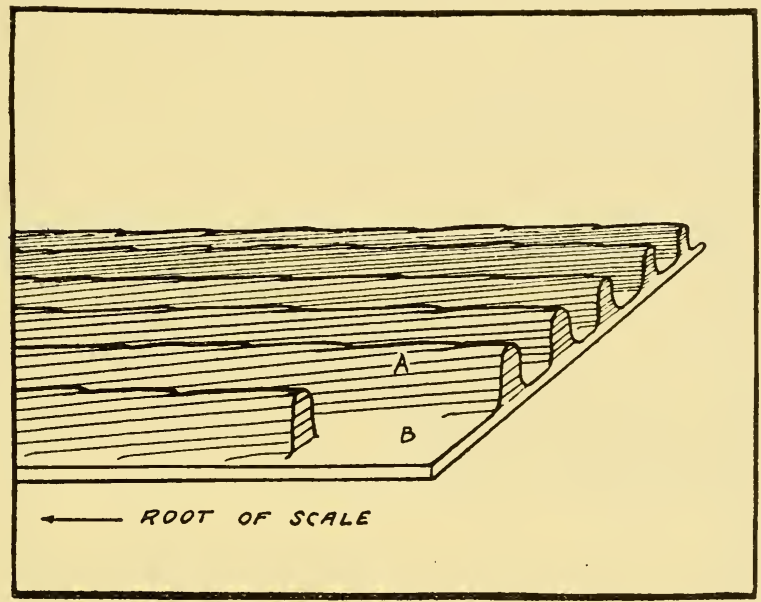

Fig. 64. Scale of Morpho type (schematic). A, longitudinal vanes, consisting of inclined multiple films, the seat of the colour. B, basal layer. (After Mason.)

parallel to the plane of the scale and may be overlaid by a ribbed or meshed structure (Fig. 63). The multiple films may reside in either the upper or the lower lamina of the scale; their plane is that of the scale itself, and their optical properties are consistent with that of a system of multiple thin films. The superposition of a ribbed (vaned) or meshed structure on the outer surface of the upper lamella of the scale modifies the visibility of the film colours, but does not prevent the recognition of their typical properties. This type was recognised by Onslow, prior to Mason, and these two authorities are in agreement as to its chief features. 
2. The Morpho type, in which the lamellæ are situated in the vanes (or ribs) and are inclined towards the base of the scale (Fig. 64). This type of structure has been demonstrated very convincingly by Suffert. A brilliant highly metallic blue is the prevailing colour, and, according to the last-mentioned observer, it is connected with the peculiar reflecting properties of the individual ribs, since it shows its full intensity and lustre on an isolated rib or on ribs which have become laterally twisted, and

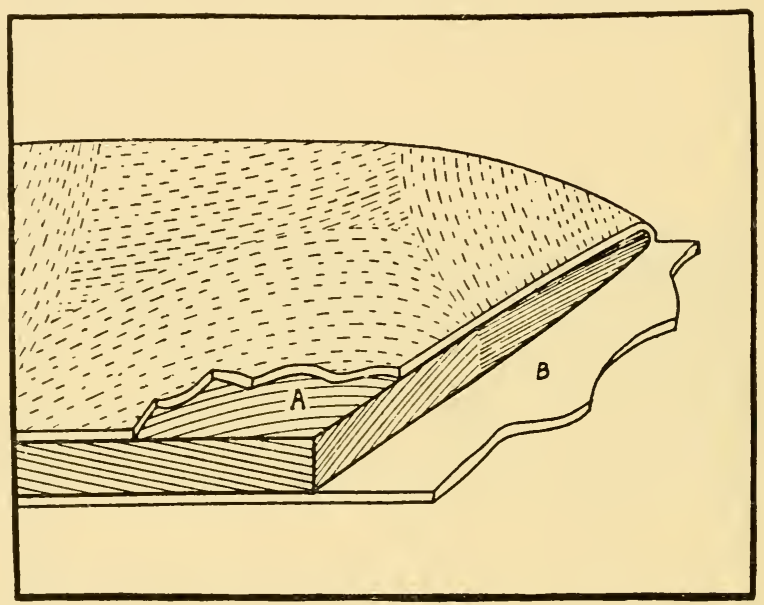

FIG. 65. Scale of Entimus type (schematic). A, multiple thin films, the seat of the colour. B, cuticle enclosing lamellar structure. (After Mason.)

consequently does not depend on their arrangement or proximity to other ribs on the scale. Onslow, who paid a large amount of attention to scales of this type, concludes that in the arrangement of the ribs they show a regular periodic structure of the correct theoretical magnitude; the thickness of the ribs and of the airfilms between them varies from one to three half wavelengths. In other words, he claimed that the ribs and the air layers between them behaved as multiple films placed on edge. He did not apparently recognise the lamellar structure of the individual vanes or that a single rib is capable of giving the full colour. Mason, who 
is in agreement with Suffert, consequently does not accept Onslow's explanation, and points out that the ribs, seen flatwise, produce no colour, although in this position they should give maximum brilliancy according to Onslow's theory.

3. The Entimus type (Fig. 65), where the lamellæ fill the interior of scale, and are inclined in different directions in sharply defined areas, with the result that corresponding colour patches are exhibited. This type is prevalent in the Diamond beetles Entimus and Cyphus, and previous observers, including Biedermann and Mallock, regarded the colour as being due to the presence of thin films. Michelson (1911) concluded, on the other hand, that since the colours exhibited by these scales are so varied and bright, and change so rapidly with varying incidence, the effect must be due to diffraction caused by a grating-like structure on the interior surface of the scale. He calculated that there were from 5,000 to 10,000 striæ per centimetre, a figure which agreed with actual counts made under a magnification of 1,000 diameters and oblique reflected illumination. Under these conditions the striæ appear clearly defined in small patches. It was necessary, in order to satisfy his theory, to postulate that the grating structure is of an asymmetric saw-tooth type, since all the light is concentrated in one spectrum. Onslow comments upon the fact that Michelson's explanation of the vivid colouring of Entimus is supported by the similarity between these scales and certain artificial saw-toothed gratings; nevertheless, he does not wholly accept the diffraction theory. He finds evidences of stratification clearly displayed in some of his microscopical sections in addition to the vertical striæ already alluded to. $\mathrm{He}$ then proceeds to discuss certain objections to Michelson's views, and concludes that, although diffraction may participate in producing the colour phenomenon observed, it is not the sole cause, and interference by thin films also plays a part. Mason holds that the multiple film theory alone affords the true explanation. and for the theoretical and experimental evidence upon which his conclusion is based the reader is referred to his original paper (1927A).

Scattering of Light by Minute Particles. This familiar 
phenomenon, so well exhibited in the blue of the sky, and in other common features of Nature, was first explained by Tindall in 1869, when he showed that finely divided particles of a transparent substance possess the property of scattering light. If white light penetrates a system composed of minute particles, immersed in a medium of different refractive index to their own, the scattered light will be blue, provided the diameter of such particles is small as compared with the wavelengths of light. Since such a system promotes the scattering of the short waves, the light is blue, while the longer red waves pass unhindered.

A number of investigators have regarded that blue produced in this manner contributes to the phenomenon of iridescence, especially in cases unexplainable by any of the more usual laws of optics. Recent research, however, has revealed very few cases that can be interpreted on this basis, and most blues are attributable to other causes. According to Mason (1926), the bluish "bloom" or efflorescence present on the bodies of certain dragon-flies, and less frequently on the wings, consists of particles in a fine state of subdivision. When wetted with a liquid of refractive index near $\mathbf{1 . 5}$ the particles become invisible and the dark integument, which they overlie, is revealed. Upon drying, the original appearance is restored. In the few cases investigated by him it was found that the bluish "powder" or efflorescence satisfied in a general way the main criteria required when light is scattered in the manner indicated.

Selective Reflection. Onslow devoted considerable attention to the highly metallic colours exhibited by many scaleless beetles and other insects. He was concerned with the question as to whether the colour is a surface effect or one due to interference. In his experiments with certain highly metallic beetles he ascertained that the colours do not disappear under pressure: on immersion in highly refractive fluids the reflected colours still persist : the transmitted colours, so far as they can be seen in the thin surface layer, also persist: the colour-producing layer appears to be so near the surface that no room is available for a suitable structure that might produce the colours observed : the colour changes, on reducing the thickness of the metallic layer by 
polishing an elytron with carborundum powder, are very abrupt and, in other respects, quite different from the colours of thin films. Onslow points out that single films have been shown to be very bright, but if the metallic colours of the insects in question are due to such films, it is essential to suppose that they are of an extraordinarily uniform thickness throughout, or the colour would not be the same all over. Moreover, the thickness in all individuals of a species must be the same, for the difference of a fraction of a wavelength would cause a considerable alteration, of colour, and it appears very difficult to conceive of an organic film complying with these requirements. He concludes that a layer of organic material, which acts like a film of a dye or of a metal, and gives rise to the metallic reflection, is a more conceivable means of colour production. $\mathrm{He}$ is, however, faced with the difficulty of not knowing how the surface layer is formed, but concludes that it is difficult to imagine how a periodic structure can arise in a homogeneous medium, about $0.5 \mu$ in thickness, during its extrusion to the exterior.

Mason (1927в) further discusses the subject of smooth iridescent integuments of the kind just referred to, and recognises the "metallic type," common in many insects, and the "enamelled type," seen in certain Cetoniid beetles. He comments upon the fact that no selectively reflecting material is known which does not absorb light very strongly and show any intense colour in very thin layers. The brilliant colour and lustre of specimens bleached to a pale straw colour, when viewed by transmitted light, is utterly at variance with the properties of substances which exhibit selective reflection. The idea that a small number of thin films is responsible for the observed effects is not inconsistent with the thickness of the material concerned, since he finds that in most specimens the colour layer exceeds $\mathbf{1} \mu$ in thickness. As with iridescent wing membranes, he concludes that lack of sufficient differences between the refractive indices of the presumed lamellæ renders it hopeless to expect to obtain their resolution under the microscope.

Notwithstanding their marked differences in lustre, Mason concludes that " enamel-like" integuments similarly are explainable 
on the multiple film theory, only the film layer is thicker in these cases. He remarks that the " colours and their changes, with angle of incidence, pressure, swelling or 'faults,' the complementary character of the transmission colours, and their low saturation, the loss of colour on penetration, after treatment with $\mathrm{HNO}_{3}$, the persistence after bleaching or in different light-all these criteria are fully satisfied and they could not be met by any other known type of structural colour." The existence of minute rod-like structures, which penetrate the cuticula perpendicular to the surface, modifies the properties of the multiple film layer: they increase the lustre and may impart a bluish-white appearance owing apparently to the scattering of light by the ends of the rods (about $0 \cdot 3 \mu$ in diameter) which function as individual particles. Mason's conclusions are in accord with those of Biedermann before him, but it may be said that neither the theory of selective reflection, nor that of multiple films, can be regarded as a fully established explanation of iridescent integuments. The problem, so briefly outlined here, awaits further evidence for its solution. Mason's contention that the existence of multiple films has to be tested by optical methods rather than by microscopical examination cannot be controverted. Nevertheless, it must be remembered that microscopical evidence of the existence of a given theoretical type of structure is of extreme importance. No very large amount of study has been directed to the histological aspects of the problem by way of applying refined methods of technique. In this respect the work of Suffert is a definite advance upon that of others, and he was able to show that definite stratification occurs in the scale-wall in species of Urania, Papilio and other genera, thereby satisfying theoretical requirements. He was also the first to make the important discovery that in scales of the Morpho type the ribs themselves actually show a stratified composition-a fact brought out by observation upon broken or split scale-ribs and by the use of polarised light. Notwithstanding Mason's belief to the contrary, some indication of lamination, if it exists, in iridescent insect integuments should prove capable of detection by the application of suitable technique to specially favourable types. 


\section{Pigmentary Colours}

Pigmentary colours in insects are of a diverse character and belong to very different groups exhibiting differences of origin and of chemical constitution. It is not intended here to enter into a detailed discussion of their nature and properties from the biochemical standpoint, but to refer to advances in knowledge of the more important pigments, and mainly from their biological aspect. For this purpose it is convenient to group the pigments of insects into four categories : (1) chlorophyll and other derived pigments ; (2) hæmoglobin and allied pigments ; (3) pigments of protein origin; and (4) pigments with purine bases. This grouping does not include all insect pigments, and certain others, either lesser known or of more restricted occurrence, have been omitted. The general subject of pigments in animals, treated both chemically and biologically, is well summarised by Verne (1926). The reader is referred to this handbook for an elementary treatise on the problems concerned and for a bibliography of their extensive literature.

1. Chlorophyll and other Derived Pigments. Included under this heading are those pigments which are absorbed from the food without undergoing very marked changes in composition. They are plant pigments which belong chemically to two very different groups. They include the carotins, anthocyanins and flavones, which have no nitrogen in their chromogenic nucleus, and the chlorophylls which have a tetrapyrollic nucleus.

The first impetus given to the study of the fundamental nature of insect pigments is due to Poulton (1893), whose experiments on the colours of Lepidopterous larvæ are familiar to entomologists. His work suggests that a modified chlorophyll, derived from plant chlorophyll, and xanthophyll occur in the blood and integument of caterpillars, and form the basis of their prevailing type of coloration. Spectroscopic examination of the blood, when compared with that of an extract of the colouring matter of the food-plant, showed an extremely close similarity in the two cases. Considering the chemical processes to which these pigments are subjected in the passage through the walls of the digestive canal 
to become incorporated with the protein constituents of the blood, the closeness of the spectral resemblances is specially remarkable. It is noteworthy that certain green caterpillars become colourless when fed upon parts of plants devoid of chlorophyll, but become green when access to green leaves is established.

In recent years great advances have been made with regard to our knowledge of the composition of chlorophyll, more especially through the researches of Willstätter and his co-workers. The green pigment or true chlorophyll consists of two components, both of which exhibit in solution a notable red fluorescence. The one, chlorophyll $a$, forms about 72 per cent. of the mixture, and is blue-green in alcoholic solution when viewed with transmitted light. The other, chlorophyll $b$, forms the remaining 28 per cent. ; it is yellow-green when viewed by transmitted light, and differs from chlorophyll $a$ in having two atoms less of hydrogen and an extra atom of oxygen. The yellow components of chlorophyll comprise an orange-yellow pigment known as carotin, which is a highly unsaturated hydrocarbon, and a second yellow pigment, xanthophyll, which is its dioxide.

Recent researches lend support to Poulton's main conclusions that many caterpillars are coloured by pigments derived from their food, which are absorbed into the blood without undergoing marked changes in their character. Whether the yellow pigment referred to by Poulton under the general term xanthophyll is true xanthophyll, or carotin, appears to be uncertain, and Palmer (1922) advances reasons for suggesting that the chief carotinoid pigment of Lepidopterous larvæ may be carotin. This substance is widely distributed among insects and is known to figure in the coloration of beetles of the families Coccinellidæ and Chrysomelidæ and in red-bugs or Pyrrhocoridx. Recent research has afforded further evidence of its presence in insects. The work of Palmer and Knight (1924A) indicates that the yellow and red coloration of the Pentatomid bug Perillus bioculatus is hypodermal, and largely due to the presence of secondarily absorbed carotin. This insect is predaceous in habit, and the favourite food of the adults and nymphs consists of the eggs and larvæ of the potato beetle (Leptinotarsa decemlineata) as well as the beetle itself. They 
were able to demonstrate that in the larva of the latter insect the blood is coloured deep orange by carotin derived from the potato plant. In the fresh blood of the beetle this pigment occurs in a concentration amounting to 0.0136 per cent., which is as high as that found in fresh green leaves. It is remarkable that no xanthophyll could be detected in the blood, since there can be scarcely any doubt that the green leaves of the potato plant are as well endowed with this pigment as other plants. It appears, therefore, that the Perillus, in the process of imbibing the blood of its prey, obtains the carotin which so largely contributes to its characteristic coloration. In both this bug and in its prey the yellow and red colours of the integument are due to differences in the degree of concentration of the same pigment. Knight (1924) has shown that temperature, by influencing the physiological processes during the active life of Perillus, indirectly affects the coloration of that insect. When reared at a temperature of $85^{\circ}$ to $95^{\circ} \mathrm{F}$. white forms are produced, while at temperatures below $78^{\circ} \mathrm{F}$. the red and yellow forms appear. When subject to the higher temperatures carotin is not deposited in the hypodermis, and the insects void chalky white excreta. Under these circumstances it appears that the carotin becomes oxidised, a fact which Palmer and others had previously noted to take place in animals having a high rate of metabolism. If white examples of Perillus be subjected to a relatively cool environment $\left(70^{\circ}\right.$ to $75^{\circ} \mathrm{F}$.) they discharge normal excreta-dark reddish, brown or black in colour, and at the same time commence to accumulate carotin in the hypodermal cells. Humidity, it appears, does not behave as an individual factor in the process, since it does not exercise notable effect upon the coloration of the insect. A relative humidity of 100 per cent. probably inhibits metabolism in various ways, particularly by slowing down physical activity, and in this way a greater deposition of carotin might be expected.

Evidence that xanthophyll plays a considerable part in insect coloration is by no means established, and experiments by feeding caterpillars on yellow maize, or other plants known to be rich in this pigment, are greatly to be desired.

In 1921 Gerould described a larval colour mutation in the Pierid 
butterfly, Colias philodice, in which the usual yellow-green coloration was replaced by blue-green. He concluded that some factor was involved which caused the yellow components of chlorophyll to become broken down or decolorised. By acting locally from the nuclei of the cells of the intestinal epithelium it changed the crude chlorophyll during its absorption into the blood. The result has been that a pigment derived from the blue-green component of chlorophyll, viz., chlorophyll $a$, is left intact and becomes the persisting colouring material. The eggs of imagines derived from blue-green caterpillars were pure alabaster-white, not the normal cream-white, an effect due to the absence of yellow pigment in the blood of the parent. The pupa is only slightly less blue-green than the larva; the exuviæ are white instead of the normal yellow. The wing colours of the adult, being due to uric acid derivatives, are not affected, but the eye colour is of a bluish-green rather than the normal apple green. A further point of great interest is that the cocoon colour of its parasite, Apanteles flaviconcho, is white instead of the usual yellow, and it thus appears that the lack of yellow pigment in the host affects the colour of the salivary secretion of its parasite. Gerould's work suggests, in the light of Poulton's observations, that the bluegreen coloration in $C$. philodice is derived from the clover upon which the larva feeds, but actual proof by way of chemical or spectroscopic examination remains to be established.

Przibram (1913) has contested the existence of chlorophyll in insects, and has classified under the non-committal name of "Tiergrun" a variety of green animal pigments. Spectroscopic examination alone he claims is insufficient to establish their identity, and chemical methods are necessary. An ether solution of the green pigment in grasshoppers and Cantharis, when heated with an equal quantity of alcohol solution of potassium hydroxide, yields a yellow precipitate and the solution becomes clear. An extract of plant pigment, on the other hand, remains green and turbid. Other striking differences appear upon heating and adding more of the hydroxide, while concentrated sulphuric acid, when added to the ether solution, and also nitric acid, give very different reactions when compared with their effects upon 
plant chlorophyll. His argument does not appear very conclusive, because insect chlorophyll has never been claimed to be absolutely identical with plant chlorophyll. Furthermore, he apparently did not investigate the pigments of Lepidopterous larvæ. Gerould (1927) criticises Przibram's conclusions and points out that the reactions described are such as one would expect in cases where the pigments are associated with proteins, as in the blood of Lepidopterous larvæ.

Faure (1932) has shown that in the solitary phase of the African Migratory Locust (Locusta migratoria subsp. migratorioides $\mathrm{R}$. and F.) green individuals are of frequent occurrence. This same feature has also been observed by Hertz and Imms (1937): the green coloration only develops in the presence of a relatively high humidity and is independent of the coloration of the immediate environment and of food. Faure finds that the green pigment involved betrays no close affinity with chlorophyll. It shows, for example, a single absorption band with its centre at $6,700 \AA$. and there is no trace of the red fluorescence characteristic of chlorophyll solutions. In the stick insect Carausius (Dixippus) and many caterpillars the green pigment is also apparently synthesised by the insect itself and is developed independently of the nature of the food (Giersberg, 1928 ; Meyer, 1930). According to Meyer it is an oxidation product of protein metabolism. It is evident, therefore, that due precaution must be exercised before concluding that the green colour of many insects is a chlorophyll derivative.

Another group of plant pigments, namely, the anthocyanins, has recently been shown to be present in insects. According to Hollande (1923) certain insects absorb pigments of this nature from their food which become concentrated in the albumen granules of the fat-body. Thus, the larva of the beetle Cionus olens, which feeds upon the purple staminal hairs of Verbascum nigrum, contains an anthocyanin derived from that plant; the pigments remain purple or become coloured either blue or red according to the prevailing degree of alkalinity or acidity present. A blue pigment of a similar nature was also found by him in larvæ of the saw-fly Athalia spinarum. In the bright vermilion-coloured aphid 
Tritogenaphis rudbeckice Palmer and Knight (1924B) found that the chief red pigment present is not soluble in fat solvents, but is readily extracted by water or cold methyl-alcohol, yielding vermilion-coloured solutions. The properties of this pigment, as determined by them, are strongly suggestive of its being an anthocyanin. Small quantities of carotin were also detected, but were insufficient to have any real influence upon the general coloration of the insect. It is noteworthy that Glaser (1917) had previously shown that another aphid, viz., Pterocomma smithice, which feeds upon willow, contains a red pigment which is apparently located in the fat-body. From preliminary tests Glaser concluded that the colouring matter appeared to be of the nature of an anthocyanin. Since, however, no anthocyanin could be detected in the shoots of the food-plant, he suggested that the aphid absorbs hydroxyflavones along with the sap, and that these become reduced to anthocyanin in the body of the aphid, and ultimately converted into the red pigment.

Pigments of the flavone group have also been recently detected in insects, and, according to Palmer and Knight (1924B), a red colouring material obtained from the Coreid bug Leptocoris trivitatus is of this nature. They also obtained a similar pigment from other Hemiptera belonging to the families Capsidæ, Lygæidæ and Reduviidæ. As to the origin of the flavone-like pigment in these cases, it is presumed that it is derived from the food-plants, but they did not pursue this subject further. In the Reduviidæ, which are predators, it would appear that the pigment would either have to be derived indirectly through some plant-feeding prey, or be synthesised by the insects themselves. More recently Thompson (1926) has provided evidence that insect pigments of the nature of flavones or flavonols are derived from the food-plant. In the Marbled White butterfly (Melanargia galatea) a small amount of a yellowish pigment is present in the wings, and gives no reaction or spectrum, which supports the assumption that it is a carotinoid. On the other hand, its properties ally it with a flavone. He was able to show further that an identical pigment is present, both free and in glucosidic combination, in cocksfoot grass (Dactylis glomerata) which is one of the known food-plants of the larva of 
this butterfly. It is probable that pigments of the flavone type are widely spread among insects, but the subject has been very little studied.

2. Hæmoglobin and Allied Pigments. The chlorophylls (sensu str.) are pigments with a tetrapyrollic nucleus and whose integral metallic constituent is magnesium. Recent research has demonstrated the chemical affinities between chlorophyll and hæmoglobin, each having as a base the substance termed porphyrin, composed of four pyrrol groups in complex linkage. It is possible, therefore, that hæmoglobin is ultimately derivable from chlorophyll, and that in the processes involved in animal evolution the latter pigment has become profoundly transformed so as to assume new functions, and its metallic constituent magnesium has become replaced by iron (vide Fulton, 1922). Among insects there are three types of pigments of this character whose metallic element is iron, viz., hæmoglobin, cytochrome and certain red pigments of Lepidoptera.

Hrmoglobin is of rare occurrence among insects and it is only in certain Chironomid larvæ that it plays any part in coloration. Among these insects it is well known to be present in the blood plasma, and not in the blood-cells, and since Chironomid larvæ possess a transparent integument it imparts to them their characteristic red appearance. Hæmoglobin also occurs under localised conditions in a few other insects, notably in the peculiar tracheal end-cells of the larvæ of Gastrophilus; Hungerford (1922) has also shown that it is found in the Notonectid Buenoa, and Mrs. Brindley has recently (1929) recorded its presence in the accessory genital gland of the male of Macrocorixa geoffroyi. The important work of Keilin (1925) on the intracellular respiratory pigment cytochrome, which is apparently of general occurrence in the animal kingdom, shows that in the possession of this pigment insects already have the chief constituents from which hæmoglobin may arise. The existence of hæmoglobin, therefore, in the isolated instances just enumerated does not necessarily imply any profound physiological difference between them and other insects devoid of this pigment. Since cytochrome plays no direct part in insect coloration it does require further consideration here. 
The red and yellowish hypodermal pigment present in the wing-scales of certain butterflies, particularly Vanessa io and $V$. urticce, plays a direct part in the coloration of those insects. The researches of the Gräfin von Linden (1905) indicate that it is derived from the chlorophyll absorbed during larval life. The transformation commences in the epithelial cells lining the digestive canal, which contain at first green granules derived from the chlorophyll of the food. So long as the digestive juices of the larva remain alkaline little change supervenes, but when transformation to the pupa is taking place the gut contents become acid and the colouring matter changes to red. During the process of change the red colour results from the combination of the actual pigmentary material with an albuminoid substance. The final colour assumed by the pigment in the hypodermis depends essentially upon its degree of oxidation ; in its reduced condition it is red-carmine, while oxidation transforms it into a dull greenishyellow. The pigment is soluble in hot or cold water, in neutral salts and mineral acids, but is insoluble in organic solvents. By the nature of its crystals, its spectrum and other properties it shows itself closely allied to bilirubin. On the other hand, it resembles hæmoglobin in that it represents the combination of an iron-containing pigment with an albuminoid substance, and in the facility with which it forms unstable combinations with oxygen. Hollande (1923) maintains that the origin of the red pigment from chlorophyll is insufficiently established, and claims that its formation is practically the reverse of that described, in that it is primarily hypodermal in origin. When pupation is about to occur disintegration of the larval hypodermis ensues, and the red granules which it contains become liberated into the blood and are then absorbed by the digestive canal. Any excess of this material passes into the gut cavity and is ultimately excreted to the exterior. One is inclined to agree with Verne (1926) that the processes described by the Gräfin are better substantiated than the more hypothetical origin explained by Hollande.

3. Pigments of Protein Origin. The pigments coming under this category are those of the melanin group. Knowledge of their chemistry is still very restricted, but they have been shown to 
be derivable from certain amino-acids, which result as the outcome of katabolic changes in proteins. True melanin is produced by the oxidation of an amino-acid, functioning as a colourless chromogen, through the action of an enzyme. It is well known that tyrosin is converted into melanin by the ferment tyrosinase and, more recently, it has been shown that "dopa" (dioxyphenylalanine) is also a source of this same pigment, under the influence of tyrosinase or of dopaoxidase. Whether these two enzymes are actually distinct appears to be doubtful, and opinions differ on the subject.

Melanin is probably a very widely spread pigment among insects, and the existence of tyrosinase in the blood, or other tissues, has been detected by a number of investigators. This bare fact, however, without evidence of the presence of a chromogen susceptible to its influence, has only a partial bearing upon the problem of melanisation. Evidence of the presence of tyrosin has been found by Van Fürth and Schneider in the blood of Lepidoptera; by Gessard in the larva of Lucilia; and by Gortner in the larva of Tenebrio. The findings of these earlier observers have been confirmed by Onslow (1916), who has shown that the black markings on the wings of Pieris brassicce are due to the presence of this pigment. By grinding pupæ of this species, before the black markings began to appear on the wings, and extracting the hæmolymph, it was shown that the latter blackened at the surface when in contact with the air. When the immature fore wings were dissected off the insects, and immersed in the hæmolymph, they became blackened, but more so at the seat of the usual markings. A dense blackening effect was produced all over when the wings were treated with a solution of tyrosin, but when placed in tyrosinase solution the blacking was confined to the actual markings. These experiments show that, although tyrosinase is generally distributed, the black markings and their position are determined by the localisation of the tyrosin in these areas, and that the process of natural melanisation occurs as soon as atmospheric oxygen has access to the developing wings.

Subsequent researches by Hasebroek, published in numerous 
papers (1921, 1922, 1925-26), and by Schmalfuss and his collaborators $(1930,1933)$ indicate that the chromogen in some insects is " dopa " (dioxyphenylalanine), as in the elytra of Melolontha or chater beetles, or dioxyphenylactic acid, as the mealworm (Tenebrio). The processes by which the antecedents of melanin are produced are unknown, but it has been suggested that the production of this black pigment involves means for the disposal of phenolic compounds which apparently are necessary for its elaboration. The amount of melanin produced in an insect has been shown to be modifiable by changes of temperature. This has been demonstrated in the Ichneumonoid Habrobracon and the effects, it is claimed, may be transmitted up to the second generation of the offspring (vide Schlottke, 1926 ; Kaestner, 1931). Schmalfuss finds that an enzyme which, in the presence of oxygen, converts dopa into melanin occurs in insects pertaining to five different orders. Hasebroek claims that the chromogen involved in certain black and brown pigmentations of the wings of Vanessa antiopa is dopa. Melanising ferments appear to be generally distributed among Lepidoptera, both in melanic and non-melanic species and, according to Hasebroek, it is the chromogen that is absent in non-melanic forms. Whether there is more than one enzyme, e.g., tyrosinase, involved in melanin production is extremely uncertain. Hasebroek (1921, 1922) maintains that a dopaoxidase exists in certain Lepidoptera at a stage before tyrosinase betrays itself. Thus, he states that the hæmolymph of larvæ and of extracts of the eggs blacken when treated with dopa, and not with tyrosin; at a later stage, hæmolymph from the pupæ and imagines exhibit melanin formation when treated either with dopa or tyrosin. According to Przibram (1922), melanin may appear in the cocoons of the moths Eriogaster lanestris and Saturnia pavonia without the intervention of any enzyme. In these cases the chromogen is dopa and he states that it differs from tyrosin in that it produces melanin by direct oxidation in the presence of moisture, provided the medium be alkaline. It may be said, therefore, that the evidence of melanin production in insects, although well established, is of an extremely conflicting nature. The researches of the English biochemists, Onslow and Robinson, 
and Raper, render it probable that dopa is the initial product of the action of tyrosinase upon tyrosin.

4. Pigments with Purine Bases. Hopkins, in his well-known researches on the chemical nature of the pigments of the Pieridx (1896), showed that the white and yellow colours in the wing scales in these butterflies are due to uric acid and its derivatives. Subsequent workers have confirmed this general conclusion and, so far as is known, the Pieridæ are the only family of butterflies which have the property of depositing uric acid in the wings. Wigglesworth (1924) has made a quantitative study of this substance in Pieris brassica and finds that part of the uric acid, contained in the fat-body of the pupa, becomes deposited in the wings just before emergence of the perfect insect. More of it becomes transferred to the alimentary canal, from which it is voided to the exterior. Estimations of the amount of uric acid present in the wings of the two sexes showed a markedly greater quantity in the male. There appears to be no actual constant difference in the uric-acid content of the two sexes, and the excess present in the male is due to the larger size of the wing scales, and hence their greater capacity for storing this substance. Wigglesworth further investigated the same problem in Vanessa urtica, a member of the family Nymphalidæ. In this species it was found that the total amount of uric acid present is approximately the same as in $P$. brassica, but that during development it is, in part, passed to the digestive canal, but not to the wings. Schöpf and Wieland (1926) have further studied the white wing pigment in Pieris brassicce and in $P$. napi and, while agreeing in its similarities to uric acid, claim that it differs from that substance in certain of its reactions. It consists according to them of a special compound which they term leucopterine. The same authors (Wieland and Schöpf) also examined the yellow pigment of another Pierid, viz., Gonepteryx rhamni, and gave the name xanthopterine to the uric acid derivative, of which it is composed. This name is apparently given to the same pigment which Hopkins termed lepidotic acid.

Uric acid and its derivatives are the end products of purine metabolism in insects, and are formed as the result of the decom- 
position of nucleic acids which occur with a protein group to form nucleoprotein. Pigments, therefore, with purine bases are excretory products which, in the Pieridæ, become deposited in the wings. With respect to the white colour of these insects, it has already been pointed out that, according to Mason, it is due to structural features rather than to the presence of urates.

\section{Combination Colours}

Combination colours are much more prevalent among insects than colours solely due to structural features. In other words, pigment very commonly co-exists with structures that are, in themselves, colour-producing. 'The structural features involved produce iridescence which is due to one or more of the four causes already discussed. Whenever a pigment is suspected to occur in combination with a structural colour its effect can be eliminated by bleaching (preferably with hydrogen peroxide); similarly, the absence of pigment can be demonstrated by the same means, when the original colour will reappear unaltered after the specimen has been dried. Iridescent colours are very often devoid of the presence of all pigment excepting black or dark brown. The dark pigment acts as a background or absorbing screen, thus intercepting white light which would otherwise reach the eye. The amount of desaturation structural colours undergo is largely proportional to the extent to which the dark pigment is developed. As a rule a background of this nature is necessary to the production of the brilliant and intense structural blues and metallic greens. The pigmentary substance may be deposited in the same scales which bear the special structural features concerned, or in a layer of scales beneath them ; it may occur either in the scale cavity or diffused in the cuticular substance of the scale.

Onslow's researches have brought to light interesting examples of combination colours among insects, besides other cases where the causes of the colours observed are entirely obscure. In the butterfly Morpho cypris, for example, there are brilliant iridescent blue scales and also white ones, and the white scales only differ in the entire absence of brown or black pigment. The absence of this absorbing screen causes areas composed of these scales 
to appear white and their iridescence to be greatly reduced. The blue scales, it may be added, can be made to appear similar to the white ones by treatment with bleaching agents. In the white and in dark purple areas of the wings of the male of Hypolimnas bolina the same phenomenon also presents itself. Onslow also describes the means of colour production in the case of the brilliant green seen in the male of Ornithoptera poseidon. This he finds is due to a structural blue combined with a yellow pigment diffused in the cuticular parts of the scales themselves. In Teracolous phlegyas a pigmentary red in the scale-wall, combined with a structural purple, produces a magenta. Also in Callitcera esmeralda a dull reddish-brown pigment alone is present, but, in such areas of the wings where it occurs, structural features of the scales combined with it produce vivid magenta red spots. The actual colour is probably largely structural, the pigment behaving more especially as an absorptive layer which serves to enhance the iridescence. A number of other examples of combination colours will be found in the literature already quoted, and do not require mention here.

\section{Further Remarks on Insect Coloration}

Much has been written regarding the relations of the colours of insects to the environment in which those animals live. It is often comparatively easy to give an explanation of the way in which a particular colour or type of coloration may be useful to a given species. Entomological literature abounds with empirical deductions of this kind. Such explanations are largely concerned with superficial appearances and do not penetrate very far into the fundamental nature of the problems involved. The more difficult subject of the function and significance of pigments, in the physiological processes of the individual, tends to be relegated to the background in such cases. Possibly, more often than not, paucity of biochemical knowledge is one of the contributing causes. Colour, it may be said, arises as a necessary result of the complex chemico-physical constitution of the organism; it is the outward expression, or the indicator, of a chain of processes within. It is primarily determined by physiological causes and it remains 
for the more ardent selectionists to prove that it is forced upon the organism by the stress of competition.

(a) There is reason to believe that carotinoid pigments, for example, are widely spread among insects, and their absorption occurs incidentally along with the food. Insects store up fat in their adipose tissue, and carotin, being fat-soluble, becomes deposited at the same time. Palmer and Knight's observations have shown that, in the Reduviid bug Perillus, carotin under ordinary conditions becomes stored in the integument in an unoxidised state. If the temperature be raised sufficiently it becomes entirely eliminated from the body, presumably after oxidation. We can safely say that many caterpillars, whose digestive secretions contain no enzymes which destroy carotinoid pigments, will assume a yellow coloration if they feed upon parts of plants in which carotin is the predominating colouring material.

Gerould, as has been previously mentioned, has described a clear case of the inheritance of a factor which suppresses carotinoid pigment in caterpillars of Colias philodice. The recessive mutants in which this occurs are blue-green, whereas the normal caterpillars are leaf-green, owing it would seem to an admixture of carotinoid pigment. Gerould formulates the conclusion that the nuclei of the intestinal epithelial cells, and especially their chromosomes, produce an inheritable enzyme, or recessive gene, capable of inhibiting or decolorising the carotinoid pigments during the digestive processes. This mutant is therefore essentially physico-chemical in nature and is apparently of negative survival value. He mentions that an outdoor culture of larvæ comprising individuals of both colour types was exposed to the attacks of sparrows for a period of twelve days. During that time the conspicuous blue-green examples were almost all taken by the birds, while many of the grass-green normally coloured larvæ were unmolested.

(b) With regard to the coloration of Lepidopterous larvæ by means of derived chlorophyll, the most significant fact is the absence of any enzyme or other chemical constituent destructive to that pigment. We have no evidence whether chlorophyll 
performs any direct physiological function or not in the life of the individual. It has been suggested by Gerould that it may play some part in the elimination of $\mathrm{CO}_{2}$ from the blood, but there is no data either for or against this idea. It may well be, as appears to be the case with carotin, that its presence is incidental and noninjurious, and consequently much of it, instead of being eliminated from the system, accumulates within the tissues. It occurs in larvæ which feed exposed during daylight upon plants, as well as in night-feeders which lie so well concealed during the day that they are hard to discover.

There are many leaf-mining dipterous larvæ which feed upon chlorophyll-bearing tissue and yet do not assume a green coloration. In these cases the explanation may be found in the biochemical nature of the secretion of the mid-intestine proving to be destructive to that pigment. There is some evidence that certain anthocyanins, derived from plants, may pass through the walls of the digestive canal in a condition sufficiently unmodified to impart their characteristic colour to specific insects. This has been demonstrated by Hollande in the case of larvæ of the beetle Cionus olens, which feed upon the purple staminal hairs of Verbascum. The presence or absence of derived pigments in different insects is a biochemical indicator of certain features in the constitution of these animals. The important rôle which such pigments play in the ecology of the organisms would, therefore, appear to be of a secondary nature.

(c) It is well known that waste products, such as uric acid and its derivatives, become deposited in the wings of Pierine butterflies. Why this should be the case has not been solved, and in the allied family Nymphalidæ no such transfer takes place. Evidence of a similar phenomenon outside the Pieridæ is very uncertain. We know that comparatively slight biochemical differences in the constitution of these substances produce very marked colour differences among different species.

(d) Much has been written with respect to melanism in insects, mainly Lepidoptera. It has long been customary to refer to all and sundry specially dark or black forms of species of this order as being melanic. The term has been applied without 
reference as to whether true melanism is involved or not, but from what is known of the occurrence of melanin in insects as a group, it is extremely probable that the presence of this pigment accounts for the phenomena just alluded to. Frequent reference occurs in literature to the prevalence of melanic forms of Lepidoptera in the neighbourhood of manufacturing towns and urban areas. They have appeared in species among which they were previously unknown, and the melanisation has in some cases increased in prevalence. On the other hand, it should be mentioned that melanic forms also occur in areas far removed from the atmospheric conditions of industrial centres.

The incidence of melanism in several species appears in some way to be bound up with the industrialisation of certain areas of England. This suggests that the presence of metallic salts contaminating the food-plants in such districts might not only affect the germ-plasm, so as to produce an inherited melanism, but also might stimulate it when once developed to attain its maximum expression. It was on premises of this kind that Harrison and Garrett (1926) and Harrison (1928) conducted a series of experiments with certain Geometrid moths, using strains from localities where melanism in the species involved is unknown. In these experiments the larval food was artificially charged with lead nitrate, manganese sulphate or manganese chloride in the different series. The most conclusive results apply to Selenia bilunaria, material of which was obtained from both England and Germany. A certain proportion of the progeny of these moths proved to be melanic forms, of a type stated to be unknown in Nature, and which did not appear in the controls. It was further shown that the melanism, thus apparently induced, was inherited as a mendelian recessive, the insects being reared upon untreated food. The experiments were carried out on three different strains of the insect, with the application of three different metallic compounds, and melanic forms appeared in each of the series. Results comparable with those of Harrison have not been obtained by McKenny Hughes (1932), who similarly attempted to induce melanism in Selenia bilunaria. Larvæ were fed upon hawthorn treated with lead nitrate and with manganese sulphate, and six 
generations, numbering 3,265 moths, were reared. No melanic examples appeared during the course of these experiments, either in the case of individuals fed on the treated food or in the controls. It would seem, therefore, that Harrison's explanation of the appearance of melanics in his cultures as the result of the treatment to which the larvæ were subjected has not been conclusively demonstrated. The reader is also referred to the paper by Thomsen and Lemche (1933).

Hasebroek (1926) has studied induced melanism in industrial areas, and arrived at the conclusion that it results through the absorption of volatile substances viâ the tracheal system. He discountenances the influence of compounds absorbed through the alimentary canal. By exposing pupæ of various species of Lepidoptera to the influence of the vapour of pyridene, sulphuretted hydrogen, both separately and in mixture, he was able to produce a considerable degree of melanism. Also sewer gas alone, ammonia, pyridin and chloroform in combination caused melanic tendencies : methane and ammonia also produced pronounced darkening. While his experiments are suggestive, and of great interest, they are open to considerable criticism. In the first place, he does not appear to have used stocks known to be free from melanic tendencies, and, consequently, the possibility that the melanism may have arisen independently of the treatment cannot be wholly excluded. Secondly, most of the species employed do not appear, in England, at any rate, to exhibit any marked melanic tendency in industrial areas, so it may be argued that his experiments do not necessarily bear upon this local problem. Thirdly, no mention is made of any breeding trials being carried out with a view to ascertaining whether the induced melanism is inheritable.

(e) Most entomologists are familiar with the results of Poulton's experiments $(1887,1892)$ with reference to the reactions of certain colour-sensitive Lepidopterous larvæ and pupæ. It will be recalled that with regard to Vanessa urtica and $V$. io, and also Pieris brassice and $P$. rape, he showed that when their larvæ take up their final resting position upon surfaces, preparatory to spinning their silken attachment, they are in a condition highly sensitive 
to the differential effects of light rays. This sensibility is influenced by certain constituents of diffused light reflected from surfaces in the immediate environment, which affects the colour assumed by the pupæ. On black, deep red, blue and certain green backgrounds, for example, darkly coloured pupæ resulted. On the other hand, orange, yellow or white backgrounds gave rise to green, or pale, bright pupæ, and the same effects were produced by surroundings of green leaves and shoots. Two pigments, a green and a black, occur in the pupr, and it appears that since rays from the orange and yellow zone of the spectrum are inimical to the superficial black pigment, they conduce to the production of green or palc pupæ. It seems tolerably certain, therefore, that those same rays, reflected from green surroundings in Nature, stimulate the pupæ to assume a green appearance. The blue rays, on the other hand, tend to produce dark pupæ. The idea that the light may act through the larval eyes led Poulton to cover the latter with black varnish, but no resultant influence upon pupal coloration was observed, and it would appear that light produces its effects viâ the general integument. These extensive researches, so briefly outlined, have stimulated others to experiment along similar lines, and their results support the general conclusion that a power of colour adjustment, in relation to their immediate surroundings, exists in certain Lepidoptera.

While it is generally agreed that the black superficial pigment is melanin, the nature of the green colouring matter is problematical. Whether an enzyme promotes its formation as suggested by Fraulein Brecher, or it is a modified derivative of chlorophyll, is still unsettled. Experiments conducted by Brecher (1921) with blood of larvæ of Pieris brassica, in vitro, appear to show that, during the sensitive period, yellow rays increased the acidity of the blood and reduced the activity of tyrosinase, while ultra-violet rays had the opposite effect. Her more recent researches (1925) do not confirm this conclusion when applied to an examination of the blood of both larvæ and pupæ living under the influence of different light rays. When the blood was drawn directly, its $p \mathrm{H}$ reaction was found to be remarkably constant $(6 \cdot 50$ to $6 \cdot 77)$. On the other hand, Fraulein 
Brecher advances evidence which suggests that the photochemical action of black, and other dark surfaces, depends upon the ultraviolet rays which they reflect stimulating melanin formation, while infra-red rays tend to inhibit the development of that pigment. She also found that tyrosinase was less active in the blood of green pupæ than that contained in the blood of darkly coloured pupæ. Her researches present a line of approach towards the fundamental nature of the phenomena observed, but further investigation is obviously needed, including the influence of temperature as well as light rays.

Przibram (1922), by electrical cauterisation of the eyes of the larvæ, and also by decapitation, came to the conclusion that the action of the light rays takes place through the eyes, since he obtained the same results as in darkness, whatever the surroundings of the larvæ were. Brecher (1924) confirmed these results by painting the larval eyes with a transparent yellow varnish, when the pupæ became green in Pieris and golden in Vanessa; when blue varnish was used the pupæ were darkly coloured, as under blue surroundings. It would, therefore, appear that light of different wavelengths exerts a differential stimulus through the larval eyes on the nervous system, but the nature of the phenomenon is unexplained.

Durken (1923) and Fraulein Brecher (1923) have further experimented on the influence of orange light in inhibiting the development of grey and black pupæ in Pieris brassicce, thus allowing the green pigment to become evident. Their results are in conformity with those already quoted, and they further suggest that the tendency to produce green pupæ is an inheritable property. Larvæ descended from the orange glass cultures, when allowed to pupate under ordinary light conditions, gave rise to more green pupæ than occurred among the controls. Durken repeated the exposure to orange-coloured rays for two generations, and when the larvæ finally transformed under normal non-coloured surroundings, almost all the pupæ were green. Experiments by Harrison (1928A) afford support to the conclusion that the induced green coloration is inherited. In the species Pieris napi a mixed lot of eggs was obtained from six captured 
females : forty-three control larvæ reared in ordinary glazed cages gave 20.9 per cent. green pupæ, while forty-six larvæ reared under orange-coloured glass produced $93 \cdot 4$ per cent. green pupæ. Larvæ derived from imagines emerging from these green pupæ were, in their turn, submitted to the same orange rays and, on transforming, $95 \cdot 2$ per cent. of the pupæ were found to be green. The latter were again used for rearing a third generation, but in this case the larvæ were reared under similar conditions to the controls. Only thirty-one pupæ were obtained, but all were green. The butterflies from these were segregated into two batches-early-emerged and late-emerged. In the first batch their offspring were allowed to pupate on a varied selection of surfaces, and 58 per cent. of green pupæ resulted (from a total of fifty individuals). The offspring of the other batch of butterflies were reared in cages whose glass walls were painted black, and $96 \cdot 4$ per cent., of the forty-eight pupæ which resulted, were green. The results are presented as they stand, and Harrison does not attempt any theoretical discussion of the factors involved.

(f) The phenomena of colour change in the stick insect Carausius have attracted the attention of several recent workers in Germany, notably Atzler (1930), Giersberg (1928) and Priebatsch (1933). This insect is able to change its general coloration in response to sudden changes in its immediate surroundings, becoming darker or paler, as the case may be. Other stimuli, such as temperature and mechanical pressure, elicit a similar response. This response is brought about by movements of the pigment in the hypodermis. The pigment granules either become aggregated or diffused, according to whether the insect becomes paler or darker in its general colour. The primary sensation of the background colour is received by the eyes, which act upon the visual centre in the brain, and apparently induce the secretion of a hormone into the blood. It would appear, therefore, that it is this hormone which activates the movements of the pigment granules. Destruction of the tritocerebrum causes all colour response to cease. Carausius is unique among insects in that its colour response seems to operate in a manner similar to those animals which have true chromatophores controlled by hormone secretion. It would, 
in fact, seem that in the stick insect the hypodermal cells are virtually unspecialised chromatophores.

(g) Mottram and Cockayne (1920) and Cockayne (1924) have shown that fluorescence is a common colour property among Lepidoptera. By using a quartz mercury vapour lamp, whose light was allowed to pass through a sheet of a special kind of black glass, which is opaque to white light, a beam of invisible ultraviolet radiation was obtained. When this beam is directed upon insects in a dark room any fluorescence present reveals itself. It was found that the phenomenon is widely spread among species that are whitish or yellow, or have markings of such colour upon their wings. The fluorescent colours vary very greatly, being pale blue in many Geometridæ, dull violet among Pieridæ, bright yellow in some Arctiidæ, and bright green in the Danainæ. The phenomenon may be common to both sexes as in Geometridæ, while many Papilionidæ have fluorescent males and non-fluorescent females. It is interesting to speculate with regard to the possible relationships of fluorescent pigments to one another, and this property may prove to be a useful index of affinity as regards chemical constitution. Whether fluorescence is of any functional importance in the lives of insects whose colours exhibit the phenomenon, or is solely an incidental feature, is problematical.

\section{Literature}

Atzler, 1930. Zeits. vergl. Physiol., XIII., 505.

Brecher, 1917. Arch.f. Entw. Mech., XLIII., 88.

1921. Ibid., XLVIII., 46.

1922. Ibid., L., 209.

1923. Zeit. Indukt. Abstammslehre, XXX., 291.

1924. Arch.f. Entw. Mech., CII., 501.

1925. Zeits. vergl. Physiol., II., 691.

Brindey, 1929. Trans. Ent. Soc. London, LXXVII., 5.

CockAYNe, 1924. Ibid., LXXII., 1.

Durken, 1923. Arch.f. Mikros. Anat., XCIX., 222.

Faure, 1932. Bull. Ent. Res., XXIII., 334.

Fulton, 1922. Quart. Journ. Mic. Sci., LXVI., 339.

Gerould, 1921. Journ. Exp. Zool., XXXIV., 385.

1926. Ibid., XLIII., 413.

1927. Quart. Rev. Biol., II., 58.

Giersberg, 1928. Zeits. vergl. Physiol., VII., 657

Glaser, 1917. Psyche, XXIV., 30.

Harrison, 1928. Proc. Roy. Soc., B, CII., 338.

1928A. Ibid., 347. 
Harrison and Garrett, 1926. Ibid., B, XCIX., 241.

Hasebroek, 1921. Biol. Centralb., XLI., 367.

1921-26. Fermentforschung, V., VII., VIII.

1922. Arch.f. Entw. Mech., LII., 261.

Hertz and Imus, 1937. Proc. Roy. Soc., B, CXXII., 281.

Hollande, 1913. Arch. Zool. exp. gen., 41, Notes, 53.

1923. Arch. Anat. micr., XVIII., 85.

Hopkins, 1896. Phil. Trans. Roy. Soc., B, CLXXXVI., Pt. 2, 661.

Hungerford, 1922. Canad. Entom., LIV., 262.

Kaestner, 1931. Arch. Entw. Mech., CXXIV., 1.

KeIlin, 1925. Proc. Roy. Soc., B, XCVIII., 312.

Knight, 1924. Ann. Ent. Soc. Amer., XVII., 258.

Linden, 1905. Ann. Sci. Nat. Zool., XX., 158.

Mason, 1926-27. Journ. Phys. Chem., XXX., 383 ; XXXI., A, 321 ; B, 1856.

McKenny Hughes, 1932. Proc. Roy. Soc., B, CX., 378.

Meyer, 1930. Zeits. vergl. Physiol., XI., 173.

Michelson, 1911. Phil. Mag. (6), XXI., 564.

Mottram and Cockayne, 1920. Proc. Ent. Soc. London, XXXVI:

Onslow, 1916. Biochem. Journ., X., 26.

1921. Phil. Trans. Roy. Soc., B, 211, 1.

Palmer, 1922. "Carotinoids and Related Pigments." New York.

Palier and Knight, 1924. Journ. Biol. Chem., LIX., A, 443 ; B, 451.

Poulton, 1887. Phil. Trans. Roy. Soc., B, CLVIII., 311.

1892. Trans. Ent. Soc. London, 293.

1893. Proc. Roy. Soc., B, LIV., 417.

Priebatsch, 1933. Zeits, vergl. Physiol., XIX., 452.

Przibrai, 1913. Pflüger's Arch. Physiol., ClIII., 385.

1922. Biochem. Zeitschr., CXXVII.,

1922A. Arch.f. Entw. Mech., L., 203.

SchlottKe, 1926. Zeits. vergl. Physiol., III., 692.

Schialfuss, 1924. Fermentforschung, VIII., 1, 86.

Schmalfuss and Barthmeyer, 1930. Biochem. Zeits., CCXXIII., 457.

Schmalfuss, Herder and Winkelmane, 1933. Ibid., CCLVII., 188.

Schöpf and Wieland, 1926. Ber. deut. Chem. Ges., LIX., 2067.

Suffert, 1924. Zeit. Morph. Okol. Tiere, I. (II)., 172.

Thompson, 1926. Biochem. Journ., XX., 73, 1026.

Thomsen and Lemche, 1933. Biol. Zentralb., LIII., 541.

Verne, 1926. "Les Pigments dans l'organisme Animal." Paris.

Wieland and Schöpf, 1926. Ber. deut. Chem. Ges., LVIII., 2178.

Wigglesworth, 1924. Proc. Roy. Soc., B, XCVII., 149. 


\section{CHAPTER VIII}

\section{SOME ASPECTS OF ECOLOGY}

Temperature. The General Subject, p. 206 ; Fatal Temperatures : A. Heat, p. 220 ; Fatal Temperatures : B. Cold, p. 221.

Ecology is primarily concerned with the relationship between organisms and their environment. It is to be regarded as a branch of general physiology which deals with the life-processes of organisms as a whole, as distinct from the functions of their individual organs. In certain of its phases ecology grades into pure physiology, and no hard and fast line can be drawn between the two. Plant ecology has made more rapid and more definite progress than animal ecology, a fact which is doubtlessly owing to their stationary habit and the greater facility with which they can be studied in intimate relation with the environment. Animal ecology has only in recent years become subject to exact experimentation, and it has, as yet, scarcely found its feet; as applied to insects, it is insufficiently advanced to admit of any far-reaching co-ordination of data, and its foundations lie in an adequate conception of their physiology which at present does not exist.

Ecology has been divided into "autecology," which treats of the individual factors of the environment together with their effects upon individual organisms ; and "synecology," which is concerned with environments as consisting of combinations of factors and their effects upon communities of organisms. In so far as the present chapter is concerned, "autecology" alone is implied, with the exception that combinations of environmental factors are also briefly considered. These several agencies are discussed more especially with reference to their influence on metabolism and general development. 


\section{Temperature}

The General Subject. It is well known that temperature exercises a profound influence upon insects in diverse ways, and their relations to this factor have been subject to more adequate

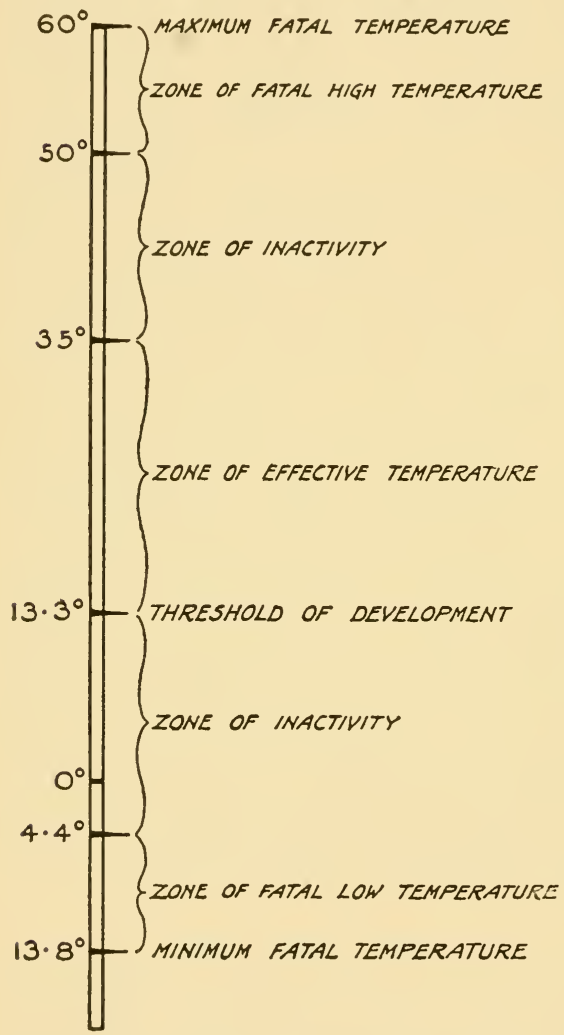

Fig. 66. Temperature zones in relation to the activities of the cotton-boll weevil. (According to Hunter and Pierce.) experimentation than any other physical agency. The most comprehensive recent work on the subject is that of Bělehrádek (1935), which deals with it from the general biological standpoint.

The extremes of temperature limit insect activities both in space and time. Their rates of metabolism and, consequently, those of growth, reproduction and general behaviour, are largely controlled by temperature. A given species of insect is active within certain limits of temperature which form the zone of effective temperature (Fig. 66). Above the maximum effective temperature there is a zone of inactivity, or heatdormancy, from whose effects the insect recovers when removed to more favourable conditions. Above this zone of inactivity, there follows a range of fatal high temperatures at which death supervenes after the lapse of a certain interval of time, according to each temperature. At the maximum fatal temperature death is rapid and almost immediate. On the 
descending scale, the minimum effective temperature is often termed the threshold of development, and at which the metabolism of the insect borders on a condition of equilibrium, but with sufficient excess of anabolism over katabolism to allow of growth and development not being quite stationary. This point obviously requires prolonged experimentation for its determination, and has been accurately ascertained in very few instances. Below the minimum effective temperature there follows a zone of inactivity, due to rigor or cold-dormancy, but from whose influence recovery takes place at a higher temperature. Still lower on the descending scale is a zone of fatal low temperatures, corresponding with the zone of fatal high temperatures, and, finally, the minimum fatal temperature.

The observations of Hunter and Pierce (1912), with reference to the cotton-boll weevil, may be taken as an illustration of these temperature ranges. Their experiments, however, were not strictly controlled, but the prevailing humidity only varied between 37 and 40 per cent. The zone of effective temperatures (Fig. 66) for this insect lies between $13 \cdot 5^{\circ} 1$ and $35^{\circ}$. Above $35^{\circ}$ up to $50^{\circ}$ the insects become inactive, and from $50^{\circ}$ to $60^{\circ}$ (soil temperatures) is the range of fatal high temperatures in which the weevils died in from fifteen minutes to one second, according to the temperature. The maximum fatal temperature was found, therefore, to be $60^{\circ}$. The lower zone of inactivity, which is due to cold, ranges between $13 \cdot 3^{\circ}$ and $-4 \cdot 4^{\circ}$, while below the latter temperature, and down to $-13 \cdot 8^{\circ}$, is the zone of fatal low temperatures, with $-13 \cdot 8^{\circ}$ as the minimum. The above observations illustrate the fact that such temperature zones exist, and are to be regarded as accurate for the particular conditions under which they were carried out. Within the zonc of effective temperatures there exists an optimum range, at which the greatest number of insects complete their normal development. Its limits naturally vary when applied to the testing of more specific phenomena; the range of optimum activity, for example, not coinciding with that of longevity.

1 Temperatures are given in Centigrade degrees throughout; in many instances Fahrenheit readings are given in the original sources of information, and their conversion accounts for the quotation of decimal degrees. 
Peairs (1927) is one of the more recent workers to investigate the relation of temperature to insect development. His experiments were made on a considerable scale with a number of different species of insects (larvæ, pupæ, and, in one experiment, eggs), which were divided into batches, each batch being subjected

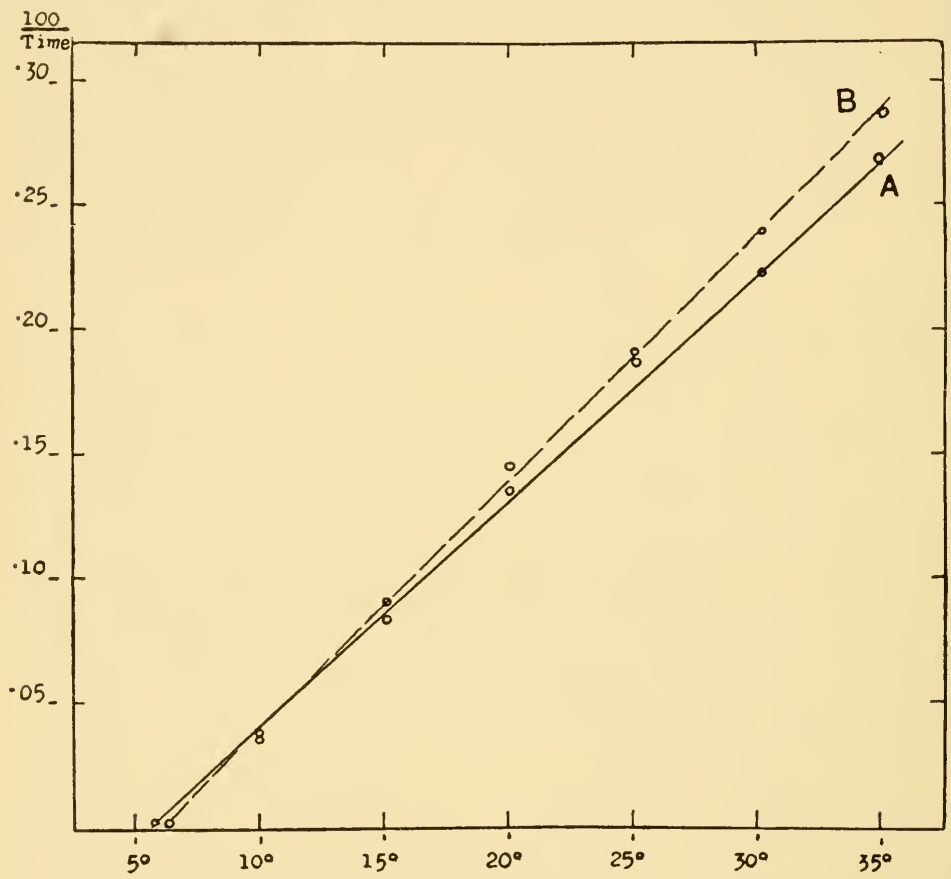

FIG. 67. Velocity of development of Lucilia ccesar larvæ. A, based upon mean time of emergence. $B$, based upon average time of first emergence for the lots at different temperatures $\left(\mathrm{C}^{\circ}\right)$. (From Peairs, West Virginia Agric. Exp. Sta. Bull., 208, 1927.)

to a different constant temperature. The relative humidity was not constant, but was usually maintained near the point of saturation. In presenting his data the reciprocals of the time factor have been plotted against the temperatures, and the curves consequently show the direct relation between increase in velocity of development and rise in temperature (Fig. 67). The curves in all cases approximate within certain limits to a straight line, 
which agrees with the previous findings of Krogh (1914) and others. Peairs advanced reasons for concluding that the average time of the first emergence of the insects, at different temperatures, is probably a more reliable index than the mean time of emergence, and both sets of data are plotted for comparison. When experiments of this kind are carried out over a sufficiently wide range of constant temperatures, the velocity curve is not a straight line

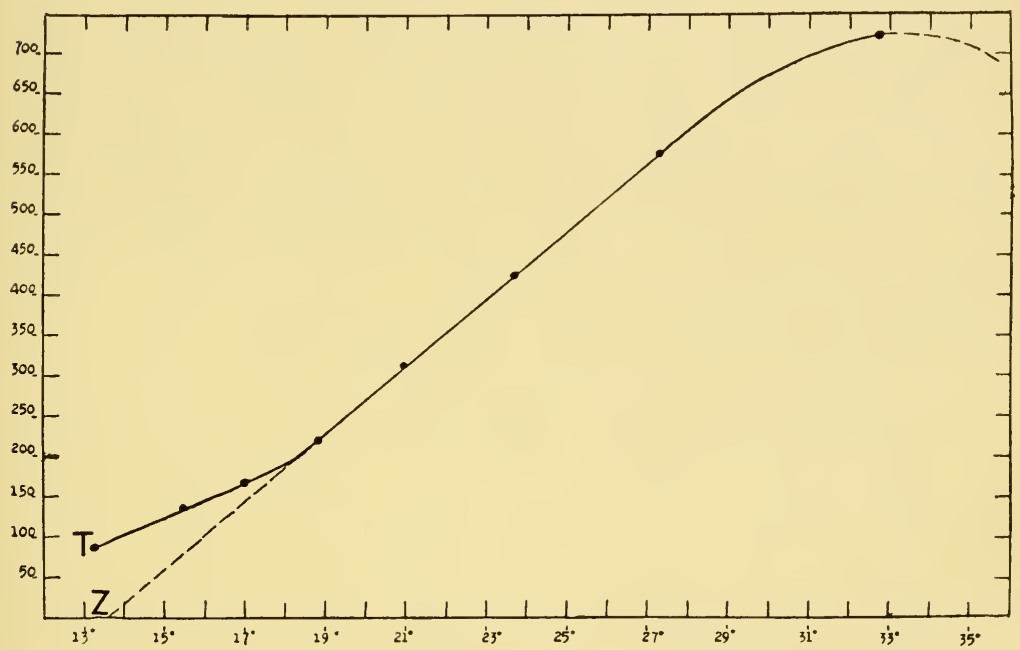

FIG. 68. Temperature-velocity curve of development of pupæ of Tenebrio. Curve T shows relation between incubation time and temperature. The broken line represents the theoretical velocity curve, with the zero of development at Z. (Adapted from Krogh.)

throughout its course, but exhibits a definite lag phase at the lower temperatures and inclines downwards at the higher. Although the threshold of development should, theoretically, be the zero of the velocity curve, or the point at which that curve intersects the temperature axis, as a rule this is not actually the case. The investigations of Krogh, Shelford (1927) and others lend reasons for believing that the threshold of development lies below the zero point of the velocity curve. There is a departure from the theoretical curve, indicating a slowing down of the 
velocity of development at low temperatures, and that the development of a stage commences at a point lower in the scale than that of the intersection of the velocity curve with the temperature axis (Fig. 68). Similarly, at the upper extremity of the velocity curve there is a high temperature retardation effect; at points ranging from about $35^{\circ}$, or less, development slows down and is rarely completed at $40^{\circ}$ (Peairs). Subject to the two deviations just mentioned, the developmental curve of an insect, when plotted as the reciprocal of the time factor, is a straight line which represents the rate of increase in the velocity of development.

The law of van't Hoff states that the velocity of a chemical reaction increases with the temperature, and that the coefficient, which expresses the rate of increase, is usually between two and three times for each ten degrees of temperature. The relation between temperatures and metabolism in cold-blooded animals has been often stated to follow van't Hoff's law. It has been shown by Krogh with reference to Tenebrio, and by many others, however, that biological processes do not follow the principle of a simple chemical reaction. The rate of increase of biological processes, which accompanies a rise of temperature, cannot be accurately expressed in terms of van't Hoff's formula, because the value of the coefficient (commonly referred to as $Q_{10}$ ) is not constant enough to represent an approximation. The metabolism of an insect, for example, is so complex and consists of a series of inter-related processes that it is perhaps scarcely surprising that it does not follow van't Hoff's rule.

Although the study of the effects of constant temperatures yields important data relative to development and metabolism, and most of the critical experiments refer to such conditions, it has to be remembered that it is variable temperatures which prevail in a state of nature. The experimental study of varying temperatures, however, has not progressed very far in relation to insects, and obviously much depends upon the length of exposure to given temperatures and the ranges of the latter. There is evidence that temperature fluctuations exert considerable influence in accelerating development among insects. Thus Bodine (1925) and Parker (1929-30) found that if the eggs of grasshoppers were 
transferred to $0^{\circ}$ immediately after they had been laid and were later removed to a favourable temperature $\left(27^{\circ}\right.$ to $\left.37^{\circ}\right)$ they developed more rapidly than the controls which remained at the higher temperature. This acceleration was progressively maintained up to a period of $\mathbf{2 4 0}$ days at the low temperature. Longer exposure resulted in only slight further acceleration. Kept at $37^{\circ}$, the eggs hatched in forty-six days. When placed at $0^{\circ}$ for thirty days and subsequently transferred to $37^{\circ}$ they hatched in thirty-seven days. There was progressive acceleration up to 240 days at $0^{\circ}$, after which they hatched in eleven days at $37^{\circ}$ (Table II.). It might be argued that $0^{\circ}$ is above the threshold of development and that growth was going on all the time, but as a matter of fact the threshold is above $8^{\circ}$, so that the result obtained is only to be explained as acceleration.

TABLE II. Development of Grasshopper Eggs at Higher Temperatures following an Exposure to $0^{\circ} \mathrm{C}$. (from Parker).

\begin{tabular}{cccc} 
& \multicolumn{2}{c}{ Days taken for hatching at temperatures given } \\
Days at ${ }^{\circ} \mathrm{C}$. & $27^{\circ}$ & $32^{\circ}$ & $37^{\circ}$ \\
0 & 26 & 32 & 46 \\
30 & 25 & 31 & 37 \\
60 & 23 & 29 & 31 \\
120 & 20 & 21 & 17 \\
180 & 17 & 18 & 15 \\
240 & 16 & 12 & 11 \\
500 & 15 & 10 & 10
\end{tabular}

The reason for the accelerative effect of exposure to low temperatures is obscure, and several hypotheses have been advanced to account for the phenomenon. For instance, it has been suggested that definite protoplasmic rhythms occur as regards susceptibility to their influence, which express themselves in subsequent acceleration of growth. Also the view has been advanced that protoplasm is highly adapted to variable conditions as a normal environment, whereas constant temperatures are abnormal and tend to retard development. As Peairs has remarked, this would interpret differences in growth rate as a retardation due to constant temperature rather than as acceleration resulting from temperature variation. Carothers (1923) showed that the eggs of the grasshopper Circotettix do not hatch normally under laboratory 


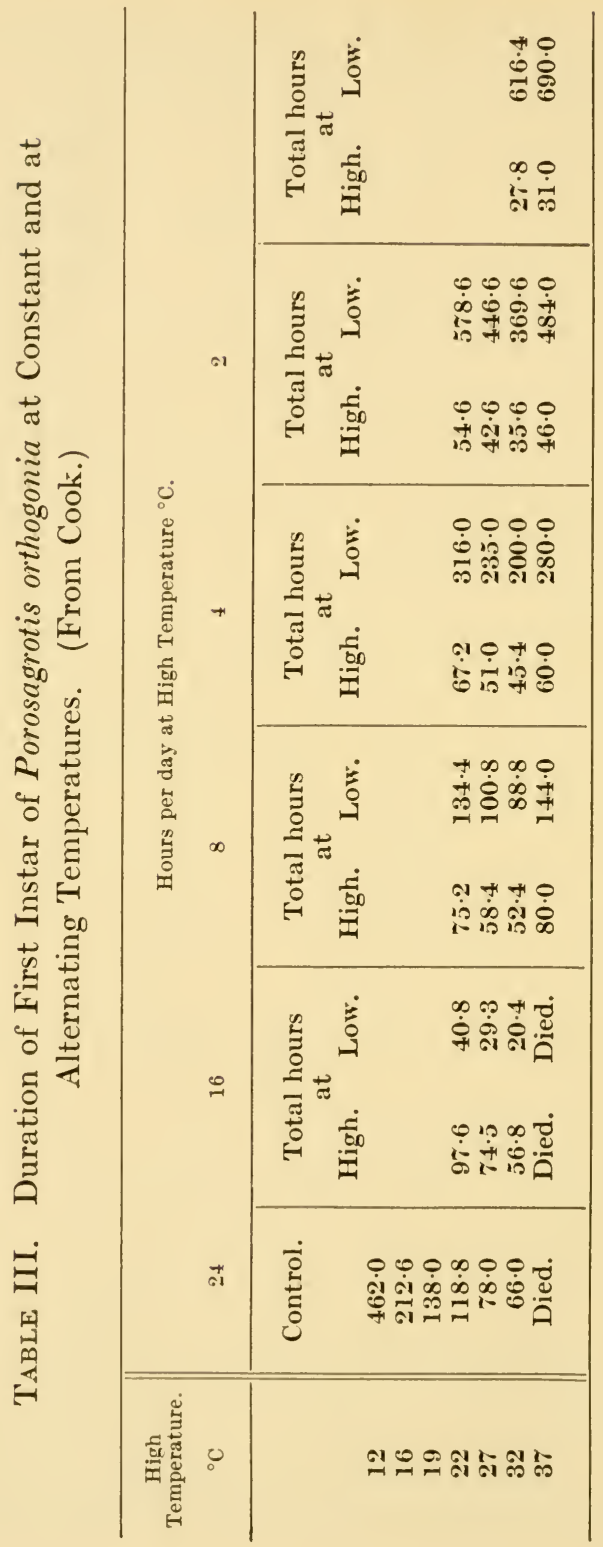


conditions unless previously subjected to low temperature, and the same principle is well known to the commercial rearers of eggs of univoltine silkworm moths.

In further illustration of this same phenomenon the work of Cook (1927) may be cited. This experimenter used first instar larvæ of the Noctuid moth Porosagrotis orthogonia which were

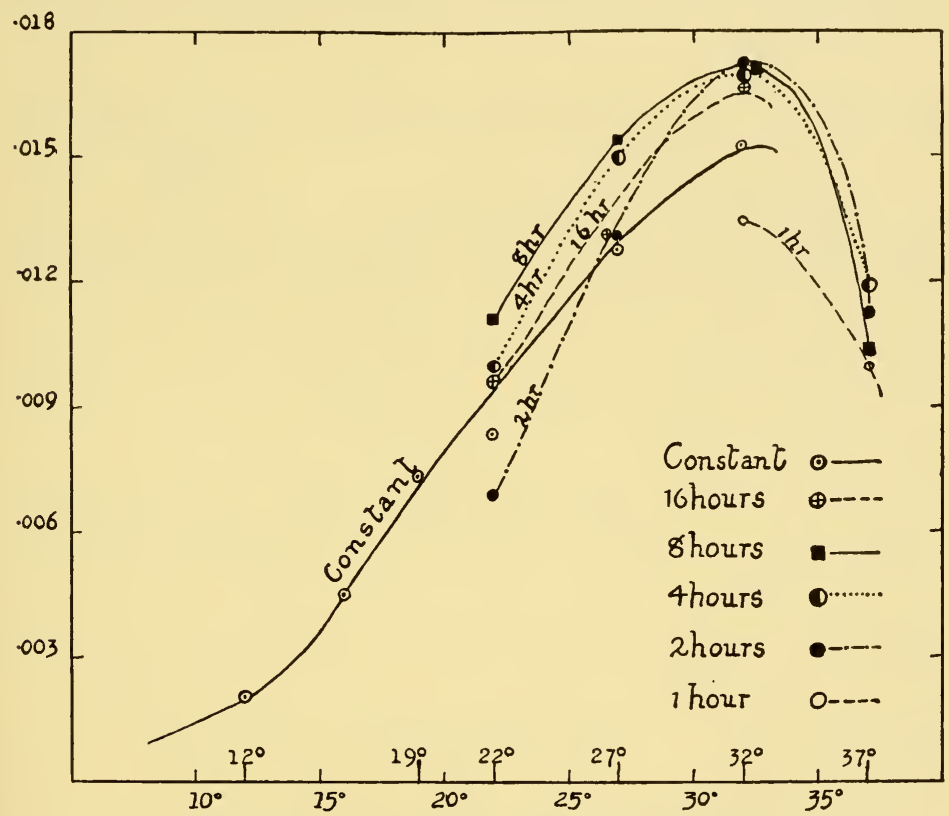

Fig. 69. Influence of temperature on the growth rate of Porosagrotis orthogonia. (From Cook, Journ. Econ. Ent., XX.)

subjected to constant temperatures of $12^{\circ}, 16^{\circ}, 22^{\circ}, 27^{\circ}, 32^{\circ}$ and $37^{\circ}$ as controls, and the time which elapsed before the first ecdysis took place was noted. Simultaneously other batches were subjected to alternating temperatures. For high temperatures $22^{\circ}$, $27^{\circ}, 32^{\circ}$ and $37^{\circ} \mathrm{C}$. were used, while $8^{\circ}$ was the low temperature in each instance. Four batches of larvæ were placed at each high temperature, one batch each for two, four, eight and sixteen hours per day, while for the remainder of the twenty-four hours they were placed at $8^{\circ} \mathrm{C}$. (Table III.). The growth rate, or the 
reciprocal of the time required to complete the first instar, is shown in Fig. 69. It must be pointed out that growth at a temperature of $8^{\circ}$ is exceedingly slow, but as the time spent under this condition was large, in some cases a considerable amount of growth must have occurred. Inspection of the curve labelled constant in Fig. 69 indicates that a value 0.001 is the approximate growth rate at $8^{\circ}$, and assuming this value Cook gives the following sample calculation :-

Larvæ exposed at $22^{\circ}$ for sixteen hours daily underwent eedysis after $97 \cdot 6$ hours at that temperature, followed by $40 \cdot 8$ hours at $8^{\circ}$ (Table III.).

Total development

40.8 hours at $8^{\circ}$ (value 0.001 ) . $\quad .=0.0408$

By subtraction this leaves 0.9592 for the value of $97 \cdot 6$ hours at $22^{\circ}$, and the value of one hour at that temperature is consequently 0.0099 , which is taken as the growth rate for the batch of larvæ in question.

The growth rates are thus calculated for each lot in the series and are shown in Table IV., together with those of larvæ maintained at constant temperatures.

TABle IV. Growth Rate for First Instar of Porosagrotis orthogonia at Constant and at Alternating Temperatures. (From Cook.)

\begin{tabular}{c|c|c|c|c|c|c}
\hline $\begin{array}{c}\text { Hours per Day at } \\
\text { High Temperature. }\end{array}$ & 24 & 16 & 8 & 4 & 2 & 1 \\
\hline $\begin{array}{c}\text { High Temperature. } \\
\text { Degrees C. }\end{array}$ & \multicolumn{5}{|c|}{ Figures below give the Value of One Hour at } \\
High Temperature. & & & \\
\hline 12 & 0.0022 & & & & & \\
16 & 0.0047 & & & & & \\
19 & 0.0072 & & & & & \\
22 & 0.0084 & 0.0099 & 0.0015 & 0.0102 & 0.0077 & \\
27 & 0.0128 & 0.0130 & 0.0154 & 0.0150 & 0.0130 & \\
32 & 0.0152 & 0.0172 & 0.0174 & 0.0176 & 0.0177 & 0.0138 \\
37 & - & - & 0.0107 & 0.0120 & 0.0112 & 0.0100 \\
\hline
\end{tabular}

Cook also gives data with respect to the rate of $\mathrm{CO}_{2}$ production by the nearly mature larvæ of another Noctuid, Chorizagrotis auxiliaris during similar combinations of temperatures. Both 
sets of experiments lead to the conclusion that length of time of exposure to given temperatures is of prime importance, and that there is an optimum combination of time and temperature for the given species - the point at which the growth rate attains its maximum value. It is further possible to secure a given growth rate by several combinations of time and temperature.

Ludwig and Cable (1933) give a useful discussion of the subject of alternating temperatures. 'They also describe the results of their experiments with pupæ of Drosophila which were exposed to daily alternations between two temperatures. When one of the temperatures is above the optimum for development, and the other is between the $a$ point $\left(10^{\circ}\right)$ and the optimum, development appears to be retarded. If, on the other hand, both temperatures lie between the $\alpha$ point and the optimum, the range of development is unaffected as compared with controls at the optimum temperature. If one temperature is between the $\alpha$ point and the actual threshold of development the rate is accelerated. This acceleration is due to development having taken place below the a point. These authors further point out that alternating temperatures provide a satisfactory method for determining the development threshold. In these experiments, if the pupre of Drosophila be exposed to a high and a low temperature, and the developmental rate is the same as that of controls at the constant high temperature; it is obvious that no development has occurred at the low temperature. If, however, the time at the high temperature is less than is required in a constant exposure to the same temperature, some development occurs at the low temperature; the latter, therefore, is above the developmental threshold. By this method it was found that the a point $\left(10^{\circ}\right)$ in the case of Drosophila pupæ is considerably above the true threshold, which lies between $7^{\circ}$ and $8^{\circ}$.

In computing the effects of variable temperatures, many entomologists have used the number of "degree-days" for this purpose. The total number of degree-days, for a given stage of development of an insect, is arrived at by taking each day from the commencement to the termination of the stage concerned, and by computing the number of degrees by which each day's 
mean temperature exceeds that of the threshold of development, and then summing the number of degrees so obtained for the whole period under consideration. Further investigation has showed that the idea of a constant total of effective temperatures, or the thermal constant as it is often termed, necessary to complete a given stage has proved to be approximately correct in certain cases. The thermal constant, however, may exhibit wide fluctuation, especially during exceptionally hot or exceptionally cold seasons. This is owing to the fact that the influence of one degree of temperature during a unit period of time is not the same at different temperatures. As an example, it may be mentioned that the beetle Sitodrepa panicea is stated to require 1,820 daydegrees at $20^{\circ}$, and 3,638 at $17^{\circ}$. As a rule, for practical purposes, temperature summations are based upon mean temperatures over twenty-four-hour periods. In many cases the thresholds of development for the species concerned are unknown, and an arbitrary figure of say $5 \cdot 5^{\circ}\left(42^{\circ} \mathrm{F}\right.$.) has to be adopted. This method is admittedly rough and ready, and its use can only be qualified in cases where no experimental study of a given species in relation to temperature has been carried out. Shelford (1927) has come to the conclusion that temperatures cannot be summed correctly for biological purposes unless readings are taken at intervals of one or two hours, instead of daily, and corrected for the effects of other factors. Such correction he terms temperaturesubstitution, and is only possible through preliminary observation or experimentation affording temperature and humidity data for the defining of standard conditions. The temperature-substitution method translates the observed conditions into terms of the response of the organism into developmental units, which can be summed for biological purposes. He claims, therefore, that a new method is required which will take into account the effects of all variations of the factors involved in small units of time. Hence he adopts what he terms the developmental unit, which is defined as the difference in amount of development resulting in one hour from a difference of one degree of mean medial ${ }^{1}$ temperature

1 Medial temperatures as implied by Shelford are those whose range lies on the straight line portion of a reciprocal (velocity) curve. 
(other conditions being average), as shown by the difference in time required to complete the stage. Shelford's work is with special reference to the Codling moth, for which he gives tables of developmental units under all combinations of temperature and humidity, and based upon data covering ten years of observation and experimentation. Such a method, however, is obviously too laborious to allow of its general adoption.

The influence of temperature on the duration of life has been shown, in a general way, to exercise a shortening effect in proportion to its rise. The most exact study of this phenomenon is found in the work of Alpatov and Pearl (1929) on Drosophila. Their experiments showed that, in this insect, length of life is doubled in the $10^{\circ}$ of temperature reduction between $28^{\circ}$ and $18^{\circ}$, which were the temperatures used. Females proved to be longer lived than males, and individuals of both sexes were used in the double series of experiments. In one series they were reared from the egg at $18^{\circ}$ and in the other series at $28^{\circ}$. The adult flies were then tested

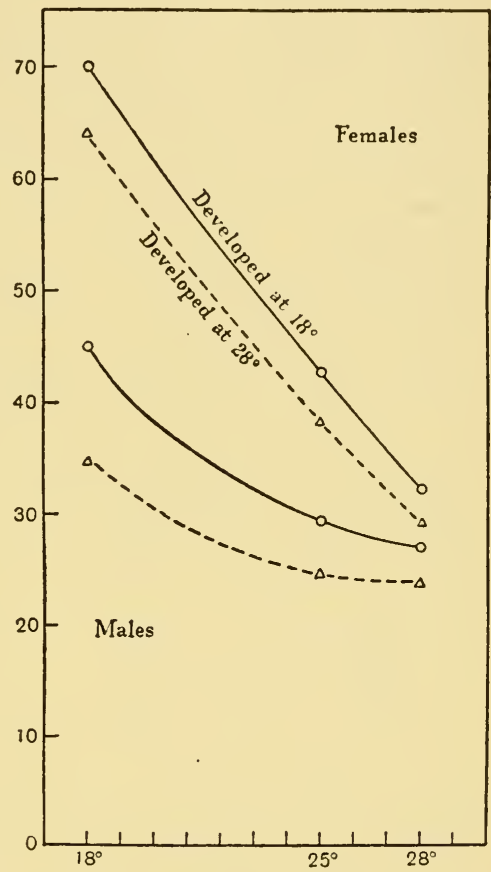

FIG. 70. Average duration of life in days : males (two lower curves) and females (upper curves) of Drosophila. Black lines indicate development at $18^{\circ}$ and broken lines at $28^{\circ}$. (From Alpatov and Pearl.)

as regards their viability at temperatures of $18^{\circ}, 25^{\circ}$ and $28^{\circ}$, and the results are shown in Fig. 70. It will be noted that the survival of individuals reared at $18^{\circ}$ was marked longer than those at $28^{\circ}$. Alpatov and Pearl's conclusion that, at the higher temperatures, the increased rate of energy expenditure during growth and imaginal life shortens survival is what would be expected. 
The influence of temperature upon insect metabolism can be measured in the respiratory exchange by computing either the carbon dioxide output or the oxygen consumption. The respiratory exchange is an extremely variable quantity, and the most important influencing factor is functional activity. It is well known that there is a certain minimum or basal metabolism inseparable from the life of the individual. Basal metabolism cannot be determined in the strict sense of the term, but an approximation to it, corresponding to a minimum functional activity, may be obtained, and is termed by Krogh (1916) standard metabolism. The latter is regarded as the result of minimum functional activity when voluntary muscular movements are in abeyance, and no food is being taken or absorbed. In so far as insects are concerned, the main source of error in many cases is the difficulty of eliminating all muscular activity. Metabolism due to the functional activity of the whole organism is an increased metabolism over and above the standard. In many cases, in dealing with adult insects or their larvæ, standard conditions have not been obtained, but such experiments require consideration in the absence of the more exact data. Standard metabolism is more nearly approached in the quiescent stages of the egg and pupa, but the more rapid morphological changes undergone in those stages are not characteristic of ordinary development. In insects the respiratory exchange is high compared with other animals, but, as Krogh remarks, since the experiments have been made on a large number of insects at a time, the latter were often probably restless, and consequently standard conditions were not always obtained.

The literature on the subject of respiratory exchange in insects has been fully reviewed by Sayle (1928), but the available data admit of few general conclusions. Most observers studying the $\mathrm{CO}_{2}$ output in different stages of an insect record a reduction in the.pupa as compared with the larva or imago. The amount produced during a given stage generally rises with the temperature within certain limits. Several observers, including Krogh (1914), Weinland (1906) and Frew (1929), have shown that the respiratory exchange $\left(\mathrm{CO}_{2}\right.$ production) of insect pupæ is high at first, then 
falls for some days, and finally rises again, the final rise being possibly partly due to muscular movement within the nearly mature pupæ themselves, which is preparatory to the emergence of the imagines. The same general conclusions were arrived at by Taylor (1927) with reference to the $\mathrm{CO}_{2}$ production of certain dipterous and Lepidopterous pupæ, but in some species a marked depression was noted just before the time of emergence-a feature not previously noted by other observers. Krogh determined the $\mathrm{CO}_{2}$ output of pupæ of the beetle Tenebrio molitor at different temperatures from $21^{\circ}$ to $33^{\circ} \mathrm{C}$. (Table V.), and concluded that the total metabolism, as judged by this criterion, was constant over the range of temperatures given for individuals of uniform

Table V. $\mathrm{CO}_{2}$ Production by Pupæ of Tenebrio molitor.

(From Krogh.)

\begin{tabular}{c|c|c|c}
\hline $\begin{array}{c}\text { Temperature. } \\
{ }^{\circ} \mathrm{C}\end{array}$ & $\begin{array}{c}\text { Duration of Pupal } \\
\text { Life. } \\
\text { Hours. }\end{array}$ & $\begin{array}{c}\mathrm{CO}_{2} \text { produced during } \\
\text { Life by 1 kg. of Pupæ } \\
\text { (litres). }\end{array}$ & $\begin{array}{c}\text { Average } \mathrm{CO}_{2} \\
\text { production } \\
\text { per hour c.c. }\end{array}$ \\
\hline $32 \cdot 7^{\circ}$ & $137 \cdot 9$ & $59 \cdot 3$ & 427 \\
$27 \cdot 25^{\circ}$ & $172 \cdot 5$ & $58 \cdot 0$ & 336 \\
$23 \cdot 65^{\circ}$ & $234 \cdot 1$ & $59 \cdot 1$ & 252 \\
$20 \cdot 9^{\circ}$ & 320 & $59 \cdot 6$ & 186 \\
\hline
\end{tabular}

weight. ${ }^{1}$ Krogh also showed that the relation between temperature and $\mathrm{CO}_{2}$ output could not be satisfactorily expressed by van't Hoff's coefficient, and that between $20 \cdot 9^{\circ}$ and $27 \cdot 25^{\circ} \mathrm{C}$. the increment in $\mathrm{CO}_{2}$ production was proportional to the temperature: above $27^{\circ}$ it decreased, as did the velocity of development. Peairs (1927) also advanced some evidence that the amount of $\mathrm{CO}_{2}$ produced during the pupal instar of the fly Calliphora vomitoria is near a constant, irrespective of temperature, and he suggests that departures from the constant may represent basal metabolism not directly associated with the developmental processes. On the other hand, Northrop (1926) found that the amount of $\mathrm{CO}_{2}$ produced by Drosophila is not constant for either

1 Similar observations made by him on the eggs of the water beetle Acilius showed that a fixed amount of $\mathrm{CO}_{2}$ is produced during their incubation. 
larval or adult life, being greater at $15^{\circ}$ than at $26^{\circ}$ or $30^{\circ} \mathrm{C}$, but the factor of movement does not appear to have been taken into account.

Fatal Temperatures. A. Heat. A large amount of data has accumulated in recent years with reference to the thermal death point for many insects, but the results are discordant, and admit of only approximate comparisons. This is largely due to the fact that the length of time different insects were subjected to different temperatures varied within wide limits, and the same applies with regard to the interval elapsing between transference from one temperature to another, the conditions of humidity and other factors. In a state of nature the highest temperatures under which insects regularly live are those prevailing in hot springs and in deserts. In the case of hot springs (vide Brues, 1927), the highest temperature supporting insect life appears to be $49^{\circ}$ to $50^{\circ}$, Chironomid larvæ being abundant at the firstmentioned temperature in hot pools in the Yellowstone Park, U.S.A. Coleoptera of the genera Hydroscapha and Bidessus are regularly found in hot springs in Europe and North America at temperatures varying from $30^{\circ}$ to $46^{\circ}$. Buxton (1924) mentions that certain insects are active in the Palestine desert on bare earth whose surface temperature reaches $55^{\circ}$ to $62^{\circ}$. The lethal temperature for insects living in situations of this kind does not appear to have been investigated, and the results would yield data of considerable interest.

With regard to other insects, it may be mentioned that Graham found little difference in the thermal death points for the larvæ and adults of three species of beetles living in logs of timber, the mean death point being between $46^{\circ}$ and $48^{\circ}$, with a maximum fatal temperature of $50^{\circ}$ to $52^{\circ}$. In the case of the honey bee, Pirsch (1923) found that the fatal temperature lay between $46^{\circ}$ and $48^{\circ}$. The grain weevils Calandra granaria and $C$. oryzoe have frequently been the subject of temperature experiments, and Back and Cotton found that all stages were killed after one hour's exposure to a temperature of $47 \cdot 8^{\circ}$ to $48 \cdot 9^{\circ}$. Dendy and Elkington (1920) found that three minutes' exposure to $48 \cdot 9^{\circ}$ was the minimum time required to kill the adults of the first-mentioned 
species. On the other hand, these same observers ascertained that five minutes' subjection to a temperature of $62 \cdot 8^{\circ}$ was required to kill Rhizopertha dominica, also a grain-infesting beetle, but one which appears to be especially resistant to a high temperature. Clothes moth larvæ are killed after thirty-one minutes at $\mathbf{5 3} \cdot \mathbf{3}^{\circ}$ (Back), and the beetle Silvanus surinamensis in all its stages succumbs at a temperature of $51.7^{\circ}$ (Back and Cotton). Pediculus humanus, according to Nuttall, is killed in dry heat at $55^{\circ}$ after five minutes' exposure, while its eggs require ten minutes at $55^{\circ}$ to $61^{\circ}$.

The practical application of fatal high temperatures, with reference to insects infesting stored grain and analogous products, has come very much to the fore in recent years, and there is a considerable literature on the subject. Under such conditions it is obviously essential to ensure that every part of the material is heated to the temperature known to be lethal to the insects concerned. Much depends, therefore, upon the nature of the stored product that it is desired to sterilise, its moisture content and its bulk. Recent experiments by Barber (1929), with reference to the killing of caterpillars of the corn borer (Pyrausta nubilalis) within the ears of maize, will serve to illustrate this point. It appears that fifteen minutes' exposure to a temperature of $54^{\circ}$ is necessary to kill these larvæ. On. the other hand, to attain this temperature within the corn cobs the latter require to be subjected to a temperature of at least $60^{\circ}$ for a period of eight hours, or for a shorter time at higher temperatures. "It is probable that if stored food-products be heated uniformly to a temperature of $62 \cdot 8^{\circ}$, and maintained at that temperature for five minutes, they will be completely sterilised as regards all insect life (Dendy and Elkington). The same result, however, would be achieved by more prolonged exposure at lower temperatures, and it appears from a recent bulletin by Dean, Cotton and Wagner (1936) that a temperature of $49^{\circ}$ to $52^{\circ}$, applied for a period of ten to twelve hours, is sufficient to kill the various insect inhabitants of flour mills.

- Fatal Temperatures. B. Cold. ${ }^{1}$ When insects are subjected to

1 The greater part of this section is taken from a paper by A. D. Imms in Annals App. Biol., XIX., 1932, p. 125. 
temperatures that descend below the threshold of development, a point is reached where cold becomes fatal. This point varies enormously in different species, but is lowest in those which hibernate and is also dependent on several factors. Certain overwintering species are well capable of withstanding a temperature of $-50^{\circ}$. Remarkable as this fact is, it seems to fade into insignificance when compared with the resting phase in rotifers and tardigrades which have been recorded by Rahm (1923) in Germany to be able to withstand a temperature of $7^{\circ}$ absolute $\left(-272^{\circ}\right)$ for several hours. The researches of Robinson and Payne in America, and of Sacharov in Russia, have shown that cold resistance in insects is explainable on certain biophysical principles. Robinson's experiments showed that cold hardiness cannot be acquired by an insect rapidly-it requires a falling temperature. As the temperature sinks below freezing-point the colloid particles in the tissues and body fluids withdraw and bind free water as films around themselves. This so-called bound or adsorbed water ceases to behave as ordinary free water since it does not freeze even at $-20^{\circ}$. It is the ratio of bound to free water which, when sufficiently high, protects insects against freezing temperatures. In pupæ of the moth (Telea polyphemus) Robinson found that the bound water increased 48 to 50 per cent. when the insects had become fully cold hardened. Payne (1929) has stressed the importance of humidity, and her numerous experiments indicate that cold hardiness bears an inverse relation to absolute humidity, regardless of temperature. For a given temperature insects are acclimatised to, their survival at lower temperatures depends upon the amount of humidity present, as is shown in the accompanying table (Table VII.). In the case of the beetle (Synchroa punctata), Payne, by using thermo-electric methods, found that when the insects were placed in a desiccator at $15^{\circ}$ their freezing and undercooling points were greatly lowered. Thus, in the normal larvæ, these points were $-3 \cdot 04^{\circ}$ and $-6 \cdot 71^{\circ}$ respectively, whereas in the desiccated larvæ these same points were $-71 \cdot 4^{\circ}$ and $23 \cdot 26^{\circ}$. It therefore appears that the moisture content of the insect itself is also an important factor in the process. Now the water content of insects is known to have a direct relation 
TABLE VI. Water Content of Various Insects and their Food. (From Robinson, 1928.)

\begin{tabular}{|c|c|c|c|}
\hline Species. & Food Plant. & $\begin{array}{l}\text { Water } \\
\text { Content of } \\
\text { Food. } \\
\text { Per cent. }\end{array}$ & $\begin{array}{c}\text { Water } \\
\text { Content of } \\
\text { Insects. } \\
\text { Per cent. }\end{array}$ \\
\hline $\begin{array}{l}\text { Granary weevil, adult } \\
\text { (Sitophilus granarius) }\end{array}$ & Stored wheat & $9-11$ & $46-47$ \\
\hline $\begin{array}{l}\text { Rice weevil, adult } \\
\quad \text { (Sitophilus oryza) }\end{array}$ & Stored wheat & $15-16$ & $48-50$ \\
\hline $\begin{array}{l}\text { Locust borer, adult } \\
\text { (Cyllene robinice) }\end{array}$ & Locust tree trunk & $30-32$ & $56-60$ \\
\hline $\begin{array}{l}\text { Colorado potato beetle, adult } \\
\text { (Leptinotarsa decemlineata) }\end{array}$ & $\begin{array}{l}\text { Potato plant, leaves and } \\
\text { stem }\end{array}$ & $70-74$ & $62-66$ \\
\hline $\begin{array}{l}\text { White grub, larva } \\
\text { (Phyllophaga spp.) }\end{array}$ & Wheat shoots and roots & $64-67$ & $73-82$ \\
\hline $\begin{array}{l}\text { Mourning cloak, larva } \\
\text { (V anessa antiopa })\end{array}$ & Willow leaves & $70-73$ & $77-79$ \\
\hline $\begin{array}{l}\text { Willow saw-fly, larva } \\
\text { (Cimbex americana) }\end{array}$ & Willow leaves & $70-73$ & $79-82$ \\
\hline $\begin{array}{l}\text { Cutworm, larva } \\
\text { (Chorizagrotis) }\end{array}$ & Lettuce & $78-79$ & $83-88$ \\
\hline $\begin{array}{l}\text { Army-worm, larva } \\
\text { (Cirphis unipuncta) }\end{array}$ & Corn leaves and stem & $77-78$ & $87-89$ \\
\hline $\begin{array}{l}\text { Imported cabbage-worm } \\
\text { (Pontia rapa) }\end{array}$ & Cabbage & $88-89$ & $83-84$ \\
\hline $\begin{array}{l}\text { Polymephus moth, larva } \\
\text { (Telea polyphemus) }\end{array}$ & Hazel leaves & $71-73$ & $90-92$ \\
\hline
\end{tabular}

Table VII. Cold Hardiness in Tussock Moth Eggs. (From Payne, 1929.)

\begin{tabular}{|c|c|c|c|}
\hline $\begin{array}{l}\text { Environmental } \\
\text { Temperature }{ }^{\circ} \mathrm{C} .\end{array}$ & $\begin{array}{c}\text { Survival } \\
\text { Temperature. }\end{array}$ & $\begin{array}{l}\text { Relative Humidity } \\
\text { in per cent. }\end{array}$ & $\begin{array}{l}\text { Absolute } \\
\text { Humidity. }\end{array}$ \\
\hline \multirow[t]{3}{*}{20} & $-1.5 \pm 0.5$ & 100 & $17 \cdot 5$ \\
\hline & $-6.1 \pm 1 \cdot 3$ & 80 & $13 \cdot 9$ \\
\hline & $-11 \cdot 5 \pm 2.4$ & 50 & $9 \cdot 0$ \\
\hline \multirow[t]{3}{*}{15} & $-7 \cdot 0 \pm 1.7$ & 100 & $12 \cdot 8$ \\
\hline & $-10.0 \pm 2.25$ & 80 & $10 \cdot 2$ \\
\hline & $-13.5 \pm 3.1$ & 50 & $6 \cdot 5$ \\
\hline \multirow[t]{3}{*}{10} & $-11 \cdot 0 \pm 2.3$ & 100 & $9 \cdot 2$ \\
\hline & $-13 \cdot 3 \pm 3 \cdot 2$ & 80 & $7 \cdot 4$ \\
\hline & $-16.5 \pm 5.6$ & 50 & $4 \cdot 6$ \\
\hline \multirow[t]{3}{*}{0} & $-16.5 \pm 4.1$ & 100 & $4 \cdot 6$ \\
\hline & $-17 \cdot 0 \pm 3.0$ & 80 & $3 \cdot 5$ \\
\hline & $-20.0 \pm 5.3$ & 50 & $2 \cdot 2$ \\
\hline
\end{tabular}


to that of food (Table VI.). Grain weevils have a water content of 45 to 50 per cent.; in the cabbage butterfly larvæ it is 83 to 84 per cent. Payne also found that cold resistance is greater in starved larvæ and lower in those fed with moist food. Her conclusions have been confirmed, and in some directions amplified, by the work of Sacharov (1930). This experimenter paid particular care to the technique employed. He avoided the insertion of thermopile needles into the insects by employing the dilatometer and criohydrate solutions. In this way surgical shock, which causes a measurable rise in temperature, was avoided. Sacharov's conclusions are apparently based upon careful technique, and they may be briefly summarised as follows. Cold hardiness depends upon two intrinsic factors : (1) the proportion of easily freezable water to the total water content, and (2) the percentage of fat present. Hibernating insects, he claims, fortify themselves by reducing the one and increasing the other. He tested these two factors in the caterpillars of the brown-tail moth taken straight from hibernation and after feeding for several days in a warm chamber. The differences are very striking, and his results are quoted below (Table VIII.).

Sacharov further carried out a number of observations upon different insects, taken from their natural habitats during winter, and subjecting them to different temperatures. His results are shown in abstract in the accompanying table (Table IX). With chafer larvæ he points out that the reason for their penetration to greater depths in the soil during hibernation appears to be due to their possessing but a limited capacity for cold hardening. They would seem to have an exceptionally high water content and even at a temperature no lower than $-5 \cdot 7^{\circ}$ the amount of non-frozen water was found to be only 25.7 per cent. of the total water. The hive bee is well known to be susceptible to the effects of cold and damp and requires well-insulated quarters for hibernation. In this connection Sacharov's results are rather unexpected, since it would seem that this insect is more resistant than chafer larvæ. The adult of the herald moth (Scoliopteryx libatrix) and the larvæ of the longicorn (Plagionotus arcuatus), are both highly resistant to the cold. In the case of the herald moth, which hibernates 
Table VIII. Freezable Water and Fat in Caterpillars of the Brown-tail Moth, Euproctis chrysorrhce L. (From Sacharov, 1930.)

\begin{tabular}{|c|c|c|c|c|c|c|c|}
\hline \multirow[b]{2}{*}{$\begin{array}{l}\text { Temp. } \\
\circ \mathrm{C} .\end{array}$} & \multirow[b]{2}{*}{$\begin{array}{l}\text { Water. } \\
\text { Per cent. }\end{array}$} & \multirow{2}{*}{$\begin{array}{c}\text { Dry } \\
\text { Substance. } \\
\text { Per cent. }\end{array}$} & \multirow{2}{*}{$\begin{array}{l}\text { Ratio of } \\
\text { Frozen } \\
\text { Water } \\
\text { to Live } \\
\text { Weight. }\end{array}$} & \multirow{2}{*}{$\begin{array}{c}\text { Ratio of } \\
\text { Frozen } \\
\text { Water } \\
\text { to Total } \\
\text { Water. }\end{array}$} & \multirow{2}{*}{$\begin{array}{l}\text { Non- } \\
\text { frozen } \\
\text { Water. }\end{array}$} & \multicolumn{2}{|c|}{ Fat. } \\
\hline & & & & & & $\begin{array}{l}\text { Ratio } \\
\text { to Live } \\
\text { Weight. }\end{array}$ & $\begin{array}{l}\text { Ratio } \\
\text { to Dry } \\
\text { Weight. }\end{array}$ \\
\hline & & \multicolumn{4}{|c|}{ A. Caterpillars from hibernating nests. } & & \\
\hline-5.75 & $71 \cdot 83$ & $28 \cdot 17$ & - & - & 100 & $4 \cdot 93$ & $16 \cdot 4 \cdot 4$ \\
\hline$-7 \cdot 8$ & $71 \cdot 83$ & $28 \cdot 17$ & - & - & 100 & 4.93 & $16 \cdot 44$ \\
\hline$-11 \cdot 1$ & $71 \cdot 83$ & $28 \cdot 17$ & $3 \cdot 63$ & $5 \cdot 06$ & $94 \cdot 94$ & $4 \cdot 93$ & $16 \cdot 4 \cdot 4$ \\
\hline$-17 \cdot 35$ & $71 \cdot 83$ & $28 \cdot 17$ & $10 \cdot 93$ & $15 \cdot 22$ & $84 \cdot 78$ & $4 \cdot 93$ & $16 \cdot 4 \cdot 4$ \\
\hline & & B. Cat & rpillars & d for : & days. & & \\
\hline$-\quad 3 \cdot 9$ & $82 \cdot 94$ & $17 \cdot 06$ & - & - & 100 & $2 \cdot 52$ & $12 \cdot 46$ \\
\hline-5.75 & $82 \cdot 94$ & $17 \cdot 06$ & $4 \cdot 13$ & $4 \cdot 98$ & 95.02 & $2 \cdot 52$ & $12 \cdot 46$ \\
\hline$-7 \cdot 8$ & $82 \cdot 94$ & $17 \cdot 06$ & $37 \cdot 20$ & $44 \cdot 85$ & $55 \cdot 15$ & $2 \cdot 52$ & $12 \cdot 46$ \\
\hline
\end{tabular}

Note. In series A the caterpillars withstood a temperature of $-\mathbf{1 7 \cdot 3 5 ^ { \circ }}$, while in series B 82 per cent. succumbed at $-7 \cdot 8^{\circ}$.

TABle IX. Freezable Water and Fat in Various Insects.

(From Sacharov, 1930.)

\begin{tabular}{|c|c|c|c|c|c|c|c|}
\hline \multirow[b]{2}{*}{$\begin{array}{l}\text { Temp. } \\
\circ \mathrm{C} \text {. }\end{array}$} & \multirow[b]{2}{*}{$\begin{array}{l}\text { Water } \\
\text { Per cent. }\end{array}$} & \multirow{2}{*}{$\begin{array}{c}\text { Dry } \\
\text { Substance. } \\
\text { Per cent. }\end{array}$} & \multirow{2}{*}{$\begin{array}{l}\text { Ratio of } \\
\text { Frozen } \\
\text { Water } \\
\text { to Live } \\
\text { Weight. }\end{array}$} & \multirow{2}{*}{$\begin{array}{l}\text { Ratio of } \\
\text { Frozen } \\
\text { Water } \\
\text { to Total } \\
\text { Water. }\end{array}$} & \multirow{2}{*}{$\begin{array}{l}\text { Non- } \\
\text { frozen } \\
\text { Water. }\end{array}$} & \multicolumn{2}{|c|}{ Fat. } \\
\hline & & & & & & $\begin{array}{l}\text { Ratio } \\
\text { to Live } \\
\text { Weight. }\end{array}$ & $\begin{array}{c}\text { Ratio } \\
\text { to Dry } \\
\text { Weight. }\end{array}$ \\
\hline$-\quad 5 \cdot 75$ & $79 \cdot 16$ & $\begin{array}{c}\text { Larvæ of } \\
20 \cdot 84\end{array}$ & $\begin{array}{l}\text { Melolon } \\
\mathbf{5 9 \cdot 1 3}\end{array}$ & $\begin{array}{c}\text { hippo } \\
74 \cdot 27\end{array}$ & $\begin{array}{c}\text { astani } \mathrm{L} \text {. } \\
25 \cdot 73\end{array}$ & 6.07 & $29 \cdot 80$ \\
\hline & & Adults & of Scolio & teryx lib & $\operatorname{trix} \mathrm{L}$. & & \\
\hline$-\quad 5.75$ & $48 \cdot 65$ & $51 \cdot 35$ & - & - & 100 & $18 \cdot 18$ & $56 \cdot 31$ \\
\hline$-11 \cdot 1$ & $48 \cdot 65$ & $51 \cdot 35$ & 13.97 & $28 \cdot 91$ & $71 \cdot 19$ & $18 \cdot 18$ & $56 \cdot 31$ \\
\hline$-17 \cdot 35$ & $48 \cdot 65$ & $51 \cdot 35$ & $25 \cdot 94$ & $53 \cdot 39$ & $46 \cdot 61$ & $18 \cdot 18$ & $56 \cdot 31$ \\
\hline & & Larvæ & Plagic & tus arcu & us $\mathrm{L}$. & & \\
\hline $11 \cdot 1$ & $54 \cdot 12$ & $45 \cdot 88$ & - & - & 100 & $14 \cdot 36$ & $30 \cdot 05$ \\
\hline $17 \cdot 35$ & $54 \cdot 12$ & $\begin{array}{c}45 \cdot 88 \\
\text { Adults of }\end{array}$ & $\begin{array}{r}1 \cdot 80 \\
\text { loney b }\end{array}$ & $\begin{array}{l}3.53 \\
\text { Apis } m\end{array}$ & $\begin{array}{c}96 \cdot 47 \\
\text { ellifera } \mathrm{L} .\end{array}$ & - & - \\
\hline$-\quad 2.9$ & 74.05 & 25.95 & $2 \cdot 58$ & $3 \cdot 48$ & $96 \cdot 52$ & $2 \cdot 66$ & $10 \cdot 26$ \\
\hline$-\quad 5.75$ & 7405 & $25 \cdot 95$ & $27 \cdot 36$ & 26.97 & $36 \cdot 03$ & $2 \cdot 66$ & $10 \cdot 26$ \\
\hline$-11 \cdot 1$ & 74.05 & 25.95 & $54 \cdot 72$ & 73.92 & $26 \cdot 08$ & $2 \cdot 66$ & $10 \cdot 26$ \\
\hline
\end{tabular}

R.A. ENTOMOLOGY. 
under bark, in thatch buildings, etc., Sacharov mentions that it has been found coated with ice and yet subsequently revived and became active. It will be observed that its total water content is very low and 71 per cent. of this water was non-frozen at $-11 \cdot 1^{\circ}$, while the ratio of fat to live weight appears to be high.

The work of the three observers mentioned has put us on the track of understanding the way of solving the problem of cold hardiness in insects and that it is linked up with the biophysics of metabolic water in the living creatures. All that we know about this water is that in cold hardy species a high proportion of it is held in a peculiar phase that does not freeze until relatively very low temperatures are attained. Whether this water is actually bound or adsorbed in the strict physical sense will not be discussed here.

In a state of nature we may picture to ourselves what appears to happen to an insect when it enters into hibernation. It ceases to feed, and wanders until it discovers an appropriate resting place. At this period it has a liberal store of fat in its tissues that has accumulated during the preceding period of activity. Its water content is reduced and, as the prevailing temperature of its environment gradually falls away during autumn and early winter, the ratio of non-freezable to total water in its body increases in relation to the fall in its freezing and supercooling points. Cold dry weather, it would seem, aids the acquisition of the insect's powers of resistance, whereas cold damp weather is much less favourable. It is probable that vast numbers of insects perish when the acquisition of cold hardening is interfered with, since the fatal supercooling point is higher and more quickly reached. The farmer, in cultivating his land during winter, disturbs the winter quarters of immense numbers of insects. These are often brought in the process into contact with much lower temperatures than their hardening capacity enables them to resist, and large numbers are killed.

For the most recent contribution to the subject of freezing temperatures in relation to insect life, the reader is referred to a paper by Salt (1936). In addition to giving a critical review of the literature up to date, this author describes improved apparatus 
for studying the undercooling and rebound points and for maintaining a continuous accurate record of body-surface temperatures. Many important aspects of the subject are dealt with, and among them the effect of moisture in contact with the body-surface may be specially mentioned. This is usually in the form of ice, and in many insects it is found to result either in the reduction or complete elimination of the capacity for undercooling. In some other insects it seems that no effect in this connection results from a relatively heavy coating of ice or water. 


\section{CHAPTER IX}

\section{SOME ASPEGTS OF EGOLOGY-continued}

Humidity, p. 228. Light, p. 235. Atmospheric Pressure, p. 237. Air Currents, p. 238. Food. The General Subject, p. 239 ; Vitamins, p. 243 ; Symbiotic Micro-organisms, p. 245. Climate. Geographical Distribution, p. 251 ; Climate in Relation to Seasonal Prevalence, p. 257. Literature, p. 259.

\section{Humidity}

THE influence of humidity on insects has attracted a good deal of attention in recent years. Before considering the effects of humidity as an ecological factor it is necessary to refer briefly to the subject of water balance and kindred problems in the insect body which have a very definite bearing upon it. While the water necessary for the maintenance of the insect organism is derived in the main from the food, there is evidence that at least some part of it may be obtained from other sources. The mealworm (Tenebrio molitor) appears to be one of the insects that is known to be able to make use of water resulting from the oxidation of its own reserve substances. According to Buxton (1930) this insect is able to regulate the proportion of water and dry matter in its body. This ratio, it was found, was constant in starved insects kept at several relative humidities over a period of a month at $23^{\circ} \mathrm{C}$. Certain insects appear to be able to absorb water from moist air. Here the best-known example is the mealworm. The actual mechanism by means of which this "hygroscopic property" functions is, however, unexplained. According to Buxton (1930) meal-worms lose weight when kept at 80 per cent. or lower relative humidity : but if kept at 90 per cent. humidity and at a temperature of $23^{\circ} \mathrm{C}$. or $30^{\circ} \mathrm{C}$. they gain in weight. The mean gain in weight, Buxton states, represents water; and during twenty-three days at $30^{\circ} \mathrm{C}$. and 90 per cent. relative humidity, from 57 to 65 per cent. of the total weight of 
the insects. It is concluded, therefore, that meal-worms are able to gain water from an atmosphere which is 90 per cent. saturated. Other instances of a kindred nature are also quoted by Buxton in his general review on humidity (1932). That the eggs of some insects also absorb water is certain. Roonwal (1936), for example, has recently shown that in the African migratory locust (Locusta migratoria migratorioides) the water content of the egg increases from about 52 per cent. of the net weight in the freshly laid egg to 82 per cent. in the fully developed egg. The water in this case is most probably absorbed from the surrounding soil in which the eggs are laid.

Both climatic conditions and metabolism affect the rate at which water is lost from the bodies of insects. This rate of water loss, when measured in air of different humidities, bears a general relation to the saturation deficiency of the air. According to Mellanby (1935) practically all the water evaporated from the body of an insect is lost through the tracheal system. This conclusion is disputed by Ramsay (1935B), who showed that in Periplaneta a considerable proportion of the water given off is evaporated from the body-surface and at $30^{\circ} \mathrm{C}$. a sudden increase in the rate of evaporation occurs. This phenomenon, he states, results from the presence of a thin film of fatty substance on the body-surface which undergoes a change of state at that temperature in that it shows a greatly increased permeability to water. Many insects can reduce their body temperature below that of surrounding air when the latter is tolerably dry and hot, and this temperature regulation is brought about by evaporation.

The existence of an insect in an atmosphere approaching saturation depends on the excretion of water through the Malpighian tubes and in the fæces. On the other hand, in an insect living under extremely dry conditions, any loss of water viâ the alimentary canal is practically nil. At the same time, by excreting solid uric acid, which is insoluble, water is conserved and any water present in the hind intestine appears to be resorbed by means of the rectal papillæ (Wigglesworth, 1932). The regulation of the water content of the insect organism is, as already mentioned (p. 222), also important in connection with its 
survival at freezing temperatures. In order to survive it must avoid ice-formation in its blood and tissues. Water loss by concentrating salts and other solutes in the body-fluid lowers the freezing point. The adsorption or "binding" of much of the remaining water by the colloids of the body still further lowers the freezing point. The relation of " bound " to free water appears to be highest in those insects which are able to withstand the greatest degree of cold.

While certain insects, such as Rhodnius, are unaffected by humidities ranging from 0 to 90 per cent., even with twenty-four hours' exposure, with others such as flea larva the death point is at a lower temperature in dry air. The cockroach, however, can survive a higher temperature in dry air- $10^{\circ}$ higher - than in moist air (Bodenheimer, 1927). The adult Calliphora and the beetle Epilachna, on the other hand, survive best at moderate humidities of 60 per cent. or over. Davies (1928) has shown that atracheate species of Collembola require a saturated atmosphere in order to survive even a few hours at a constant temperature of $25^{\circ}$. On the other hand, the tracheate form, Sminthurus viridis, proved more resistant and was able to live fifteen hours at 20 per cent. humidity before all were killed off.

Experiments by Headlee (1917), on the effects of atmospheric humidity on the bean weevil (Bruchus obtectus) and the Angoumois grain moth (Sitotroga cerealella), are noteworthy. The insects were kept uniformly in the dark and at a constant temperature of $21 \cdot 1^{\circ}$. In their late larval and pupal stages these two species exhibited a marked reduction in rate of metabolism in relation to increase of humidity. The pupal stage of the moth lasted seventeen days in 100 per cent. humidity, and was reduced to twelve days when the humidity was 21.8 per cent. ; in the case of the weevil the corresponding periods were twenty-two days in 100 per cent. humidity, and fourteen days at $44 \cdot 6$ per cent. humidity. With the adult insects the evidence pointed to decreased humidity shortening the life of the moth, and lengthening that of the bean weevil. In the case of the eggs of the latter insect, two days longer were required for hatching when the humidity was 100 per cent., as compared with one of $\mathbf{2 3 . 6}$ per cent. Taking the life- 
cycle as a whole, development was most rapid at about 90 per cent. humidity, the shortening apparently occurring at the stages when feeding was most active; with a humidity of 25 per cent. comparatively few of the insects attained maturity, and even fewer at lower moisture conditions. The same author's earlier, and well-known, experiments with the aphid Toxoptera graminum show a much greater tolerance of variations of atmospheric humidity. At a constant temperature of $26 \cdot 6^{\circ}$ the same developmental rate was maintained at relative humidities varying from 37 to 100 per cent. It has been suggested that, with sap-sucking

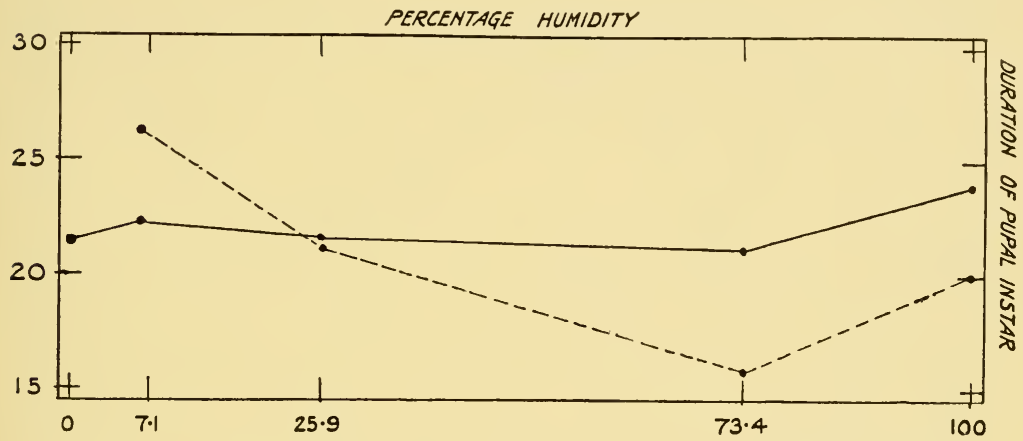

Fig. 71. Relation between humidity percentage and length of pupal instar in days for Protoparce quinquemaculatus and its parasite Winthemia 4-pustulata (broken line). (Adapted from Hefley.)

insects, this range of tolerance is explainable on account of the relative unimportance of atmospheric humidity, since the insect is rendered largely independent of such conditions on account of the moisture obtainable through its food. This conclusion is supported in a general way by more recent observations by Wadley (1931).

The experiments of Hefley (1928), with the pupæ of the hawk moth Protoparce quinquemaculatus, and its Tachinid parasite Winthemia quadripustulata, will serve to illustrate the differential effects of humidity upon two separate species, living in close association. The host does not, it appears, exhibit a definite optimum reaction to humidity, since the duration of its pupal 


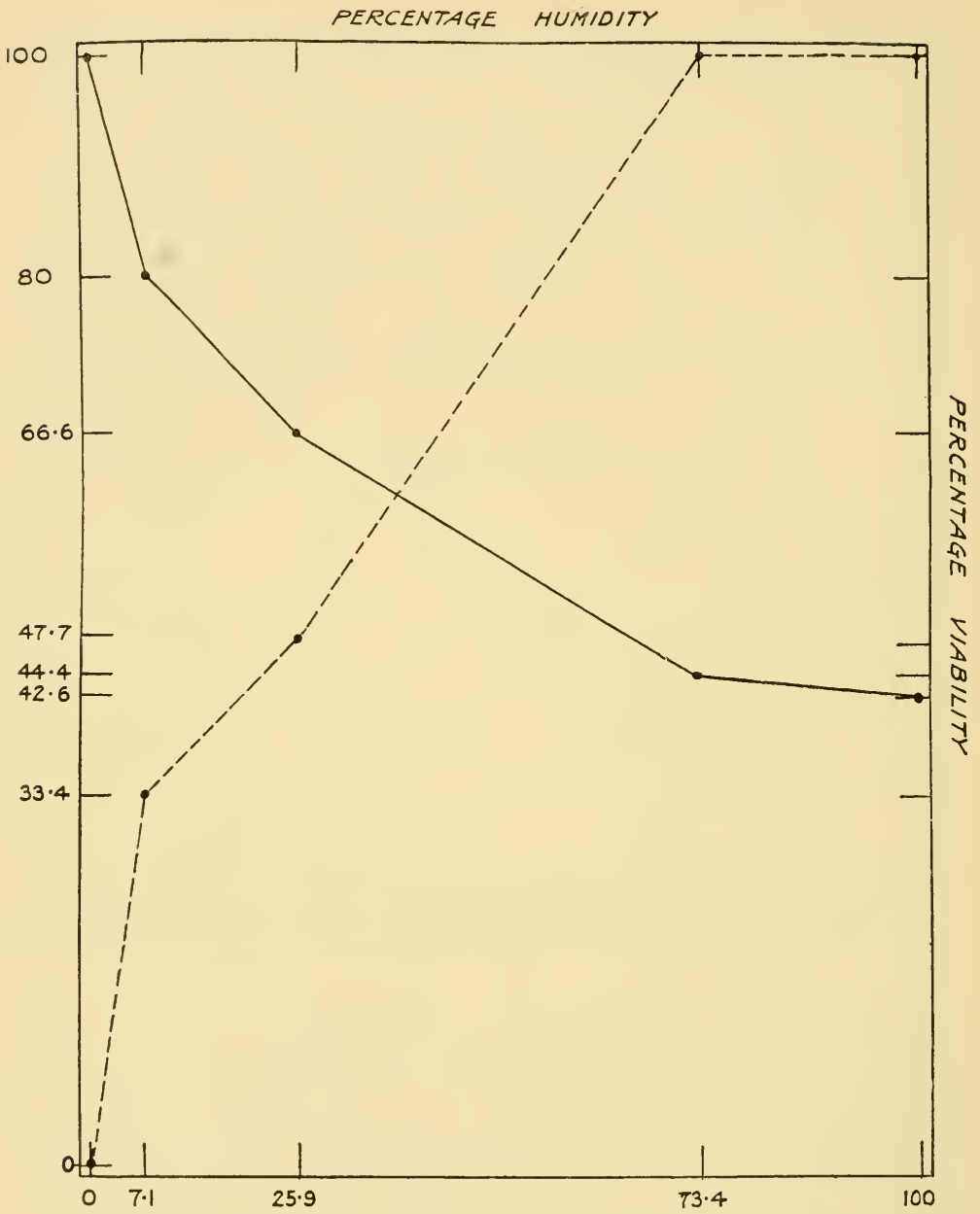

Fig. 72. Relation between humidity percentage and percentage viability (emergence from the pupa) for Protoparce quinquemaculatus and its parasite Winthemia 4-pustulata (broken line). (Adapted from Hefley.)

instar only varied $\mathbf{1 . 5}$ days over a range of atmospheric moisture from 0 to 73.4 per cent., where the temperature remained nearly constant at $27^{\circ}$. The optimum humidity for the parasite at the 
same temperature is at $\mathbf{7 3 \cdot 4}$ per cent., when the length of its pupal instar is at its minimum; between that percentage and $\boldsymbol{7 \cdot 1}$ per cent. humidity its developmental period showed a difference of 10.5 days. At 0 per cent. humidity and $27^{\circ}$ temperature all the parasites failed to complete their development, whereas all the hosts emerged. This feature does not appear to be attributable to variations in metabolic activity, but rather to differential powers of resistance to desiccation in the two instances, since both species of insect showed their highest rate of development at. about $\mathbf{7 3 \cdot 4}$ per cent. humidity. Above the latter figure, up to 100 per cent. humidity, the duration of the pupal period of both host and parasite showed a progressive lengthening. If viability be judged by the percentage emergence from the pupæ, it is noteworthy that host and parasite behave very differently in this respect, dryness favouring the former and high humidity the latter (vide Figs. 71 and 72).

Griswold and Crowell (1936) discuss the influence of humidity on the length of life-cycle in the webbing clothes moth (Tineola biselliella). At a constant temperature of $25^{\circ} \mathrm{C}$. this insect developed under relative humidities ranging from 20 to 93 per cent. At 75 per cent. humidity development was more rapid than under other moisture concentrations, mortality was lowest and adults lived longest. A humidity of 93 per cent. proved more deleterious to the insect than 20 or 30 per cent. In the case of the cockroach (Blatta orientalis), Gunn (1934) states that the preferred temperature range is $20^{\circ}$ to $29^{\circ} \mathrm{C}$., and that this zone is not affected by changes in the humidity of the air. With tsetse flies (Glossina), Buxton and Lewis (1934) found that the effects of humidity are complex. Flies kept at $30^{\circ} \mathrm{C}$. behaved under 44 per cent. humidity in a way which suggests that this concentration is near the optimum : at humidities above or below this figure the flies fed less often, and at 88 per cent. humidity they nearly always refused to feed and died. It was also observed that the adults lived longest and bred best at 44 per cent. humidity. At higher temperatures the effects of humidity are clearly shown, since the insects are able to survive in drier air for a short period at $42^{\circ}$ to $43^{\circ} \mathrm{C}$--temperatures which are fatal in moist air. Field observa- 
tions were found to be in good accord with those conducted in the laboratory. Thus, at the end of the dry season, adults of Glossina tachinoides are abundant and a high proportion of the females are pregnant, and it was found that at this period the seasonal climatic conditions were close to the optimum as defined in the laboratory. For a detailed discussion of the relations of various insects to humidity, reference should be made to the writings of Uvarov (1931) and of Buxton (1932).

Readers interested in the various methods of technique relative to the measurement and control of humidity should consult papers by Buxton (1931) and Buxton and Mellanby (1934), which are mainly concerned with the maintenance of required humidities within closed vessels such as desiccators. In many cases it is preferable to pass air, conditioned to the required humidity, through the containers within which the insects are lodged: such a method, for example, is described by Gunn (1934). The purely physical problems, which are fundamental in attempts to establish a relation between the loss of water from an animal and the evaporating power of the air, are discussed by Ramsay (1935A).

It is customary in entomological experiments to express humidity in relative terms-i.e., if the relative humidity, for example, be 60 per cent, it means that the air holds that amount of water vapour, as compared with the maximum, at the particular temperature of the experiment. The loss of water from the insect and the direct influence of humidity upon it are related to the evaporating power of the air. The relative humidity may be the same in two separate experiments under different temperatures, yet the amount of water which the air would require to take up before reaching the saturation point would be different in the two cases. Relative humidity consequently does not express the evaporating power of the air, and in cases where it is desirable to measure this latter factor the saturation deficiency of the air is the index required. The saturation deficiency, it may be added, provides comparable figures for the evaporating capacity of the air upon which loss of water depends. The rate of evaporation is influenced by several factors, including temperature, air move- 
ment and barometric pressure. Shelford, in America, has devoted a good deal of attention to this subject and has adopted the method of measuring evaporation from an exposed surface of water by means of a porous cup atmometer. Several types of the latter instrument have been devised and are described in Shelford's recent work on ecology (1929). By use of an atmometer he conducted experiments on the reactions of insects to air of different evaporating powers. It was found that certain species reacted to air of similar evaporating capacity irrespective of whether humidity, air currents or temperature was the chief controlling factor influencing the rate of evaporation. The atmometer is probably the most convenient instrument so far devised for giving a single measurement of the combination of factors that are involved, but, at the same time, it provides little or no information as regards any individual effects. When critical analyses of the factors involved are desired it is necessary to take measurements of wind, temperature and humidity at the same time.

\section{Light}

Almost all experimental work dealing with the effects of light on insects is in relation to their sensory behaviour and not to its influence upon general metabolism and growth. Northrop (1926) is one of the few experimenters who have investigated the effect of light intensity in relation to growth; he tested this factor with reference to the duration of the larval and imaginal instars of Drosophila, using cultures which had been previously kept in the dark for 200 generations. The source of light used was a concentrated filament Mazda bulb immersed in a vessel of running water, and its intensity was measured with a contrast photometer against a standard Hefner amyl acetate lamp. At intensities around 2,500 metre candles the duration of thr larval life was slightly reduced, but it became increasingly lengthened at higher intensities until they were killed at 7,000 to 10,000 metre candles, while the pupæ were killed at 5,000 metre candles. Above 1,000 metre candles the duration of the imaginal life was rapidly shortened. The actual effect of the action of the light is difficult 
to evaluate owing to its influence upon movement. A number of observers have recorded an increase in $\mathrm{CO}_{2}$ production under its influence as compared with darkness, the increment in most cases being attributable to the stimulating effect of light upon movement. In the case of the larvæ of Drosophilat this same explanation may hold good and excess of movement thus caused may result in retarded development. It would seem desirable that critical experiments, upon the influence of light, be carried out with reference to eggs and pupæ in which conditions of standard metabolism prevail.

It is very questionable whether light, even when of high intensity, is ever the cause of death in insects. Closely connected is the problem of radiant heat, and there is good evidence that the death of insects under direct sunlight is due to this cause, or to its effect on water loss from the body.

The effects of the daily duration of light upon the production of different types of reproductive forms in aphides have been investigated by Marcovitch (1924), and by Davidson (1929). They have shown that the incidence of the sexuales generations appears to be influenced by length of day under the conditions of their experiments. By reducing the normal amount of daylight per diem the production of sexual forms was induced at times of the year when they do not normally occur. Conversely, by extending the duration of daylight, asexual viviparous reproduction results during times of the year when only sexual reproduction normally prevails. The influence of light in such experiments appears to be important, but it is not a clearly defined result, owing to its effect on the host plants upon which the aphides were feeding. Also, the factor of temperature cannot be entirely excluded.

Very similar results have been obtained more recently by Wadley (1931), who found that in the aphid Toxoptera graminum sexual forms can be induced to appear under defined experimental conditions. These conditions involved the shortening of the days to less than twelve hours and temperatures averaging below $22^{\circ} \mathrm{C}$. No other conditions affecting their appearance were noted.

Early experiments, on the differential effects of limited parts of 
the spectrum, have shown that violet rays exercise an apparent stimulating effect upon growth in the case of flesh-fly larvæ and silkworms and also with animals other than insects. This subject, however, has not been followed up in recent years, but is one which merits critical examination with modern technique.

\section{Atmospheric Pressure}

Observations on the influence of changes of atmospheric pressure upon insects are too scanty to admit of any deductions to be drawn. A few field observations have been recorded which indicate that such changes do affect insect behaviour, and certain early experimenters adduced evidence that insects are able to survive in a partial vacuum even for many days. The evidence appears to indicate, however, that ordinary barometric changes which prevail in Nature probably exercise no very profound influence upon insect life. Recent experimental investigations on the subject are very few. According to Pictet (quoted from Uvarov, 1929), a uniform reduced pressure of 710 to $728 \mathrm{~mm}$. maintained throughout the pupal instar of Pieris rapce greatly shortens development, the duration of this stage being reduced to nine days as compared with a normal period of fifteen days. The emergence of the adults appears to take place mostly at times of reduced barometric pressure, a diminution of only $1 \mathrm{~mm}$. being stated to be sufficient to induce eclosion, provided the insect be in a condition ready for emergence. It would appear that a fall in atmospheric pressure operates through creating a difference in relation to the internal pressure within the insect itself.

Experiments conducted by Back and Cotton (1925) with reference to the effects of vacuum treatment upon insects affecting stored products revealed considerable differences in their powers of resistance. Adults and pupæ succumbed more quickly than larvæ when subjected to a vacuum of 28 to 29 inches in a bell-jar, and of 24 to 28 inches in a concrete vault, at a temperature in both cases of $15 \cdot 5^{\circ}$ to $21 \cdot 0^{\circ}$. Three days' treatment in a concrete vault killed not only all the adults of twelve out of eighteen species, but also the pupæ of all the species present in that stage, and all the larvæ of several species. It required seven days' treat- 
ment, however, to kill the surviving adults of every species, but that duration proved insufficient for the complete extinction of the larvæ of Attagenus piceus, Tenebrio obscurus and Trogoderma tarsale. The last-mentioned species proved the most resistant and suffered a mortality of only 30 per cent. These results are not in accord with those carried out in the bell-jar experiments, when complete mortality of the insects in all their stages occurred within four days. The experiments prove, however, that individuals of certain species of insects can withstand several days' subjection to an almost complete vacuum. The treated specimens, it may be added, were retained for two weeks after the experiment and frequently examined to ascertain whether recovery took place.

\section{Air Currents}

Within the last fifteen years or so some attention has been given by Coad (1931) and others in America, and more recently by Berland (1934) in France, to the carriage of insects by currents of the upper air. By the adoption of trapping arrangements attached to aeroplanes, small insects, including a good many wingless forms, have been collected up to an altitude of at least 14,000 feet. Once such creatures become carried upwards by convection or other movements it would appear that it is possible for them to be transported long distances, since the upper air currents are stated to be both strong and constant in direction. Buxton (1935) in discussing the Samoan fauna, concludes that a number of facts concerning the distribution of the insects can be best explained on the supposition of their having reached the islands viâ the upper air. It is obvious that when a more extended study of insects occurring in the upper air has been undertaken we may be in a position to be able to account for some of the anomalies of insect distribution. It has also certain very obvious economic implications regarding the entry of injurious species into lands which they did not previously inhabit. Furthermore, quarantine regulations naturally have to be considered in a new light, and previously unaccountable cases of their inefficacy seem now to be explained, The fortuitous transport of noxious 
insects by aeroplanes is scarcely any longer an entirely novel subject. The possibility, for example, of mosquitoes infected with the virus of yellow fever becoming stowaways in aeroplanes and thus obtaining passages to territory free from that disease is a subject of inquiry at the present time. In England an investigation of insects of the upper air is being carried out under the direction of Professor A. C. Hardy of University College, Hull. By the use of suitable kites, with opening and closing nets attached, the heights at which insects are obtained can be properly registered. This method is an adaptation of the tow-net principle used in sampling life in the depths of the sea. Professor Hardy informs me that, so far, rather more than 2,000 feet is the maximum height sampled. A series of nets, attached at different heights, to the 300 feet masts of a wireless station in Lincolnshire is another experiment. It is providing information respecting the drift of insects at such heights in relation to meteorological data on a linear distance of approximately one mile. Similarly, by flying kites with nets attached, while on board a fisheries research vessel in the North Sea, Professor Hardy states that quite surprising collections were obtained of insects drifting above the sea up to a distance of $\mathbf{1 5 0}$ miles from the land. In these cases the kites were flown up to 400 feet in the air, while other nets were attached to the masthead of the vessel. The preparation of some of the results of this work is now nearing completion for the press.

\section{Food}

The General Subject. In dealing with the influence exercised by food we arrive at the point where physical and biological factors intergrade. A large amount of scattered and uncoordinated information exists with regard to the rôle of food and its constituents upon insect life, and an annotated bibliography of the subject, including nearly 600 titles, has been compiled by Uvarov (1928). Much of this information belongs to the realm of pure physiology, and a considerable proportion of it requires revision in the light of improved methods of technique. From the ecological standpoint, the effects of nutriment upon growth and reproduction are fundamental, but the subject cannot be 
divorced from physiology. Recent research has been directed towards analyses of the influence of individual constituents of the food, and the part played by vitamins or substances allied to them. Increasing attention is also being given to the behaviour of micro-organisms in the nutritional process, but, for the most part, we know as yet very little concerning their actual functions.

In illustration of the effects of different host-plants upon the metabolism of Aphis rumicis, as expressed in the reproductive capacity of this insect, certain experiments carried out by Davidson (1921, etc.) at the Rothamsted Experimental Station may be taken as an example. The figures given below represent the average number of aphides (average of five plants in each case) produced on one plant of the undermentioned hosts, by single adult apterous viviparous females, during a fourteen-day period. The aphides used were all the progeny of a single parent, and the experiments were carried out simultaneously under identical environmental conditions.

Table $\mathbf{X}$.

\begin{tabular}{|c|c|c|c|c|c|}
\hline Plant. & $\begin{array}{l}\text { Longpod } \\
\text { Bean. }\end{array}$ & $\begin{array}{l}\text { Sugar } \\
\text { Beet. }\end{array}$ & Red Beet. & Mangold. & $\begin{array}{l}\text { Shirley } \\
\text { Poppy. }\end{array}$ \\
\hline $\begin{array}{l}\text { Number of aphides } \\
\text { produced }\end{array}$ & 896 & 123 & 115 & 114 & 164 \\
\hline
\end{tabular}

Similar experiments carried out with different varieties of broad beans (Vicia $f a b a$ ) showed that if the longpod bean be taken as the standard or control, and the mean reproductive figure for the aphid on that host-plant be represented by 100, the corresponding figures for other varieties of beans may be grouped into classes yielding reproductive figures ranging from 98 per cent. to 3 per cent. The last-mentioned figure was obtained on Vicia narbonensis, which some authorities regard as the prototype of all the cultivated varieties of the broad bean. It appears that these differences, in the reproductive capacity of the aphid, are correlated expressions of the influence of the cell-sap, of different host-plants, upon the metabolism of the insect. Certain further experiments by Davidson lend support to this contention, since they show that 
factors influencing the nutrition of the host-plants are reflected in corresponding deviations in the reproductive capacity of the aphid as shown below.

\section{TABLE XI.}

Grown in sand, treated with tap water only

The same, but watered with complete nutritive solution

Grown in standard soil

Control : taken as $\mathbf{1 0 0}$

The same treated with complete artificial fertilisers

i.

140

200

These figures represent, as before, the mean number of aphides produced (on five plants in each experiment) by a single apterous viviparous female per plant over a fourteen-day period.

The familiar practice of pinching off the growing points, along with the adjacent young leaves of bean plants, has also a very marked influence on the number of progeny produced by Aphis rumicis in a given time. In one series of five plants, in which this treatment had been carried out, the mean reproductive rate of the aphid was $104 \cdot 8$ (in fourteen days), while for plants that remained intact the mean reproductive rate was more than three times as high, viz., 335.2. It appears, from this experiment, that the cell-sap of the young growing tissue of the host-plant is of a very definitely higher nutritive value as food for the aphid than the older tissues. Screening experiments, cutting off varying amounts of daylight and thereby reducing the photosynthetic activity of the host-plants, support the conclusion that the nutrition of the latter affects the metabolism of the insect, since aphides on the most heavily screened plants produced the lowest number of progeny in a given time.

In further illustration of the influence of food upon insect metabolism as expressed by fecundity, and also by the duration of life, experiments by Simmons and Ellington (1925) with regard 
to the beetle Necrobia rufipes are noteworthy. Thirteen pairs of this beetle were kept under observation from the times of emergence from their cocoons until they died, the average daily mean temperature being $\mathbf{1 9} \cdot 4^{\circ}$. During the whole period the insects were fed entirely upon stale fat bacon, and the average life of the female insects was $\mathbf{1 3 6}$ days with a maximum of $\mathbf{1 8 3}$ lays. The average number of eggs laid per female was 137 , with 312 as the maximum. In another experiment 76 pairs of the same species were fed throughout their existence upon migrant larvæ of the fly Piophila casei. In twenty selected pairs of this series the average life of the female beetle was 279 days, with a maximum of 409 days. The average number of eggs laid per female was 906 , with 2,131 as the maximum. 'The average daily mean temperature, from readings given by these two authors, works out at about $20.5^{\circ}$ during the experiment. It is evident that there is an increase in the duration of the life of the individual amounting to over 100 per cent., but this fact is apparently not solely accountable for the high increase in fecundity recorded. This conclusion is borne out by the fact that one female nourished upon Piophila larvæ lived only 121 days, but nevertheless laid 576 eggs.

With reference to oviposition by the Noctuid moth Hadena (Polia) oleracea, Lloyd (1920) has shown that unfed imagines, although prolific, produce a greatly reduced number of eggs as compared with those allowed to feed, the food in this case being broken ripe tomato fruits. Lloyd's results, which, however, are based upon small numbers, are given below.

\section{TABLE XII.}

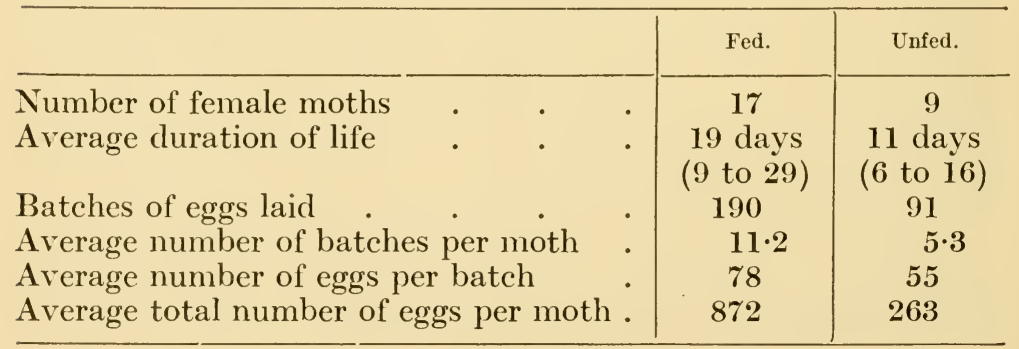


Glaser (1923) has shown that the house-fly in captivity lives only a few days and lays no eggs on a diet of proteins or products of protein hydrolysis, or of raw starch. When fed on sucrose, longevity is increased but no eggs are laid, while on a diet either of sucrose and bouillon, sucrose and blood serum, glucose and bouillon or of glucose and blood serum, longevity and oviposition reach their maximum. Longevity is also high and eggs are laid on a diet of soluble starch and bouillon or of hydrated starch and bouillon. It appears, therefore, from his experiments that sugar or assimilable starch, together with a solution of proteins or products of protein hydrolysis, like bouillon or blood serum, are necessary for oviposition.

Vitamins. Further and more detailed analyses of the nutritional requirements of certain insects lend support to the conclusion that they, similarly to the higher animals, exhibit certain vitamin requirements in order to undergo normal growth. In some cases complete growth is unobtainable unless certain accessory foodsubstances are included in the diet, while in other cases such requirements do not appear to exist. The latter conclusion is always confronted with the difficulty that unless the insect be reared aseptically from the egg, the possibility that growthpromoting substances are contained in micro-organisms present in the gut, or other organs of the insect, cannot be excluded. The difficulties to be faced in rearing many species of insects under absolutely aseptic conditions can scarcely be overcome, since in a number of cases micro-organisms are known to be present in the egg and are transmitted from generation to generation.

A considerable amount of research has been carried out with respect to the influence of vitamins on the growth of Drosophila and other insects, and short reviews of the subject are given by Richardson (1926) and by Uvarov (1928). With respect to the species Drosophila melanogaster, the earlier work of Loeb and Northrup, and of Northrup, showed that the larvæ of this insect require a growth-promoting substance present in yeast in order to complete their development. Guyénot confirmed their findings, and concluded that the substance present in yeast, which is indispensable for growth, resembles in certain respects the water- 
soluble vitamin $B$, which is necessary for the higher animals. Baumberger, two years later, advanced evidence which led him to conclude that the substance necessary is yeast nucleoprotein. Bacot and Harden (1922) grew Drosophila larvæ aseptically, and were able to confirm that this insect requires vitamin $\mathrm{B}$ for its complete development, but not vitamin $\mathrm{C}$; at the same time, it was able to develop in the presence of very small quantities of vitamin $\mathbf{A}$, and it was uncertain whether the latter was essential or not.

Certain other insects have also been the subject of vitamin investigation. The experiments of Wollman, for example, with the blow-fly Calliphora and the cockroach Blatella appear to lead to the conclusion that vitamins are not essential for the growth of either insect. Notwithstanding sterilisation precautions, the complete elimination of micro-organisms from within the eggs or larvæ cannot be ensured, and these alone may contain sufficient vitamin to enable the insect to undergo development in sterilised food. The careful experiments of Richardson (1926), with reference to the Mediterranean flour moth (Ephestia kuhniella), afford evidence that vitamins are necessary for the complete development of that insect. Full growth occurs when the insect is reared upon normal entire-wheat flour, but when the latter be treated to prolonged extraction with chloroform, all the larvæ, when fed on the residue, die at an early age. If, however, the extract containing the growth-promoting substance was added to the wheat, residue growth of the insect took place at nearly normal rate. Similarly, ether-extracted wheat allowed of but few larvæ to reach the pupal stage, but when the extract is added to the flour residue practically normal growth results. It would appear that the extract in these experiments contains a substance similar to, or identical with, vitamin A. When an ether extract of eggyolk containing vitamin $A$ was added to the wheat residues of the previous experiments, the larvæ grew normally. Richardson also found that highly milled patent flour retarded larval growth and resulted in moths of significantly lower weight. Since, however, the growth value of this medium is considerably improved by the addition of an alcoholic extract of yeast, it is believed that its 
deficiency lies at least partly in the low concentration of vitamin $\mathrm{B}$ which appears to be present largely in the wheat kernel.

Chapman (1924), using another flour insect, the beetle Tribolium confusum, came to the conclusion that the wheat embryo itself is more satisfactory for growth and transformation than other food substance. Vitamin B from the wheat embryo did not appear to be able to supplement deficient diets, and it would seem that some substance other than this vitamin may be involved.

The nutritional requirements of the larvæ of the Sheep Blow-fly (Lucilia sericata) have attracted a good deal of attention during the last few years. This work has been in connection with the importance of this species as an animal pest. The old idea that bacteria play an essential rôle in the process of digestion is not borne out. The extensive researches of Hobson, in a series of ten papers published between 1931 and 1935, and of others, have been reviewed by Evans (1936). It appears that the chief functions played by bacteria are to supply a growth-promoting substance and to liquefy the food. Other accessory growth factors necessary for normal growth and development are cholesterol, vitamin B, together with certain substances analogous to members of the vitamin $\mathbf{B}$ complex.

Without further discussion of this subject it will be evident that substances of the nature of vitamins are essential for the growth of certain insects, but it should not be too readily assumed that they are necessarily identical with those required by the higher animals. For certain other insects, evidence that vitamins are essential factors in the nutritional process is far from conclusive.

Symbiotic Micro-organisms. The literature dealing with the association of micro-organisms with insects has assumed extensive proportions, but restrictions of space will only permit of limited reference to the subject. In a number of cases, of which the malaria parasite and Nosema disease are familiar examples, such organisms are parasitic in behaviour. In other instances their relationship is of the nature of inquilines, or they are neutral, in that they neither confer obvious benefit to their hosts nor occasion deleterious consequences to the latter; the intestinal bacterial flora prevalent in many insects probably comes under 
this category. Further species of micro-organisms are believed to be definitely symbiotic in that they play an important part in the digestion of the food of their hosts and, at the same time, meet their own nutritive requirements in the process. Micro-organisms of this type are more especially present in insects feeding upon dead or decaying animal and vegetable material, or in plantsucking insects. A large number of cases of reputed symbiosis of this kind have been brought to light in recent years, but the relationship has more often been accredited from inference than as the result of definite physiological proof. For example, the intracellular and intestinal yeast-like, conidia-like and bacteroidal bodies present in so many insects, and transmitted from generation to generation through the eggs, are usually regarded as symbionts, but until such micro-organisms can be studied apart from the hosts, definite proof of their physiological rôle would seem to be unobtainable.

One of the best established cases of symbiosis between microorganisms and an insect host is afforded by the intestinal Protozoa harboured by the lower termites. The present writer suggested in 1919 that many of the peculiar forms of flagellate Protozoa harboured by wood-feeding termites were not parasitic as commonly stated. On the other hand, it appeared that they derived their nutriment by ingestion of the wood-particles rendering the latter, in the process, assimilable as food by their hosts. The important researches of Cleveland $(1924,1925)$ have proved the truth of this contention and are of exceptional interest, since they demonstrate that the principal constituent of the wood utilised by the Protozoa is cellulose. He showed that the Protozoa can be readily killed off, without injury to the termites, by incubation at $36^{\circ} \mathrm{C}$. for twenty-four hours, by starvation or by increasing the oxygen pressure of the atmosphere. Termites thus defaunated die within ten to twenty days if fed upon normal wood diet, but when reinfested with Protozoa their ability to utilise wood is regained, and they are able to live indefinitely. Cleveland further demonstrated that termites are able to live and actively multiply on a diet of nitrogen-free cellulose so long as Protozoa are present. He, therefore, suggested that these insects must in 
some way be able to fix atmospheric nitrogen or transform carbohydrate into protein. This faculty would appear to reside, however, in the Protozoa, and it may be pointed out that since the latter multiply and die in thousands within their hosts their remains alone might furnish the nitrogen required by the latter. Cleveland did not investigate the constituents extracted from the wood by the Protozoa and what substances, if any, are thereby released as food for the termites are undetermined. In a recent, and very extensive, memoir by Cleveland and his collaborators (1934) a rich Protozoan fauna, akin to that found in termites, is described from the gut of the wingless, wood-feeding cockroach Cryptocercus punctulatus of the United States. It was found that the Protozoa of this insect contain the enzymes cellulase and cellobiase, which produce dextrose in vitro. The cockroach, on the other hand, does not possess cellulase, and probably not cellobiase. It is, however, able to live longer without Protozoa when dextrose is used as food, and it is concluded that this carbohydrate is one of the important food constituents supplied by the activities of the Protozoa. Trager (1932) has also investigated the occurrence of cellulase in connection with the above problem, and finds that it can be extracted from the Protozoa living in the termite Termopsis, and also from those present in Cryptocercus. In the defaunated hosts this enzyme was found to be wanting.

Apart from termites, most other wood-inhabiting insects harbour micro-organisms of various types in the alimentary canal, its appendages or other organs, and the subject is admirably discussed by Buchner (1928). The actual nature of the food of such insects is, in many cases, quite obscure, and it has been too readily assumed that the wood-particles excavated during the tunnelling process serve as food. The regular presence of microorganisms, generally in localised situations, lends indirect support to the conclusion that the latter are symbionts which perform an important digestive function. Thus Sitodrepa panicea, and many other wood-boring beetles, possess special intestinal cæca harbouring yeast-like organisms. In the larva of the beetle Potosia cuprea, which feeds upon dead pine needles, Werner (1926) has 
shown that cellulose-digesting bacteria are constantly present in relation with the intestine. Although it is held that the microorganisms referred to are symbionts, the part they actually play in the physiology of nutrition is obscure, and knowledge of this aspect of the problem is greatly needed.

Mansour and Mansour-Bek (1934) in their review of this subject conclude that the intra-cellular micro-organisms of xylophagous insects cannot be considered as playing an important part in the digestion of wood. The work of Ripper (1930), and of others, appears to indicate that many more insects than was previously believed possess the ability to digest various components of wood by means of the action of their own enzymes, particularly cellulases. Extra-cellular micro-organisms found in the intestines of various insects likewise play no part, they believe, in breaking down cellulose for the use of the hosts. These organisms appear to be used by the latter as a source of food. It is evident that the subject is not one which it is possible to dogmatise over in the present state of knowledge, and micro-organisms have been too readily credited with performing functions of which there is still a lack of conclusive proof of their actuality.

In many plant-sucking Hemiptera micro-organisms are likewise constantly present, and they often bear close resemblance to yeasts both in form and method of reproduction. As a rule they are located in special "symbiont" cells termed mycetocytes, which form a compact and very characteristic organ known as the mycetome. The latter is lodged in the body cavity (usually in the abdomen), and is unconnected with the digestive system by ducts or other means. The physiological significance of these organisms remains unsolved, and this subject, along with their origin and incidence in different insects, is discussed by Buchner (1921) and by Uichanco (1924). Infection of the host takes place through the egg, and for the details of the process the recent papers by Uichanco and by Schrader (1923) may be consulted. It is generally believed that the micro-organisms profit by the protection and nutritive material which they receive from their hosts, and that they benefit the latter as absorbers of waste products and excess food materials. Efforts have been made to 
cultivate these micro-organisms when removed from their hosts, but the results are by no means conclusive. Berlese, in 1906, for example, succeeded in growing the yeast-like organism, found in association with the Coccid Ceroplastes rusci, on artificial media. A fungus, which he termed Oöspora saccardiana, resulted, and it grew rapidly on gelatine and showed a powerful liquefactive action on the latter. Pierantoni (1910) similarly was able to grow the yeast-like organisms from the mycetocytes of Icerya purchasi on a gelatine medium. More recently, Brues and Glaser (1921) reported that they were successful in cultivating the symbionts of the Coccid Pulvinaria innumerabilis which occur, not in a definite mycetome, but diffused in the fat-body of the insect. The yeast-like bodies developed on suitable media into a separate fungus of undetermined affinities which had the property of secreting proteolytic, lipolytic and diastatic enzymes. It is evident that the hosts in some unexplained manner are able to inhibit any excess of multiplication of their symbionts, as the number of mycetocytes remains very constant and does not appear to increase beyond certain limits. Whatever rôle these organisms may play, it would appear to be exercised upon materials contained either in the blood or the fat-body of their hosts, since, as has already been pointed out, they do not occur in direct relation with the digestive canal. Plant-sucking Hemiptera absorb large quantities of soluble carbohydrates in the cell-sap, which are eliminated to a considerable extent as honey-dew. Buchner's hypothesis, that the symbionts are able to assimilate atmospheric nitrogen, appears to be based upon the assumed deficiency of nitrogen in the food of these insects. There is, however, no evidence that plant-sucking insects do not obtain all the proteins they require from the cell-sap, and it appears more probable that the symbionts are in some way concerned in dealing with an excess of carbohydrates present. It is evident, therefore, that more definite information is required as to the digestive physiology of the hosts before the rôle of their symbionts can be elucidated.

The cultivation of symbionts in vitro does not carry the problem much nearer solution for the reason that their activities are often very diverse, and no light is shed upon their essential functions 
in relation with their hosts. The most important work in recent years is that of Aeschner and Ries (1933) and Aeschner (1932, 1934) with reference to the body louse, Pediculus. The symbionts in this creature are localised in a small organ situated in the mid-ventral line of the abdomen rather nearer the anal end of the body. The complete life-cycle of these micro-organisms has been worked out by Ries (1932). Aeschner (1932) and Aeschner and Ries (1933) were able to show that extirpation of the mycetome when filled with symbionts caused marked deficiency symptoms in the louse. If, however, extirpation took place after the microorganisms had migrated to the oviduct it had no influence on the well-being of the insect. From these results it was concluded that it was not the operation, or the absence of the mycetome, but rather the absence of the symbionts that induced the deficiency symptoms. In his later work Aeschner (1934) studied the effect of centrifugalisation on the eggs of the louse. It appears that the symbionts are eliminated in the process and are wanting in the young insects. The latter fed and developed normally until the fifth or sixth day, when they died. This result was in complete accord with that obtained by extirpating the mycetome, and it is concluded that the relationship of micro-organisms and host is one of true symbiosis. What rôle these organisms play in Pediculus is unknown, but it is possible they are concerned with the production of some "vitamin" or growth-promoting substance.

Blood-sucking insects regularly contain intracellular microorganisms, and Wigglesworth (1936) describes a bacterial organism which occurs constantly in Rhodnius prolixus. Hobson found that sterile blood was a deficient diet for blow-fly larvæ unless "vitamin B" was added. This same investigator (quoted by Wigglesworth) has carried out a few experiments adding the bacteria from Rhodnius to sterile horse serum and then feeding Lucilia larvæ on the mixture. The results appear to point to the conclusion that when blood is so infected it becomes an adequate diet for insect growth. These observations lend support to the view that symbiotic organisms, in exclusively blood-sucking insects, provide an endogenous source of vitamin. 


\section{Climate}

Climate is the expression of a combination of physical factors, and is of paramount importance in connection with the survival of all forms of life. The effects of the more important of the individual factors which collectively make up a climate have already been referred to, and their combined influence now remains for consideration. Climate may be defined as the complex of meteorological factors prevailing throughout the year for a given area, while the incidence of these same factors at some particular point of time constitutes weather. Climate in the broader sense influences the geographical and ecological distribution of species, while weather influences their local prevalence by seasons : the one operates in space, the other in time.

Geographical Distribution. It is well known that the vast majority of insects are more or less restricted to definite areas. Without taking into account past geological changes, the factor governing such distribution at the present day is very largely climatic. On the other hand, topographical barriers, such as mountain ranges, deserts and oceans, play an extremely important part. Their influence, it is true, is partly in relation to the climates they engender, but, apart from such, they remain as obstacles which few species can overcome. The tsetse fly, for example, is unable to survive the ecological conditions presented by the Sahara desert, and consequently does not penetrate north of that vast area. Similarly, it has not spread into Asia, where the Arabian desert presents a more formidable barrier than the relatively narrow strip of water forming the Red Sea. The Atlantic Ocean effectually precludes the spread of most elements of the western European fauna into North America, and it has only been due to the relatively recent facilities, afforded by maritime communications, that certain species of insects have become accidentally transported across that barrier. The latter event is one of outstanding importance, since it demonstrates that once topographical barriers are overcome, some species of insects find other climatic areas at least as favourable for their colonisation as their lands of origin. The significance of this fact is becoming increasingly appreciated, and is witnessed in the rigidity with 
which quarantine regulations are being drawn up and enforced in progressive states. While probably no quarantine regulations can be devised that will wholly effect the purpose intended, their maintenance has served to check or delay the introduction of many noxious insects, which would have readily entered a country in the absence of such restrictions.

The strict maritime quarantine upheld at San Francisco, and other Californian ports, appears to be responsible for the effective exclusion of the Mediterranean fruit-fly (Ceratitis capitata) from that state, and the freedom which the whole North American continent has enjoyed from this widespread pest must be largely attributable to similar measures. In April, 1929, an infestation of the fruit-fly was discovered in part of Florida. Fortunately the application of effective measures, involving the expenditure of a large sum of money, resulted in its complete eradication.

The original home of the Mediterranean fruit-fly was probably tropical Africa: from that region it has become very widely spread, probably mainly through fortuitous agencies of commerce. There appears to be no evidence that the insect will become a serious pest in any country where the mean monthly temperature falls to, or below, $10^{\circ}$ for three or four consecutive months (Back and Pemberton, 1918). As Verguin (1928) has pointed out, if all the areas known to be infested by this insect be plotted on a world map, they are found to lie almost entirely between the January isotherms of $10^{\circ}$ in the two hemispheres. Outside these limits it appears to occur constantly only in territory bordering on the northern Mediterranean coast. It has been reported as causing damage in the environs of Paris, but without becoming regularly established, and in this district it is stated to be capable of passing through only two generations per year as compared with four on the Mediterranean littoral. The available information respecting this insect all points to temperature being the most important of the climatic factors concerned: the optimum conditions are a warm and more or less equable climate which, at the same time, allows of a continuous supply of some or other of the host-fruits being available throughout the year. In Europe the insect is largely checked by winter temperatures which 
likewise preclude the fruiting of suitable hosts for long periods. It would appear, therefore, from these remarks that the insect exhibits a greater tolerance of heat than of cold, and that it is a species incapable of hibernation in the usual sense of the term. In the Hawaiian Islands, for example, the development of the insect progresses most rapidly when the mean temperature exceeds $23 \cdot 8^{\circ}$ to $26 \cdot 1^{\circ}$. Back and Pemberton state that complete mortality follows continued exposures to temperatures below $10^{\circ}$, and that no immature stages can withstand subjection for two weeks at freezing point. On the basis of the foregoing remarks, inferences may be drawn with respect to the possibility of the insect extending its range into lands free from its presence. The recent incidence of the pest in Florida points to the liability to infestation of all the southern states of North America where suitable climatic conditions prevail, and also of Mexico and Central America. The West Indies, East Indies and many of the Pacific Islands, to mention but a few other areas, afford ideal climatic conditions, and their greatest danger lies, perhaps, in the unintentional transfer of infested fruits carried by travellers enjoying the facilities now available for world tours.

Zwolfer (1934), in Germany, has made a special study of the temperature relations of the different instars of the nun moth (Lymantria monacha), together with the regional distribution of this insect over Europe. He has determined the thermal constants in day-degrees and the threshold of development for the egg, the six larval instars, pupa and imago. Since the complete development within the egg occurs in the autumn, no growth occurs during hibernation in this stage. Beginning with the first larval instar and ending with the egg stage, the thermal constants and thresholds of development (in brackets) are stated to be as follows : $65(4 \cdot 9): 217(3 \cdot 2): 84(5 \cdot 7): 84(7 \cdot 2): 90(7 \cdot 6): 132(7 \cdot 8)$ : $197(6): 130(8 \cdot 4): 240(6 \cdot 8)$. The thermal constant for the total development of this insect is given as $1,240 \pm 40$ day-degrees. Zwolfer further mentions that the stages up to the fourth larval instar lend themselves best for control measures, and that their appearance can be calculated by means of experimental data coupled with the use of mean monthly temperatures. He states 
that a "nun moth temperature index" may be obtained for a given locality by dividing the sum of monthly temperature indices for the months in which development has gone on by the thermal constant for the total development. The monthly indices are obtained by subtraction of the threshold of development from the mean monthly temperature and by the multiplication of the remainder by the mean number of days in that month during which any particular stage of the insect occurs. If the temperature index for the month is equal to or in excess of 1 , then the existence of the insect is, at any rate, theoretically possible. If it be less than 1 , then the total temperatures in a given locality are below the limit required to allow of the development of a complete generation. By means of this index Zwolfer has provided maps showing the world range of $L$. monacha, and these are in general accord with what is known relative to its actual distribution. These maps further indicate where the insect may be expected to occur in Asia, where its range is very little known. Typical nun moth areas or regions, it may be added, have a temperature index ranging from $1 \cdot 1$ to $1 \cdot 4$. Zwolfer's ideas have so far been very little tested, and there are not many species of insects for which the necessary data are available. The codling moth, Mediterranean fruit-fly and the Dytiscus beetle, however, may be indicated as being species with reference to which his method might be applied.

Davidson (1934) has studied the distribution of the Collembolan Sminthurus viridis in Australia in relation to climatic factors. The regions favourable to the insect and where it may become established are determined primarily by rainfall and temperature. The range of mean monthly temperatures most favourable to the insect lies between about $11^{\circ}$ and $16^{\circ}$. This author has shown that these temperature conditions are intimately connected with those of moisture. The ratio of mean monthly rainfall to evaporation as determined by the saturation deficiency of the air is a guide to the months in which the moisture will be favourable for population increase. Where the rainfall evaporation ratio falls below a value of $\mathbf{1}$, fluctuating moisture conditions will inhibit multiplication. When this ratio is much in excess of $\mathbf{1}$, 
the wetness will likewise restrict population increase. By combining data respecting temperature and moisture in conjunction with the prevalence of soils of the right type, regions favourable to the incidence of the insect appear to be tolerably clearly explained.

The life-history of the Colorado beetle (Leptinotarsa decemlineata) affords an interesting ecological study. Its original home was in the Rocky Mountains region, where its native food-plant is the buffalo bur (Solanum rostratum). Following the westward march of civilisation in North America came the potato, and the insect found in this new food-plant one admirably suited to its economy. The subsequent history of the species shows that it has extended its range over a vast territory, which it did not previously inhabit, owing to the presence of the new plant-host. The insect was detected, for example, in Nebraska in 1859, and by 1874 it had reached the Atlantic coast. On the other hand, its spread towards the Pacific slope has been very slow, owing to the barrier of the Rocky Mountains : it did not occur in British Columbia until 1919, and its presence in the states of Washington and Oregon is likewise comparatively recent, and there does not appear to be any evidence that it crossed the mountain range by its own unaided activities. It would seem that the original restricted distribution of this insect has to be ascribed largely to biological causes and not to climatic influences. Once suitable food-plants, such as the potato, tobacco and others, became available in new areas, the impetus to spread was imparted. The history of its diffusion shows that climatic factors have played a relatively minor part in the process, since its range to-day is from Mexico in the south to Quebec in the north. This territory lies between the North American January isotherms of $10^{\circ}$ and $-12^{\circ}$ and between the July isotherms of $30^{\circ}$ and $20^{\circ}$. The annual rainfall over the whole infested area varies from about 15 inches in the north-west to some 60 inches in the south. It would appear obvious, therefore, that the Colorado beetle can withstand a wide range of climates before meeting such extremes as are likely to become effective as limiting factors. In this connection its accidental entry into France in 1922 is of particular importance. 
After becoming established first in the Gironde, it has steadily extended its range, notwithstanding the application of measures of repression. The result is that it has now spread over the greater part of France and Belgium; it has also reached the Swiss frontier and entered the Saar region of Germany. In 1933 a small outbreak was discovered in the Tilbury-Gravesend district of England, but measures taken by the Ministry of Agriculture resulted in its eradication. It is, however, unlikely that England will remain free from outbreaks indefinitely in view of the extent to which the Colorado beetle is multiplying and spreading on the continent of Europe. A species so prone to migrate will most likely find a ready means of ingress afforded by cross-Channel steamer traffic, even if it does not often succeed in crossing the intervening strip of sea by flight. The insect now constitutes a real and potential menace to potato cultivation over part of Western Europe, and no climatic factor prevailing in this area appears very likely to restrict its further dissemination (vide Fryer, 1934, 1935).

The foregoing examples have been selected in order to illustrate the relationship of climate to the spread of insect pests. Although emphasis has been laid upon the temperature factor, it scarcely requires pointing out that the range of a given insect is governed by a complex of climatic and other environmental influences. Such a combination of factors may act in unison over the greater part of the range of a given species, but when any one of them approaches the limit of toleration that factor will be the major controlling influence.

With the advent of highly developed communications by land, sea and air it has become no longer sufficient to take cognisance only of the existing distribution of insects known to be pests : the zones of their possible distribution cannot be wholly neglected, at least by the applied entomologist. An investigation of the climatic conditions prevailing over the area covered by the existing range of a given species will enable certain general conclusions to be drawn relative to its possible spread. The influence of the individual factors upon that species can, to some extent, be subjected to analysis by adequate laboratory experimentation. 
The technique of the latter, it may be added, has greatly improved in recent years, and is dealt with in the recent books by Chapman (1931) and Shelford (1929). It will, therefore, become evident that two parallel lines of inquiry are desirable, one applicable to actual field conditions and the other to be prosecuted in the laboratory. Taken in conjunction, they are more likely to advance knowledge than if laboratory experimentation be pursued without reference to field conditions; in other words, the latter provide the real problems which are to be taken to the laboratory for analysis.

Climate and Weather in Relation to Seasonal Prevalence. The relations of climate and weather to seasonal and periodic behaviour of insects afford more difficult problems than those governing the general distribution of those animals. In certain parts of the tropics the climate is extremely uniform throughout the year, with relatively small fluctuations of temperature around either the daily or the annual mean. Under such conditions seasonal or periodic behaviour of insects is but little pronounced. True dormancy, for example, is almost a non-existent phenomenon, and insects are able to pass through uninterrupted cycles of development and activity from year to year. In other parts of the tropics, where there are sharply contrasted dry and wet seasons, the former with a prevailing high temperature and the latter with a cooler temperature, these changes are directly reflected upon the insect life. The incidence of special dry and wet season forms, for example, is well known in Lepidoptera, but the most marked phenomenon is the tendency of the life-cycle in most insects to be interrupted during the dry season. Heat and drought, often accompanied by leaf-fall, are prejudicial to insect life in general, and it is at this period activity becomes arrested and a condition of æstivation is entered upon. In temperate and cold regions the most prejudicial period is the winter, when insect activities attain their minimum and the phase of hibernation supervenes. Hibernation and æstivation, in the true sense of those terms, are so deeply impressed upon the species, as the result of environmental influences affecting many thousands of generations, that these phases have become definite rhythms 
expressing certain physiological conditions. Neither phase can be readily engendered out of season by modification of temperature or other physical influences, nor can they be easily dispelled and activity reinduced by similar means. It is not proposed to deal here with established rhythms in insect life, but to refer to climatic factors in so far as they are correlated with fluctuations in the abundance or scarcity of insects which recur at more or less irregular intervals.

It is a matter of common observation that there is a more or less strongly marked fluctuation in the prevalence of certain species of insects taken over a period of years. Probably few species are exempt, in temperate regions at any rate, from such rises and falls, and the literature of entomology contains frequent reference to such occurrences. In the case of noxious insects, upon which most observation has been concentrated, the majority occasion what may be described as average damage during ordinary seasons, while now and again mass outbreaks of variable duration occur. Diverse causes have been attributed to such outbreaks, but it needs to be emphasised how difficult it is in many cases to definitely prove that any observed factor is actually responsible. Much exact and prolonged observation is required before it will be possible to discriminate between the direct effects of weather upon insect prevalence, as distinct from its indirect influence, operating through such potent biological factors as food-plants, parasites, predators and disease organisms of various kinds. In certain instances tolerably close correlation has been observed between weather conditions and the prevalence of individual pests. Examples of such phenomena will be found in text-books by Wardle and other writers, and in the published proceedings of the Empire Meteorologists' Conference ${ }^{1}$ held in London in 1929. It has been recorded, for instance, that the prevalence of low temperatures, unaccompanied by snowfall, has a marked effect in reducing the prevalence of the Colorado beetle in Manitoba : low temperatures following a previous mild spell in early spring

1 Conference of Empire Meteorologists, 1929. Agricultural Section. I, Report; II, Papers and Discussions. Each obtainable, price $1 s$., post free, from the Ministry of Agriculture and Fisheries, 10 Whitehall Place, London, S.W.1. 
appear to be a potent factor in destroying large numbers of newly emerged aphides : a temperature of $16 \cdot 6^{\circ}$ is said to totally inhibit oviposition by the codling moth : in North America wet periods during May and June tend to bring the pale western cutworm to the surface of the soil and, by thus favouring its biological control, is usually followed by a decreased infestation. It will thus be evident how important it is to establish such correlations. Their main desideratum is the accumulation of sufficient accurate quantitative and qualitative data to enable the prediction of insect outbreaks to be made with a degree of certainty that would warrant the preparation, in advance, of appropriate control measures.

The collection of information of this kind is possibly best organised and most advanced in Germany. In a paper by Schnauer (1929) a very large amount of information, systematically collected, year by year, through the auspices of the German Agricultural Society since 1893, is summarised and analysed. The causes of the outbreaks of major pests are surveyed in conjunction with data respecting the chief meteorological factors. The information thus accumulated has enabled it to be possible to trace the probable connection of fluctuations in the prevalence of specific pests with particular weather conditions. The data is now being utilised as the basis for future forecasting.

\section{Literature}

Aeschner, 1932. Naturwiss., XX., 50.

1934. Parasitology, XXV., 309.

and Ries, 1933. Zeits. Morph. Okol. Tiere, XXVI., 529.

Alpator and Pearl, 1929. Amer. Nat., LXIII., 37.

BACK and Cotton, 1925. Journ. Agric. Res., XI., 1035.

and Pemberton, 1918. U.S. Dept. Agric., Bull. 640.

Bacot and Harden, 1922. Biochem. Journ., XVJ., 148.

Barber, 1929. U.S. Dept. Agric., Circ. 71.

BĚlenrádeK, 1935. "Temperature and Living Matter." Berlin.

Berland, 1934. Soc. Biolgeog., Mem. 4, 155.

Berlese, 1906. Redia, III., 8.

Bodenheiner, 1927. Zeits. angew. Ent., XII., 89.

Bodine, 1925. Journ. Exp. Zool., XLII., 91.

Brues, 1927. Quart. Rev. Biol., II., 181.

and Glaser, 1921. Biol. Bull., XL., 299.

Buciner, 1921. "Tier und Pflanze in intrazellular Symbiose." Berlin. 1928. "Holznahrung und Symbiose." Berlin. 
Buxton, 1924. Proc. Roy. Soc., B., XCVI., 123.

1930. Ibid., CVI., 560.

1931. Bull. Ent. Res., XXII., 431.

1935. “Insects of Samoa," IX., 43.

and Lewis, 1935. Phil. Trams. Roy. Soc., B., CCXXIV., 175.

and Mellanby, 1934. Bull. Ent. Res., XXV., 171.

Carothers, 1923. Trans. Ent. Soc., XLIX., 7.

Chaphan, 1924. Journ. Gen. Phys., VI., 565.

1931. "Animal Ecology." London.

Cleveland, 1924. Biol. Bull., XLIV., 177.

1925. Ibid.. XLVIII., 282, 289, 295, 309, 455.

and others, 1934. Mem. Am. Acad. Sci. and Arts, XVII., 185.

CoAd, 1931. Yearbook U.S. Dept. Agric., 320.

Cook, 1927. Journ. Econ. Ent., XX., 769.

Davidon, 1934. Commonwealth of Australia, Dept. Sci. and Indus. Res., Bull. 79.

Davies, 1928. Brit. Journ. Exp. Biol., VI., 79.

Dean, Cotton and Wagner, 1936. U.S. Dept. Agric., Circ. 390.

Dendy and Elinington, 1920. Reports Grain Pest Comm. Roy. Soc., 7. London.

Evans, 1936. Trans. Roy. Ent. Soc., LXXXV., 363.

Frew, 1929. Ibid., VI., 205.

Fryer, 1934. Journ. Min. Agric., XL., 907.

1935. Ibid., XLI., 1058, 1089.

Glaser, 1923. Journ. Exp. Zool., XXXVIII., 395.

Griswold and Crowell, 1936. Ibid., XVII., 241.

Gunn, 1934. Zeits. vergl. Phys., XX., 617.

Headlee, 1917. Journ. Econ. Ent., X., 31.

1921. Ibid., XIV., 264.

Hefley, 1928. Ibid., XXI., 213.

Hunter and Pierce, 1912. Bur. Ent. U.S. Dept. Agric., Bull. 114,

Krogh, 1914. Zeits. für allg. Physiol., XVI., 178.

1916. "Respiratory Exchange of Animals and Man." London.

Lloyd, 1920. Ann. App. Biol., VII., 66.

Ludwig and Cable, 1933. Physiol. Zool., VI., 493.

Mansour and Mansour-BeK, 1934. Biol. Rev., IX., 363.

Marcovitch, 1924. Journ. Agric. Res., XXVII., 513.

Mellanby, 1935. Biol. Rev., X., 37.

Norturop, 1926. Journ. Gen. Phys., IX., 81. 1926A. Ibid., 319.

Payne, 1926. Quart. Rev. Biol., I., 270.

1929. Ann. Ent. Soc. Am., XXII., 601.

1930. Journ. Econ. Ent., XX., 80.

Pealrs, 1927. Bull. 208, West Virginia Exp. Sta.

Pierantoui, 1910. Zool. Anz., XXXV., 96.

Pirsch, 1923. Journ. Agric. Res., XXIV., 275.

Rausay, 1935A. Journ. Exp. Biol., XII., 355.

1935в. Ibid., 373.

Richardson, 1926. Journ. Agric. Res., XXXII., 895.

RıEs, 1932. Zeits. Morph. Okol. Tiere, XX., 233.

Ripper, 1930. Zeits. vergl. Physiol., XIII., 313.

Robinson, 1926. Minnesota Agric. Exp. Sta. Tech. Bull. 41.

1927. Journ. Econ. Ent., XX., 80.

1928. “Colloid Symposium Monograph," V., 199.

1928A. Journ. Agric. Res., XXXVII., 749. 
Roonwal, 1936. Bull. Ent. Res., XXII., 431.

Sacharov, 1930. Ecology, XI., 505.

SAlt, 1936. Univ. Minnesota agric. Exp. Sta. Tech. Bull., 116.

SAYLE, 1928. Quart. Rev. Biol., III., 542.

Schnauer, 1929. Zeits. angezo. Ent., XV., 565.

Schrader, 1923. Biol. Bull., XLV., 279.

ShelforD, 1927. Bull. Illinois Nat. Hist. Survey, XVI., 311.

1929. "Laboratory and Field Ecology.". London.

Simmons and Ellington, 1925. Journ. Agric. Res., XXX., 845.

TAYlor, 1927. Journ. Morph., XLIV., 313.

Trager, 1932. Biochem. Journ., XXVI., 1762.

Uichanco, 1924. Philipp. Journ. Sci., XXIV., 143.

Uvarov, 1928. Trans. Ent. Soc., LXXVII., 255.

1931. Ibid., LXXIX., 1.

Verguin, 1928. Rev. Zool. Agric. et Appl., XXVII., 141.

Wadley, 1931. Ann. Ent. Soc. Am., XXIV., 325.

Weinland, 1906. Zeits. f. Biol., XLVII., 186.

Werner, 1926. Zeits. Morph. Okol. Tiere, VI., 150.

Wigglesworth, 1932. Quart. Journ. Mic. Sci., LXXV., 131. 1936. Parasitology, XXVIII., 284.

Zwolfer, 1934. Zeits. angew. Ent., XXI., 333. 


\section{CHAPTER $\mathrm{X}$}

\section{THE PRACTICAL APPLICATION OF ECOLOGY}

Regulation of the Growth of the Crop. Time of Sorving, p. 263 ; Crop Nutrition and Soil Conditions, p. 267. Resistant Varieties, p. 276.

There are many insect pests affecting agriculture which do not lend themselves to direct control measures with any real prospects of success. Or, the crop may be of such an extent or character which renders such measures impossible from the practical standpoint. Difficulties of this kind assert themselves wherever agriculture is practised, but more especially in the vast areas of newly developed country inhabited by backward races, where insecticidal measures are usually out of the question. In these contingencies, biological control may prove applicable in certain cases, and this subject is fully discussed in Chapter XIV. On the other hand, there are numerous instances where biological control does not afford promise, or cannot be attempted. Under such conditions control methods largely resolve themselves into devising modifications of cultural practice as will place the pest at some disadvantage and, at the same time, ensure a better crop yield. In formulating such measures an acquaintance with the chief ecological features in the life of a given pest in relation to its plant-host is called for. Knowledge so gained, when translated into practice, resolves itself into what may be termed cultural methods of control.

Cultural methods of control have definite practical advantages as contrasted with physico-chemical methods. In the first place, they are, as a general rule, preventive, and serve to restrain losses that would otherwise supervene. Further, in the case of most crops, they usually incur little or no extra financial expenditure upon the practical grower, they are generally easy to apply, and 
frequently involve no drastic disturbance of accepted routine. It also has to be remembered that the present trend of agricultural conditions in many countries is such as leaves a narrowing margin of expenditure available for insecticidal treatment, or other more or less costly measures. There is, in consequence, an increasing tendency to study the relations between insect attack and the conditions under which the crops are grown. This in its turn involves the application of ecological methods, and in the present chapter endeavour will be made to show that success, in this direction, is dependent upon adequate knowledge of the biology of the insect in relation to the growth phases of the crop which it attacks.

In the present instance the application of ecological methods will be discussed under four aspects. (1) The regulation of the growth of the crop; (2) the production of varieties of plants immune, or highly resistant, to insect attacks ; $(3)$ the bearing of host selection by insects, and the evolution of biological races of the latter; and (4) the ecological aspects of the locust problem. It is in relation to these four problems that ecology, in the broad sense of the term, enters into closest relations with practical entomology to-day.

\section{Regulation of the Growth of the Crop}

This procedure aims at regulating the growth of the crop in such a way that it either escapes infestation or is subjected to appreciably lighter attack. In a general way, two methods are applicable. Firstly, the adoption of an early sowing date in order to ensure a given crop is sufficiently advanced in growth to withstand attack at the usual period of the latter. Secondly, the investigation of the nutritional requirements of the crop in order to accelerate its growth at its most vulnerable period, or to promote its growth in such a manner that it becomes less susceptible to infestation.

Time of Sowing. In the case of certain cereals time of sowing of the crop has a very direct bearing upon their subsequent liability in relation to insect attack. With the frit-fly (Oscinella frit) the earlier the date of sowing in spring the better, providing 
cultural conditions and the prevailing weather admit of such a procedure. Evidence gathered from many sources shows that late sown spring crops suffer most of the attacks of this insect. The frit-fly is so well known as a pest of oats, and also of other cereal crops, that a detailed account of its biology is unnecessary. In a few words, it may be said that, under English conditions, the flies of the first generation oviposit on the leaves or stems of spring oats and on various grasses; they attain their greatest abundance about May 26th. ${ }^{1}$ The larvæ bore into the shoots, causing the death of the central leaves and growing point. Flies of the second generation oviposit in largest numbers about July 15 th $^{1}$ on the ears of oats, and the larvæ feed upon the spikelets and young grain. Oviposition by the third generation of flies occurs during August and September or later, the eggs being laid on the leaves of winter cereals and various grasses; the flies are most numerous about August 22nd. ${ }^{1}$ Winter is passed in the larval condition at the bases of the shoots, which are ultimately destroyed, and the over-wintering larvæ give rise to the first generation of flies of the next year.

Oat plants in the shoot and panicle stages have definite phases of growth within which they are most susceptible to attack. The shoot is most susceptible when in the stage bearing two or three leaves; once it has attained the four-leaf stage, liability to infestation declines rapidly (Cunliffe, Fryer and Gibson, 1925 ; Cunliffe, 1928). The grain is most susceptible about the time of fertilisation, and the period of greatest liability terminates before the grain attains half its normal size (Fryer and Collin, 1924).

With varieties of oats at present under cultivation the provision of an adequate growing period, to ensure that the plants reach the four-leaf stage sufficiently early, depends upon the date of sowing. It is only practicable with spring oats by eliminating sowings later than the end of February, or in some years the middle of March. Adverse soils or climatic conditions may easily entail a set-back in plant growth, and this necessitates a safety margin,

1 These dates appcar to indicate a three-cycle rhythm in the annual life of the insect, and were observed to hold good during six years' observations (vide Cunliffe, 1929). 
probably of about two weeks, which requires a total of ten weeks from the sowing date to the appearance of the plants in the resistant stage. Early sowing, furthermore, reflects its advantages upon reduced grain infestation, since it tends to the early exsertion

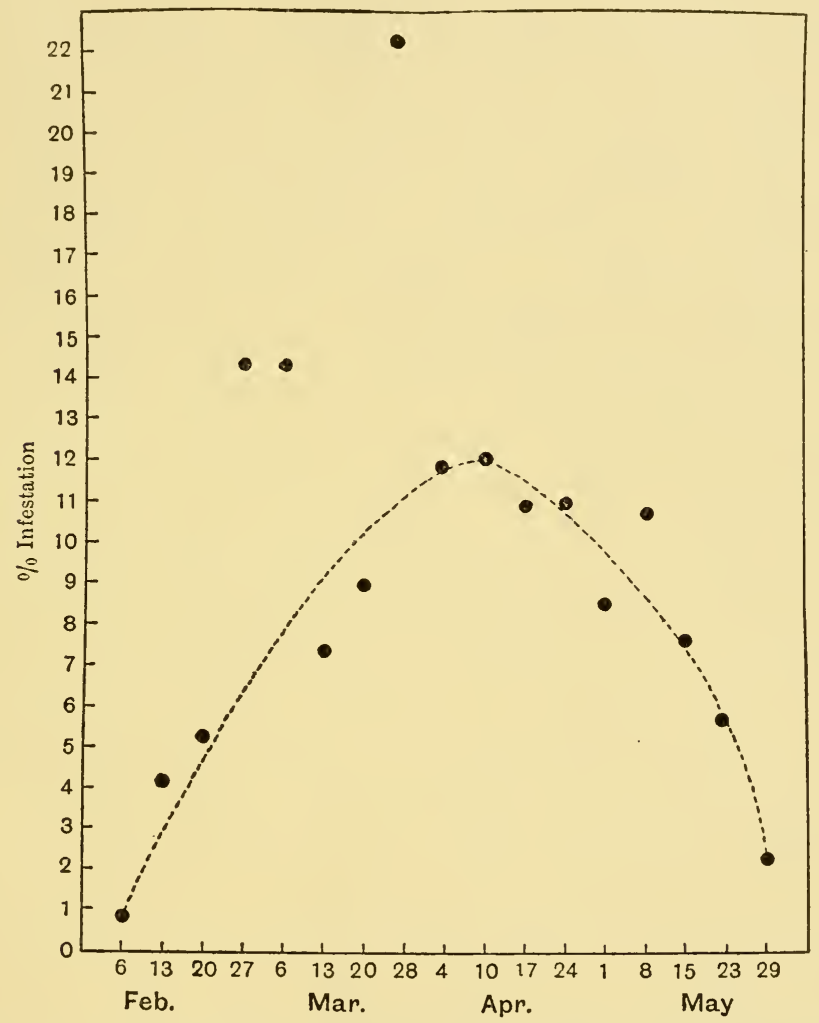

FIG. 73. Graph showing correlation between dates of sowing of barley and degrees of subsequent infestation by gout-fly. (After Frew.)

of the panicles. Since the majority of the second swarm of flies appear about mid-July, the risk of heavy grain attack is often obviated, since by that time the grain should be half-way towards maturity and therefore approaching its resistant stage (vide also Cunliffe, 1929). 
Observations conducted by Frew (1924) at Rothamsted likewise show that time of sowing has a direct bearing upon the infestation of barley by the gout-fly (Chlorops taniopus). The comparative immunity of early sown spring barley from the attacks of this insect has been noted by previous observers, but apparently without any experimental work having been conducted. In Frew's experiments an area as uniform as possible was divided into a series of plots which were sown with barley at successively later dates. Although Frew's experiments were hampered by heavy soil conditions, they nevertheless demonstrate the advantages to be derived from sowing of spring barley before the end of March (Fig. 73). Reference to the graph shows that exceptionally high infestation figures were obtained for three of the plots, which appear to have been due to retarded plant growth, owing to the caking of the soil on the particular areas concerned.

The ordinary culinary varieties of the broad bean (Vicia faba) are well known to suffer from heavy attacks of the aphid Aphis rumicis over most parts of Europe. It has been previously pointed out on p. 241 that this insect finds ideal conditions for prolific agamic production on the growing, sappy, terminal shoots of that plant. It has long been the practice of growers to sow the seed as early as possible in the season, or even in the preceding autumn. The advantage gained is in the advanced condition of growth attained by the crop by the time the aphid becomes prevalent. From among experiments conducted by Davidson at Rothamsted, the reproduction of aphides on broad beans sown on March 15th and April 27th was compared. In the former case the mean number of young produced at the end of fourteen days by single apterous females was 548, while on the later sown plants the corresponding reproductive figure was 1,341 .

In 1918 Hopkins, in the United States, advanced the hypothesis now generally referred to as the Bioclimatic Law. His contention has a phenological basis, and it formulates the rule that such events as the opening of the buds of a particular plant, dates of appearance of species of insects, first dates of flowering, and other phenomena, occur in North America according to a more or less definite law. Phenological events of this kind occur later in 
spring and earlier in autumn if they be followed in northward, eastward or vertical directions. The law states that the variation in time is at the rate of four days for each degree of latitude, for each five degrees of longitude and for each 400 feet in altitude. The hypothesis has a purely empirical basis, and was originally founded upon data afforded by certain beetles destructive to forests. Subsequent studies by Hopkins (1919) and other observers have led to its application to other biological phenomena, the most important being in relation to the time of incidence of the autumn generation of the Hessian fly (Mayetiola destructor). In the case of this insect time of sowing of wheat has a very definite bearing in relation to subsequent attack. The method is to sow wheat sufficiently late, so that it will appear above ground in the susceptible stage, at a time when the second generation of the Hessian fly has died out. At the same time the crop must be sown early enough to have attained sufficient growth to enable it to withstand the winter. Based on the bioclimatic law, the critical dates for sowing range from about September 10th in the north-east to October 25th in the south-west. It has been found that the actual emergence dates of the insect, taken over a very wide area, all appear to fall within one week of the calculated time under the bioclimatic law. Flint and Larrimer (1928) have examined the problem in some detail with respect to the State of Illinois. They conclude that under normal weather conditions the relatively "fly-free" date is September 15th in the northernmost counties in the state, and October 9th for the southernmost. They present experimental data which show, without exception, that wheat heavily infested with Hessian fly gives appreciably lower yields than wheat grown during the same year, and in the same field, but sown later according to the law enunciated.

A "law" of so comprehensive a character has its limitations and is based upon climate, and not upon weather. Due allowance has to be made for local fluctuations of the latter, and exceptional seasons. West of the Rocky Mountains it breaks down, and it does not appear to hold good for the conditions prevailing over continental Europe.

Crop Nutrition and Soil Conditions. The problem of regulating 
the nutrition of a given crop in relation to its susceptibility to insect attack is one in which the entomologist becomes largely dependent upon knowledge derived from other sciences. The nutritional requirements of different crops form in themselves a specialised branch of plant physiology, and they are intimately associated with questions of soil conditions, rainfall, and other factors. Recent research is bringing to light evidence which points to the conclusion that excess or deficiency of certain foodmaterials required by the plant betrays itself in the response the plant exercises towards insect injury. Similarly, particular soil conditions in some cases appear to conduce to heavier damage resulting from insect attacks than when plants are grown under different conditions. The future is likely to see increasing attention being given to the cultural conditions under which certain crops, particularly liable to insect infestation, are grown. The possibility is, therefore, opening out of ensuring a measure of insect control by regulating the nutrition of crops in such a way that they become less liable to suffer severe injuries.

1. The problem of froghopper 1 damage to sugar cane in Trinidad has become more one for the plant physiologist and the agricultural specialist than for the entomologist. The injuries caused by the sucking propensities of the insect appear to be intimately connected with the internal physiological condition of the cane ; the crop does not necessarily suffer the greatest damage when the froghoppers have been most numerous in attack. The important observation that there is a marked difference in the degree of attack resulting on cane growing in red acid soil and that growing in alkaline black-marl soil in certain localities, ${ }^{2}$ in that the former suffers severe injury whilst the latter does not, has opened up the whole question of the nutrition of the cane-plant in this connection. It was found that a positive correlation prevails between the degree of saturation of soils with lime and cane susceptibility. It appears that soils of areas free from severe injury by the froghopper are absorbtively saturated by lime, and

1 The species involved is Monecphora (Tomaspis) saccharina, family Cercopidæ.

2 The greatest number of eggs also appears to be laid in heavy acid soils, and the fewest in black marl soil. 
those regularly affected by the insect are less than 60 per cent. saturated. There seems to be no correlation between gross limecontent and susceptibility to insect damage, and there is stated to be little doubt that the soils of areas liable to severe froghopper attacks are lacking in combined lime (exchangeable calcium), and therefore usually give a definitely acid reaction. The reason why damage prevails under these conditions has not so far been elucidated. Both Williams (1921) and Withycombe (1926) have advanced the theory that the severest injury is largely dependent upon the water-relations of the crop. Field observations, subsequently carried out, show that differences between the acidic and alkaline areas are reflected in the moisture contents of the leaves of the cane-plants growing on these areas. In the unfavourable areas the transpiration rate of the canes is increased, which in itself leads to rapid drying-out during the afternoon and evening, which is the time when the froghoppers feed. It has been further noted that a field survey of canes, growing in soils known to favour froghopper damage, yielded evidence that marked amounts of iron and aluminium accumulate in their nodal tissues. Toxic aluminium, for example, often begins to appear when the degree of lime saturation falls below 60 per cent., and this may markedly increase the plants' susceptibility to insect attack.

The foregoing empirical observations serve to indicate how closely susceptibility to froghopper damage is correlated with factors relating to the soil and to plant nutrition; for further information the reader should consult the Froghopper Committee's publications (1925 onwards).

2. The extensive observations conducted by Frew (1924), at the Rothamsted Experimental Station, have a direct bearing on the influence of the nutrition of barley upon attacks by the gout-fly (Chlorops taniopus). The flies commence to appear in May, and deposit their eggs on the leaves of young spring-sown barley. They are usually laid singly, on the upper side of a leaf, and it is rarely that a shoot bears more than one egg. Upon eclosion the larva bores its way downwards into the centre of the shoot, and eats a groove along one side of the developing ear and to the 
internode below it. A typical attack, at this period, shows a stem with two or three internodes, terminated by a swollen region, consisting of the ear enclosed by its ensheathing leaves, from which it never escapes, and therefore cannot ripen. A striking feature in the behaviour of the insect is its instinct always to bore downzards. Should the fly deposit its egg upon a leaf, whose base
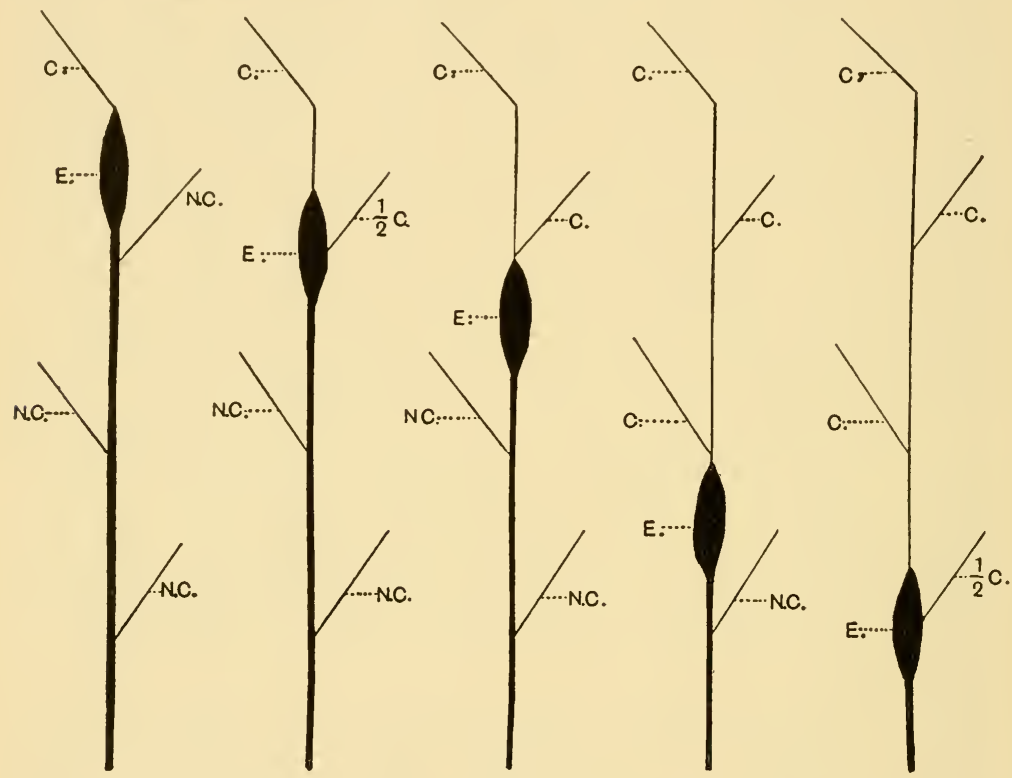

Fig. 74. Diagram of barley shoots, showing C, "critical" leaves ; $\frac{1}{2} C$, "half critical" leaves; $E$, ear ; and $N C$, " non-critical" leaves. (After Frew.)

comes off from the shoot below the ear, the newly hatched larva cannot reach the ear to feed; such leaves may be termed " non-critical leaves." In thirty-six instances dead larvæ were discovered by Frew in the ear-bearing internodes, and in all cases the ear had remained untouched. In these examples the young larvæ entered the shoots below the ear, and, owing to the toughness of the tissue and lack of suitable nourishment, they had perished. If, on the other hand, an egg is laid on a leaf which arises from the shoot above the base of the ear, the ensuing larva, by migrating 
downwards, reaches the ear; such leaves may, therefore, be termed "critical leaves." A leaf arising from a shoot half-way up the ear is to be regarded as a "half critical leaf," since the larva would only be able, at most, to attack the base of the ear (Fig. 74).

The permanent barley plots, on the Hoos Field at Rothamsted, have yielded significant data indicating that the summer infestation by gout-fly shows a wide range of intensity, according to the manurial treatment adopted. Frew's observations indicate that manurial treatment affects infestation by altering the early growth of stem and ear, and, consequently, by altering the number of "critical leaves" present at the time the insect is egg-laying, and during the period of incubation of eggs already deposited. Field counts showed that the number of critical leaves per shoot was lowest on plots least affected by the insect, and vice versâ. Two years' observations, conducted on the twenty-eight plots of the Hoos Field at Rothamsted, involved the counting of over 60,000 separate barley shoots, and the noting of the numbers infested by gout-fly in each case. It became evident, as the result, that plots receiving superphosphate, farmyard manure or complete mineral fertilisers, ${ }^{1}$ were remarkably constant in showing the lowest percentage of infestation. Untreated (control) plots were heavily infested, while those treated with nitrogenous fertilisers indicated that the latter, in some cases, exercise a beneficial effect, but that heavy dressings do not conduce to reduction of infestation, and may increase it through retarding the growth of the ear. The application of nitrogenous fertilisers, in conjunction with either superphosphate or complete minerals, however, proved markedly beneficial in each case.

3. A further example of the influence of differential nutrition of crops, in relation to insect damage, is afforded by the experiments of Jepson and Gadd (1926) in Ceylon with reference to the shot-hole borer (Xyleborus fornicatus) of the tea plant. This insect injures about 80 to 90 per cent. of all tea bushes growing below an elevation of approximately 4,000 feet. The insect does

1 These comprise sulphate of potash, superphosphate of lime, and sodium and magnesium silicates. 
not limit its attacks to any special season, and the bushes, except for a brief period of respite after each pruning, are liable to continuous infestation from the time of planting onwards. The injuries entailed are caused by the tunnelling of the beetles, and their larvæ, in the stems and branches of the bushes. Most experimental work in the past has been devoted to applying insecticidal measures of control; some have had obvious practical disadvantages, and most of them have proved costly, since treatment requires to be directed against virtually every bush on an infested estate.

An early observation made by Green, relative to the prevalence of healed-over gallery entrances in well-cultivated bushes, led to an investigation of the subject upon an experimental basis. The most obvious damage caused to tea bushes by the attacks of the shot-hole borer is the loss of branches, which break off at spots weakened by the galleries of the insect. High winds, and the movements of coolies among the bushes, are together responsible for heavy destruction of this kind. It appeared feasible, therefore, to discover whether it were possible to so improve the vigour of the bushes as to induce rapid healing over of the gallery entrance holes or "shot-holes," and so lessen the tendency of the branches to break.

After preliminary trials, field experiments were carried out at Peradeniya during the three years 1923-1925, some forty plots being utilised for the purpose. The treatments included two experiments with nitrogenous manures, two with potassic, two with phosphoric acid, and also one with lime. There were, including controls, eight treatments, each being repeated on five separate plots. The main result of the experiments was shown in the accelerated healing of the galleries caused by the shot-hole borer, which was most marked in those plots treated with nitrogenous fertilisers. Healing was completed on these plots in 2.9 months, as compared with $\mathbf{3 \cdot 7 5}$ months in the controls. The authors conclude that suitable manuring of tea bushes offers a ready and satisfactory means of diminishing the effects of attack by the insect in question, and that it should aim at increasing the nitrogenous content of the soil. 
4. In connection with tea pests, mention needs to be made of the now well-known experiment by Andrews (1923), who showed that a high ratio of available potash to available phosphoric acid in the soil, in which tea bushes are growing, greatly reduces attack by Helopeltis theivora. 'The latter is a Capsid bug, and a persistent enemy of tea, against which spraying appears to be an impracticable proposition. Andrews found that where a constant supply of soluble potash is directly applied to the roots of the bushes, this substance is absorbed and the bushes are freed from the pest, remaining free from attack the rest of the season. This would lead to the obvious conclusion that the addition of a potassic fertiliser to the soil was needed. Success, however, cannot be regularly obtained by such treatment, for the reason that the plants are apparently unable always to utilise the added potash. The effect of the potash in manurial experiments is transient, and some factor, operating to cause the original shortage in available potash obtained by the plant, intervenes to prevent its continued absorption. Andrews' inquiry showed that the composition of the leaf of the tea plant shows differences corresponding with those deduced from observation of the soils, and that comparative immunity from attack accompanies an increase in the proportion of potash, as compared with phosphoric acid, in the leaf. The factors controlling this ratio, however, are not understood, since the chemical composition of the leaf may be quite different when grown in the same soil under different cultural conditions, with a resulting difference in liability to attack by Helopeltis. It would appear, therefore, that before practical application can be made of this discovery, an inquiry into the behaviour of the substances mentioned in the soil under different conditions is called for.

5. In South Australia the springtail Sminthurus viridis has, during the last forty years, become one of the most important pests of field crops in that country, particularly to lucerne and clovers. The damage is caused by the insect gnawing the epidermis and underlying mesophyll of the leaves of the young plants, giving a field a scorched appearance as the result of a bad attack.

This insect has recently been the subject of a comprehensive ecological study by Davidson (1934), while earlier contributions 
have been made by Holdaway (1927) and by Maclagan (1932). It has been shown by these three observers that the soil reaction has a marked effect upon the number of eggs laid. Soil moisture is the dominant factor affecting oviposition, and this needs to be considered in conjunction with $p \mathbf{H}$ values of the soil. Below 10 per cent. soil moisture the number of eggs laid decreases, and where the moisture approaches saturation it also becomes unfavourable. Davidson finds that above 12 per cent. moisture normal egg batches are produced. The optimum $p \mathbf{H}$ value is about 6.5 , but the possible range for free oviposition extends between about $5 \cdot 5$ to $7 \cdot 0$. Since the insects ingest considerable quantities of soil, it seems that in passing through the gut the soil would influence the normal $p \mathrm{H}$ of the digestive tract and so affect general metabolism. In view of the economic relationship between Sminthurus and leguminous crops, it may be pointed out that lucerne is intolerant of acid conditions and prefers a $p H$ of over $7 \cdot 0$, while clovers exhibit a greater tolerance to acidity than lucerne. Whether the soil $p \mathrm{H}$ can be so altered from what appears to be an optimum for the insect, and maintained within a range favourable to the production of leguminous crops, appears to be doubtful. Davidson remarks that, considering the lime requirement of the soils of many infested areas, it would be impracticable to raise them to a $p \mathrm{H}$ value unfavourable for the Sminthurus. Such a method, it appears, would have very restricted application under Australian conditions. On the whole, it seems that pasture management and the possibility of biological control by the introduction of suitable predators offer better prospects for the exploration of measures of control.

6. French viticulturists have observed that infestation of vines by the Phylloxera is accompanied by the most severe injury where the plants are growing on certain types of soils. In other types of soil, even in the same vine-growing district, injuries are commonly much less severe. The correspondence between the two series of phenomena appeared to be sufficiently close to be regarded as an axiom. Some years back, the French vinegrowers came to the conclusion that light-textured or sandy soils, containing' up to 60 per cent. of silicate sand, contributed to the 
resistance of the crop to attacks by the insect in question. More recently the same subject has been re-investigated in California by Nougaret and Lapham (1928), since it appeared possible that if certain soil types in that state are inimical to Phylloxera propagation, a certain degree of control might be achieved by the wider planting of vineyards under such conditions. These observers found that infestation appears to be particularly frequent and pronounced in flat or depressed localities, where inferior soil drainage is aggravated by the occurrence of shallow, compact and impervious subsoils which readily cake, giving rise to a condition of shallow-rooted vines and stagnated soil drainage. Where infestation occurs in deep friable soils, with porous subsoils, destruction of the vines is less rapid than in more shallow soils. The texture of the soils appears to be a factor which exerts itself in a number of ways. It is suggested that in those of a heavy compact type, which cake, shrink and crack when dry, conditions are rendered more favourable for the development and migration of the root-forms of the insect. Facilities for movement, it is claimed, are afforded by intersecting cracks, and along the courses of the roots, from which the soil tends to withdraw slightly in shrinking. If forced to the highly heated surface of sandy soils, which do not cake and crack, and which may be more uniformly in close contact with the roots, the delicate and minute insect would not long survive under the hot arid conditions to which many of the interior valleys of California are subjected. Various soil types in relation to Phylloxera infestation are discussed and the whole area shown in a coloured map. Their bulletin is too lengthy for detailed discussion here, but it may be said that the authors conclude that the correlation between susceptibility to Phylloxera infestation and soil types is a tolerably close one. In certain areas of light-textured soils it is recommended that planting can be extended with a wide margin of safety, while in others, at present free from infestation, the soil types are such that if the insect became established, immunity from attack would not probably be wholly maintained. Loams and soils of heavy texture are favourable to general infestation, and on such lands areas of widespread and long-standing attacks prevail. 
The foregoing examples will serve to illustrate the influence of plant nutrition, and soil conditions, in relation to the susceptibility of crops to insect infestation. Recent research emphasises the complexity of the subject, but, at the same time, it indicates the importance of studying the ecological relations between host and pests as an interconnected problem. Progress of knowledge on this field is necessarily slow, and consequently its application to cultural practice can only result very gradually. We are only just beginning to realise that persistent heavy attacks by insects may be the result of the particular cultural conditions under which a given crop is grown. The possibility is, therefore, opened out of so regulating the growth of the crop that it will be rendered less prone to such attacks, and still yield an adequate economic return.

\section{Resistant Varieties}

In the wild state many plants appear to suffer relatively little injury from insect attacks as compared with their cultivated representatives. They appear to have acquired, through many thousands of generations, a degree of tolerance to such interference, whereas cultivated varieties of these same plants suffer severely from repeated infestation. This difference in plant response appears attributable to two main causes. (1) The conditions under which the cultivated varieties are grown which favour infestation. (2) It would seem that during the process of selection and breeding, which has led to the production of cultivated varieties, certain properties, inherent in the wild state, have been out-bred; that the plants are rendered in this way, not only more attractive to their respective insect enemies, but also less able to sustain the injuries incurred.

The problem which presents itself is likewise two-fold. Firstly, an ecological study of the conditions in which a given crop is grown, in order to trace those conducive to infestation, which has already been discussed. Secondly, the discovery of varieties or strains of plants which betray high resistance to insect attack and, at the same time, exhibit desirable properties from the standpoint of the grower. In practice, strains which exhibit one or 
other of these attributes are well known, but the real problem involves their judicious selection and combination, which has, as a rule, proved extremely difficult of attainment.

Much has been written with reference to the nature and meaning of resistance. Absolutely resistant plant varieties are of great rarity, and resistance, more often than not, implies little more than a low degree of susceptibility to attack. The factors which control, or influence, this susceptibility are extremely varied, and have been classified in various categories. In many cases it is probable that no single factor is in itself responsible for the observed effect, and that multiple factors are involved. Among these contributing causes, thickness of cuticle, development of sclerenchyma or other mechanical tissue, general hairiness or its absence, acidity or alkalinity of the cell-sap, silica content, presence or absence of certain glucosides, date of maturity, power of recuperation and other attributes have been regarded as accountable in particular cases.

Another type of so-called resistance is brought out by the work of Davidson (1922) at Rothamsted, which concerns the reproductive capacity of Aphis rumicis on different varieties of culinary and field beans (Vicia faba). Discrimination on the part of the insect in the selection of one variety in preference to another was eliminated in these experiments, which were conducted throughout under identical conditions. His observations show that the insect exhibits a wide range of fecundity on different hosts. These differences are probably due to differences in the constitution and nutritive values of the cell-sap in the respective varieties. There appears to be a direct inhibiting effect of the cell-sap upon the reproductive capacity of the aphid when grown on certain varieties of beans, and the opposite effect when grown upon other varieties, as is shown in the table on p. 278 .

It is probable that varietal differences in the properties of the cell-sap of many other species of plants are reflected, in the manner described, in the relative abundance of numerous kinds of sucking insects feeding upon them. Much the same kind of reaction, it may be added, has been observed by Monzen with reference to the fecundity of Eriosoma lanigera on different 


\section{TABLE XIII}

\begin{tabular}{|c|c|c|c|c|}
\hline Varieties. & & & $\begin{array}{l}\text { Mean Infestation and } \\
\text { Probable Error. }\end{array}$ & $\begin{array}{c}\text { Degree of Susceptibility. } \\
\text { Per cent. }\end{array}$ \\
\hline $\begin{array}{l}\text { Prolific Longpod } \\
\text { Bohus (Swedish), Mazagan }\end{array}$ & . & $\cdot$ & $\begin{array}{c}1,037 \pm 51 \cdot 8 \\
1,012\end{array}$ & $\begin{array}{c}\text { Standard, taken as } \\
100 \\
98\end{array}$ \\
\hline English field bean & . & - & $737 \pm 43 \cdot 7$ & 71 \\
\hline $\begin{array}{l}\text { Heliogland } \\
\text { Scotch var. Granton } \\
\text { Winter bean (Dorset) } \\
\text { Winter bean (Somerset) }\end{array}$ & $\begin{array}{l}\dot{.} \\
\dot{.}\end{array}$ & \} & $570 \pm 19 \cdot 2$ & 55 \\
\hline $\begin{array}{l}\text { Winter bean (Essex) } \\
\text { Spring tick (Suffolk) : } \\
\text { Carse bean } \\
\text { Kilbride bean and five o } \\
\text { varieties }\end{array}$ & $\begin{array}{l}\dot{\cdot} \\
\text { other } \\
\dot{ }\end{array}$ & 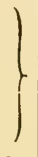 & $407 \pm 11 \cdot 1$ & 39 \\
\hline Winter bean (Suffolk). & $\cdot$ & $\cdot$ & $286 \pm 27 \cdot 2$ & 27 \\
\hline Vicia narbonensis & . & . & 37 & 3 \\
\hline
\end{tabular}

Reproduction of Aphis rumicis upon different host varieties. The infestation figures are the mean in each case of five plants, each plant being infected with a single apterous viviparous female which was allowed to reproduce for a period of fourteen days.

varieties of apple (vide p. 280). There is evidence, both in the case of varieties of beans and of apple, that those most desirable, from the point of view of human consumption, appear to favour and stimulate the highest reproductive rates in their respective aphid enemies. This, in itself, lends support to the suggestion already made that certain properties, contributing to the greater "resistance" of the wild forms of plants, have become out-bred in the course of repeated selection in cultivation.

It may be said that, up to the present, comparatively few discoveries of insect-resistant varieties of plants, of proved commercial importance, have come to light. The methods involved in the search for such varieties are either those of selective breeding, varietal hybridisation, or graft hybridisation. Selective breeding entails either the continued selection of individual plants of a crop, observed in the field to betray least injury; or line 
selection and propagation, which involves breeding for highly resistant special strains. A good example of selective breeding is afforded by the work done in South Africa with regard to jassidresistant strains of cottons. Varietal hybridisation is practised with the object of combining desirable features present only in separate and different strains. It is dependent for its success upon the purity of the segregation of the resistance and other factors involved. The method has been practised by Harland in Barbados in the crossing of Sea Island and Upland cottons with resistant native strains as a means of control against the leaf blister mite (Eriophyes gossypi). In the Southern U.S.A. the crossing of commercial sweet maize with native field varieties is stated to have resulted in strains better able to resist attack by the corn earworm (Heliothis obsoleta). Inter-specific hybridisation has resulted in the production of the Leconte and Keiffer varieties of pears which are resistant to the San José scale. These varieties are $\mathbf{F}_{1}$ hybrids between Pyrus communis and the Chinese pear (Pyrus sinensis); both inherit the desirable qualities of $\boldsymbol{P}$. communis, in combination with the resistance to scale injury characteristic of $\boldsymbol{P}$. sinensis. The need for discovering varieties of spring oats resistant to infestation by frit-fly is referred to on p. 282, and it appears that more promise of success is likely to result by adopting varietal hybridisation, rather than by relying upon any varieties, yielded by selective breeding, exhibiting the desired combination of characters. Graft hybridisation, which is an old method, involves the grafting of commercially valuable, but highly susceptible, plants upon root-stocks of resistant varieties. It has proved successful in the now classical cases of apple trees infested by woolly aphis, and of vines attacked by the Phylloxera.

The foregoing remarks will serve as a brief outline of the nature of the problems involved and, in further illustration of this phase of insect control, certain examples will be taken in connection with recent researches.

1. With regard to the susceptibility of different varieties of apple trees to the attacks of the woolly aphis (Eriosoma lanigera), an extensive literature exists on the subject, but no very conclusive deductions can be drawn. Some authorities maintain 
that resistance is dependent upon mechanical factors, while others believe that physico-chemical influences are the most important.

It has been recognised as long ago as 1831 that certain sour varieties are much less liable to attack by the aphis in question, and this observation led to utilisation of sour apples as grafting stocks as a preventive measure. In this way the resistant varieties Northern Spy and Winter Majetin came into prominence, but they have not proved an unqualified success in other ways, since dwarf trees result, productivity is not high and they do not react well to adverse local conditions. A number of other resistant varieties have come to be recognised in different countries, but it appears that varieties that prove to be resistant in one country are not invariably so when grown under different conditions in another country. Thiele (1902), for example, states that Northern Spy becomes susceptible in certain regions of Germany, while under English conditions it has been found to be immune to both the root and branch phases of aphis attack. According to Monzen (1926) the variety Jonathan is susceptible in Japan, whereas Theobald showed that it was almost free from aphis attack in England. Similarly, the last-mentioned authority found Cox's Orange Pippin to be subject to attack in England, yet Misra (1920) states that under Indian conditions it is immune.

It would appear that the resistance in these immune, or slightly susceptible, varieties of trees to attack by the Eriosoma is to a large extent an inherent property, but that this property can either be intensified or reduced by cultural conditions.

According to Crane (1937) in the results of crossing immune with susceptible root stocks the variety Northern Spy has a higher value in respect to the transmission of immunity than any other of the immune varieties used. The proportion of immune plants obtained is often as large, and frequently much larger, in crosses between susceptibles and immunes than that obtained in families raised from immune crossed with immune. Some susceptibles carry factors or genes concerned with immunity and some do not, and there is a gradation in the inheritance of susceptibility. All the immune stocks used were heterozygous. The results of breeding investigations are not discussed in detail in the present 
stage of the work, but they indicate that the hereditary behaviour of immunity is complex. It seems to be determined by and dependent upon a certain balance of genetical factors and governed by a number of genes of somewhat varied action-in part complementary and in part cumulative. Monzen (1926) lays stress upon the physico-chemical nature of resistance, and gives certain data lending support to his contention. He determined the $p \mathbf{H}$ values of the cell-sap of eleven varieties of apple by the colorimetric method, and ascertained that it ranged between 4.4 and 5 . The variations, therefore, are very limited, and from these determinations it appears that the $p \mathrm{H}$ of susceptible varieties ranged from 4.5 to 5 , while that of the immune varieties (including Northern Spy) was $4 \cdot 4$. The acidity of the immune varieties he regards as being due to the larger amounts of malic acid present. With the object of further testing this conclusion, he carried out a series of experiments with apple trees grown in carefully washed sand and nourished with Pfeïffer's solution. The latter medium was rendered alkaline or more acid in different degrees, and the fecundity of the aphis was determined during a definite period on trees grown in the different solutions. The results, shown below, indicate that acidity appears to markedly reduce the fecundity of the aphid, while alkalinity favours it. Monzen further adduces evidence that manuring with acid fertilisers will tend to increase the resistance of the trees to infestation.

TABLE XIV

\begin{tabular}{|c|c|c|c|c|c|}
\hline \multirow{2}{*}{ Trees. } & \multirow{2}{*}{$\begin{array}{c}p \mathrm{H} \text { of } \\
\text { Solution. }\end{array}$} & \multicolumn{3}{|c|}{ Number of Progeny of the Aphid. } & \multirow{2}{*}{ Average. } \\
\hline & & Colony A. & Colony $\mathrm{B}$. & Colony $\mathrm{C}$. & \\
\hline I. & $9 \cdot 4$ & 279 & 104 & 75 & $152 \cdot 7$ \\
\hline II. & $8 \cdot 8$ & 131 & 65 & No progeny & $98 \cdot 0$ \\
\hline III. & $6 \cdot 8$ & 27 & No progeny & - & $27 \cdot 0$ \\
\hline IV. & $5 \cdot 6$ & 41 & 19 & 一 & $30 \cdot 0$ \\
\hline V. & $3 \cdot 6$ & 92 & 61 & 68 & $73 \cdot 7$ \\
\hline VI. & $2 \cdot 8$ & 42 & 37 & 一 & $39 \cdot 5$ \\
\hline
\end{tabular}

It is improbable that relative acidity or alkalinity is the whole explanation of the questions involved, and Monzen's conclusions 
with regard to the application of acidic fertilisers are not in complete accordance with opinions in Germany.

It may be added that the belief that the acidity of the cell-sap is an important factor in relation to the attacks of sucking insects is by no means new. Petri in 1911 claimed that it played an important rôle with regard to the infection of vines by the Phylloxera, and Comes in 1914 held that it presented means of defence of various plants, more particularly against Coccidæ.

The factor, or factors, responsible for immunity to woolly aphis attack in Northern Spy and other varieties of apple are discussed by Roach (1937). In the experiments described by this author indications were obtained which point to the conclusion that immunity is probably a biochemical problem and that it is not due to mechanical or other properties rendering such varieties more or less impenetrable to the stylets of the insect. The woolly aphis was reared on artificial media prepared from the bark of Northern Spy and of susceptible trees. It was found that the development of the insects, when fed upon media of this kind, corresponded to their development on living trees in the smaller number and shorter life of the progeny associated with immune extracts. The results seem to show that the cause of immunity (or susceptibility) resides in some chemical substance insoluble in alcohol or ether and only slightly soluble after prolonged boiling in water. 'The behaviour of the insects on the media suggests that, whatever the factors concerned may be, they are not necessarily destroyed when the tissues containing them are killed.

2. The problem of the relative degrees of resistance of different varieties of oats to attacks of the frit-fly (Oscinella frit) has, in recent years, received considerable attention in England (vide Cunliffe and Fryer, 1924). As to what is exactly implied by "resistance" in this case little is definitely known, and it is gauged by the relative freedom from infestation of different varieties grown under similar conditions. Direct resistance implies that the plant can resist entry by the larva of this insect, or that it provides conditions so unfavourable as to cause the death of the larva before material injury is sustained. On the 
other hand, it is possible that it may depend upon characters associated with growth and which vary with the age of the plant. Such characters might comprise silica content, hardness or thickness of cuticle, hairiness, sap qualities, etc. Since it has been shown (p. 264) that susceptibility appears to be correlated with the age of the plant, one or more of these features may be involved.

In Cunliffe and Fryer's experiments twelve varieties of oats were grown in two widely separated localities, viz., Sandford (Oxon.) and Harpenden (Herts). The infestations of both stem and panicles were noted in detail, and the results obtained were subjected to statistical analysis. The correlation between stem infestation of different varieties at the two localities was high, but the grain infestation exhibited no correlation whatever. Of the varieties submitted to experiment, Goldfinder and Supreme are those least and most subject to infestation, respectively. Consistent and significant differences in the extent of shoot infestation, of the order of 20 per cent., were noted in favour of Goldfinder. Unfortunately, correlated decrease of seed infestation was not so marked; Goldfinder was not in the group suffering least infestation, but it suffered less than 5 per cent. heavier attack than those varieties least attacked. The variety New Abundance was found to be almost equal to Goldfinder in its freedom from the stem infestation, but, on the other hand, it was decidedly the heaviest sufferer from the grain attack.

It is not possible to say how far the results of these experiments can be held to be of general application. The fact, however, that such varietal differences do exist is hopeful for the future. The great difficulty in many parts of England is to sow oats sufficiently early to escape attack, owing to the fact that weather and soil conditions are frequently adverse to this procedure. It seems, therefore, that the chief hope for the future lies in the production of varieties which combine resistance with good yield, since heavy yielding strains for the most part occupy inferior positions in the scale of resistance. Cunliffe (1936) describes a series of experiments designed to ascertain whether it is possible to breed resistance to attack by this insect into the best varieties of English oats, which are highly susceptible. It appears that the most 
highly resistant variety yet found is "Sommar" (summer) from Gotland, and this along with "Spet" from Sweden and "Hede" from Denmark were used in hybridisation experiments. Many varieties, such as "Victory," "Abundance," and "Star," were used in conjunction with the aforementioned resistant types, some seventy-five or eighty hybridisations being made. The outcome of the trials points to the conclusion that resistance to attack is an inheritable character (or complex of characters) that is not incompatible with desirable agricultural qualities. The nature of resistance is unknown, but it is suggested that it may be connected with crude fibre production or deposition of silica in such varieties.

3. The cotton jassid, Empoasca (Chlorita) fascialis, of East, South and West Africa is one of the most important pests of the cultivators of the crop concerned. It occurs in colonies on the leaves of the cotton which, in bad attacks, become deformed and are finally shed; growth of the plant becomes arrested and it may ultimately be killed. The possibility of discovering resistant varieties has attracted a good deal of attention in South Africa, and much valuable breeding work has been carried out at the Empire Cotton Growing Corporation Station at Barberton. The discovery that some strains of varieties and individual plants of the American Upland Cotton (Gossypium hirsutum) resist jassid attack, to a remarkable degree, gave impetus to the work. None, however, has been found to be absolutely immune to the ravages of the insect, and all sooner or later succumb and serve for its breeding and multiplication. Worrall $(1923,1925)$ observed that the resistant strains are markedly hairy, but not all the hairy strains are necessarily highly resistant. The qualities which constitute resistance are not understood, and it appears that hairiness may be mainly the outward expression of such qualities. Míere hairiness alone is not necessarily important and, in the resistant varieties, this character also involves length of hair and density of hairiness per unit area. Worrall expressed the opinion that hairiness is one of the characters to be included by cotton-breeders in their selection work, but that care will need to be exercised to select only those plants with a good staple, because hairiness on 
the whole appears to exhibit a tendency to be correlated with short staple.

A further step was taken when the Cambodia variety of resistant cotton, introduced into India a number of years ago from French Indo-China, was tested out under South African conditions. This variety has also the definite property of hairiness and, according to Parnell (1925), it was found to show immunity-the jassid does not appear to breed upon it or injure it in the least degree. The large size of the plant, and its rather weak and delicate stems, which render it susceptible to storm injury, make it of doubtful promise as a field crop. Only further work will show whether it is possible to obtain less rampant strains. At the same time, research is being carried out with the object of selecting and testing promising local varieties betraying evidence of jassidresistance in the field. In the latest available Report on the subject, it is stated that remarkable progress has been made in this direction and has resulted in the discovery of several strains, of which those known as Z.1 and U.4 are both highly resistant to jassid attack, of good staple and prolific yielders. This has led to supplies of their seed being sent to farmers, and to an increase of acreage given over to cotton-growing. It would appear that the discovery of these resistant varieties has brought the solution of the problem within sight. Doubtlessly, much further work is still necessary with regard to re-selection and improvement of these types, and it remains for the future to show whether their inherent properties will be retained under diverse local conditions. Their discovery, under the ægis of the Empire Cotton Growing Corporation, is one of great importance, and will lend encouragement to further efforts in the same direction, with reference to pests in other parts of the world. 


\section{CHAPTER XI}

\section{THE PRAGTICAL APPLICATION OF ECOLOGY- continued}

Host-Selection and Biological Races, p. 286. The Adoption of New Food-plants, p. 294; Hybridisation Experiments, p. 297; The Interpretation of Host-selection, p. 297. ECOLOGICAL ASPECTS OF the Locust Problem, p. 299. The Phase Theory, p. 300 ; Factors Governing Swarming, p. 305; The Species of True Locusts, p. 306 ; Phase Development in Grasshoppers, p. 311. Literature, p. 313.

\section{Host-selection and Biological Races}

THE last few years have witnessed the publication of a number of papers bearing upon the theory enunciated by Hopkins (1916) and now generally known as the "host-selection principle." According to this authority, in a given insect species that is capable of breeding in two or more hosts, individuals will normally continue to select the particular host species upon which their own life-cycle was passed. In other words, this host predetermines selection by the ovipositing female of the same plant species for her offspring as that in which her own developmental stages took place. The outcome of the principle is the evolution of special physiological strains, or races, each betraying its own particular host-preferences, but, at the same time, exhibiting little or no indications of morphological differentiation. This general phenomenon was recognised more than sixty years ago by Benjamin Walsh, who maintained that we have, in such hostpreferences, the beginnings of species differentiation. Such preferences, he claimed, become habituated and destined through heredity to result, in course of time, in increasing divergence and to lead ultimately to the formation of separate species.

Many cases of the apparent separation of polyphagous or oligophagous species into different phytophagic or biological races have been recorded (vide Thorpe, 1930). In some cases 
slight structural differences, or differences in size or colour, are involved, in other cases not. For many years experimental studies of host-preferences of this kind, and of their possible repetition in succeeding generations, was lacking. It is only comparatively recently that the problem has received critical investigation, but in all cases larger scale and more prolonged studies are still a desideratum. The whole subject is not only of importance in relation to the general question of the origin of species, but also from the standpoint of applied entomology.

It is necessary here to refer briefly to the instance of host-selection specifically stressed by Hopkins. His example concerns the mountain pine beetle (Dendroctonus monticola), which attacks various species of pines. According to him, in this insect, when it becomes established in one species of pine through many generations, the beetles upon emergence show a marked preference for that species, and will not attack any other. Hopkins applied this observation to control measures, and held the view that each such "strain" can be dealt with as if it were a separate species. In 1922 Craighead published the results of a number of years' experiments with about a dozen species of Cerambycidæ, which afforded support to Hopkins' general contention. He found that, in practically all the species studied, the adults exhibited marked predilection for the host-species in which their larval existence was passed, provided they were not deterred by such factors as unfavourable conditions or the scarcity of their host. Continued breeding appeared to intensify the preference and, in some species, transference to another species of host for only a year was said to be sufficient to determine a preference for this host by the resulting adult beetles. In 1927 Larson discussed the host-selection principle very fully and tested it with reference to the cowpea weevil (Bruchus quadrimaculatus). His results were not in accordance with those of Craighead, since he concluded that the insect in question showed no marked preference for the host in which it had been bred, and that continued breeding in any one specific host did not appear to intensify preference for that host. In 1928 Thompson and Parker examined the question with regard to the corn borer (Pyrausta nubilalis). This insect 
is notably polyphagous, but, in Europe, it chiefly attacks maize in regions favourable to the cultivation of that crop; in regions north of the maize-growing areas it mainly attacks weeds and more especially Artemisia vulgaris. In some regions, however, it attacks both maize and Artemisia, but in others it favours only one of these two hosts. Thus in the Department of Gers, in south-western France, maize is practically its only food-plant, while around Paris it lives principally upon Artemisia, and has no opportunity of attacking maize owing to the absence of that crop. It appeared likely, therefore, that material from these two areas, where the conditions have remained relatively stable for a long period of time, would be specially suitable for the study of the host-selection principle. The conclusions derived from these experiments show that, notwithstanding the long association of the corn borer with Artemisia, which may indeed be its original host, it exhibits no marked preference for this plant and laid the majority of its eggs upon maize. In fact, the latter host is the favoured one both by the Artemisia and maize strains of the insect, as is shown by the following records of oviposition (in percentages) :

Table XV

\begin{tabular}{|c|c|c|c|c|c|c|c|}
\hline \multirow{2}{*}{\multicolumn{2}{|c|}{ Strain. }} & \multicolumn{2}{|c|}{ Maize. } & \multicolumn{2}{|c|}{ Artemisia. } & \multicolumn{2}{|c|}{ On Woodwork, etc. } \\
\hline & & Masses. & Eggs. & Masses. & Eggs. & Masses. & Eggs. \\
\hline Artemisia & & $58 \cdot 4$ & $55 \cdot 6$ & $38 \cdot 8$ & $41 \cdot 2$ & $2 \cdot 8$ & $3 \cdot 2$ \\
\hline Maize . & . & $69 \cdot 6$ & $70 \cdot 1$ & $13 \cdot 2$ & $11 \cdot 5$ & $17 \cdot 2$ & $18 \cdot 4$ \\
\hline
\end{tabular}

It would appear, therefore, that the corn borer is a species having a strong innate preference for maize, and that the Artemisia strain exhibited a greater attraction for that host than for its original host. It is true that this strain exhibited a stronger preference for Artemisia than was evidenced by the maize strainin the latter case, in fact, the preference does not appear to be significant, since even more eggs were deposited away from any specific food-plant than upon Artemisia.

Experiments by Thorpe (1929, 1931), with the moth Hyponomeuta padella, indicate that this insect is divisible into two biological races which were formerly regarded as separate 
species. One race is specially attached to apple as its foodplant, and the other to hawthorn and blackthorn. The applebred moths exhibit a great preponderance of forms with pure white fore-wings, while those reared upon hawthorn seldom exhibit this feature, the wings being most often suffused with grey. The two forms also exhibit differences in cocoon texture and methods of oviposition. The results obtained in these experiments are shown in tabular form below.

\section{Table XVI}

\begin{tabular}{c||c|c||c|c}
\hline & \multicolumn{2}{|c|}{ Hawthorn Race. } & \multicolumn{2}{c}{ Apple Race. } \\
\hline $\begin{array}{c}\text { Hawthorn and } \\
\text { Blackthorn. }\end{array}$ & Apple. & $\begin{array}{c}\text { Hawthorn and } \\
\text { Blackthorn. }\end{array}$ & Apple. \\
\hline $\begin{array}{c}\text { Number of egg- } \\
\text { batches . }\end{array}$ & 26 & 7 & 10 & 87 \\
\hline \begin{tabular}{c} 
Number of eggs \\
\hline $\begin{array}{c}\text { Average number of } \\
\text { eggs per batch }\end{array}$
\end{tabular} & $311(79 \cdot 3 \%)$ & $237(20 \cdot 7 \%)$ & $367(9 \cdot 75 \%)$ & $3,395(90 \cdot 25 \%)$ \\
\hline
\end{tabular}

When the hawthorn race was reared upon apple, the resulting females laid all their eggs upon hawthorn. On the other hand, when the apple race was reared upon hawthorn, $69 \cdot 2$ of their eggs were laid on apple and 30.8 per cent. on hawthorn. Experiments carried out with hawthorn- and blackthorn-reared moths, allowing them free choice of the two food-plants, indicated that the hawthorn-blackthorn is subdivided in the same way. It appears that out of 825 eggs laid by hawthorn-reared moths, 18.8 per cent. of them were laid on blackthorn and $81 \cdot 2$ per cent. on hawthorn. Furthermore, out of 4,293 eggs laid by the blackthorn race, 69 per cent. were on blackthorn and 31 per cent. on hawthorn. 'Thorpe's results, therefore, lend strong support to the host-selection principle and they raise the practical point as to whether it is necessary for the apple grower to deal with infestations on surrounding hawthorn hedges. It would appear from the data already given that such an infestation is unlikely, under normal conditions, and that treatment of the hedges would not be a sound practical proposition. 
The discovery by Lal (1934), in Edinburgh, of two biological races of the common hemipterous insect Psylla mali, is of considerable interest. The forms $P$. peregrina of the hawthorn and $P$. mali of the apple have hitherto been regarded as two separate species. Lal has shown that the imagines of both forms are identical and the only differences are those shown by the nymphs. In peregrina the last instar nymph has a brown streak on the developing wings which is absent in mali. Also, in peregrina the setæ surrounding the abdominal margin are all of one kindlong and spatulate: in mali they are of two types, long, pointed, variously curved setæ and small setæ of spear-like shape. In peregrina the dorsal surface bears round tubercles which are replaced in mali by very minute setæ, which cover the body of the latter. The two forms are closely confined to their individual food-plants : they do not interbreed and neither will oviposit on the host of the other. The nymph of either, when transferred to the food-plants of the other, does not survive long. In view of the foregoing evidence, it is pointed out that $P$. mali Schmidt has a race peregrina Forst which has previously been regarded as another species. This example, wherein similar adults betray nymphal differences, affords an instance of what Giard termed pocilogony, which is a rare phenomenon among insects.

So far the subject of biological races has only been considered with reference to their expression in differences of food-preference. Evidence of such races with very different characteristics requires mention. Thus, the moth Ephestia kuhniella appears to occur as two strains or races with marked different rates of development. Payne (1933) found that the slow strain was able to complete its developmental cycle between $8^{\circ}$ and $34^{\circ} \mathrm{C}$. and the fast strain between $10^{\circ}$ and $32^{\circ} \mathrm{C}$. A number of observers had previously noted marked differences in the rates of development of larvæ hatched upon the same day. The most recent worker, Ahmad (1936), has confirmed Payne's observations and points out that this insect is only susceptible to parasitisation by Nemeritis during the last larval and pupal stages, but the mixture of strains, he states, results in the continuous presence of the host in the right condition for parasitisation. 
An extensive literature has grown, during the past few years, around the subject of biological races in mosquitoes. The prevalence of "anophelism" without malaria in many districts has formed the basis of the idea that races may exist which vary in ability to transmit the malaria Plasmodium and in diverse other biological features. Thus Anopheles maculipennis labranchice lays a maculated grey egg, is especially prevalent in human habitations and does not undergo complete hibernation. This race occurs wherever malaria is prevalent in Europe, and its larvæ are stated to tolerate brackish water. Anopheles maculipennis messea lays eggs marked with two transverse black bars : it frequents stables, undergoes hibernation and is the predominating form in nonmalarial districts. Its larva are stated to show preference for fresh water. Differentiation of two races upon the foregoing criteria as stated by Hackett, Martini and Missiroli (1932) has been confirmed in the main, but according to Roubaud and Gaschen (1933), the so-called maxillary index or, in other words, the number of serrations on the maxillary stylets is a better criterion than the egg-characters already alluded to. More recent work by Missiroli, Hackett and Martini (1933) has led to the conclusion that in addition to the two races mentioned, three or possibly four others also occur. These differ, among other features, in their feeding habits : thus, labranchice and sacharovi are the important malaria carriers: messece and atroparvus normally resort to animal hosts, but attack man in the absence of the latter, while melanoon and typicus have no significance in connection with malaria transmission.

The researches of Roubaud and his co-workers, published in a number of papers between 1929 and 1932, have shown that in France there are two definite biological races of Culex pipiens. These races are characterised as follows : (1) C. pipiens pipiens, which undergoes cyclical hibernation, does not oviposit without blood-meals (anautogeny) and requires a large area for pairing (eurygamy). (2) C. pipiens autogenicus, which does not hibernate, but breeds continuously throughout the year. Females of this race lay fertile eggs, without partaking of any food as adults, the ova maturing at the expense of food-reserves accumulated during 
larval growth (autogeny) and fertilisation occurs in confined spaces such as very small vessels (stenogamy). A number of other workers have confirmed the existence of two such races, but differing in various ways from the two French races just referred to. The extensive literature on this subject is discussed by Tate and Vincent (1936), and these authors have maintained three autogenous strains of $C$. pipiens, and the general result of their work confirms the conclusions of Roubaud and others that there are two distinct races of $C$. pipiens in Europe. They point out that confusion has arisen from the fact that Roubaud described the autogenous race as an urban form, whereas it occurs in rural areas also. It is true that it may breed freely in towns where conditions are not suitable for the anautogenous race, but is not confined to such habitats. The result of cross-mating experiments show that interbreeding may take place in nature where the two races co-exist. They find that the English autogenous race is not subject to obligatory, cyclical hibernation. Prolonged illumination has an activating influence on the females, both hibernating and laboratory bred, and greatly stimulates gorging. With the aid of artificial light during the winter months this race has been kept breeding in the laboratory throughout the year for eleven generations without occurrence of cyclical hibernation. They think that the reduced daylight may have an important influence in inducing hibernation in autumn, since if given extra illumination they remain active and feed. The females, whether they be of hibernating or active generations, laid normally after one bloodmeal. Unfed females lived for a maximum of nineteen days and never developed fat-body autotrophically. If fed on carbohydrate food, in the form of fruit juice, for five weeks they accumulated sufficient reserves to enable a small proportion of them to survive fifteen weeks of subsequent starvation. Pairing always begins in the air, but may be completed on the ground. The females do not lay without a blood-meal and they show little tendency to bite man, but attack birds voraciously.

The strains of the autogenous race have been kept breeding without blood-meals for several years and through forty-five to forty-nine generations. 'This had no deleterious effects, a fact 
which is at variance with Roubaud's conclusion that a gradual decrease in the number of females produced in successive generations followed prolonged continuous autogeny. The feeding of the females with fruit juice is apparently without influence on egg-production, but after a blood-meal the number of eggs in a raft is about twice as many. The males pair with resting females, and it is evident that mating can occur in very small vessels or restricted areas. The females are voracious blood-suckers of both birds and man. Tate and Vincent regard the term autogeny as being unfortunate, owing to its being a variable character, since on an average only 60 per cent. of the females lay autogenous eggs and under unfavourable conditions very few may do so. They consider that eurygamy and stenogamy are more constant characters for differentiating between the two races. Roubaud (1935) has described differences in the micro-structure of the eggfloats of the two races, and Marshall and Staley (1935) found differences in the chætotaxy of the larvæ.

Reciprocal cross-mating between individuals of the sexes of the two races was easily obtained. The experiments show that autogeny and stenogamy are genetical characters transmitted to the progeny. Stenogamy always appears in the $\mathbf{F}_{1}$ generation, but autogeny may not appear until the $\mathrm{F}_{2}$ generation or later. Much further genetical work is necessary, however, before the inheritance of the racial characters can be discerned with confidence.

The question naturally arises as to the evolutionary significance of biological races. Do they, in fact, afford evidence of evolutionary divergence which, if carried far enough, will ultimately lead to the production of new species? A number of workers have answered this question in the affirmative. If, at any rate, some of the races are species in the making, and where their characters are germinally fixed there seems good evidence for this view, we have to conclude there is some degree of isolation of a physiological or behaviouristic kind which ensures their continuance. None of the evidence so far presented provides sufficient data to carry full conviction in this matter. It does, however, suggest a profitable field for further enquiry, and for a discussion of the 
subject the reader is referred to the general review by Thorpe (1930).

The Adoption of New Food-plants. A certain amount of experimental evidence exists with reference to the adoption of new plant-hosts by various insects. One of the earliest experiments of this kind appears to be that of Schroeder (1903), with reference to the leaf beetle Phyllodecta (Phratora) vitellince. The larvæ of this insect skeletonise the leaves of Salix fragilis so as to leave only the upper epidermis intact. Young larvæ transferred to Salix viminalis which, unlike $S$. fragilis, has its leaves densely pilose beneath, adapted themselves to this new food-plant. By cutting and pushing aside the hairy covering they reached the central parenchyma and one larva excavated a mine in the leaf-tissue. After four generations upon $S$. viminalis the larva became adapted to leaf-mining, and in each generation the proportion of adults which selected this food-plant in preference to the original host steadily increased from 9 per cent. to 42 per cent.

Experiments conducted by Marchal (1908) with the scale insect Euclecanium persica involved the transfer of the eggs of individuals living upon peach to false acacia (Robinia pseudacacia). Only certain of the young scales resulting from these eggs were able to adapt themselves to the new host, but in the following year their progeny had so completely accepted the unusual food-plant that the transfer of individuals back again to peach resulted in their failing to reach sexual maturity. The individuals reared upon Robinia, it may be added, closely resembled in their large size, form and colour the race or species $E$. robiniarum of that same host. Since the Robinia species was unknown in France prior to 1881, Marchal was of opinion that it was a recent derivation from the species $\boldsymbol{E}$. persica. Evidence in support of this contention is not entirely conclusive, since the Robinia is a tree imported from America, where the scale insect $E$. robiniarum is also known to occur.

Sladden (1934), in experiments dealing with induced foodpreference in the stick-insect Carausius, came to the conclusion that individuals reared upon ivy showed a greater ability to feed 
on that plant, or even a greater preference for it, than their parents or controls of the same generation derived from privetfed stock. In a later paper (Sladden, 1935) this conclusion is confirmed and the experiments show that the offspring of each subsequent generation accepted ivy more readily than did their parents, and even exhibited an increased preference for it.

Harrison (1927) published the results of certain field experiments with the gall-forming saw-fly Pontania salicis. He removed a strain of this insect which is locally adapted to Salix phylicifolia to a district where various species of Salix grew, and the insects were allowed to oviposit unhindered in the open. They showed a marked preference to adopt Salix andersoniana to the comparative neglect of the very closely allied original host $S$. phylicifolia, a feature that was particularly evident during two successive years. In other experiments he found that a strain of the same saw-fly from Salix andersoniana brought to another locality where only Salix rubra was available became adapted to that host. Later, when plants of $S$. andersoniana were established in that locality in proximity to $S$. rubra the former species of willow remained entirely free from the galls of this saw-fly. He further mentions that the latter, in its reaction to a changed food-plant, shows corresponding colour differences. Mention needs also to be made of Pictet's experiments (1911) with larvæ of Lasiocampa quercus, which feed upon deciduous trees and bushes. When placed upon Pinus many of them died and those which survived fed by biting into the parenchyma at the extremities of the pine needles. In the second generation the insects became adapted to the new diet to the extent that they either starved when offered leaves of deciduous trees, or they only attacked the apices of the leaves, which they hollowed out in a manner similar to that performed by larvæ of the previous generation.

It will be gathered from these experiments that it is possible for an insect to become rapidly adapted to a new food-plant to an extent that it may partially or completely reject its original host. It is reasonable, therefore, to conclude that similar behaviour may occur in a state of Nature, particularly if the normal food-plant be lacking. Harrison's experiments, already alluded to, indicate that 
such change of habit may be equally rapid under natural conditions. There exists in entomological literature many records of insects adopting food-plants which they were previously unknown to affect, but apart from the actual observation of the facts little else is known with respect to this behaviour. In one or two instances, however, well-attested evidence points clearly to the change having occurred within recent years, and appears to be leading to the evolution of special biological races. A wellknown example is familiar to North American entomologists in the case of the Trypetid fly Rhagoletis pomonella. The larvæ of this insect have long been known to live in the blueberry, but in the north-eastern states its more recent spread to apple is a matter of direct record. According to Woods (1915) it has developed into two distinct races distinguished by the small size of both larvæ and adults derived from blueberry as compared with those from apple. Attempts to transfer the apple race to blueberry and vice versâ were unsuccessful, the two forms being seemingly independent. What appears to be a parallel example in England is afforded by the Capsid Plesiocoris rugicollis which has now become a widespread and serious pest of the apple. It is practically certain that it was not an apple pest in England prior to 1900 , and since that time a race appears to have developed which has adopted this tree as its host in preference to Salix, which is its usual wild food-plant. This change seems to have involved some readjustment in the life-cycle of the insect since, when living upon willow, it usually occurs from June to August; whereas, upon apple, eclosion from the eggs takes place from the middle of April onwards, and adults occur from about the first of June until the end of July. The whole life-cycle, it appears, has been advanced by about one month. There is need for exhaustive experiments with reference to the behaviour of this insect; under artificial conditions it can be readily transferred from willow to apple, or even to new food-plants such as plum. In a state of Nature, however, it shows a tendency to remain upon the host-plant on which hatching took place. In certain cases willow trees were found with their branches actually touching or interlacing those of apple, yet although the willows 
were extensively infested, no transfer to apple took place. For further information and references to the principal literature on Plesiocoris vide Fryer (1929).

Hybridisation Experiments. Evidence of the nature of the food-preferences of crosses between biological races and subspecies is of a very scanty nature. In this connection the experiments of Göschen (1913), therefore, are of particular interest. The European Sphingid moth Celerio euphorbice is represented by two races or sub-species named euphorbice and mauritanica respectively. In both races the usual food-plant is Euphorbia and neither will accept Salix. Göschen found that the hybrid mauritanica $\delta \times$ euphorbice + and known as wagneri, and also the reciprocal cross, both can be reared to maturity without difficulty upon Salix. Similarly the hybrid known as $C$. kinderwateri, produced by the cross euphorbice $\hat{0} \times$ galii o, feeds readily upon Salix, a food-plant upon which neither of the parents naturally occur. On the other hand, observations made by Field (1910), in North America, appear to show that host-selection is not necessarily affected by hybridisation. Field's observations bear upon the feeding propensities of the butterflies, Basilarcha arthemis, $B$. astyanax and $B$. proserpina, the last named being regarded as a natural hybrid between the first two. Larvæ produced from a captured proserpina female refused birch, sallow and poplar, the usual food-plants of arthemis, and were reared upon wild cherry, which is one of the favoured plant-hosts of astyanax. These same larvæ finally produced all the three forms of Basilarcha named. He suggests that the constitution of the original parent was proserpina (hybrid) $\times$ arthemis (colour recessive), since astyanax does not prevail in the district where the insect was captured. The unexpected preference of the astyanax foodplant is explained as having been inherited from a grandparent of that form. Unfortunately, neither Göschen nor Field were able to continue their observations to later generations of the species mentioned.

The Interpretation of Host-selection. It has been seen that the results of recent research afford definite support in favour of Hopkins' host-selection principle in a considerable proportion 
of the cases studied. The phenomenon is most in evidence where the species concerned are able to exercise freedom of choice in the selection of their food-plants. In the absence of such freedom, under experimental conditions, it has already been shown that host-preference may be insufficiently habituated to preclude an insect from adopting new hosts. In cases where host-preferences are most strongly developed they appear to have led to the evolution of definite biological, or phytophagic, races which are now known to occur in widely separated groups of insects. Such races may further exhibit differences of form, colour and behaviour.

The factor or factors involved in the exercise of host-selection are, as yet, very little understood, and various hypotheses have been advanced to account for the repetition of similar habits in this respect from generation to generation. There is considerable evidence in favour of the contention that for many insects polyphagy is phylogenetically the older habit, oligophagy and monophagy being more recent developments. Both Hering for Lepidoptera and Mordwilko for Aphididæ, who have specially considered this problem, hold that it applies to the groups referred to. A very large number of records occur in recent entomological literature of insects resorting at times to unusual, or hitherto unknown, food-plants. It may be argued that, in certain cases, this sporadic habit is to be interpreted as a physiological mutation in the species concerned. On the other hand, it appears equally probable that such instances may be examples of the exercise of a latent, more or less vestigial, former polyphagic habit. If this latter explanation be the true one, it accounts for the varying degree of potential polyphagy found in so many insects. Little is known with respect to the host-preferences exercised by different individuals of a true polyphagic species-whether they do exhibit selection of the specific hosts upon which they themselves have developed in preference to all others. The beginnings of oligophagy are initiated by preference of this kind, and the more the oligophagic habit is developed, the more the species loses its former trophic plasticity or power of accommodation to new hosts. The repetition of the habit of specific host-preference 
appears to be explainable as the result of a chemical influence, derived from the food-plant, acting upon each successive generation. Specific host-preference and its repetition in each generation seems to afford an analogy with what Pavlov has termed a conditioned reflex. The conditioning takes place during the developmental cycle of the insect and influences the chemotropic responses of the female during oviposition. It determines the preference for selecting the same host-species upon which her own developmental stages were passed. The faculty for conditioning, which appears to be present in all insects to a greater or lesser degree, is almost certainly inherited. The chemical influence derived from the food-plant, on the other hand, seems to determine the direction along which the conditioning shall take place. It has already been shown that there is some evidence that specific host-selection may become intensified in successive generations, or, in other words, intensified specific conditioning may occur. The question naturally arises as to whether this is due to the passing on and accumulation in successive generations of some chemical agency derived from the food-plant? There is, again, experimental evidence showing that if an insect be transferred to a different food-plant, the effects of this conditioning may become lost and a new conditioning substituted. If, on the other hand, a specific conditioning be repeated through a sufficient number of generations as to become unalterable, it would appear to have directly affected the germ cells of the insect. Up to the present, however, we have not adequate experimental data in order to determine whether a permanent effect can be so induced and reflected in a rigid hostselection. The available evidence will hardly be considered by most biologists to be sufficiently well grounded to demonstrate a principle of inheritance so open to controversy.

\section{Ecological Aspects of the Locust Problem}

The more or less irregular periodicity of locust outbreaks has long attracted attention, and various explanations have been advanced to account for the phenomenon. There seems to be very little doubt that the periodicity is the result of certain 
environmental influences acting either directly or indirectly upon the insect. If this be correct it follows that a thorough ecological study of each locust species in relation to fluctuations in external conditions, over a period of years, would be the most profitable way of arriving at an understanding of the factors regulating outbreaks of these insects.

While the menace of locust swarms can be better counteracted by the prompt application of artificial control measures than has happened in the past, these measures still remain hopelessly inadequate when combating great invasions. Being remedial in effect their application may alleviate pressing needs, but the menace of subsequent swarms is left unaffected. In other words, they leave the main problem unsolved, i.e., the causes of locust outbreaks and the areas of their origin.

In 1921 Uvarov advanced what has subsequently become known as the phase theory of locusts. His views were first put forward as a working hypothesis, but later observations conducted both in the laboratory and in the field by Faure (1932) and other workers have so fully corroborated its main contentions that the phase theory of locusts is regarded to-day as an established biological phenomenon.

The Phase Theory. The starting point of the theory is that the gregarious species of Acrididx or true locusts are polymorphic. Such species are not constant in all their characters, but are capable of producing a series of forms differing from one another, both morphologically and biologically. In their notable discussion on polymorphism, Uvarov and Zolotarevsky (1929) propose a standard phase nomenclature which, although referring more especially to the well-known species, Locusta migratoria, will probably prove applicable to the other species also. According to their interpretation a locust can exist in three unstable biological phases, namely, a solitary one, phasis solitaria; a gregarious one, phasis gregaria; and a transitional phase between these two, which they term phasis transiens. These phases differ from each other in morphological and colour characteristics, on the one hand, and in biological features (mainly behaviour) on the other. The phases gregaria and solitaria are often so strikingly distinct 
that they have hitherto been regarded as different species, which has naturally resulted in confusion.

Taking the African migratory locust (Locusta migratoria migratorioides) as an example, the essential characteristics of the phases may briefly be diagnosed as follows (sexual differences being excluded).

The phasis gregaria is the swarming or migratory phase which is so highly destructive. It is characterised in the nymphal instars by the great predominance of black and deep orange-yellow coloration which develops quite independently of the nature of the environment. The adults have the pronotum somewhat concave, rather short and prominently constricted: there is clearly no marked dorsal carina. Biometrical studies show difference in the size and proportion of the tegmina and hind femora as compared with those organs of individuals in the solitary phase, the femora being relatively shorter and the tegmina relatively longer. Colour differences are of minor importance in diagnosing adult individuals of this phase, and the most reliable characters are afforded by ascertaining the values of the following ratios.

\section{Table XVII}

\begin{tabular}{|c|c|c|}
\hline Ratio. & Gregaria. & Solitaria. \\
\hline$\frac{\text { Length of tegmen }}{\text { Length of femur }}$ & $\begin{array}{l}\text { Equal to or greater } \\
\text { than } 2 .\end{array}$ & Always less than 2. \\
\hline$\frac{\text { Length of pronotum }}{\text { Width of head }}$ & Very near 1. & $\begin{array}{l}\text { Notably more than } 1 \text { : } \\
\text { about } 1 \cdot 58 \text {. }\end{array}$ \\
\hline$\frac{\text { Height of pronotum }}{\text { Width of head }}$ & Very near 1. & $\begin{array}{l}\text { Notably more than } 1 \text { : } \\
\text { about } 1 \cdot 47 \text {. }\end{array}$ \\
\hline $\begin{array}{l}\text { Width of pronotum at } \\
\text { constriction } \\
\text { Width of head }\end{array}$ & $\begin{array}{l}\text { Notably less than } 1 \text { : } \\
\text { that is, } 0.6 \text { to } 0.8 \text {. }\end{array}$ & 1, or slightly below 1 . \\
\hline
\end{tabular}

The phasis solitaria, or solitary non-swarming phase, is relatively harmless. It is characterised by the nymphs being extremely plastic in their coloration, which shows a strong tendency to 
simulate that of the immediate environment. The adults have the pronotum somewhat arched with an evident longitudinal carina: there is no marked constriction and the pronotum is relatively longer than in the gregarious phase. The hind femora are also relatively longer and the tegmina shorter. The diagnostic ratios are given in the table above.

The phasis transiens is not represented by any definite form, but by a continuous series of transitional forms between the solitary and gregarious phases. Such a series may be observed either $(a)$ when the transformation is from the solitary phase towards the gregarious phase, when it may be termed phasis congregans; or $(b)$ when the tendency is in the opposite direction, when it is termed phasis dissocians. These two phases are

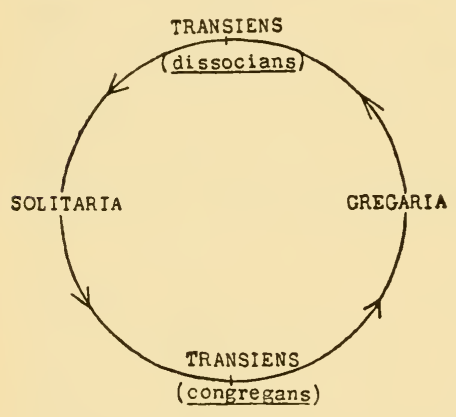
essentially of a biological nature, but it appears that it may be possible to distinguish them also by minor details of structure and colour.

In the accompanying diagram the general scheme of cyclic interrelations between the four phases just described is represented. It must be pointed out that the phasis transiens may be represented by forms morphologically and biologically quite close to either $p$. solitaria, or $p$. gregaria, into both of which the series merges almost imperceptibly.

Under experimental conditions, given the right combination of temperature and humidity, plenty of sunlight and adequate suitable food, it is easy to rear locusts in one or other of their phases. If the newly hatched nymphs are reared under crowded conditions, they show all the main features of the phase gregaria, although it is doubtful whether absolutely typical gregaria are always produced under these conditions. Under less crowded conditions the locusts develop into phase transiens, while if each early nymph be reared in a separate container it develops into solitaria. Faure (1932) showed clearly that in this phase the individual nymphs assume a coloration more or less resembling 
that of the background of the cages in which they are reared. Hertz and Imms (1937) have explored this subject further and analysed the relation between this phenomenon and the spectral and other qualities of the light rays that are involved. It was also shown by Faure that green nymphs are produced as the result of humid conditions and an abundance of moist green food irrespective of the nature of the background. In the production of the green nymphs, Hertz and Imms came to the conclusion that high humidity alone is involved and that the threshold of humidity in this connection appears to differ for different individuals. Below this threshold green forms are not produced and the insects assume a coloration in conformity with the nature of the background. A green background, however, produces yellowish forms and never green. It would appear that this faculty of colour adaptation may serve a protective function of rendering the developing insects less conspicuous in their environment. The green nymphs in a state of nature, it may be added, occur among an abundance of green herbage when the humidity would presumably be relatively high. Physiological differences between the two extreme phases have not so far been explored in any detail. Butler and Innes (1936), however, have shown that the oxygen uptake of individuals in the gregarious phase is markedly greater than those in the solitary condition. Strel'nikov (1936) states that careful body-temperature readings indicate that the black and orange hoppers of the gregaria phase absorb more radiant heat than individuals (green) in the solitaria phase. In the shade the body temperature of hoppers of both phases was more or less alike and slightly above that of the surrounding air. After six minutes in the sun the temperature of gregaria rose by $15^{\circ} \mathrm{C}$. and that of solitaria by only $10 \cdot 2^{\circ} \mathrm{C}$. On being shaded, gregaria individuals lost heat more rapidly than solitaria.

Under crowded conditions the nymphs become extremely active and this naturally affects the rate of metabolism of the organism. Faure believes that more excretory products are produced than are liberated by the Malpighian tubes and that these, or their derivatives, become deposited in integument, thus imparting the black and orange coloration that is an invaluable 
attribute of nymphs in the gregarious phase. Faure gave the tentative name of "locustine" for the products of the excessive metabolism which lead to the development of the gregaria coloration. He points out that the black coloration appears in nymphs of the gregaria phase an hour or less after hatching. It could not, therefore, he says, be possibly due to the activity of the nymphs themselves and concludes that it is due to the passing on of locustine from the female to the embryo in the nutritive yolk of the egg. The interesting problem of the biochemical nature of the pigments concerned is as yet unexplored. The morphological characters of the thorax which differentiates the two extreme phases are also an expression of this activity. Strains and stresses accompanying muscular exertion appear to exercise an influence which moulds the thorax into the form characteristic of gregaria-the more typical or ancestral form being retained by individuals in the solitaria phase. The hypothesis that the characteristic pigmentation of the gregaria hoppers is produced as a by-product of high metabolic activity receives support from recent experiments by Husain and Mathur (1936). These authors found that when hoppers of the locust Schistocerca gregaria, in the solitaria phase, were forced to crawl a certain distance daily in revolving gauze drums and cylindrical cages that rotated vertically at intervals, they assumed the black coloration characteristic of hoppers in the gregaria phase. The pigmentation of the latter phase was also induced when individual solitaria hoppers were placed in cages crowded with hoppers of Pocilocerus pictus and adults of Chrotogonus.

In the phase solitaria the nymphs are relatively sluggish : they sit about the food-plants quietly eating and undergo little movement unless disturbed. We are still in the dark, however, as to why mere crowding exercises an influence which appears to activate a gregarious instinct-whether the actual stimulus involved is, for example, contact, visual or odour, etc. Within the limited space available it is not possible to discuss at all adequately the immense and rapidly growing literature dealing with the different aspects of locust life. The reader is referred to the useful abstracts which appear monthly in the Review of 
Applied Entomology, Series A, for further information and references to the literature concerned.

Factors Governing Swarming. The first impulse for a locust to increase in numbers appears to be provided by favourable meteorological conditions. This is automatically followed by evolution towards the swarming phases. Once swarming has taken place a crisis is reached, a decline supervenes, and this usually leads to the solitary phase.

In the case of Locusta migratoria, sub-sp. migratorioides, the solitary phase has an enormous area of distribution, whereas the gregarious phase only occurs in certain regions. The areas where the latter phase can be produced are characterised by the extensive development of reeds, bamboos and similar tall plants. It would appear that such vegetation provides the most suitable food, but it is also possible that the connection between the gregarious phase of this insect and reed-beds may be due to the climatic conditions associated with the latter. Such a uniform environment, providing an abundance of food and shelter, is very suitable for mass development of the locust, and the appearance of large numbers of hoppers in a favourable year leads to transformation into the swarming phase. The stimulus to increase in numbers appears to be provided by dryness in tropical countries, while in temperate lands a high temperature is of great importance in this respect. Once the dense migrating swarms have left their breeding grounds, the latter remain almost free until a fresh increase in numbers results. Migrating swarms usually settle on lands very different from whence they came. Difference of conditions appears to reduce the numbers of the generation which results from their egg-laying, and transformation into the solitary phase supervenes. The activities of parasites, birds, and other natural enemies increase at this period and further accelerate the transformation. The hoppers of the solitary phase do not differ in their general behaviour from those of other solitary grasshoppers, and do not exhibit any tendency towards gregariousness.

The actual stimuli which promote the migratory flight are, according to Uvarov, physiological. Lack of food can be dismissed, since the vast stretches of reed-beds in their breeding 
ground afford an inexhaustible supply upon which the winged swarms make relatively little impression. There appears to be no doubt that migration is intimately connected with the development of the genital products, as happens also in the case of the nuptial flights of termites and of ants. With locusts the flight acquires a regularity and duration of such a character that it goes on so long as physiological causes impel it. It may terminate or only be interrupted owing to unfavourable environmental conditions, but physiological causes such as the exhaustion of the fat-body by oxidation, and the rise of body temperature, resulting from flight, accelerating the maturity of the sexual products, appear to be of greater importance. It is further noteworthy that the available evidence indicates that the emigration is not concerned with the quest for suitable new areas for egg-laying. The settling of swarms in places totally unsuited either for feeding or oviposition has often been recorded and is totally opposed to this, at one time, prevalent belief.

There is obviously much that remains obscure in the phase theory, and the various factors involved require deep and searching investigation with respect to different species of locusts. The theory, although an established fact, is still very largely hypothetical as regards fundamental causes. It lends, however, a new and essentially ecological interpretation of locust outbreaks. By directing research along a defined course, it will co-ordinate investigation, hitherto largely prosecuted blindly in the hope of eventually alighting upon some solution of the problems concerned. It opens up the possibility that mass transformation of locusts into the gregarious phase may be foretold, while discovery of the locations of the favoured breeding grounds may lead to the destruction, by aeroplane dusting, of immense numbers of potentially harmful individuals. Further, ecological study opens up the possibility of altering the character of such breeding grounds, either by cultivation or other means, and thereby rendering them less potent sources of the invasion of other lands.

The Species of True Locusts. The species of true migratory locusts are relatively few in number. In the light of the phase theory their number has been about halved, since forms hitherto 
known under separate specific designations have been shown to be merely phases of one or other kind. This has naturally involved changes of nomenclature, and many old specific names must now be replaced by standard phase designations (vide Uvarov, 1928).

1. The Migratory Locust (Locusta migratoria L.).

Phasis gregaria = migratoria $\mathbf{L}$.

Phasis solitaria = danica $\mathbf{L}$.

Although confined to the Old World, this insect enjoys a wider range of distribution than any other species. Its range is practically universal between latitude $60 \mathrm{~N}$. and $20 \mathrm{~S}$., besides extending into New Zealand. Recent studies by Uvarov and Zolotarevsky (1929), Zolotarevsky (1933) and Uvarov (1936) have shown that, although this species is a very definite entity in itself, it is divisible into a number of sub-species of which five are at present known, each being characteristic of a geographical area. The characters differentiating these sub-species are of a relatively minor order and require expert determination : their biometrical features are given in the table below. (1) The Palæarctic Locust or sub-sp. migratoria L. (sen. str.), South-East Russia. (2) The Central Russian Locust or sub-sp. rossica Uv. and Zol., Central Russia and Western Europe. (3) The African Locust or sub-sp. migratorioides R. and F., Africa and Western Asia. (4) The Madagascar Locust or sub-sp. capito Zol., Madagascar. (5) The Oriental Locust or sub-sp. manilensis Mey., Malaysia, East Indies, Philippines, China.

TABle XVIII. Average Measurements and Ratios of the $p h$. gregaria in Different Sub-species of Locusta migratoria (from Uvarov).

\begin{tabular}{|c|c|c|c|c|c|c|c|c|c|c|c|c|}
\hline \multirow{2}{*}{ Sub-species. } & \multicolumn{6}{|c|}{ Males. } & \multicolumn{6}{|c|}{ Females. } \\
\hline & E. & F. & $\mathrm{E} / \mathrm{F}$. & $\mathrm{P} / \mathrm{C}$. & $\mathrm{H} / \mathrm{C}$. & $\mathrm{M} / \mathrm{C}$. & E. & F. & E/F. & $\mathrm{P} / \mathrm{C}$. & $\mathrm{H} / \mathrm{C}$. & $\mathrm{M} / \mathrm{C}$. \\
\hline Rossica & $3 \cdot 8$ & 1.9 & $2 \cdot 0$ & $1 \cdot 30$ & 1.22 & 0.88 & $4 \cdot 1$ & $2 \cdot 3$ & 1.78 & $1 \cdot 14$ & $1 \cdot 21$ & 0.86 \\
\hline Migratori & $5 \cdot 1$ & $2 \cdot 4$ & $2 \cdot 13$ & $1 \cdot 10$ & $1 \cdot 16$ & 0.85 & $5 \cdot 35$ & $2 \cdot 5$ & $2 \cdot 11$ & $1 \cdot 17$ & $1 \cdot 16$ & $0 \cdot 87$ \\
\hline Manilensis & $4 \cdot 26$ & $2 \cdot 08$ & $2 \cdot 11$ & $1 \cdot 11$ & $1 \cdot 10$ & 0.81 & 4.58 & $2 \cdot 13$ & $2 \cdot 16$ & $1 \cdot 11$ & 1.08 & 0.83 \\
\hline Migratorioides & $4 \cdot 71$ & $2 \cdot 18$ & $2 \cdot 17$ & 0.99 & 1.06 & $0 \cdot 75$ & $4 \cdot 98$ & $2 \cdot 25$ & $2 \cdot 22$ & 0.94 & 1.07 & $0 \cdot 74$ \\
\hline Capito & $4 \cdot 64$ & $2 \cdot 22$ & $2 \cdot 09$ & 1.04 & 1.07 & $\mid 0 \cdot 72$ & $4 \cdot 83$ & $2 \cdot 27$ & $2 \cdot 13$ & 1.00 & $1 \cdot 11$ & $0 \cdot 72$ \\
\hline
\end{tabular}

Note. E, length of elytron ; $\mathrm{F}$, length of femur ; P, length of pronotum ; $\mathrm{H}$, height of pronotum $M$, width of pronotum at the constriction ; $C$, maximum width of the head, 
Each of these sub-species develops into the phases already alluded to. The very wide range of this species, as a whole, refers more especially to the limits to which odd specimens from swarms extend and transformation into the phase solitaria takes place. In the palæarctic region its breeding grounds, as at present known, are centred more especially in middle Asia among the vast reed-beds located in the vicinity of the Caspian and Aral Seas and of Lake Balkhash. In Western Europe permanent breeding grounds (swarm centres) no longer exist, most probably owing to the spread of cultivation and its effects upon the original ecological conditions of such areas. The Central Russian Locust has its breeding grounds in small areas of sandy soil with sparse vegetation. The African Locust has a most important breeding ground in reedy areas in the Middle Niger region of the French Sudan, from which all the recent invasions of that insect took origin. The breeding grounds of the Madagascar Locust in South Madagascar are in arid country with light soil and liable to be flooded during rains. The Oriental Locust has diverse types of breeding grounds: in China they resemble those of the African Locust, while in Borneo, etc., they appear to be in areas of humid tropical forest. It needs to be stressed that comparatively little is yet known as to these breeding grounds of each sub-species : their discovery and study forms one of the most important aspects of the locust problem.

2. The Desert Locust (Schistocerca gregaria Försk).

Phasis gregaria = gregaria Försk.

Phasis solitaria $=$ flaviventris Burm.

The Desert Locust has likewise a very wide distribution in the Old World. It covers nearly the whole of Africa, besides Arabia, Palestine, Syria, Persia and Western India. It is definitely connected with dry desert and semi-desert conditions and, ecologically, it differs markedly from the preceding species. In point of destructiveness it deserves first place among locusts of the Old World, and records of its ravages extend far back into history, including Biblical times. A very extensive literature, which is rapidly growing, exists with reference to this species, and in particular the memoirs by Bodenheimer (1929) and by Ballard 
and collaborators (1932) may be mentioned. In the latter work an illustrated account of the phases and their chief characteristics will be found. Very little definite information is available as to the permanent breeding grounds of this species owing to the vast extent and difficult nature of the countries wherein they are believed to be located. A good deal of evidence points to the source of recent outbreaks as being in lands bordering the Red Sea (Sudanese-Arabian region). The localisation of these breeding grounds by aerial surveys and other means is one of the most important of the schemes now being undertaken by international arrangement regarding anti-locust investigation.

3. The Moroccan Locust (Dociostaurus maroccanus Thnb.).

Phasis gregaria = maroccanus Thnb.

Phasis transiens = degeneratus Brnov.

The area of distribution of this locust comprises dry, hilly, and upland regions of those countries which form the Mediterranean littoral and the greater part of Southern Russia. Its permanent breeding grounds are the stony slopes of mountains and hills where vegetation is somewhat scanty. From these regions swarms invade the plains of neighbouring territory and the insect is more especially prevalent in Spain, Cyprus, Transcaucasia and Turkestan.

4. The South American Locust (Schistocerca paranensis Burm.). Phasis gregaria $=$ paranensis Burm.

Phasis solitaria $=$ ? americana $\mathrm{F}$.

Knowledge of South American locusts is still very incomplete, and it has been claimed that several species are involved, but the evidence on the whole points to there being only one of true migratory habits. It is further probable that the North American species $S$. americana is only the solitary phase of the locust under consideration. The range of the South American locust is from Argentina north of the fortieth parallel up through parts of Brazil to Venezuela and Central America. Migrating swarms further extend to Mexico and the West Indies. Relatively little is known as to its bionomics and periodicity, and its breeding grounds have not so far been located. 
5. The Brown Locust (Locustana pardalina Walk.).

Phasis gregaria = pardalina Walk.

Phasis solitaria $=$ solitaria $\mathrm{Uv}$.

This insect is the chief destructive locust of South Africa, where its swarms have been recorded at various times since 1653 . It has been studied in both the laboratory and the field by Faure (1932), who found that the behaviour of the insect in the solitary phase exhibits many of the phenomena also found in L. migratoria. The nymphs exhibit similar colour adaptations to their environment and, likewise, green forms appear as the result of humid conditions. Important breeding grounds are located in the Karoo and in South-West Africa.

6. The Red Locust (Nomodacris septemfasciata Serv.).

Phasis gregaria = septemfasciata Serv.

Phasis solitaria = coangustata Luc.

The range of this locust includes the whole of South Africa, together with the Southern Sudan and Abyssinia. In its solitary phase only it is also known from Madagascar, Reunion and the Comoro Islands. Two of its important breeding grounds are in parts of Tanganyika and Northern Rhodesia, while the southern shore of Lake Chad, along with other areas, are regarded as being potential centres for swarm development.

7. The Rocky Mountain Locust (Melanoplus mexicanus Sauss.). Phasis gregaria = spretus Walsh.

Phasis solitaria = atlanis Riley.

There is strong reason to suspect that the common North American grasshopper Melanoplus (atlanis) mexicanus has an intimate relation with the well-known but now extinct Rocky Mountain Locust ( $M$. spretus) which was formerly so dreaded a pest in the United States. The differences between the two are relatively small and suggest that spretus was the long winged or gregarious phase of mexicanus. Faure (1933) conducted some experiments in which the solitary form (mexicanus) was transformed into the gregarious form or phase (spretus). There seems in consequence every probability that the transformation of this Acridian from one phase into the other occurs in Nature in the presence of suitable ecological conditions. The disappearance of 
spretus may possibly be traced to changes in its former breeding grounds on the slopes of the Rocky Mountains from whence swarms invaded the American plains. It is generally maintained that the spread of agriculture has altered these breeding grounds to an extent which has led to this loss of capacity to develop into the gregarious phase. The form mexicanus, however, still occasions severe damage in Canada and the United States. During outbreaks it shows a definite tendency to form loose swarms and to become semi-migratory or gregarious. The conditions which might favour this kind of behaviour to an extent that would lead to the development of a true migratory phase are unknown. It is, however, noteworthy that specimens collected in the field under outbreak conditions showed a strong tendency to vary in the direction of spretus as regards wing length and in size. It would seem, therefore, that the species mexicanus occupies an intermediate position between the true solitary grasshoppers and migratory locusts in that it becomes at times exceedingly abundant and develops incipient swarms.

Phase Development in Grasshoppers. It has been generally believed that the existence of phases is a peculiarity belonging to locusts and one not betrayed among non-migratory Acrididæ, or ordinary grasshoppers. Recently evidence has been brought forward by Rubtzov (1935) showing that an essentially similar phenomenon occurs in grasshoppers, but that the amplitude of such phase differences is less pronounced than in locusts. Rubtzov's important observations were carried out in Siberia, where he was impressed by the colour variations found among individuals of the same species of grasshoppers. Since some of the species in which the phenomenon has been found occur often commonly in Britain, a new field for study is opened up for workers in this country. Certain species of grasshoppers were found by Rubtzov to differ in coloration more or less in accordance with the population density per unit area of territory. Individuals collected from relatively dense associations, with up to 300 grasshoppers per square metre, were notably dark coloured, larger, and had longer wings than those distributed in the proportion of one, or fewer, over the same unit area. These 
differences are especially marked in Eropus sibiricus and Chorthippus albomarginatus, while a number of other species can be arranged in descending order of their tendency to show marked colour differences. The most pronounced differences are found in A. sibiricus, which is an active species, tending to form dense aggregations of individuals. These differences are almost equally well shown in $C$. albomarginatus. In all cases the dark coloured forms occurring collectively are interpreted as representing the phase gregaria, while the pale examples found singly and sparsely are regarded as representing the solitaria phase. This conclusion is supported by such experimental evidence as is available.

Thus, individuals of $C$. albomarginatus, reared in isolation, showed a tendency to develop into the pale coloured solitaria form, while those reared gregariously, in crowded conditions, produced a very definite gregaria type. Apart from the colour differences alluded to, the supposed phase differences are also betrayed in : (1) solitaria individuals being smaller, with femur and tegmen shorter; (2) shortening of the tegmen in solitaria being more pronounced than that of the femora, the ratio being greater in solitaria than gregaria; and (3) variability in solitaria being always greater than in gregaria-as can be seen by comparing the maximum and minimum figures. Rubtzov's data are accompanied by coloured figures portraying supposed phase differences, and they unmistakably suggest that we have, among non-swarming grasshoppers, clear evidence of the existence of those same phases that feature so markedly in the economy of locusts.

A further phenomenon, discussed by Rubtzov, can only be briefly alluded to here. He shows that a homologous series of colour variations reveals themselves through many species of Acrididx. These are inheritable variations and, according to him, each such race possesses the potentiality, to a greater or lesser degree, to exhibit such phase characteristics. The latter, as it were, are super-added to the former in response to the extreme conditions of individual life. In practice, it resolves into the necessity, fully recognised by this author, of clearly determining which race of a given species is being utilised in all studies designed to explore the phase idea. 


\section{Literature}

\section{A. Regulation of Crop Growth}

Andrews, 1923. "Factors Affecting the Control of the Tea Mosquito Bug." Indian Tea Association.

Cunliffe, 1928. Ann. App. Biol., XV., 473.

1929. Ibid., XVI., 135.

1936. Ibid., XXIII., 822.

Cunliffe and Fryer, 1924. Ibid., XI., 465.

Cunliffe, Fryer and Gibson, 1925. Ibid., XII., 516.

Davidson, 1934. Commonrvealth of Australia, Dept. Sci. and Indus. Res., Bull. 79.

Flint and Larrimer, 1928. Illinois Nat. Hist. Survey Bull., XVII., Art. XI. Frew, 1924. Ann. App. Biol., XI., 175.

Froghopper Committee (Trinidad and Tobago), 1925, et seq. Minutes and Proceedings.

Fryer and Collin, 1924. Ann. App. Biol., XI., 448.

Holdaway, 1927. Commonvealth of Australia, Dept. Sci. and Indus. Res., Pamphlet 4. Melbourne.

Hopkins, 1919. Scientific Monthly, June, 496.

Jepson and Gadd, 1926. Dept. of Agric., Ceylon, Bull. 78.

MacLagan, 1932. Bull. Ent. Res., XXIII., 101, 151.

Nougaret and Lapham, 1928. U.S. Dept. Agric., Tech. Bull. 20.

Willians, 1921. Mem. Dept. Agric., Trinidad and Tobago, No. 1.

Withyсомве, 1926. Ann. App. Biol., XIII., 64.

\section{B. Resistant Varieties}

Crane, 1936. Ann. App. Biol., XXIV., 188.

Davidson, 1922. Ibid., IX., 135.

MISRA, 1920. Agric. Journ. India, XV., 627.

Monzen, 1926. Internat. Congr. Ent., Zurich, II., 249.

Parnell, 1925. Empire Cotton Growing Rev., II., 330.

RoAch, 1936. Ann. App. Biol., XXIV., 206.

\section{Host-Selection and Biological Races}

Ahmad, 1936. Journ. Anim. Ecol., V., 67.

Craighead, 1922. Journ. Agric. Res., XXII., 189.

FIELD, 1910. Psyche, XVII., 87.

Fryer, 1929. Trans. Internat. Congr. Ent., Ithaca, II., 229.

Göschen, 1913. Zeits. wiss. Insektenbiol., IX., 72.

Hackett, Martini and Missiroli, 1932. Am. Journ. IIyg., XVI., 137.

Harrison, 1927. Proc. Roy. Soc. B., 115.

Hopkins, 1916. U.S. Dept. Agric., Progr. of Work, 1917, 353.

LaL, 1934. Ann. App. Biol., XXI., 641.

Larson, 1927. Ann. Ent. Soc. Am., XX., 37.

Marchal, 1908. C. R. Soc. Biol., Paris, LXV., 2.

Marshall and Staley, 1935. Parasitology, XXVII., 501.

Missiroli, Hackett and Martini, 1933. Rev. Malariol., XII., 1.

Payne, 1933. Biol. Bull., LXV., 187.

Pictet, 1911. Arch. Soc. Phys. Nat. Geneve (4), XXXI., 561.

Roubaud and Gaschen, 1933. Bull. Soc. Path. Exot., XXVI., 965.

Roubaud, 1935. Ibid., XXVIII., 443.

Schroeder, 1903. Verh. deutsch. zool. Ges., 158. 
Sladden, 1934. Proc. Roy. Soc. B., CXIV., 441.

1935. Ibid., CXIX., 31.

Tate and Vincent, 1936. Parasitology, XXVIII., 115.

Thompson and Parker, 1928. Bull. Ent. Res., XVIII., 359.

Thorpe, 1929. Journ. Linn. Soc. Zool., XXXVI., 621.

1931. Ibid., XXXVII., 489.

1930A. Biol. Rev., V., 177.

Woons, 1915. Bull. 244, Maine Agric. Exp. Sta., 249.

\section{The Locust Problem}

Ballard and others, 1932. Min. Agric. Egypt, Bull., 110.

Bodenhemer, 1929. Zeits. angere. Ent., XV., 1.

Butler and Inves, 1936. Proc. Roy. Soc. B., CXIX., 296.

Faure, 1932. Bull. Ent. Res., XXIII., 293.

1933. Journ. Econ. Ent., XXVI., 706.

Hertz and Imms, 1937. Proc. Roy. Soc. B., CXXII., 281.

Husain and Mathur, 1936. Ind. Journ. Agric. Sci., VI., 591.

Rubtzov, 1935. Bull. Ent. Res., XXVI., 499.

Strel'nikov, 1936. Vide Rev. Appl. Ent. A., XXIV., 312.

Uvarov, 1921. Bull. Ent. Res., XII., 135.

1928. "Locusts and Grasshoppers." London.

Uvarov, 1936. Bull. Ent. Res., XX., 261.

Uvarov and Zolotarevsky, 1929. Ibid., XXVII., 91.

Zolotarevsixy, 1933. Ann. Epiphyt., XIX., 47. 


\section{CHAPTER XII}

\section{PARASITISM}

Introductory Remarks, p. 315. Host-Selection, p. 318. Phases of Parasitisn. Multiparasitism, p. 322 ; Superparasitism, p. 325 ; Hyperparasitism, p. 326.

\section{Introductory Remarks}

In discussing parasitism among insects it is necessary, in the first instance, to define the limits of the subject. A generally accepted definition describes a parasite as a living organism which takes up its abode temporarily or permanently on or within some other living organism (its host), and at whose expense it obtains its nourishment. This definition is generally held to imply that the host has developed tolerance to the presence of the parasite, and consequently suffers no fatal effects from its activities.

(a) Among insects there exists a considerable number of species whose behaviour is covered by the above definition. They are true parasites and include the kinds discussed in text-books of medical entomology and parasitology. Such parasites are almost always insignificant in size as compared with their hosts which, it may be added, are almost always vertebrates. Anoplura, CEstrid larvæ, Aphaniptera, Streblidæ, Nycteribiidæ and Hippoboscidæ are familiar examples.

(b) There are, however, a much larger number of insect parasites which exhibit a different behaviour. They belong to various families of Diptera and Hymenoptera, but are very rare outside those orders. They are parasites only as larvæ, while the adults, into which they transform, are highly developed, free-living creatures. Their hosts are nearly always members of their own class, and are nearly always destroyed as the result of the parasitism. Furthermore, such parasites are relatively large in size in comparison with their hosts, and this fact appears mainly 
accountable for their fatal activities. At the outset they behave as true parasites, deriving their sustenance mainly from the blood of their hosts, which suffer little ill-effects and continue to feed and grow. Sooner or later the fat-body and less vital organs are attacked, and the parasites become, in the biological sense, internal predators. Growth of the hosts at this stage virtually ceases, but they continue to live, and often feed voraciously. As the parasites near maturity their carnivorous propensity intensifies, and all food-yielding parts of their hosts are ultimately consumed until only the exoskeleton remains. As their final economy they, as often as not, conduct their pupal transformation within the husks of their hosts, and thus sheltered in these grim cells they are able to dispense with cocoons. "Fatal" parasites of this kind have been termed by O. M. Reuter, and subsequently by W. M. Wheeler, " parasitoids." Among other entomophagous parasites the Strepsiptera are to be regarded as non-fatal parasitoids, since their hosts are not usually destroyed as the direct result of the parasitisation; in this respect they are annectant between $a$ and $b$.

(c) Parasitoids may live either externally or internally in relation to their hosts. It seems tolerably clear that the ectoparasitic life is the simpler condition of the two, and that the endoparasitic method is a development from it. There is every probability that the parasitoidal mode of life originated from simple predatism. A predaceous insect is one which seeks out and devours a succession of living organisms or prey until its needs are satisfied. It follows, therefore, that a true predator must have its locomotory and sensory organs sufficiently developed to equip it for this mode of existence. In the eventuality of a single individual prey being large enough to provide a carnivorous insect with all the food it needs, there would seem to be little difference between a predator and an "ectoparasitoid." Since, however, the larval life of the latter is spent in close and continuous association with a single host, and it exhibits the degeneration correlated with such an existence, it shares the characteristics of a parasite rather than of a predator, and this distinction is the one commonly adopted. 
(d) A third type of parasitism is met with among those social insects which have themselves adopted a life of parasitism in the colonies of other social insects. They parasitise a colony instead of an individual of a species and obtain their food and that of their larvæ at the expense of supplies brought in by the members of the colony. Social parasites occur among ants, bees, wasps and termites, and their behaviour has been fully discussed in numerous contributions by W. M. Wheeler.

(e) Among solitary wasps and bees there is found an intergrading series between parasitism on the one hand and inquilinism on the other. In many cases it is difficult to draw any hard and fast lines between the several types of behaviour. In the primitive Vespoid families Scoliidæ, Thynnidæ and Mutillidæ the parent insect seeks out insect larvæ living in concealed situations; these they immobilise by stinging and then lay their eggs upon them, and their larvæ are parasitoids living externally to their hosts. Most other solitary wasps store up in their nests one or more insects which they have previously paralysed, and attach one of their eggs to the body of the prey. The wasp larva upon hatching behaves as an ectoparasite (or predator) and devours the prey; or, if there be several, it consumes them in succession. This behaviour differs but little from that of the Scoliid and other wasps except that the parent insect transfers the prey from its natural habitat into the nest. Many parasitic bees lay their eggs in the cells of other bees of allied genera, among the stores of honey and pollen. The parasitic larva, upon emergence from the egg, finds itself in close proximity to the normal occupant of the cell. In cases studied by Graenacher the parasitic larva has more powerful jaws than its rival, and easily succeeds in destroying it. It then proceeds to consume the food-supply and casts its enlarged mandibles with the first ecdysis. There are, again, other so-called parasitic wasps whose larvæ are solely nourished upon the food-stores of the host, the parent removing and destroying the egg or young larva of the host preparatory to the emergence of its own offspring. In Sapyga quinquepunctata and $S$. similis, which live at the expense of solitary bees, both Fabre and Nielsen have shown that the long ovipositor- 
like sting is used for piercing the cell and depositing an egg within. The first instar Sapyga larva devours the egg of the host and subsequently feeds solely upon the vegetarian stores within the cell.

The foregoing remarks emphasise the diversity and intergrading exhibited by parasitism among insects. Growth of recent knowledge of the subject is too extensive to allow of adequate treatment of all its phases within a restricted compass. For this reason discussion is mainly limited to the parasitoid Hymenoptera and Diptera (Tachinidæ).

\section{Host-selection}

Our knowledge of the fundamental aspects of parasite specificity admits of but few generalisations. Notwithstanding the mass of information which exists relative to the hosts of entomophagous parasites, we are completely in the dark as to the determining causes which lead certain parasites constantly to select certain host-species, while others utilise hosts of different taxonomic relationships. The vast majority of parasites are but seldom restricted to a single host-species, not many are confined to an individual genus, and those so accredited are becoming fewer in number with increasing knowledge.

Among Hymenopterous parasites examples of more or less restricted host specificity are numerous. Thus, the Proctotrypid Embidobia is only known to develop in the eggs of Embioptera; the Proctotrypid Polygnotus selects Cecidomyid larvæ as its hosts; the whole family Scelionidx are egg-parasites, while the species of Scelio appear to attack only locust eggs; the Braconid Dachnusa parasitises Dipterous larvæ of the family Agomyzidæ; the Cynipid Ibalia and the Ichneumonid genera Rhyssa and Thalessa are parasites of Siricidæ; Aphidius and its allied Braconids attack Aphididæ, while another Braconid genus, e.g., Perilitus, confines itself almost exclusively to adult Coleopterá ; and so on.

Among Tachinid parasites specificity of host-selection is, as a rule, far less restricted than in Hymenoptera, but the exceptions present certain puzzling problems. Thus the species of the 
Phasiine group mainly attack Pentatomidæ, but, as Thompson and Parker (1927) point out, the genera, Frercea, Weberia and Rondania are parasites of Coleoptera. Of four related Dexiine genera, Thelaira, Fortisia, Cyrillia, and Thrixion, their hosts are Lepidopterous larvæ, the Chilopod Lithobius, the Isopod Metaponorthus and certain Phasmidæ respectively. The relations of Tachinids parasitic upon woodlice (Oniscidæ) have formed the subject of a detailed study by Thompson (1934). The available data appear to suggest that the parasitisation of woodlice depends, in the main, on the habits of the latter. Those Oniscidæ living in large colonies, under loose bark of logs, are the kinds most usually parasitised, for the reason that they frequent situations favourable to attack.

Among the many parasites of polyphagous habits it will suffice if two examples be quoted. The Tachinid Compsilura concinnata, which was introduced from Europe into the United States in 1906, has been reared, according to Webber and Schaffner (1926), from over ninety species of American insects representing three orders-Lepidoptera are mostly selected, and no less than eighteen families are included in their host list. There appears to be no one distinctive character common to all its hosts-neither colour nor colour-pattern; hairiness or absence of hairs ; low-feeders, bush-feeders or tree-feeders; habit, whether the hosts be gregarious or solitary, diurnal or nocturnal ; specific food-plants, whether they be Gymnosperms, Monocotyledons, Dicotyledons or lichens; odour or absence of odour; presence or absence of urticating hairs, etc.-as Thompson points out, all these categories are represented among the host-species, and from whatever standpoint this varied assemblage be considered its members have in common only the fact that they are all hosts of Compsilura. Among Hymenopterous parasites a parallel example is afforded by the Ichneumon Hemiteles areator, which has been reared from a remarkable range of hosts comprising many Lepidoptera, various Hymenoptera, including other Ichneumonidæ, besides several Coleoptera and Diptera.

In the two foregoing examples the insects mentioned are endoparasites, and it appears probable that at least some of the 
innate determining factors are physiological. Certain experiments recorded by Thompson and Parker (1927) are significant in this connection, who mention that although larva of the Tachinid Sturmia scutellata develop freely in caterpillars of Porthetria dispar they die immediately after penetrating into those of Hemerocampa leucostigma and Notolophus antiquus, which belong to the same family. On the other hand, Sturmia larvæ develop freely in caterpillars of Malacosoma, which belong to a different family - the Lasiocampidx. Webber and Schaffner mention that one of the numerous hosts of Compsilura concinnata is also Porthetria dispar, but yet this Tachinid rejects caterpillars of Malacosoma, which are acceptable to the Sturmia. The opinion has been advanced that the activities of the phagocytes of the hosts constitute a defensive mechanism against endoparasites. It is claimed that species of the latter are destroyed by this agency, and only those kinds specially adapted by physiological or structural features are able to survive and become regular parasites of specific hosts. The evidence in support of this contention is scanty, and the theory is discussed in a recent paper by Thompson (1934, p. 433).

The host-preferences of ectoparasites present several peculiar features. The ectoparasitic mode of life is unknown, for example, in the whole family of the Tachinidæ, whereas it is frequent among diverse groups of Hymenopterous parasites. The factors that determine whether a species lives within or external to its host are evidently fundamental, since the endoparasitic mode of life involves a complete change in methods of respiration. In this connection it is remarkable that certain parasite genera, notably the Chalcid Aphelinus, include among their species some which are endoparasites and others that are ectoparasites. It is open to speculation whether the internal physiological reactions of the host are a determining factor which force, as it were, certain parasites to live externally, while better adapted, but closely related, species are able to pursue an endozoic existence. Whether such reactions are a potent factor in this case or not is scarcely amenable to proof, and, at any rate, the capacity of a species to undergo the correlated respiratory changes involved in an endoparasitic mode of life is at least as important. 
The outstanding feature with respect to host-selection by ectoparasites is that they very rarely affect hosts living openly and exposed. This peculiarity is very constant and it may possibly have originated as an adaptation whereby the exposed parasites are enabled to secure a measure of protection from the attacks of hyperparasites. Among parasites exhibiting this kind of host-preference the Chalcid Melittobia acasta affords an instructive example, since it selects a wide range of victims, which are distributed among the orders Diptera and Hymenoptera. As Thompson and Parker point out, in all cases the hosts are enclosed in cells or nests of mud or "paper," in silken cocoons or in chitinised puparia. Also, in their analysis of features common to these hosts they find that the latter are at least twice the size of the parasite and are surrounded by a protective envelope which is separated from the body of the host by an intervening space. Genieys (1925) has made an experimental study of the Braconid Habrobracon brevicornis, which is an ectoparasite of naked and more or less sedentary Lepidopterous larvæ living in galleries in plants or immersed in stored vegetable products. His efforts to induce this species to parasitise hosts that live exposed or are densely hairy usually failed; in such cases oviposition either did not occur or the young parasitic larvæ generally failed to develop after hatching. Certain pupal parasites of Cyclorrhaphous Diptera are sensu stricto ectoparasites, since they live attached to the outsides of the pupæ just beneath the puparial shell. The larval stages of several species of the Staphylinid genus Aleochara and of the Chalcid Mormoniella vitripennis (Nasonia brevicornis), for example, are passed in this manner.

In a few exceptional instances, exposed, free-living hosts are selected. Certain species of the Chalcid genus Euplectrus are ectoparasites of Noctuid larvæ which feed openly on low plants. This genus is also exceptional in that it has acquired the habit of cocoon-formation which is wanting in other Chalcids (vide Thomsen, 1927). The cocoon substance is a product of the Malpighian tubes which is discharged through the anus, and it would seem that its utilisation in this manner has been evolved as a protection for the vulnerable pupæ. In another Chalcid, Schizonotus sieboldii, Cushman has shown that its larvæ are ectoparasites of the exposed pupæ of the beetle Melasoma interruptum. The Ichneumon Paniscus parasitises Noctuid and other caterpillars 
which usually form their cocoons shortly afterwards ; Polysphincta is a parasite of spiders and the Vespoid Rhopalosoma payi is similarly an ectoparasite of the tree cricket Orocharis.

\section{Phases of Parasitism}

Multiparasitism. Multiparasitism is the simultaneous infestation of the same individual host insect by two or more species of primary parasites. The phenomenon is more usually known as superparasitism, but it is proposed to limit the use of the latter expression to instances in which an individual host is attacked by two or more parasites pertaining to the same species.

The prevalence of multiparasitism is frequently dependent upon whether or not the female parasites, at the time of oviposition, are able to distinguish between unattacked healthy hosts and those already parasitised. In other words, its occurrence would appear to be dependent upon errors of instinct. It also obtains in other cases as the result of pressure of competition induced by a high ratio of parasites to host-population, when oviposition in at least some proportion of already parasitised individuals becomes unavoidable. Irrespective of the inducing cause, multiparasitism plays an important part in the economy of parasites, but it has so far been subject to very little exact experimental investigation. The manifestations of the phenomenon are various, and the following classification covers the phases which prevail.

1. Multiparasitism Involving the Survival of a Single Parasite Species. This occurrence appears to be very prevalent and the survivor may bring about the death of the other parasite or parasites in one of two ways, viz., either by direct attack or by the indirect effects of its presence. The studies of Pemberton and Willard (1918) on the inter-relations of fruit-fly parasites in Hawaii have shown that when the Braconids Diachasma tryoni Cam. and Opius humilis Silv. occur together in the same individual fruit-fly larva the last-mentioned species was usually killed. It succumbs as the result of wounds and lacerations inflicted upon it by the long, curved, sickle-like mandibles of the newly hatched Diachasma larvæ. They mention that from a total of 627 fruitfly puparia examined, 143 contained larvæ of the two species of parasites, and that in 133 of these the Opius larvæ were found to 
have been destroyed. Pierce (1910), in his paper on insect enemies of weevils, enumerates a number of examples of multiparasitism involving competition between two species of parasites; the surviving species is recorded where known, but whether it gained the ascendancy by direct attack upon its competitor or by indirect nutritional effects was apparently not determined.

In other cases of multiparasitism a passive struggle for existence results, and the death of one or other parasite supervenes upon exhaustion of the food-supply by the survivor. As a rule those parasites which attack a given host earlier reach the destructive feeding stage first and are consequently survivors in the struggle. Thus, Tothill (1922), in discussing the parasites of Hyphantria cunea, mentions that one caterpillar which he dissected contained twenty-two parasitic larva belonging to four species, and it is doubtful whether any would survive to complete their transformations. Sometimes the larvæ of the Ichneumon Campoplex succumbs as the result of the presence of the Tachinid Ernestia, and sometimes the opposite occurs. When another Tachinid, Therion, enters into competition it stands little chance of survival, since it is the latest to attain the destructive feeding stage. It will be observed in the accompanying table that the incidence of the different parasites affecting the Hyphantria is more or less in a sequence which consequently reduces the possibilities of multiparasitism to a considerable degree.

TABle XIX. Sequence of Parasites of Hyphantria in 1913 (after Tothill).

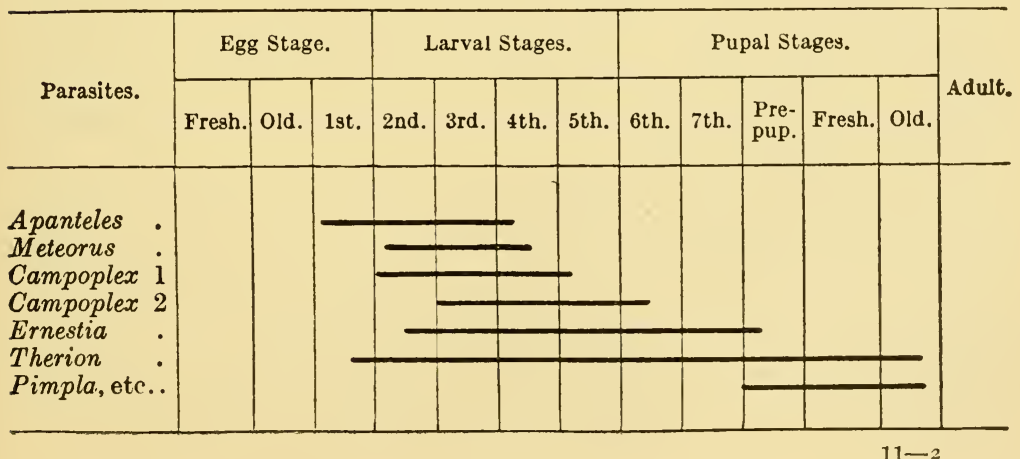


Since the Apanteles attacks only very young caterpillars, and the other parasites do not, it is only subject to competition in its later instars-when it is most likely to prove the survivor. Pimpla, on the other hand, attacks only pupæ, and for that reason is largely out of range of severe competition.

Another noteworthy example is instanced by Muesebeck (1918) in his studies of the parasites of the brown-tail moth (Euproctis chrysorrhøa L.). As a result of the dissections of over 13,000 host caterpillars it was found that whenever larvæ of the Braconid Apanteles lacteicolor enter into competition with those of Meteorus versicolor Wesm. or of the Tachinid Zygobothria nidicola Town., or with both species, these latter are killed, evidently as the result of some toxic secretion induced by the Apanteles.

2. Multiparasitism without parasite mortality. This phase is probably by no means infrequent, especially with regard to the parasites of Lepidopterous larvæ and of the Lecaniine scale-insects. In the case of Coccus caprea of the hawthorn, multiparasitism is a common event, the parasites involved being the Chalcids Blastothrix sericea (britannica) and Aphycus punctipes (melanostomatus). In localities in Britain where these two parasites are abundant, a dozen or more examples of both species may sometimes be reared from the same individual host. Pierce mentions an instance among weevil parasites in which nine examples belonging to two species of Aphiochata were reared from a single host, and cases where two species of ectoparasites were reared under similar circumstances.

The effects of the competition upon the insects concerned are usually in proportion to the numbers present. The most obvious result is the development of individuals stunted or reduced in size, and according to Fiske material reduction in their reproductive capacity is also common.

3. Multiparasitism involving the death of the parasites. Instances of this kind have been seldom recorded, but it appears that the fatal consequences are the result of exhaustion of the food-supply or of the premature death of the host. In his study of the parasites of the white-marked tussock moth L. O. Howard states that, when the Ichneumon Pimpla inquisitor oviposits in 
caterpillars already infested with Tachinid larvæ, both types of parasites succumb in every case, with but one exception. Pierce found with weevil parasites that survival was rare when more than two species of parasites were involved.

Superparasitism. Superparasitism is but a phase of multiparasitism in which two or more parasites pertaining to the same species occur in the same individual host. In many cases it is a normal and regular occurrence, and results in no fatal effects upon the parasite individuals involved. It is especially prevalent, for example, among Braconids and Chalcids, as records of rearings of these parasites testify. In the polyembryonic Chalcids superparasitism is obligatory, and as many as nearly 3,000 individuals of a single species have been reared from one individual Plusia larva. In other cases its occurrence is irregular, and is the result either of errors of instinct or of pressure of competition induced by scarcity of suitable hosts. In such instances fatal consequences commonly supervene. Thus H. S. Smith (1912) records finding up to five planidia ${ }^{1}$ of the Chalcid Perilampus in a single individual host, but in no instance out of many hundreds has more than one adult Perilampus emerged. It appears that the individual most advanced in its development gains the ascendancy by starving out its confrères, either through devouring the host, or by rendering it unsuitable as a source of food. E. W. Wheeler (1923) states that from one to eight larvæ of the Braconid Aphidius phorodontis may occur within the same individual aphid host, but never more than one attains maturity. This same fact has been noted by Spencer and other observers of Aphidiine parasites. Timberlake (1912) has induced superparasitism under obligatory experimental conditions. In one experiment five females of the Ichneumon Limnerium validum were placed in consort with ten caterpillars of the brown-tail moth. All the hosts were heavily attacked, and succumbed before the parasitic larvæ had grown to any appreciable extent, as the result of the parasitisation.

In many cases it is noteworthy that the female parasites are guided by their own instincts. so as to avoid hosts which they

1 For definition, see p. 333. 
themselves, or other members of their species, have already parasitised. Thus, Haviland (1922) has observed that the Braconid Dacnusa areolaris Nees never attacked larvæ of the leaf-miner Phytomyza angelica if they were already parasitised, and in the considerable quantity of material examined two parasites were never found in the same individual host.

Salt (1934-37) has shown that the Chalcid Trichogramma evanescens is able to distinguish between parasitised and unparasitised hosts. Before parasitising a host (which is always an insect egg) the female walks repeatedly over it and in course of that process an odour is left on the egg-surface which can be perceived by another female coming later. If this odour be removed by washing the host-egg the second parasite is unable to detect that the egg has already been attacked. After inserting the ovipositor, however, the female becomes aware of the egg being already parasitised and soon goes away without having oviposited. If hosts are relatively few in number superparasitisation occurs: this does not happen immediately, since the Trichogramma female is able to withhold her eggs for a period rather than lay them in parasitised hosts. As the density of the parasites in relation to a fixed population is increased the more intensive the superparasitisation becomes: when it is severe there is either no resulting progeny, or the individuals of the latter which emerge are dwarfed or imperfect. When given a choice of hosts Trichogramma selects the larger of the eggs: also, when the number of hosts is limited the larger ones are selected for superparasitisation. It further transpired that the females are unable to distinguish between suitable and unsuitable non-parasitised hosts and will select the latter for oviposition if of larger size than the former. When given false hosts of various kinds such as flour particles, tiny glass globules, sand particles, Lobelia seeds, etc., the insect attempted to oviposit in these objects, where they were of larger dimensions than the true hosts which were available along with them. Whether this error of instinct, so evident under experimental conditions, often prevails in a state of Nature is unknown.

Hyperparasitism. Probably comparatively few primary para- 
sites, of a given insect, are immune from attacks by their own specific parasites, which are termed hyperparasites or secondary parasites. Hyperparasitism, consequently, is a significant factor in the maintenance of the balance between insect species in Nature, and the biological association of hosts, primary parasites and secondary parasites is a highly adjusted complex. It is probable that hyperparasitism is a development of multiparasitism and, in some cases, it is difficult to distinguish between the two phenomena, since one may intergrade into the other.

By far the largest number of hyperparasites are members of the Ichneumon sub-families Cryptinæ and Ophioninæ, and of various families of Chalcids, but it is among the latter group that they are the most numerous. The Proctotrypoidea and Cynipoidea also comprise a considerable number of hyperparasites. Outside Hymenoptera secondary parasitism is very rare, and the few known examples include certain Bombyliidæ among Diptera and two records among Coleoptera (vide Muesebeck and Dohanian, 1927).

In frequent cases it is not possible to distinguish, absolutely, certain species as primary parasites or as hyperparasites, since their behaviour is plastic and largely determined by the types of hosts adopted. Timberlake (1913), for example, found that the Chalcid Coccophagus lecanii Fitch is a common primary parasite of the soft scale (Coccus hesperidum), but, when associated with other Chalcid primary parasites (Microterys or Aphycus), may becomes hyperparasitic. ${ }^{1}$ The Chalcids Monodontomerus areus Walk. and Eupteromalus nidulans (Foerst.) occur as primary parasites of the gipsy moth and brown-tail moth respectively, but both species also frequently become hyperparasitic through Braconid or Tachinid parasites of those hosts. Many examples of this character are known, and further references will be found in the excellent bulletin by Muesebeck and Dohanian.

When two or more secondary parasites occur in the same

1 It may be mentioned that Coccophagus is normally parthenogenetic and thelyotokous, producing females generation after generation, but when it is hyperparasitic, Timberlake states that the resulting progeny are all males. This unique phase has been ascertained to be prevalent both in the field and under laboratory conditions. 
individual host super- or multiparasitic relations are involved. An example of this kind is instanced by Haviland (1922A) with respect to hyperparasites of aphides through the Braconid Aphidius. The Aphidius may be attacked by the endoparasitic Cynipid Charips or by the ectoparasites Lygocerus (Proctotrypoidea), Asaphes or Pachycrepis, the two latter being Chalcids. The Charips, along with its Aphidius host, perishes as the result of attack by one or other of these ectoparasites. The latter, on their part, frequently suffer from mutual competition. Thus, Haviland states that when two of these hyperparasites occur together, and they may belong to the same or to different species, only one survives or both may perish consequent upon the exhaustion of the nutritive supply.

Hyperparasites in general are far less restricted in their hostselection than most Hymenopterous primary parasites. They are able to adapt themselves to a wider range of hosts, especially in the absence of preferred species - a trait which explains the heavy attacks certain introduced primary parasites undergo in countries where the normal and regular hyperparasites are absent. The Chalcid Dibrachys cavus (boucheanus Ratz.), for example, will attack an immense range of hosts, including many Lepidoptera and Diptera and several Coleoptera; as a rule it behaves as a hyperparasite, but in other instances it is a primary parasite, especially of the larvæ of Microlepidoptera. In many cases, when Hymenopterous parasites exercise a wide and apparently indiscriminate range of host-selection, they will prove to be secondary rather than primary parasites.

The vast majority of hyperparasites live externally to their immediate hosts, which are either concealed within the original host or enclosed in puparia or cocoons. The internal feeding habit is consequently rare; it obtains in Charips, already mentioned, and also as a special adaptation in certain other instances.

Parasites of a tertiary order are often referred to in literature, but proof that this type of parasitism is a constant and obligatory feature of the species concerned, and not merely a phase of multiparasitism, is in many cases non-existent. As an example 
of what appears to be true tertiary parasitism, the observations of Muesebeck and Dohanian on the Chalcid Pleurotropis are noteworthy. Out of several hundred cocoons from which the species $\boldsymbol{P}$. tarsalis Ashm. emerged, in $\mathbf{9 7}$ per cent. it had developed at the expense of Hymenopterous secondary parasites. Only in very few instances the Pleurotropis itself behaved as a secondary parasite of the host concerned (Apanteles). Since the Pleurotropis is an internal parasite, which pupates within the larval or pupal covering of the host it destroys, its actual biological relationships can be readily determined. Reputed quarternary and even quinquenary parasites are on record, but it is extremely doubtful whether their behaviour is of the order ascribed to them. 


\section{CHAPTER XIII}

\section{PARASITISM-continued}

Types of Life-Cycle. Group $A$, p. 331 ; 1. Ingestion of Parasite Eggs by the Host, p. 331 ; 2. Types of Migratory Primary Larvae, p. 333 ; 3. Non-Migratory Primary Larvae, p. 336 ; Group B, p. 337 ; Group C, p. 339 ; Group D, p. 340. Host Relations of Parasites, p. 343. Hymenoptera, p. 344 ; Diptera, p. 351 . Polyembryony and Related Phenomena, p. 353.-(a) Chalcidoidea, p. 354; (b) Proctotrypoidea, p. 356 ; (c) Ichneumonoidea, p. 358 ; (d) Vespoidea, p. 358; Origin of Polyembryony, p. 358 ; The Embryonic Membranes, p. 359 ; Origin of Mixed Broods of Parasites, p. 361. Adult Parasites. Feeding Behaviour, p. 363 ; Phoresy, p. 364. Literature, p. 365.

\section{Types of Life-Cycle}

Probably no branch of entomology has grown so rapidly in recent years as our knowledge of the biology of entomophagous parasites. It has revealed an amazingly wide diversity of phases in the life-cycle and of adaptations to different modes of life. This subject has become too extensive to admit of discussion from every aspect in a limited space, and it is only intended to lay the more important facts before the reader in a summarised and co-ordinated form.

In a broad general way the life-cycles of parasitoid Diptera and Hymenoptera may be grouped into four categories.

Group A. The eggs, or more rarely the larvæ, are not deposited on the hosts, but in situations favourable to the latter becoming infested. Post-embryonic development may be either ecto- or endoparasitic.

Group $B$. The eggs are deposited externally on the hosts and an ectoparasitic life supervenes.

Group $C$. The eggs or larva are deposited externally on the hosts, but the subsequent development is endoparasitic.

Group $D$. The whole parasitic life is endoparasitic from 
the outset, the eggs or larvæ as the case may be being inserted within the bodies of the hosts.

Each of these types of life-cycle and the adaptive features involved will be briefly discussed.

Group A. Since the eggs, or, in other cases, larvæ, are not actually deposited on the hosts it is obvious that special provision is necessary whereby the parasites are enabled to obtain access to the latter. Such provision is forthcoming either (1) by very high fecundity and the deposition of minute eggs adapted to be ingested by the host during the ordinary process of feeding; or (2) by the primary larval stage being essentially a migratory phase enabling the parasite to discover its hosts by its own efforts ; or (3) by the primary larva developing an erect stationary habit and awaiting an opportunity of attaching itself to the first suitable host coming within reach.

\section{The Ingestion of Parasite} Eggs by the Host. This habit is peculiar to certain of the Tachinidx and its prevalence was made known by the earlier researches of Townsend (1908) and especially of Pantel (1909);

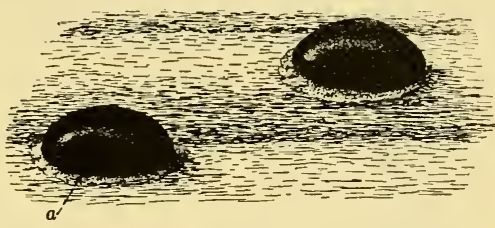

FIG. 75. Eggs of a Tachinid fly (Gonia capitata) laid on blade of wheat. $\times 50$. $a$, Adhesive material. (After Strickland, Tech. Bull. 26, Dept. Agric., Canada.) more recently Thompson (1924) has considerably extended our knowledge of the subject. These observers have shown that species which lay very large numbers of minute more or less fusiform eggs (microtype eggs of Pantel) deposit them upon the food-plant of the host. The larvæ within these eggs are fully formed, and only await a favourable opportunity for emergence. The species Gonia capitata, a parasite of the prairie cutworm (Porosagrotis orthogonia) in Canada, has been studied by Strickland (1923) and may be taken as an example. It lays upwards of 4,000 small black eggs, measuring $0 \cdot 24 \mathrm{~mm}$. long $\times 0 \cdot 15 \mathrm{~mm}$. wide and $0.12 \mathrm{~mm}$. high, which do not normally hatch until they are swallowed by the cutworm larva along with its food (Fig. 75). Upon coming in contact with the digestive juices the 
chorion speedily ruptures and the larva issues forth. After a variable period in the mesenteron it bores its way through the gut wall and migrates to the supra-œesophageal ganglion. Within this nerve centre it feeds apparently very little and subsequently escapes into the body-cavity of the host. Here it does most of its active feeding, establishes a respiratory connection with the exterior and completes its development (Fig. 76). Clausen (1931) states that certain Trigonalidæ lay their eggs on foliage and they

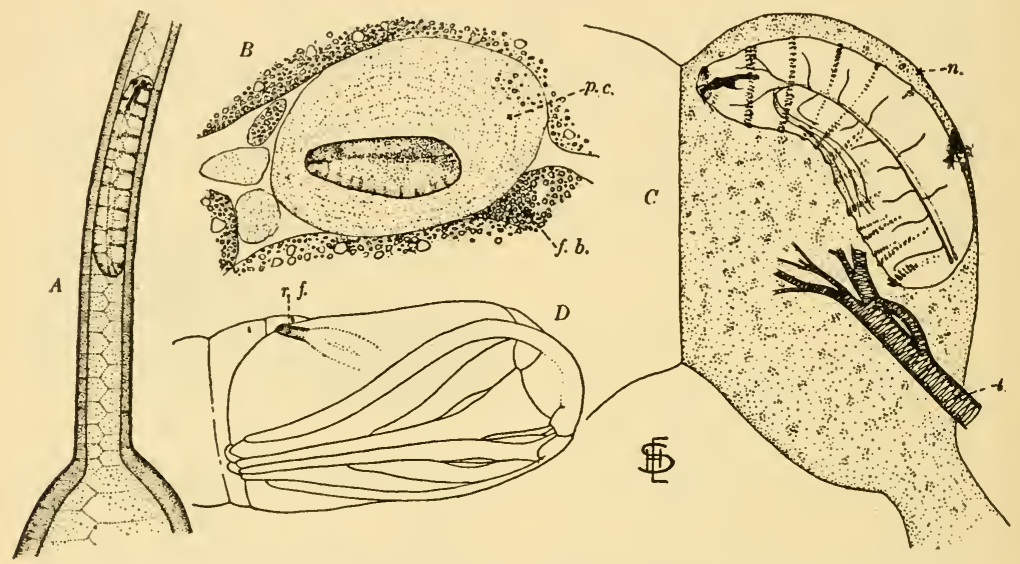

Fig. 76. Gonia capitata De G. A, First instar larva on salivary duct of host. B, Unfed larva surrounded by phagocytic cyst $(p . c.) ; f . b .$, fat-body. $C$, Larva in right lobe of supra-œsophageal ganglion. $D$, Late larva attached to host-pupa by respiratory funnel (r.f.). (After Strickland, loc. cit.)

are swallowed with the food by caterpillars of saw-flies and of Lepidoptera. The eggs hatch into spinose larvæ, which require as their true hosts either Ichneumon or Tachinid larvæ. Those Trigonalid larvæ which occur in unparasitised caterpillars presumably perish.

Thompson (1928) has studied the behaviour of the Tachinid, Rhacodineura antiqua, a parasite of the common carwig in England and other parts of Europe. It likewise lays minute eggs $(0 \cdot 13$ $\mathrm{mm} . \times 0.10 \mathrm{~mm}$.$) , which are ingested by the earwig and hatch$ in the mid-intestine. The subsequent history is incomplete, 
but it appears that having left the gut the larva bores through the neck region of the host in order to establish respiratory connection with the exterior. In this position it becomes enveloped in an integumentary sheath and, when nearing maturity, the sheath is ruptured and the larva becomes free in its host, mainly feeding upon the fat-body.

2. Types of Migratory Primary Larvæ. In many cases where the parasitic insect deposits her eggs or larvæ on leaves, buds, in soil or other situations, but not actually on the host itself, the primary larva assume a form very different from that found in subsequeut instars, and hypermetamorphosis results. Under such conditions the young larvæ are active migratory organisms well adapted for the business of seeking their hosts. This kind of behaviour has been independently acquired among certain members of no less than five orders of insects, which will be discussed separately.

(a) In the Chalcid family, Perilampidæ, the first stage larvæ of a number of species of Perilampus are minute,
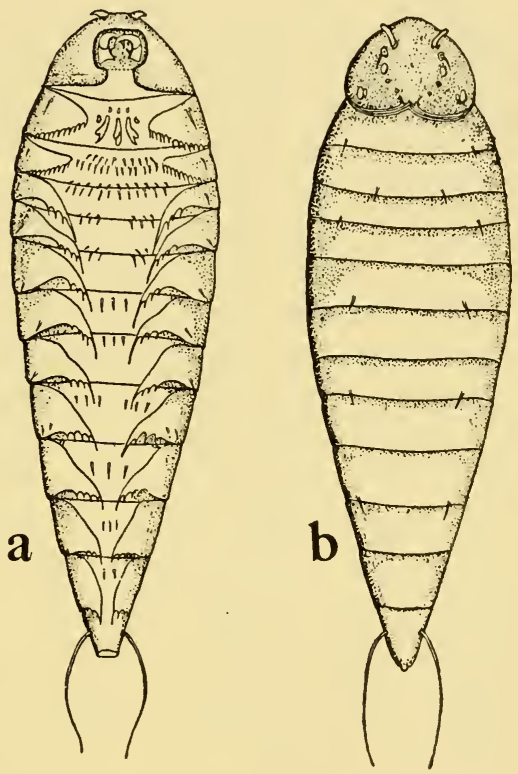

Frg. 77. Planidium of Perilampus. $a$, Ventral ; $b$, dorsal. (After H. S. Smith.) elongate, darkly coloured objects about $0 \cdot 1$ to $0.16 \mathrm{~mm}$. long. The dorsal integument is heavily sclerotised, there is a welldefined head followed by twelve body-segments and a pair of cerciform caudal setæe ventrally the body is provided with an armature of spines and spinous processes which aid in locomotion. Such a larva is termed a planidium (Fig. 77). H. S. Smith (1912) has shown that the planidium of Perilampus hyalinus bores into caterpillars of Hyphantria textor, of which it is a hyperparasite. 
The planidium undergoes no further development until it meets within this host one of its parasites, i.e., the Ichneumon Limnerium validum or the Tachinid Varichota aldrichi. It then enters the larva of one or the other, but remains there in a quiescent state until either host pupates. Once the latter phase is assumed, the planidium gnaws its way out and becomes an ectoparasite and subsequently transforms into an inert, maggot-like larva.

In the related family of the Eucharidæ, whose nembers parasitise certain ants, the first stage larva is likewise a planidium. It was in the species Orasema viridis, which parasitises the Texan ant Pheidole instabilis, that Wheeler first discovered this peculiar larval type in 1905. The most complete observations are those of Clausen (1923) on Schizaspidia tenuicornis, whose host is the Japanese carpenter ant Camponotus japonicus. It appears that the Schizaspidia lays large numbers of minute eggs within the buds of certain trees, and the planidia, upon emergence, await opportunity for attaching themselves to the Camponotus workers which roam about the trees attending aphides. On meeting an ant the planidium attaches itself to the hairs of the tarsi and thus gains entry into the nest. It then becomes an ectoparasite of an ant larva, upon whose back it settles down and perforates the cuticle behind the head, on the thorax. Two instars follow, during which the planidium becomes a vermiform grub of the usual Hymenopterous type and, after the host has pupated, the parasite regains its hold following the ecdysis. It reattaches itself on the metathorax beneath the wings or legs and finally pupates within the host's cocoon. When the parasite becomes an imago it leaves the nest and flies away. The effect of the extraction of the bodyjuices of the host by the parasite results in its inability to become an adult, although death may not supervene until some time afterwards.

(b) In the Dipterous family Tachinidæ there are certain species whose primary larvæ emerge from the egg as active migratory organisms somewhat resembling planidia. In Digonochceta setipennis the eggs are laid in the immediate vicinity of resting earwigs, which serve as the hosts. They hatch almost immediately into deeply pigmented larvæ, $0.6 \mathrm{~mm}$. long, armed 
with plates, bands and spines, and the tracheal system is metapneustic (Thompson, 1928). Such a larva moves rapidly towards an earwig and, having secured itself, bores its way through the neck, or between the thoracic segments, until only its caudal extremity is exposed to the exterior (Altson). Certain other Tachinids deposit their eggs in the soil, and the first stage larvæ burrow through that medium in search of Scarabæid larvæ which serve as their hosts. Thus, both Dexia ventralis Ald. and Prosena sibirita Fab. betray this type of behaviour. Their first stage larvæ are elongate and vermiform and consequently adapted for burrowing; the tracheal system is metapneustic and the body is armed either with segmental setæ or with a caudal pair only (Fig. 78). Upon meeting a host they bore their way within; the larva of the Prosena subsequently becomes attached by its spiracular extremity to one of the main tracheæ of the host, while that of the Dexia maintains its caudal end in the original perforation hole and thus breathes the outside air (Clausen, King and Teranischi, 1927).

In another Dipterous family, the Cyrtidæ, King (1916) has shown that the species Pterodontia flavipes deposits her eggs on tree-trunks, and the first stage larvæ are strikingly planidium-like. Its
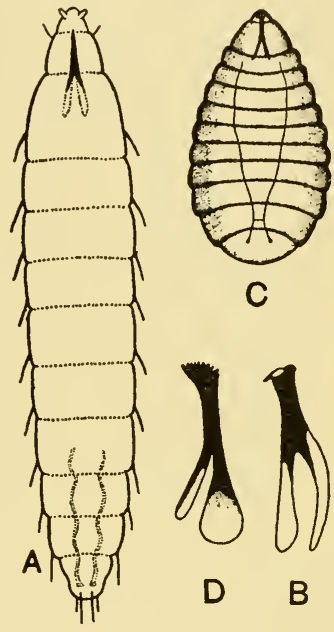

Fig. 78. $A$, First instar larva of Prosena sibirita, and $B$, its mouth-parts. $C$, First instar larva of Centeter cinerea, and $D$ its mouth-parts. (Adapted from Clausen, King and Teranischi, U.S. Dept. Agric. Bull., 1429.)

hard integument is armed dorsally and ventrally with segmental bands of powerful spines and pectinate scales. At the caudal extremity it bears a sucker flanked on either side by a long seta. These active larvæ bore their way into Lycosid spiders, within whose bodies they transform into maggot-like endoparasites.

An active first stage larva is also known in the parasitic families Nemestrinidæ and Bombyliidæ.

(c) Among the few known parasitoid Coleoptera the first stage 
larva is of a typical, active, campodeiform type. Thus, in certain species of the Staphylinid genus Aleochara the primary larva is engaged in seeking out Anthomyiid puparia, and having discovered its host, it bores its way within and transforms into an inert eruciform parasite, its obvious degeneration being correlated with the changed mode of life (vide Wadsworth, 1915 ; Kemner, 1926 ; Voris, 1934). Silvestri (1904) has shown that the Carabid Lebia scapularis, whose host is the Chrysomelid beetle Galerucella luteola, passes through a very similar type of hypermetamorphosis.

The triangulin or first stage larva so characteristic of the order Strepsiptera, and present also in the Meloidæ and Rhipiphoridæ among Coleoptera, is comparable with the campodeiform larva of Aleochara and Lebia just alluded to, and entomologists are familiar with the campodeiform primary larva of Mantispa among Neuroptera. There is little doubt that in these examples the first stage larva is the primitive one, and the adoption of a parasitic mode of life is responsible for the highly modified instars that supervene. Comparison with the ontogeny of members of allied families which lead a normal non-parasitic existence supports this contention. It is noteworthy that the general similarity, both in structure and behaviour, of the Hymenopterous planidium and these campodeiform primary larve has been commented upon by several observers. Wheeler is inclined to pursue the analogy further and to regard the planidium as an archaic, though often considerably modified stage which has bcen suppressed in other families of Hymenoptera. In the Tachinid Diptera, however, evidence points to the migratory phase being an adaptive one secondarily intercalated in the ontogeny.

3. Non-migratory Primary Larva. This habit appears to be infrequent, but prevails among certain members of the Tachinidæ which betray leaf oviposition. It is probable that true larviposition does not occur, as has been sometimes stated, but that the larvæ issue from the eggs almost immediately after the latter have been laid. The behaviour of Bonnetia compta (Strickland, 1923) and of Ernestia (Panzeria) rudis (Prell, 1915) which parasitise caterpillars, may be regarded as typical. Oviposition occurs on the food-plants of the host, and the young 
larva breaks through the upper or cephalic pole of the egg. It gradually works the remains of the chorion and vitelline membrane over its body to the anal extremity, where they persist as a crumpled annular base of attachment to the leaf. With the approach of a moving object, the larva stands erect within the cup-like base referred to, and its whole body rotates vigorously in the efforts made by the parasite to obtain a hold on the object in its vicinity (Fig. 79). If it be a cutworm, the parasite speedily bores through the integument, and in a few minutes it has passed within its host with the exception of its spiracular extremity, which rests in the original perforation, in free communication with the outside air. An integumental sheath grows around the larva and, maintained in this position, it completes its development at the expense of the blood and the fat-body of the host.

This stationary habit prevails in the group Echinomyiinæ whose members are essentially parasites of caterpillars (vide Thompson, 1923). The primary larvæ are well adapted to remain on the host food-plant for considerable periods, and are notably different in structure from those which live within their hosts at a correspondingly early stage. The integument is tough, resistant and deeply coloured with

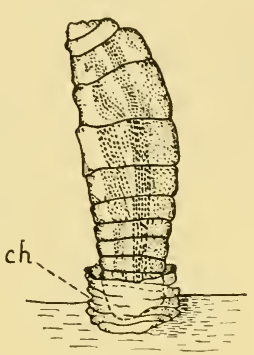

Fig. 79. N ew ly hatched larva of Panzeria $r u d i s$ a t t a c h ed to remains of chorion (ch.) (From Prell.) an armature of scale-like plates and spines. Thus equipped they are not only able to resist desiccation, but are also enabled to hold on to and bore a way rapidly into their hosts.

According to Strickland the larva of Bonnetia may leave its cup-like basal pad and migrate a short distance to assume again its erect position. This apparently insignificant feature is noteworthy, since species with sedentary primary larvæ intergrade with others like Digonochata (p. 334) whose larvæ are actively migratory.

Group B. The habit of depositing eggs externally on the body of the host, which hatch into ectoparasitic larva, is of common occurrence among Chalcids and Ichneumonoids. It is, however, 
unknown among Tachinids and rare in other parasitoidal Diptera, ${ }^{1}$ a feature which contrasts with its prevalence among Hymenoptera. Adaptations to an exclusively ectoparasitic life of this kind are not markedly different from those exhibited by most non-parasitic Hymenoptera, whose larvæ likewise pass an inert existence in contact with ample nutriment. In view of the uniformity of conditions prevailing during the whole parasitic life, it is scarcely surprising that the metamorphoses of such ectoparasites do not involve the striking diversity of larval forms so frequent among the endoparasitic members of the same order.

Upon emergence from the egg the ectoparasitic larva punctures the skin of its host with its mandibles and imbibes the bodyfluids through the rupture thus formed. It rarely moves from the position originally taken up, and this method of nutrition commonly prevails throughout the larval existence. In cases where predatory instincts subsequently develop the larva may become more active and finally consume its host bodily.

Structurally, ectoparasites present few constant features which are unquestionably correlated with their mode of life and at the same time undeveloped in some or other of the endoparasitic forms. The most important character is afforded by the respiratory system and, as a rule, open spiracles are present from the first instar onwards. In some cases, as in Aphelinus mytilaspidis, for example, the full complement of spiracles is present at the time of eclosion from the egg (which never obtains in endoparasitic Hymenoptera), in others it is not acquired until later. It should be pointed out, however, that information respecting the tracheal system of the early instars is very incomplete and generalisations relating thereto may require subsequent modification. In the primary larvæ of many ectoparasites the head is relatively larger and more firmly sclerotised and the mandibles more powerful than in subsequent instars, characters which are correlated with the maintenance of a firm hold upon the host and with the initial perforation of the integument. The body frequently exhibits a definite chætotaxy,

${ }_{1}^{1}$ Instances of this type of life-cycle are found in the Bombyliidæ among Diptera. 
little developed in some forms and more evident in others. In the Chalcid genera Eupelmus, Eurytomus, Torymus and Leucospis, bands of slender macrochætæ are very characteristic. The foregoing characters disappear in the later instars and finally there remain few or no evident structural differences whereby an ectoparasite can be distinguished from the later instars of most endoparasites. This subject is also discussed by Evans (1933) with reference to certain Hymenopterous parasites of Diptera.

Group C. External oviposition or larviposition, followed by an endoparasitic life, is exemplified in many Tachinidæ which form Groups I., III. and VI. of Pantel (1909).

In Pantel's Group I. those Tachinids with a macrotype egg (i.e., relatively large and of a short, somewhat flattened form) oviposit on the bodies of the hosts, fastening the eggs in position by means of a glutinous secretion. The embryos in such eggs are but little developed at the time of oviposition, and are covered with a tough, durable chorion. Emer. FIG. 80. Empty egg $(e)$ of Thrixion gence from the eggs may take place in one of two ways. Either the chorion dehisces, but aids in maintaining the larva in position as

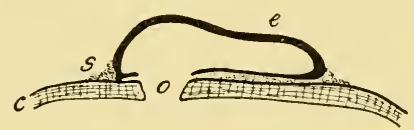
attached by secretion $(s)$ to cuticle $(c)$ of its host; at $o$ is shown the passage eaten by the larva in entering the host. (From Pantel.)

it bores its way through the integument of the host (Winthemyia 4-pustulata and Tricholyga major); or, the chorion does not rupture and the larva eats its way through that part of it which is in contact with the integument of the host, entering the latter without exposure to the exterior (species of Tachina, Gymnosoma, Thrixion (Fig. 80), Centeter, etc.). In Centeter cinerea Clausen and his co-workers (Fig. 78) mention that the eggs are laid on the hard integument of the Japanese beetle, and the first instar larva has its mouth-parts armed with a dentate rasper ${ }^{1}$ which enables it to bore through the cuticle of the host. Owing to errors of the oviposition instinct, many larvæ perish on account of the

1 This structure is frequently present in larvæ which bore through the integument of the host. 
eggs being lodged on parts of the integument too thick for penetration.

Pantel's Group III. comprises those Sarcophagidæ which deposit larva on the bodies of their hosts. They are true viviparous flies with many parasitic species and are now often regarded as a sub-family of the Tachinidxe. A good example of supra-cutaneous larviposition is afforded by Sarcophaga kellyi which deposits its larvæ beneath the folded wings or on the abdomen of Melanoplus grasshoppers. The young parasites quickly bore their way through the inter-articular membranes and lead an endoparasitic life (Kelly, 1914).

There are again other Tachinids, forming Group VI. of Pantel, which are ovo-viviparous. Their eggs are thin-shelled, and the larvæ issue either in the uterus of the parent or almost immediately after oviposition. They differ from those mentioned in Group A in that the integument is devoid of chitinous armature, and they are ill-adapted for prolonged exposure. Many species of Tachinids come under this category, but it is probable that actual larviposition occurs less frequently on the host itself, and more often eggs are deposited which hatch almost immediately. Townsend has pointed out that certain Dexiine species parasitise insects living in concealed situations, such as leaf-miners, wood-borers, etc. The flies penetrate into the burrows of these concealed hosts depositing their larvæ in their immediate proximity. Such unarmoured parasites, finding themselves in confined spaces, have only short distances to traverse before discovering their hosts. Among ovo-viviparous Tachinids, species of Sturmia, Exorista, Thelaira, Bucentes, Plagia, Voria, and other genera are enumerated by Baer (1920) and by Thompson (1926).

Group D. In this group are included the greater number of the parasitic species of Hymenoptera and certain of the Diptera, including the Pipunculidæ, Conopidæ, the Agromyzid genus Cryptochatum and a few of the Tachinidx.

Among endoparasitic Hymenoptera the eggs may be inserted either within the eggs, larvæ, pupæ or adults of the hosts concerned. The Mymaridx, Trichogrammidx, Scelionidæ and many Platygasteridæ are essentially egg-parasites completing their 
whole development in the eggs of various insects. Certain of the Encyrtidæ and Eulophidæ parasitise cggs of Lepidoptera or Coleoptera, but complete their development in the larval stages of their hosts. An enormous number of Hymenoptera parasitise larvæ only, or subsequently complete their development within the pupæ, while certain others are exclusively pupal parasites. Parasites confined to imagines are less frequent, but the Braconid genera Perilitus and Dinocampus are well known to parasitise adult Coleoptera.

The ovipositor is an instrument often used with extreme accuracy; as a rule the eggs are placed in the general body-cavity of the host, but in other cases intra-organic oviposition prevails, the eggs being laid in the fat-body, gut, salivary glands, brain or other situations. The eggs as a rule are poor in yolk, or are almost devoid of that material, while the chorion is thin or even membranous or may be absent. After deposition the eggs frequently increase markedly in size until eclosion of the larva supervenes. Thus in the Ichneumon Meteorus dimidiatus the newly laid egg measures $0.14 \mathrm{~mm} . \times 0.04 \mathrm{~mm}$., but it finally attains a maximum size of $1.2 \mathrm{~mm} . \times 1.5 \mathrm{~mm}$. (Fig. 84); in Dinocampus rutilis, another Braconid, Jackson states that the egg may increase in cubic content over 1,200 times. The primary larvæ frequently emerge in a very early stage of ontogenetic development, they assume great diversity of form and hypermetamorphosis prevails (vide Chapter III.). The significance of the morphological features thus exhibited is very obscure; certain of them appear to be inherited ancestral survivals, while some are most likely adaptive in significance. In the final instars, however, the apodous maggotlike type common to all Hymenoptera-Apocrita is assumed. The chief features of endoparasitic life are discussed on pp. 343-353, and consequently will not be referred to here.

Among Tachinidæe both subcutaneous oviposition and larviposition occur, and the species exhibiting the habit form groups VII., VIII. and IX. of Pantel. The female fly is provided with an instrument for perforating the integument of the host, and in its most usual form, as exhibited in Compsilura concinnata, it consists of a curved acutely pointed piercer which is grooved dorsally to 
receive the tubular larvipositor (or ovipositor). The two structures act in unison, and the introduction of the larvipositor follows upon the action of the piercer in perforating the host. The ventral region of the abdomen is strongly carinate, and bears backwardly directed spines together with a prominent backwardly directed process of the fifth sternum. These structures evidently aid the fly in maintaining a firm grip on the host while the puncture is being made. In Neocelatoria ferox which parasitises the beetle Diabrotica Walton (1914) concludes that the host is gripped, as it were, by the "forceps" formed by the piercer and the sternal
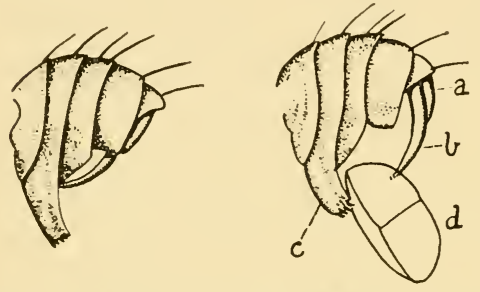

process while the parasite makes the perforation. In this species the sternal process is borne on the second segment, and is strongly dentate (Fig. 81).

In Compsilura the instrument is a true larvipositor, and the larvæ are present in the uterus Fig. 81. Neocelatoria ferox Walt. Left : of the parent prior to abdomen of female. Right : figure deposition. In certain other
showing probable functioning of appendages. $\quad a$, Ovipositor. $b$, 'Tachinidæ (species of Alophora, Piercer. $c$, Process of second abdominal segment. $d$, End view of host beetle (Diabrotica). (From Walton.)

Hyalomyia and Xysta) Pantel concludes that oviposition takes place by an analogous procedure. The presence of eggs but little advanced in development when in the uterus, the absence of an incubatory pouch, and the existence of a complex piercing ovipositor support his contention. He also places the Conopida provisionally in this same group.

In the Agromyzid Cryptochctum a highly specialised piercing ovipositor is present: it appears to afford a striking example of adaptation to a parasitic mode of life, since the eggs arc inserted within the body-cavity of coccids of the sub-family Monophlebinæ. The ovipositor has peculiar structural features which seem to preclude its origin as a specialisation of the rasping type of organ found among other Agromyzidæ ('Thorpe, 1934). 


\section{Host Relations of Parasites}

The behaviour of entomophagous parasites in relation to their hosts reveals many striking and remarkable features. As a general rule their activities result in the death of the insects attacked, which usually succumb very soon after the parasites have left their bodies. In other cases the fatal effects of parasitisation may reach this climax more slowly, and the host is capable of limited reproduction before its premature death supervenes. This regularly happens with the adult females of the brown scale (Coccus caprece) when parasitised by certain Chalcids, while some aphides are capable of restricted viviparous reproduction when parasitised by Aphidius if they have passed the third ecdysis. Instances are known of adult Coleoptera which have remained active, and laid eggs, after larvæ of the Braconid Dinocampus have issued from their bodies. In this connection it is noteworthy that Timberlake (1916) was able, under experimental conditions, to rear two generations of $D$. americanus from a single individual Coccinellid before death of the latter supervened. Such survivals are probably exceptional and the result of relatively light parasitisation affecting robust and well-developed host individuals. Furthermore, the parasites feed upon the blood and fat-body, sedulously avoiding injuring the more vital organs. Many hæmophagous or steatophagous parasites bring about the death of their hosts largely on account of the nutritive drain which their feeding activities entail upon the latter. In cases when the hosts are adult insects, the partial or complete suppression of the reproductive functions of the parasitised individuals (parasitic castration) is a common feature. This occurs with the European earwig when parasitised by the Tachinid Digonochceta setipennis, with many Homoptera parasitised by Dryinidæ and in both the Homopterous and Hymenopterous hosts of Strepsiptera. As previously mentioned, the activities of the Strepsiptera rarely result in the death of the hosts, which continue to live and feed after the male parasites have left their bodies.

During their early life endoparasites lie within their hosts surrounded by the blood or other serous fluid from which they 
derive their nutriment. Respiration, under these circumstances, has much in common with that of aquatic insects, and the necessary oxygen is obtained either from the surrounding medium or by establishing a direct or indirect connection with the outer air. With many parasites the demands of growth cannot be fulfilled in this manner throughout life and, as the body-fluids of the host tend to become exhausted, the parasites turn to the more solid tissues as their source of food and become, as it were, internal

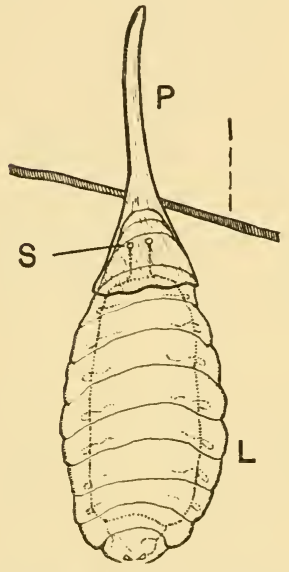

FIg. 82. Metapneustic first instar larva $L$ of Blastothrix attached to chorion of egg whose pedicel $P$ protrudes through the integument $I$ of the host. $S$, Spiracles. predators. Their feeding activities entail the laceration of many of the smaller tracheal vessels, which results in the liberation of air in the body of the host. Direct respiration by the parasites now becomes possible, and correlated changes in the respiratory system result. Hymenopterous parasites develop at this stage a peripneustic tracheal system, and Dipterous parasites may no longer need the special adaptations previously acquired as a means of breathing the outside air. Finally, when larval development is completed, the parasites either pupate within their host or gnaw their way through its integument and transform outside its body. This, in a few words, is the course of life followed by most entomophagous parasites, but the behaviour of different groups exhibits so great a diversity of phases that few generalisations are possible. It will be convenient, therefore, to discuss Hymenopterous and Dipterous parasites separately.

Hymenoptera. In its first instar a Hymenopterous parasite is characterised by the absence of spiracles, the tracheal system is rudimentary or wanting, and the body integument is a delicate, flexible membrane. At this stage its diet consists solely of the blood or serous fluids of its hosts; the mouth-parts are represented by a pair of sharp, piercing mandibles, while the remaining trophi 
are reduced to the condition of fleshy lobes forming the boundary of the suctorial mouth. Salivary glands and Malpighian tubes are usually well developed, and the mid-intestine is a capacious sac, but without direct continuity with the proctodæum. Respiration is cutaneous, and the necessary oxygen is derived from the blood of the host. It is true that little is definitely known with respect to the oxygen-carrying capacity of insect blood, but all the evidence strongly indicates that it is from the latter source that endoparasites first obtain the oxygen they may require. Species of certain Chalcid genera, including Blastothrix, Encyrtus, Microterys and Phonodiscus (Fig. 83), which parasitise Coccidæ, are exceptional in being metapneustic in the first instar (Imms, 1918; Silvestri, 1919 ; Maple, 1937). In these genera the egg is provided with an elongated pedicel, whose apex protrudes through the integument of the host to the exterior. The anal extremity of the larva, in such cases, is closely grasped by the persistent chorion of the egg in such a manner that the

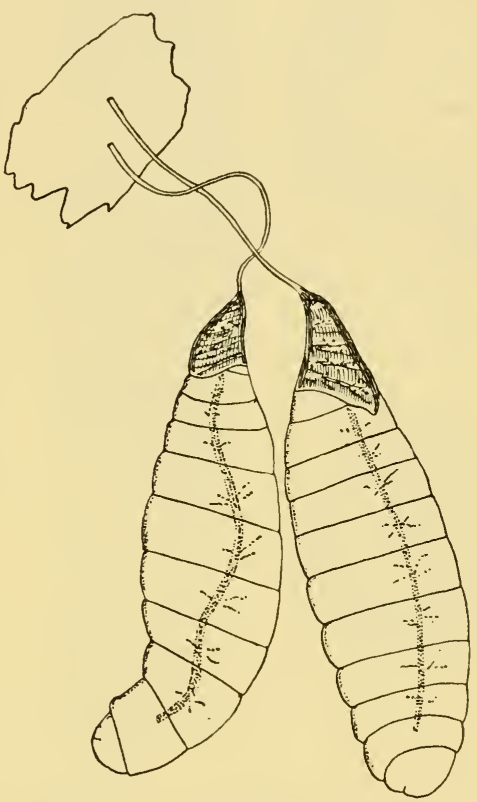

FIg. 83. Two metapneustic larvæ of Phonodiscus aneus attached by their egg pedicels to integument of host (Sphcrolecanium). (After Silvestri.) spiracles are able to inspire the outside air through the pedicel, which serves as a respiratory funnel (Fig. 82). The chorion in this region is specially modified and is freely permeable to air. During their later life these parasites free themselves from all connection with the egg pedicel, and acquire a peripneustic respiratory system. Special organs, either in the form of a caudal appendage or of an anal vesicle, are present in diverse 

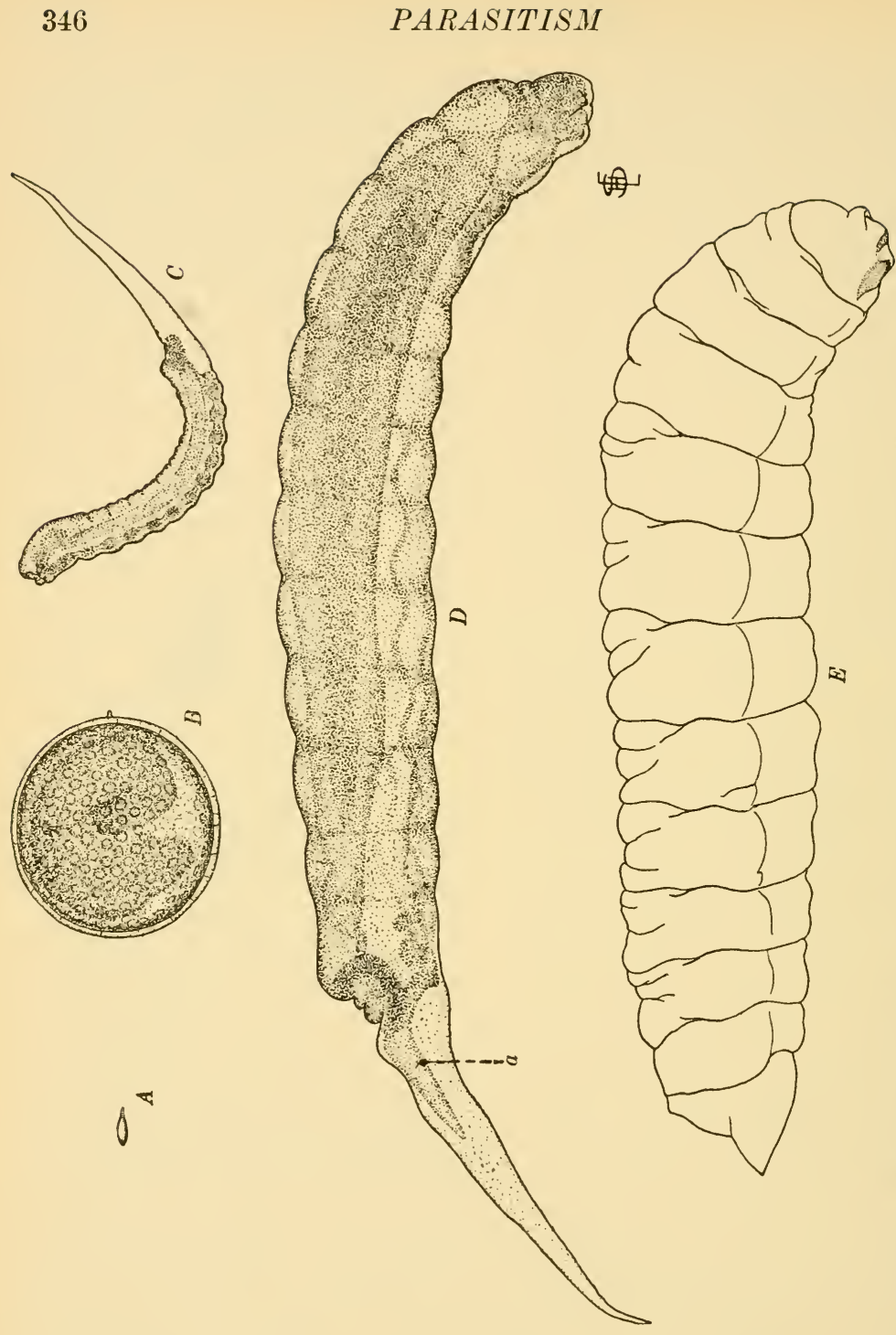

है.

80.0

$\pm x$

i.

$\cdot \frac{\pi}{\pi}$

ค.

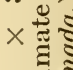

政

.

कै

일

宅

녹

๑์ ڤิ

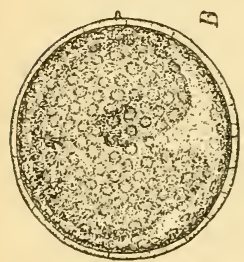

$0^{4}$

ت.

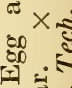

- ज्ञึี

.

它

की

屯.

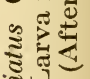

ปீं

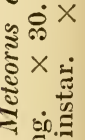

का

$\underset{1}{0}$

groups of parasitic Hymenoptera. These structures are found only in the early instars, and become gradually resorbed as growth proceeds and spiracular respiration becomes established. 
This fact, along with the absence of such organs in all ectoparasitic forms, suggest that they exercise a respiratory function. A caudal appendage has been acquired in certain genera among all the great groups of parasitic Hymenoptera. Among Ichneumons it is prevalent in Exochilum (Anomalon), Limnerium, Mesochorus, Campoplex, Mesoleius, Thersilochus and others. In Braconidxe (Fig. 83) it is found in Dinocampus and Adelura; it is exceptionally well developed in Meteorus, but greatly reduced in Praon and in Aphidius. A similar organ is present in several Chalcid genera (vide Parker, 1924); it is always prevalent in the primary larvæ of the Figitidæ, and in some Proctotrypoidea. There appears to be nothing in the structure of this organ to contradict the view that it is respiratory in function, since it is a thin-walled tube lined by a delicate hypodermal layer and filled with blood, and in some cases it contains trachæ also. It appears to be a kind of blood gill which serves to increase the general respiratory surface of the body in order to fulfil the breathing requirements of the young growing larva. This explanation, which has been accepted in some quarters, is controverted by the researches of Thorpe (1932). By the use of biological indicators it was shown where, over the body-surface of endoparasitic larvæ, oxygen absorption was going on while carbon dioxide output was investigated mainly by means of $p H$ indicators. Parasitic larvæ were dissected out from their hosts, washed free from the tissues of the latter and examined under a microscope in salt or Ringer's solution. Use was made of certain Protozoa, of which Polytoma was found most suitable, and advantage taken of the fact that such organisms migrate to a region where the oxygen tension is lower than that in water saturated at atmospheric pressure. When a culture of these organisms is run under the coverslip these creatures at once arrange themselves in a zone around the parasitic larva where oxygen is being absorbed from the fluid. As the oxygen tension falls below the optimum, owing to respiratory activity of the parasite, the Protozoa retreat further away from the region of the parasite concerned. By using luminous bacteria (B. phosphorescens), which were introduced into the solution in the same way, examination was made in complete 
darkness. As the oxygen became used up by the parasite the luminous zone gradually spread outwards until luminosity was only betrayed at the edges of the coverslip, where oxygen was passing into solution from the outside air. By means of this technique it was shown that the tail of Ichneumon larvæ performs no apparent function in respiration, the Protozoa grouping themselves entirely in relation to the body of the parasite only. The absence of any proper blood circulation in the caudal appendage appears also to argue against this organ performing a respiratory function. It is probable also that the "tail" of Proctotrypid and Cynipid larvæ is likewise devoid of a respiratory function. With regard to the caudal vesicle of Braconids, referred

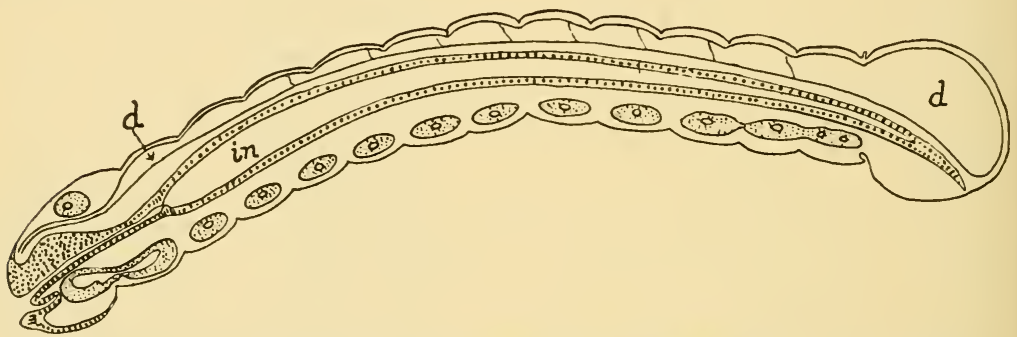

FIG. 85. Longitudinal section through larva of Apanteles. $d, d$, Dorsal. vessel. in, Intestine. (Adapted from Grandori.)

to below, Thorpe's experiments show that where this vesicle is large and supplied with a good blood circulation it is undoubtedly of importance as a respiratory organ. It is not, however, the sole or even the most important organ of respiration, since gaseous exchange takes place over the whole surface of the larva. It is concluded that in Apanteles and Microgaster the vesicle, when at its maximum development, cannot be responsible for more than about one-third of the total respiration. In other Braconids (Orgilus) its respiratory function is less. 'The caudal vesicle found in Apanteles, Microgaster, Microplitis, and some other Braconid larvæ has been much discussed by various investigators (vide Tothill, 1922). It is evidently the everted proctodæum which becomes gradually withdrawn into the body during later growth 
to form the hindmost region of the intestine (Grandori, 1911). ${ }^{1}$ The greater part of the cavity of the vesicle is occupied by the much enlarged terminal chamber of the heart, which suggests that the organ mainly functions as a specialised type of blood gill. According to Grandori, the character of its lining epithelium indicates that it also plays some part in excretion (Figs. 85 and 87).

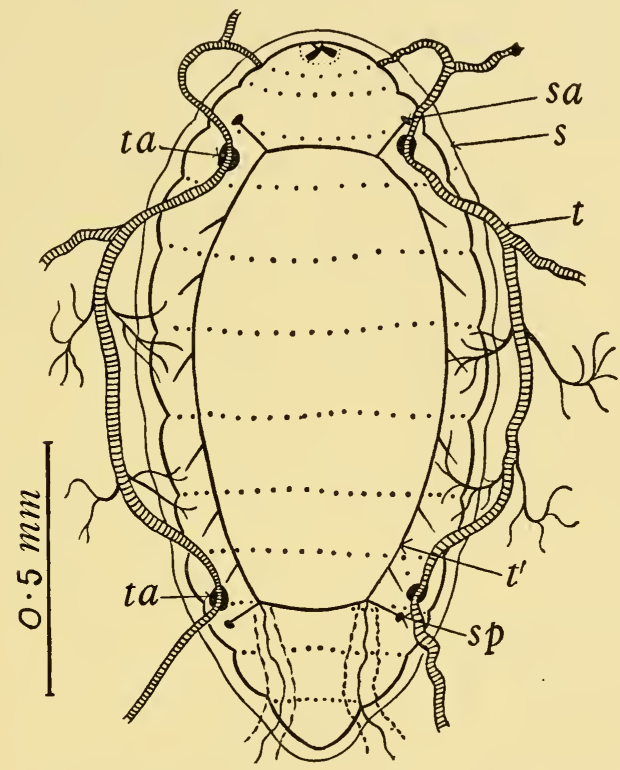

FIG. 86. Fifth instar larva of Encyrtus infelix dissected from its host while still enclosed in its sheath, $s$, together with the longitudinal tracheal trunks, $t$, of the host attached. $s a$, anterior spiracle; $s p$, posterior spiracle ; $t^{\prime}$, longitudinal trachea of a parasite ; $t a$, tracheal attachment. (From Thorpe.)

In all endoparasitic Hymenopterous larvæ there is no through passage between the mid-intestine and the exterior, an arrangement which ensures against the contamination of the host by fæcal products. It is only at the last ecdysis, prior to pupation, that direct continuity becomes established and the contents of the

1 A somewhat similar view has been expressed by Gatenby (1919), who, along with Tothill, was not aware of Grandori's important memoir on Aapnteles. 
intestine discharged. The waste matter usually assumes the form of a chain of freal pellets which is commonly found in close proximity to the pupa.

A new type of respiratory inter-relationship between a Hymenopterous parasite and its host has been recently described by Thorpe (1936). The parasite, Encyrtus infelix (Chalcidoidea), utilises the Coccid Saisettia hemisphorica as its host. In its first three larval instars the Encyrtus is metapneustic, the spiracles being in communication with the atmospheric air by means of the protruding pedicel of the egg in the manner already described in
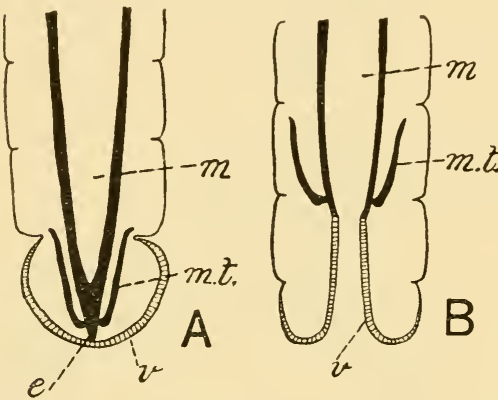

FIG. 87. $A$, diagram of anal extremity of young larva of Apanteles. $B$, The same of fully grown larva. $e$, Blind extremity of gut. $m$, Mid-intestine. $m . t$., Malpighian tubes. $v$, Caudal vesicle. the case of certain other Chalcids. In the fourth and fifth instars the mode of respiration of the parasite becomes completely altered. The parasite now becomes dependent upon a special structural development of its host. It turns round within the body of the latter and becomes invested with a closely fitting membranous sheath which is formed by the phagocytes and tracheal branches of the host. The sheath becomes attached to the main lateral tracheal trunks of the host in four or six places in the vicinity of the spiracles of the parasite (Fig. 86). An actual continuity becomes developed between the lumen of the host trachea at these points and the narrow space between the sheath and the parasite. In this manner the larval parasite is able to breathe air from the tracheal system of its host.

Another peculiar type of host relationship, of a different nature, has been recorded by Flanders (1936) with reference to the Chalcid Coccophagus. In the species studied the progeny of parthenogenetic females consists, as is often the case, of males only. Fertilised females produce females only, and these develop 
entirely as primary parasites of Lecaniine scale insects and mealy bugs. The males, on the other hand, only develop as hyperparasites of larvæ of its own or other species of parasites. It would seem that the stimulus of fertilisation results in a marked change in host-selection by the female Chalcid. Prior to mating these oviposit freely in the body-cavity of a parasitic Hymenopterous larva, but after mating egg-laying only occurs within a scale insect. This peculiar and apparently unique phenomenon requires further investigation.

Diptera. Endoparasitic Dipterous larvæ differ from those of almost all Hymenoptera, which lead a similar mode of life, in two important features: (1) When they issue from the egg they are provided with a metapneustic tracheal system; and (2) they nearly always establish a respiratory connection with the outside air during some stage of their development. Exceptions to these generalisations are relatively few. In cases where the early parasitic life is passed in the body-cavity of the host or within some specific organ of the body the spiracles, although well developed, appear to be non-functional, or they may sometimes be vestigial or wanting. Also, in a small number of species, chiefly Pipunculidæ and Sarcophagidæ, the whole larval existence is passed within the bodies of the hosts without acquiring any respiratory connections with the exterior. The vast proportion of the parasitoid Diptera belong, however, to the family Tachinidæ and almost all the species of this extensive group respire free air, either by means of a perforation of the body-wall of the host or by acquiring a secondary connection with its tracheal system. In either event the parasitic larva becomes enclosed in a sheath ("gaine de fixation" of Pantel), which may be of a primary or secondary character. Whichever way it is formed it benefits host and parasite alike ; it maintains the parasite in intimate connection with the necessary oxygen supply, but it is also a protective reaction on the part of the host against irritation and microbic infection induced by the presence of the parasite.

A primary sheath is always cutaneous in origin, and is formed as an integumentary ingrowth from the margin of the initial perforation made by the larva in entering the host. The perfora- 
tion functions as a respiratory pore ("soupirail" of Pantel) and the parasite is maintained in the body-cavity of the host, with its spiracular extremity firmly wedged in the aperture. The sheath consists of the same layers as the integument, its lining being continuous with the external cuticle. It forms a stout funnel, which grows around the hindmost segments of the parasite, and its walls often become thickened by the incorporation of fat cells, dead phagocytes and other tissues which become bound together by a copious infiltration of chitin produced by the hypodermal layer. Distally the sheath is membranous, and may entirely enclose the larva and, under

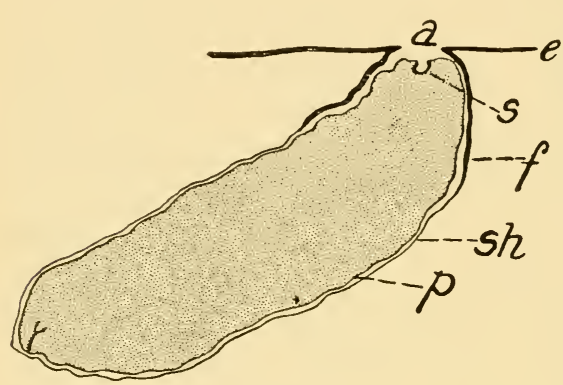

FIG. 88. Section through a larva of Thrixion attached to cutaneous respiratory funnel $f$. $a$, Primary entrance hole through integument $e$ of host. sh, Integumental sheath enclosing parasite. $s$, Spiracle. (Adapted from Pantel.) such circumstances, it appears to be permeable to the body-fluids of the host which form the sole nutriment of the parasite within. The first two ecdyses commonly occur while the parasite is thus enclosed, and the exuviæ are cast off within the cavity of the sheath. Ultimately the parasite either frees itself completely from this investment and becomes actively carnivorous among the organs of the host; or, it ruptures the membranous bag, but continues to respire the outer air with its spiracular extremity still retained within the basal funnel of the sheath (Fig. 88).

A secondary sheath may be either cutaneous or tracheal in origin (Fig. 89), and is formed with respect to species whose early life is passed either free in the body-cavity of the host, or within an individual organ of its body, usually a nerve centre or the mid-intestine. It is formed at a stage when the respiratory needs of the growing parasite demand a more adequate supply of oxygen than can be derived from the body-fluids. The parasite fulfils its 
own requirement either by perforating the integument or by rupturing one of the larger trachex or an air-sac of its host. It uses its armoured spiracular extremity to make the necessary perforation in the integument or trachea as the case may be, and the wound thus caused leads to the formation of a sheath similar to the primary sheath already described. Many Tachinids maintain this respiratory adaptation until ready to pupate, while others, such as Centeter cinerea, free themselves after attaining the third instar, and proceed to devour the viscera of their hosts.

In the case of the endoparasitic genus Cryptochatum, of the family Agromyzida, Thorpe (1931) has studied the economy of the species $C$. icerya in detail, while that of C. grandicorne formed the subject of a later communication (Thorpe, 1934). The larvæ of these two species occur in the bodycavity of certain Coccidre, the host being Icerya purchasi in the case of the firstmentioned species and Guerinia serratula in the case of the second species. The larvæ are provided with a pair of filamentous prolongations of the last abdominal segment which increase in length in succestive instars in conformity with the needs of the growing parasite. These filaments contain blood and trachex and ramify among the organs of the host. Experiments of a similar kind

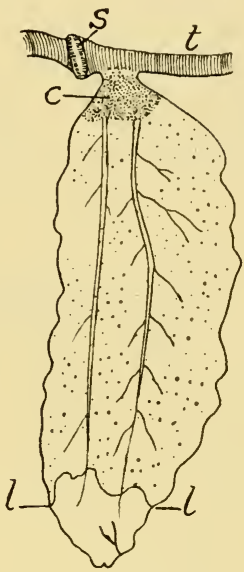

Fig. 89. Tachinid larva attached to a tracheal trunk $t$ by means of a secondary respiratory funnel $c$. $l$, Limits of tracheal sheath. $s$, Spiracle. (From Pantel.) to those referred to on p. 347 indicate that these caudal filaments serve to increase the surface available for respiratory exchange between the larva and the blood of the host. When the tracheal system becomes in communication with the outside by means of the spiracles, the caudal filaments shrivel and are no longer functional.

\section{Polyembryony and Related Phenomena}

Polyembryony is rare in the whole animal kingdom, and among insects it is almost exclusively confined to certain of the parasitic 
Hymenoptera, ${ }^{1}$ where it exhibits a remarkable sequence of biological processes. In view of the immense number of a species of parasitic Hymenoptera already described, and the very small number whose economy has been adequately studied, it is likely that the incidence of polyembryony will eventually be found to be more frequent. The researches of Martin (1914) in Germany, Silvestri (1906) in Italy, and of Leiby and Hill (1923-24) and of Patterson in America-which followed upon the earlier fundamental discoveries of Marchal in France-have led to the elucidation of the essential features of the phenomenon. It is known to have arisen independently in three families belonging respectively to the Chalcidoidea, Proctotrypoidea and Vespoidea, and its phases will be briefly considered in each of these groups separately.

(a) Chalcidoidea. It was in the species Ageniaspis (Encyrtus) fuscicollis that Marchal definitely proved in 1898 the occurrence of polyembryony in insects. It has only so far been observed within the single family Encyrtida. where it prevails in species belonging to a group of closely related genera. Polyembryony has been recorded in species of Ageniaspis, Encyrtus, Copidosoma, Litomastix, and Berecyntus, whose hosts so far as known are Lepidoptera. ${ }^{2}$ In all cases the eggs of the parasites are deposited within those of their hosts which duly hatch into larvæ, and the developing parasites are contained within their bodies. The main features of the embryonic development are very similar in the individual cases studied, irrespective of whether the eggs are fertilised or not, vide Fig. 90. Development commences by the oocytc nucleus dividing twice to form two polar bodies, and the first formed of the latter may also undergo division (Fig. 90, A).

${ }^{1}$ In 1923, Noskiewicz and Poluszynski published a very brief preliminary communication on the occurrence of polyembryony in the Stylopid IIalictostylops, which parasitises the bee, IIalictus simplex. Their much condensed account is difficult to interpret in the absence of any illustrations, but it appears that two types of embryos are formed. In those destined to develop polyembryonically the blastoderm becomes divided into groups of cells which form separate vesicles, and the latter ultimately give rise to the embryos. It is stated that the number of em bryos produced may vary from two to more than forty.

2 These Lepidopterous hosts pertain to the families Gelechiidx, Hyponomeutidæ, Coleophoridæ, Gracilaridæ, Tort ricidæ and Noctuidæ. 
The cytoplasm around the nucleus then becomes separated off from the rest of the egg, which contains the polar nuclei, and consequently the egg becomes divisible into an embryonic area and a polar area (Fig. 89, B). A little later, the embryonic nuclei are seen in division, and the polar nuclei have given rise to the paranucleus or nucleus of the future trophamnion (Fig. 91). The developing egg then soon becomes enclosed in a cellular adventitious sheath derived from the surrounding tissues of the host; the embryonic nuclei increase in number, the paranucleus also undergoes division, and the original polar area comes to form a definite covering, or trophamnion, surrounding the whole of the embryonic area of the egg (Fig. 91). The first indication of polyembryony is the division of the embryonic area into small groups of cells, or morulæ, which are seen to lie in cavities within the trophamnion. The whole egg increases in size, and meantime both the adventitious sheath and trophamnion
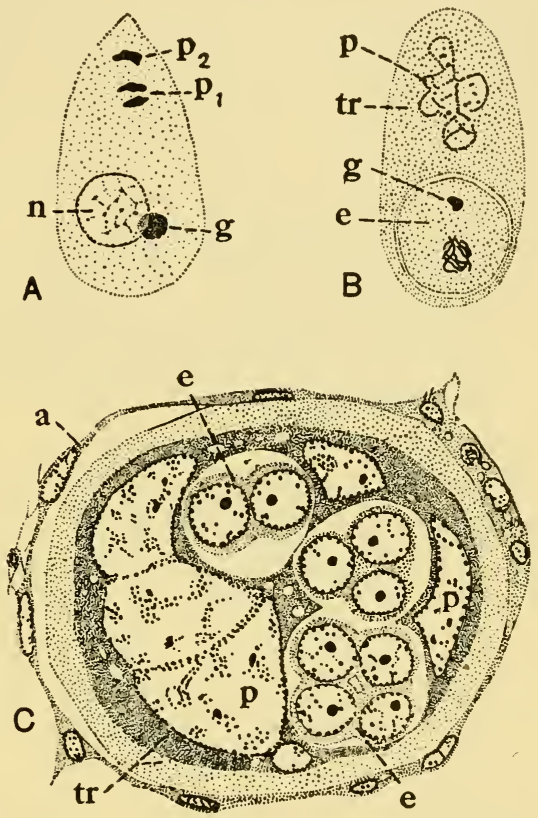

FIG. 90. Encyrtus fuscicollis, early polyembryonic development. $A, \mathrm{Egg}$ with first and second polar bodies $p_{1}, p_{2}$. $B$, Division into embryonic area $e$ and trophamnion $t r . \quad C$, Transverse section of polygerminal mass. a, Adventitious sheath. $e, e$, Embryos. g, Germ-cell determinant. $n$, Oocyte nucleus. $p$, Paranucleus. $t r$, Trophamnion. (Adapted from Martin.)

grow simultaneously and maintain a complete double investment (Fig. 90, C). The further development of the morulæ need not concern us here, and it will suffice to add that each subsequently becomes a separate embryo, destined to transform into an individual parasite. The number of embryos which originate 
from a single egg varies in different species; in Ageniaspis testaceipes 13 are produced (Marchal); in Copidosoma gelechice from about 163 to 191 are recorded (Patterson, Leiby), while in Litomastix truncatellus an average of about 1,500 embryos results (Silvestri). It appears that, as the number of embryos derived from a single egg increases, the polyembryonic process becomes more complicated. The first-formed morulæ may each divide into two, as in $\boldsymbol{G}$. gelechice, while in $L$. truncatellus secondary morula divide to form tertiary bodies which finally develop into larva. When fully formed the individual larvæ break through the investing membranes and become free within the body of the host.

(b) Proctotrypoidea. Polyembryony occurs in this group in the genera Polygnotus and Platygaster, belonging to the family Platygasteridæ. Their hosts in all cases are Cecidomyidæ, which are parasitised either as eggs or as young larvæ. Polygnotus minutus utilises the Hessian fly (Mayetiola destructor) and the oat midge $(\boldsymbol{M}$. avence) as its hosts and deposits its egg in the midintestine of the young larva, where it ultimately produces usually 10 to 12 embryos. Since the egg is bathed in the chyle of the gut no adventitious sheath is formed around the embryonic mass. Platygaster hiemalis, according to Lieby and Hill, also parasitises the Hessian fly, attacking the eggs or, more occasionally, the young larva. It is of particular interest because the egg may develop either monoembryonically or polyembryonically. From 4 to 8 eggs are laid in an individual host; some develop into single embryos, others give rise to two embryos, and the remainder degenerate. The embryos become dispersed in the body-cavity of the host embryo or larva, as the case may be, and become invested by certain of the tissues which form an adventitious sheath. The embryonic nucleus divides to form four nuclei and subsequently the whole embryonic mass divides, and the two daughter masses become separated by an extension of the trophamnion between them. The cells of each embryo thus formed then undergo further division until a hollow 16-celled blastula is formed (Fig. 91). Without following the development further, it may be added that finally the resulting larvæ feed upon 
the host tissues, which they wholly consume. In eggs which develop monoembryonically, the 4-celled stage gives rise to a single blastula, but otherwise the development is similar in the two cases. We have in $\boldsymbol{P}$. hiemalis the simplest possible type of polyembryony, and it appears that it has arisen from an already specialised method of monoembryonic development, which is also found in other Platygasterids. In another species, $P$. vernalis, which is also parasitic upon the Hessian fly, these same observers

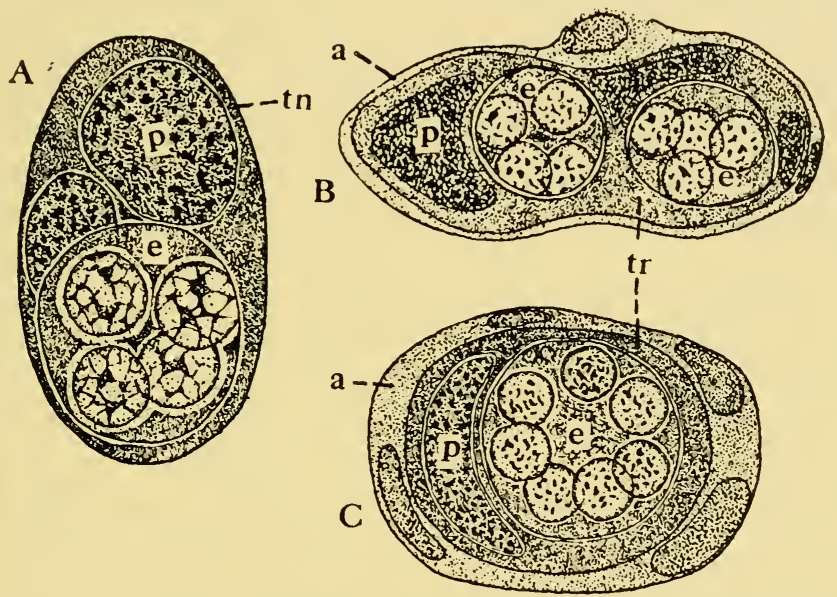

Fig. 91. Platygaster hiemalis, early polyembryonic development. $A$, Egg with four embryonic nuclei. $B$, Division into two embryos surrounded by a common trophamnion. $C$, Transverse section of an embryo in early blastula or 16-celled stage, of which seven are shown. (Adapted from Leiby and Hill.) Lettering as in Fig. 90.

state that it lays a single egg in the egg of its host. The parasitic egg is deposited in such a manner that it eventually comes to lie in the mid-intestine of the host larva and consequently does not become invested by an adventitious sheath. During early development the embryonic nucleus undergoes division until 16 nuclei are produced. A cell membrane, enclosing a small amount of cytoplasm, becomes formed around each nucleus, and the cell thus constituted is recognised as a germ. Each germ may be the progenitor of either one or two larvæ, depending upon 
whether it undergoes division in the morula stage or not. Since a number of the embryos abort during development, the brood finally results on an average of only eight parasites being produced from one egg.

(c) Ichneumonoidea. Among the ichneumonoid flies polyembryony occurs in the Braconid genus Macrocentrus, which parasitises larva of the Lepidoptera. According to Parker (1931) the species $\boldsymbol{M}$. gifuensis, which has been introduced into North America in connection with the control of the European corn borer, produces eggs each of which may yield up to eight or ten larva. In this species there appears to be no proliferation of the host tissue to form an adventitious sheath. Polyembryony is also stated to occur in $\boldsymbol{M}$. ancylivorus, which parasitises the oriental fruit moth larva among other hosts. According to Daniel (1932) only a single polyembryonically produced individual survives in each host.

(d) Vespoidea. 'The only example of polyembryony in solitary parasitic wasps is afforded by Aphelopus thelic, a member of the family Dryinidxe. According to Kornhauser (1919) its host is Thelia bimaculata, one of the largest and commonest of the Membracidx found in north-eastern America. The parasite usually lays a single egg in each host, selecting individuals which are in a nymphal instar. The full details of the polyembryonic process are not given, but it is evident, from Kornhauser's account, that a trophamnion is present surrounding the developing polygerminal mass. The latter becomes converted into branching chains of embryos which ultimately result in the production of about 50 parasites. When the larva become fully grown, the host is either in its last nymphal instar, or has become an adult, and is killed as the result of the larva boring their way out to pupate beneath the soil.

Certain features of the polyembryonic process require further mention, viz., the origin of polyembryony, the function of the embryonic membranes, and the significance of mixed broods of parasites.

Origin of Polyembryony. Among parasitic Hymenoptera polyembryony occurs where the eggs are immersed in a fluid 
medium-either the blood or gut contents of the host-and, as will be mentioned later, a certain amount of the fluid is absorbed to nourish the developing embryos. As development proceeds and the embryonic area becomes enclosed in a cavity within the trophamnion, fluid accumulates in the narrow intervening space (Fig. 90, C). It is possible that, owing either to the osmotic action of this fluid or to pressure exerted on it during growth of the egg, the embryonic mass becomes constricted with the result that it finally becomes separated into two groups of blastomeres, each capable of development into an individual parasite. The simple condition described in Platygaster hiemalis appears to be explainable on this hypothesis and that the more complex cases of polyembryony are highly specialised phases derived from it. Marchal lays stress upon the influence of relatively sudden changes of osmotic pressure in promoting embryonic dissociation, and points out that a parallel is afforded by the experimental results obtained by Loeb and by de Bataillon with the eggs of sea urchins and of the lamprey. By using fluids exerting different degrees of osmotic pressure, they were able to induce separation of the blastomeres and their development into distinct individuals.

The Embryonic Membranes. In recent years many instances have been brought to notice, among endoparasitic Hymenoptera, in which the embryo is surrounded by a cellular membrane. Its existence has been observed in members of all the main parasitic groups, but in some cases only in its last stage as a remnant still attached to the newly hatched larva. Authors have variously referred to it as the trophic membrane, trophamnion, amnion, serosa or pseudoserosa. Its method of origin, however, has only been determined in a few instances, and there appears to be little doubt that it is not the same in all cases. The fact that an embryonic membrane of this type is developed in eggs very deficient in yolk, or almost devoid of it, has led to the conclusion that it plays an important part in nourishing the developing embryo. It is believed to absorb and elaborate food material from the host tissues and act as a means of transferring such products to the embryo with which it is in close association, 
hence the term trophamnion. In the eggs just alluded to the chorion is either wanting, or is shed at an early stage. The type of membrane which, as already described, originates from the polar area of the egg occurs in polyembryonic forms irrespective of their taxonomic affinities, and also in certain closely related monoembryonic species. In other examples an embryonic membrane is described as originating either as the result of simple delamination of the blastoderm, or by the extrusion of cellular material to the exterior, and its ultimate fusion to form a complete investment of the egg. The process of delamination is described by Henneguy (1892) in Chalcis (Smicra) clavipes and by Silvestri (1908) in Encyrtus aphidivorus and Oopthora semblidis, these three species being Chalcids. Spencer (1926) states that in the Braconid Diceretus rape the embryonic membrane is formed by the delamination or extrusion of cells from the ectoderm early in development. A unique condition is described by Silvestri (1906) in Litomastix truncatellus in which two embryonic membranes are present, viz. an outer membrane or true trophamnion, and an inner membrane formed by delamination during the morula stage of development. It is evident that the actual method of origin of the second type of envelope needs fuller investigation, but it is probable that functionally both types behave alike and their subsequent history is very much the same. The term trophamnion is best confined to a membrane derived from the polar bodies of the egg, while in those cases where the fate of the polar bodies is different, and the embryonic membrane is formed by delamination or by cellular extrusion, such a membrane may be termed a pseudoserosa. The use of the terms amnion or serosa is open to objection, since these envelopes have a different origin and significance.

Either just before, or a short time after, the larva has assumed independent existence the embryonic membrane (either trophamnion or pseudoserosa) usually distintegrates ; its cells separate apart or adhere in small aggregations and become liberated into the body-cavity of the host. Here they may continue to grow in size, but undergo evident nuclear changes, and it is probable that they usually serve as food for the growing parasitic larva. 
Both Spencer (1926) and Jackson (1928) have definitely shown that they serve this function, and in Perlitus rutilis Jackson mentions that they absorb fatty material from the host and increase notably in size ; in cases where the parasitic larva happens to die the unconsumed membrane cells increases from an original size of about $60 \mu$ to a maximum dimension of $580 \mu$.

According to Parker (1931), "pseudogerms" or dissociated fragments of the trophamnion in Macrocentris are liberated into the body-cavity of the host. They grow, and also divide by fusion, into many smaller entities and eventually they are consumed by third and fourth stage larvæ.

In some cases the membrane remains intact for a time after the young larva has emerged from the egg. In the Ichneumon Therion morio, a parasite of the caterpillars of the fall webworm in Canada, Tothill (1922) states that the embryonic membrane completely invests the first stage larva from August until the following June. He terms this phase the feeding embryo, since the young Therion grows, and absorbs the body-fluid of its host, while thus enclosed. Grandori (1911) found that in Apanteles glomeratus the whole envelope encloses the larva throughout its life. At first it is a complete closed membrane, but subsequently lacunæ form and it assumes the condition of a protoplasmic reticulum

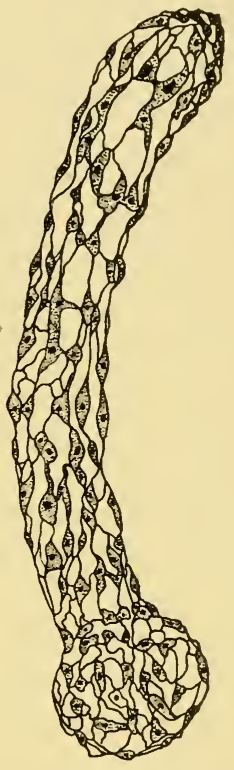

Fig. 92. Larva of Apanteles glomeratus invested by its embryonic envelope, whose cells have assumed the form of a reticulum. (Adapted from Grandori.)

(Fig. 92). When the larva is fully grown the protoplasmic prolongations break down, and the cells themselves become free, but retain their vitality up to the time the parasite bores its way out of the host.

Origin of Mixed Broods of Parasites. The factors governing the production of broods of polyembryonic parasites, containing 
individuals of both sexes, have been much discussed. Evidence points very strongly to the conclusion that an egg laid by a fertilised female gives rise to an exclusively female brood of parasites, while an unfertilised egg produces males. It has frequently been observed that among the individual parasites emerging from a host both sexes are represented, and this fact is accounted for on the basis of more than one egg having been laid originally. Giard noted that nearly 3,000 individual Litomastix may issue from a single Plusia larva; both sexes were represented, and it is certain that so large a number of parasites were not derived by the division of one egg. Patterson records instances where only a single male has been reared among broods of 919 and 1,550 individuals respectively, and it is believed by Leiby (1926) that in such cases the male resulted from a monoembryonic egg. Patterson (1919), on the other hand, believed that individuals of both sexes can, and do, develop from a single fertilised egg on the basis of Bridges' idea of somatic non-disjunction of the sex chromosomes in a fertilised egg; if certain of the blastomeres received only a single $\mathbf{X}$-chromosome those blastomeres so affected ultimately give rise to one or more male embryos. In view of the absence of cytological evidence supporting this hypothesis the first-mentioned explanation is the one generally accepted. Leiby's studies on Platygaster are based on carefully controlled experiments supplemented by microscopic examination, and it appears that a female may deposit several eggs in one host individual and mixed broods result. Some of the eggs are inseminated while others are not, and unfecundated eggs are deposited along with those containing sperms by a female known to have been fertilised. In controlled experiments with Copidosoma gelechice, in which a fecundated female was only allowed to oviposit once in each host, either pure male or pure female broods resulted. Ten broods resulting from eggs laid by virgin females were comprised of males only. His studies of various factors involved in these experiments have led him to conclude that insemination of the eggs is apparently under the control of the female, as is believed to obtain in the hive bee. 


\section{The Behaviour of Adult Parasites}

Feeding Behaviour. Little definite information exists relative to the feeding habits of many groups of adult parasites; there are a number of species which may be reared under experimental conditions, where they freely mate and deposit their eggs in the normal manner without food, owing perhaps to the exigencies of the reproductive instinct. The vast majority of the Ichneumonoidea, and probably all the Tachinidx, occur freely in the open and are very constant visitors to umbelliferous and other flowers. On the other hand, there are many parasitic Hymenoptera which never appear to frequent flowers, and probably subsist upon honey-dew and other organic material available.

A phenomenon first noted by Marchal in 1905 in the Chalcid genus Tetrastichus, and frequently recorded in other Hymenoptera by subsequent observers, is the habit of feeding upon the blood of the same, or another, individual of the species which is destined to serve as the host for the offspring. In these cases the actual feeding takes place at punctures made by the ovipositor through which the blood of the victim exudes. It is possible that nitrogenous food of this kind is necessary to ensure complete maturation of the eggs, but whether or not this is the correct explanation, the habit is prevalent in many species. The punctures may be made in the eggs, larvæ, pupæ or adults of the species attacked and, when expressly made for feeding purposes, oviposition often takes place in another individual of the same species. Not infrequently a number of individuals may be punctured in succession without any deposition of eggs taking place. Muesebeck and Dohanian (1927) are among the most recent observers of this behaviour, and they state that it prevails among nearly all the parasites of Apanteles melanoscelus, a primary parasite of the gipsy moth. The habit is sometimes so extensive that the entire fluid content of the Apanteles may be consumed, and in other instances, where oviposition has followed, the young hyperparasitic larvæ perished through insufficient nutriment being afforded by the primary parasite. These observers consider 
that the habit increases the capacity for destruction by the hyperparasites concerned, since the primary parasites thus fed upon always fail to develop. This peculiar method of feeding ${ }^{1}$ has been mainly recorded among Chalcids, with but few examples among the Ichneumonoids, and it has also been noted in Vespoid parasites of the family Bethylidæ.

In 1921 Trouvelot published observations, which were subsequently extended in a later paper (1924), upon a remarkable development of the same type of behaviour in the Braconid Habrobracon johannseni, which punctures the cocoons of its host, the potato tuber moth. It appears that in piercing the cocoon, in order to reach the moth larva within, the Braconid secretes at the same time a viscid fluid which forms into a minute gelatinous tube, thus establishing a connection between the body-fluid of the larva and the exterior. After completion of the operation, the parasite withdraws its ovipositor and applies its head to the mouth of the tube and sucks the blood of the host through this improvised fumnel. In 1921 Lichtenstein also recorded an identical method of feeding in the Chalcid Habrocytus cionicida which oviposits in pupæ of the weevil Cionus. Its ovipositor is inserted through the cocoon of the host until it enters the pupa within; the organ is retained in this position for about thirty minutes, until the secretion hardens around it, after which it is withdrawn and feeding takes place. Faure (1924) has described the same process in considerable detail with respect to two Chalcids of the genera Pteromalus and Eurytoma, which parasitise Apanteles glomeratus after the latter has formed its cocoon. He concludes that the habit is probably frequent as a method of extracting nutriment from hosts enclosed in cocoons, or in other receptacles, which offer difficulties to feeding by the more direct method already described. Other instances of this remarkable phase of behaviour are alluded to by Faure which render it unnecessary to make further mention here.

Phoresy. According to Howard (1927) P. Lesne proposed the word phoresie in 1896 with reference to cases where one animal

1 Many recorded instances are enumerated by Wheeler, The Social Insects, London, 1928, p. 52. 
acts as a vehicle of transportation to another, and this term in its anglicised form, phoresy, as suggested by Howard is adopted here. The habit has so far been little investigated and appears to be mainly developed among parasites, where it is evidently an adaptation enabling them to obtain access to their hosts. Several examples are instanced by Ferrière (1926), which are quoted along with certain others in the article by Howard just alluded to. It is well known that the triungulin larvæ of certain blister beetles attach themselves to the legs and hairs of bees in order to reach the nests of these insects, where they complete their transformations. Very similar habits are displayed by the Chalcid Schizaspidia studied by Clausen (1923), whose primary larvæ, or planidia, attach themselves to the legs of passing ants and are carried by them to their nests, where they become parasites of the brood (vide also p. 334). Phoresy, in the case of adult parasites, is a recent discovery of particular interest in that it leads to the beginning of parasitism by the imago. Certain Scelionid egg-parasites of Orthoptera attach themselves as adults to female grasshoppers and remain until those insects deposit their egg-masses, whereupon the parasites utilise the latter as hosts for their own eggs. An advanced type of similar behaviour is described by Chopard (1922) with reference to the species Riela manticida Kieff., whose development takes place in the eggs of the common praying mantis. Upon emergence the adult parasites make their way to the mantids, upon whose bodies they settle down. In this situation they cast off their wings and lead a true ectoparasitic life, since Chopard asserts that they undoubtedly feed upon their mantid vector. In cases where the latter is a female, and has commenced oviposition, the Riela moves to the genital region in order to lay its eggs in the viscid mass of the ootheca as it is being formed. Individuals which settle upon male mantids are stated to be short-lived and perish with their hosts.

\section{Literature}

BAEr, 1920. Zeits. Angew. Ent., VI., 185.

Сhopard, 1922. Ann. Soc. Ent. Fr., XCI., 249. 
Clausen, 1923. Ann. Ent. Soc. Am., XVI., 195.

1931. Proc. Ent. Soc. Washington, 72.

1936. Ann. Ent. Soc. Am., XXIX., 201.

Clausen, King and Teranischi, 1927. Vide p. 419.

Daniel, 1932. Tech. Bull., 187, N.Y. Agric. Exp. Sta.

Evans, 1933. Bull. Ent. Res., XXIV., 385.

Faure, 1924. Rev. Zool. Agric. et Appl., XXIII., 225.

Ferrière, 1926. Mitt. Schrveiz. ent. Gesell., XIII., 489.

Flanders, 1936. Journ. Econ. Ent., XXIX., 468.

Genieys, 1925. Ann. Ent. Soc. Amer., XVIII., 143.

Grandori, 1911. Redia, VII., 363.

Haviland, 1922. Parasitology, XIV., 167.

1922A. Quart. Journ. Micros. Sci., LXVI., 322.

Henneguy, 1892. C. R. Acad. Sci. Paris, CXIV., 133.

Howard, 1927. Ent. Neres, XXXVIII., 145.

1929. Ann. Ent. Soc. Am., XXII., 341.

Imss, 1918. Quart. Journ. Mic. Sci., LXIII., 293.

Jackson, 1928. Proc. Zool. Soc. London, Pt. II., 597.

Kelly, 1914. Journ. Agric. Res., II., 435.

King, 1916. Ann. Ent. Soc. Am., IX., 309.

KorNhauser, 1919. Journ. Morph., XXXVII., 195.

Lkiby, 1926. Ann. Ent. Soc. Am., XIX., 290.

LeIB $Y^{\prime}$ and Hilc, 1923. Journ. Agric. Res., XXV., 337.

1924. Ibid., XXVIII., 829.

Lichtionstein, 1921. C. R. Acad. Sci. Paris, No. 17, October.

Maple, 1937. Ann. Ent. Soc. Am., XXX., 123.

Marchal, 1898. Arch. Zool. Exp. et Gen., Ser. 4, II., 257.

1904. Ibid., CXXVI., 662.

1906. Ibid., IV., 485.

Martin, 1914. Zeits. zviss. Zool., CX., 419.

Muesebeck, 1918. Journ. Agric. Res., XIV., 191.

Muesebeck and Dohanian, 1927. Bull. 148\%, U.S. Dept. Agric.

Pantel, 1909. La Cellule, XXVI., 27.

Parker, 1924. Ann. Soc. Ent. Fr., XCIII., 261.

1931. Tech. Bull. 320, U.S. Dept. Agric.

Patterson, 1919. Journ. Ileredity, X., 344.

1927. Quart. Rev. Biology, II., 408.

Pemberton and Willard, 1918. Journ. Agric. Res., XII., 285.

Pierce, 1910. Journ. Econ. Ent., III., 451.

Prell, 1914. Zeits. angere. Ent., I., 172.

1915. Ibid., II., 57.

SAlt, 1934. Proc. Roy. Soc. B., CXIV., 450.

1935. Ibid., CXVII., 413.

1936. Journ. Exp. Biol., XIII., 363.

1937. Proc. Roy. Soc. B., CXXII., 57.

Silvestri, 1904. Redia, II., 68.

1906. Ann. R. Scuola Agr. Portici, VI., 1.

1908. Boll. Lab. Zool. Gen. e Agrar., Portici, III., 29.

1915. Ibid., X., 66.

1919. Ibid., XIII., 70.

Smin, H. S., 1912. U.S. Bur. Ent., Tech. Ser. Bull. 19, Pt. IV.

1929. Bull. Ent. Res., XX., 141.

Spencer, 1926. Ann. Entom. Soc. Am., XIX., 119.

Strickland, 1923. Dept. Agric. Canada, Tech. Bull. 26 (N.S.).

Thomsex, 1927. Vidensk. Medd. fra Dansk. naturh. Foren., LXXXIV., 73. 
'T'hompson, 1923. Ann. des Epiph., X., 137.

1924. Ann. de Parasit., II., 185, 279.

1926. Ibid., IV., 111, 207.

1928. Parasitology, XX., 123.

1934. Ibid., XXVI., 378.

'Thompson and Parker, 1927. Ibid., XIX., 1.

Thorpe, 1931. Proc. Zoo. Soc., 929.

1932. Proc. Roy. Soc. B., CIX., 450.

1934. Quart. J. Hic. Sci., LXXVII., 273.

1936. Parasitology, XXVIII., 517.

Thmberlake, 1912. U.S. Bur. Ent., Tech. Ser. Bull. 19, Pt. IV. 1913. Journ. Econ. Ent., VI., 293.

1916. Canad. Ent., XLVIII., 89.

Tothill, 1922. Tech. Bull. 3 (N.S.), Dept. Agric., Ottawa.

Townsend, 1908. U.S. Bur. Ent., Tech. Ser. Bull. 12, Pt. VI.

Trouvelot, 1924. Ann. des Epiph., X., 1.

Voris, 1934. Trans. Acad. Sci. St. Louis, XXVIII. (8), 242.

Wadsworth, 1915. Journ. Econ. Biol., X., 1.

Walton, 1914. Proc. Ent. Soc. Washington, XVI., 11.

Webber and Schaffner, 1926. Bull. 1363, U.S. Dept. Agric.

Wheeler, E. W., 1923. Ann. Ent. Soc. Amer., XVI., 1. 


\section{CHAP'TER XIV}

\section{BIOLOGICAL CONTROL}

Biological Control of Insect Pests, p. 369. I. Parasite IntroDuctions. The Introduction of Vedalia into Califormia, p. 370; The Harvaiian Islands, p. 371 ; Later Work in California, p. 376 ; The Gipsy and Brown-tail Moths in Nerv England, p. 379 ; Other Biological Control Problems in the United States, p. 381 ; New Zealand, p. 385 ; Canada, p. 386 ; Fiji, p. 387 ; Experiments in England, p. 389.

In its natural or original habitat a species of animal or plant is ordinarily maintained in a condition of equilibrium ${ }^{1}$ by the interaction upon it of biological and other agencies. If, on the other hand, any factor or factors disturb this state of equilibrium, an animal or plant may be able to maintain a supernormal ascendancy for a variable period. Similarly, one or the other may find a home in a foreign country, affording it a favourable environment where those agencies which control it in its original habitat are ineffective or wanting. Under either of these conditions the probability is that the animal or plant, as the case may be, will multiply and spread so as to assume the status of a pest.

Among the natural agencies exercising a controlling influence upon insect life the complex of meteorological factors constituting climate is ever present. Simultaneously another complex of a biological nature is exerting its influence, and represents the sum total of the activities of bacterial, fungal and other diseases, of insectivorous birds and mammals, and of parasites and predators. The restraint exercised by these several biological agencies is known as biological control, and in so far as insect life is concerned, the influence of parasites and predators alone is of immense significance. Plant life is likewise affected by a complex of biological agencies including fungal, bacterial, and other

1 Equilibrium, in the strict meaning of the word, is not implied, but a condition involving relatively small fluctuation within narrow limits. 
diseascs, together with the depredations of those insects directly dependent upon vegetation for their sustenance. From the entomological viewpoint, thercfore, the problems of biological control may be divided into those affecting insects and those affecting plants.

The economic significance of insect parasites and predators, which live at the expense of other members of their class, has led during the last forty years to their increasing practical utilisation as natural agents in pest repression.

\section{Biological Control of Insect Pests}

Biological control of insect pests may be considered under two categories: (a) introductions of parasites into countries where they did not previously exist, and $(b)$ the utilisation of the indigenous parasites of a country. The remarkable developments which the application of this method has undergone in recent years are almost exclusively with reference to parasite introductions.

The chief principles underlying the theory and practice of biological control are outlined by Thompson (1930), and a general text-book of the subject by Sweetman (1936) has recently appeared. The mathematical theories underlying certain of these principles have been discussed by several writers, and of these the most recent are Nicholson (1933), H. S. Smith (1935), and Nicholson and Bailey (1935). The last named have brought into prominence the fact that if there is a balance in the population of a particular insect some of the factors causing mortality must be dependent upon host density and destroy a greater proportion of the individuals of a specific host when the density of the latter is high than when it is low. In the case of parasites and predators, it is assumed that they search for their hosts at random, and it is shown that the mortality which they cause will be dependent upon host density. Since climate and other factors operate irrespective of such density, parasites and predators are regarded as the main factors bringing about balance. The reader who is specially interested in this side of the subject is referred to these two papers, which form a notable contribution to the theoretical aspects. 


\section{Parasite ${ }^{1}$ Introductions}

Biological control has been notably successful in certain cases where injurious insects have become established in lands they did not previously inhabit, and have there developed into persistent pests. In such instances the noxious species have been free from the attacks of the parasites which restrain them in their country of origin. Biological control aims at restoring the condition of natural equilibrium by the introduction of the missing parasite factor. The first definite experiment of this character appears to have been made in 1873, when Planchon and Riley introduced an American predatory mite (Tyroglyphus phylloxerce Riley) into France for the purpose of endeavouring to secure a measure of natural control over the Phylloxera of the vine. Although the mite became established, no appreciable restraint over the pest resulted, and control to-day has to be exercised by other methods. In 1883 Riley attempted the control of the cabbage white butterfly (Pieris rape. L.) by importing into North America one of its chief European enemies, the Braconid Apanteles glomeratus. This parasite has become well established.

The Introduction of Vedalia into California. Biological control received its first stimulus in the subjugation of the fluted or cottony-cushion scale (Icerya purchasi) in California. In the year 1886 the Icerya became so virulent a pest in the orange and lemon groves of that state that the matter attracted national attention. Accidentally introduced on plants imported from Australia, it multiplied to a degree which threatened the industry concerned with extinction. The mission of A. Koebele, on behalf of the U.S. Dept. of Agriculture, to study the natural enemies of the fluted scale in its original habitat has often been recounted. Suffice to say, he discovered in the small Coccinellid beetle, Vedalia ${ }^{2}$ cardinalis, an extraordinarily efficient predator. Its successful transmission from Sydney to Los Angeles was speedily followed by its liberation in the open, and in less than five years the Icerya was so completely destroyed that the survivors became

1 As a convenience, the word "parasite" is often used in this chapter in a general sense which implies both parasites and predators.

2 Now known as Rodolia cardinalis. 
numerically insignificant. The entry of the Icerya into other regions of the globe subsequently led to the introduction of the predatory beetle into Florida, the Hawaiian Islands, New Zealand, South Africa, Portugal, Italy, Syria, Egypt, the South of France and Malta, with the same satisfactory results.

The remarkable efficiency of the Vedalia is to be ascribed to a combination of biological features. The insect is very active both as larva and adult, which easily seeks out the sedentary fluted scales on the trees. Also, it has at least two generations in the time its prey is passing through but a single generation. Furthermore, the Vedalia appears to be free from natural enemies of its own, an important and remarkable fact. The rapid and complete establishment of the Agromyzid fly Cryptochatum iceryce, which was introduced from Australia along with the Vedalia, has also proved an important factor in the control of the cottony-cushion scale. It has become evident that the success of the Vedalia cannot wholly be dissociated with the activities of this fly. The widespread publicity accorded to the success of the Vedalia experiment was, in a sense, a pit-fall for the growers, who soon came to believe that the expense involved in insecticidal treatment against other pests was no longer necessary; all that was required was to obtain the natural enemies of a pest and subjugation of the latter would follow. As Howard remarks, by blinding people to other and assured methods of repression, the predominant success of the Vedalia actually retarded the general progress of insect control in California.

The Hawaiian Islands. The sugar planters of these islands have set an example to the rest of the world in the reliance they have placed on the application of scientific knowledge to the cultivation and protection of their crops. Among the severest factors they have had to contend with have been the insect enemies of cane. The latter are almost entirely immigrant species which have become established in the Islands unaccompanied by parasites or predators, which control them to a large extent in the lands from whence the pests originally came (Imms, 1925; Timberlake, 1927). The fact that artificial methods of repression generally proved expensive, and gave poor results, had much 
to do with the adoption of biological control. Encouraged by the early success of Vedalia in California, followed by the subjugation of the cottony-cushion scale in the Islands in $\mathbf{1 8 9 0}$ by similar means, the growers turned to biological methods of relieving them of the immense damage wrought in the cane fields by the leafhopper Perkinsiella saccharicida. The introduction in 1905-1906 by Perkins and Koebele of Paranagrus optabilis Perks. from Queensland, and of Ootetrastichus beatus Perks. by Koebele from Fiji, led to a rapid decline in the damage occasioned by the leafhopper. Both these insects are small Chalcids attacking the eggs of their host and, valuable as they proved to be, they scarcely gave the degree of control required by the growers. It became evident that some robuster type of leafhopper enemy was needed which would, at the same time, withstand the bad conditions occasioned by heavy rains. In 1920 Muir introduced the predaceous Capsid bug Cyrtorhinus mundulus (Bred.) from Fiji and Queensland. The habits of this insect are exceptional in that it preys upon the eggs of the leafhopper, whereas other Capsidæ are almost exclusively plant-feeders. Muir's observations showed that the habit was a fixed one, and the possibility of its varying its behaviour under new surroundings and becoming a plant pest was happily not fulfilled. After some difficulty the insect became securely established in the Islands, and it is now generally conceded that the Cyrtorhinus has completed the subjugation of the leafhopper. The latter, which was once so abundant and so destructive, requires searching for in the cane fields to-day.

Muir's success with the Cyrtorhinus followed his long journeys in the Orient for the purpose of investigating other sugar cane pests. The cane borer weevil Rhabocnemis obscurq (Boisd.) was one of the pests which demanded a measure of control. Search for the weevil in Southern China, the Malay States, Java and other of the East Indian Islands brought no success, but eventually Muir found the insect in Amboina, and furthermore discovered that it was attacked by the Tachinid Ceromasia sphenophori Vil. Difficulties in transporting living material of the fly to Honolulu proved too great, and it became necessary to discover some other locality from whence it would be easier to effect shipment. After 
visiting Ceram, Muir proceeded to New Guinea, which yielded both the weevil and its parasite. Owing to the shortness of the life-cycle of the Tachinid and difficulties attending the breeding of it in small cages, it was found desirable to establish intermediate breeding stations in Australia and in Fiji. After further difficulties and delays a supply of parasites reached Fiji and sufficient stock was bred from them to be conveyed to Honolulu. The first examples reached Oahu in 1910, and by 1913 the Tachinid was firmly established in the Islands, and noticeable reduction, not only in the number of borers in the field, but also in loss of the crop harvested, resulted. At the present day it would seem that the Tachinid has attained its maximum efficiency, and Swezey (1928) states that losses from the borer are negligible over the greater part of the sugar cane area. In certain districts, which have heavy rainfall and high winds coupled with a varicty of cane that lodges, the effectiveness of the Tachinid is much less marked. In such areas the borer gains the ascendancy, and notwithstanding efforts made in other lands to discover further enemies of the borer beetle, the Tachinid remains as its most efficient controlling agency (vide Williams, 1931).

In the case of the Lamellicorn beetle, Anomala orientalis (Waterh.), a remarkably complete degree of control has been achieved. It was probably introduced along with potted plants prior to 1910, but fortunately the infestation had only assumed local proportions before it was checked. When abundant this species nearly, or quite, kills out the cane, and was causing an annual loss of $£ 10,000$ to two plantations. Attempts were made to control the beetle by various parasites, but success was not achieved until Muir obtained the solitary wasp Scolia manilice Ashm. in the Philippines. Introduced in 1916, it increased so rapidly that within two years the damage caused by the Anomala was reduced to a remarkable extent. The Scolia appears to have effectively checked the spread of the beetle and there are now only occasional local outbreaks, not of a very serious character.

Another remarkably complete example of biological control within a short interval of time is afforded by the avocardo mealybug (Pseudococcus nipce Mask.) which affected, besides 
avocardo, fig, mulberry, guava, coconut and other trees. Through the efforts of H. T. Osborn, the Encyrtid parasite Pseudaphycus utilis Timb. was introduced from Mexico into Oahu in 1922. In about two years the mealybug has been practically exterminated and the rapidity of spread and the completeness of the parasitism exercised by this Chalcid have been truly remarkable.

The army worms Cirphis unipuncta (How.) and Spodophera mauritia (Boisd.) have been troublesome for many years, especially in sugar plantations adjacent to grass land. A number of parasites have been introduced from time to time until the army worms were well controlled. Outbreaks to-day seldom occur in most of the Islands, and not so often, or so extensively, on the island of Hawaii, where they have been the most prevalent (Swezey). The introduction of the Chalcid Euplectrus platyhypence How. and the Tachinid Archytas cirphis Cur. by H. T. Osborn from Mexico in 1923 and 1924 had much to do with achieving this result. Several other parasites, including the egg-parasite Telenomus nawaii Ashm. from Japan, were also contributing factors.

The Mediterranean fruit-fly, Ceratitis capitata Wied., was discovered in the Islands in 1910, and had probably made its entry a year or two previously from Australia. It spread rapidly and severely attacked nearly all kinds of fruits of importance, excepting banana and pineapple; peach, mango and guava were the worst infested, and sound fruits of these kinds became hard to obtain. In 1912 Professor F. Silvestri was engaged by the Hawaiian Board of Commissioners of Agriculture and Forestry to search for fruit-fly parasites. Silvestri mainly concentrated his efforts in Africa, but also visited Australia, and of the species of parasites he brought to Honolulu, the Braconids Opius humilis Silv. from South Africa and Diachasma tryoni Cam. from Australia became effectively colonised. In 1914 the Territorial Government commissioned D. T. Fullaway and J. C. Bridwell to visit West Africa in order to endeavour to obtain other parasites. The result of their efforts was that the Braconid Diachasma fullawayi Silv. and the Chalcid Tetrastichus giffardianus Silv. were successfully established. All four of the above-mentioned species are now widely distributed through the Islands, and on an average from 
$36 \cdot 2$ per cent. to $56 \cdot 4$ per cent. of the fruit-fly larvæ are parasitised. It is recognised that, although a sufficiently high degree of control from the commercial standpoint has not been obtained, the parasites have decreased the infestation to a marked extent. While coffee cherries and guavas have been largely freed from infestation, other fruits, like the mango, which have a thick pulp, are much more severely attacked, since the parasites are unable to reach many of the Ceratitis larvæ within them. With the object of effecting a more adequate measure of biological control of this insect, entomologists are now engaged in studying the possibility of further parasite introductions to this end being effected from abroad.

It would require too much space here to recount all the examples of biological control attempted or achieved in these islands : a chronological list of them up to about 1930 is given in the book by Williams (1931). At the present time the horn-fly pest of cattle is still uncontrolled, and the same applies to the pineapple mealybug, and some other pests. It must not be assumed that success in biological control in these Islands has come easily, or that every beneficial insect introduced has become established in its new surroundings. A history of the subject would have to record a number of failures, and the expenditures of strenuous effort and large sums of money. Thus, the complete control of the cane leafhopper only resulted after the introduction of about a score of different parasites and after about twenty years of work. On the other hand, the control of the Anomala beetle and the avocardo mealybug was achieved in a remarkably short interval of time.

Viewed as a whole, biological control has achieved a degree of success in the Hawaiian Islands not so far attained elsewhere. The majority of the important pests have become subjugated by this method, and there is little necessity for the application of insecticides. At the same time it must be remembered that the limited area of the terrain, its isolation, and its warm, equable climate, all favour measures of this character. Beneficial insects can be introduced at almost any time of the year, and are able to pass through uninterrupted cycles of development owing to the absence of a dormant season. It is true that such conditions conduce to the multiplication of pests, but they are at least as favourable to parasites and predators. Furthermore, the unique 
character and simplicity of the indigenous fauna with its paucity of hyperparasites and other competing forms, provide a biological association exceptionally favourable to the introduction of beneficial species which meet with but few obstacles in the struggle for existence.

Later Work in California. Following the introduction of Vedalia cardinalis, already alluded to. biological control in

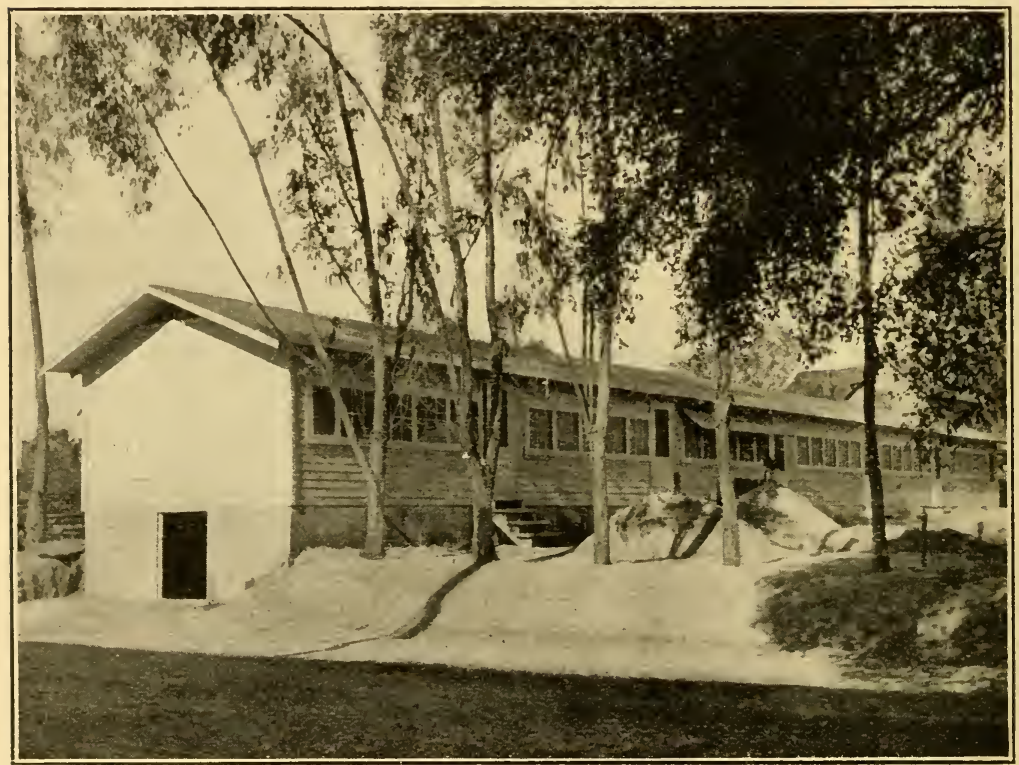

F1G. 93. A typical insectary used for rearing Cryptolcemus. San Gabriel Valley Pest Control Association, Lamanda Park, California. (Photo supplied by courtesy of Professor H. S. Smith.)

C'alifornia had, for a time, a somewhat chequered record. Grave mistakes were made by unscientific enthusiasts, large sums of money expended with no appreciable results, and world travel undertaken by agents of the State with disappointing consequences. But as H. S. Smith remarks (1926), this is past history, and the enthusiasm of the public for biological control is now tempered by a far better knowledge of its limitations. The worst pests of the citrus groves are Coccidr, and following the control of the 
Icerya scale, mealybugs (Pseudococcus spp.) next demanded attention. The introduction of the Coceinellid Cryptolcemus montrouzieri by Koebele from Australia about 1892 is familiar to entomologists, and the most interesting feature respecting this predator is the fact that in areas where it has been unable to maintain itself, it can be induced to dominate its prey by continuous laboratory breeding and distribution. It seems eertain that the citrophilous mealybug ( $P$. gahani Green), a citrus pest of first importance, has been largely kept under control by this method. There are a number of special insectaries (Fig. 93), located in infested counties or districts, which are given over to the rearing and distribution of the Cryptolcmus, an enterprise which has been developed on a commercial basis (vide Smith and Armitage, 1931). In these structures the mealybugs are reared on shoots of potato previously sprouted in the dark, and when a sufficient supply of the host is available the Cryptolcemus is introduced and allowed to multiply freely under favourable conditions of constant temperature. During 1924, 4,038,238 Cryptolcemus were reared and distributed at an inclusive cost of $\$ 48,750$, and the total citrus area infected with mealybugs was approximately 20,000 acres. In comparison with this method it has been pointed out that the cost of a single spraying for that acreage would amount to about $\$ 200,000$, and several spray applications per year are necessary, in order to ensure control of the pest. Notwithstanding the destruction exercised by the Cryptolcmus, the citrophilous mealybug has steadily increased its range in Southern California; in 1928 the infested area increased to about 50,000 acres, and some $40,000,000$ of the predators were being bred for distribution. Believing that the efficacy of biological control would be strengthened if additional enemies, especially internal Hymenopterous parasites, were available, efforts have been made to locate the country of origin of the pest. In 1916 and 1917 Clausen explored Japan, China, Formosa and the Philippines without success. Further search was made by F. Silvestri, who was already in the Orient, in the countries visited by Clausen, and also in Indo-China and the Malay Archipelago without revealing its presence. In 1927 Compere located the insect in 
Australia, where he also discovered that it was attacked by important enemies. Of the latter two Chalcid parasites (Coccophagus gurneyi and Tetracnemus pretiosus), which were introduced along with other enemies, have proved remarkably successful. The Pseudococcus has become reduced to negligible numbers and the saving of large annual expenditure has resulted. The contention that the observed results have been due to the activities of these two species of parasites is based upon the fact that, without exception, the presence or absence of serious infestations has been positively correlated with the absence or presence of the parasites referred to (Compere and Smith, 1932). The outcome has been that the Cryptolamus has now become relegated to second place and its propagation no longer has its former importance.

Among other mealybug parasites that have been introduced into California the Chalcid Leptomastidea abnormis (Gir.) is noteworthy. Established in 1915 from stock colonies obtained in Sicily, this insect has played an appreciable part in the reduction of Pseudococcus citri. Attempts have also been made to augment its effectiveness by mass breeding in the county insectaries referred to, and over one million examples were liberated in 1924 . In 1922 the Coccinellid Scymnus bincevatus was successfully introduced from Cape Town, and is now an accessory in the control of Pseudococcus gahani. The most important of all Californian citrus pests is the black scale (Saissetia olece) and the biological control of this insect is one of the main projects of the Citrus Experiment Station at Riverside. The ladybird Rhizobius ventralis, introduced by Koebele many years ago, and the Chalcid Scutellista cyanea brought in from South Africa in 1902, destroy great numbers of this scale insect, but their combined activities fail to exercise the standard of control demanded by the growers. In 1919 the Chalcid Metaphycus lounsburyi was introduced from South Africa, and it has since become well established in the coastal zone of the State. In this region the life-cycle of its host is such that the phases of development, upon which the Metaphycus is able to breed, exist at all seasons of the year. On the other hand, in the interior of the State, owing to different climatic 
conditions, the necessary phases of the host are not available for many months, and the parasite consequently becomes scarce. After a few years, wherein this parasite effected marked control of its host, its activities became largely neutralised by the secondary parasite Quylea whittieri. Notwithstanding the combined activities of the entomophagous insects already mentioned, together with others of lesser importance, the black scale maintains its rank as the worst of citrus pests.

The red scale (Chrysomphalus aurantii) and the purple scale (Lepidosaphes beckii) likewise have not so far been subject to satisfactory biological control. In 1925 a search for further parasites of the first-mentioned species was undertaken on behalf of the State by F. Silvestri in China. Various new parasites and predators were located, and shipments made to California, but owing to the civil war and other circumstances work in the Orient has had to be discontinued for the time being.

For detailed information respecting the application of biological control in California, and the various hosts and their parasites that are involved, reference should be made to the work by Essig (1931).

The Gipsy and Brown-tail Moths in New England. The most prolonged and extensive campaign of biological control so far waged in any quarter of the globe is that centred round the gipsy moth (Porthetria dispar L.) and the brown-tail moth (Euproctis chrysorrhoea L.) in New England. Both insects came originally from Europe, and appeared first in Massachusetts; the gipsy moth in 1867 and the brown-tail in 1897. Some twenty years elapsed before the gipsy moth developed into a serious pest, and it was not until 1905 that any campaign was formulated for introducing natural enemies of either of these insects. Previous observations had shown that the aggregate effectiveness of indigenous parasites in controlling these species was wholly insignificant. On the other hand, both species were found to be heavily parasitised in Europe, and it seemed further evident that whatever degree of restraint is exercised by natural enemies in Europe, it is the result of a sequence of species attacking the eggs, larvæ and pupæ respectively. Through efforts initiated by 
L. O. Howard, the work of parasite introduction has now gone on for about twenty-five years, and after exploring European countries Federal entomologists have also directed their attention to Japan. Some 47 species of parasites and predators have been brought into the United States, where many millions of individuals have been reared and liberated (Burgess and Crossman, 1929). This vast experiment is governed by the contention that only the strongest possible sequence of enemies is likely to exercise any appreciable influence over the pests in question now that they are so firmly established. Continuous effort is consequently being made to assemble all likely parasites from whatever country the hosts inhabit. Up to 1929 fifteen species of introduced parasites had become established in New England, and of these the following are now abundant : the beetle Calosoma sycophanta $\mathrm{L}$., a predator of the larva and pupse; the Tachinid parasites Compsilura concinnata Meig. and Blepharipa scutellata R.D., and the Braconid Apanteles melanoscelus Ratz., which attack the larva; and the Chalcid egg-parasites Anastatus bifasciatus Fonsc., and Schedius kuwance How. It is extremely difficult to evaluate the effects of these parasite introductions, owing to the existence of a number of other controlling agencies. Among the latter climatic variations, wilt disease, the reduction of favoured shade trees, arsenical spraying, and the wholesale destruction of egg-clusters, all have to be taken into account. It is noteworthy that the average collective parasitism was at its highest in 1923, and in the summer of 1924 gipsy moth infestation reached its lowest level for twenty years. Since then a decline in parasitism has been observed, and in several parts of the infested area this has been followed by increased abundance of the pest. Fluctuations of this character will most likely recur periodically, and at present there is no reliable indication as to whether the gipsy moth or its enemies will uitimately gain control. Those who are inclined to believe that parasite control has been a failure in this particular instance are in the difficult position of having to prove that the infestation to-day would not have gained materially, either in intensity or distribution, if parasite introductions had not been made.

The brown-tail moth, on the other hand, gives every indication 
of tolerably successful control, and it now only occurs in destructive numbers in limited areas. This result is credited to the establishment of a more effective sequence of parasitism, but owing to the multiplicity of other factors involved absolute proof of the contention is scarcely attainable.

Other Biological Control Problems in the United States. Among noxious insects which have accidentally entered the United States in recent years, the alfalfa weevil, Hypera variabilis Hbst. (Phytonomus posticus Gyll.), the European corn-borer, Pyrausta mubilalis Hübn., Oriental fruit moth, Cydia molesta Busek., and the Japanese beetle, Popillia japonica Newm., are especially noteworthy. They continue to increase and spread to a degree which affords conclusive evidence of their escape from effective control. As W. R. Thompson observes (1928), the only factor present in the native home of most introduced species and absent in their new terrain is the parasitic factor. The probability, therefore, is that the absence of parasites and predators is the real cause of their increase. Attempts to restore the loss of balance occasioned by the absence of the parasite factor form an important part of the programmes of control with respect to the four pests mentioned.

The alfalfa weevil appears to have been first reported in America in 1904, when it appeared in Utah; by the end of 1912 it had also invaded Idaho and Wyoming, and by 1926 it had spread into Washington, California, Montana and Nevada : since then further States have come under infestation. The introduction of several European parasites has resulted in one important species, e.g., the Ichneumonid Bathyplectes curculionis Thoms. becoming well established. During the years 1912 to 1914 liberations were made in the fields of Utah and colonisation appears to have been easily effected, although the area of dispersion remained extremely limited (Chamberlin, 1926). Later the parasite spread rapidly, and after about eight years its distribution was about coincident with that of the weevil. In 1925 it parasitised weevil larvæ to the extent of 85 per cent. near Salt Lake City, and to an even higher degree in some other places. On the other hand, it attacks only the older larvæ and is not 
uniformly effective during the whole period when these are available as hosts. Apart from Bathyplectes, only one other introduced parasite of the weevil is stated to have become properly established. Control of this pest by biological means docs not, at any rate, at present seem to afford more than an accessory measure. Cultural and other methods of control remain the most important weapon in combating it.

The European corn-borer is proving to be one of the most formidable of all foreign pests that have become introduced into North America. Discovered in Massachusetts in 1917, when it was already infesting a known area of about 100 square miles, it has since extended its range with great rapidity, and is still continuing to do so. In 1924 it had infested territories in Southern Ontario and the United States amounting to 42,773 squarc miles, and by the end of 1926 this area was increased to about 93,000 square miles. In 1934 the total area infested was stated to amount to over 312,000 square miles. Substantial commercial losses, however, only occurred in scattered districts over this wide expanse of territory. In 1919 an investigation of the status and controlling factors of the insect in Europe was commenced, and this has led to the accumulation of a large amount of ecological and other data. It appears that, with the exception of certain parts of central Europe, the corn-borer is controlled by a complex of climatic, cultural and parasitic factors, with the result that it seldom attracts attention. These several factors vary both quantitatively and qualitatively in different ecological zones inhabited by the insect, and also from year to year. In so far as parasitism is concerned, it is clear that it forms but one of the many factors operating against the corn-borer. At least nineteen species of parasites had been reared from this host up to 1928, but their relative frequency varies enormously in different regions. Thus in the vicinity of Paris an average parasitism of over 36 per cent. has been noted, but only four species of parasites are present, while in south-western France the parasites number nine species, yet their collective parasitism averages less than 15 per cent. Thompson (1928) has computed the relative importance of the different components of the parasitic factor in the control 
of the corn-borer in different zones or areas, and in a bulletin written in conjunction with H. L. Parker (1928) he remarks as follows: "Since control in any given region results from the action of all the factors working together, it seems reasonable to assume that the absence of any constant cause of mortality will ordinarily disturb the natural equilibrium, and permit an inevitable, though perhaps gradual, increase in numbers from generation to generation until great economic injury results." The introduction of parasites of the corn-borer has been in progress since 1920. European shipments are received at the special laboratory located at Arlington (Mass.), where stocks are bred up in sufficient numbers prior to liberation. At the present time no imported parasite is sufficiently numerous in the field to be an appreciable factor in corn-borer control, but in view of the magnitude of the area to be covered a more optimistic result would be a premature expectation. It is evident, however, that from among about twenty introduced species of parasites two are of special importance, viz., the Ichneumonid Inareolata punctoria and the Tachinid Lydela stabulans (Masicera senilis). These latter show considerable promise as controlling agencies, but success in a project of this kind is a matter of continued efforts spread over what will probably prove to be a very considerable length of time.

The Oriental Fruit Moth Cydia (Grapholitha) molesta Busek. as a larva bores into the shoots and later the fruit of especially the peach. It was probably an accidental immigrant into the United States from Japan about 1913. First detected in the environs of Washington city, it has spread to every peach-growing district in the eastern states and also further west. It is common in the Ontario province of Canada and appears to be still extending its range in America. In the absence of uniformly satisfactory artificial measures of repression, biological means of control have come to the fore in recent years in regard to this pest. Notwithstanding the importation of foreign parasites, the most effective natural agent has proved to be the Braconid Macrocentrus ancylivorus - an indigenous parasite which had been previously known to utilise the strawberry leaf-roller as its host. The Macrocentrus can be bred in large numbers and liberated where 
required, and in this way it has been widely disseminated wherever it did not previously occur. It has now become to be relied upon in preference to any other natural cnemies, since it often attains 90 per cent. or more parasitism of the fruit moth larva. Its chief value is as an accessory, since artificial control usually has to be maintained also in the chief centres of infestation. The promise shown by Macrocentrus has led to its introduction into other countries where the fruit moth is prevalent, notably into Italy and Japan.

The Japanese beetle was introduced in shipments of Japanese iris in 1911, and in the course of ten years it has invaded about 14,000 square miles of territory, including the entire state of New Jersey and portions of Connecticut, New York, Pennsylvania and Delaware (L. B. Smith, 1928). At the present time, however, it covers a still wider area and has reached the Middle West, while its entry into ('anada is being closely watched. The heaviest infestations still occur in New Jersey and adjacent territory. Its chief depredations are caused by the adult beetle attacking the fruit and foliage of apples and peaches, but it also affects a great variety of other fruits, together with vegetable crops, shade trees, etc., while the larvæ, it may be added, are destructive to lawns and pastures. In 1920 work on the insect enemies was commenced in Japan, where parasites are important agents in controlling the insect. The fact that at least five species of parasites participate in reducing the abundance of the beetle in Japan led the United States Bureau of Entomology to undertake the problem of building up an ecological association of parasites similar to what obtains in that country (King, 1928). In 1922 investigations were cxtended to Korea, where the study of parasites of closely allied beetles was commenced, and later the work embraced also parasites of allied beetles found in China and India. Since this expansion has taken place, parasites have been transmitted to America from each of the countries mentioned. From among about a dozen or more possible species, those established in the United States up to 1927 included three Tachinids and two solitary wasps of the genus Tiphia. Of the Tachinids, Centeter cinerea parasitises the adult beetles, while Prosena siberita and Dexia 
ventralis are larval parasites. 'The two wasps, viz., Tiphia popillivora and $T$. vernalis, are ectoparasites of the beetle larvæ (Clausen, King and Teranishi, 1927). Other species of parasites have been introduced since that year, but the total area so far colonised is too restricted to warrant any definite forecast being made as to the final outcome of these biological measures.

New Zealand. In so far as forest pests are concerned the introduction into New Zealand of the Coccinellid Rhizobius ientralis from Australia in 1900 for the purpose of controlling the eucalyptus scale (Eriococcus coriaceus) has proved exceptionally successful. The eucalyptus leaf weevil (Gonipterus scutellatus) is now present in greatly reduced numbers in the North Island owing to the activities of the Mymarid Anaphoidea nitens which was introduced from Australia in 1927. The golden oak scale (Asterolecanium variolosum) is stated to be under adequate control in most localities owing to the introduction of Habrolepis dalmanni from the United States. The control of the "Chermes," Pineus pini, was attempted in 1932, when the Agromyzid fly (Leucopis sp.) was introduced from England, but so far no satisfactory results have been obtained. The introduction of the large Ichneumon Rhyssa persuasoria in 1928 for the purpose of controlling the wood wasp (Sirex noctilio) has apparently resulted in its becoming established, but the economic outcome of the project cannot yet be forecasted. The Cynipid Ibalia, introduced about the same time, proved a failure.

As regards fruit pests, the reduction of the cottony-cushion scale to the status of an occasional and minor pest of citrus, pear and apple by the efficacy of the Coccinellid Vedalia cardinalis is now well known. The control of the woolly aphis of apple by the introduction of Aphelinus mali from the United States in 1921 is an outstanding example of the biological method. The Aphelinus is now successfully established throughout New Zealand and its host has been reduced to the condition of a minor pest. ${ }^{1}$

1 The importance of Aphelinus mali as an agent in the control of the woolly aphis of the apple has attracted almost world-wide attention (vide Howard, 1929). In several countries of South America it is now well established, and exercising a high degree of control ; in Argentina the control is stated to have exceeded all expectations. In Italy it has been introduced from Uruguay and 
Among field crop pests the accidental establishment of Pieris rape in 1929 led to the introduction of the Chalcid Pteromalus puparum. This scheme is proving strikingly successful and the parasite is stated to be destroying over 90 per cent. of the pupæ of this butterfly.

A number of other introductions have been made for the purpose of controlling various insect pests : some of these have proved failures, but as regards the larger number of cases the process of colonisation is either too recent or not sufficiently known to warrant definite conclusions being drawn. The next few years, however, should teach much with regard to the outcome of these experiments.

Canada. The enormous damage entailed by the European larch saw-fly (Lygceonematus erichsoni Htg.) to Canadian forests led C. G. Hewitt to seek to relieve the situation by parasite introduction. In 1912-13 importations of cocoons of the saw-fly, collected in the larch woods of England, were received in Canada. The distribution of these cocoons in a heavily infested larch area in South Manitoba led to the establishment of the Ichneumon parasite Mesoleius tenthredinis Motl. Collections of saw-fly cocoons made in 1916 revealed that 19 per cent. contained the parasite, and in succeeding years the proportion steadily increased from 40 per cent. in 1919, to 66 per cent. in 1920, and again in 1926 ; while in 1927 it averaged at least 75 per cent., rising as high as 88 per cent. in some localities (Criddle, 1928). In the course of these years the parasite has withstood the rigours of the climate and spread across a patch of open prairie not less than six miles in extent to a larch swamp twenty miles across, penetrating to its utmost limits. The parasite has become well established and. according to Swaine, it has been recovered as far as 200 miles from

France, and is proving an efficient parasite, destroying its host at all seasons of the year. It has also been introduced from New Zealand into parts of Australia, and re-introduced into South Africa; in New South Wales it has become as completely successful as in New Zealand, but in South Africa it has so far proved less efficient. Introductions have also been made into France, Germany, Holland, Spain, and some other countries. Although established, it has not, up to the present, given evidence of exercising appreciable control in Germany, or Holland, while in France it appears to be rather more promising in the south than elsewherc. 
the original place of liberation. While there is no doubt that the Mesoleius has played an important part in the decline of the larch saw-fly it is possible that certain indigenous parasites have also participated in the process.

The introduction from the Imperial Institute of Entomology Laboratory at Farnham Royal, England, of the Chalcid Blastothrix sericea into British Columbia has proved strikingly successful. According to Glendenning (1933), the trouble arose in connection with the scale insect Eulecanium coryli, which had become one of the most destructive insects in the coastal region of British Columbia. The city of Vancouver constantly had to adopt oil-spraying in order to preserve its shade trees. Greater Vancouver, it appears, is now freed from an objectionable pest.

Several of the biological control projects in Canada are organised in collaboration with Federal or State entomologists of the United States. This arrangement obtains in connection with the gypsy and brown-tail moths, European corn-borer, Oriental fruit moth and other pests.

Fiji. The Zygænid moth Artona catoxantha Hamps. has been known as a coconut pest in Malaysia for many years, but it was not until 1914 that it was discovered to be affected by parasites. Subsequent observations showed that the Tachinid fly Ptychomyia remota Ald. was an important enemy of the moth in question. Out in Fiji, another Zygænid, Levuana iridescens Beth. Baker, was causing serious depredation in coconut plantations, and it led the Government of those islands to explore the possibilities of biological control. Several entomologists have been concerned in this work, and the ultimate outcome has been the successful colonisation of the Tachinid in Fiji. In the Malay States its efficacy is largely restrained by the activities of hyperparasites, but, notwithstanding this drawback, it is able to parasitise its host to the extent of 30 to 40 per cent. or more. In Fiji the Tachinid bore out previous expectations in parasitising the Levuana as readily as it affects the Artona. The fly was reported to be definitely established in 1925, when 75 per cent. parasitism of the Levuana caterpillars was being commonly attained, and even 90 per cent. was occasionally reached. The parasite has now spread to all infested parts of Fiji, 
and the control attained appears to be of a permanent nature. The whole history and the biology of the host and parasite are described in an elaborately produced book by 'Tothill, Taylor and Paine (1930).

The success achieved by the introduction of Ptychomyia led to the further application of biological methods of control in the Islands. The scale insect Aspidiotus destructor is another severe enemy of coconut besides attacking bananas, avocardo and other plants. It is not known how, or exactly when, this insect became introduced into Fiji, but several attempts have been made to control it by parasite introductions without success. It was not until 1928 that certain predators of the family Coccinellidx were introduced from 'Trinidad, where they had been observed to exercise notable control over the same host scale in that island. The Coccinellid Cryptognatha nodiceps soon proved itself superior to the other species that were introduced along with it. Only nine months after liberations were made in Fiji the scale insect was brought under control in all the more important islands of the group. In his full account of this campaign Taylor (1935) states that the scale has become reduced to negligible proportions and an apparently permanent check has been maintained upon it.

The complete success of the introduction of $C$. nodiceps is attributable to a combination of factors. First, it breeds continuously with a high rate of multiplication throughout the year in Fiji. It is a voracious predator, both as larva and adult, and in the latter phase it is long-lived. Secondly, it has remarkable powers of dispersal. Thirdly, it has no serious enemies in Fiji. Finally, the Cryptognatha is able to survive even when the Aspidiotus has become reduced to a condition of great scarcity. In this connection, the fact that it has an alternative host in another scale insect, namely, Diaspis pentagona, which is not a serious pest in Fiji, is important.

An even more recent success is that achieved in the repression of the leaf-mining Hispid beetle of the coconut, Promecotheca reichei, an account of which has been published in detail in a special volume by Taylor (1937). The introduction of the Chalcid Pleurotropis parculus from Java in 1933 led to the rapid and 
effective suppression of this pest. There is adequate reason for believing that the good results will be maintained after the manner that prevails in connection with the two previously mentioned examples. The details of the campaign and the factors involved are discussed at length in Taylor's well-illustrated monograph, to which the reader is referred. It is thus evident that the results achieved in Fiji rank among the most strikingly successful examples of biological control under restricted or islandic conditions.

Experiments in England. (1) Encarsia formosa. Several species of the Chalcid genus Encarsia are known to parasitise Aleurodidx or "White-flies" in certain parts of the world, including North America, the Orient, Africa and Barbados. The first occurrence of a member of the genus in England was in 1914, when a species, probably $E$. partenopea Masi, was noted by Fox Wilson in a tomato house at Wisley (Surrey). In $1926 \mathrm{E}$. formosa Gahan was found in a small greenhouse at Elstree (Herts.), and an account of this insect is given by Speyer $(1927,1928)$. Its country of origin is uncertain, but it appears to be a tropical species, possibly imported on plants from India. It parasitises the common white-fly Trialeurodes caporariorum (Westw.), attacking and destroying the pupæ. Under suitable conditions of temperature a number of generations can be bred under glass each year, and stocks of the insect distributed among tomato and cucumber houses have resulted in clearance of the white-fly to an extent which rendered fumigation unnecessary. Owing to its intolerance of cold, it is desirable to maintain the parasite in a specially heated house over winter, so that large numbers are available for distribution the following spring. 'The maintenance and distribution of this parasite have been undertaken by the Experimental and Research Station at Cheshunt (Herts.), and the outlook for its utilisation as a permanent measure appears to be promising. (2) Aphelinus mali. The encouraging results derived from the introduction of Aphelinus mali into New Zealand and to a lesser degree in some other countries led J. C. F. Fryer, of the Ministry of Agriculture, to explore its possibilities of controlling the woolly aphis under English conditions. In 1923 colonies 
derived from stock originally of American descent were received from France. They multiplied with great rapidity in captivity, and in 1924 liberations were made in the open in a number of widely separated localities. Notwithstanding the prevailing inclement weather, coupled with an abnormal scarcity of the host, the Aphelinus survived in certain orchards until the following year. At the present time it appears to be maintaining itself in a few places in small numbers, but without spreading or increasing to any appreciable extent (vide also Thompson, 1934). 


\section{CHAPTER XV}

\section{BIOLOGICAL GONTROL-continued}

II. Factors Governing Parasite Introductions, p. 391. Geographical Location, p. 392 ; Multiparasitism, p. 396 ; Hyperparasitism, p. 398 ; The Sequence Theory of Parasitic Control, p. 401 ; Other Factors, p. 402. III. The Utilisation of Indigenous Parasites, p. 405. -Conservation of Parasites, p. 406 ; Direct Increase of a Parasite Population, p. 407 ; Transference of Parasites to Nere Areas, p. 409. Biological Control of Noxious Weeds. Principles Involved, p. 410 ; Control of Lantana, p. 412; Control of Prickly Pear, p. 413; Control of Prickly Pear in Other Lands, p. 416 ; Control of Clidemia, p. 418 ; Problems in Nere Zealand, p. 418. Literature, p. 419.

\section{Factors Governing Parasite Introductions}

Is the foregoing section a number of the more important parasite introductions are discussed. They are by no means exhaustive, and many other experinents have been undertaken in various parts of the world. Certain of these have yielded beneficial results, but in a much larger number of cases no successful outcome has been recorded; in other instances the introduced species failed to establish themselves or the experiments were doomed to failure from the outset owing to the haphazard nature, lack of requisite knowledge and other causes.

In judging success or failure it is, of course, important to bear in mind that the primary objective is to bring about an economic reduction in the abundance of the pest concerned. If, for example, introductions are attempted with ten different species of parasites and only two of these succeed in establishing themselves, and these are effective in restraining the pest in question, the experiment has been successful. It would be wide of the mark to assert there had been eight failures, since the objective was pest control, and once this is achieved it matters little as to what becomes of the ineffective parasites. Also it needs to be pointed out that biological control aims at bringing about a permanent measure 
of pest repression ; in the most successful cases it may result in artificial methods being no longer necessary, while in others biological control may serve to supplement insecticidal or other treatment. It is only in rare instances and in the most favourable environment that almost complete suppression of a pest results, and in most cases a successful outcome is regarded as having been achieved once an appreciable degree of permanent control over a given pest has been accomplished. Thus if an injurious insect A, feeding within the stems of a cereal crop and exempt from the effects of any practicable artificial method of control, is affected by biological measures to an extent of reducing the damage which it occasions by an average of 20 per cent., taken over a period of years, few would assert that the experiment was not justified. Or again, if a scale insect $B$, infesting fruit trees to an extent which demands spray treatment several times annually, is reduced by biological control so that spraying becomes necessary, on average, only once every three years, immense benefit will have resulted to growers in the saving of expenditure incurred.

It is desirable at this point to discuss the more important factors and principles which have a definite bearing upon the success or failure of parasite introductions.

Geographical Location. $\mathrm{U}_{\mathrm{p}}$ to the present time some of the most spectacular and complete examples of the application of biological control have resulted from parasite introductions made under insular conditions. The successes achieved in the Hawaiian Islands, New Zealand and Fiji are examples in question. In continental areas the most encouraging results have been achieved where parasite introductions have been made, $(a)$ with respect to certain tracts which are, ecologically, separate islands, e.g., California; and $(b)$ with respect to the control of pests affecting a localised crop, e.g., citrus fruits, mulberry, etc. In the case of widespread pests affecting crops or trees whose range of distribution extends over a vast continental area, involving varied climatic and other conditions, no indubitable success has so far been achieved.

(a) Insular Areas. The most favourable type of physical and biological environment afforded by insular conditions is 
exemplified in the Hawaiian group. These conditions may be summarised as follows, and they probably hold good for most oceanic islands :

(1) Warm and equable climate allowing parasites to multiply unchecked by seasonal factors.

(2) An indigenous fauna of a peculiar and restricted character, evolved as the result of long isolation. Introduced parasites meet with relatively little competition from indigenous forms, and the parasitic element is but poorly developed.

(3) The area to be covered by parasite colonisation is circumscribed and, as there are only few main crops, adequate organisation and centralisation of control experiments are greatly facilitated.

In most islands of continental origin parasite introduction has to contend with a different type of environment. In Trinidad, for example, conditions (1) and (3) hold good, but (2) is entirely different. Owing to the geological formation of the island, and its close proximity to the mainland of South America, the fauna is essentially that of the neighbouring continent. Introduced parasites consequently have to contend with a high degree of environmental resistance of a biological character. Among a fauna already rich in the parasite element new introductions, if they are to be effective from the economic standpoint, require to be species capable of forcing their way into and exerting influence in already complexly adjusted biological associations. On the other hand, in New Zealand, although (1) is far less ideal than in Hawaii, the climatic conditions are more favourable than those from which the introduced pests have come, and from where parasite introductions have been made. Condition (2) has many characteristics of an insular fauna, and although rich in many dominant groups of insects, other groups are wanting or but poorly represented in New Zealand, and the indigenous parasite and hyperparasite element is not highly developed.

In New Zealand there are, for example, according to Tillyard, no indigenous Thysanoptera, only thirteen species of Odonata, and the same number of Neuroptera; Hemiptera number about 300 species (Australia 1,970), and Hymenoptera include 316 species (Australia 
6,250). It is further noteworthy that among the Hymenoptera there are only two species of saw-flies, and less than 250 species of the parasitic groups. The paucity of the latter is well emphasised by comparison with Great Britain, where there are about 1,500 species of Chalcidoidea alone.

In Great Britain none of the three groups of conditions previously mentioned appears to favour parasite introduction. A variable, and on the whole, cool humid climate; a complex and highly adjusted continental insect fauna; and a diversity of crops and cultural methods all appear to militate against the possibility of any striking economic results being achieved through the application of biological control. An environmental resistance of this character has stood the country in good stead, since it is almost free from introduced insects affecting agriculture. It is evident, therefore, that parasite introductions would naturally have to be framed to cope with one or other of the major indigenous pests. In the future it may be found feasible to explore the possibilities of north temperate countries with this object in view.

(b) Localised Continental Areas. Biological control in continental areas has proved successful in certain cases where the crops involved occupy more or less circumscribed tracts of country and require climatic conditions of a warm and equable nature. This applies especially to mulberry cultivation in Italy and to the cultivation of citrus fruits in various parts of the world. These same conditions, it would appear, favour parasite introductions, and a partial explanation may be found therein of the success attending the importation of Prospaltella berlesei and of Vedalia cardinalis into many countries. The effective control exercised by Aphelinus mali has so far only been evident under continental conditions in areas of a more or less localised character, areas where the climate is favourable and apple cultivation is prosecuted on a large scale. ${ }^{1}$

The successes achieved in California are to be ascribed to a combination of special conditions. Bounded partly by the Pacific Ocean and partly by barriers of mountain and desert, the

1 As mentioned previously, other contributing factors appear to be the rapid multiplication of the parasites in question, and the fact that they attack hosts which are largely sedentary in behaviour. 
State is physiographically isolated to an exceptional degree. Much of the country was originally desert, and has been brought under cultivation through the development of irrigation, which has established sub-tropical conditions in its southern territory. The insect fauna in such parts is consequently largely introduced and built up of immigrants from adjoining territory with certain accidental importations from abroad. Compared with the rest of the continent, the climate is wonderfully equable in the long tract of country between the mountains and the sea. The area where parasite introductions have been made covers the zone of citrus cultivation in the south, which is exceptionally uniform ecologically and circumscribed by physical conditions.

Conditions apparently analogous to those found in California occur in other parts of the world. As Tillyard has observed, Australia is made up of a number of diverse areas separated from each other by mountain barriers or great stretches of desert. Looked at from this point of view, Western Australia, the elevated apple lands of South Queensland and other parts, should offer favourable conditions for the application of biological control. Egypt, limited as it is by desert and sea, Mesopotamia, Palestine and other lands would also appear to afford ideal conditions for parasite introductions, provided judicious selection, based upon sound preliminary investigation, be exercised (vide also Myers, 1928).

(c) Wide Continental Areas. Biological control applied to imported pests menacing crops widely distributed over vast continental areas has to contend with manifold difficulties. Competent investigators have expressed serious doubts whether the method is likely ever to prove really efficient under conditions of this character. The United States suffers more than any other region of the world from the depredations of pests now disseminated over immense tracts of territory. In the case of the gipsy and brown-tail moths parasite introductions have been going on for over a quarter of a century. More recently attention has also been directed to the alfalfa weevil, the European corn-borer and the Mexican bean beetle. The corn-borer, for example, now infests well over 300,000 square miles of territory, while the areas 
covered by the alfalfa weevil and Mexican bean beetle are already of great extent.

The problem of parasite introduction in continental areas is discussed by Thompson (1928), who points out that the effects which follow the establishment of foreign pests in such areas constitute a clear demonstration of their escape from control. The evidence indicates that the factor whose absence has allowed of increase and spread is the parasitic factor. In any attempt to establish equilibrium over so vast an area, he is of opinion that we have to rely upon biological methods if permanent and inexpensive control is to be hoped for. Under such conditions no one parasite or predator is likely to effect appreciable control. With the European corn-borer the parasitic enemies do not exist all together in any individual zone yet discovered in Europe. The composition of the parasitic fauna differs in every region, and in view of the differences of climate obtaining over the great area of North America affected by this insect, it is most probable that only a limited quota of the introduced parasites will colonise a given zone. In order to establish the best results, species of parasites failing to become colonised should be reintroduced as the corn-borer reaches new areas differing climatically from those now infested. ('Thompson and Parker, 1928.) In other words, re-establishment of natural equilibrium appears to stand the best chance of being accomplished on an ecological basis.

Multiparasitism. The factor of a multiparasitism is discussed on p. 322, and a well-known example is afforded by the parasites of the Mediterranean fruit-fly (Ceratitis capitata Wied.) in the Hawaiian Islands (p. 374). When first introduced, the Braconid Opius humilis Silv. was the most efficient of the imported enemies of this insect. In 1915 it parasitised 31.5 per cent. of all the Ceratitis larvæ developing in fruits about Honolulu ; since then its efficiency has declined, and in 1923 it was as low as $4 \cdot 1$ per cent. In 1924 and 1925 its effectiveness increased, when it parasitised 14.5 per cent. of the larvæ each year. Among coffee cherries in Kona the Opius parasitised from 59 to 97 per cent. of the fruit-fly in 1915 , but its effectiveness gradually declined, and in 1926 not a single example was reared from the larva from 18,955 coffee cherries 
(Willard, 1926). Its decline has been traced to the fact that $O$. humilis frequently occurs within the same individual host larva, which is also harbouring either of the other Braconids, Diachasma tryoni Cam. and D. fullawayi Silv. When this happens the multiparasitism invariably results in the death of the Opius.

The view has been expressed that had the biology of these parasites been fully studied prior to their liberation, their mutual relations would have been disclosed and the desirability of liberating $O$. humilis only, in the first instance, might have been apparent. It is possible, therefore, that this single species of parasite might

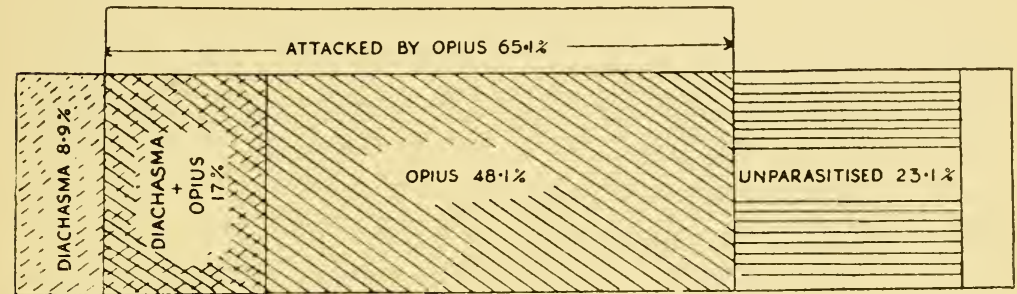

ATTACKED BY DIACHASMA

$25.9 \%$

Fıg. 94. Diagram representing multiparasitism, showing percentages of hosts attacked and destroyed by Diachasma and Opius and percentage of overlaps, which in most cases produced Diachasma. From data of Pemberton and Willard. (After H. S. Smith, Bull. Ent. Res., XX., 1929.)

have proved more efficacious than the combined activities of the four species already liberated.

H. S. Smith (1929) has critically analysed this problem and concludes that it is far from proven that the effects of the multiple parasitism would have been less beneficial than the activities of the Opius alone. He stresses the superior "balancing " effect of several species of parasites over a single one in that they are not all likely to suffer to the same degree from deleterious factors. Several species would tend to stabilise a parasite population, whereas a single species would tend to fluctuate in efficiency annually. In Fig. 94 one phase of the problem is represented graphically, and Smith claims that even if the $\mathbf{1 7}$ per cent. of the 
puparia affected by multiparasitism were attacked by the Opius alone, it is very uncertain whether it would have raised the efficiency of the latter to more than 65 per cent.

Hyperparasitism. The incidence of secondary parasites attacking a primary parasite of an injurious insect has a very definite bearing upon biological control. There is direct evidence that the efficiency of certain introduced parasites has been enormously reduced or even nullified by the activities of secondary parasites. The perplexing and involved problems centred around the interrelations of hyperparasites and their different hosts have already been alluded to (p. 327), but in illustration of their practical bearing certain concrete examples may be quoted. A primary parasite of one species of insect may function as a secondary parasite of another, as is well exemplified by the Chalcid Monodontomerus areus Walk., which was introduced into the United States in connection with the control of the gipsy and brown-tail moths. Although a primary parasite of the pupæ, and especially those of the brown-tail moth, it has also proved to be a secondary parasite. Among imported primary parasites which this species utilises as its hosts are the Braconid Apanteles lacteicolor and the Tachinid Zygobothria nidicola. This dual behaviour has rendered it extremely difficult to determine whether its occurrence as a secondary parasite outbalances its value as a primary agent in control. Another example is afforded by Schedius kuvance How., a valuable egg-parasite of the gipsy moth, introduced from Japan. Later observations have shown that this species also behaves as a secondary parasite, since it occasionally attacks the Braconid Apanteles melanoscelus Ratz. The latter species, it may be added, is a native of Europe, and was also introduced for controlling the gipsy moth.

A striking example of the importance of hyperparasitism is to be found in California, where the Chalcid Metaphycus lounsburyi was introduced from South Africa for purposes of controlling the black scale of citrus fruits (p. 378). This introduction gave promise at first of an almost complete control of the scale insect in the coastal areas. Gradually, however, its efficiency has become checked by a secondary parasite, Quaylea whittieri (Gir.), 
which had been introduced at an earlier date and without adequate knowledge of its host-relationships. This same hyperparasite also attacks Scutellista cyanea, and there seems little doubt that its activities constitute a most serious inhibitory factor in the achievement of adequate biological control over the scale insect in question. Although due care may be exercised in the exclusion of hyperparasites when parasite introductions are made, it is obviously impossible to guard against the contingency of subsequent attacks by indigenous secondary parasites, as has happened with certain of the parasites of the gipsy moth after their introduction into the United States.

In the Hawaiian Islands the earlier attempts to control the sugar cane leafhopper involved the introduction of various species of Dryinidæ. These introductions proved unsuccessful partly owing to the prevalence of hyperparasites. Some of the latter were probably native species which, owing to their minute size, had previously remained undetected, while others were chance immigrants brought in from the United States. It is noteworthy that in England the common earwig Forficula auricularia (L.) is feebly parasitised by the Tachinid Digonochceta setipennis; observations conducted by A. M. Altson on earwigs collected from various localities failed to reveal more than a 7 per cent. parasitism. At the same time the Digonochota is subject to attack by the Chalcid Dibrachys cavus (boucheanus Ratz.) and by the Ichneumon Phygadeuon scaposus Thoms. In attempts to establish this Tachinid in New Zealand in the expectation that in a new and favourable environment it may prove a more efficient element in earwig control, it is important that these hyperparasites be excluded, since they are unknown in that country. On the other hand, it is problematical whether the exclusion of the Dibrachys from consignments of the Tachinid which have been introduced for earwig control into the Pacific side of North America will result in any advantage for the reason that the hyperparasite is already widely distributed over that continent.

Proper (1934) is one of the most recent writers who discusses the subject of hyperparasitism from a considerable body of evidence. In dealing with the secondary parasites of certain 
Lepidopterous larva he arrives at the conclusion that about one-third ${ }^{1}$ of the cocoons and puparia of the primary parasites are destroyed in this way. Since the Lepidopterous hosts are notable defoliators, etc., and their primary parasites are important factors in their control, the activities of the hyperparasites function to a great disadvantage. His observations support the conclusion that one of the chief causes of the reduction in numbers of the parasites imported into New England to aid in controlling the gypsy moth, the brown-tail moth and other Lepidoptera has been the activities of hyperparasites.

Taylor (1937) is of opinion that the importance of secondary parasites has been greatly exaggerated in some cases. He remarks, "Many secondaries are wholly incapable of hindering extensively the primaries which they attack, mainly because the percentage of primary individuals which they succeed in finding increases directly as the concentration of the primaries and the percentage cannot approach 100 until the primaries are already sufficiently plentiful to suppress the pest. In other cases, inferior eggcapacity, or other factors of this nature, may ensure economic negligibility in the secondaries. For these reasons it is unwise to refrain from introducing a parasite which seems otherwise desirable, and to search for another, merely because the former is certain to be attacked by secondaries which are already present. The elimination of the secondaries from the consignment of primaries introduced is an obviously desirable and usually simple precaution, but in many cases the introduction of the former would not be harmful to an appreciable extent."

The available facts lead to the conclusion that hyperparasitism is most likely to supervene where parasite introductions are made into continental areas, especially where a sequence involving numerous species is aimed at. Increasing knowledge may to some extent reduce the possibility of species liable to betray this habit being introduced. On the other hand, in view of the general behaviour and widespread activities of hyperparasites, a

1 In the case of some of the primary parasites, the average mortality, over a four-year period, was only from 5 to 16 per cent., while in others it ranged from 44 to 84 per cent. 
greater or lesser degree of influence from indigenous species will usually have to be contended with in such projects.

In insular areas, if due precautions be taken, the problem of hyperparasitism is frequently capable of circumvention, and this appears to be an important contributory factor in the successes attained with parasite introductions under such conditions.

The Sequence Theory of Parasitic Control. The sequence theory of the application of parasitic control is due to Fiske, and its practical importance has been stressed by Howard in various publications (vide Howard, 1924). The theory applies especially to the control of Lepidoptera, in which the component stages of the life-cycle differ in activity, habit, seasonal appearance, and other factors. In a state of nature such species are almost invariably attacked by a succession of different parasites affecting the eggs, larvæ and pupæ respectively. When, therefore, an insect like the gipsy moth, for example, has become accidentally established in another country the theory postulates the necessity of reproducing as nearly as may be possible its original parasite association. It is claimed that there exists a delicately adjusted condition of equilibrium between the host and each of its parasites. This involves a limitation of the activities of the latter by environmental and other factors which preclude the percentage of the hosts it destroys from rising above a certain mean figure. The theory maintains for this reason that a single species of parasite is incapable of destroying as many of a host population as is destroyed by a succession of different enemies. It is claimed that it is only when a certain percentage of the eggs have been destroyed that parasites of the larvæ will be able to reduce a given pest to a sufficient degree that the final pupal parasites will bring the species measurably under control. According to Fiske, the gipsy moth has a six-fold rate of increase per generation, and consequently a total parasitism of 88.33 per cent. is necessary in order to attain effective control.

The theory is ably criticised by Thompson (1923), to whose paper the reader is referred for the detailed arguments. He points out that insufficient evidence exists to prove that a sequence of parasites is essential to the biological control of a given pest; 
or that, if the sequence be incomplete, the pest would not be held in check. According to Thompson's view, control depends primarily upon the ratio between the respective rates of reproduction of host and parasite. If the rate of reproduction of one species of parasite is equal to, or greater than, the rate of reproduction of the host, this parasite could, in many cases, increase to the point when complete control of a host is achieved by its unaided activities. The time taken for the attainments of effective control of the host by the parasite will depend, not only upon the reproductive ratios just mentioned, but also upon the ratio between the number of individuals of a parasite introduced and the number of individuals of the host at the time the introduction is made. Thompson concludes that, although there are cases where the percentage of parasitism of a given species may never rise above a certain maximum, instances must be rare in Nature where all the parasites of a host are thus limited in their activities, and it will usually not be found true of most members of a parasite sequence. According to him the theory is invalid as a general theory of parasitic action, since it can only apply to a limited number of special cases. On the other hand, Thompson supports the general idea of the introduction of a sequence of parasites for a reason entirely different from the one implied by the theory. It is simply because by introducing a number of species of parasites the probability is greatly increased of selecting one whose reproductive potentialities are equal to, or greater than, those of the host concerned and which, for this reason, offers possibilities of exercising the desired degree of control.

Other Factors. Among other factors which may have a direct bearing upon parasite introductions, the following will be briefly discussed :-

1. The subject of host-parasite relationship is discussed in Chapter XIII, and little can be usefully added here. The bulk of the information relative to this factor is of an empirical nature. No means exist of predicting the results of parasite introductions for the reason that it is not possible to forecast with any certainty how a particular parasite will behave towards its possible hosts 
in a new area or country. Investigations conducted in the country of origin of a parasite are of prime importance, but actual experiment alone can provide the solution of its behaviour in a fresh environment.

The introduction of a multivoltine parasite to attack a univoltine host may be selected as an example of a particular type of hostrelationship. In an eventuality of this kind success may largely depend upon the availability of other suitable hosts at whose expense the parasite will be able to maintain itself during the period when the requisite stage of the intended host is no longer in evidence. A comparison of possible hosts indigenous to the country of introduction with the known hosts in the country of origin of the parasite will obviously provide tentative information, but only experiment will determine the extent to which any forecast of this kind will be realised.

2. The effects of artificial control measures upon the progress of introduced parasites can only be studied in a broad general way when reduced to mathematical terms. No data exist which permit of this problem being considered from its experimental aspect. In the theoretical analyses given by Thompson the initial numbers of reproducing parasites and hosts present at the beginning of a given experiment, the effective rates of reproduction. and sex ratios of the two species and the proportions of each eliminated by artificial control before the period of reproduction are taken into consideration. It is shown that if artificial controlling measures eliminate at least as many hosts as parasites, precautions for conserving the latter are unnecessary. If, on the other hand, conditions are such that artificial measures of control result in the destruction of appreciably more parasites than hosts, they may exercise a disastrous effect upon the progress of an introduced parasite and delay its gaining effective control for many years. For a full discussion of the theoretical aspects of this subject the reader is referred to Thompson's original paper $\left(1927_{A}\right)$, and also to a recent paper by Clausen (1936).

3. What may be termed the time factor is of particular importance, and lack of its due recognition may lead to erroneous conclusions respecting the supposed failure of parasite activities 
in certain instances. For example, Howard (1924) mentions the case of the Hessian fly parasite, Pleurotropis epigonus, which was introduced into the United States from England in 1894. After liberation in the field this species was not recovered until twentytwo years later, and since then it has become one of the dominant parasites of its host over a large area in the eastern States. Thompson (1927) has discussed the rate of progress of introduced parasites from the mathematical standpoint and, although his conclusions are necessarily theoretical, they serve to show the bearing of the relationship between the ratios of the rates of reproduction of parasite and host, together with the initial numbers of parasite and host, and the time involved before a given parasite could exercise a dominant influence. Thus, when the rates of reproduction of parasite and host are equal and the host population is very large in relation to that of the parasite, the advance of the latter will be so slow as to be barely recognisable. Periodical field investigations may reveal the presence of the parasite, but for many years there will be no evidence of increase in its numbers. In cases where a parasite reproduces less rapidly than its host it will never subjugate the latter unless its initial population is much larger in relation to that of the host than is ever the case in any practical undertaking. In certain cases where a multivoltine parasite with a high rate of fecundity is able to attack a univoltine host, or one with a much lower reproductive rate, control has been achieved under favourable conditions in a remarkably short interval of time. This is exemplified in the case of the control of the cottony-cushion scale in various parts of the world, of the mulberry scale in Italy, and of the woolly apple aphis in New Zealand.

4. Finally, the capacity of a parasite to discover its host is a factor often overlooked and one difficult to evaluate except in a very general way. This capacity appears to be most often inversely proportional to its fecundity, and it affords examples of Nature's prodigality or economy as the case may be. When the chances of a parasite discovering its host are small, the progeny are numerous (e.g. Stylops, leaf-ovipositing Tachinidæ, etc.), and where the chances are great (e.g. Scoliid wasps) the 
progeny are relatively few in number. The cfficiency of Scolia manilice in Hawaii is largely attributed by Muir to its highly developed faculty for discovering its host. Furthermore, a fragile and minute parasite with restricted powers of locomotion may prove highly effective when hosts are abundant, but play an insignificant part in control when they are scarce. The converse would appear to be the case with certain of the more robust parasites of low fecundity.

\section{The Utilisation of Indigenous Parasites}

The relationship between a given indigenous insect and its parasites is one involving a complex condition of ecological equilibrium which, moreover, is subject to seasonal fluctuation. The component factors, together with their individual and collective effects, which govern these fluctuations, have not so far been subjected to other than the most elementary analysis, and we are hardly in a position to assert whether adequate analysis is at all possible. In the absence of fundamental information of this kind the feasibility of the utilisation of indigenous parasites can only be answered by actual experiment. It needs to be recollected that the subject involves somewhat different principles from those concerned with parasite introductions. In the latter case the building up of a condition of natural equilibrium is aimed at, whereas the utilisation of indigenous parasites is largely concerned with efforts to modify a condition of equilibrium usually already highly adjusted. In order to secure practical results it is necessary to maintain a permanently readjusted equilibrium against tendencies which are constantly operating in the opposite direction.

Suggestions have been frequently made and, in certain cases, actual attempts carried out, with a view to making use of indigenous parasites as auxiliary agents in pest control. Such operations consist either of conserving or increasing the numbers of a parasite or predator in a given area with the idea of obtaining a higher degree of control over some individual species of pests, or of attempting to colonise such enemies in an area of a country where they did not previously exist. 
Conservation of Parasites. The principle involved in parasite conservation consists of either altering the host-parasite ratio by the adoption of methods which allow of more hosts than parasites being destroyed; or, the abandonment of measures which tend to reduce the existing parasite population. The earliest application of any method directly aimed at conserving indigenous parasites appears to have been made by $F$. Decaux in 1880 with regard to the insect enemies of the apple blossom weevil (Anthonomus pomorum) in Picardy. By collecting infested or " capped" blossoms from about 800 trees and placing them in gauze-covered boxes, he claimed to have evolved a procedure far superior to destruction by burning. All that was necessary afterwards, he stated, was to raise the gauze from time to time to allow of the parasites escaping. This process was repeated for a second year, and since the orchards were isolated in the middle of cultivated land all serious damage from the weevil was stated to have been held in abeyance for ten years. A similar procedure was advocated by Berlese in 1902, with reference to the conservation of the parasites of the grape-vine Cochylis.

With regard to the Hessian fly, Marchal (1907) pointed out that the destruction of wheat stubble, if carried out a little late after the harvest, results in the annihilation of great numbers of parasites, since the Hessian flies emerge before their parasites. Similarly, Kieffer has shown that one of the measures for controlling the wheat midge, viz., burning the débris after threshing, has only an injurious effect, for the reason that the healthy pupæ occur in the soil, while those found in the débris are parasitised. In Louisiana it has been pointed out by T. E. Holloway and others (1928) that the practice of burning the trash or débris left in the fields after the cutting of sugar cane is not an effective method of decreasing infestation by the moth-borer Diatrcea saccharalis Fab. The trash, it appears, is the hibernating place for large numbers of parasitic insects. Following this contention the collected trash was left unburned at the sugar experiment station near New Orleans for a period of years, while the State planters, as a whole, burned their trash. A comparison of losses 
at the experiment station with those represented by the average for the State as a whole is given below.

\begin{tabular}{l|c|c|c|c|c|c}
\hline & \multicolumn{6}{|c}{ Percentage of Loss due to Diatra. } \\
\hline 1915 & 1916 & 1917 & 1918 & 1919 & 1921 \\
\hline $\begin{array}{l}\text { Trash unburned } \\
\text { Trash burned (State } \\
\text { average) }\end{array}$ & 12 & 13 & 7 & 19 & 6 & 18 \\
\hline
\end{tabular}

With increasing knowledge of host and parasite behaviour, instances where analogous methods may appear to be applicable will undoubtedly be multiplied. On the other hand, it is difficult to prove that any observed effect is due to the method in question. Also, such methods are not likely to prove effective unless they be carried out by general agreement among cultivators over a wide area; under more restricted circumstances only a fraction of the insect population would be affected, and no appreciable result is likely to supervene.

Direct Increase of a Parasite Population. It has been contended on theoretical grounds that the alteration of the host-parasite ratio in specific cases by the artificial quantitative breeding of suitable parasites is an evident possibility. A species of parasite whose behaviour appears to lend itself favourably to the application of the idea is the Chalcid Trichogramma minutum Riley, one of the best known of all egg-parasites. It has a wide geographical range, while its hosts include over 50 species of Lepidoptera, including such notable pests as the sugar cane borer (Diatrcea saccharalis Fab.), the European corn-borer (Pyrausta nubilalis Hub.), and the codling moth (Cydia pomonella L.). Early in the season this parasite is relatively scarce, while its spread is slow owing to its limited power of distribution, but it is maintained that if intensive infestation can be induced at the right time potential outbreaks of certain pests might be largely counteracted. At the present day attention is being centred on this parasite in many parts of the world, and it promises to be the first species of 
its kind likely to be propagated much along the same lines as the introduced predator Cryptolcemus (p. 377). The largest scale experiments are being conducted in Louisiana and California, with reference to the control of the cane-borer and codling moth respectively. According to S. E. Flanders the Trichogramma can complete its life-cycle in eight days at a temperature of about $83^{\circ} \mathrm{F}$. It is readily bred in captivity upon the eggs of the Angoumois grain moth (Sitotroga cerealella Oliv.), which likewise is capable of many generations in the year, and the whole technique for the mass-rearing of the parasite on this host has become a matter of skilfully standardised routine. With comparatively simple and inexpensive technique it has been possible to rear 200,000 individual Trichogramma a day at certain periods, while numbers approaching one million per day are stated to have been attained subsequently. Whether the reduction of the host population can be regularly attained to a degree which justifies the expenditure of money on projects of this kind has given rise to a good deal of doubt. While encouraging results are reported by Tucker, in Barbados, on carefully analysed evidence, satisfactory data are wanting elsewhere. The use of Trichogramma for the purpose mentioned is, it may be added, inspiring less confidence than formerly.

Another experiment of this kind concerns the Coccinellid, Hippodamia convergens, in California. This insect is generally distributed in the areas involved by the experiment, but is ineffective in controlling the great abundance of aphides on truck crops, etc. It has been estimated that an increase of about 30,000 individuals per acre might be expected to give the result desired. Watch was therefore kept in autumn in the canyons of the Sierra Nevada Mountains where the Hippodamia congregate in masses prior to hibernation, and the particular assembling places marked. Before the snows melted in spring the hibernating lady-birds were collected in enormous numbers and transferred to storage plant in Sacramento, where they were retained at a suitable temperature until required.

On reports being received from farmers concerning aphid outbreaks, shipments of the Coccinellids were made to the desired 
localities, where they were liberated. Notwithstanding the considerable mortality which occurred while in artificial storage, upwards of $75,000,000$ have been distributed among farmers in a single season. The operation was carried on by the State Horticultural Commission for seven years in succession before the subject was given expert study as to its value as a commercial undertaking. In 1918 and 1919 W. M. Davidson, of the United States Bureau of Entomology, made a series of experiments in order to ascertain the distribution of the Coccinellids after liberation. Large numbers were collected and sprayed with "silver" or "gold" aluminium paint which rendered them recognisable, and caused only slight mortality. It was found that the insects distributed themselves over large areas so rapidly that they were of little value in controlling local aphid outbreaks. Only one out of every 65,000 sprayed individuals was recovered (Davidson, 1924).

Transference of Parasites to New Areas. The conception of the transfer and colonisation of parasites, from an area of a given country where they are prevalent into a district where they are apparently non-existent, dates from about 1872. Theoretically, the method appears feasible if physiographical barriers have precluded the entry of a parasite into a given area. On the other hand, if its absence is to be ascribed to climatic causes, the chances of its successful colonisation would seem to be remote.

Three examples of the application of this method may be instanced. The incidence of the Braconid Macrocentrus ancylivorus has already been referred to on p. 383 in connection with the control of the Oriental fruit moth. It appears that the New Jersey strain of this parasite has a higher efficiency in bringing about host mortality than examples derived from other localities. The result has been that this so-called race has been widely disseminated artificially in many states where it has been subsequently bred in large numbers followed by liberation. Its colonisation is now an established fact, and it is regarded as the most effective biological agent in the control of its host so far discovered.

The colonisation of Aphelinus mali, another North American indigenous parasite, in the Pacific North-West, has, it is stated, 
resulted in complete control of the woolly aphis (Eriosoma lanigera) in that region. Owing to some unexplained factor, or factors, the natural spread of the host in the area mentioned had been accomplished without the usual accompaniment of the Aphelinus. In the third example the experience of Hazelhoff (1929) may be quoted. He states that the transfer of the Chalcid Encarsia scutellum, from the older or established cane-fields in Java into newly planted sugar cane areas, has proved definitely successful in maintaining the aphid Oregma lanigera under control. The powers of dispersal of this parasite, it appears, are very restricted, and consequently its incidence in new cane-ficlds is greatly delayed if the insect be left to disseminate itself by its unaided efforts.

\section{Biological Control of Noxious Weeds}

The application of biological control to weeds presents itself as a possibility where alien plants have invaded and colonised land to the extent of rendering it useless. It is well known that in certain parts of the world introduced weeds have resisted all attempts at cultural, chemical or other methods of control, or such methods have proved to be economically impracticable. It is in circumstances of this character that insect control of the noxious plants concerned has been attempted in several different countries.

Principles Involved. In any scheme to control noxious weeds by the introduction of insects living at their expense certain guiding "principles" require emphasis (vide also Imms, 1929).

1. It has already been pointed out that there is abundant evidence that alien insects which have entered countries unaccompanied by their natural parasites can become firmly established and cause great depredations to cultivated crops. On the other hand, there appears to be no valid reason why suitable types of insects deliberately introduced, free from their natural enemies, should not likewise exercise a destructive effect upon noxious alien weeds, given an environment favourable to the colonisation of such insects. It is this principle that is fundamental to the problem concerned. 
2. The second principle involved is that any insects utilised must be species known to exercise a controlling influence over the weeds concerned in their own habitat. At the same time they must be kinds which are known to be specific to the host concerned or confined to a very restricted range of host-plants and, unlikely in a new environment, to infest important economic plants.

With certain plant-hosts, such as Opuntia, the possibility of insects which feed upon them resorting to other kinds of plants is remote. Insects feeding upon plants of such unusual characteristics and endowed with acrid juices, resistant cuticle, along with other specialised morphological and physiological properties, exhibit so peculiar and rigid an adaptation to that particular mode of life that they are unlikely to infest plants with entirely different physico-chemical attributes. With plants of the natural order Rosaceæ, for example, on the other hand, there is always the looming possibility that in a new environment insects which normally feed upon a single genus or species of that order will infest one or other of its numerous cultivated members.

3. In contingencies where a pest-plant has close allies of economic importance, insect control requires exceptionally cautious procedure. In such instances the method is beset with manifold difficulties, and lack of foresight may only too easily result in the remedy proving worse than the disease.

If insect control of such types of pest-plants commends itself as a feasible economic measure, recourse should be rigidly confined, in the writer's opinion, to the introduction of species of specialised habits and behaviour. Root-borers, stem-borers and internal seed- or fruit-feeders are preferable to leaf-feeders, since their economy is usually more delicately adjusted to their specific hosts, and for this reason they are probably less liable to seek other hosts in a new environment.

4. Any insects deemed likely to prove valuable in the biological control of weeds require exhaustive testing with reference to the possibility of their feeding upon plants other than the particular host concerned. Such experiments require to be carried out firstly in the native country of the insects, and, if the tests prove 
negative, further experiments are necessary under the new environmental conditions wherein it is proposed to colonise them.

5. It will be readily understood that, under the conditions demanded by noxious weed control, parasites assume the opposite rôle to the one they perform in the repression of insect pests. In other words, parasites require to be rigidly excluded in all cases where insects are utilised in weed repression. Under a new and favourable environment the unforeseen entry of such agents might well result in the activities of a valuable phytophagous insect being permanently nullified to a degree which, in an extreme case, might almost amount to totality.

6. It needs to be recollected, as W. R. Thompson has pointed out, that, although insects entail a vast amount of destruction to economic plants, they rarely cause sufficiently vital damage which will affect the survival of well-established species to a marked degree. Measured in economic terms, such damage frequently assumes vast proportions, but in the biological sense it is not necessarily of the same importance. Furthermore, the recuperative powers of plants are so great that they are much less liable to be killed outright as the result of insect attack than insects themselves, which almost always succumb from the effects of their parasites.

In the pages which follow an account is given of the principal examples of the biological control of pest-plants.

Control of Lantana. The first attempt to control a noxious plant by its insect enemies was made in the Hawaiian Islands. Nearly seventy years ago Dr. Hillebrand, the distinguished botanist of the Islands, introduced the thorny species of Lantana, L. camara, for ornamental purposes. This shrub subsequently became a veritable scourge to the pastures of low-lying regions, especially on the leeward side of the Islands. It is a native of the warmer parts of America, and during a visit made by Koebele to Mexico in 1898 it was observed in its habitat, and some insects were bred from Lantana seeds. In 1902 Koebele again visited Mexico, this time with the object of securing any promising insect enemies of the plant for purposes of introduction into the Islands. The result of his work was that 23 species of insects 
were sent to Perkins in Honolulu, and of these 8 were successfully established (vide Perkins and Swezey, 1924). Each of these 8 species attacks the Lantana in a somewhat different way. The most effective appears to be the Tortricid moth Crocidosema lantana Busck., whose larvæ bore into the flower stems and consume the flowers and fruit. The larvæ of the seed-fly Agromyza lantance Frogg. attack large numbers of the ripening berries, either destroying the seeds or causing the berries to shrivel up on the bushes. The Tingid bug Teleonemia lantance Dist. destroys the young leaves so effectively that extensive areas of Lantana are checked in growth and fail to blossom. The larva of the Trypaneid gall-fly Eutreta xanthochata Ald. to some extent check the growth of new shoots. The larva of the plume moth Platyptilia pusillidactyla Walk. destroy many of the flowers in very much the same manner as those of the Tortricid already referred to ; on the whole it appears to be less efficient than the latter insect. The Tineid leaf-miner Cremastobombycia lantanella Busck. is of minor importance, but its larvæ when abundant cause the death of the leaves, and to some extent restrain the vigour of the plant. Finally, two species of Lycrenid butterflies Thecla echion L. and T. bazochii God. are important, since their larvæ destroy a great many of the flowers, and thus restrain the production of the berries. Unfortunately the Chalcid Pantarthron flavum Perk. parasitises the eggs of the Theclas to some extent, while, on the other hand, the larvæ of $T$. echion have proved not entirely harmless to garden plants, being occasionally found feeding on fruits of the egg-plant. The most valuable of the insects just enumerated are those which inhibit seed production, and the result has been that the spread of the plant has been greatly checked, and it does not so readily re-infest land from which it had been previously eradicated. Although the work of repressing Lantana has been materially lightened by these introductions, the control of that plant can only be regarded as having been partially accomplished, and it is possible that the colonisation of other insects will be attempted in the future.

Control of Prickly Pear. In Australia the area infested by prickly pear (Opuntia spp.) is estimated to amount to $60,000,000$ 
acres in Queensland and New South Wales, and in 1925 the plant was stated to be spreading at the rate of a million acres a year, but this increase is no longer being maintained. In the main the affected areas embrace natural grazing country, where the land is worth less than $£ 3$ per acre. Under such conditions chemical or mechanical control is impracticable except in lightly infested country. In their native terrain in North and South America about 350 species of Opuntia are known, but none is a very serious enemy, yet of the few kinds introduced into Australia, at least four are to be regarded as major or minor pests. In America insects, diseases, and other agencies keep the prickly pear within reasonable bounds, whereas in Australia such natural controlling factors are wanting, and there is little to check the reproduction and spread of the pest. The Prickly Pear Board of Australia is concerned with an attempt to bring about a condition of biological equilibrium by the introduction of insects and plant diseases likely to act as natural checks; the control aimed at depends upon the introduction of a complex of organisms working together in destructive unison (vide Dodd, 1927, 1929). It needs to be recollected that the two chief pest pears in Australia are Opuntia inermis and $\boldsymbol{O}$. stricta, while several others are of minor importance. This fact complicates the problem, for the reason that a particular species of insect may prove effective against one kind of prickly pear, and yet be of little value with respect to other kinds of those plants. Officers of the Board have been engaged in studying the insects affecting Opuntias in their native surroundings. They have covered widespread cactus areas in North America, where field stations have been set up, and have also visited South America and the West Indies. In work of this character it is important to study on the spot, not only the insects actually attacking prickly pear, but also the natural parasites of such insects. The exclusion of the parasitic forms from Australia is of prime importance if their host insects are to multiply freely and vigorously attack the prickly pear. At the Board's Station at Urvalde, in Texas, extensive biological work has been prosecuted, and the most promising cactus-feeding insects bred under caged conditions ; furthermore, their life-histories have been worked out, 
such insects were tested relative to the possibilities of their attacking economic plants, and freedom from parasites being ensured. The material received from America was transferred to quarantine buildings at Sherwood, near Brisbane, where they were bred through one or more generations as an additional safeguard against the accidental introduction of their parasites. At Sherwood, also, further tests were conducted with respect to the possibility of the introduced insects attacking crops and other useful plants. From Sherwood the insects were eventually forwarded to acclimatising and breeding centres where, as a rule, the first liberations were also carried out. The acclimatisation of North American insects in a country where they are faced with opposite seasonal conditions naturally presents considerable difficulties. Generally it has been found that repeated shipments of a species of over a period of one or more years have been necessary before it has become established, but in a few cases efforts have failed altogether.

A number of species have become acclimatised to Australian conditions, and among them the moth Cactoblastis cactorum, whose larvæ tunnel through the tissues, is the most important. The cochineal, Dactylopius tomentosus, became distributed almost throughout the infested areas, and the plant bug, Chelinidea tubulata, spread in countless millions in many localities. The red spider, Tetranychus opuntice, also covered many thousands of square miles. A. P. Dodd, in his 1929 Report on this problem, stated that the established complex of insect enemies was already bringing about a considerable degree of control of this noxious pest. In the heart of the prickly pear country it was possible to travel for 100 miles without seeing any healthy plants. In his 1936 paper Dodd emphasises that the Board's policy was based upon the conception that biological control offered best chance of success if a carefully selected group of species working more or less in association was established. It was unforeseen that the outstanding success, evident in 1936, would have been effected by the agency of a single species of insect in the space of a few years. Nevertheless, this is what actually has happened, and the insect in question is the Phycitid moth, Cactoblastis cactorum. The 
fact is all the more remarkable for the reason that only 2,500 eggs (from the Argentine) of the insect were introduced into Australia, yet between 1928-30 about three thousand million eggs, laid by descendants of insects issuing from the original batch, have been distributed in the great prickly pear areas. The eggs are laid by the moth in "sticks," averaging seventy-five eggs in each : these sticks are readily collected and artificially attached to the cladodes of the host-plants. The resulting larvæ are gregarious, internal feeders which tumnel in companies through the tissue of the plant, thus also providing for the ingress of disease organisms. In this way the prickly pear ultimately becomes so completely destroyed that it is reduced to a rotting mass of pulp. The various insects, established prior to the Cactoblastis, have either been largely suppressed or their activities nullified, owing to competition with its larva. It is only locally, and in relation to a few species of Opuntia of lesser importance, that the Cactoblastis has proved more or less ineffective. Such problems, however, are being dealt with through the operations of other phytophagous insects, including cochineal (Dactylopius) and Cerambycid beetles. To-day, the enormous rate of increase of the prickly pear has been arrested and less than 10 per cent. of the former great body of infestation survives : the whole of the primary pear in Queensland and much in New South Wales has broken down and collapsed. Approximately 25 million acres of good land are now cleared and are being developed and brought under production.

Control of Prickly Pear in other Lands. 'The spectacular success attending the control of prickly pear in Australia has rather masked the efforts made to check Opuntias in other lands. In Ceylon an extensive area of the Northern Province was formerly infested by Opuntia monocantha, but was ultimately almost completely exterminated by the cochineal Dactylopius ceylonicus, which is stated to have come from Madras. This insect, it may be added, has exereised a high degree of control over $O$. monocantha in many parts of India for a number of years past. According to Jepson (1930) the cochineal insect has not maintained the same efficiency in controlling this species of prickly pear in the Southern Province of Ceylon. Another Opuntia, viz. O. dillenii, has become 
very prevalent in recent years in the Northern Province, and it is believed to be an accidental introduction from Madras. Dactylopius ceylonicus does not appear to be capable of exercising any controlling influence over this plant, a fact which led to the introduction in $\mathbf{1 9 2 4}$ of $\boldsymbol{D}$. tomentosus (opuntice) from Australia. According to Jepson, the experiment has proved remarkably successful. A large area of scrub in the neighbourhood of Trincomalee was cleared by its agency in eighteen months. It has also given equally satisfactory results in other districts, land which was previously occupied by Opuntia scrub, 6 to 10 feet high, is now under cultivation.

In 1926-27 consignments of Dactylopius tomentosus were forwarded to Mysore and to Tuticorin with the object of endeavouring to control Opuntia dillenii. The insects have become established and it is stated that an area of 40,000 square miles is now covered by the cochineal in southern Madras. Very large tracts of land have been cleared through its agency, and land so liberated has now come under cultivation for the first time for many years. It is further claimed that the whole prickly pear area of 114,000 square miles offers prospects of being cleared by 1940, judging by the progress so far achieved. As Jepson remarks, if this forecast be fulfilled, the experiment promises to become a classic example of the control of weeds by biological methods.

Several species of Opuntia have become troublesome pests in Mauritius, notably $O$. tuna and $O$. monocantha. The introduction of Dactylopius ceylonicus by d'Emmerez de Charmoy resulted in rapid destruction of Opuntia monocantha, and in his 1929 report on the subject it is stated that within fifteen years this plant has become completely controlled on the Island. The introduction of D. tomentosus from Ceylon in an attempt to control O. tuna is a much more recent experiment. Its establishment has proved successful and this prickly pear has been cleared from large areas.

In Madagascar it appears that rather an anomalous state of affairs exists. R. Decary states that Opuntia dillenii was formerly prevalent in a wild state on uncultivated land and was a local fodder plant. Since 1924 the commercial cochineal Dactylopius coccus entered Madagascar under accidental circumstances, it is 
believed from the neighbouring Island of Reunion. 'The insect spread so rapidly under the prevailing conditions that, in about two years, the Opuntia was virtually destroyed and the cochineal insect itself became no longer evident. Decary has more rccently suggested the introduction of some spineless species of Opuntia suitable to take the place of $O$. dillenii, and which, at the same time, is resistant to the Dactylopius.

Control of Clidemia. An experiment has been carried out in Fiji for the purpose of attempting to control the noxious shrub Clidemia hirta. In Trinidad the plant is not regarded as a pest, and is kept under restraint by a combination of various factors, of which phytophagous insects are but one of them. Studies carried out in Trinidad showed that the Thrips, Liothrips urichi, is common on this plant throughout the Island. It apparently causes its host to become stunted and to flower less freely. It therefore appeared to be a suitable insect for introduction into Fiji, provided that it were proved to exhibit no tendency to attack plants of economic importance. In October, 1929, W. H. Simmonds visited Trinidad and studied the Thrips on the spot. It was found to be attacked by a number of natural enemies which had to be excluded in any effort madc to introduce the insect into Fiji. He was able to send a large consignment of the species to Suva, where a proportion of its individuals were released in the field in 1930 and the remainder kept for breeding further stock. The Liothrips has taken readily to Fijian conditions and has continued to spread. To-day it is claimed that it has brought Clidemia definitely under control in large areas. This has been attained not by killing the plant, but by so inhibiting its growth that it is no longer able to compete with dominant local plants.

Problems in New Zealand. A campaign was inaugurated in 1927 in order to attempt the control of four kinds of pest-plants - gorse (Ulex europœus), blackberry (Rubus fruticosus), ragwort (Senecio jacobece) and piri-piri (Acana spp.). In the case of gorse the plant is by no means wholly injurious, and for this reason only control of its ultimate spread through seeding was aimed at. In this connection the introduction from England of the podinfesting weevil, Apion ulicis, shows promise of success and its 
establishment in New Zealand is now becoming achieved. With blackberry the preliminary testing of the stem-boring Buprestid beetle (Corøebus rubi) from South Europe has given unfavourable results, since both the larva and adult gave evidence of capability for attacking economically useful plants. The outcome has been the discarding of the project of biological control of blackberry, since no other insect was deemed safe for the purpose. Ragwort control is being attempted by the introduction of the Hypsid moth, Tyria jacobece, from England, but the results obtained are not very promising. This insect has become established in various parts of New Zealand, but the activities of parasites of indigenous insects and unknown influences are proving deleterious factors. Owing to these difficulties, a second ragwort-feeding insect is being studied with the object of being utilised in place of Tyria. The insect in question, Pegohylemia jacobea, appears to be an effective seed destroyer in its larval stage and is a member of the Dipterous family Anthomyidæ. No liberations appear to have yet been made, and its possible success is still in the balance. In the case of Accena, the burrs become entangled in the wool of the grazing sheep and the market value of this product is estimated to suffer an annual loss of $£ 250,000$. In this connection the introduction of the saw-fly, Antholcus varinervis, from South Chile offers promise of checking the plant in question, but no liberations have yet been made. The flea-beetle, Haltica virescens, has also been tested out as a potential beneficial insect, but it had to be abandoned owing to the revelation of polyphagous propensities.

The present situation, therefore, as regards weed control in New Zealand is that, although the project has not fulfilled the promise hoped for by Tillyard, who originated the scheme, in another ten years' time a useful degree of control will possibly have been achieved in certain cases (vide Miller, 1936).

\section{Literature}

Burgess and Crossman, 1929. Tech. Bull. 86, U.S. Dept. Agric.

Chamberlin, 1926. Journ. Econ. Ent., XIX., 302.

Clausen, 1936. Aun. Ent. Soc. Am., XXIX., 201.

Clausen, King and Teranisir, 1927. Bull. 1429, U.S. Dept. Agric.

Compere and Smith, 1932. IIIlgardia, VI., 585. 
Criddle, 1928. Canad. Ent., LX., 51.

Davidson, W. M., 1924. Trans. Amer. Ent. Soc., I., 163.

DoDd, 1927. Bull. 34, Council for Sci. and Indus. Res., Melbourne.

1929. Progress of Biological Control of Prickly Pear in Australia, Brisbane.

1936. Bull. Ent. Res., XXVII., 50:3.

Essig, 1931. ' History of Entomology," New York.

Flanders, 19:9. Journ. Econ. Ent., XXII., 24.5.

Glendenning, 1933. Canad. Ent., LXV., 169.

Hazelnoff, 1929. IV. Internat. Cong. Ent., Ithaca., II., 55.

Holloway, Haley and Loftin, 1928. Tech. Bull. 41, U.S. Dcpt. Agric.

Howard, 1924. Proc. Ent. Soc. Washington, XXVI., 27.

Imss, 1926. Ann. App. Biol., XIII., 40:2.

1929. IV. Internat. Cong. Ent., Ithaca., II., 10.

Jepson, 1930. Trop. Agriculturist, LXXV., 63.

KING, 1928. In U.S. Yearbook of Agric., 1927, 403.

Marchal, 1907. Ann. de l'Inst. Agronom., Ser. 2, VI.

MILLER and Others, 1936. N.Z. Journ. Sci. Tech., XVIII., 579.

Myers, 1928. Empire Cotton Grozving Rev., V., 1.

Nicholson, 1933. Journ. Anim. Ecol., II., 132.

and BaIley, 1935. Proc. Zool. Soc., 551.

Perkins and Swezky, 1924. Ent. Bull. 16, Harcaiian Sugar Plant. Exp. Sta.

Proper, 1934. Journ. Agric. Res., XLVIII., 359.

SiItir, H. S., 1926. Journ. Econ. Ent., XIX., 294.

1929. Bull. Ent. Res., XX., 141.

1935. Journ. Econ. Ent., XXVIII., 873.

Smith, H. S., and Armitage, 1931. Univ. Calif. Exp. Sta. Bull., 509.

Suith, L. B., 1928. In U.S. Yeaibook of Agric., 1927, 398.

SPEYER, 1927. Bull. Ent. Res., XVII., 301.

1928. In Thirteenth Ann. Rep. Exp. and Res. Station, Cheshunt, 75.

Sweetian, 19:36. "The Biological Control of Insects," Ithaea.

Swezey, 1923. Proc. IIarcaiian Ent. Soc., V., 299.

1928. Journ. Econ. Ent., XXI., 669.

TAYlor, 1935. Bull. Ent. Res., XXVI., 1.

1937. "The Biological Control of an Insect in Fiji," London.

Thompson, 1923. Ann. Ent. Soc. Amer., XVI., 115.

1927. Bull. Ent. Res., XVII., 273.

1927A. Ibid., XVIII., 13.

1928. Parasitology, XX., 90.

1930. Ann. App. Biol., XVII., 306.

1934. Parasitology, XXVI., 4.49.

Thompson and Parker, 1928. Tech. Bull. 59, U.S. Dept. Agric.

Timberlake, 1927. Proc. IIazaiian Ent. Soc., VI., 529.

Tothill, Taylon and Paine, 1930. "The Coconut Moth in Fiji," London.

Willard, 1926. Proc. IIarvaiian Ent. Soc., VI., 505.

Williams, 1931. "Insects and other Invertebrates of Hawaiian Sugar Cane Fields,' Honolulu. 


\section{INDEX OF AUTHORS}

Аввотт, С. E., 137, 150, 169

Ahmad, T., 290, 313

Ainslie, C. G., 165, 170

Albro, H. T., 70

Alpatov, W. W., and Pearl, R., 217, 259

Anderson, A. L., 137, 169

Andrews, E. A., 273, 313

Aschner, M., 250, 259 ; and Ries, F., 250,259

Atzler, M., 202, 203

BACK, E. A., and Cotton, R. T., 2:20, 237, 259; and Pemberton, C. E., 252,259

Bacot, A. C., and Harden, A., 244, 259

Baer, W., 293, 365

Baier, L. J., 150, 169

Ballard, E., 165, 170 ; and others, 308-9, 314

Barber, G. W., 221, 259

Barnes, T. C., 146, 169

Barrows, W. M., 160, 163, 170

Becker, R., 28, 50

Bělehrádek, J., 206, 259

Berland, L., 238, 259

Berlese, A., 51, 70, 126, 168, 249, 259

Bertholf, L. M., 114, 121, 168

Bodenheimer, F. S., 230, 259, 308, 314

Bodine, J. H., 210, 259

Börner, C., 28, 33, 50

Bounhoil, J., 68, 70

Bozler, E., 111, 168

Brecher, L., 200, 201, 203

Brindley, M. Haviland, 189, 203. See also Haviland.

Brues, C. T., 229, 259 ; and Glaser, R. W., 249, 259

Buchner, P., 247, 248, 260

Buddenbrock, W. von, 118, 122, 154, 168, 170 ; and Schultz, E., 122, 168

Bugnion, E., and Popoff, N., 132, 169

Burgess, A. F., and Crossman, S. S., 380,419

Butler, C. G., and Innes, J. M., 303, 314
Buxton, P. A., 220, 228, 234, 238, 260 ; and Lewis, D. J., 233, 260; and Mellanby, K., 234, 260

Carothers, E. E., 211, 260

Carpenter, F. M., 81, 102

Caspari, E., and Plagge, E., 68, 70

Chamberlin, T. R., 381, 419

Chapman, R. N., 245, 260

Chopard, L., 365

Christophers, S. R., 47, 50

Chrystal, R. N., 51, 71

Clausen, C. P., 334, 365, 366, 403, 419 ; King, J. L., and Teranischi, C., 335, $366,384,419$

Cleveland, L. R., 246, 260

Coad, B. R., 238, 260

Cockayne, E. A., 203. See also Mottram.

Cockerell, T. D. A., 93

Compere, H., and Smith, H.S., 378, 419

Comstock, J. H., 49, 55, 71 ; and Needham, J., 17, 18, 49

Cook, W. C., 163, 170, 213, 214, 260

Craighead, F. C., 287, 313

Crampton, G. C., 11, 33, 37, 50

Crane, M. B., 280, 313

Criddle, N., 165, 170, 386, 420

Crow, S., 137, 169

Crumb, S. F., 161, 170

Cunliffe, N., 264, 283, 313 ; Fryer, J. C. F., and Gibson, G. W., 264, 313 ; and Fryer, J. C. F., 28:, 313

DANiel, D. M., 358, 366

Davidson, J., 236, 240, 254, 260, 266, $273,277,313$

Davidson, W. M., 409,420

Davies, W. M., 230, 260

Dean, G. A., Cotton, R. T., and Wagner, G. B., 221, 260

Dendy, A., and Elkington, H. D., 2:0, 221,260

Denny, A., 50

Dodd, A. P., 415, 420

Durken, B., 201, 203 
Easthai, L. E. S., 5, 49, 51, 71

Eggers, F., 144, 170

Ellsworth, J. K., 112, 168

Eltringham, H., 108, 138, 168, 169

Essig, E. O., 379, 420

Evans, A. C., 245, 260, 339, 366

Ewing, H. E., 22, 50

Fatre, J. C., 187, 203, 300, 302, 310, $314,364,365,366$

Ferrière, C., 365, 366

Field, W. L. W., 297, 313

Flanders, S. E., 350, 366, 408, 420

Flint, W. P., and Larrimer, W. H., 267, 313

Folsom, J. W., 11, 49; and Bondy, F. F., 167, 170

Forbes, W. T. M., 83, 102

Fowler, R., 157, 170

Fraenkel, G., 69, 71

Frew, J. G. H., 218, 260, 266, 269, 313

Friedrich, H., 111, 168

Frisch, K. von, 113, 130, 137, 168

Frost, S. W., 157, 170

Fryer, J. C. F., 256, 297, 313 ; and Collin, J., 264, 313 . See also Cunliffe.

Gaffron, M., 119,168

Genieys, P., 321, 366

George, C. J., 47, 50

Gerould, J. H., 185, 196, 204

Giersberg, H., 187, 202, 203

Glaser, R. W., 110, 131, 168, 169, 188, $203,243,260$

Glendenning, R., 287, 420

Göschen, F., 297, 313

Grandori, R., 261, 349, 366

Griswold, G. H., and Crowell, M. F., 233,260

Gryse, J. J. de, 51, 71

Gunn, D. L., 233, 260

Hacketт, L. W., Martini, E., and Missiroli, A., 291, 313. See also Missiroli.

Handlirsch, A., 49, 102

Handschin, E., 93, 102

Hansen, H. J., 10, 2.2, 27, 28, 30, 49, 50

Hanström, B., 8, 49

Hardy, A. C., 239

Harrison, J. W. H., 198, 201, 203, 295, 313 ; and Garrett, F. C., 198, 204
Harukawa, C., Takato, R., and Kumashiro, S., 167, 170

Hasebroek, H., 191, 192, 199, 204

Haviland, M. D., 326, 328, 366. See also Brindley.

Hazelhoff, E. H., 410, 420

Headlee, T. J., 230, 260

Hefley, H. F., 231, 260

Henneguy, L. F., 360,366

Hertweck, H., 146, 170

Hertz, M., 116-20, 168; and Imms A. D., 187, 204, 314, 363

Hess, W. N., 170

Heymons, R., 28, 50

Hobson, R. P., 245, 250

Holdaway, F. G., 274, 313

Hollande, A. C., 187, 190, 204

Holloway, T. E., and others, 406, 4:20

Hopkins, A. D., 266, 287, 313

Hopkins, Sir F. G., 193, 204

Hoskins, W. M., and Craig, R., 2, 49, 163

Howard, L. O., 364, 366, 401, 420

Howlett, F. M., 161, 170

Hungerford, H. B., 189, 204

Hunter, W. D., and Pierce, W. D., 207, 260

Husain, M. A., and Khan, A. W., 165, 170 ; and Mathur, C. B., 304, 314

ILSE, D., 114, 117, 169

Imms, A. D., 3, 49, 51, 71, 221, 345, 366, 371,420 ; and Husain, M. A., 155, 160, 170. See also Hertz.

JACkson, D. J., 341, 361, 366

James, H. C., 51, 71

Jepson, F. P., 417, 420 ; and Gadd, C. H., 271, 313

Kaestner, H., 192, 204

Keilin, D., 189, 204

Kelly, E. O. G., 340, 366

Kemner, A., 336

King, J. L., 335, 366, 384, 420

Knight, H. H., 185, 204

Knoll, F., 114, 169

Koebele, A., 370, 372, 412

Koller, G., 70, 71

Kopéc, S., 68, 71

Kornhauser, S. I., 358, 366

Krogh, A., 209, 218, 219, 260 
Kugler, F., 114, 169

Kuhn, A., 69, 71, 114, 115, 169

LAL, K. B., 290, 313

Lameere, A., 19, 50, 102

Larson, A. O., 287, 313

Leiby, R. W., 356, 362, 366 ; and Hill, C. G., 354,366

Lichtenstein, J., 364, 366

Linden, Grafin G. von, 190, 204

Lloyd, Ll., 158, 167, 170, 242, 260

Loeb, J., 122, 168

Ludwig, D., and Cable, R. M., 215, 260

MacLagan, D. S., 274, 313

Mansour, K., and Mansour-Bek, J. J., 248,260

Manton, S. M., 8, 49

Maple, J. D., 345, 366

Marchal, P., 57, 71, 294, 313, 354, 363, $366,406,420$

Marcovitch, S., 236, 260

Marshall, J., 131, 163, 169

Marshall, J. F., and Staley, J., 293, 313

Martin, F., 354, 366

Martynov, A. B., 80, 102

Mason, G. W., 173, 204

Mayer, A. G., 148, 170

McIndoo, N. E., 123, 124, 128, 130, 133, $137,139,155,158,163,168,169,170$

McKenny-Hughes, A. W., 198, 204

Mehta, D. R., 43, 47, 50

Mellanby, H., 6,49

Mellanby, K., 2229, 260

Metcalfe, M. E., $43,47,50$

Neyer, P. F., 187, 204

Michelson, A. A., 179, 204

Miller, D., 419, 4:0

Minnich, D. E., 129, 133, 149, 169

Misra, S., 280, 313

Missiroli, A., Hackett, L. W., and Martini, E., 291, 313. See also Hackett.

Monzen, K., 277, 280, 313

Mottram, J. C., and Cockayne, E. A., 203

Muesebeck, C. F. W., 324; and Dohanian, S. M., $327,363,366$

Muir, F., 372, 373

Müller, E., 111, 169

Myers, J. G., 152, 170, 395, 420
NABert, A., 66, 71

Nel, R. I., 50

Nelson, J. A., 71

Neustadt, E. A. von, 165, 170

Newton, H. C. F., 128, 169

Nicholson, A. J., 369, 420 ; and Bailey, V. A., 369,420

Northrop, J. H., 219, 235, 260

Noskiewicz, J., and Poluszynski, G., 354

Nougaret, R. L., and Lapham, M. H., 275,313

Nuttall, G. H. F., 167, 22:1

OxsLow, H., 173, 191, 204

Palmer, L. S., 184, 204; and Knight, H. H., 184, 188, 196, 204

Pantel, J., 331, 366

Parker, H. L., $347,358,361,366$. See also Thompson.

Parker, J. R., 210, 260

Parnell, F. R., 285, 313

Patterson, J. T., 354, 362, 366

Payne, N. M., 223, 260, 290, 313

Peairs, L. M., 208, 219, 260

Pemberton, C. E., and Willard, H. F., $32 \cdot 2,367$

Pérez, C., 71

Perkins, R. C. L., 372 ; and Swezey, O. H., 413, 420

Peterson, A., 157, 161, 170; and Heussler, G. J., 121, 169

Philiptschenko, J., 1I, 49

Pictet, A., 237, 295, 313

Pierantoni, U., 249, 260

Pierce, W. D., 323, 366

Ping, C., 74, 92, 102

Pirsch, G. B., 220, 260

Poulton, E. B., 183, 199, 204

Power, F. B., and Chesnut, V. K., 159, 170

Prell, H., 28, 50, 336, 366

Priebatsch, J., 121, 169, 202, 204

Proper, A. B., 399, 420

Przibram, H., 186, 192, 201, 204

Pumphrey, R. J., and Rawdon-Smith, F., 148, 152, 170

Raysay, J. A., 229, 260

Redtenbacher, J., 17, 19, 50

Richardson, C. H., 161, 170, 243, 244, 260 
Pichmond, E. A., 159, 170

Ries, E., 250, 260

Ripley, L. B., and Hepburn, G. A., 163, 169

Ripper, W., 248, 260

Roach, W. A., 28:, 313

Robinson, W., 22:2, 261

Roonwal, M. L., 6, 30, 37, 49, 229, 261

Roubaud, E., 291, 293, 313; and Gaschen, H., 291, 313; and Veillon, R., 161,170

Rubtzov, I. A., 311, 314

SACHAROV, N. L., 224, 261

Salt, G., 326, 366

Salt, R. W., 226, 261

Sander, W., 120, 169

Sanders, J. G., and Fracker, S. B., 167, 170

Sayle, M. H., 218, 261

Schlegtendahl, 115, 169

Schlieper, C., 115, 169

Schmalfuss, H., 192, 204 ; and Barthmeyer, H., 192, 204

Schnauer, W., 259, 261

Schopf, C., and Wieland, H., 193, 204

Schrader, F., 248, 261

Schroeder, C., 294, 313

Severin, H. H. P., and H. C., 163, 170

Shelford, V. E., 209, 216, 261

Shiraki, T., 165, 170

Sihler, H., 104, 128, 168

Silvestri, F., 11, 49, 336, 345, 354, 360, 366

Simmons, P., and Ellington, G. W., 241, 261

Singh Pruthi, H., 43, 47, 50

Sladden, D. E., 294, 314

Slifer, E. H., 146

Smith, H. S., $325,333,366,369,397$, 420 ; and Armitage, 377, 420. See also Compere.

Smith, L. B., 384, 420

Snodgrass, R. E., 1, 9, 22, 27, 28, 34, 37, $49,50,104,126,168$

Spencer, H., 360, 361, 366

Speyer, E. R., 160, 171, 389, 420

Stear, J. R., 157, 171

Stickney, F. S., 37, 50

Strel'nikov, I. D., 303, 314

Strickland, E. H., 336, 366

Suffert, F., 173, 182, 204

Sweetman, H. L., 369, 420
Swezey, 0. H., 373, 420. See also Perkins.

TAte, P., and Vincent, M., 292, 314

Taylor, I. R., 219, 261

Taylor, T. H. C., 388, 400, 420. See also Tothill.

Theile, R., 280

Theobald, F. V., 165, 171

Thompson, D. L., 188, 204

Thompson, W. R., 293, 319, 331, 332, $337,369,381,396,401,403,404,420$; and Parker, H. L., 287, 314, 319, 320, 396,420

Thomsen, M., 321, 366 ; and Lemche, H., 199, 204

Thorpe, W. H., 286, 288, 314, 342, 347, $350,353,367$

Tillyard, R. J., 18, 50, 85, 102

Timberlake, P. H., 325, 327, 343, 367, 371,420

Tothill, J. D., 348, 361, 367 ; Taylor, T. H. C., and Paine, R. W., 388, 420

Townsend, C. H. T., 331, 367

Trager, W., 247, 261

Trouvelot, L., 364, 367

Turner, W. L., 165, 171

UichaNCO, L. B., 248, 261

Urban, F., 122, 169

Uvarov, B. P., 234, 237, 239, 243, 248, $261,300,307,314$; and Zolotarevsky, B. N., 307,314

Uzel, H., 49

VALentine, J. M., 131, 169

Verguin, J., 252, 261

Verne, J., 190, 204

Verschaffelt, E., 158, 171

Vigier, P., 107, 169

Vignon, P., 21, 50 ; and Séguy, E., 21, 50

Vogel, R., 103, 127, 144, 168, 170

Voris, R., 336, 367

WADLEY, F. M., 236, 261

Wadsworth, J. T., 336, 367

Walker, E. M., 37, 46, 50

Walsh, B., 286

Walton, W. R., 342, 367

Webber, R. T., and Schnaffner, J. V., 319,367 
Weber, H., 1, 28, 49

Weed, I. G., 68, 70, 71

Weinland, H., 218, 261

Weis, I., 137, 169

Werner, E., 247, 261

Wever, E. G., and Bray, C. W., 152, 170

Wheeler, E. W., 325, 364

Wheeler, W. M., 110, 127, 168, 169

Wieland, H., and Schopf, C., 193, 204

Wiesmann, R., 5, 49

Wigglesworth, V. B., 3, 49, 66, 70, 71, $154,170,193,204,229,250,261$

Willard, H. F., 297, 420

Willcocks, F. C., 165, 171
Williams, C. B., 166, 171, 269, 313

Williams, F. X., 373, 375,420

Withycombe, C. L., 269, 313

Wolf, E., 119, 169

Wolsky, A., 153, 170

Woods, W. C., 296, 314

Worrall, L., 284

Yothers, M. A., 156, 171

Zerrhan, G., 117, 169

Zolotarevsky, B. N., 307, 314. See also Uvarov.

Zwolfer, W., 253, 261 


\section{GENERAL INDEX}

(Generic names only are given in italies)

abdominal appendages, 41

Acerentulus, 28

Ageniaspis (Encyrtus), 354

air currents, 238

Aleochara, 336

alfalfa weevil, 381

Anomala, 373

Anomochorista, 78

Anopheles, races of, 291

antennæ, 40

anthocyanins, 187

Anurida, 11

A panteles, 186, 348, 361, 363, 370, 398

Aphelinus, 320, 338, 385, 389, 409

A phelopus, 358

a phides, 188, 231, 236

Aphidius, 325, 328, 343

Aphis, 240, 241, 266, 277

Aphycus, 324

Apion, 418

A pis, 7. See also bee.

a podous larvæ, 60

Archipanorpa, 90

Archotermopsis, 93

Aristopsyche, 90

Artona, 387

Aspidiotus, 388

Asterochiton, 167

atmometer, 235

atmospheric pressure, 237

Australia, biological control in, 413

Balisarcha, 297

Bathyplectes, 381

bee, 137, 220 ; colour vision, 114

Belmontia, 86, 99

bioclimatic law, 266

biological control, 368 ; factors involved, 391 ; weed repression, 410 ; literature, 419

biological races, 286

biramous limbs, 22

blackberry control, 418
Blastothrix, 324, 344, 387

Blatella, 7, 44, 45

Blatta, 45,233 ; sensillæ, 128

Bonnetia, 336

" bound" water, 222

Brodia, 96

brown-tail moth, 379

Bruchus, 230, 287

Cactoblastis, 415

Calandra, 220

California, biological control in, 370 , $376,394,408$

Calliphora, 69, 136, 230, 319

Calosoma, 380

Campodea, 7, 13, 23, 24, 28

Canada, biological control in, 386

Carausius, 5, 7, 12, 294; colour phenomenon in, 121, 187, 202

carbon dioxide output, 214,219

Carboniferous insects, 86

carotin, 184

Centeter, 339, 384

Ceratitis, 252, 374, 396

cerci, 42

cercoids, 43

Ceylon, prickly pear control in, 417

Chalicodoma, 7

Charips, 328

chemoreceptors, 123

chemotropism, applications of, 155

chlorophyll, 183

Chlorops, 266, 269

chordotonal organs, 140 ; functions, 145

Cicadidæ, tympanal organs, 144, 152

Cimex, 66

Cionus, 197

claspers, 45,49

Clidemia, biological control of, 418

climate, 251 ; and weather, 257

Coccophagus, 327,350

codling moth, 123

cold, effects of, 221 
cold hardiness, 222-7

Coleoptera ; trochanters, 25 ; gula, 38 ; genitalia, 47; fossil forms, 93 ; coloration, 179,181 ; parasitic forms, 335,336

Colias, larval colour, 186, 196

Collembola, 11, 28, 230 ; fossil forms, 86

Colorado potato beetle, see Leptinotarsa, 159

coloration, 172 ; literature on, 203

colours, structural, 172 ; pigmentary, 183 ; combination colours, 194

colour vision, 113

compound eyes, 107

Compsilura, $319,341,342$

continental areas, biological control in, 395

Copidosoma, 356, 362

Corcebus, 419

corpora allata, 65

cotton boll weevil, 139, 207

cotton Jassid, 284

coxites, $41,45,46$

coxosternum, 41

Cretaceous insects, 92

crops and insect attacks, 263

Cryptocercus, 247

Cryptochatum, 342, 353, 371

Cryptognatha, 388

Culex, races of, 291

cyclopoid larva, 57,58

Cydia molesta, 156, 381, 383

Cydia pomonella, 140, 156. See also codling moth.

Cyrtidæ, 335

Cyrtorhinus, 372

Dachnusa, 326

Dactylopius, 416

Dacus, 162

Datana, 150

Dendroctonus, 287

developmental units, 216

Devonian insects, 86

Dexia, 335

Diachasma, 322, 374, 397

Diceretus, 360

Diatrcea, 406

Dibrachys, 3?8, 399

Dieconeura, 76

diffraction colours, 174

Digonochreta, 399

Dinocampus, 341, 343
Diptera, 21 ; genitalia, 47 ; larvæ, 60 ; fossil forms, 91, 94; chemotropic responses, 160, 161; parasitism in, 351

Dissosteira, 13

Ditaxineura, 96

Dociostaurus, 309

"dopa," 191

double ocelli, 110

dragon-flies, see Odonata.

Drosophila, response to light, 111 ; chemotropism, 160 ; development, 215 ; duration of life, 217 ; $\mathrm{CO}_{2}$ output, 219; effects of light, 235 ; nutrition, 243

Dunbaria, 89

Dytiscus, 25

ectoparasites, 320,339

embryonic phases, 52

Empire Cotton Growing Corporation, 284

Encarsia, 389,410

Encyrtus, 349, 350, 355

England, biological control in, 389, 394, 399

Entimus, coloration, "178, 179

Eosentomon, 28, 42

Ephemeroptera, 15, 20 ; fossil forms, 97

Ephestia, 244, 290

Ephialtites, 91

Eriosoma, 410

Ernestia, 336

Euclecanium, 387

Eugereon, 82

Eulecanium, 294

Euplectrus, 321

Euproctis, 324

European corn borer, see Pyrausta.

Figites, polypod larva, 58

Figitidæ, 58

Fiji, biological control in, 387,418

flavones, 188

fluorescence, 203

food plants, change of habits with respect to, 294

Forficula, 7, 399

fossil insects, 72 ; sequence of, 86,101 literature on, 102

frit-fly, see Oscinella. 
genitalia, 43,49

geographical distribution, 251

geological history of insects, 86

gipsy moth, 379, 399, 401

Glossina, 233, 251

Gonepteryx, 193

Gonia, 321

gorse, control of, 418

Gout fly, see Chlorops.

grasshoppers, phase development, 311 ; development, 211

Grylloblatta, 46, 47

Gryllus, 7, 104, 105, 148

gula, 37

gustatory sense, 132

Habrobracon, 192, 321, 364

Habrocytus, 364

Hadena (Polia), 158, 242

hæmoglobin, 189

halteres, 154

harpagones, 45

harpes, 47

Hawaiian Islands, biological control in, $371,393,399,412$

head, segmentation of, 4

heat, effects of, 220

Helopeltis, 273

Hemiptera, gula, 38; genitalia, 47 ; fossil forms, 98; gustatory organ, 132 ; colours of, 184,188 ; symbionts of, 248

Hemiteles, 319

Hessian fly, see Mayetiola.

Heterojapyx, 14

Hippodamia, 408

hormones and metamorphosis, 64

host-selection, 286, 318 ; interpretation of, 297

host-selection principle, 287

hot springs, 220

house-fly, 243

humidity, 228

hybridisation, 297

Hymenoptera, trochanters, 26 ; larval types, 57, 58, 60 ; fossil forms, 91,94 ; parasitism in, 344

Hypera, 61

hypermetamorphosis, 62

hyperparasitism, 326,398

Hyphantria, parasites of, 323

Hyponomeuta, 288

hypopharynx, 14, 15
Ibalia, 58, 59

Icerya, 353,370

India, prickly pear control in, 416

indigenous parasites, utilisation of, 405

intercalary segment, 12

interference colours, 175

islands, biological control in, 392

Isoptera, 35 ; fossil forms, 93

Isotoma , 28, 29

Japanese beetle, sec Popillia .

Japyx, 7, 10, 24, 39, 40, 41

Johnston's organ, 141, 143

Jurassic insects, 90

Kennedya, 88, 96

labium, 35

labrum, 5, 7

Lachnosterna, 166

Lantana, biological control of, 412

larch sawfly, 386

larvæ, 54, 55 ; types of, 56

Lebia, 336

leg, 23 ; primitive structure, 31

Lemmatophora, 79

Lepidoptera, genitalia, 47 ; fossil forms, 93; colour vision, 114 ; tympanal organs, 144; sound perception in larvæ, 149 ; melanism, 196 ; structural colours, 177 ; pigmentary colours, 183 ; fluorescence, 203

Lepisma, 4, 7, 24, 28

Leptinotarsa, 159, 255

Leptomastidea, 378

Levuana, 387

light-compass orientation, 122

light, reactions to, 121,164 ; action of, 235

Limnerium, 325

Liothrips, 418

Lithobius, 14, 26, 32

Litomastix, 356, 362

Locusta , 6, 7, 12, 30, 37, 152, 229 ; coloration, 187 ; phases of, 300,307

Locustana, 310

locustine, 304

locusts, 299; swarming of, 305 species of, 306

Lucilia, 112, 208, 245

Lygcoonematus, 380

Lymantria, 68 
Machilis, 15, 25, 28, 44

Macrocentrus, 358, 361, 383, 409

Madagascar, prickly pear control in, 417 mandibles, 38

Mantis, 7

Mastotermes, 35, 44, 45, 93

maxilla, 32

maxillulæ, 10, 11

Mayetiola, 267, 356

Mecoptera ; fossil forms, 92,99

Mediterranean fruit fly, see Ceratitis.

Megasecoptera, 77,95

Megatypus, 90

melanin, 191

melanism, 197

Melanoplus, $68,70,110,146,310$

Melittobia, 321

Mesoleius, 386

Mesotitan, 90

metamorphosis, 51

Metaphycus, 378, 398

Meteorus, 341, 346

micro-organisms and insects, 245

Micropterygidæ, 93

Miomoptera, 80

Mischoptera, 78

Morpho, coloration, 174, 177, 178, 194

multiparasitism, 322,396

mushroom bodies, 9

mycetocytes, 248

naiad, 55

Necrobia, 242

Nemeritis, 290

Neocelatoria, larvipositor of, 342

Nesomachilis, 14

New England, biological control in, 379, 393

New Zealand, biological control in, 385 , 399,418

Nicoletia, 41, 48, 49

Nomodacris, 310

nun moth, 253

nutrition, the general subject, 239

nymphs, 54, 55; and pupæ, 63

ocelli, 109

Odonata, 15, 21 ; trochanters, 27 ;

fossil forms, 88, 96 ; vision, 107

nenocytes, 70

olfactometers, 158, 163

olfactory sense, 124 ; sensillæ, 126

oligopod larvæ, 60
Oniscidæ, parasites of, 319

Ootetrastichus, 372

Opius, 322, 374, 396

Opuntia, biological control of, 411,413

oriental peach moth, see Cydia molesta.

Orthophlebia, 92

Orthoptera, 20, 36 ; ovipositor, 45 ; genitalia, 46 ; tympanal organs, 143 , 146

Oryssus, 61

Oscinella, 263, 28:

ovipositor, 43,49

Palæodictyoptera, 19, 74, 94

palæontology, 72

Panorpoid complex, 18, 20

Parabelmontia, 86

paragnaths, 11

Paramecoptera, 85, 99

parameres, 48

Paranagrus, 372

parasites, 315 ; host-selection in, 318 ;

life-cycles of, 330 ; host relations,

343 ; phoresy, 364

parasitism, 315; phases of, 322 ;

sequence theory of, 401

parasitoids, 316

Paratrichoptera, 85

Paroryssus, 91

Pediculus, 147, 221, 250

Pegohylemyia, 419

penis, 47

Perilampus, 325 ; planidium of, 333

Perillus, 184, 185

Periplaneta, 33, 131, 146, 148, 229

Perkinsiella, 372

Permian insects, 87

Permochorista, 99

Permosialis, 89

Permotipula, 85

Phcenodiscus, 345

Phonoserphus, 59

phases of locusts, 300

Philonthus, 25

phoresy, 364

Phormia, 135

Phyllodecta, 294

Phylloxera, 274

phylogeny of insect orders, 94

physiology of insects, 2

Pieris, 5, 191, 193, 199, 200, 370, 386 ; chemotropism in, 129,158 ; sound perception, 150

Pimpla, 324 
Piophila, 242

planidium, 333

Platyedra, 165

Platygaster, 356 ; protopod larva, 57

Plecoptera, 21,36 ; fossil forms, 97

Plesiocoris, 296

pleuron, 28

Pleurotropis, 329, 386, 404

polyembryony, 353

Polygnotus, 356

polypod larvæ, 58

Polysphincta, 60

Pontania, 295

Popillia, 159, 381, 384

Porosagrotis, 212

postmentum, 35

pre-antennæ, 12

prementum, 35

prepupa, 64

pretarsus, 23

prickly pear, biological control of, 413

Promecotheca, 388

Prosena, 335, 384

Protagrion, 80

Protelytron, 84

Protelytroptera, 83

Protereisma, 89

Protoblattoidea, 76, 95

Protocoleoptera, 82

Protocoleus, 83

Protodiptera, 85

Protodonata, 79

Protohemiptera, 81, 97

"Protohymenoptera," 78

Protomecoptera, 99

Protoparce, 231

Protoperlaria, 80, 97 ; nymph, 81

Protophasma, 77

protopod larvæ, 56

Protorthoptera, 75, 95

Protozoa and termites, 246; and Cryptocercus, 247

Protura, 28, 42

Pseudaphycus, 374

Pseudococcus, 373

Psylla, races of, 290

Pteromalus, 386

Ptychomyia, 387

pupæ, 63

Pyrameis, 133, 137, 138

Pyrausta, 221, 287, 381, 382

Quaylea, 379, 398 ragwort, control of, 418

rectal papillæ or " glands," 229

respiration in endoparasites, 347

Rhabocnemis, 372

Rhacodineura, 332, 334

Rhagoletis, 296

Rhodnius, 6, 7, 12, 132, 154, 230, 250 ; hormones in, $66,69,70$

Rhyniella, 86

Rhyssa, 385

Riela, 365

Rodolia, see Vedalia.

Saissetia, 378

Schistocerca, 304, 308

Schizaspidia, 334, 365

Schœnobius, 165

Scolia, 373, 405

scolopale, 105

Scolopendra, 7, 14, 32

Scutellista, 378, 399

Scutigera, 14

Scutigerella, 28, 32

Selenia, melanism, 198

sense organs, 103

sense-rods, 105

sensillæ, 103

sequence theory of parasite control, 401

shot-hole borer, 271

sinigrin, 158

Sitodrepa, 216, 247

Sitotroga, 230, 408

Sininthurus, 230, 25t, 273

soil conditions and insect attack, 267

standard metabolism, 218

Stenobothrus, 7

Stenodictya, 76

Stenoperlidium, 89, 97

stimulatory organs, 153

subcoxa, 27

sugar cane froghopper, 268

superparasitism, 325

symbiosis, 245

Symphyla, 24, 28

Tachinidæ, parasitism in, 251

tactile sense, 139

tarsal perception, 133

Telea, 222

temperature, 206 ; alternating, 210 ;

summation, 216

Tenebrio, 47, 131, 209, 219, 228

tentorium, 14, 15 
termites and Protozoa, 246

Tertiary insects, 92

Tetrastichus, 363, 374

Therion, $36 \mathrm{I}$

Thrixion, 339,352

Thysanura, $11,23,28,36$; abdominal appendages, 41 ; genitalia, 48

Tibicina, 30

Tineola, 233

Tiphia, 385

transtarsus, 23

Triassagrion, 90

Triassic insects, 90

Triassolestes, 90

Triassopsychops, 90

Triatoma, 66

Tribolium, 245

Trichogramma, 326, 407

Trichlosoba, 87

Trichoptera, 91

trochanter, 25, 26, 27

trochantin, 29

trophamnion, 360

tropisms, 122

tsetse flies, see Glossina.

tympanal organs, 143 ; functions, 151

Tyria, 419

tyrosin, 191, 193

tyrosinase, 191, 193, 201 ultra-violet perception, 114, 121

United States, biological control in, 370 , $376,379,381,395$

Urania, coloration, 176

uric acid, 193

vacuum, effects of, 237

Vanessa, 109, 133, 149, 153, 190, 192, 199

van't Hoff's law, 210, 219

varietal resistance to insect attack, 276

Vedalia, 370, 385

velocity curve, 209

venation, 16

vision, 108 ; by ocelli, 110 ; colour vision, 113

vitamins, 243

weeds, biological control of, 410

white-fly control, 289

Winthemia, 231

woodlice, parasites of, 319

woolly aphis, 277,279

Xiphidium, protopod phase, 57

Xyleborus, 271 






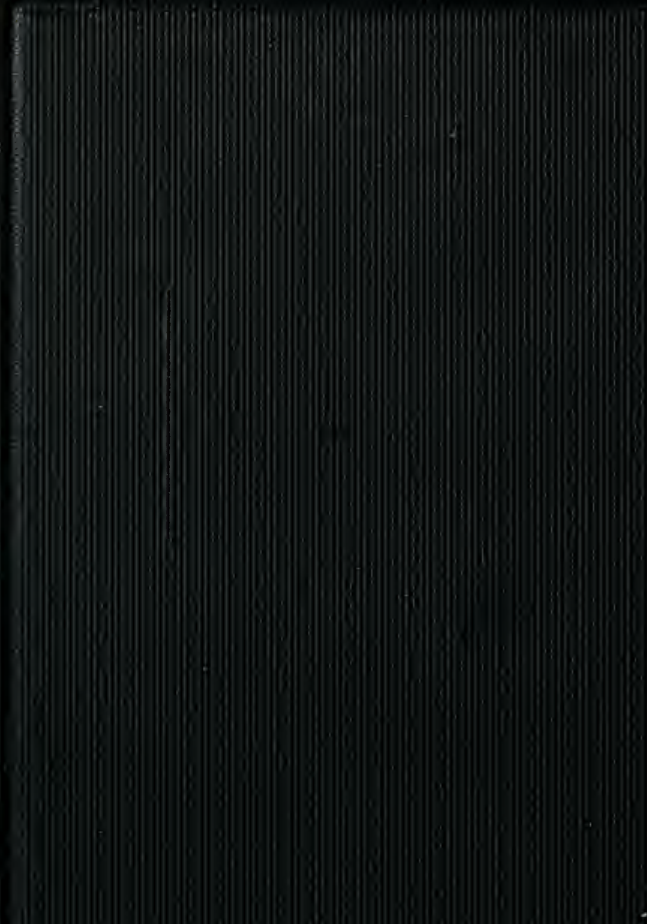

6 